\title{
Elsa-Maria Tschäpe
}

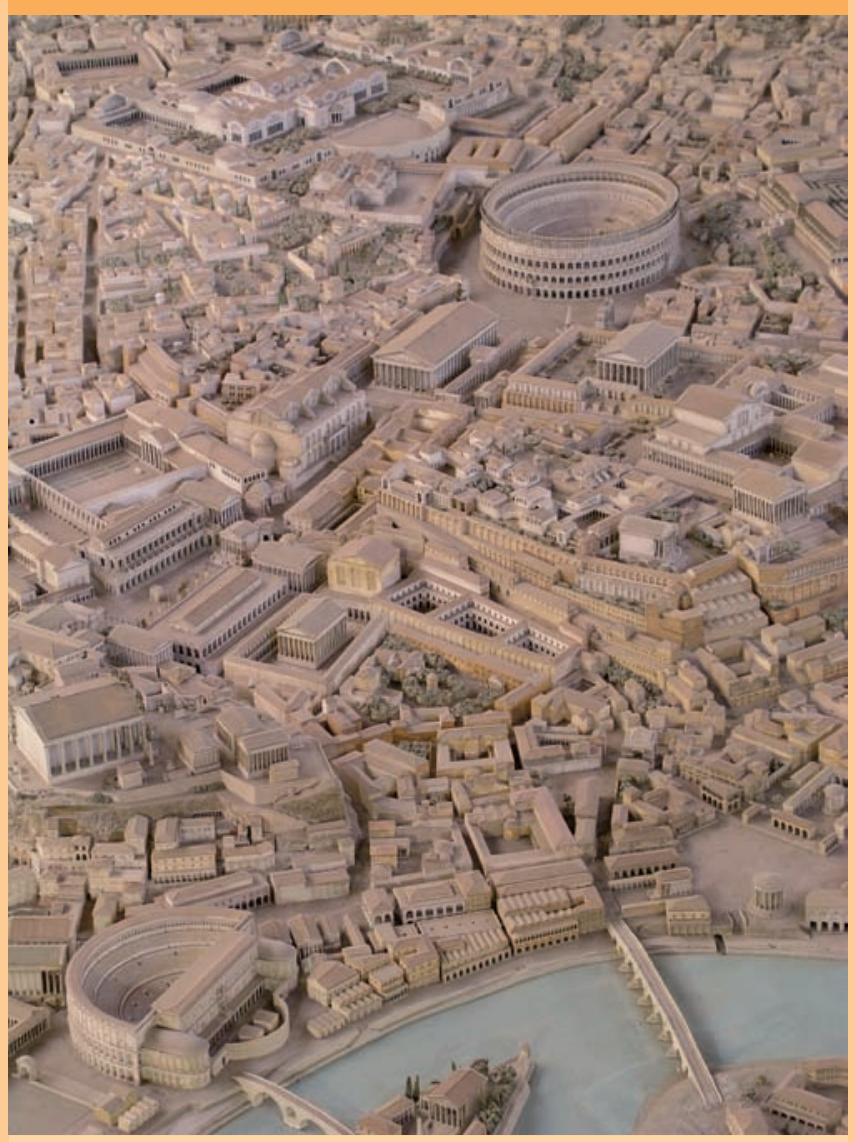

\section{Die Großstadt als literarischer Raum in der römischen Dichtung}





$$
\text { Elsa-Maria Tschäpe }
$$

Die Großstadt als literarischer Raum in der römischen Dichtung

Dieses Werk ist lizenziert unter einer

Creative Commons

Namensnennung - Weitergabe unter gleichen Bedingungen

4.0 International Lizenz.

(c) (†) (?) 
erschienen im Universitätsverlag Göttingen 2015 
Elsa-Maria Tschäpe

Die Großstadt als

literarischer Raum in der römischen Dichtung

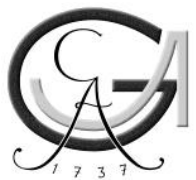

Universitätsverlag Göttingen 2015 


\section{Bibliographische Information der Deutschen Nationalbibliothek}

Die Deutsche Nationalbibliothek verzeichnet diese Publikation in der Deutschen Nationalbibliographie; detaillierte bibliographische Daten sind im Internet über $<$ http://dnb.dnb.de $>$ abrufbar.

Anschrift der Autorin

Elsa-Maria Tschäpe

E-Mail: Elsa-Maria.Tschaepe@phil.uni-goettingen.de

Dieses Buch ist auch als freie Onlineversion über die Homepage des Verlags sowie über den Göttinger Universitätskatalog (GUK) bei der Niedersächsischen Staats- und Universitätsbibliothek Göttingen (http://www.sub.uni-goettingen.de) erreichbar. Es gelten die Lizenzbestimmungen der Onlineversion.

Satz und Layout: Annett Eichstaedt Umschlaggestaltung: Jutta Pabst

Titelabbildung: The Great "Plastico", the model of ancient Rome in 1:250 by Italo Gismondi von seier+seier+seier [CC BY 2.0 (http://creativecommons.org/licenses/by/2.0)], via Wikimedia Commons

(C) 2015 Universitätsverlag Göttingen http://univerlag.uni-goettingen.de ISBN: 978-3-86395-225-9 


\section{In memoriam}

Dr. Rudolf Tschäpe

(1943-2002) 



\section{Danksagung}

Diese Arbeit hat von den Gesprächen und der Unterstützung vieler Menschen außerordentlich profitiert. Ihnen allen möchte ich für die vielfältigen Anregungen und Hinweise wie auch für das Interesse an Inhalt und Gelingen meines Vorhabens herzlich danken.

Herrn Prof. Dr. Siegmar Döpp, der das Entstehen dieser Arbeit über seine Emeritierung hinaus begleitet hat, möchte ich an dieser Stelle im Besonderen danken, sowie Herrn Prof. Dr. Wilfried Barner für seine großzügige Gesprächsbereitschaft und für wertvolle Impulse und Herrn Prof. Dr. Peter Kuhlmann für die spontane und bereitwillige Erstellung des Zweitgutachtens.

Darüber hinaus danke ich dem gesamten Kollegium des Seminars für Klassische Philologie Göttingen für eine äußerst angenehme Zusammenarbeit und dabei besonders Herrn Prof. Dr. Heinz-Günther Nesselrath für seine Förderung und sein Interesse am Fortschreiten meiner Arbeit.

Den Kolleginnen und Freundinnen Dr. Friederike von Criegern, Dr. Frauke Geyken, Dr. Aniela Knoblich, PD Dr. Meike Rühl und Dr. Anne Pinkepank danke ich für ihre kritische Lektüre in verschiedenen Stadien dieser Arbeit und einen stets anregenden und ebenso vergnüglichen akademischen Austausch. Für eine derartige Unterstützung danke ich auch meiner Familie, insbesondere Frau Gudrun Tschäpe. 
Darüber hinaus fühle ich mich den Mitarbeitern der Universitätsbibliothek Göttingen zu großem Dank verpflichtet, vor allem Frau Sonnenberg, die mir wiederholt und großzügig Arbeitsmöglichkeiten in der SUB zur Verfügung stellte, und Frau Pabst, die sich für die Übernahme in das Verlagsprogramm einsetzte und den gesamten Ablauf der Drucklegung begleitete.

Das Korrektorat und das aufreibende Geschäft der Formatierung übernahm wohl gelaunt und umsichtig Frau Annett Eichstaedt (Karlsruhe), die lateinischen Zitate prüfte akribisch Frau Vanessa Engelbrecht (Bielefeld). Ihnen beiden meinen herzlichen Dank für ihre Unterstützung.

Elsa-Maria Tschäpe 


\section{Inhaltsverzeichnis}

Danksagung ................................................................................ III

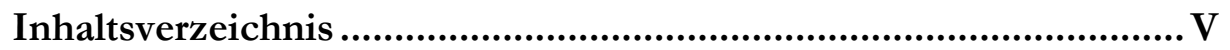

Vorbemerkungen ...................................................................... 1

1 Forschungsbeiträge zur Großstadt als Raum der römischen

Literatur............................................................................5

1.1 ROM. Stadtrömische Topographie in der Dichtung der augusteischen und kaiserzeitlichen Epoche

(Forschungsbericht I) ..................................................................... 5

1.2 RAUM. Untersuchungen zu Raumdarstellungen in der antiken Literatur (Forschungsbericht II) ...................................................... 10

1.3 STADT. Stadt und Land - Eine textübergreifende Dichotomie? (Forschungsbericht III) .............................................. 16

1.4 Die Großstadt in römischer Dichtung. Bestimmung des Untersuchungsgegenstands 
2 Kriterien der Textauswahl und methodische Überlegungen zur Analyse räumlicher Physis in narrativen Texten.....................21

2.1 Referenzen auf den Großstadtraum. Kriterien einer

Textauswahl

2.1.1 Urbs und Roma als Kernlexeme einer lateinischen GroßstadtIsotopie?

2.1.2 Die Verwendung von urbs und Roma in der römischen Dichtung

2.2 Die Analyse räumlicher Physis in narrativen Texten.

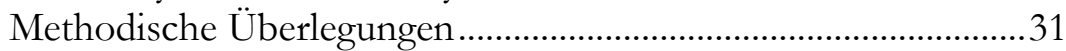

2.2.1 Die Raumwahrnehmung des Menschen......................................... 31

2.2.2 Verbale Wiedergabe räumlicher Eigenschaften ............................. 37

2.2.2.1 Die lexikalische Dimensionierung. Substantive und Adjektive .............................................................................. 37

2.2.2.2 Positionierung und Direktionalisierung. Die Entstehung von Räumlichkeit.......................................... 40

2.2.3 Literarisch gestaltete Wiedergabe des Raums ................................. 42

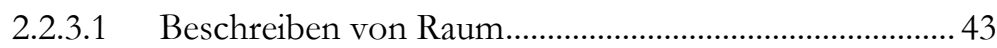

2.2.3.2 Erzählen von Raum ............................................................ 44

2.2.3.3 Erzählte Raumwahrnehmung: Panorama und

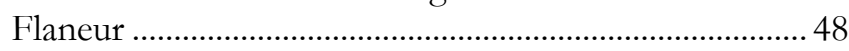

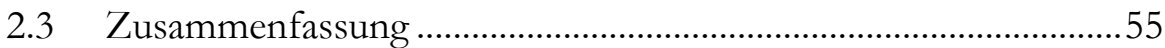

3 Der literarische Raum Großstadt in der augusteischen und kaiserzeitlichen Dichtung.............................................................57

3.1 Die Vielfalt räumlicher Inseln .....................................................58

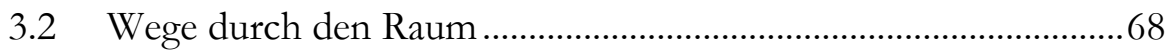

3.3 Formen der Ausdehnung. Die Größe einer literarischen Großstadt

3.3.1 $\mathrm{Zu}$ weit. Entfernungen in einer literarischen Großstadt.............. 81

3.3.2 Mobilität als Lebensform. Bewegungsbereich Großstadt ........... 88

3.3.2.1 Ländliche Bewegungsarmut............................................... 96

3.3.2.2 Tempo Großstadt. Schnelle und langsame

Bewegungen in der Stadt.................................................... 101

3.3.3 Qualitätssprung. Die große Stadt - Die Großstadt..................... 105

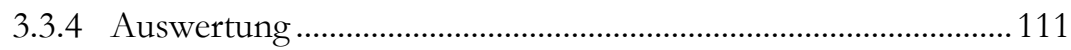


3.4 Formen der Begrenzung und des Übergangs. Räumliche

Vereinnahmungen einer literarischen Großstadt ......................... 114

3.4.1 Aussichtspunkte. Panoramablick auf den Großstadtraum........114

3.4.2 Natürliche und architektonische Grenzen. Mauern, Flussläufe und Grenzsteine

3.4.3 Grenzbereiche. Anzeichen der Verstädterung ............................ 127

3.4.4 Tiberim defluxit Orontes. Durchlässige Grenzen .............................. 136

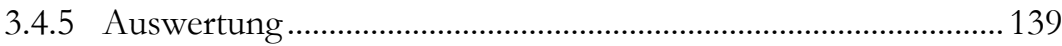

3.5 Innere Strukturen. Raumnot in der literarischen Großstadt ..... 142

3.5.1 Dichte Bebauung........................................................................... 142

3.5.1.1 Gefährliche Enge I. Entgrenzungen von innen nach

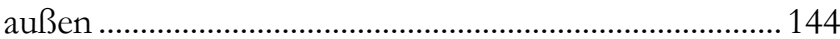

3.5.1.2 Klangteppich Großstadt. Entgrenzungen von außen nach innen ..................................................................... 147

3.5.1.3 Versperrte Sicht. Monumentale Beengtheit..................152

3.5.2 Densum volgus - Wahrnehmung der Masse.................................... 157

3.5.2.1 Theater, Circus, Atrium - Städtische Konzentrationspunkte....................................................... 160

3.5.2.2 Gefährliche Enge II. Die Widerständigkeit der Masse............................................................................. 167

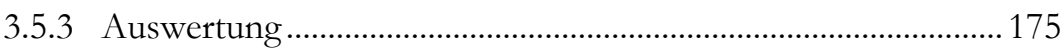

4 Die Großstadt als erklärter Gegenstand römischer Dichtung....181

4.1 Voraussetzungen der Großstadtdichtung .................................... 185

4.1.1 Rom als Lebenswirklichkeit. Biographien in der Großstadt .... 185

4.1.2 Vorprägungen im Rhetorikunterricht. Von der Schulaufgabe

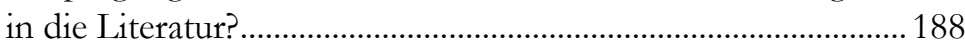

4.1.3 Die Poetisierung einer antiken Großstadt.................................... 193

4.1.3.1 Der Stadt abgelauschte Dichtung. Ein poetologischer Essay über Dichtung und Großstadt (Mart. praef. XII) ……………………………………...... 193

4.1.3.2 Der Dichter, wie er im Buche steht. Mehrstimmigkeit als Merkmal der Fiktion

4.2 Die Großstadt als Dichterlandschaft ............................................202

4.2.1 Eine Stadt, die nicht zum Aushalten ist. Der Dichter aus Empörung (Iuv. sat. 1) ................................................................... 203

4.2.1.1 Nonne libet medio ceras implere capaces quadrivio (...)? Großstadt und Dichtung.. 
4.2.1.2 Cum te summoveant, qui (...) - Großstadt und Dichter.207

4.2.2 Mutatus locus. Die urbs Roma der Imagination und die

Metamorphose des Stils (Ov. trist. 1, 1)

4.2.2.1 (...) sine me, liber, ibis in urbem - Großstadt und Dichtung....

4.2.2.2 Tu tamen i pro me, tu, cui licet, aspice Romam - Großstadt und Dichter

4.2.3 Der Einzug der Großstadt urbs Roma in die römische

Dichtung

4.2.3.1 Ein programmatischer Antiurbanismus inmitten der literarischen Großstadt. Großstadt und Dichtung (Hor. sat. 1, 4)

4.2.3.2 Das Wogen der Großstadt. Ausreden eines

Musensohnes (Hor. epist. 2, 2) - Die Großstadt und der Dichter I

4.2.3.3 Der dichtende Stadtgänger. Die Großstadt und der Dichter II (Hor. sat. 1, 6; 1, 9)

4.3 Auswertung. Die Großstadt als Gegenstand neuartiger

Literatur.

5 Zusammenfassung 255

6 Bibliographie 263

6.1 Quellen. 263

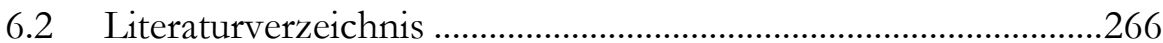

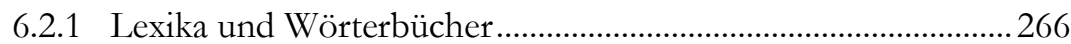

6.2.2 Sekundärliteratur und Kommentare.............................................267

6.3 Glossar 


\section{Vorbemerkungen}

Die Entdeckung der Großstadt für die Literatur gilt gemeinhin als besonderes Verdienst der Klassischen Moderne. Baudelaires Les Fleurs du Mal, James Joyces Uyyses oder Alfred Döblins Berlin Alexanderplatz sind Paradebeispiele einer innovativen und hochgradig experimentellen Literatur, die mit dem Ende des 19. Jahrhunderts die Spezifika der Großstadt als Lebensumwelt des modernen Menschen in den Blick nimmt. Vorläufer dieser literarischen Auseinandersetzung mit der „großen Stadt" finden sich verschiedentlich bei den Literaten der Romantik und sind auch bereits in Texten des beginnenden 18. Jahrhunderts greifbar. ${ }^{1}$ Nie geleugnete Traditionslinien dieser Literatur reichen bis zu den biblischen Beschreibungen von Jerusalem und Babylon sowie Sodom und Gomorrha zurück. ${ }^{2}$

1 Vgl. Riha (1970). R.-R. Wuthenow, Die Entdeckung der Großstadt in der Literatur des 18. Jahrhunderts, in: Meckseper/Schraut (1983), 7-27. Stierle (1993), 12 pointiert: „In Paris kommt die Stadt zu Bewußtsein. Die Stadt hat hier zuerst ihre Ausdrücklichkeit gefunden." Erste Anzeichen eines Stadt-Bewusstseins erkennt er in der Literatur der Spätaufklärung, dessen Entfaltung jedoch erst in der Literatur des 18. Jahrhunderts. Zur Vorgeschichte des Stadt-Bewusstseins, vgl. ebd., 53-87 und Corbineau-Hoffmann (2003). Die Studie von Lehan (1998), The City in Literature beginnt zwar mit den historischen Ursprüngen städtischen Siedelns in Mesopotamien, Griechenland und Rom, bezieht aber die literarischen Texte der Epochen nicht ein.

2 Die neutestamentliche Gegenüberstellung der Hure Babylon und des heiligen Jerusalems (Off. 17-19; 21) stehen in der Literatur der Klassischen Moderne für die ambivalente Begegnung des Menschen mit der Stadt. Die doppelte Sicht auf die Stadt als Ort der Versuchung bzw. des Un- 
Auf die Literatur der griechisch-römischen Antike dagegen haben sich die Autoren einer selbsterklärten Moderne kaum berufen. Literarische Stadterfahrungen aus griechischer Literatur werden nicht rezipiert. Aus römischer Literatur sind vor allem diejenigen Passagen gegenwärtig, die die antike Metropole Rom als Mittelpunkt eines gewaltigen Imperiums und als ewige Stadt feiern. ${ }^{3}$ Diese marginale Bedeutung ist jedoch durchaus überraschend: Im späten 17. Jahrhundert nahmen französische und englische Autoren noch vielfach die Texte der augusteischkaiserzeitlichen Literatur für ihre eigene literarische Auseinandersetzung mit den gerade entstehenden Großstädten - Paris und London - auf und machten panegyrisch, aber auch satirisch ausgerichtete „Rom-Ansichten“ für ihre Literatur fruchtbar. ${ }^{4}$ Im 18. Jahrhundert begann aber eine Entwicklung, bei der die antike Metropole Rom als Ort der Literatur zunehmend zu einer Kontrastfolie für eine eigene Gegenwart avancierte. Fortan versinnbildlichte sie in deutscher Literatur einen Ort der Musen, der Gelehrsamkeit, der Künste und Wissenschaften und verlor damit ihren einst ambivalenten Charakter. ${ }^{5}$

Infolge dieser Entwicklungen ist es wohl nur wenig verwunderlich, dass in einschlägigen Handbüchern der Literaturwissenschaft für die Anfänge der literarischen Auseinandersetzung mit der (Groß-)Stadt zwar durchaus auf antike, wenn auch ausschließlich auf römische Autoren verwiesen wird, dass man es aber bei einer Nennung der Autoren Horaz und Juvenal und dem sehr allgemeinen Hinweis belässt: „Ansätze zu der Abwertung des Stadtlebens bestehen bereits im Altertum".6

tergangs der Menschen (Babylonmythos) und als Ort der Freiheit bzw. Erlösung (Jerusalemoder Romerwartung) bleibt bis in die Gegenwart vertrautes Muster. Der neutestamentliche Text (Abfassungszeit wohl 120 n. Chr.) wird in der klassischen Auslegung auf Rom bezogen. Vgl. Sim (1996), bes. 18-22. Der alttestamentliche Bericht vom Untergang der Städte Sodom und Gomorrha gilt als Urbild derjenigen Stadt, die in ihrer Unheil bringenden Schrankenlosigkeit letztlich untergehen muss. Ausführlich dazu Karlheinz Stierle, Der Tod der großen Stadt. Paris als neues Rom und neues Karthago, in: Smuda (1992), 110. Zum Babylon-Vergleich vgl. auch Riha (1970), 52 f. und Conrad Wiedemann, Supplement seines Daseins, in: ders. (1988), 4.

3 Diese Vorstellungsmuster wurden in antiker Literatur angelegt, jedoch erst in christlicher Panegyrik verfestigt. Dazu Classen (21986), 10 f., 18 f., 27 f., 30 f., 34; Edwards (1996), 82-88. Vgl. auch Oesterle, Paris - das moderne Rom? in: Wiedemann (1988), 375-419.

4 Zur Rezeption in der englischen Literatur vgl. Werner von Koppenfels, Rom - London, oder die Hauptstadt als satirischer Ort, in: Mahler (1999), 86-103.

5 In deutscher Literatur der Neuzeit ist der Vergleich moderner Metropolen, etwa Paris oder London, mit Städten des Altertums, meist Babylon und Rom, durchaus verbreitet. Dabei sind allerdings die Zuschreibungen an die vormaligen Großstädte einseitig: Babylon gilt als verrufen, diesseitsverfallen und steht für lockere Sitten und sinnliche Freuden, Rom dagegen ist ein Ort der Bildung, Kunst und Kultur. Aus der Gegensätzlichkeit der Stadtbilder ergibt sich in der Konsequenz das einheitliche Bild der problematischen neuzeitlichen Stadterfahrung. Siehe dazu Oesterle (1988), 375-419. Zum Wechsel vom negativen zum positiven Rombild im 4. Jh. aus christlicher Sicht vgl. Walraff (2004), Fuhrmann (1968), Schmitzer (2005).

6 Daemmrich (1987), 297. Diese sehr allgemeine Feststellung kann jedoch auf zahlreiche literarische Werke der römischen und auch griechischen Literatur bezogen werden. Unterschiede zwi- 
Corbineau-Hoffmann beginnt ihre „Kleine Literaturgeschichte der Großstadt“ (2003) zwar mit einem Zitat aus den poetischen epistulae 2, 2 des Horaz, das sie als eine erste Auseinandersetzung mit der Großstadt und auch als deren „Einzug in die Literatur“ würdigt, konstatiert aber binnen Kurzem: „Dass die Großstadt selbst ein poetischer Gegenstand sein könnte, kommt Horaz schon gar nicht in den Sinn."7 Dieses Ergebnis verallgemeinert sie für die gesamte antike Literatur und beschließt den Abschnitt mit der Ansicht, dass erst „im Laufe der Zeiten die Großstadt zu einem der ,großen' Gegenstände der Literatur"'8 wurde.

Auch nach Meinung Stierles (1993) hatte ,die Antike (...) für das Bewußtsein der Stadt in ihrem konkreten Lebenszusammenhang keine Sprache, obschon die griechische polis und die römische urbs für die Stadtkultur Europas wegweisend wurden. "9 Allein die Werke der Satiriker Juvenal und Horaz sind es seiner Einschätzung nach, die die Großstadt in der antiken Literatur, wenn auch „,nur in partikularer Perspektive, zu Wort" ${ }^{\text {"10 }}$ brächten.

Diese hier skizzierten Einschätzungen der Neuen Philologien zum Einzug der Großstadt in die Literatur haben das Interesse für die vorliegende Untersuchung geweckt, denn sie scheinen einem ersten, rein intuitiven Eindruck eines heutigen Lesers antiker Literatur zu widersprechen. Für den Gegenwartslyriker Durs Grünbein etwa ist der römische Autor Juvenal ,ein Dichter, der wie kein zweiter seiner Zeit instinktiv den wahren Minotaurus moderner Lyrik bei den Hörnern packte: die Großstadt selbst."11 Ihm zufolge steht ein antikes Bewusstsein für die Großstadt und deren Einzug in die Literatur außer Frage. Er weist auf die geschichtslose Größe der Großstadt in den entsprechenden römischen Texten hin ${ }^{12}$ und stellt ihre Aktualität in der Beschreibung einer menschlichen Grunderfahrung heraus. ${ }^{13}$ Sichtet man Handbücher zur Literatur der augusteischen und kaiserzeitlichen

schen einem im weitesten Sinne städtischen und ländlichen Leben finden sich bereits in der frühgriechischen Literatur. Tendenzen einer Abwertung des Stadtlebens lassen sich bereits in den griechischen Komödien (Aristophanes, Menander) ausmachen. Vgl. dazu Reinhardt (1988), 3-18 und Rosen/Sluiter (2006).

7 Corbineau-Hoffmann (2003), 7.

8 Ebd.

9 Stierle (1993), 53. Dabei denkt er vor allem an staatstheoretische Schriften wie die von Platon, Aristoteles, Cicero und Augustin, aber auch an die geographischen Schriften von Pausanias und Strabo, die eine Stadt als Ansammlung denkwürdiger Kunstdenkmäler präsentierten.

10 Stierle (1993), 53.

11 Grünbein (2005), 329.

12 „Juvenal beschreibt um das Jahr 100 unserer Zeitrechnung ein Rom, das mir sehr ähnlich vorkommt wie die Situation heute in New York, auch ein wenig wie in Berlin. Also dieses Ineinander vieler Kulturen, Religionen und neuer Lebensformen, die Arten des Verbrechens, der Geschäftemacherei, dazu alle möglichen Affekte des Menschen." Grünbein (1995), 224. Vgl. auch Grünbein (2005), 328-368.

13 Vgl. auch v. Albrecht (2002), 102: Die „Antike interessiert Grünbein nicht qua Vergangenes (...), sondern im Rahmen einer eigenständigen Sicht der Welt.“ 
Literatur, so gehört laut ihnen die Großstadt Rom zum wichtigen „literaturwissenschaftlichen Rahmen"14. Die Beziehung zwischen Literatur und Großstadt geht jedoch darüber hinaus. Stellt man die schlichte Frage, wo ein literarisches Werk spiele, so lautet die Antwort für die Dichtung dieser Epochen recht häufig: in Rom. Naturbesonderheiten, zahlreiche Monumente und zentrale Platzanlagen, aber auch Einrichtungen einer großstädtischen Infrastruktur wie Theater, Circus, Stadttore, Aquädukte oder Straßennetze hielten durch entsprechende Referenzen ${ }^{15}$ Einzug in die Dichtungen ihrer Zeit. ${ }^{16}$ Gerade dieser außergewöhnliche Bezug auf eine reale Großstadt macht diese Texte für die Antike bereits einzigartig. ${ }^{17}$

Einen „unmittelbaren Ausdruck römischer Urbanität“, in der sich der Dichter „unzählige Einzelheiten des alltäglichen Lebens zu eigen“ mache, gesteht zwar Stierle den Texten Juvenals zu. Jedoch nutzt der antike Dichter sie seiner Auffassung nach allein, um ,sie zum immer gleichen Zeugnis gegen die Stadt zu nötigen, deren negative Wirklichkeit am positiven Ideal des einfachen, unverkünstelten Landlebens tadelnd gemessen wird." 18 Was Stierle in den antiken Texten vor allem fehlt, ist die „Betrachtung und Wahrnehmung der Stadt selbst“"19, die genau dadurch zu einem Gegenstand der Literatur wird. Zentraler Unterschied zur Moderne ist für ihn, dass in der antiken Literatur die Großstadt nicht in ihrer Physis als Stadt, in ihrer räumlichen Ausdehnung oder inneren Struktur, gezeigt werde und sie in einen unmittelbaren Lebenszusammenhang der Figuren gestellt wird.

Genau hier will die vorliegende Untersuchung ansetzen, deren Ziel es ist, diesem Eindruck Stierles nachzugehen und zu modifizieren. In den Blick genommen werden soll die erzählerische Ausgestaltung eines literarischen Raumes unter der Fragestellung, ob räumliche Eigenschaften und Strukturen einer Großstadt in augusteischer und kaiserzeitlicher Dichtung vergegenwärtigt werden und in wieweit diese als eine sperifische Physis einer Großstadt bewertet werden können (Kapitel 3). Außerdem soll nach Anhaltspunkten dafür gesucht werden, ob die Großstadt für römische Autoren wie Juvenal, Horaz und womöglich auch weitere ein eigener, erklärter Gegenstand dichterischer Reflexion gewesen ist (Kapitel 4). Eine Sichtung zentraler Forschungsergebnisse über die antike Metropole Rom in der römischen Literatur, wie auch zur literarischen Darstellung von Raum und Räumlichkeit in der Antike und zu der von Stierle angesprochenen unausgewogenen Darstellung der Dichotomie Stadt und Land (1.1-1.3) soll dazu genutzt werden, diesen Untersuchungsgegenstand zu positionieren und schärfer zu konturieren (1.4).

14 Cancik (1974), 267-271.

15 Zum Begriff Referen₹ vgl. Vater (1991), 10-14.

16 Vgl. dazu ausführlich Abschnitt 2.1.

17 Vgl. dazu ausführlicher Kapitel 4.

18 Stierle (1993), 53. Vor allem Juvenals dritte Satire charakterisiert Stierle als „Antiverse“ ohne „einen Mehrwert über die bloße Negativität hinaus“, ebd., 54.

19 Stierle (1993), 56. 


\section{Forschungsbeiträge zur Großstadt als Raum der römischen Literatur}

\subsection{ROM. Stadtrömische Topographie in der Dichtung der augusteischen und kaiserzeitlichen Epoche (Forschungsbericht I)}

Die Versuchung, auf heutigen Stadtplänen Schauplätze römischer Literatur aufzufinden oder Bewegungen der Figuren ${ }^{20}$ durch den antiken Großstadtraum auf ihnen nachzuvollziehen, ist wegen der außergewöhnlichen Dichte an Referenzen auf die Topographie Roms in der augusteischen und kaiserzeitlichen Dichtung hoch. Und auch die Faszination, Orte, an denen die Literatur spielt, selbst aufzusuchen und ihren Genius loci auf sich wirken zu lassen, ist eine vertraute Kulturtechnik, die für die antike Metropole seit Jahrhunderten gepflegt wird und sich bis in die Gegenwart hinein in der Herausgabe von literarischen Reiseführern spiegelt. ${ }^{21}$ Die Be-

20 Fiktive Ereignisträger können Personen oder personenähnliche Entitäten (z. B. sprechende Tiere, Götter) sein. Sie werden als Figuren bezeichnet. Vgl. Zipfel (2001), 80.

21 Grundsätzlich zum Verhältnis von fiktionaler Literatur und Geographie vgl. Moretti (1999), Piatti (2008). Vorschläge zu einer Geographie über die Entstehungsorte (!) lateinischer Literatur unterbreitet Gualandri (1998). In griechischer Literatur Romm (1992), 183-214. Literarische Reiseführer für Rom unter Berücksichtigung antiker Literatur Neumeister (1991), Giebel (1995), Waiblinger (32009) a, Waiblinger (32009) b. Am umfassendsten van Heck (1977). 
ROM. Stadtrömische Topographie in der Dichtung

rechtigung zu diesem Vorgehen provozieren die literarischen Texte selbst. Denn jeder literarische Text baut mehr oder weniger deutlich „Handlungsorte und -räume auf, wobei die Skala von gänzlich imaginär bis hin zu (...) präzise lokalisierbaren Schauplätzen mit hohem Wiedererkennungswert reicht.“22 Zahlreiche Autoren der augusteischen und kaiserzeitlichen Literatur haben sich damit absichtsvoll für einen Ort der tatsäcblichen Welt, nämlich die Metropole Rom, entschieden, die somit in die Literatur, metaphorisch gesprochen, immigriert und zu einem „Ort der Literatur“, sprich zum Bestandteil der erzä̈lten Welt der Dichtung wird. ${ }^{23}$ Die Grenze zwischen erzählter und tatsächlicher Welt, zwischen Fiktionalität und Faktualität ${ }^{24}$, wird in diesen Texten damit willentlich verwischt. ${ }^{25}$

Bei der Verwendung von topographischen Referenzen, also Referenzen, die sich auf Naturbesonderheiten, Monumente oder zentrale Platzanlagen der antiken Metropole Rom beziehen, sind in den einzelnen Werken der augusteischen und kaiserzeitlichen Epoche durchaus Gemeinsamkeiten und Unterschiede ausgemacht worden. So weist Döpp (2003) darauf hin, dass die Dichter Vergil, Horaz und Ovid ,ganz überwiegend das Zentrum der Stadt (...) dem Leser vor Augen führen“26. Eine Untersuchung von Dyson und Prior (1995) legt offen, dass in den Epigrammen Martials der Gebrauch topographischer Referenzen stärker zu einer eindeutigen Lokalisierung im realen Stadtraum führt, während Horaz bei konkreten Ereignissen eher Referenzen auf eine allgemein städtische Infrastruktur wählt.27 Diese Ergebnisse könnte man nach dem Vorschlag Piattis (2008) dahin-

22 Piatti (2008), 16. Die antike Rhetorik trägt dem Unterschied zwischen imaginierten und realen Orten bisweilen durch die Unterscheidung von Topothesie und Topographie Rechnung. Vgl. Lausberg (42008), \$ 819.

23 Vgl. Zipfel (2001), 90-97. Zipfel bezeichnet, reale Entitäten“ in fiktiven Geschichten im Anschluss an Parson als immigrant objects.

$24 \mathrm{Zu}$ den Begrifflichkeiten vgl. Martinez/Scheffel (52003), 9-19. Die grundlegende Differenz zwischen Fiktionalität und Faktualität ist eine anerkannte Konvention, die auch für antike Dichtung gilt. Vgl. dazu Rösler (1980), Liebermann (1989) zur möglichen „Enttäuschung des Erwartungshorizontes“, ebd., 199, Hose (1996), der das Zugrundelegen von „Fiktionalität“ gerade für das Verständnis römischer Literatur als angemessen erklärt, ebd., 274. Bereits in frühen literaturtheoretischen Überlegungen wurde die Nachprüfbarkeit einer Erzählung mit einer außerhalb des literarischen Textes liegenden Wirklichkeit als unangemessen bewertet. Vgl. Arist. Poetik 1451 b. Dazu Büttner (2006), 86 und grundsätzlich Zipfel (2001).

25 Die Großstadt Rom in den Epigrammen Martials ist grundsätzlich fiktional wie die mythische Insel Ogygia in der Odyssee Homers. Der Unterschied zwischen diesen beiden Orten der Literatur liegt nach Ansicht Piattis allein darin, dass entsprechende Referenzen auf außerhalb der Literatur existierende Orte mit Nachdruck eine Faktualität suggerieren sollen. Legten Autoren jedoch Wert auf eine überprüfbare „Richtigkeit“ ihrer Angaben, sei es plausibel, diese dahingehend zu überprüfen. Abweichungen seien jedoch nicht „falsch“, sondern müssen in eine Interpretation einbezogen werden. Vgl. Piatti (2008), $136 \mathrm{f}$. Man kann durch einen Vergleich lediglich nachweisen, dass eine Erzählung beispielsweise nicht so unverfälscht ist, wie es der Erzähler glauben machen will. Vgl. Maatje (1975), 392, Nerdinger (2006), $10 \mathrm{f}$.

26 Döpp (2003), 29.

27 Vgl. Dyson/Prior (1995), 255. 
gehend reformulieren, dass bei den Autoren unterschiedliche Grade einer Fiktionalisierung des literarischen Raums vorliegen. ${ }^{28}$ Während die Epigramme Martials aufgrund ihrer topographischen Präzision stärker eine Faktualität suggerieren ${ }^{29}$, ist der Grad der räumlichen Fiktionalisierung bei Horaz höher. Denn in seinem Werk wird allein eine allgemeine Handlungs zone Rom ,importiert‘.

Was die Ausgestaltung einer räumlichen Physis durch derartige topographische Referenzen betrifft, macht Schmitzer (2001) auf etwas Entscheidendes aufmerksam: Wegen des ,selbstverständliche[n] Umgang[s] mit der urbanen Realität“"30 erweisen sich die Dichtungen der augusteischen und kaiserzeitlichen Epoche trotz der Fülle an topographischen Referenzen als „,[w]irkliche literarische Stadtführungen“31 für wenig brauchbar. Wenn der Leser die räumliche Beziehung topographischer Referenzen allein heutigen Karten $^{32}$, nicht aber der Literatur selbst entnehmen kann, so wird offensichtlich: Diese können zwar für einen Kenner stadtrömischer Topographie zu einer räumlichen Illusionsbildung ${ }^{33}$ führen, sie ersetzen aber die eigentliche erzählerische Ausgestaltung von räumlichen Eigenschaften und Strukturen nicht, sondern lassen die physische Präsenz des Raumes in der Literatur weitgehend unberührt.

Mahler (1999) hat sich in Bezug auf die literarischen Stadt-Texte der Moderne, die in der Regel ebenfalls einen mehr oder weniger starken Bezug zum Georaum aufweisen, dafür ausgesprochen, der „Illusion der Mimesis“ nicht darin zu folgen, dass „eine bereits existente Stadt im Text lediglich dargestellt, abgebildet, nachgeahmt“ werde. Für ihn ist vielmehr der umgekehrte Weg als der einer „Vorgängigkeit der Stadt vor dem Text“ zielführend: „,nämlich daß die jeweilige Stadt erst durch den Text hervorgebracht, hergestellt, produziert wird. Das wäre die Kraft

28 Vgl. dazu ausführlich Piatti (2008), 123-147. Unterschiedliche Grade des Bezugs auf einen Georaum müssen bei dem Nachverfolgen und Aufsuchen literarischer Schauplätze auf Karten selbstverständlich berücksichtigt werden.

29 Aus dem Hantieren mit topographischen Referenzen ergeben sich für den Autor der augusteischen und kaiserzeitlichen Literatur Regeln und Verpflichtungen, die Eco (21999), 114 pointiert beschreibt: Hinsichtlich der Richtigkeit topographischer Angaben waren die Erwartungen eines zeitgenössischen Publikums einzuhalten. Dieses war der communis opinio zufolge innig vertraut mit der Topographie Roms. Vgl. z. B. Schmitzer (1994) zur Satire 1, 9 des Horaz. Vgl. dagegen Greg Woolf, The city of letters, in: Edwards/Woolf (2003), 202-221, bes. 205 f., der zu plausibilisieren sucht, dass sich literarische Texte über Rom besonders an Leser in der Provinz wandten.

30 Schmitzer (2001), 524. Vgl. auch Jaeger (1995), 178. Vgl. Piatti (2008), 140, laut der Roudaut gezeigt hat, dass ,eine imaginäre Lokalität weitaus mehr deskriptiven Aufwand erfordert - während die Verwendung eines realen Toponyms den Autor/Erzähler, so er das will, von detailreichen Schilderungen gerade dispensiert. Erwähnt werden muss nur, was tatsächlich eine Funktion im Text hat."

31 Schmitzer (2001), 516.

32 Zu Karten und Raumerfassung in der römischen Antike vgl. Brodersen (1995).

33 Zum Begriff vgl. Nünning (32004), $281 \mathrm{f}$. 
ROM. Stadtrömische Topographie in der Dichtung

des Imaginierens (...), daß etwa Kafkas Prag nichts anderes ist als das durch Kafkas Texte konstruierte Prag.“"34

Wenn auch nicht in dieser Allgemeinheit, wurden in der altphilologischen Literaturwissenschaft einige vergleichbare Überlegungen angestellt. So trägt Jaeger (1995) ausgehend von den Oden des Horaz die Frage vor: „,...) by piecing together references to historical topography, we construct a place as a pre-existent setting for a poem, all the while omitting to ask the complementary question, how does the poem construct the place? ${ }^{\text {* } 35}$

Bei einer Untersuchung zur Präsenz eines Raumes in seiner Physis sollte demzufolge „die dichterische Anschaulichkeit, nicht (...) die sinnliche Anschaubarkeit ${ }^{\text {‘36 }}$ im Vordergrund stehen, denn diese dichterische Anschaulichkeit macht, pointiert formuliert, den Ort der Literatur erst zu einem Gegenstand der Literatur. Der Bezug der Dichtung zum Georaum ist daher für die dieser Untersuchung zugrunde liegenden Frage nach der Physis eines literarischen Raumes nicht von entscheidender Bedeutung.

Damit ist eine wesentliche Abgrenzung von einem aktuellen Forschungsgebiet formuliert, das sich vorrangig mit denjenigen Passagen in der Dichtung der augusteischen und kaiserzeitlichen Literatur auseinandersetzt, die einen starken Bezug zum Georaum der Metropole Rom aufweisen. Denn die Beobachtung Zankers (1987), dass in der augusteischen Epoche städtebauliche Maßnahmen einem komplexen semiotischen System von Kommunikation unterlagen ${ }^{37}$, regte auch Literaturwissenschaftler dazu an, im Hinblick auf die zahlreichen topographischen Referenzen Repräsentationen einer kulturellen Identität (romanitas) oder Intentionen einer politischen Direktive (etwa aurea Roma) aufzuspüren. ${ }^{38}$ Im Zentrum der

34 Mahler (1999), 12.

35 Jaeger (1995), 179. Vgl. auch Edwards (1996), 1: „Rome is a city that has generated many books over the centuries (...). Books have also played their part in generating Rome - or rather a multiplicity of Romes.“ Döpp (22003), 47 weist auch auf die ,sehr unterschiedlichen Facetten eines Rombilds" der augusteischen Dichter Vergil, Horaz und Ovid hin.

36 Hellwig (1964), 29, Fn. 8.

37 Vgl. Zanker (42003). Vgl. auch Wallace-Hadrill (1991) und Favro (1993), deren Versuch, eine Bewegung von dem Stadttor entlang des Campus Martius zu simulieren, vor allem die Einmischungen augusteischer Bauprojekte in die urbane Gestaltung aufzeigt.

38 Vgl. Schmidt (1995), 96. Nach dessen Ansicht sei bei der Suche nach derartigen Bausteinen eines Diskurses Literatur als ,System in Bewegung' zu analysieren, da sie von einer größeren Individualität und Eigenständigkeit geprägt ist. Wegweisend für die lateinische Literaturwissenschaft ist Edwards (1996). Ihr rezeptionsästhetischer Zugriff, der weit über die Grenzen der lateinischen Literatur und ihrem implizierten Publikum hinaus reicht, stellt Edwards auch in die Nähe älterer Arbeiten wie die von Rehm (21960), der eine Interpretation der Dichtungen über Rom von der Spätantike bis in die Renaissance vorlegt. Einen rezeptionsästhetischen Ansatz führt auch Henderson vor, indem er diesen Ansatz um einen dekonstruktivistischen erweitert. Vgl. dazu den Sammelband früherer Aufsätze „Writing down Rome“ von Henderson (1999) zu Einzelinterpretationen von Ausschnitten römischer Dichtung. Trotz des vielversprechenden Titels geht es ihm in den Beiträgen nicht um den Raum. 
Untersuchungen stehen dabei vor allem die Werke von Vergil, Properz, Tibull, Ovid, aber auch die Epigramme Martials und die Satiren Juvenals, jedoch allein diejenigen Passagen, die sich mittels entsprechender topographischer Referenzen unmittelbar auf den Georaum der realen Stadt Rom beziehen. Das verstärkte Forschungsinteresse lag dabei im letzten Jahrzehnt in einer hochkomplexen Fragestellung: Welchen kulturellen Kontext reflektieren dichterische Texte als Kommunikationsmedium zwischen Autor und idealem und tatsächlichem Rezipientenkreis, wenn topographische Referenzen in augusteischer und kaiserzeitlicher Literatur auftauchen? ${ }^{39}$ Rom als Ort der Literatur steht folglich in diesem Forschungsgebiet durchaus im Fokus, jedoch nicht Rom als großstädtische Metropole. Es fällt unmittelbar ins Auge, dass bei den in den Mittelpunkt gestellten Texten ein Autor wie Horaz, der laut Corbineau-Hoffmann (2003) und Stierle (1993) gerade die Großstadt in der Literatur in partikularer Weise darstellt, weitgehend unberücksichtigt bleibt. Auch über die Satiren Juvenals und die in ihnen wiedergegebene stadtrömische Topographie äußert sich Larmour in einem 2007 erschienenen Sammelband „The sites of Rome“ daher folgendermaßen: „All these preoccupations [of the figures, Anm. d. Verf.] are mapped onto the topography of the city, so that (...) figures are presented to us in a cityscape made up of an apparently haphazard, yet nonetheless surprisingly comprehensive, collage of the most famous and significant sites of Rome. Although their rôle in the text often makes them more than mere names or allusions providing couleur locale, the absence of much in the way of detailed description or particular locations suggests that this is not where the main interest of the poem lies." 40

39 Eigler (1998) zur erzählerischen Vermittlung von augusteischer Repräsentationskunst. Scheithauer (2000) stellt die Ergebnisse der althistorischen und archäologischen Forschung zum Bauprogramm der literarischen Überlieferung gegenüber. Klodt (2001) zeigt die symbolische Inszenierung von Raumarchitektur und städtischen Erinnerungsorten in Bezug zur Körpergröße des Herrschers anhand von Passagen aus Vergils Aeneis, Statius' Silven und bei Ammianus Marcellinus. Von einem „alternativen Bauprogramm“ in ausgewählten Passagen bei Ovid geht Holzberg (1999) aus; umfassend zu den Monumenten im gesamten CEuvre Ovids Boyle (2003). Zum Wettstreit des Autors mit dem augusteischen Bauprogramm bei Properz vgl. Welch (2005). Über den Palatin und das Kapitol im Werk Tibulls vgl. Rea (2007). Ebd., 5 auch weiterführende Literaturhinweise für die augusteische Literatur. Für eine mit der kaiserlichen Direktive übereinstimmende Autorenintention in den Epigrammen Martials plädiert Sullivan (1991), 147-155. Verschiedene Aufsätze zur Topographie Roms aus der Sicht römischer, aber auch griechischer Literatur (Plutarch) vereint der Sammelband von Larmour/Spencer (2007). Übertragen wurde die Fragestellung nach der Semiotik stadtrömischer Topographie auch auf eine entsprechende Bedeutung der natürlichen „Landschaft“ bzw. des „Gartens“. Entscheidende Impulse für diese Fragestellung gehen von Leach (1988) und Edwards (1996) aus. Vgl. dazu Eigler (2001), Diana Spencer, Horace's Garden Thoughts: Rural Retreats and the Urban Imagination, in: Rosen/Sluiter (2006), 239-274, Giesecke (2007), Spencer (2010), hier mit einem Überblick über die Forschung zum Thema „Landschaft“.

40 Larmour (2007), 172. Diese Ausführungen entsprechen bereits den Feststellungen Schmitzers (2001). Sie stützen aber auch den Eindruck Stierles (1993). 
Larmours Meinung nach sei Rom in den Satiren Juvenals nicht wesentlich präsent, was sich an den fehlenden Beschreibungen ausgewiesener städtischer Schauplätze zeige. Daran lasse sich gleichfalls auch ein geringes Interesse des kaiserzeitlichen Autors an der Darstellung der Großstadt Rom ablesen. Ob die Bescbreibung die alleinige Darstellungstechnik eines Raumes ist, um physische Merkmale des Raumes auszugestalten, wird im nächsten Abschnitt anhand von Forschungsergebnissen zur Raumdarstellung in antiker Literatur (1.2) und in einer größeren Ausführlichkeit und mit einer größeren Systematik im Methodenkapitel (2.2) erörtert.

\subsection{RAUM. Untersuchungen zu Raumdarstellungen in der antiken Literatur (Forschungsbericht II)}

Die Beobachtung Larmours (2007), dass es in Juvenals Satiren an Beschreibungen der antiken Metropole oder der ausführlicheren Darstellung eines innerstädtischen Schauplatzes mangele, oder die Feststellung Schmitzers (2001), dass die Dichtungen der augusteischen und kaiserzeitlichen Epoche sich als Stadtfübrungen wenig eignen, sind als ein Negativergebnis bemerkenswert. Denn für Beschreibungen, sogar speziell für Beschreibungen von Wegen durch städtische Siedlungen hätte es in antiker Dichtung durchaus Vorbilder gegeben. Dies zeigen bereits die Forschungsergebnisse zu den ältesten literarischen Zeugnissen griechischer Literatur, den homerischen Epen.

Über die Darstellungstechnik der Beschreibung hat Friedländer (1912) in seiner hundert Seiten umfassenden Einleitung zu verschiedenen Gattungen der griechischen und lateinischen Literatur geschrieben. Auch wenn es ihm dabei wesentlich um die Beschreibung von Kunstwerken und nicht von Räumen ging, sind dort wichtige Punkte eines jeden Beschreibungsvorgangs benannt und bereits für die homerischen Epen nachgewiesen. Eine Bescbreibung setze beim Epitheton an, finde sich im Rüstungs- und Ankunftsschema ${ }^{41}$ und weite sich schließlich in einer ausführlichen Wiedergabe zum „Wirklichkeitsmotiv“ aus. Dem allgemeinen Verständnis nach rückt gerade diese letzte, ausführliche Form der Wiedergabe den zu beschreibenden Gegenstand in den Mittelpunkt. ${ }^{42}$

41 Vgl. Friedländer (1969), 3-7. Vgl. auch Hellwig (1964), 32-35.

42 Vgl. Fowler (1991), 25 f. Zur Definition von ,Beschreibung' kann eine lebhafte, fächerübergreifende Diskussion verfolgt werden, die bis heute noch nicht abgeschlossen ist. Vgl. Dennerlein (2009), 132-139. Sie kann und soll hier nicht nachgezeichnet werden. Zentral ist Folgendes: Neben der allgemeinen Abwertung einer Beschreibung für die erzählende Literatur als ancilla narrationis (in Folge etwa von Lessings wirkungsmächtiger Unterscheidung von Dichtung und Malerei und Genettes Fokussierung auf die Ereignishaftigkeit als Wesensmerkmal von Literatur) bezieht sich ein m. E. wichtiger Diskussionspunkt auf die Frage, ob die Handlungs- und Geschehenslosigkeit für das Vorliegen einer Beschreibung zwingend ist. Bei einem derartigen Verständnis wären z. B. die so genannten Rüstungsszenen keine Beschreibungen. Auch die gemeinhin als erste Kunstbeschreibung in griechischer Literatur gewürdigte Schildbeschreibung im 18. Buch der Ili- 
Hellwig (1964) hat in ihrer Studie zu „Raum und Zeit im homerischen Epos“ für die Odyssee einen Qualitätssprung speziell in der erzählerischen Wiedergabe von räumlicher Erfahrung herausgestellt. Vor zentralen Wendepunkten der Handlung, so Hellwig, werden einige Schauplätze durch recht ausführliche Beschreibungen dargestellt, der Schauplatz würde in diesem Epos zu einem Gegenstand der Literatur. ${ }^{43}$

Im Buch 6 der Odyssee findet sich die wohl erste Beschreibung einer literarischen Stadt in Form einer Wegbeschreibung. Nausikaa, Bewohnerin der Stadt der Phäaken, erklärt Odysseus, wie er vom Strand aus zum Haus ihres Vaters gelange. ${ }^{44}$ Mit dieser Wegbeschreibung liegt nicht nur eine „Arbeitsdefinition der antiken Stadt“ vor, sondern es ist eine Darstellungsform gefunden, „, in de[r] auch das Publikum ein solches Kennenlernen mitverfolgen kann". 45

Literarische Konventionen für Stadtbeschreibungen und laudes urbium in griechischer und lateinischer Literatur hat Classen (21986) untersucht, wobei es ihm allerdings wesentlich darum ging, geläufige inhaltliche Bestandteile eines Stadtlobs oder einer Stadtbeschreibung von eigenständigen Arbeiten abzusetzen. ${ }^{46}$ Beispiele aus der Dichtung der augusteischen und kaiserzeitlichen Epoche behandelt er daher knapp, um eine bereits in der griechischen Literatur festgestellte Tendenz festzuhalten: „(...) wo eine Stadt gepriesen oder beschrieben wird, läßt man sie als Ansammlung von Bauwerken oder als Urzelle oder Mittelpunkt eines großen politi-

as wäre keine Beschreibung, da das Aussehen des Schilds während des Vorgangs seiner Herstellung erzäblt wird. Vgl. Hom. Il. 18, 468-608 und dazu Friedländer (1969), 2 f.

43 Vgl. Hellwig (1964), 38.

44 Vgl. Hom. Od. 6, 262-307: Nausikaa beschreibt zunächst einen außerstädtischen Bereich mit Feldern und bebautem Land und benennt die Position eines väterlichen Landguts als in Rufweite zur Stadt. Vergleichsweise ausführlich beschreibt sie die städtische Grenze als eine hohe Umwallung und einen Hafen auf beiden Seiten der Stadt. Sie nennt auch optische Bezugspunkte: Der Weg innerhalb der Stadt ist zu beiden Seiten mit Schiffen gesäumt, die Agora der Stadt, an der sich Odysseus an einen Bewohner zur weiteren Orientierung wenden soll, ist optisch an verschiedenen Merkzeichen erkennbar, nämlich an einem Poseidon-Tempel in der Mitte des Platzes und an den als typisch herausgestellten Arbeitsvorgängen der Bevölkerung vor Ort.

45 Schmitzer (2001), 517. Zum Zusammenhang der Stadtbeschreibung bei Homer und der Stadtbeschreibung von Atlantis bei Platon vgl. Schmitzer (2001), 518-520, bes. 519: „Platon weitet das homerische Modell zur wohl umfangreichsten literarischen Stadtbeschreibung der Antike aus.“ Classen (21986), 7 würdigt die Stelle aus der Odyssee als erste zusammenhängende Beschreibung einer Stadt. Unberücksichtigt bleibt sie bei Elliger (1975). Hellwig (1964), 33 fasst die zweite Erwähnung der Stadt der Phäaken in Hom. Od. 7, 37-46 zusammen. Im Unterschied zur ersten Darstellung setzt der Autor allerdings nicht mehr die Technik der Wegbeschreibung, sondern die einer erzäblten Wabrnehmung aus der Figurenperspektive des Odysseus ein. Auch auf diesen Unterschied in der Wahl der Darstellungstechnik weist bereits Hellwig (1964), 35, Fn. 15, allerdings im Hinblick auf eine andere Passage in der Odyssee hin. Die Vermittlung räumlicher Eigenschaften muss folglich nicht zpingend mit der Erzählinstanz zusammenfallen. Eine Erzählinstanz kann die Vermittlung der Beschaffenheit einer räumlichen Gegebenheit - wie auch jede andere Form der Vermittlung - an eine weitere oder mehrere Instanzen abgeben.

46 Vgl. Classen (21986), 2. 
schen Organismus erscheinen, nicht als Schauplatz der zahlreichen Aktivitäten der Bürger. ${ }^{\text {" } 47}$ Hier findet sich, wenn auch in einer etwas anderen Gewichtung, eine mit Stierle vergleichbare Einschätzung, nämlich dass die Stadt nicht in einem unmittelbaren Lebenszusammenhang dargestellt wird. Jedoch ist bemerkenswert, dass laut Classen die Stadt durchaus von Dichtern thematisiert wird, sobald sie „aus einem oder anderen Grunde auf das Leben in der Stadt verzichten müssen Ovid etwa während seiner relegatio oder Martial."“8 Die Stadt wird Classen zufolge in dieser Dichtung zu einem literarischen Gegenstand, aus einer räumlichen Entfernung der Autoren heraus.

$\mathrm{Zu}$ dem Schluss, dass antike Literatur auch in einem Falle offensichtlicher Fiktionalisierung stets nur das Ferne beschreibe, kam Goebel (1971) in einer Untersuchung zur erdichteten Architektur. „Das [(ausschließliche) Beschreiben des Fernen, Anm.d. Verf.] gilt nicht nur für die babylonischen oder ägyptischen Gegenstände von Herodots Periegesen. Es gilt auch für die Bauten der Dichtung. Der Königspalast von Ithaka, in der Odyssee Schauplatz eines großen Teils der Handlung, wird zwar von dieser Raum für Raum so ausgezeichnet genutzt, daß sich aus den szenischen Hinweisen der Erzählung ein Gesamtplan rekonstruieren läßt; doch eigentlich beschrieben wird er nirgends. Beschrieben wird der andere Hauptschauplatz der Odyssee, jener, an dem die phantastische Irrfahrt endet: der märchenhafte Palast des Alkinoos im fernen, nur von Odysseus er-fahrenen Phäakenland Scheria“".49 Goebel zufolge suspendiert den antiken Autor demnach jede Verwendung von Referenzen auf allgemein bekannte architektonische Bauformen. Beschrieben werde seiner Ansicht nach nur, was der Erfahrungswelt des Lesers nicht entspreche.

Aus diesen sehr unterschiedlichen Beiträgen zu Formen der Beschreibung in der antiken Literatur lässt sich entnehmen, dass einerseits die Beschreibung als Darstellungstechnik einer räumlichen Physis durchaus in antiker Dichtung etabliert ist und diese Darstellungstechnik nicht nur dekoratives Beiwerk ist, sondern dem beschriebenen Gegenstand eine herausgehobene Relevanz zuspricht. ${ }^{50}$ Anderer-

47 Classen (21986), 12. Classen führt dazu an: Prop. 4, 1, Verg. Aen. 8, 306-369, Tib. 2,5 und Stat. silv. 3, 5, 78-104, ebd., 11.

48 Classen (21986), 13. Er greift dazu Ov. trist. 3, 12 und Ov. Pont. 1, 8 sowie Mart. praef. 12 heraus.

49 Goebel (1971), 14. Goebel bescheinigt der antiken Literatur im Hinblick auf imaginierte Architektur eine generelle „Raumblindheit“. „Die antike Dichtung imaginiert nur privilegierte Bauten, Wohnungen von Göttern, Königen (...); und auch diese werden in ihrer tektonischen Gestalt nicht vergegenwärtigt, weder als konstruierter noch als erlebter Raum.“ Ebd., 20. Er attestiert der antiken Dichtung vielmehr eine „Schwelgerei im Stofflichen“, ebd., 15. Ausnahmen sieht er in Platons Atlantis-Episode und bei den griechischen Epikern. Er beschränkt sich in seiner Analyse ausdrücklich auf imaginierte Architektur und lässt daher z. B. die Silven des Statius unberücksichtigt.

50 Vgl. Friedländer (1969), 7: „Im wirklichen Leben wird sich die Beschreibung dort einstellen, wo die Umstände sie erzwingen; also Beschreibung einer Landschaft, wenn man etwa dem anderen einen Weg oder ein Ziel weisen will, einer Person oder ihrer Tracht im Sinne des ,Steckbriefes‘.“ 
seits lässt sich aus den Beiträgen von Schmitzer (2001), Larmour (2007), Classen (21986) oder Goebel (1971) trotz ihrer sehr unterschiedlichen Fragestellungen als gemeinsame Tendenz für die uns interessierende römische Literatur entnehmen, dass mit einer ausführlichen Beschreibung einer,Großstadt ${ }^{6}$, noch dazu einer, die in einer Alltagswirklichkeit ${ }^{51}$ der antiken Welt existierte, in der Dichtung nicht zu rechnen ist.

Auf etwas anderes, aber sehr Entscheidendes macht Goebel in seinen Ausführungen aufmerksam: Der Palast auf Ithaka nimmt für den Leser räumlich Gestalt an, auch ohne dass er ausführlich beschrieben werde. Die Bewegungen der Figuren, das Erzählen von Ereignissen ermöglicht es dem Leser, zu einer räumlichen Vorstellung dieses Schauplatzes zu gelangen. ${ }^{52}$

Einer solchen ,indirekten Schilderung“"53 ist es beispielsweise zu verdanken, dass der Leser zu einer, wenn freilich auch nur schemenhaften, Vorstellung der städtischen Anlage von Troja gelangt, indem er den Weg Hektors durch die Stadt nachverfolgt, als er sie das letzte Mal aufsucht. ${ }^{54}$ Für das homerische Epos sind damit bereits zwei grundlegende Techniken der literarischen Raumwiedergabe nachweisbar ${ }^{55}$, mit deren Hilfe die Physis eines Raumes von größerem Umfang, sogar konkret in Bezug auf eine städtische Siedlung, vermittelt wurde: die Beschreibung

In jedem Fall plausibilisieren diese Beobachtungen die Behauptung, einer jeden Beschreibung komme stets ein besonderes, interpretatorisches Gewicht zu. Vgl. zur Diskussion um das interpretatorische Gewicht einer Ekphrasis Fowler (1991).

51 Vgl. zum Begriff und zum Verständnis im Hinblick auf fiktionale Literatur Zipfel (2001), 76.

52 Eine aus dem Epos gewonnene Beschreibung (!) des Palastes findet sich bei Bérard (1955), 556, ebenso ein Grundriss und eine Legende des fiktiven Königspalastes von Ithaka ebd., Cartes et Plan, Nr. 6, sowie eine Karte seiner Irrfahrten, Cartes et Plan, Nr. 4 und 5.

53 Vgl. Hellwig (1964), 31-39.

54 Vgl. Hom. Il. 6, 237-529. Hektor betritt die Stadt durch das Skäische Tor, gelangt zum Palast und sendet von dort seine Mutter und seinen troischen Frauen zum Tempel der Athene. Er selbst begibt sich zu Paris und Helena und kehrt von dort zurück zum Palast. Dort trifft er seine Frau nicht an und geht daher zurück zum Skäischen Tor, wo er sich an der Grenze zwischen Stadt und Feld von seiner Frau und seinem Sohn trennt. Die Physis der Stadt Troja besteht daraus, dass einzelne Bereiche von ihr (Tor, Palast, Haus der Laodike, Tempel der Athene, Haus des Paris) durch das Erzählen von Ereignissen, die sich in, an oder bei ihnen abspielen, benannt werden und durch die Bewegung von Figuren, Hektor und Hekabe, mehrfach miteinander verbunden sind. Damit werden die jeweiligen Bereiche radial zum Palast angeordnet und dieser selbst wird gleichzeitig als ein räumlicher Fixpunkt der Siedlung herausgestellt. Diese erzählerische Wiedergabe übermittelt eine, wenn auch in der Tat äußerst vage Vorstellung von der räumlichen Physis dieser Stadt. Wesentliche Literaturhinweise zu dieser Passage bei Stovesandt (2008), 87-140, bes. 87. Vgl. auch Mannsperger (2001) mit einem schematisierten Vorstellungsbild. Mannsperger weist dem Palast des Priamos allerdings nicht die Funktion eines Zentralpunktes zu. Zur linguistischen Repräsentation vgl. Létoublon (2003).

55 Hellwig unterscheidet in ihrer Untersuchung zwischen zwei grundlegenden Darstellungstechniken des Raumes, der „direkten Ortsbeschreibung“ und der „,indirekten Schilderung“. Die Darstellungstechnik der ,indirekten Schilderung“ findet sich Hellwig zufolge bereits in der Ilias, vgl. Hellwig (1964), 38. Sie geht aber nicht auf die räumliche Darstellung von Troja ein. 
eines Raums mittels einer Wegbeschreibung und das Erzählen von Ereignissen in, an oder bei verschiedenen Bereichen, die durch die Bewegung von Figuren zu einem ,räumlichen Kontinuum 'verbunden werden.

Verschiedene Untersuchungen zu räumlichen Phänomenen in der griechischen und römischen Dichtung haben dazu beigetragen, weitere Formen der Raumgestaltung in den verschiedenen Gattungen zu identifizieren. ${ }^{56}$ Da die Schwerpunktsetzungen der einzelnen Arbeiten sehr unterschiedlich sind und sich die Untersuchungen in ihren methodischen Überlegungen und Termini kaum aufeinander beziehen, ist es nicht zielführend, diese hier einzeln vorzustellen. Wichtiger scheint es an dieser Stelle, an wesentliche Erkenntnisse zu erinnern, die das Interesse an der Untersuchung eines Raumes grundsätzlich, auch über einen literaturwissenschaftlichen Rahmen hinaus, legitimieren. ${ }^{57}$

Der Raum gehört ebenso wie Zeit und handelnde Figur zu einer Grundkomponente jedes literarischen Werkes. ${ }^{58}$ Die räumliche Gestaltung eines Werkes, etwa die Abfolge bestimmter Schauplätze, ermöglicht Einsichten in dessen Struktur. ${ }^{59}$ Die

56 Vgl. Hellwig (1964), 35, Fn. 15, die auf eine Sonderform der Beschreibung, nämlich die erzählte Wahrnehmung, als eine innovative Darstellungstechnik der Odyssee aufmerksam macht. Zur erzählten Wahrnehmung vgl. Abschnitt 2.2.3.3. Vgl. Goebel (1971), 5, der darauf aufmerksam macht, wie die Reihenfolge der Wiedergabe räumlicher Details der Reihenfolge der Wahrnehmung der Figuren entspricht. Vgl. dazu Abschnitt 2.2.2.2. Vgl. Willenbrock (1969) der auf die Möglichkeit der Raumerzeugung durch ein Teilelement des Raumes im Sinne einer pars pro toto aufmerksam macht. Vgl. dazu Abschnitt 2.2.2.1.

57 Deutlich mehr Monographien sind zum Themenbereich eines nicht-städtischen Lebensraumes erschienen. Zur Landschaft in Vergils Werken vgl. Snell (1946), Reeker (1971), Leach (1974), Witek (2006). Die Arbeit von Troxler-Keller (1967) zur Dichterlandschaft des Horaz geht auf den städtischen Raum nicht ein. Harrison (2007) gibt einen Überblick über die Thematisierung von Stadt und Land in den verschiedenen Gattungen des Horaz, allerdings mit einem deutlichen Schwerpunkt auf dem ländlichen Raum. Dort findet sich auch (ebd., 247) weiterführende Literatur, die eine ähnliche Tendenz zeigt. Vgl. auch Diana Spencer, Horace‘s Garden Thoughts: Rural Retreats and the Urban Imagination, in: Rosen/Sluiter (2006), 239-274. Einen Schwerpunkt auf die Satiren und damit auf die Stadt legt dagegen Braund (1989). Höhn (1951) kommt in seiner an Beschreibungen ausgerichteten Untersuchung zum „Rom des Horaz“ zu dem Schluss, dass andere augusteische Autoren anschaulicher präsentieren, meint dabei aber die Beschreibung von Kunstwerken (ebd., 64). Zur Landschaft in Ovids Metamorphosen vgl. Segal (1969). Trotz einem allgemeinen Zugriff auf den Raum etwa als Landschaft, Dichterlandschaft oder space findet die Stadt nur selten eine Erwähnung in Elliger (1975) mit einem Exkurs zur Landschaft in der römischen Dichtung, 432-442, Leach (1988). Die Arbeiten zum locus amoenus könnten hier ebenfalls genannt werden. Siehe Schoenbeck (1962) autorenübergreifend zum locus amoenus, zu Vorformen bei den griechischen Epikern vgl. Haß (1998). Allgemeiner zu Vorstellungen des einfachen Landlebens vgl. Vischer (1965), Römer (1981), hier zu Stadt und Land vgl. 7-50.

58 Vgl. Hallet/Neumann (2009), 11; Pfister (112001), 327; Ritter (1975), 1. Bereits Kayser (71961), 352. Ungern-Sternberg (2003), 878 bezeichnet die Kategorie Raum als eine „condicio literaria“ (sic!). Die Dominanz der Dimension Raum bei der Imagination führt laut Bal ( $\left.{ }^{3} 2009\right)$ dazu, dass jeder Leser sich einen Raum hinzudenken wird, auch wenn im Text kein Raum angedeutet wird. Vgl. ebd., 220.

59 Zur Strukturierung der griechischen Komödie durch Raumwechsel vgl. Landfester (1977), 201 f. 
Wahl bestimmter Räume, etwa ,wilde Natur ${ }^{6}$ oder ,Palast', wird bisweilen als zentrales Kriterium für eine Gattungspoetik angeführt. ${ }^{60}$ Die Lokalisierung einer Handlung oder gar die Beschreibung räumlicher Gegebenheiten sind dabei nicht nur dekoratives Beiwerk. Die Nennung und Ausgestaltung von Räumen lassen Rückschlüsse auf den sozialen Hintergrund ${ }^{61}$ oder die Charakterisierung handelnder Figuren zu. ${ }^{62}$ Wegen dieser engen „Verflechtung literarischer Raumpraktiken mit kulturellen Praktiken und Mentalitäten, mit sozialen und politischen Rahmenbedingungen" "63 dienen bei kulturwissenschaftlichen Fragestellungen literarische Räume als kulturelle Sinnträger oder als Schausteller einer Geschlechterordnung. ${ }^{64}$ Räume sind demzufolge wie Figuren und Zeit eingeordnet in die intentionale und

60 Geplant ist eine Abhandlung über den Raum als dritter Sammelband der Studies in ancient Greek narrative von Irene J. F. de Jong und René Nünlist. In einem von Paschalis/Frangoulidis (2002) herausgegebenen Sammelband finden sich Beiträge des Symposiums „Space in the Ancient Novel" zu aktuellen Fragestellungen der literarischen Raumforschung wie Identität, Kultur, Topographie oder Territorialisierungen. In einem Beitrag von Konstan werden strukturelle Unterschiede zwischen den Raumkonzepten im lateinischen und griechischen Roman offengelegt. Zur Stadt als typischem Schauplatz der römischen Satire vgl. Braund (1989). Bereits Vitr. 5, 6, 9 ordnet den verschiedenen dramatischen Gattungen jeweils typische Kulissen zu: der Tragödie Palastarchitektur, der Komödie Straßenszenarien, dem Satyrspiel Landschaft. Gattungskonstituierend ist die Kategorie des Raumes bei Itinerarien oder bukolischer Dichtung, hier vor allem in der lateinischen Literatur. Vgl. auch Kayser (71961), 355 f., der als „Kurzformen“ das Eidyllion nennt.

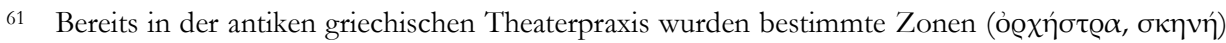
als Bereiche für eine besondere Rollenidentität reserviert. Der Auftritt einer Figur, von innen durch die Tür kennzeichnete sie z. B. als zum Palast zugehörig. Eine zweite Spielebene - ein flaches Dach - war in der Regel dem Auftritt von Götter-Darstellern vorbehalten. Vgl. dazu Seeck (2000), 76 und $206 \mathrm{f}$.

62 Vgl. z. B. Rachel Hall Sternberg, Dido in her settings: Carthage and Environs, in: Rosen/Sluiter (2006), 275-296. Sie deutet die Stadt Karthago als ein räumliches, äußeres Abbild des inneren Zustands von Dido.

63 Hallet/Neumann (2009), 16. Die literarische Kategorie Raum verweist als sozial-kulturelles Phänomen mimetisch auf eine vorhandene soziale Realität bzw. geht über diese emanzipatorisch hinaus. Besonders Räume des Nahbereichs - Wohnung, Zimmer, Werkstätten u. ä. - gelten als „Milieuschilderung“. Jäger (1998), 263, 267. Fitter begreift Theokrits Idyllen als „Milieu-Studie“ und sieht in ihnen gleichzeitig den Beginn einer ,poetry of place“, vgl. Fitter (1995), $40 \mathrm{f}$. So auch bereits Snell (1946), 234 im Gegensatz zu Vergils Eklogen, der „im Leben der theokritischen Hirten ein erhöhtes und verklärtes Dasein“ sah.

64 Die literarische Kategorie Raum als sozial-kulturelles Phänomen ist vielfältigen Semantisierungen unterworfen, die den Raum zum Schauplatz geschlechterorientierter Territorialisierung, aber auch zum Schauplatz der Grenzüberschreitungen machen. Vgl. grundsätzlich Würzbach (2004), 49, 51-58. Für Beiträge aus der Altertumswissenschaft vgl. Sammelband von Foley (1981), u. a. mit Beiträgen zur geschlechtsspezifischen Raumaufteilung in der Ilias oder zur emanzipatorischen Raumnahme der Stadt in Theokrits Idyllen. Jaeger (1995) zum Campus Martius als Raum der männlichen Adoleszenz. Vgl. ebenfalls den Sammelband zu Gender Studies von HarichSchwarzbauer/Späth (2005) u. a. mit Beiträgen zum Raum in augusteischer und kaiserzeitlicher Literatur. 
konventionale ${ }^{65}$ Gesamtstruktur eines jeweiligen Werkes und womöglich hoch bedeutsam für ein Gesamtverständnis.

\subsection{STADT. Stadt und Land - Eine textübergreifende Dichotomie? (Forschungsbericht III)}

Textübergreifend ist für die klassisch-philologische Forschung bisher hinsichtlich einer Raumgestaltung vor allem die Dichotomie von Stadt und Land in den dichterischen Werken der augusteischen und kaiserzeitlichen Epoche von Interesse gewesen. Dabei lag der Schwerpunkt allerdings nicht auf der Wiedergabe einer unterschiedlichen Physis beider Lebensräume, sondern vor allem auf der mit den jeweiligen Räumen verbundenen Semantik, etwa als Ausdruck philosophischer oder ideologischer Standpunkte. ${ }^{66}$ Die Thematisierung dieser Dichotomie ist in römischer Literatur in besonderer Weise ausgeprägt ${ }^{67}$, wenngleich ihre Wurzeln bis in die frühgriechische Epik hinein reichen. ${ }^{68}$ So sind in einem von Rosen und Sluiter herausgegebenen Aufsatzband „City, Countryside, and the Spatial Organization of Value in Classical Antiquity“ aus dem Jahre 2006 Untersuchungen versammelt, die dem Gegensatzpaar von Stadt und Land in griechischer und lateinischer Literatur des Altertums und anhand von archäologischen Zeugnissen nachgehen. Bereits aus dem Titel wird das zentrale Anliegen ersichtlich: Bei der Gegenüberstellung der beiden Räume interessieren vor allem die verschiedenen semantischen Zuweisungen wie unschuldig, gut, dumm, wild oder unzivilisiert für das Land, sowie korrupt, geordnet, qivilisiert für die Stadt. Festgehalten wurde in den einzelnen Forschungsbeiträgen wiederholt, dass die jeweiligen Semantisierungen keineswegs einseitig und unumstößlich präsentiert werden, wie man bisher angenommen hat. Sogar innerhalb eines Werkes - wie etwa in den Eklogen Vergils - finden sich flexible Bewertungen. ${ }^{69}$

65 Zur literarischen Konvention vgl. Weninger (1994). Zum Begriff konventional vgl. ebd., 5-11. Das Kennzeichen jeder literarischen Erzählform ist grundsätzlich die perspektivische Bedingtheit und Relativität des Erzählens, deren Gründe in der Intention eines Autors oder in einer literarischen Konvention liegen können. Vgl. dazu Karlheinz Stierle, Geschehen, Geschichte, Text der Geschichte, in: Koselleck (1973), 530-534 und Nünning (2009), 43. Dies gilt auch für die Gestaltung des Raumes. Dass diese Vorstellung auch römischen Autoren nicht fremd war, beweisen Passagen wie Plaut. Cas. 64-66: is, ne exspectetis, bodie in hac comoedial in urbem non redibit: Plautus noluit, / pontem interrupit, qui erat ei in itinere. Hier zeigt sich deutlich, dass auch bei den antiken Autoren nicht von der Vorstellung einer Vorgängigkeit eines Raumes die Rede sein kann.

66 Zu Horaz vgl. Harrison (2007). Über die Darstellung dieser Lebensbereiche in der Komödie Hunter (1985), 109-113.

67 Weber (1989), 24.

68 Vgl. Reinhardt (1988), 1-18. Vgl. Edwards (1993), 28 zu Homer.

69 Vgl. Mathilde Skoie, City and countryside in Vergil's Eclogues, in: Rosen/Sluiter (2006), 297326. Auch für das Euvre Martials konnte Merli in ihrer Untersuchung durchaus komplexe und 
Aus diesen Ergebnissen wird deutlich, dass einzeltextübergreifende Kontinuitäten im inneren Erleben und der Bedeutung der jeweiligen Räume nur mit großen Einbußen herausgearbeitet werden können. Zu stark ist jeder einzelne Text individueller Semantisierung unterworfen, die eher als eine persönliche Präferenz in Sinne der Intention eines Einzelwerkes verstanden werden muss. ${ }^{70}$ Von einer generell negativen Darstellung des Städtischen, wie es beispielsweise Stierle behauptet hat, kann laut diesen Ergebnissen keine Rede sein. ${ }^{71}$

\subsection{Die Großstadt in römischer Dichtung. Bestimmung des Untersuchungsgegenstands}

Die augusteische und kaiserzeitliche Literatur erfreut sich in den altertumswissenschaftlichen Forschungsbeiträgen der letzten Jahre eines großen Interesses. Auch die Metropole Rom gerät dabei als Ort dieser Literatur in vielen Facetten in den Blick. Eine Untersuchung der räumlichen Ausgestaltung des literarischen Raums Großstadt stand jedoch bisher noch nicht im Mittelpunkt einer Abhandlung.

Wie im Forschungsbericht I gezeigt werden konnte, führt eine Fülle topographischer Referenzen noch nicht zu einer räumlichen Anschaulichkeit in den literarischen Texten. Auch eine Textauswahl, die sich nur an einem derartigen Kriterium orientiert, bleibt unbefriedigend. Wie gezeigt werden konnte, fällt ein Autor wie

sogar gegensätzliche Bewertungen des jeweiligen räumlichen Bereichs aufzeigen. Vgl. Merli, Martial between Rome and Bilbilis, in: Rosen/Sluiter (2006), 327-348.

70 Aus der lateinischen Literatur sind Vergils Aeneis und Eklogen, Horaz' Oden und die Epigramme Martials versammelt. Zur Dichotomie vgl. Braund (1989), 23, Cairns (2012) und Abschnitt 4.1.2 dieser Arbeit. Auch die Beobachtung, dass die Semantisierungen häufig vor einem popularphilosophischen Hintergrund verhandelt werden, zeigt m. E. deutlich, dass eine individuelle Bewertung im Vordergrund steht.

71 Dass es sich bei den Semantisierungen der Räume Stadt und Land in antiker Literatur um eine kaum zu bändigende Vielschichtigkeit handelt, wird bei Rosen/Sluiter (2007) bereits in der Einführung festgehalten. Vgl. ebd., $1 \mathrm{f}$. Es sollte stets Vorsicht walten, ob es tatsächlich der jeweiligen Textgrundlage entspricht, dass beide Räume explizit als Oppositionen gestaltet sind. Vgl. Purcell (1987), der zu zeigen versucht, dass das Verständnis von rus nicht als polarer Gegensatz zur Stadt verwandt wurde, sondern auch „städtische“ Eigenschaften, z. B. im Sinne der Domestizierung der Natur, einschloss: „,Their landscape consciousness definitely included - if it did not indeed center on - the city" (ebd., 196). Vgl. Spencer, Horace's Garden Thoughts: Rural Retreats and the Urban Imagination, in: Rosen/Sluiter (2006), 243. Giesecke (2007) geht in ihrer Untersuchung von einer unterschiedlichen Integration von Natur im athenischen und römischen Stadtbild aus. Gärten sind ihr zufolge sowohl in die römische villa/domus, als auch in das römische Stadtbild in Form von öffentlichen Gärten integriert, eine Entwicklung, die gerade mit dem Beginn der augusteischen Zeit zusammenfällt. Vgl. ebd., xiii. Giesecke untersucht die Gestaltung dieser Räume als Utopie oder als Abbild der Unterwerfung und bezieht dabei literarische Zeugnisse (aus römischer Literatur Vergils Eklogen, Georgika und Aeneis, Lukrez, Tibull) ein. 
Horaz, dem eine Bedeutung für die Wiedergabe städtischer Lebensumwelt zugeschrieben wird, durch ein auf das Stadtrömische konzentrierte Raster. Eine Untersuchung der Physis einer literarischen Großstadt richtet ihr Augenmerk auf eine narrative Vermittlung und Ausgestaltung räumlicher Merkmale. Ob diese literarische Großstadt sich aber auf den Georaum bezieht, ist dafür nicht entscheidend.

Verschiedene Darstellungstechniken einer narrativen Raumwiedergabe wurden für die antike Literatur durch eine Vielzahl von Untersuchungen zu räumlichen Phänomenen herausgestellt - wie im Forschungsbericht II deutlich wurde. Bereits im frühgriechischen Epos findet sich eine räumliche Wiedergabe von städtischem Lebensraum in Form einer Wegbeschreibung und des ,Erzählens von Ereignissen'. Wegen eines gegenwärtig steigenden literaturwissenschaftlichen Interesses an Räumen und Räumlichkeiten in der Literatur finden sich in einzelnen Forschungsbeiträgen der Klassischen Philologie bereits elaborierte Beiträge zur literarischen Raumdarstellung. ${ }^{72}$ Was jedoch fehlt, ist eine Verständigung über verbindliche oder wenigstens nachvollziehbare Termini und Instrumentarien der Analyse. ${ }^{73}$ Diese fehlende Systematik und Terminologie geht jedoch bis hinein in die literaturtheoretischen Arbeiten und wird als Tatsache auch häufig beklagt. ${ }^{74}$ Es

72 Vgl. Wulfram (2009) zur Karthagobeschreibung im ersten Buch von Vergils Aeneis und Danek (2009).

73 In Bezug auf räumliche Darstellung einer Stadt wird in den Forschungsbeiträgen z. B. häufiger von Wanderung oder Spaziergang oder gar von einem Flaneur gesprochen. Dabei wurde dieses Vorstellungsbild auf die Darstellung eines konkreten Weges angewandt, wie z. B. auf die Passage aus dem 8. Buch der Aeneis, in der Euander und sein Gast Aeneas innerhalb des Gebiets des künftigen Roms unterwegs sind. Gleichzeitig wurde es - um nur ein anderes Extrem zu nennen - für ein gesamtes Euvre verwendet. Dyson/Prior (1995) verstehen die beiden Dichter Martial und Horaz als „two ancient Roman, urban wanderers who used aspects of the urban experience of contemporary Rome in their creative process“ (ebd., 248). Larmour (2007), 173: „The satiristnarrator is a prototype of the flaneur, who, as he strays across the physical space of Rome, wanders through an ideological landscape laden with chronotopic significance that might solidify his identity as a subject, but always fails to do so." Stierle (1993), 54 f. sieht dagegen nur in einzelnen Passagen aus dem satirischen Cuvre des Horaz „die Gestalt des Pariser Flaneurs vorgeprägt“.

74 Nünning (2009), 36. Dennerlein (2009), 4 f. führt es vor allem auf die fehlende einheitliche Definition von ,Raum' zurück, da die Untersuchungen zum Raum in Erzähltexten diesen sowohl konkret als auch metaphorisch (Gedächtnisraum, Raum, den die Buchstaben einnehmen, usw.) verwenden. Außerdem beklagt Dennerlein (2009), 9 eine fehlende gegenseitige Bezugnahme der bereits existierenden unterschiedlichen Ansätze. Ein knapper Überblick zur Forschung zum konkreten und metaphorischen Raum in der Narratologie findet sich bei Würzbach (2001), 105108. Ein ausführlicher Überblick über die Versuche einer systematischen Auseinandersetzung mit dem konkreten Raum in Erzähltexten bei Dennerlein (2009), 13-47. Eine Einführung in den aktuellen Forschungsstand zu interdisziplinären Fragestellungen erhält man bei Hallet/Neumann (2009), bes. 11-32. Eine Ursache für die Vernachlässigung dieser zentralen Komponente wird u. a. in der Tradition der Lessing'schen Unterscheidung zwischen der Malerei als räumlicher und der Dichtung als zeitlicher Kunstart gesehen. Vgl. Lessing, Laokoon: oder über die Grenzen der Mahlerey und Poesie [1766], in: Lessing (31995), 7-166. Vgl. Hoffmann (1978), 14-16. Bereits Friedländer (1912. Nachdruck 1969), 1 f. weist allerdings die Behauptung Lessings, dass Homer nicht beschreibe - als zentraler Modus der Raumpräsentation -, als unrichtig zurück. Dennerlein 
muss daher mithilfe neuerer literaturtheoretischer Überlegungen ein entsprechendes Instrumentarium zusammengestellt werden, um damit operierend die räumliche Ausgestaltung eines Raumes in der Literatur beschreiben zu können. Erst nach der Klärung, wie ein literarischer Raum in seinen Eigenschaften und seiner Struktur in der Dichtung präsentiert wird, ist es überhaupt sinnvoll, danach zu fragen, wie zentral räumliche Phänomene für die jeweiligen Texte sind. ${ }^{75}$

Wie im Forschungsbericht III gezeigt wurde, sollten semantische Bedeutungszuweisungen nicht in einer textübergreifenden Untersuchung beurteilt werden. Um die Bedeutung der antiken Großstadt im Sinne eines Gegenstands der Dichtung einschätzen zu können, scheint es eher angebracht, ausgewählte Einz̧eltexte auf diese Frage hin zu untersuchen, um ihre Mehrstimmigkeit nicht durch Generalisierungen zu überdecken.

Aus diesen Einsichten ergibt sich der weitere Aufbau der Arbeit in drei großen Abschnitten: Zunächst muss ein Vorgehen festgelegt werden, wie aus dem enormen Textkorpus eine sinnvolle Auswahl an Texten getroffen werden kann, die auf eine räumliche Ausgestaltung hin untersucht wird. Dies soll Gegenstand eines ersten Abschnitts sein (2.1).

Im Gegensatz zur Bühnenkunst ist bei allen narrativen Texten eine direkte Anschauung des Raumes nicht möglich. Der Leser bedarf einer erzählerischen Vermittlung. ${ }^{76}$ Daher sollen Techniken, die zu einer Ausgestaltung räumlicher Strukturen führen, vorgestellt werden (2.2). Da sie in der allgemeinen Literaturwissenschaft und in der Klassischen Philologie begrifflich und systematisch wenig etabliert sind, könnte womöglich mithilfe eines geeigneten Instrumentariums präziser als bisher geschehen der textübergreifend literarisierte Raum Großstadt in seiner darstellerischen Güte beschrieben werden.

Im Anschluss an diese theoretischen Überlegungen soll eine Auswahl von poetischen Texten, die sich auf die Großstadt beziehen, eingehender im Hinblick auf ihre räumliche Gestaltung besprochen werden. Ziel ist es dabei, eine Breite der narrativen Ausgestaltung räumlicher Physis in Konstanten und Varianten aufzuzeigen, um damit einen Grad der Literarisierung dieses Raumes in der Dichtung beschreiben zu können (Kapitel 3).

(2009), 4 erklärt das schon topisch beklagte Desiderat in der Erzählforschung nach 1960 mit der Wirkungsmächtigkeit von Genettes Discours de récit, der ,den Geltungsbereich der Narratologie auf die Untersuchung von Ereignissen beschränkt. (...) Da der Raum in einem schriftlichen Erzähltext kein Parameter der Vermittlung der Geschichte ist, blieb er außen vor.“

75 Vgl. Jäger (1998), 231 und Dennerlein (2009), 47.

76 Vgl. Hellwig (1964), 1: „Erzählen: das bedeutet Umwandlung des räumlichen Nebeneinanders, das in der sinnlich anschaubaren Realität und in der Bühnenkunst statthat, in das zeitliche Nacheinander der geistig vorstellbaren epischen Dichtung.“ Chatman (1980), 101: „In verbal narrative, story-space is doubly removed from the reader, since there is not the icon or analogy provided by photographed images on a screen. Existents and their space, if ,seen' at all, are seen in the imagination, transformed from words into mental projections." 
In einem letzten Abschnitt soll die Relevanz der Großstadt für die Dichtung anhand von Einzeltexten behandelt werden, denen aber möglichst eine exemplarische Bedeutung zukommt. Hierbei soll der Frage nachgegangen werden, inwieweit einzelne Autoren der augusteischen und kaiserzeitlichen Epoche der Großstadt eine Bedeutung für ihre Dichtungen zuschrieben (Kapitel 4). 


\section{Kriterien der Textauswahl und methodische Überlegungen zur Analyse räumlicher Physis in narrativen Texten ${ }^{77}$}

\subsection{Referenzen auf den Großstadtraum. Kriterien einer Textauswahl}

„Wie erkennt ein Leser einen Text als Stadttext?“78 Die lateinische Literatur kennt kein Werk, dessen Titel bereits auf eine Großstadt verweist wie etwa Döblins Berlin Alexanderplatz. Auch kennt sie kein Lehrgedicht wie Gays Trivia; or, The Art of walking the streets of London, das nach dem Vorbild von Vergils Georgika die Kunst lehrt, sich durch die Straßen einer Großstadt zu bewegen und dazu Vorschläge zur Ausrüstung und zum Verhalten unterbreitet. ${ }^{79}$ Wie der Einzug der Großstadt in die augusteische und kaiserzeitliche Dichtung trotzdem so bestimmt werden kann, dass eine erste Textauswahl erfolgen kann, soll in diesem Abschnitt erklärt werden.

77 Alle ab dem Kapitel 2 verwendeten Begriffe, die sich im Glossar am Ende der Untersuchung befinden, werden bei ihrer Ersterwähnung in den einzelnen Kapiteln in einfache Anführungszeichen gesetzt.

78 Mahler (1999), 13.

79 Vgl. Assmann (22008), $160 \mathrm{f}$. 
Auf einer sehr basalen Ebene kann man von der Präsenz eines Raumes in der Literatur sprechen, wenn ein entsprechendes Kernwort im Text auftaucht. ${ }^{80}$ Kernwörter, die auf die Präsenz einer Großstadt in moderner Literatur hinweisen, wären zum Beispiel die Namen von bekannten Großstädten, also ,Toponyme wie Paris, New York, London oder sogenannte räumliche ,Gattungsbezeichnungen ${ }^{61}$ wie Großstadt, Metropole, Weltstadt. Tauchen derartige Referenzen in einem literarischen Text auf, zählen die damit bezeichneten Räume zum sogenannten ,erzählten Universum ' ${ }^{82}$ Da man davon ausgeht, dass das Wissen von Großstädten und ihren spezifischen Besonderheiten zur Alltagswirklichkeit ${ }^{83}$ des Lesers gerechnet werden kann, reicht auch ein lediglich metonymischer Hinweis wie die Erwähnung bekannter Gebäude, Naturbesonderheiten oder sonstiger Sehenswürdigkeiten, wie Louvre, Hudson River, Big Ben aus ${ }^{84}$, um nicht nur von der Präsenz dieser konkreten ,topographischen Merk- oder Wahrzeichen' im ,erzählten Universum' auszugehen, sondern um behaupten zu können, die Metropole selbst gehöre nach dem Prinzip des pars pro toto ebenfalls zum erzählten Universum des entsprechenden Textes.

Um von einer besonderen Präsenz oder gar einem Gegenstand der Literatur sprechen zu können, müsste eine darüber hinausgehende Auseinandersetzung mit dem entsprechenden Raum in den Texten zu beobachten sein. Schließlich taucht z. B. das Toponym Roma in der ersten Ekloge Vergils auf, dennoch ist es nicht angebracht, von einer Großstadt als einem Gegenstand dieser Ekloge zu sprechen. Erst im Laufe der weiteren Lektüre stellt sich heraus, ob und in welchem Umfang ein Text eine Großstadt mit ihren räumlichen Merkmalen in den Mittelpunkt stellt oder nicht.

Die Präsenz des literarischen Raumes Großstadt nähme in den Texten der Moderne z. B. zu, wenn ,typische Teilelemente' eines derartigen Raumes wie Hochbäuser, Menschenströme, Automobile, U-Babn im Text benannt werden. Sind entsprechende Wörter im Text gehäuft auszumachen, stabilisiert sich die Hypothese, dass

80 Vgl. zum Folgenden Mahler (1999), 13-20.

81 Zum Begriff Gattungsbezeichnung als Bezeichnung für eine spezifische Gruppe raumreferentieller Ausdrücke vgl. Dennerlein (2009), 77.

82 Vgl. Ryan (2009), 422. Das alleinige Auftauchen einer Referenz sagt noch nichts über deren Relevanz oder Funktion für die Erzählung aus. Aber sie gehört in dem Moment, wo sie auftaucht, zum erzählten Universum, i. e. ,the world (in the spatio-temporal sense of the term) presented as actual by the text, plus all the counterfactual worlds constructed by characters as beliefs, wishes, fears, speculations, hypothetical thinking, dreams, and fantasies. (...) For a possible world to be part of the metaphorical concept of narrative universe, it must be textually activated." Piatti (2008), 361 f. unterscheidet zwischen einem nur erwähnten Raum und einem Schauplatz bzw. einer mehrere Schauplätze umfassenden Handlungszone, den Aufenthaltsort der handelnden Figuren.

83 Vgl. Zipfel (2001), 76.

84 Vgl. Mahler (1999), 15 und Fn. 16 mit weiterer Literatur. Zum Verständnis von topographischen Merk- und Wahrzeichen vgl. Lynch (1975), 62 und Dennerlein (2009), 52. 
der Rede-Gegenstand eine Großstadt sei. Diese „Wiederkehr von Wörtern desselben Bedeutungs- bzw. Erfahrungsbereichs in einem Text" ${ }^{\text {"85 }}$ wird als Isotopie bezeichnet. Aus diesem Grunde spricht Mahler (1999) von einer ,Konstitutionsisotopie' Stadt, wenn Gattungsbezeichnungen und typische Teilelemente einer Stadt vermehrt in einem Text auftauchen. ${ }^{86}$

Ausgehend von diesen Beobachtungen, wie in basaler Form eine Großstadt Einzug in die Literatur hält, stellt sich hinsichtlich der Kriterien für eine Textauswahl zunächst folgende Frage: Welche Kernwörter eignen sich als ein erstes Indiz dafür, dass in literarischen Texten der römischen Antike von einer Großstadt die Rede ist, und lassen somit eine erste Textauswahl sinnvoll erscheinen? Welche Teilelemente kommen infrage, um von einer Konstitutionsisotopie Großstadt in lateinischen Texten sprechen zu dürfen?

\subsubsection{Urbs und Roma als Kernlexeme einer lateinischen Großstadt- Isotopie?}

Sucht man nach der Gattungsbezeichnung für Großstadt, so muss man feststellen: Eine adäquate Bezeichnung existiert in der lateinischen Sprache nicht. Zur Bezeichnung einer Stadt kennt das Lateinische die Begriffe oppidum, urbs und civitas. Die ersten beiden Begriffe, oppidum und urbs, bezeichnen dabei den konkreten Siedlungsraum, also das mit einer Mauer umschlossene Areal mit darin befindlichen Häusern und Plätzen. ${ }^{87}$ Eine Übersetzung des Begriffs civitas mit Stadt dagegen träfe die Sache nicht. Civitas bezeichnet ähnlich wie der griechische Begriff тó $\lambda ı \varsigma$ die politische Gemeinschaft von partizipierenden Bürgern, die im städtischen Areal oder auch in der näheren Umgebung wohnen, nicht aber den konkreten, sinnlich wahrnehmbaren Ort, das städtische Territorium..$^{88}$

Von den beiden Begriffen, die das konkrete städtische Areal bezeichnen, urbs und oppidum, kommt als Kernwort zur Bezeichnung einer Großstadt am ehesten urbs in Betracht. Urbs ist laut der Untersuchung von Lorenz (1987) „die vornehmste unter den Bezeichnungen für ,Stadt'“"89 In der Gegenüberstellung mit oppidum be-

85 Bußmann (32002), 322.

86 Vgl. Mahler (1999), 17.

87 Vgl. Cic. rep. 1, 26. Vgl. Kolb (2005), 263. Urbs und oppidum existieren unabhängig von Menschen und Objekten. Für einen Betrachter sind Innen und Außen klar zu unterscheiden und räumliche Merkmale wie Ausdehnung, Begrenzung, Dichte u. ä. sinnlich wahrnehmbar. Zur Definition konkreter Räume vgl. Dennerlein (2009), 48. Zur Grundsatzdiskussion der Existenz von absoluten oder relativen Räumen vgl. Dünne/Günzel (2006), 19-42.

88 Vgl. Kolb (2005), 183. Nach Thuk. 7, 77, 7 bilden die Menschen die polis, nicht die leeren Mauern oder Schiffe. Das Verständnis von $\pi$ ó $\lambda ı \varsigma$ ist aber wohl auch einer Entwicklung unterworfen. Pausanias beschreibt die $\pi$ ó $\lambda ı \varsigma$ eher über die Existenz typischer städtischer Teilelemente wie öffentliche Gebäude, Gymnasia, Theater, eine Wasserquelle etc. Vgl. Paus. 10, 4, 1.

89 Lorenz (1987), 7. Kolb (2005), 184. 
zeichnet man mit urbs die größere, die Hauptstadt, die sich von kleineren Landstädten durch ihre Größe und Bedeutung abhebt. So definiert auch das OLD unter dem Lemma urbs: ,a city, large town “90.

Innerhalb großer Zeiträume verschiebt sich jedoch nicht nur das Verständnis von dem, was eine Stadt ist, sondern auch eine Wortbedeutung. Althistoriker warnen daher vor einer vorschnellen Gleichsetzung aufgrund von sprachlichem Material: Eine in den Quellen mit Stadt bezeichnete Siedlung muss keineswegs mit einer Stadt nach heutigen Vorstellungen übereinstimmen, sondern es kann „sich dabei (...) um nicht mehr als ein kleines Dorf handeln“. ${ }^{91}$ Ursprünglich bezeichnete auch urbs lediglich eine Siedlung, die nach einem etruskischen Ritus gegründet worden war. ${ }^{92}$ Um einen heiligen Mittelpunkt (mundus), einer mit Opfergaben gefüllten Grube, wurde eine heilige Furche gepflügt, die als magische Grenze ( $p o^{-}$ merium) das Böse abhielt und dadurch die Bereiche, die innerhalb und außerhalb der urbs lagen, voneinander schied. Dieses Vorgehen entspricht dem berühmten Gründungsmythos der Stadt Rom, die daher als urbs Roma bezeichnet wurde. Deren einstmals sakrale Grenze umfasste aber spätestens ab dem 4. Jahrhundert v. Chr. nicht mehr das gesamte Siedlungsgebiet Roms. Bereits die sogenannte Severianische Mauer umschloss weitere Stadtteile. In der Zeit der späten Republik wurde daher das pomerium erweitert. Trotz erneuter Vergrößerungen unter den Kaisern Claudius und Vespasian ,hielt es $[d$. h. die Erweiterung des pomerium, Anm. d. Verf.] (...) nicht Schritt mit der Ausdehnung des Siedlungsareals“. ${ }^{93}$ Bereits ab der späten Republik verlor das Wort urbs daher seine ursprünglich sakrale Bedeutung und bezeichnete zunehmend die höchste Ausformung einer Stadt in der Siedlungshierarchie. Diese Hierarchie bezog sich jedoch auf die relativen Strukturen eines Umlandes und nicht auf absolut gesetzte Standards. Mit urbs bezeichnete man fortan die Hauptorte, z. B. urbs Attica für Athen, und verband damit nicht eine feste bevölkerungsstatistische Qualität oder territoriale Ausdehnung. Bürgerkolonien, die als „Abbilder Roms“ galten, wurden ebenso wie besonders alte Orte, beispielsweise Capua oder Syrakus, als urbes bezeichnet. ${ }^{94}$

90 OLD (1992), s.v. urbs, 1 a, 2105.

91 Kolb (2005), 61.

92 Vgl. zum Folgenden die Quellensammlung antiker Autoren bei Lorenz (1987), 13-18 und Kolb (2005), $150 \mathrm{f}$.

93 Kolb (2005), 151. Den Vorgang der Erweiterung des Pomeriums beschreibt Gell. 13, 14. Demzufolge blieb der Aventin trotz seiner Bebauung und Nähe zu den anderen Hügeln (zunächst) außerhalb des Pomeriums. Zur Erweiterung des Pomeriums ausführlich bei Kolb (22002), 400403.

94 Kolb (2005), 184; Lorenz (1987), 7. Eine relationierende Definition von Großstadt liegt auch der modernen Begriffsbestimmung zugrunde. Vgl. dazu Pfeil (21972), 4-7. Mit einer eingehenden Problematisierung der Definition von Großstadt als Definition e contrario zur Stadt. Bei den antiken Autoren ist kein Versuch einer bündigen Definition von Stadt überliefert. Vgl. Lorenz (1987), 3; Braunert (1980), 12. 
Infolge dieser Bedeutungsentwicklung kann die Raumreferenz urbs nicht als ein eindeutiges Kernlexem interpretiert werden, das den basalen Einzug einer Großstadt in das erzählte Universum der jeweiligen antiken Dichtung signalisiert. Denn von einer Großstadt spricht man auch in der althistorischen Forschung erst bei einer topographisch-administrativ geschlossenen Siedlung mit einer Bevölkerungszahl von mehreren 100000 Einwohnern, die sich durch eine ausgeprägte Arbeitsteilung und soziale Differenzierung auszeichnet und von einer vielfältigen Bausubstanz, einem urbanen Lebensstil und einer weitreichenden Funktion als Zentralort für ein Umland geprägt ist. ${ }^{95}$ Derartige Großstädte existierten in römischer Zeit mehrfach. Alexandria, Antiochia, Karthago, Aquileia und einige kleinasiatische Städte zählen dazu. Nur fehlt der lateinischen Sprache für genau diese besondere Siedlungskonzentration ein spezifisches Wort.

Die urbs Roma erreichte diese geforderte Qualität einer Großstadt nach dem Sieg über Hannibal, ,als (...) verarmte Landbewohner nach Rom wanderten und die Zahl der Sklaven infolge der Kriege im griechischen Osten stark anwuchs. Die Stadt Rom vollzog im 2. Jahrhundert den entscheidenden Schritt zur Großstadt mit den entsprechenden Wohnungs- und Versorgungsproblemen. “96

Rom gilt ab diesem Zeitpunkt als die prototypische Großstadt der römischen Antike, deren Strahlkraft weit über ein näheres Umland und bis in die Gegenwart hinein reicht. Anstelle einer ausführlichen Begründung, wieso das Toponym Roma daher als Kernwort für eine Großstadt gewertet werden kann, ${ }^{97}$ seien nur einige Superlative kurz vor Augen geführt: Rom war bis zur Gründung von Konstantinopel (330 n. Chr.) das wichtigste Zentrum des Imperium Romanum. Bereits die augusteische Metropole hatte den Status einer Millionenstadt erreicht und sollte diesen für mehrere Jahrhunderte behalten. Als Lebensraum für Menschen unterschiedlicher Herkunft bot sie trotz oder gerade wegen ihrer „bis zum 19. Jh. einmaligen Bevölkerungskonzentration“"98 viele Lebenschancen für unterschiedliche

95 Vgl. Kolb (2005), 15. Diese statistische Größe entspricht auch der einer modernen Großstadt, vgl. Pfeil (21972), 4 f. Trotz aller Kritik an einer vorrangig statistischen Definition (ebd., 6), ist man der Meinung: „Mit der Größe ändert sich die Struktur, sie hat nicht nur einen relativen, sondern einen absoluten Wert. Wie in der gesamten Lebenswelt gibt es auch in den menschlichen Ballungen Stellen, wo Quantität umschlägt in Qualität. Bei einer Größe von 100000 Einwohnern beginnt die Unübersichtlichkeit eines Gemeinwesens: Seine Verhältnisse sind nicht mehr durch den bloßen Augenschein beurteilbar, seine Verwaltung bedarf der Statistik" (ebd., 5 f.). Strukturveränderungen ergäben sich auch bei weiterer Zunahme der Bevölkerung, so sei bei modernen Millionenstädten eine „Orientierung auf einen Kern nicht mehr möglich, die Städte dieser Größenordnung werden multinuklear" (ebd., 6).

96 Kolb (2005), 156. Gegen diese These vgl. Willem Jongman, Slavery and the growth of Rome. The transformation of Italy in the second and first centuries bce, in: Edwards/Woolf (2003), 100-122. Er ist der Ansicht, dass für den enormen Zuzug zum einen die Attraktivität der Großstadt eine wesentliche Triebfeder darstellte, zum anderen der enorme Bedarf an Sklaven dafür verantwortlich war.

97 Eine ausführliche und anschauliche Stadtgeschichte Roms bietet Kolb (22002).

98 Jongman (2001), Sp. 1078. 
Berufsgruppen. Zu den wichtigen Wirtschaftszweigen in der Stadt zählte das Bauwesen, denn die Stadt erfreute sich einer öffentlichen Bautätigkeit, die an Ausmaß und großzügiger Förderung durch die Herrscher ,nie zuvor und in Europa bis zur Industrialisierung nicht mehr erreicht worden ist" ${ }^{\star 99}$ und zu einer lückenlosen Bebauung des Stadtgebietes führte.

Aufgrund der Größe des Siedlungsareals wurde aus administrativen Überlegungen heraus unter Augustus die Stadt in 14 Regionen unterteilt, deren innerstädtische Grenzen Hauptverkehrswege, der Tiber, aber auch ehemalige Mauerverläufe bildeten. Zentraler Verkehrsknotenpunkt blieb die Senke des Forum Romanums. Hier gingen sternförmig die Hauptstraßen ab, die außerhalb des Stadtgebietes in Überlandstraßen übergingen. ${ }^{100}$ Eine Mauer, die das gesamte Areal umschloss, existierte nicht: Rom war in diesem Sinne eine offene Stadt mit einer ausgeprägten Peripherie. Dionysios von Halikarnassos sieht sich bereits in augusteischer Zeit nicht in der Lage, eine Grenze der Stadt anzugeben: ,Wenn jemand, mit Blick auf diese (um Rom gelegenen) Siedlungsplätze, die Größe Roms ermessen will, so wird er sich verloren fühlen und keinen sicheren Anhaltspunkt in Händen halten, der ihm erlauben würde zu bestimmen, bis wohin Rom sich noch als Stadt erstreckt und von wo es aufhört, eine Stadt zu sein; so sehr sind städtischer und ländlicher Siedlungsbereich ineinander verwoben und bietet sich dem Betrachter der Eindruck einer sich ins Unendliche ausdehnenden Stadt dar." ${ }^{\text {"101 }}$ Rom war mithin auch für antike Verhältnisse eine ungeheuer große Stadt, zudem ein politisches und religiöses Zentrum eines gewaltigen Reiches.

Eine kontextlose, separate Verwendung von urbs oder eine in der Verbindung mit einem anderen Toponym muss nicht eine Großstadt bezeichnen. In der engen Verzahnung mit dem Toponym Roma oder ggf. dem einer anderen, anerkannt

99 Jongman (2001), Sp. 1080. Die rege Bautätigkeit ging nicht ausschließlich vom Kaiser aus, wurde aber von ihm gefördert. Zur öffentlichen Bautätigkeit gehörten Aquädukte, Tempelanlagen, Fora, Thermen unter Nero, Titus, Trajan, Gebäude, die der Unterhaltung dienten wie ein Circus unter Caligula, ein hölzernes Amphitheater unter Nero, das Kolosseum unter Vespasian. Natürlich war auch die Bereitstellung von genügend Wohnraum durch den Bau von mehrstöckigen Wohnhäusern von Anfang an ein wichtiges Projekt.

100 Entgegen der antiken Vorliebe für orthogonalen Straßenbau behielten viele Stadtteile Roms ihren unregelmäßigen, verwinkelten Straßenverlauf. Nur wenige innerstädtische Straßen waren für den Wagenverkehr geeignet, zu den Tagesstunden waren sie für diesen gesperrt. Die breitesten Straßen Roms maßen 6-7 m. Kolb (22002), 415 und 417. Zum Folgenden vgl. ebd., 409-425.

101 Dion. Halik. 4, 13, 4-5. Übersetzung Kolb (22002), 309. Ausführlich zum Umland ebd., 309-316. Kolb zählt einen Umkreis von 20 km zum Einzugsgebiet Roms. Vgl. die Definition des Stadtgebietes in der juristischen Terminologie der continentia, die das Gebiet einer zusammenhängenden städtischen Bebauung meint. Vgl. dazu Kolb (2002), 406-409. Zur Bebauung in der Kaiserzeit vgl. ebd., 409-425. Sobald man die genaue geographische Ausdehnung und Bevölkerungsdichte dieser Großstadt berechnen will, verkomplizieren sich die Dinge, die für die vorliegende Untersuchung nach der literarisierten Darstellung allerdings zu vernachlässigen sind. Vgl. Kolb (22002), 400-409, 448-457. 
großstädtischen Siedlung wächst der Bezeichnung urbs erst die Qualität eines Kernworts für Großstadt zu. ${ }^{102}$

Für die Textauswahl ist es sinnvoll, auf eine synonyme Verwendung von Roma und urbs zu achten. So kann wohl am ehesten sichergestellt werden, dass die im Text dargestellten räumlichen Eigenschaften ein einheitliches Raumschema ${ }^{103}$ meinen, gleichzeitig aber ein erzählerischer Gestaltungsspielraum in seiner Breite erfasst wird.

Welche typischen Teilelemente und topographischen Merk- und Wahrzeichen über die Gattungsbezeichnung urbs und das Toponym Roma hinaus als Indizien für den Einzug einer Großstadt in den literarischen Text dienen können, wurde durch die vorangehenden Ausführungen schon implizit beantwortet. Als spezifische Eigenschaften einer antiken Großstadt galten ihre besondere horizontale Ausdehnung und eine hohe Besiedlungsdichte. Diese besondere Ausdehnung eines großstädtischen Siedlungsareals machte Zentrum und Peripherie unterscheidbar. ${ }^{104}$ Aus administrativen Gründen wurde das großstädtische Areal in verschiedene Viertel unterteilt. ${ }^{105}$ Eine antike Großstadt war durch Häuserfronten und -blöcke, durch Haupt- und Nebenstraßen geprägt und wies eine differenzierte Bausubstanz auf. Gerade die variantenreiche Bausubstanz gilt in der althistorischen Forschung als ein städtisches Charakteristikum und könnte somit auch in literarischen Texten als wichtiger Baustein einer Isotopie fungieren. ${ }^{106}$ In der römischen

102 Der Begriff urbs tritt häufig in Verbindungen wie urbs Roma und Romana urbs auf, er wird sogar synonym - also ohne jeglichen Zusatz - für das Toponym Roma verwendet, wie Quintilian bezeugt: ut ,urbem' Romam accipimus (...), cum sint urbes aliae quoque (...). Quint. inst. 8, 2, 8. Vgl. auch Quint. inst. 6, 3, 103 und die wohl weniger im alltäglichen, aber im literarischen Zusammenhang gebrauchte Zählung: ab urbe condita. Vgl. dagegen Cic. Brut. 18, 72 post Romam conditam. OLD (1992), 2105 differenziert unter dem Lemma urbs ebenfalls die spezielle Bedeutung: ,the city of Rome“. Georges (1969), Bd. 2, 3313, s.v. urbs B) 1) „die Stadt Rom (...) als Hauptstadt und Mittelpunkt des römischen Reiches". Diese spezifische Verwendung von urbs wird in den Textausgaben bisweilen durch die Großschreibung (Urbs) kenntlich gemacht. Rom gilt als die bedeutendste urbs ihrer Art, was Niederschlag auch in einer Formulierung wie urbs urbium findet.

103 Vgl. Dennerlein (2009), 240.

104 Die Peripherie einer städtischen Siedlung bildeten Friedhöfe, spezielle Werkstätten und Stadtvillen (villae urbanae). Im Umkreis von einigen Kilometern standen außerhalb der Stadt die villae rusticae und einige Tempel. Im Zentrum einer Stadt befand sich meist das Forum. Vgl. Vitr. 1, 7, 1. Es war von einer Säulenhalle umgeben, wichtige öffentliche Gebäude befanden sich dort, Ehrenstatuen, Tempel der wichtigsten Gottheiten, Basiliken und in der Nähe ein spezieller Verkaufsmarkt und Lagerhallen. Vgl. Kolb (2005), 192 f., 253. Vgl. dagegen Vitr. ebd., der vorschlägt, die wichtigsten Tempel auf der höchstgelegenen Stelle der Siedlung zu errichten.

105 Bei einer in der Regel sehr heterogenen Bevölkerungsstruktur waren die Viertel einer antiken Stadt nicht bestimmten ethnischen Gruppen oder sozialen Bevölkerungsschichten zugewiesen oder durch Mauern o. ä. voneinander getrennt. (Eine Ausnahme bildete hier Alexandria.) Die Viertel waren vielmehr nach Funktionen wie Wohnviertel, Gewerbeviertel, administrativ-sakrales Viertel (Tempel, Amtsgebäude) unterteilt. Vgl. Kolb (2005), 264 und 267.

106 Vgl. im Folgenden Kolb (2005), 192-194. 
Referenzen auf den Großstadtraum. Kriterien einer Textauswahl

Antike assoziierte man mit einer Stadt Aquädukte, Amphitheater, Thermen, Latrinen, Brunnenhäuser, Basiliken, Säulenhallen, Bibliotheken, Märkte, Fora mit zahlreichen öffentlichen Gebäuden und Ehrenstatuen, Tempeln und Befestigungsmauern. ${ }^{107}$ Ein weitverzweigtes Straßennetz prägte das Stadtbild und große Verkehrsachsen teilten einzelne Viertel voneinander. ${ }^{108}$ Keines dieser Bauwerke ist einzeln betrachtet ein ausgewiesen städtisches Element. Auch in kleineren Siedlungen wurden bisweilen Fora, Säulenhallen, Thermen oder Theater gebaut. Allein Größenunterschiede und eben „die Anbäufung der (...) Bauten an einem Ort [war] Städten vorbehalten." ${ }^{109}$ Dies trifft wohl auch für heutige Teilelemente einer Stadt zu. Die städtischsten Bauwerke der römischen Antike waren Kolb (2005) zufolge Bibliotheken, Amphitheater und der Circus, die „,wegen ihrer gewaltigen Größe zu aufwändig für eine durchschnittliche civitas "110 waren und daher meist nur in den Provinzhauptstädten errichtet wurden.

Neben den typischen Teilelementen einer Großstadt gab es in Rom zahlreiche topographische Merk- und Wahrzeichen. Die Lage der Metropole zwischen den Hügeln und dem Fluss Tiber war bereits von dem natürlichen Siedlungsareal her markant. Neben den Naturbesonderheiten bot Rom auch an Bauwerken genügend Wahrzeichen, die in literarischen Texten als Metonyme für die Metropole verwandt werden konnten.

\subsubsection{Die Verwendung von urbs und Roma in der römischen Dichtung}

Kann man die Textauswahl sinnvoll auf einen Zeitraum begrenzen, in dem man unter der urbs Roma eine pulsierende Millionenstadt versteht, und dadurch die Wörter urbs und Roma mit einigem Recht in einem literarischen Text als Kernwörter für den Redegegenstand Großstadt gelten lassen, so hält man dennoch nach einem Suchlauf durch entsprechende Datenbanken ${ }^{111}$ nicht nur Großstadttexte in den Händen. Wenn auch das Ausschlusskriterium - nur derjenige Text oder Text-

107 Befestigungsmauern waren ein typischer Bestandteil einer städtischen Siedlung, auch wenn sie weniger funktionalen Zwecken als dem Schmuck derselben dienten.

108 Die breiten Straßen führten auf ein gemeinsames Zentrum und z. T. monumentale Gebäude zu. Im Gegensatz zum altorientalischen und mittelalterlichen Straßensystem, in dem die verwirrende Straßenführung nur den Bewohnern der Viertel vertraut war, „tendieren die Viertel der antiken Stadt auch von ihrer Straßenführung her zu einer Benutzung durch alle Stadtbewohner“. Kolb (2005), 264.

109 Kolb (2005), 194. Die als typisch geltende Bausubstanz geht vor allem auf Vitruvs Abhandlung De architectura zurück, das als ein Handbuch römischen Städtebaus gilt. Eine „Standardausrüstung“ für hellenistische Städte im Westen Kleinasiens waren dagegen gepflasterte, regelmäßig angelegte Straßen, prächtige Hauptalleen mit mehrstöckigem Häuserbau, Gymnasien, Theater, Stadien, evtl. ein Hippodrom, Thermenanlagen, Kanäle, Aquädukte und Nutzbauten. Kolb (2005), $177 \mathrm{f}$.

110 Kolb (2005), 193.

111 Zugrunde gelegt wurde die Bibliotheca Teubneriana Latina, BTL 3 (2003) hg. von Paul Tombeur. 
ausschnitt soll als Großstadttext gelten, der eindeutig auf eine Großstadt referiert - das Material gewaltig reduziert, ersetzt eine computergestützte Zusammenstellung von Texten die Arbeit eines Lesers selbstverständlich nicht. Nicht jeder Handlungsort, der den Namen einer antiken Metropole trägt, wird zwangsläufig auch als ein städtischer Raum präsentiert. So liegen mit Vergils Aeneis, Ovids Fasten oder auch zahlreichen Elegien von Properz und Tibull Texte vor, deren literarischer Ort zwar Rom ist, die jedoch eher eine arkadische Landschaft mit Weideplätzen, Rindern und einfachen Hütten imaginieren. Derartige ätiologische Texte über Roms mythische Frühzeit sind besonders in augusteischer Zeit recht häufig zu finden, sie werden aber nicht im Mittelpunkt dieser Untersuchung stehen.

Des Weiteren wird gerade das Toponym Roma in dichterischen Texten nicht zwingend als Bezeichnung eines konkreten Raumes verwendet. Entsprechend dem Interessenschwerpunkt dieser Untersuchung werden daher all diejenigen Passagen weitgehend vernachlässigt, in denen es etwa metonymisch oder metaphorisch auf das Imperium Romanum bezogen wird oder den Kaiser oder eine göttliche Instanz meint. ${ }^{112}$ Auswahlkriterium ist, dass sich in den Texten eine Konstitutionsisotopie Großstadt feststellen lässt. Daraus ergibt sich eine sinnvolle und breite Auswahl an Texten und Textpassagen augusteischer und kaiserzeitlicher Dichtung, die hinsichtlich der räumlichen Ausgestaltung untersucht werden können. Im Mittelpunkt stehen für die augusteische Zeit vor allen Dingen die Satiren und Episteln des Horaz und weite Teile aus dem Cuvre des Ovid, aus kaiserzeitlicher Epoche vor allem die Epigramme Martials und die Satiren Juvenals. ${ }^{113}$ Diese Darstellungen

112 Zur Personifikation von Rom vgl. Roberts (2001). Zum Imperium Romanum in Rom vgl. Favro (1993), 248.

113 In Horazens satirischer Dichtung wird urbs 29-mal verwendet. Davon lassen sich folgende Belege nicht auf Rom beziehen: Verwendung im Plural (Hor. epist. 1, 2, 19; 1, 11, 5; Hor. ars 66; 142) oder bezogen auf Siedlungen in mythischer Zeit (Hor. epist. 1, 2, 19; Hor. ars 142; 394) oder eindeutig nicht auf Rom bezogen (Hor. sat. 1, 5, 37). Die Bezeichnung oppidum verwendet Horaz 3-mal und zwar stets für Siedlungen in mythischer Zeit (Hor. sat. 1, 3, 105; Hor. epist. 2, 1, 8; Hor. ars 399), ein einmaliger Beleg für die Bezeichnung oppidulum (vgl. Hor. sat. 1, 5, 87).

In Ovids liebeselegischer und liebesdidaktischer Dichtung wird urbs 20-mal verwendet, davon fünf Belege im Plural und zwei weitere Belege für Siedlungen mythischer Zeit (Ov. ars 2, 421; 3, 155). In den übrigen Belegen wird urbs nicht immer eindeutig für Rom verwendet. Allein die Schilderung einer ausgeprägten städtischen Struktur legt in diesen Fällen eine Gleichsetzung von Rom und urbs nahe. Das Toponym Roma dagegen wird achtmal direkt verwandt. In der Mehrzahl der Belege wird dabei Roms Bedeutung für das Reich hervorgehoben. In der Exildichtung Ovids wird urbs für verschiedene Siedlungen mythischer und gegenwärtiger Zeit verwendet, so auch wiederholt für Tomi (Ov. Pont. 1, 8, 11; 3, 4, 2; 4, 7, 24). Von 27 Belegen meinen acht nur Rom. 23-mal wird dagegen Rom direkt benannt, wobei der Schwerpunkt auf der Bedeutung der Stadt für das Imperium - Rom des Mars (Ov. Pont. 1, 8, 24; 4, 9, 66), Rom als bellatrix (Ov. trist. 2, 1, 321) bzw. victrix (Ov. Pont. 4, 3, 46, ähnlich Ov. trist. 1, 5, 70; 3, 7, 52) - liegt. Die Bezeichnung oppidum verwendet Ovid durchgehend zur Bezeichnung eroberter oder barbarischer Städte mit Ausnahme von Ov. trist. 1, 2, 78: oppida Asiae, und ebenso Ov. Pont. 2, 10, 21: magnificas Asiae urbes. 
werden gestützt und ergänzt durch Ausschnitte weiterer Vertreter ihrer Epoche, etwa Tibull, Properz, Calpurnius Siculus oder Statius. Ziel einer Auseinandersetzung mit diesen Texten ist es, gemeinsame Merkmale in der räumlichen Gestaltung dieses gattungsübergreifend präsenten Raumes herauszuarbeiten. Im Mittelpunkt stehen daher diejenigen Passagen, die auf die Physis des Makroraumes abzielen, in denen er in seiner dreidimensionalen Ausdehnung und seiner inneren Struktur „hervorgebracht, hergestellt, produziert wird““.114 Die Untersuchung bleibt damit weitgehend textimmanent. Aus dem Übereinanderlegen verschiedener literarischer Verarbeitungen entsteht jedoch ein dichtes Porträt eines Raumes und seiner Literarisierung in der römischen Dichtung, das auf einem Textkorpus basiert, das diesen bestimmten Raum, eine Großstadt, literarisiert. Unter dieser Voraussetzung - der Präsenz eines gemeinsamen Raumschemas ${ }^{115}$ - wird ein höchst heterogenes Textgemenge zum Ausgangspunkt der Untersuchung: Texte unterschiedlicher Gattungen und damit verbundener Konventionen, aus verschiedenen Epochen und von unterschiedlicher Qualität.

Das Vorhandensein von Kernlexemen, topographischen Merk- und Wahrzeichen und Teilelementen ist jedoch nur die Vorbedingung, an die eine nun mögliche erzählerische Ausgestaltung eines literarischen Raumes geknüpft ist. Damit kommen wir zur eigentlichen methodischen Schwierigkeit dieser Untersuchung: Wie soll man die über einen lexikalischen Befund hinausgehende Präsenz der Physis eines Raumes in der Literatur fassen? Wie können Aussagen über die Wahrnehmung und Nutzung eines Großstadt-Raumes durch literarische Figuren getroffen werden?

In Martials Epigrammen wird urbs 68-mal verwendet, davon zwölfmal im Plural bzw. nicht auf Rom bezogen. Einmal wählt Martial sogar die Formulierung exigua urbs (Mart. 13, 112, 2). Die Verwendung in den übrigen Fällen bezieht sich eindeutig auf Rom bzw. kann als solche interpretiert werden. Andere Begriffe für städtische Siedlungen sind selten. Von den römischen Bürgern spricht er als civitas (Mart. praef. 12). In der praefatio zum zwölften Buch nennt Martial das Verhalten seiner spanischen Mitbürger municipalium robigo dentium (Mart. praef. 12, 14 f.). Für das Leben in der Kleinstadt wählt Martial die Bezeichnung vita municipalis (Mart. 4, 66, 1). Oppidum gebraucht Martial zweimal: zum einen im Zusammenhang mit dem Toponym Formiae (Mart. 10, 30, 1), zum anderen meint er Landstädte (Mart. 3, 95, 7).

In Juvenals Satiren kommt urbs 33-mal vor. Davon bezieht er sich fünfmal nicht auf Rom: Einmal benutzt Juvenal urbs im Zusammenhang mit dem Toponym Babylon (Iuv. 10, 171), viermal wird urbs im Plural allgemein für die Siedlungsform verwendet (Iuv. 6, 411; 10, 34 und 284; 11, 101). Oppidum wird in den Satiren dreimal verwendet in stets eindeutiger Bezeichnung für eine Landstadt (Iuv. 3, 35; 8, 129; 15, 8).

114 Mahler (1999), 12.

115 Vgl. Dennerlein (2009), 240. 


\subsection{Die Analyse räumlicher Physis in narrativen Texten. Methodische Überlegungen}

nota magis nulli domus est sua quam mibi lucus

Martis et Aeoliis vicinum rupibus antrum

Vulcani

Iuv. 1, 7-9

Im ersten Buch der Aeneis Vergils besteigt Aeneas gemeinsam mit seinem Gefährten Achates einen Hügel und betrachtet von dort aus die Stadt Karthago: miratur molem Aeneas ... / miratur portas strepitumque et strata viarum. ${ }^{116}$ Von seinem erhöhten Standort aus überblickt er den vollen Umfang der Siedlung (molem) und ihre Begrenzung (porta). Er sieht ein Netz von Straßen und hört die Geräusche (strepitum) der vor ihm liegenden Stadt. Es sind in diesen zwei Versen allein physische Eigenschaften der literarischen Stadt Karthago, die multisensuell wiedergegeben werden: Visuell wahrgenommen wird ihre Ausdehnung und Begrenzung. Gleichzeitig erzeugt der Hinweis auf Straßen und die akustische Wahrnehmung der Geräusche eine Vorstellung von der inneren Struktur der Siedlung. ${ }^{117}$

Im Mittelpunkt des folgenden Abschnittes steht der Versuch zu klären, mit welchen erzählerischen Techniken ein Leser oder Zuhörer überhaupt zu einer Vorstellung von einer räumlichen Physis gelangen kann, wie allein durch die Texte ein literarischer Raum „hervorgebracht, hergestellt, produziert wird“. ${ }^{118}$ Aus dem Gebiet einer sich gerade neu formierenden Erzähltheorie des Raumes sollen diejenigen Aspekte vorgetragen werden, die nach meinem Dafürhalten den Texten der römischen Dichtung und der an sie in dieser Untersuchung gestellten Frage gerecht werden. Einige Begriffe werden daher im Folgenden erläutert. Wichtige Bezeichnungen, ihre Definitionen und entsprechende Hinweise auf die Forschungsliteratur, der sie entnommen wurden, werden in einem Glossar am Ende dieser Untersuchung zusammengefasst.

\subsubsection{Die Raumwahrnehmung des Menschen}

Um Erwartungen abzustecken, wie die Physis eines Raumes erzählerisch gestaltet werden kann, ist es zunächst sinnvoll, sich einige wesentliche Aspekte der Raumwahrnehmung des Menschen zu vergegenwärtigen. Denn sie ist die Grundlage einer jeden mündlichen und schriftlichen Raumbeschreibung, unterscheidet sich

\footnotetext{
116 Verg. Aen. 1, $421 \mathrm{f}$.

117 Ausführlich dazu Wulfram (2009), 17.

118 Mahler (1999), 12.
} 
jedoch wesentlich von der Wiedergabe eines Raumes, wie sie durch einen architektonischen Aufriss, einen Stadtplan oder einen Dokumentarfilm erfolgt.

Der Alltagserfahrung zufolge, wie sie die Anthropologie beschreibt, nimmt der Mensch seine konkrete räumliche Umgebung auf drei Achsen, also dreidimensional wahr. ${ }^{119}$ Diese drei Raumachsen Vertikale, Sagittale und Horizontale definiert der Mensch über seinen Körper, genauer dessen drei (a-)symmetrische Körperachsen Kopf-Füße (oben-unten), Brust-Rücken (vorn-binten) und Schultern (linksrechts). ${ }^{120}$ Auf diesen Körperachsen und ihren Polen ist für den Betrachter die Ausdehnung eines Raumes in seiner Höhe-Tiefe-Breite erfahrbar und kann auf diese Weise auch kommuniziert werden. Zur Strukturierung und auch Orientierung nimmt der Betrachter räumliche Objekte innerhalb eines Raumes mit seiner ihm eigenen Wahrnehmungssensibilität (Hören, Riechen, Sehen) wahr. Eine räumliche Wahrnehmung auf den drei Achsen ist also nicht auf die visuelle Fähigkeit des Menschen beschränkt. Ebenfalls können taktile, akustische und sogar olfaktorische Sinneseindrücke genutzt und zur Orientierung kommuniziert werden. ${ }^{121}$

Aus dem Bewusstsein der eigenen, aktuellen Position im Raum ergibt sich gleichzeitig ihre Privilegierung als hier gegenüber der Position eines anderen als dort. Diese subjektive Relation zwischen der eigenen Position und der anderer Objekte wird vom Betrachter als Nähe und Ferne mit dazwischenliegenden Abstufungen unterschieden. ${ }^{122}$

119 Zur dimensionalen Raumauffassung des Menschen vgl. Grabowski (1999), 72-75. Hinweise auf weitere raumbezogene Überblicksdarstellungen ebd., 40 f. Grundlegende Untersuchungen zum Zusammenhang von menschlichen Raumkonzepten (z. B. räumliche Strukturen) und Sprachbildern (Metaphern) bei Lakoff/Johnson (1998), 39-43, 70-74. Rosen/Sluiter (2006), 2 setzen für ihren Sammelband „City, Countryside, and the Spatial Organization of Value in Classical Antiquity" ebenfalls so grundsätzlich bei der kognitionslinguistischen Studie von Lakoff/Johnson (1998) an. Kritik an diesem räumlichen Konzept bei Dennerlein (2009), 62-65.

120 Vgl. Assmann (2008), 154. Dazu auch schon Bollnow (1963), 44-55. Die Aufnahme der asymmetrischen Körpervertikale und -sagittale sowie der symmetrischen Körperhorizontale findet sich auch in römischer Architektur. Vgl. Vitr. 1, 2, 2 und 7, praef. 11 und dazu Senett (1997), 116, 131, 150 und 155. Zur Dreidimensionalität vgl. Fitter (1995), 40 zu Verg. Aen. 1, 164: „Virgil's celebrated landskip of the Carthaginian harbour he termed a scaena', and Vitruvius uses the term ,scaenographia" to designate any perspective view."

121 Vgl. Dennerlein (2009), 176. Laut Aristoteles unterscheidet zwar jeder Sinn seine spezifischen Gegenstände, aber es gibt auch gemeinsame, zu denen Aristoteles Form und Größe zählt. Vgl. Aristot. an. 425 a 15 und Scheerer, s.v. Sinne, die, in: HWdPh (1995), Bd. 9, 832. Das Konzept der fünf Sinne wiederum ist nicht anthropologisch, sondern Resultat eines philosophischen Reflexionsprozesses, der zwischen sensorischer und intellektueller Erkenntnis unterscheidet und eine Beziehung zwischen beiden herstellt. Vgl. ebd., 825.

122 Zur Origo als Raumpunkt, der durch Elemente ich, hier, jeţt bestimmt ist, vgl. Grabowski (1999), und erstmalig Bühler (21965), allgemein (bzw. „Deixis ad oculos") 102-104, zur Verschiebung des Koordinatensystems (bzw. „Deixis am Phantasma“) 121-140. Brodersen (1995), 49 bewertet entsprechend kognitionspsychologischer Erkenntnisse die egozentrische Raumerfassung als die einfachste Form der Raumerfassung. „Der eigene Standpunkt wird einem undifferenzierten Fernraum, eben dem ,Rest der Welt", gegenübergestellt." Zur Raumauffassung in römischer Zeit vgl. ebd., 110, zum miliarium aureum bzw. umbilicus Romae auf dem Forum Romanum ebd., 254- 
Diese wahrgenommenen Relationen zwischen der eigenen Position und anderer Objekte überträgt der Betrachter auch zur Bestimmung von Positionen und Relationen der räumlichen Objekte zueinander. ${ }^{123}$ Die Wahrnehmung dieser Relationen entspringt demzufolge einer hochgradig subjektiven Raumvermessung, die von einer euklidischen, maßgenauen Abbildung der wirklichen Welt abweicht und in diesem Sinne ,verzerrt“ sein kann. ${ }^{124}$ Wichtig ist: Die allgemeine menschliche Raumwahrnehmung ist subjektiv, da die eigene Wahrnehmungssensibilität und die eigene Position im Raum für die räumliche Wahrnehmung und eine entsprechende Vermittlung ausschlaggebend sind. Die Wiedergabe räumlicher Physis hat demzufolge mit kartographischer oder photographischer Genauigkeit wenig gemein, dennoch ist sie ohne weitere Verständigungsschwierigkeiten kommunizierbar.

Es gehört es zu den Grundannahmen menschlicher Wahrnehmung, dass jedes im Raum befindliche räumliche Objekt zu einer bestimmten Zeit nur einen bestimmten Ort einnehmen kann, der als, Eigenort' des Objektes bezeichnet wird. Über diese konkrete dreidimensionale Ausdehnung des Objektes hinaus wird aber jedem Objekt noch eine spezifische ,räumliche Umgebung ${ }^{6}$ zugeschrieben. Dieser in der Kognitionspsychologie untersuchte Sachverhalt ist sofort einsichtig, wenn man sich vergegenwärtigt, dass es einen Orientierungsradius gibt, in dem man z. B. innerhalb eines Zimmers eine Tasche sucht, wenn es heißt: Deine Tasche steht beim Klavier. Der für den Suchenden infrage kommende spezifische Radius der räumlichen Umgebung eines Klaviers ist zwar ebenfalls subjektiv, aber nach allgemeiner Erfahrung meist ohne weitere Verständnisschwierigkeiten kommunizierbar. Durch ihre daran erkennbare grundsätzliche räumliche Begrenztheit können derartige räumliche Umgebungen von Personen auch betreten und verlassen werden. ${ }^{125}$

260. Grabowski (1999), 42 präzisiert die Formulierung egozentrische Raumauffassung in anthropozentrische Raumauffassung, da Menschen von der eigenen Egozentrik abstrahieren und Äußerungen anderer verstehen können, obwohl jeder einen eigenen, egozentrischen Ausgangspunkt der Raumauffassung hat.

123 So Grabowski (1999), 41-43 mit ausführlicher Begründung und Diskussion.

124 Downs/Stea (1985), 32 f. Die Gründe für eine „Verzerrung“ sind vielfältig, vgl. Canter (1977), 87-96.

125 Der relevante Radius eines Kleiderschrankes, Tisches oder Tellers entspricht der Umgebung, in dem sich die Menschen in der Regel aufhalten, um diese Gegebenheiten zu nutzen, oder in dem sie die in den Handlungskontext gehörenden Dinge (Leiter, Stühle, Besteck) platzieren, wenn sie diese Objekte benutzen. Zu diesem der Kognitionspsychologie entstammenden Konzept vgl. Grabowski (1999), 46-50, zur Anwendung dieses Konzepts auf eine Narratologie des Raumes vgl. Dennerlein (2009), 123-126. Die Begrenzung einer räumliche Umgebung, etwa er stand vor dem Schrank oder am Haus wirkt womöglich räumlich etwas unschärfer begrenzt als die Information er stand in einem Zimmer. Dennoch begibt sich ein Mensch in die räumliche Umgebung eines Schrankes wie in ein Zimmer oder in ein Haus. Diese Beobachtung ist m. E. für die literarische Raumgestaltung in der antiken Literatur von großer Wichtigkeit, da besonders häufig Ereignisse 
Der jeweilige Umfang einer solchen räumlichen Umgebung, was man also noch als Nähe bezeichnen würde, ist abhängig von dem Umfang des Eigenortes des jeweiligen räumlichen Objektes. So hat das Klavier aufgrund seines Eigenortes einen bestimmten Radius, den man noch mit beim Klavier bezeichnen würde. Der Radius dagegen, den man einem Teller zuschreibt, wenn es hieße neben dem Teller, ist bedeutend kleiner. Eine Lokalisierung bei Rom könnte dagegen einen Radius von mehreren Kilometern umfassen und einige kleinere Siedlungen dazwischen liegen. Denn je größer der Eigenort ist, desto größer ist auch die räumliche Umgebung, desto weniger ist aber eine solche Lokalisierung auch zu einer präzisen Orientierung geeignet. Eine größere Genauigkeit wird dagegen erzeugt, wenn mehrere räumliche Umgebungen sich überschneiden. Schnell kann man aus der Wahl der Objekte herausfinden, ob jemandem an einer räumlich präzisen (,,realistischen") Orientierung liegt oder ob er eine Lage nur vage bestimmt. ${ }^{126}$

Um eine möglichst verständliche räumliche Beschreibung zu bieten, ordnet der Mensch räumliche Objekte, andere Personen seiner Umgebung und sich selbst streng hierarchisch nach strukturellen topologischen Beziehungen: Räumliche Objekte sind entweder ineinander enthalten (,Inklusion') oder grenzen aneinander an (,Kontakt); um aneinander anzugrenzen, müssen sie mindestens einen gemeinsamen Randpunkt haben, sonst sind sie lediglich benachbart (,Nähe). ${ }^{127}$ Man meint bei der letzten Relation nicht eine tatsächliche räumliche Nähe im Sinne einer räumlichen Umgebung, sondern allein die Tatsache, dass die Objekte nicht aneinander angrenzen.

Aus diesen drei, sehr abstrakten Relationen, die man mit Inklusion, Nähe und Kontakt bezeichnet, ergibt sich eine räumliche Struktur, auf die jede ,räumliche Gegebenheit', auch eine Stadt, reduzierbar ist: Ähnlich einer Matroschka128 enthält die größere Einheit Stadt mehrere Einheiten, in denen wiederum kleinere Einheiten enthalten sind, wie z. B. Stadt-Wohnblock-Haus-Zimmer (Inklusion), oder mehrere Einheiten, die direkt aneinander angrenzen, wie z. B. Haus-Straße oder OberstadtUnterstadt (Kontakt), oder aber Einheiten, die räumlich nicht aneinander grenzen, wie z. B. Haus-Brunnen-Mark.t-Wall (Nähe). ${ }^{129}$

nicht in Eigenorten, sondern in der Umgebung von räumlichen Gegebenheiten stattfinden. Vgl. Willenbrock (1969), bes. 31-38.

126 Die Information Deine Tasche steht beim Klavier am Fenster erleichtert die Orientierung, da die unterschiedlichen räumlichen Umgebungen innerhalb eines Raumes als Überschneidungen wahrgenommen werden und damit ein kleinerer Raumausschnitt für die Position infrage kommt.

127 Vgl. Ryan (2009), 421.

128 Dieses Bild verdanke ich der Lektüre von Piatti (2008), 130. Ausführlicher und differenzierter zur Inklusion Grabowski (1999), 50-61.

129 Auch hier gibt die Wahl des Objektes Auskunft über die vom Autor intendierte Präzision: Die Mitteilung Er kaufte gestern Schube in einem Laden im Stadtzentrum ist aufgrund des Eigenortes des Stadtzentrums sehr viel unpräziser als die Auskunft Er kaufte gestern Scbube in dem Laden neben der Apotheke auf dem Marktplat: 
Deutlich sollte geworden sein: Der Mensch, im Raum positioniert, nimmt dessen dreidimensionale Ausdehnung über seine Körperachsen wahr, ebenso die Entfernung zwischen sich selbst und räumlichen Objekten wie auch die Entfernung zwischen den jeweiligen Objekten. Ebenfalls ordnet er seinen Standort und die Objekte nach topologischen Beziehungen der Nähe, des Kontakts oder der Inklusion. In gleicher Weise, wie er den Raum wahrnimmt, kommuniziert er ihn auch.

Großstädte oder Landschaften können nicht wahrgenommen und wiedergegeben werden, indem die Relationen aller vorhandenen einzelnen räumlichen Objekte wahrgenommen und beschrieben werden. Dies ist für das menschliche Individuum nicht möglich. Gerade Großstädte gehören zu den sogenannten Makroräumen, die sich der Wahrnehmung eines Einzelnen aufgrund ihrer räumlichen Ausdehnung, ihrer Unübersichtlichkeit und ihrer besonderen baulichen Dichte entziehen. ${ }^{130}$ Notwendigerweise muss der Betrachter Objektgruppen zusammenfassen, einzelne, aus seiner Sicht besonders markante Objekte aus Gruppen von Objekten selektieren und wiederum andere übergehen. ${ }^{131}$ In einer viel beachteten Studie hat der Stadt- und Raumplaner Kevin Lynch in den 1960er-Jahren die Wahrnehmung amerikanischer Großstädte durch ihre Bewohner untersucht und dabei fünf grundlegende Elemente herauskristallisieren können, die in den Beschreibungen der Bewohner immer wieder auftauchten, mit denen sie demzufolge die Wahrnehmung ihrer Städte strukturierten: Merk- und Wahrzeichen, Bereiche, Wege, Grenzlinien und Brennpunkte. ${ }^{132}$

Die Ergebnisse Lynchs, die sich mit denen der Kognitionspsychologie und der kognitiven Kartographie ${ }^{133}$ zur generellen Raumauffassung des Menschen weitgehend decken, haben sich für die Beschreibung räumlicher Strukturen in narrativen Texten - nicht nur für Städte und auch nicht nur für Texte der Gegenwart - als sehr fruchtbar erwiesen. ${ }^{134}$ Brodersen (1995) zeigte in seiner Habilitationsschrift

130 Zum besonderen Merkmal der Unübersichtlichkeit für den Großstadt-Raum vgl. Becker (1993), 31 f. und Pfeil (21972), 6.

131 Vgl. Grabowski (1999), 41. Diese unvollständige und schematisierte Wahrnehmung eines Raumes führt dazu, dass sich Typen von Räumen herausbilden können. Hierdurch entstehen Schemata, auf die man sich intersubjektiv einigen kann, wenn man typische Ausformungen von Räumen wie Großstadt, Dorf, Problemviertel, Jahrmarkt oder Wohnzimmer meint. Vgl. Downs/ Stea (1985), 33 f. Vgl. auch ausführlicher und mit Verweis auf weiterführende Literatur Dennerlein (2009), $180 \mathrm{f}$.

132 Vgl. Lynch (1975), 60-110.

133 Vgl. dazu grundlegend Downs/Stea (1982).

134 Vgl. Dennerlein (2009), 190 mit weiterführender Literatur, erstmals bei Jahn (1993), 15 f. weiterführende Literatur ebd., 12, Anm. 7. Für die althistorische Forschung vgl. Brodersen (1995), 47, Favro (1993) und (1996) wendet diese Ergebnisse für die Beschreibung des architektonischen Stadtbilds von Rom in augusteischer Zeit an. Brodersen (ebd.) und Favro (1993), 234 weisen auf die besondere Bedeutung visueller und räumlicher Merkzeichen für die Orientierung in der Großstadt hin. 
über die römische Raumerfassung, dass die verbreitete Überzeugung, es hätte in römischer Zeit Kenntnis objektiver Kartographie gegeben, die über ein ausgesuchtes Fachpublikum hinausgeht, nicht nachgewiesen werden kann. Vielmehr erfolgte seinen Ergebnissen zufolge die räumliche Erfassung des Großraums (die „Welt") allein über Merkzeichen (Brodersen benutzt den englischen Begriff landmarks) ohne Berücksichtigung ihrer geographischen Lage im Raum. Mittlere Räume dagegen, die tatsächlich bereist wurden, sind entlang von Wegen (bei Brodersen routes) erfasst worden, an denen eine Kette von Merkzeichen (landmarks) mit relativen Lagebeziehungen zur Orientierung angeordnet waren und an denen lediglich Richtungswechsel, wenn auch ohne objektive Winkelangaben, verzeichnet wurden. Vergleichbar sind derartige Formen der Raumerfassung mit heutigen topologischen U-Bahnplänen von modernen Großstädten. ${ }^{135}$ Allein der Kleinraum, so Brodersen, sei über Faustskizzen ${ }^{136}$ als survey erfasst worden. Zur Orientierung innerhalb des Kleinraumes, zu denen Brodersen auch Städte zählt, dienten aber, wie für mittlere Räume, wiederum Beschreibungen von Wegen (routes) mit der Abfolge entsprechender Merkzeichen (landmarks). Die Raumerfassung in römischer Zeit erfolgte diesen Untersuchungen zufolge entsprechend der oben skizzierten basalen menschlichen Raumerfassung, die im Vergleich mit einem euklidischen Raum unvollständig, verzerrt und topologisch schematisiert war. ${ }^{137}$ Sie entspricht einer mündlichen Wegbeschreibung, die man einem Fremden zur Orientierung in der Stadt vortragen würde: Nach subjektiven Entfernungsmaßstäben und unter Vernachlässigung genauer Winkelangaben wird ein Weg durch das selektierende Aufzählen von Merkzeichen beschrieben, das in seiner Schematisierung der Vergewisserung des richtigen Weges dienen soll.

135 Vgl. Brodersen (1995), 59-65.

136 Faustskizzen sind literarisch zahlreich belegt. Vgl. dazu Brodersen (1995), 243-245.

137 Vgl. Downs/Stea (1985), 31-36. Brodersen differenziert in seiner Studie zur römischen Raumerfassung zwischen Großraum, Mittelraum und Kleinraum. Hierbei ist der Mittelraum derjenige Raum, der über die eigene Bewegung, die Reise, zu erschließen ist, zum Kleinraum zählt er zwar die Stadt, allerdings ohne genauere Definition von Stadt, vgl. Brodersen (1995), 33. 


\title{
2.2.2 Verbale Wiedergabe räumlicher Eigenschaften
}

\author{
Ich bin als Emigrantenkind geboren \\ in einer kleinen, klatschbeflißnen Stadt, \\ die eine Kirche, zwei bis drei Doktoren \\ und eine große Irrenanstalt hat.
}

Mascha Kaléko

\subsubsection{Die lexikalische Dimensionierung. Substantive und Adjektive}

Zur mündlichen oder schriftlichen Beschreibung von Eigenschaften und Strukturen eines Raumes greift man auf lexikalische Referenzen und grammatische Strukturen zurück. Einige derartiger lexikalischer Referenzen wurden bereits im Abschnitt 2.1 vorgestellt: Bestimmte ,Kernwörter', typische Teilelemente und topographische Merk- und Wahrzeichen geben z. B. einem Leser Indizien an die Hand, es handele sich bei dem entsprechenden Text um einen Großstadt-Text. Gleichzeitig vermitteln derlei Substantive aber auch eine Vorstellung von den physischen Eigenschaften dieses Raums. Gelangt der Leser doch aus der Summe der damit aufgezählten Eigenorte zu einer vagen Vorstellung seiner Gesamtausdehnung. ${ }^{138}$ So ergibt sich aus der reinen Aufzählung solcher substantivischen Raumreferenzen eine, wenn auch ebenfalls sehr basale, innere Struktur des Makroraums: Der gröBere, umfassende Raum wird in kleinere, räumlich unzusammenhängende ,Inseln` unterteilt (Nähe). Werden räumlichen Einheiten ausgewählt, die aneinander angrenzen (Haus-Vorgarten-Straße), werden strukturell zusammenhängende ,räumliche Ensembles' (Kontakt) gestaltet.

In je höherer Dichte folglich derartige Referenzen in einem Text auftauchen, desto mehr nimmt einerseits die Präsenz des literarischen Raums, auf den sie referieren, zu. Andererseits wird er gleichzeitig differenzierter und damit anschaulicher, da variantenreicher, wiedergegeben.

Selbstverständlich liegt aber mit einer alleinigen Aufzählung substantivischer Raumreferenzen eine recht schlichte räumliche Gestaltung vor. ${ }^{139}$ Gleiches gilt auch für die andere Möglichkeit, räumliche Eigenschaften rein lexikalisch zu vermitteln, nämlich die Attribuierung mit entsprechenden Adjektiven wie groß, flach, eng, weit, klein, schmal. Vater (1991) fasst die Gruppe derartiger substantivischer und adjektivischer Referenzen unter dem Begriff Dimensionierung zusammen. ${ }^{140}$

138 Vgl. auch Ronen (1986), 421: „Various expressions in the text construct different types of frames which compose the global structure of the space of a story."

139 Vgl. dazu die Ausführungen im Abschnitt 2.2.2.2.

140 Vater (1991), 42. Aus Mangel einer entsprechenden Zusammenstellung für das Lateinische orientiere ich mich in dieser Untersuchung an den Versuchen für die deutsche Sprache von Vater (1991), 42-47 und Dennerlein (2009), 75-83 und 208 f. Vater (1991), iii [sic!] und Dennerlein 
Der allein über Substantive und Adjektive wiedergegebene Raumeindruck ist ausgesprochen subjektiv und darüber hinaus auch kulturell oder historisch variablen Vorstellungen unterworfen. Mit den Überlegungen im Abschnitt 2.1.1 wurde bereits vorgeführt, welche unterschiedlichen Vorstellungen sich im Laufe der Zeit mit dem Substantiv urbs verbanden.

Mit dieser Gruppe von Referenzen wird folglich ein großer Problembereich der literarischen Kommunikation zwischen Autor und Leser bzw. zwischen Erzähler und intendiertem Rezipienten berührt: Da jede räumliche Gegebenheit in narrativer Dichtung ein rein semantisches Konstrukt ist, das sich einer direkten Wahrnehmung des Lesers entzieht, bedarf sie beständig und in besonderer Weise einer erzählerischen Vermittlungsinstanz, auf deren Wahrnehmung oder Beschreibung der Leser seine Vorstellung vom Raum zurückführen kann. Fehlen eingehende Veranschaulichungen, können mangelndes Vorwissen des Lesers oder unterschiedliche kulturelle Vorstellungen angemessene Rückschlüsse auf die Dimensionierung eines literarischen Raumes mitunter gewaltig erschweren, etwa wenn bestimmte Sachverhalte nicht für die Konstitution einer fiktiven Welt abgerufen werden können. Es bedarf daher ,der Reflexion über die historische und kulturelle Bedingtheit und Variabilität dessen, was als Wirklichkeit aufgefasst wird“. ${ }^{141}$

Auf ein weiteres Problem hat u. a. Willenbrock (1969) in seiner Studie zum homerischen Epos aufmerksam gemacht. Er zeigt, wie die Erwähnung bestimmter Gegenstände (Webstubl) bereits ausreicht, um zur Vorstellung eines Raumes zu gelangen, ohne dass der Raum selbst durch ein entsprechendes Substantiv genannt wird. ${ }^{142}$ Das bedeutet, dass unter bestimmten Umständen substantivische Referenzen gleichzeitig implizit auf einen sie umgebenden Raum verweisen können. ${ }^{143}$ Die räumliche Information Penelope hielt sich am Webstubl auf führt laut Willenbrock dazu, dass der Leser die Erwähnung des Webstuhls zum Anlass nimmt, sich einen entsprechenden Raum um Penelope und den Webstuhl herum dazu zudenken. Auch Ronen (1986) weist in ihren theoretischen Ausführungen zum literarischen Raum darauf hin, dass räumliche Gegebenheiten (Zimmer, Garten, Stadt) in erzählerischen Texten häufig nicht explizit benannt werden, sondern durch sogenannte ,implizite Referenzen' ersetzt werden, aber der gemeinte Raum vom Leser wieder-

(2009), 77 erheben jedoch für ihre Systematisierungen ausdrücklich keinen Anspruch auf Vollständigkeit.

141 Zipfel (2001), 87. Er bezeichnet diese Reflexion im Anschluss an Margolin als Prinzip der allgemeinen Überzeugung (mutual belief principle). Vgl. auch Zapf, H.: s.v. Intersubjektivität, in: Nünning (32004), 299 und Schulte-Sasse/Werner (1994), 108. Die Interaktion zwischen Autor und Leser wird gemeinhin anhand eines Kommunikationsmodells erklärt, wobei - grob formuliert dem Autor die Rolle des Senders und dem Leser die Rolle des Empfängers zugeschrieben wird. Vgl. das Modell bei Schmid (2008), 43-112.

142 Vgl. Willenbrock (1969), bes. 31-38.

143 Dieser Erkenntnis wurde sich bereits im Abschnitt 2.1 bedient, als behauptet wurde, dass die Erwähnung von typischen Merk- und Wahrzeichen (Louvre, Hudson River, Big Ben) ausreiche, um auf die gemeinte Großstadt (Paris, New York, London) schließen zu können. 
erkannt wird. ${ }^{144}$ Solche impliziten Referenzen wären für einen explizit als domus bezeichneten Raum zum Beispiel eine Schwelle (limen) ${ }^{145}$ als Grenze eines städtischen Hauses oder das Atrium (atrium) als typischer Bestandteil aus dem Inneren einer domus. Folgt man diesen Ausführungen, ist es demnach zulässig, auf mehrere Häuser (domus) im literarischen Raum zu schließen, ohne dass sie explizit genannt werden, wenn in einer Passage lediglich von mehreren Atrien (atria) oder Schwellen (limina) die Rede ist.

Neben dem komplexen Alltagswissen, das mit derartigen impliziten Referenzen vom Leser erwartet wird, ergibt sich aus diesem einsichtigen Postulat noch ein weiteres, aber gewichtiges Problem der Hermeneutik. Man kann sich bei jeder substantivischen Referenz fragen, ob sie im konkreten Falle metonymisch oder eigentlich gebraucht wird, wobei der Entscheidungsspielraum wesentlich von weiteren textlichen Indizien abhängt. So können gerade entsprechende Substantive, die auf Grenqlinien oder Ränder referieren, gewählt worden sein, um ihren liminalen Charakter in den Vordergrund zu stellen, d. h., die Unterbrechung des räumlichen Zusammenhangs und eine Unterscheidung zwischen außen und innen zu betonen. Man muss daher nach weiteren Indizien Ausschau halten, ob die Referenz eine Begrenzung anzeigen oder die Funktion einer Metonymie übernehmen und somit auf einen umfassenderen Raum verweisen soll.

Eine einzelne substantivische und adjektivische Referenz muss als eine sehr geringe räumliche Ausgestaltung gewertet werden. Häufen sich derartige Referenzen, so ist es darstellerisch zwar immer noch eine schlichte, aber signifikantere Form der Präsenz. Gerade die lexikalisch manifestierte „subjektive Eindeutigkeit“ der Eigenschaftswörter - etwa die Behauptung, die urbs Roma sei eine besonders große Stadt - sollte zum Anlass genommen werden zu untersuchen, inwieweit derartige räumliche Eigenschaften auch ausgestaltet und in den Lebenszusammenhang der Figuren gesetzt werden. ${ }^{146}$

144 Vgl. Ronen (1986), 422. Dem Leser genügt laut Ronen eine Referenz auf einen typischen Gegenstand (ein Bett, ein Blumenbeet, das Theater) oder eine Referenz auf die Grenze eines Raumes (eine Gardine, ein Zaun, ein Stadttor), um zu wissen, welcher Raum gemeint ist. Dennerlein (2009), 95 weist darauf hin, dass auch der Hinweis auf Ereignisse und Handlungen, die typischerweise mit bestimmten Räumen verbunden werden, wie z. B. predigen als typische Handlung für eine Kirche oder kochen als typische Handlung für die Küche, es ebenfalls zulässt, Rückschlüsse auf die gemeinte räumliche Gegebenheit zu ziehen, wie auch Figuren, deren Rollenidentität konkrete Räume voraussetzen, da „man sich normalerweise [in ihnen] befindet, wenn man die Rolle einnimmt“, z. B. der Kellner als typische Rollenidentität für das Restaurant. Dennerlein ergänzt Ronens Ausführungen darüber hinaus um den Hinweis, dass der Leser idealerweise in der Lage sein müsse, derartige Rückschlüsse auch dann zu ziehen, wenn die gemeinten räumlichen Gegebenheiten vorher noch nicht im Text explizit genannt wurden. Diese Rückschlüsse seien ihm möglich, da er über ein komplexes Alltagswissen verfüge.

145 Zur Funktion der Schwelle als Trennung zwischen Haus und Straße bei einer städtischen domus vgl. Kunst (2006), 69.

146 Vgl. dazu die Ausführungen im Abschnitt 2.2.3.3. 


\subsubsection{Positionierung und Direktionalisierung. Die Entstehung von Räumlichkeit}

Eine weit realistischere Raumvorstellung ergibt sich, wenn einzelne Objekte, Bereiche oder Figuren zueinander positioniert werden, wenn ersichtlich wird, was sich vor, binter oder neben räumlichen Objekten befindet. Vorrangig geschieht dies lexikalisch mit Präpositionalphrasen (am Haus, hinter dem Baum, südlich von Rom), Adverbien (bier, oben, vorn) oder mit entsprechenden adverbialen Nebensätzen. Solche Referenzen fasst Vater (1991) unter dem Begriff statische Raumreferenz oder Positionierung zusammen.

Die Verwendung statischer Raumreferenzen wie hier, rechts von, oben zeigt die Abhängigkeit von einer räumlichen Position der Vermittlungsinstanz. Dennerlein (2009) bezeichnet diese subjektiven, da standortabhängigen Angaben als ,deiktische Referenzen'.147 Davon grenzt sie standortunabhängige Referenzen ab (auf dem Tiber, in/an/bei etwas, zwei Meilen weiter) und bezeichnet sie als ,absolute Referenzen'. ${ }^{148}$ Da letztere objektiv nachprüfbar scheinen, erzielen sie einen enormen Realismuseffekt bei einer Raumdarstellung.

Werden einzelne räumliche Gegebenheiten innerhalb eines Raumes zueinander positioniert, werden gleichzeitig Informationen über seine physische Gesamtgestalt vergeben. Diese kann aber auch durch eine weitere Gruppe raumreferentieller Ausdrücke veranschaulicht werden, die nämlich auf die Verlagerung einer Figur oder Objektes von einem Ort an den anderen verweisen, wie ins Haus, nach Rom oder hierher. Diese Gruppe nennt Vater dynamische Raumreferenz oder Direktionalisierung. ${ }^{149}$ Durch die Verlagerung werden zwei räumliche Gegebenheiten als Anfangs- und Endpunkt der Bewegung miteinander verknüpft. Damit entsteht eine Vorstellung über die Struktur oder die Ausdehnung des Gesamtraums, da der Leser mit der Figur von einem Bereich zum anderen voranschreitet, verschiedene Bereiche miteinander verknüpft oder in einer bestimmten Reihenfolge abschreitet. 150

147 Dennerlein (2009), 78 und 209. Grabowski (1999), 116-124.

148 Vgl. dazu ausführlich Dennerlein (2009), 78 f. und 209.

149 Vgl. Vater (1991), 42-47. Vater (ebd., 45 und 47) zählt zu den raumreferentiellen Ausdrücken als Art einer Positionierung und Direktionalisierung auch Verben wie liegen, stehen, stecken (Positionierung) und legen, stellen, fabren (Direktionalisierung).

150 So verlässt Penelope die räumliche Umgebung des Webstuhls von oben, um in die Halle mit den Freiern nach unten zu gelangen, beide Räume befinden sich innerbalb des Palastes des Odysseus, der Palast wiederum befindet sich in einiger Entfernung zur Hütte des Eumaios, beide aber auf der Insel Ithaka. Troja, Scheria und der Aufenthaltsort des Polyphem dagegen sind nicht angrenzende Umgebungen, sondern im Gegenteil besonders entfernt liegende räumliche Gegebenheiten. Aus einer entsprechenden Anordnung der verschiedenen Stationen der Irrfahrt, von Troja, Scheria und Ithaka, aber auch von kleineren Gegebenheiten wie dem Palast des Alkinoos oder dem Schafstall des Polyphem ergibt sich die, wenn auch mitunter vage räumliche Vorstellung der Lagebeziehung aller räumlichen Gegebenheiten der Odyssee. Vgl. auch Ronen (1986), 421. Vgl. dazu ausführlicher Abschnitt 2.2.3.2. 
Eine Besonderheit der lateinischen Sprache liegt darin, dass mithilfe rein grammatikalischer Mittel, nämlich entsprechender Kasus (Ablativ, Lokativ, Akkusativ), räumliche Vorstellungen erzeugt werden können. ${ }^{151}$

Auf derartige lexikalische und grammatikalische Referenzen greift jeder narrative Text zur Raumdarstellung zurück, sei er fiktional oder nicht-fiktional. Ihr Einsatz entscheidet über die Anschaulichkeit und die Realitätswirkung einer Raumwiedergabe. Das Spektrum zeigt sich besonders frappierend bei einem Vergleich einer alleinigen aufzählenden Darstellungsweise substantivischer Referenzen mit derjenigen, die durch Positionierungen und Direktionalisierungen eine Nach- bzw. Abbildung einer räumlichen Gegebenheit vermittelt. ${ }^{152}$ Eine Aufzählung reiht verschiedene räumliche Phänomene aneinander. Geräusche, Gerüche oder Gegenstände, mit denen der Raum angefüllt ist, werden benannt und aufgezählt, in welcher räumlichen Beziehung sie jedoch zueinander stehen, bleibt ohne konkrete räumliche Zuordnung. Bei dieser Form der Präsentation erhält der Leser einen Eindruck von einer Vielfalt innerhalb eines Raumes, aber keinen räumlichen Eindruck im eigentlichen Sinne. ${ }^{153}$ Im Gegensatz dazu versteht Jäger (1998) unter Nach- bzw. Abbildung eine Darstellung von zwar ebenfalls simultan im Raum

151 Vgl. Ernout/Thomas (1972), 106: „Le Latin exprime les relations spatiales (...) avec un important matériel de formes casuelles employées seules et de tours prépositionnels, sans d'ailleurs éliminer tout flottement." Sie unterscheiden die Fragen nach dem Ort auch entsprechend der Unterscheidung von Vater nach sans mowvement und avec mouvement. Zum Akkusativ der räumlichen Ausdehnung vgl. Kühner/Stegmann (1912), 282-284, zum Ablativ als Bezeichnung des räumlichen $W o$, als Vertreter des Lokativs, und zum Ausdruck des Raumes, über den sich eine Bewegung erstreckt, vgl. ebd., 348-355 und zum räumlichen Woher und dem Verhältnis der Entfernung von einem Ort, ebd., 361-375. Zum Dativ zur Angabe eines Ziels in der Dichtersprache, vgl. ebd., 320.

152 Jäger (1998) führt in einer Studie verschiedene Verfahren zur Wiedergabe von Räumen in narrativer Literatur ein. Er unterscheidet das Nennen, das Sagen, das Aufzählen, das Nach- bzw. Abbilden und das Umdeuten. Vgl. Jäger (1998), 23. Als sechstes Verfahren erwägt Jäger die Erörterung (Reflexion, reflektorische Behandlung), ,bei der die verschiedenen Aspekte der Wirklichkeit, deren Komponenten und das Verhältnis des Betrachters zu seiner Umgebung gedanklich verarbeitet werden. Doch wird sie dabei nicht eigentlich ,dargestellt" oder ,wiedergegeben'“" Nünning (2009), 45 konstatiert, „dass damit das Spektrum narrativer Techniken der Raumdarstellung noch nicht erschöpft" sei. Zur Entwicklung der Raumdarstellung vom bloßen Nennen zur ausführlichen Wiedergabe am Beispiel des Waldes vgl. Stauffer (1959), 17, 166, 169 f., 174 f.

153 Die Darstellungsform der Aufzäblung wird verschiedenartig interpretiert: „Man kann sie als Ausdruck dafür ansehen, daß die Fülle der Erscheinungen den Aufnehmenden überwältigt, aber ebenso dafür, daß er ihrer dadurch Herr zu werden versucht, daß er sie in Einzelheiten zerlegt und dergestalt ,bannt'. Daneben ist zu bedenken, daß es das traditionelle Mittel der enumeratio gibt, dessen Herkunft und Symptomcharakter schwer zu bestimmen sind.“ Jäger (1998), 229. Als Gründe für die Wahl dieser Technik werden auch „,die Freude am Wortklang und Malen“, „das stete Kreisen um denselben, meist unaussprechlichen Gedanken“ oder „die Fülle des Lebens auszudrücken“ angeführt. Vgl. ebd., 227, Fn. 26. Bal (32009), 138 meint, räumliche Objekte bestimmten die Befüllung des Raumes durch ihre Form, ihre Maße und ihre Farbe. Ein unordentliches Zimmer wirke kleiner, ein Raum mit wenigen Möbeln größer. Aber auch die Art, in der Objekte in einem Raum angeordnet sind, habe Einfluss auf die Wahrnehmung des Raumes. 
vorhandenen räumlichen Objekten und Figuren, die aber durch kontrastreiche Referenzen wie hier-dort, nah-fern, hell-dunkel, links-rechts oder eng-weit einander zugeordnet werden. Durch derartige Referenzen werden die räumlichen Verhältnisse zwischen Objekten untereinander und Figuren in vielfältige Beziehung gesetzt, strukturiert und hierarchisiert. Erst bei einer solchermaßen mimetischen Darstellung ist nach Jäger ,in strengerem Sinne von Raum und von Räumlichkeit zu reden". ${ }^{154}$ Denn es entsteht eine im bildkünstlerischen Sinn visuell vermittelte Räumlichkeit, „was worüber hinweg gesehen, was wodurch teils halb verborgen, teils ganz verdeckt wird, was sich vor etwas Weiteres schiebt usw.“" 155 Die visuelle Raumkomposition kann durch Geräusche, Gerüche, die stärker oder schwächer werden oder von verschiedenen Seiten auf die ,Wahrnehmungsinstanz' einströmen, oder durch taktile Wahrnehmungen ergänzt oder ersetzt werden. ${ }^{156}$ Die so präsentierte räumliche Gegebenheit ist damit nicht nur durch eine detailreiche Fülle gekennzeichnet, sondern sie wird in ihrer eigentlichen räumlichen Gestalt, ihrer Dreidimensionalität dargestellt. ${ }^{157}$ Die unterschiedlichen Verfahren bestimmen damit maßgeblich den Realismuseffekt narrativer Raumwiedergabe ${ }^{158}$ und sind in Bezug auf literarische Texte folglich vor allem ein stilistisches Merkmal.

\subsubsection{Literarisch gestaltete Wiedergabe des Raums}

Die im vorangegangenen Abschnitt vorgestellten Gruppen von Referenzen werden in literarischen Texten innerhalb von drei grundlegenden Darstellungstechniken eingesetzt. Die im Forschungsbericht kurz vorgestellten Darstellungstechniken der ,Beschreibung' und des ,Erzählens von Ereignissen“ sollen im Folgenden etwas ausführlicher betrachtet (2.2.3.1 und 2.2.3.2) und um eine dritte Darstellungstechnik, die ,erzählte Wahrnehmung‘ (2.2.3.3), ergänzt werden. Die Wahl der jeweiligen Darstellungstechnik gibt unabhängig von dem stilistischen Merkmal der Anschaulichkeit über die Relevanz des Raumes für den jeweiligen Text Auskunft.

154 Jäger (1998), 34. Die Unterscheidung von Aufzäblung und Abbildung ist nicht immer eindeutig. Vgl. Dennerlein (2009), 155-160. Für die antike Literatur vgl. Friedländer (1969), 10, 14, 18, 20.

155 Jäger (1998), 34.

156 Eine Form von Abbildung besteht auch in der Kongruenz von Inhalt und äußerer Form. Jäger (1998), 27 nennt als Beispiele Verg. Aen. 8, 596, der mit seinem holodaktylischen Versmaß Pferdegetrappel imitiere oder Verg. georg. 4, 174, dessen Versmaß den gleichmäßigen Takt von Hammerschlägen wiedergebe. Vgl. dazu und zu weiteren Beispielen Curtius (111993), 49. Eine lautmalerische Absicht vermutet man auch bei Ov. met. 6, 376: quamuis sint sub aqua, sub aqua maledicere temptant, wo das Froschgequake nachgebildet werde. Diese Stilmittel dienen dem Hörer/Leser von Literatur, seine räumliche Vorstellung jenseits der Beschreibung im literarischen Text über die Akustik zu erweitern. Die Performanz der mündlich vorgetragenen römischen Literatur bleibt in der vorliegenden Untersuchung unberücksichtigt.

157 Jäger (1998), 254.

158 Vgl. Nünning (2009), 38. 


\subsubsection{Beschreiben von Raum}

In erzählender Literatur liegt eine besonders markante Raumwiedergabe dann vor, wenn Eigenschaften und Strukturen einer räumlichen Gegebenheit in einem längeren Abschnitt beschrieben werden. Die Präsenz und damit die Relevanz eines Gegenstandes werden bei der Beschreibung somit nicht durch deren Anschaulichkeit, sondern über die Variable Erzähldauer bestimmt. ${ }^{159}$

Von einer ,Beschreibung' spricht man, wenn stabile Eigenschaften mitgeteilt werden und zwar während gleichzeitig die Handlung ruht, d. h., die Erzählinstanz gerade kein einmaliges Ereignis wiedergibt ${ }^{160}$, sondern „den Anblick, wie er sich im Moment bietet“"161, beschreibt. Die einzige Ausnahme von dieser geforderten Ereignislosigkeit stellt die Wiedergabe von typischen, sich wiederholenden „Handlungen von kollektiven oder anonym bleibenden Akteuren"162 dar. Auch nach antiker Vorstellung werden derartige sich wiederholende Ereignisse zu den räumlichen Eigenschaften gerechnet. ${ }^{163}$

Eine Beschreibung rückt einen Gegenstand ins Zentrum. Die Wahl des Gegenstandes, der beschrieben werden soll - ob nun Raum, Figur, ein einzelner Gegenstand o. ä. - obliegt dem Autor. Die Relevanz einer räumlichen Gegebenheit wird deswegen in besonderer Weise hervorgehoben, da bei einer Beschreibung die Erwähnung eines Raumes folglich optional ist - im Unterschied zu den anderen Darstellungstechniken, wie gleich zu zeigen ist. ${ }^{164}$

159 Die Variable Erzählfrequenz (zum Begriff Eržälfrequenz vgl. Martinez/Scheffel (52003), 39-47) hat zwar geringen Einfluss auf die Präsentation der Raumgestaltung, wohl aber auf die Qualität der Veranschaulichung des literarischen Raums.

160 Nach Dennerlein (2009), 134 und 141 sind Ereignislosigkeit und die Mitteilung von stabilen Eigenschaften jeweils notwendige, jedes für sich jedoch nicht hinreichende Bedingungen für das Vorliegen einer Beschreibung. Vgl. auch Hellwig (1964), 32. Etwas allgemeiner bei Lausberg (42008), \810 (evidentia), 399-401, bes. 400: „Der Gesamtgegenstand hat in der evidentia kernhaft statischen Charakter, auch wenn er ein (...) Vorgang ist: es handelt sich um eine Beschreibung eines wenn auch in den Einzelheiten bewegten, so doch durch den Rahmen einer (...) Gleichzeitigkeit zusammengehaltenen Bildes" und speziell $₫ 819,406$ f. die Ortsbeschreibung (descriptio loci, тотоү९ $\alpha \phi i ́ \alpha$ bisweilen unterschieden von der Beschreibung eines fingierten Ortes, der Topothesie); ebd., \1133, 544 (descriptio) und Andersen (2001), 82 setzen descriptio und ekphrasis gleich: „(...) die ausführliche Beschreibung eines Handlungsverlaufs, Ortes, Gegenstands oder Menschen."

161 Hellwig (1964), 34.

162 Dennerlein (2009), 141. Vgl. dazu Chatman (1980), 139: „It makes no sense to treat crowds of walk-ons or extras as characters. (...) they are parts of the (...) setting."

163 Vgl. Lausberg ( $\left.{ }^{4} 2008\right)$, \811, 401 zu kollektiven Rahmenvorgängen wie Aufbau einer Stadt, Holzfällerei, Schlachtengetümmel, Seesturm, Trinkgelage u. ä.

164 Vgl. Dennerlein (2009), 118. 


\subsubsection{Erzählen von Raum}

Räumliche Gegebenheiten werden in antiker Dichtung - wie dem Forschungsbericht II bereits entnommen werden konnte - eher in Ausnahmefällen en bloc, etwa in Form einer kürzeren oder längeren descriptio loci (тотоүо $\alpha$ фí $\alpha$ ), präsentiert. Häufiger nehmen räumliche Gegebenheiten erst sukzessiv konkretere Gestalt für den Leser an. Als Beispiel diente im Forschungsbericht dafür der Palast des Odysseus auf Ithaka, der - im Gegensatz zur Insel der Kalypso oder den Besitzungen des Alkinoos - an keiner Stelle der homerischen Odyssee ausführlich beschrieben wird. Dennoch, so hieß es, werde er als Schauplatz der Handlung über die Büchergrenzen hinweg „Raum für Raum so ausgezeichnet ausgenutzt, dass sich aus den szenischen Hinweisen der Erzählung ein Gesamtplan rekonstruieren lässt" ${ }^{\text {“ }} 165$ Diese „,szenischen Hinweise“, aus denen sich eine Gesamtvorstellung ergibt, entstammen dem für poetische Literatur typischen ,Erzählen von Ereignissen' ${ }^{\prime}{ }^{166}$ $\mathrm{Da}$ jedes Ereignis nicht nur zu einem bestimmten Zeitpunkt, sondern auch obligatorisch in, an oder bei einer räumlichen Gegebenheit stattfindet, beinhaltet jede Wiedergabe eines Ereignisses (was?) notwendigerweise neben einer zeitlichen Einbettung (wann?) auch den räumlichen Kontext (wo?). Dennerlein schlägt für den hier interessierenden räumlichen Kontext eines jeden Ereignisses den Terminus ,Ereignisregion ${ }^{6}$ vor. ${ }^{167}$ Während der Lektüre ist der Leser in der Lage, Informationen über eine bereits erwähnte Ereignisregion wieder abzurufen, zu ergänzen oder zu modifizieren und so - als Endergebnis der Lektüre - aus einzelnen räumlichen Informationen eine zusammenhängende räumliche Vorstellung zu bekommen. ${ }^{168}$ Hellwig (1964) unterscheidet in ihrer Untersuchung zur Raumgestaltung in den homerischen Epen eine Mikro- und Makrostruktur. Während sich das Geschehen an wenigen großen Bereichen abspielt, wie z. B. in der Stadt, am Strand, auf dem Olymp, spielen die konkreteren Ereignisse auf kleineren Plätzen, die „Ausschnitte aus den umfassenden Gebieten sind“". ${ }^{169}$ Einen Vorschlag zur Strukturierung der „Raumgestaltung der Gesamthandlung“ oder - wie es heute bezeichnet wird - des

165 Goebel (1971), 14. Vgl. allgemein zu dieser Darstellungstechnik Ryan (2009), 423. Dennerlein (2009), 140 zeigt, wie stabile Informationen zu räumlichen Gegebenheiten sowohl im Zusammenhang mit Ereignissen, als auch in beschreibenden Textpassagen vergeben werden.

166 Unter dem Begriff Ereignis wird hier eine ganz allgemeine Zustandsveränderung verstanden, die durch ein Prädikat benannt wird, das eine Veränderung beschreibt. Der Begriff Ereignis sagt somit nichts über die Relevanz der Zustandsveränderung für die Gesamtgeschichte aus. Vgl. Hühn (2009), 80-83. Dennerlein (2009), 122 f. und 237 unterscheidet drei Arten von Ereignissen: (1) nichtintendiertes Geschehen nach den Regeln der erzählten Welt (!) (z. B. Der Blitz schlug ein.), (2) Handlungen von Figuren (z. B. Sie traten in den Garten.) und (3) intentionale Zustände (z. B. Er lag den ganzen Tag auf dem Bett.).

167 Vgl. Dennerlein (2009), 125 f. und 237.

168 Grundlegend dazu Emmott (1997), 141-174.

169 Hellwig (1964), 23. 
gesamten erzählten Universums ${ }^{170}$ bietet Ronen (1986). Sie differenziert alle innerhalb eines narrativen Textes erwähnten räumlichen Gegebenheiten nach ihrer Mittelbarkeit zur eigentlichen Handlung. Daraus ergeben sich auch Indizien, welcher räumlichen Gegebenheit eine Relevanz zugeschrieben wird.

\section{Schauplätre, Nebenräume und Fernräume}

Diejenigen räumlichen Gegebenheiten, die die tatsächlichen und unmittelbaren Ereignisse raumbildend umgeben, bezeichnet man als ,Schauplatz' ${ }^{6}{ }^{171}$ Dies entspricht im Drama demjenigen Raum, der durch die Bühne dargestellt wird. Die Ausdrücke tatsächlich und unmittelbar verweisen auf die besondere raum-zeitliche Konstituierung des Ereignisses. Der Schauplatz ist die faktische Umgebung einer Figur. Gemäß den Regeln der erzählten Welt muss das Ereignis also gerade tatsächlich geschehen, die Ereignisregion tatsächlich existieren und nicht nur der Vorstellung oder der Erinnerung einer Figur entspringen. ${ }^{172}$ Unmittelbar weist zeitlich auf die Erzählgegenwart ${ }^{173}$ der entsprechenden Erzählebene und räumlich auf den nächstliegenden Bereich, also auf die konkrete räumliche Umgebung hin, in, an oder bei der Figuren und Ereignisse situiert werden. Bei einem Makroraum liegt es demzufolge nahe, dass nicht die Großstadt an sich, sondern eher einzelne Bereiche, die innerhalb der Großstadt situiert sind, zu einem Schauplatz werden.

Als besondere Form eines städtischen Schauplatzes möchte ich den Begriff ,Kontaktbereich' einführen, um damit zu beschreiben, dass der Autor diesen Bereich durch die gleichzeitige Anwesenheit von einer Figur und weiteren Figuren ausgestaltet hat, denn nicht notwendigerweise müssen sich an jedem Schauplatz gleichzeitig auch weitere Figuren aufhalten. Von Interesse ist, ob die Figur in einem Kontaktbereich mit den anderen Figuren in Kontakt tritt und es sich dabei um die Schilderung eines einmaligen Ereignisses handelt, oder ob es sich um kollektive, anonym bleibende Akteure handelt, die damit zu den stabilen Eigenschaften des Raumes gerechnet werden können.

170 Vgl. Ryan (2009), $421 \mathrm{f}$.

171 Statt von Schauplatz spricht man in der Narratologie häufig auch von setting. Vgl. Ronens (1986), 423-425, bes. 423 die Definition von setting: ,, actual immediate surroundings of an object, a character, or an event". Ryan (2009), $421 \mathrm{f}$. unterscheidet zwischen spatial frames als der eigentlichen Umgebung der Figuren und setting als ,the general socio-historico-geographical environment in which the action takes place. In contrast to spatial frames, this is a relatively stable category which embraces the entire text." Setting entspräche damit einer sehr allgemeinen Formulierung wie: „Der Schauplatz der Epigramme Martials ist das kaiserzeitliche Rom.“

172 Die Tatsächlichkeit einer literarischen räumlichen Gegebenheit lässt sich nicht an ihrem Verhältnis zur aktualen Welt bestimmen, sondern allein anhand der Regeln, die innerhalb der erzählten Welt gelten. Vgl. Dennerlein (2009), $129 \mathrm{f}$.

173 Ein Jetzt-Eindruck wird durch die Verortung des raum-zeitlichen Orientierungszentrums, der sogenannten Origo, erzeugt. Vgl. Dennerlein (2009), 130 f. 
Innerhalb eines Textes kann eine Reihe von disparaten räumlichen Gegebenheiten in das Zentrum der Handlung gestellt werden. ${ }^{174}$ Gerade diese räumliche Flexibilität narrativer Texte ermöglicht es, Makroräume wie eine Irrfahrt ${ }^{175}$ oder eben eine Großstadt erzählerisch darzustellen. Dabei kann ebenso wie bei einer filmischen Montage der Erzähler zwischen simultan existierenden Schauplätzen wechseln und sie jeweils zu einer unmittelbaren und tatsächlichen Umgebung von Figuren werden lassen. Oder der Erzähler kann die einzelnen Schauplätze durch Figurenbewegung miteinander verbinden. Im ersten Fall wären die einzelnen Bereiche ohne einen räumlichen Zusammenhang, als räumliche Inseln dargestellt. ${ }^{176}$ Eine übergreifende Struktur und Physis eines Makroraums werden durch eine derartige Aneinanderreihung einzelner Schauplätze nur sehr basal präsentiert. ${ }^{177} \mathrm{Im}$ zweiten Fall treten die übergeordneten Strukturen eines Makroraumes und seine Physis schon deutlicher hervor. Durch die Bewegung einer oder mehrerer Figuren werden unterschiedliche Schauplätze zu einem zusammenhängenden Raum zusammengefasst und seine Ausdehnung den Bewegungsradius der Figuren indirekt beschrieben. ${ }^{178}$ Aus einzelnen Inseln entsteht durch das Ereignis der Bewegung ein ,räumliches Kontinuum', ein sogenannter ,Bewegungsbereich‘.179 Durch die Bewegung der Figur(en) werden die unterschiedlichen Schauplätze in einer bestimmten Reihenfolge verbunden, auf einen Fixpunkt hin angeordnet oder auch mehrfach untereinander verknüpft. ${ }^{180}$ Damit werden räumliche Strukturen eines Makroraums sichtbar gemacht.

174 Zum Schauplatzwechsel in Verbindung mit dem Wechsel der Erzählebene vgl. Ronen (1986), 423; Konstan (2002), 2.

175 Vgl. Hellwig (1964), 1 und 31.

176 Vgl. Lynch (1975), 107. Meist werden mit diesem Verfahren auch zwei parallele Erzählstränge gelegt. Ein prominentes Beispiel für eine derartige Raumkonstellation ist der Anfang der Odyssee. Nach einem kurzen Schwenk auf die Insel Ogygia und deren Bewohner, Kalypso und Odysseus, wird über Äthiopien, dem derzeitigen Aufenthalt des Poseidon, zum Olymp „geschwenkt“, auf dem eine Götterversammlung anberaumt ist. Die Handlung setzt sich sodann in Ithaka fort und schwenkt erst in Buch 5 auf die Insel Ogygia zurück. Während der ersten vier Bücher ist somit die Insel Ogygia größtenteils kein Schauplatz. Im Buch E ändert sich deren Status wieder. Hellwig (1964), 1 spricht in diesem Zusammenhang von verschiedenen Handlungssträngen, durch die bestimmte Bereiche im Vordergrund und Hintergrund dargestellt werden. Die Hintergrundhandlung ruht, wird aber anschließend wieder aufgenommen, vgl. auch ebd., Fn. 2.

177 Aus einer solchen räumlichen Darstellung ergäbe sich die „partikulare“ Sicht, wie sie Stierle (1993) der antiken Literatur im Hinblick auf die Großstadt attestiert.

178 Vgl. Konstans Definition eines continuous action space: „Though characters move from one spot to another, as long as they (or some of them) are continually in sight, so to speak, their movements constitute what I call a trail. If any agent leaves a trail, the action space is continuous." Konstan, Narrative Space, in: Paschalis/Frangoulidis (2002), 2.

179 Dennerlein (2009), 126 f. und 237.

180 Vgl. Lynch (1975), 107-108. Lynch unterscheidet vier Raumtypen: 1) Einen Inselraum, bestehend aus Bereichen, die unverbunden nebeneinander bestehen, und zwischen denen es „weiße Stellen“ gibt. 2) Einen Raum, bestehend aus Bereichen, die auf Zentralpunkte hin angeordnet sind, aber untereinander nicht verbunden sind. 3) Einen Raum, bestehend aus Bereichen, die in 
Wird die Bewegung einer Figur selbst erzählt und zusätzlich beispielsweise die Art bzw. das Tempo der Bewegung (mit dem Pferd, zu Fuß, schlendern, rennen) oder die zu überwindenden Hindernisse genannt, wird eine räumliche Vorstellung über die Länge und Beschaffenheit der zurückgelegten Strecke und damit gleichzeitig über die räumliche Ausdehnung des Makroraumes vermittelt. ${ }^{181}$ Die erzählte Bewegung ist eine weit anschaulichere Wiedergabe räumlicher Physis. ${ }^{182}$

Diesen Überlegungen zufolge sind nicht alle räumlichen Gegebenheiten, die in narrativer Dichtung erwähnt werden, Schauplätze. Dennoch liegen bisweilen über den eigentlichen Schauplatz recht spärliche Informationen vor, während ein Erzähler oder eine Figur über entfernte räumliche Gegebenheiten zahlreiche Details präsentiert. Man unterscheidet daher wie im Drama einen Schauplatz als denjenigen Raum, in dem sich die Figuren aufhalten, von demjenigen, der in Berichten anderer, der Phantasie oder der Erinnerung von Figuren präsentiert wird.

Die Mittelbarkeit und Präsenz aller räumlichen Einheiten des gesamten erzählten Universums unterscheidet Ronen (1986) nach ihrer räumlichen Distanz ${ }^{183}$ oder anders formuliert - nach der topologischen Beziehung zum Schauplatz. Befindet sich die räumliche Gegebenheit in unmittelbarer Nachbarschaft zum Schauplatz will Ronen von einem ,Nebenraum ' (secondary frame) sprechen. Sein Kennzeichen ist, dass er unmittelbar an den Schauplatz anschließt. ${ }^{184}$ Eine Figur kann vom Schauplatz aus ihre Wahrnehmung auf diesen Raum ausdehnen, sie kann Geräusche hören, Gerüche riechen oder aus dem Fenster hinausschauen und ihre Wahrnehmungen mitteilen, Figuren können aus diesem Nebenraum auf die Bühne treten. Damit gehört der Nebenraum zu demselben räumlichen Kontinuum wie der Schauplatz. In einem erzählerischen Text wird eine derartige strukturelle Glie-

einer bestimmten Reihenfolge miteinander verbunden sind. 4) Einen Raum, bestehend aus Bereichen, die mehrfach untereinander verknüpft sind, und unter denen es kaum Leerstellen gibt.

Zur Anwendung auf die Literaturwissenschaft vgl. Dennerlein (2009), 191. Beschrieben wurde dieses Phänomen bereits anhand der inneren Struktur der Stadt Troja im Buch 6 der Ilias. Vgl. Abschnitt 1.2.

181 Zur Bewegung von Figuren vgl. auch Abschnitt 2.2.3.3.

182 Vgl. Aristot. an. 425 a. Bal (32009), 139 formuliert dieselbe Beobachtung m. E. aus einer anderen Perspektive, wenn sie meint, dass die Größe des Raumes erst eine bestimmte Handlung ermöglicht: „A dynamically functioning space is a factor which allows for the movement of characters. Characters walk, and therefore need a path. They travel, and so they need a large space, countries, seas, air. The hero of a fairy tale has to traverse a dark forest to prove his courage. So there is a forest."

183 In der Erzähltheorie wird der Grad der Mittelbarkeit von Rede und Gedanken bei der Präsentation des Erzählten als Distanz zum Erzählten unterschieden, vgl. Martinez/Scheffel (52003), 47 63; als Übersicht 62. Auf den Raum übertragen bezeichnet Distanz verschiedene Grade an Mittelbarkeit der räumlichen Präsentation, vgl. Ronen (1986), 425. Vgl. entsprechend Chatman (1980), 139-141 über die Frage nach Kriterien für einen Protagonisten.

184 In einem Drama wäre ein Nebenraum derjenige Raum, der sich hinterszenisch unmittelbar an die Bühne anschließt, der mittels einer Tür oder einem Fenster o. ä. auf der Bühne bereits angedeutet wird. 
derung entweder durch Referenzen auf Grenzen (Wand, Mauer, Zaun) explizit benannt oder sie ist entsprechend des Alltagswissens als bekannt voraussetzbar. ${ }^{185}$ Neben der Tatsache, dass die Einbindung solcher Nebenräume der räumlichen Anschaulichkeit dient, wird dadurch der zusammenhängende Raum in einer feineren Untergliederung wiedergegeben. Gleichzeitig verdienen derartige Strukturen eine erhöhte Aufmerksamkeit, da sie in der Regel den beiden Bereichen unterschiedliche Funktionen ${ }^{186}$ oder räumliche Eigenschaften zuweisen und zusätzlich als innen-außen, privat-öffentlich, betretbar-unbetretbar usw. gekennzeichnet sind. ${ }^{187}$

Als weitere Raumkonstellation kommt einer räumlichen Gegebenheit besondere Aufmerksamkeit des Interpreten zu, wenn diese nicht unmittelbar an den Schauplatz anschließt und sowohl vom eigentlichen Schauplatz räumlich als auch von der Erzählgegenwart zeitlich entfernt liegen kann. ${ }^{188}$ Ronen bezeichnet sie als ,raumzeitlichen Fernraum' (spatio-temporally distant frame). ${ }^{189} \mathrm{Nach}$ Ronen wird der Schauplatz häufig mit ihm um eines Kontrastes willen in Beziehung gesetzt ${ }^{190}$, der sich auch in der Darstellung ihrer jeweiligen Physis spiegeln kann. ${ }^{191}$

\subsubsection{Erzählte Raumwahrnehmung: Panorama und Flaneur}

Neben dem Beschreiben und dem Erzählen von Ereignissen ist seit den homerischen Epen eine weitere Darstellungstechnik etabliert, die erzählte Wahrneh-

185 Berechtigt ist der Hinweis Dennerleins (2009), 129, dass nur diejenigen räumlichen Gegebenheiten als Nebenräume in Betracht kommen, die entsprechend der erzählten Welt und nicht entsprechend dem Weltwissen nahegelegt werden.

186 Hellwig (1964), 26 f. zeigt auf, dass den Göttern in der Ilias verschiedene höhergelegene Orte (der Olymp, der Ida, der Berg auf Samothrake, das Grabmal des Herakles, der Hügel Kallikolone) als Beobachtungsposten dienen, von denen aus sie die Kampfhandlungen beobachten. Damit wird auch räumlich der Unterschied zwischen Menschen und Göttern herausgestellt.

187 Von diesem Nebenraum unterscheidet Ronen (1986), 426, 436 den ,unzugänglichen Raum (inaccessible frame). Er grenzt zwar ebenfalls direkt an den Schauplatz an, jedoch liegen den Figuren keine Informationen über seine Beschaffenheit vor. Er ist eine Art explizit genannter weißer Fleck auf der literarischen Landkarte. Seine Erwähnung ist daher besonders auffällig.

188 Entspringt ein räumlicher Wechsel einem Wunsch oder einem Traum einer Figur, zeigt also eine wie auch immer geartete modale Äußerung an, dass die räumlichen Eigenschaften möglich oder in Zukunft vorstellbar sind, handelt es sich nach den Regeln des fiktionalen Wirklichkeitsmodells um eine bypothetische räumliche Gegebenheit, nicht um einen „Schauplatzwechsel“. Ein derartiger Raum wird daher nach den Regeln der erzählten Welt als ein , nicht bestehender Raum' (frame with a non-factual status) bezeichnet. Vgl. Ronen (1986), 428 f., bes. 429.

189 Vgl. Ronen (1986), 427.

190 Vgl. Ronen (1986), 428. Ähnlich auch Dennerlein (2009), 133 ohne Verweis auf Ronen. Wie bei einem „Szenenwechsel“ können derartige Fernräume aber auch innerhalb der Erzählung zu einem Schauplatz werden. Dennerlein zeigt an einem Beispiel auf, dass eine derartige Statusveränderung zu einem zentralen Ereignis innerhalb einer Erzählung werden kann.

191 Vgl. auch Bal (32009), 140 und 222: „Oppositions are constructions; it is important not to forget that and ,naturalize" them.“ 
mung. ${ }^{192}$ Sie liegt vor, wenn die Wahrnebmung einer räumlichen Gegebenheit als Ereignis erzählt wird, wie etwa eine Figur einen Raum betritt und im Folgenden mitgeteilt wird, was sie wahrnimmt. Eine derartige erzählte Wahrnehmung lässt sich daran erkennen, dass der Akt der Wahrnehmung durch entsprechende Prädikate signalisiert wird. ${ }^{193}$

Ästhetisch betrachtet handelt es sich bei der erzählten Wahrnehmung um eine besonders markante Form der literarischen Raumwiedergabe. Wie bei der Beschreibung wird der Gegenstand in den Mittelpunkt der Betrachtung gerückt, ihm folglich über die Variable der Erzähldauer eine erzählerische Relevanz und sogar ein besonderer Erlebniswert für eine wahrnehmende Figur zugesprochen. ${ }^{194}$ Die Wiedergabe von Eigenschaften des Raumes ist im Unterschied zum Wiedergabemodus der Beschreibung an die Wahrnehmungsmöglichkeiten und -grenzen einer Figur gebunden. Für die räumliche Wiedergabe eines Makroraumes wie die Großstadt haben sich in der Moderne vor allem zwei Formen der erzählten Wahrnehmung herauskristallisiert: der Panoramablick und der Flaneur. ${ }^{195}$ Unter Panoramablick versteht man in der Regel die erzählte Wahrnehmung aus der Perspektive einer Figur, die einen erböhten Standort innerhalb oder außerhalb des Siedlungsareals eingenommen hat und von diesem aus, also von einem Turm oder einer Anhöhe herab, ihre Wahrnehmung wiedergibt. Der Flaneur dagegen ist eine Figur, deren Bewegungsbereich der Großstadtraum, präziser die Menschenmenge als geschäftige Masse, ist, deren eigene Haltung sich jedoch von ihr gezielt absetzt. Das Gemüt des Flaneurs ist sorg- und absichtslos, sein Gehen richtungslos, er durchschreitet den Raum, ohne das Erreichen eines bestimmten Ziels im Auge zu haben, und gibt zufällige Erlebnisse oder subjektive Wahrnehmungen aus seiner Perspektive wieder. ${ }^{196}$

Diese an sehr verschiedene Bedingungen gebundenen Darstellungstypen der Moderne sollen für die vorliegende Untersuchung auf Grundformen zurückgeführt werden. Voraussetzungsloser soll zwischen der Wahrnehmung von einem festen Standort und der Wahrnehmung in Bewegung unterschieden werden.

Die besondere Anschaulichkeit der Darstellungstechnik der erzählten Wahrnehmung liegt in dem eingenommenen Standort, der Wahrnehmungssensibilität und

192 Vgl. Hellwig (1964), 35, Fn. 15.

193 Ich folge darin Dennerleins (2009), 146 Definition von eræäblter Wabrnehmung in Abgrenzung von den für die Wiedergabe räumlicher Merkmale weniger relevanten Theorien der Fokalisation. Fehlen Verben der Wahrnehmung, kann von einer erzählten Wahrnehmung nur dann gesprochen werden, wenn wichtige Indizien wie eine offensichtlich gestaltete Subjektivität, Standortabhängigkeit des Wahrgenommenen oder die Aktualität der Wahrnehmung vorliegen. Vgl. auch zur Verwendung von impliziten Referenzen Abschnitt 2.2.2.

194 Aus der Individualisierung einer Wahrnehmungsinstanz ergeben sich erzählerisch vor allem zwei Konstellationen, nämlich dass eine Erzählinstanz die Wahrnehmung einer Figur oder eine Figur ihre eigene Wahrnehmung in der Ich-Perspektive wiedergibt.

195 Dennerlein (2009), 115.

196 Vgl. dazu Neumeyer (1999), 10 f. 
Die Analyse räumlicher Physis in narrativen Texten. Methodische Überlegungen

Blickinszenierung sowie in einer besonders erlebnisnahen Wiedergabe von räumlichen Eigenschaften in Bewegung, was in den folgenden drei Abschnitten kurz vorgestellt werden soll.

\section{Fester Standort}

Von einem erhöhten Standort aus kann die räumliche Physis des vor einem liegenden ,Wahrnehmungsbereiches' in einer Draufsicht wiedergegeben werden. ${ }^{197} \mathrm{Bal}$ (32009) vergleicht daher diese Raumwiedergabe mit einer Photographie ${ }^{198}$, auch wenn man einwenden muss, dass die erzählerische Raumwiedergabe gemäß der menschlichen Raumwahrnehmung - wie im Abschnitt 2.2.1 erläutert - selektiver und unpräziser als eine Photographie ist. Zudem muss die Wahrnehmungsinstanz dabei nicht nur statische Eigenschaften des Raumes wiedergeben, sondern denkbar wären auch ,mobile Objekte' oder Figuren, die sich hin- und wieder wegbewegen. Die Raumwiedergabe wäre hier vergleichbar mit einem Film, in dem mit einer Kamera von einem festen Standort aus verschiedene Ereignisse festgehalten werden. Die Bewegungen anderer Figuren oder mobiler Objekte im Wahrnehmungsbereich verursachen eine ständige Veränderung räumlicher Eigenschaften, wie z. B. nah-fern, eng-weit, weswegen ein derartiger Raum als, transitorischer Raum' bezeichnet wird. Bei der Wiedergabe derartiger Ereignisse obliegt es der Figur oder dem Erzähler, sie als einmalige oder als typische Ereignisse zu bezeichnen. Werden sie als typische Ereignisse erzählt, handelt es sich wiederum um stabile Eigenschaften des jeweiligen Wahrnehmungsbereiches.

Wo sich der feste Standort der Wahrnehmungsinstanz befindet, ist in der Regel direkt bezeichnet. Neben einem erhöhten Standort ist auch eine ebenerdige Position der Wahrnehmungsinstanz (auf Augenhöhe) oder eine, die unterhalb des Wahrnehmungsbereichs (von unten) liegt, denkbar. ${ }^{199}$ Durch die Offenlegung des Standor-

197 Eine derartige Wiedergabe findet sich bereits in griechischer Epik. Vgl. Fitter (1995), 33 f.: „The first defined ,prospect' in Greek poetry occurs when Jason, in the Argonautika (1, 1112 ff.) sends his voyaging comrades to climb Mount Dindymon to scan the view. (...) Indeed, as early as Homer ,reconnaissance landscape is eagerly purveyed (...).“ Vgl. Hom. Od. 19, 194-197. Zur Wahrnehmung der Stadt Karthago durch die Figuren Achates und Aeneas im ersten Buch von Vergils Aeneis vgl. Wulfram (2009). Zur Inszenierung des Ausblicks in römischer Villenarchitektur vgl. Schneider (1995), 76-94.

198 Bal (32009), $134 \mathrm{f}$.

199 Zum Folgenden vgl. Dennerlein (2009), 150-153. In der antiken Literatur ist grundsätzlich die Perspektive von einem erhöhten Standpunkt (Panoramablick), von unten (Froschperspektive) oder auf Augenhöhe denkbar. Vgl. für die frühgriechische Epik Hellwig (1964). Die Blickinszenierung auf vertikaler Achse wird als Vogelperspektive (birds-eye view) bezeichnet, davon ist der Panoramablick zu unterscheiden. Interessanterweise verwirklicht Apoll. Rhod. bereits im Zusammenhang mit der Figur des Eros in den Argonautika 3, 165 f. die (womöglich einmalige) Perspektive von oben (Vogelperspektive) als göttliche Perspektive auf das Geschehen in Kolchis. Allgemein zur Deutung der eingenommenen Perspektive Assmann (22008), 154. Auch Bal (32009), 19 weist darauf hin, dass die Perspektive von einem erhöhten Standpunkt (Panoramablick) im westeuropäischen Diskurs symbolisch aufgeladen ist und als beherrschender, kolonisierender Blick gilt. 
tes ${ }^{200}$ lassen sich Aussagen über die Perspektive auf den Raum oder die damit verbundenen Wahrnehmungsmöglichkeiten der Wahrnehmungsinstanz machen. ${ }^{201}$ So wird eine Figur, deren Standort sich inmitten eines Menschenknäuels befindet, wohl über die innere Struktur berichten können, Ausdehnung und Tiefendimension eines Gesamtraums sind ihr aber womöglich verstellt. Einer Figur, deren Standort sich auf einer Anhöhe befindet, bietet sich dagegen ein freier Blick über ein weiträumiges Areal. ${ }^{202}$

\section{Blickinszenierung und Wahrnehmungssensibilität der Wahrnehmungsinstan₹}

In narrativen Texten erfolgt die erzählte Wahrnehmung räumlicher Gegebenheiten laut Bal vorwiegend über die Wiedergabe dreier Sinneseindrücke: Sehen, Hören und Tasten. ${ }^{203}$ Der Sehsinn gilt als „die privilegierte Sinneswahrnehmung“"204 narrativer Literatur, da vornehmlich visuelle Eindrücke wiedergegeben werden.

Ethologische Überlegungen für die Antike dazu bei Fehling (1974), bes. 52-58. Einen möglichen Bezug zwischen Blickinszenierung und römischer Expansion sieht Brodersen (1995), 242. Vgl. auch Schneider (1995), 78 zur Standortwahl hellenistischer Höfe. Zur Ausdifferenzierung der Anlässe, z. B. in magisterial gaze und tourist gaze, vgl. Vout (2007), 306 bes. Anm. 26 mit weiterführender Literatur. Dort finden sich auch Hinweise auf theoretische Literatur zum ,Blick' in der Literatur, ebd., 305, Anm. 23. Zum magisterial gaze als kolonisierenden Blick ebd., 307-313, Anm. 16, 10, 14. Vgl. auch Abschnitt 3.4.1.

200 Ist dies nicht der Fall, kann der Ort indirekt durch die Beschaffenheit dessen, was wahrgenommen wird, erschlossen werden. Ist auch dieses Verfahren aufgrund unzureichender Hinweise nicht ausführbar, wird letztlich allein die Anwesenheit der Wahrnehmungsinstanz innerhalb des Raumes vorausgesetzt.

201 Offenlegungen subjektgebundener Wahrnehmung werden häufig für eine Charakterisierung der Wahrnehmungsinstanz genutzt. Die eingeschränkte Möglichkeit einer Raumwahrnehmung, wie die eingenommene Perspektive einer Figur, können z. B. in ihrer sozialen Stellung begründet liegen. Vgl. dazu Würzbach (2001), 117-119. Die Veränderung einer derartig konnotierten Perspektive kann eine geglückte oder misslungene Emanzipation verdeutlichen. Die Beobachtung einer Stadt durch ein Fenster wurde als Zeichen für ein Emanzipationsstreben einer Figur interpretiert.

202 Vgl. Bal (32009), $144 \mathrm{f}$.

203 Bal (32009), 136. Für den griechisch-römischen Kulturkreis findet sich die Fünfzahl der Sinne erstmals bei Demokrit 68, B 11. Als vollständig etabliert gilt sie seit Aristoteles, der den Sinnen psychische Funktion zuschreibt. Die Rangfolge der Sinne ist ihm zufolge je nach Gesichtspunkt verschieden. „Für das Leben ist das Tasten (einschließlich des Schmeckens) wesentlich; jeder nicht-stationäre Organismus braucht es. Die anderen S[inne]. sind für das ,gute Leben' da, indem sie Orientierung in der Umwelt ermöglichen." Scheerer, s.v. Sinne, die, in: HWdPh (1995), Bd. 9, 832. Vgl. Aristot. an. 434 b, 1-30.

204 Würzbach (2001), 116. Bühler (21965), 127 bezeichnet den Sehsinn und den daraus resultierenden Sehraum für die räumliche Orientierung als entscheidend. Die Privilegierung des Sehsinns gegenüber den anderen Sinnen (im Hinblick auf ihre Funktion für den Logos) geht bereits auf Überlegungen frühgriechischer Philosophen zurück. Zunächst galten die Fernsinne, das Hören und das Sehen, gleichberechtigt. Jedoch ist wohl schon bei Heraklit, 22, B 101 a ein Vorzug

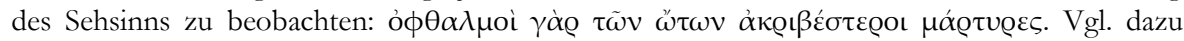
Schirren (1998), 165 f. Das Verb $\theta \varepsilon \alpha ́$ o $\mu \alpha \iota$ wird in der Odyssee zur Betrachtung von Landschaften häufig genutzt. Vgl. Fitter (1995), 33. Vgl. Hom. Od. 5, 75 f. und 7, 133 f. 
Über ihn werden Farben und Formen, aber auch physische Eigenschaften von Räumen vermittelt. ${ }^{205}$ Mithilfe von Begriffen aus der Filmtechnik wie Großaufnahme $^{206}$ und Nahaufnahme ${ }^{207}$ lassen sich ,Blickinszenierungen' einer visuellen Wahrnehmung differenzieren. ${ }^{208}$ Sie veranschaulichen vor allem den unterschiedlichen Abstand der Wahrnehmungsinstanz zu ihrem Wahrnehmungsbereich, verbunden mit Standortwahl und Perspektive. Die Grenzen der visuellen Wahrnehmungsmöglichkeit werden entweder explizit genannt oder entsprechen „den Grenzen der menschlichen Perzeption“.209

Gerüche und Geräusche können zweifellos zu wichtigen Eigenschaften eines Raumes gehören. Gerade wegen ihrer besonderen Flüchtigkeit ist es bemerkenswert, wenn eine Wahrnehmungsinstanz sie als charakteristisch oder eindrücklich für eine entsprechende räumliche Gegebenheit hervorhebt. ${ }^{210}$ Der taktile Sinn

205 Vgl. Bal (32009), 136. Vgl. Aristot. sens. 6; Cic. nat. deor. 2, 58, 145.

206 Von Großaufnabme spricht man, wenn der Bereich der Wahrnehmung und der Bereich des Wahrgenommenen verschieden sind, zwischen dem subjektiven bier und dort ein entsprechender Abstand herrscht. Die Wahrnehmungsinstanz bietet einen weiträumigen Überblick und kann womöglich ihre Wahrnehmung über angrenzende Räume hin ausdehnen. Die Wahrnehmung von Details ist aus dieser Perspektive eher unwahrscheinlich.

207 Von Nabaufnahme spricht man, wenn der räumliche Bereich des Wahrnehmens mit dem räumlichen Bereich des Wahrgenommenen weitgehend zusammenfällt, die Relation zwischen bier und dort als gering eingeschätzt werden muss. Die Wahrnehmungsinstanz selektiert vor allem das räumlich Naheliegende, also Dinge von kleinerer Gestalt oder in einer größeren Detailliertheit.

208 Vgl. dazu Würzbach (2001), 120; Bal (32009), 134; Konstan (2002) („under a fixed spotlight“, ebd., 2; „camera“, ebd., 7; „cut“, ebd., 8). Anleihen an filmische Begriffe auch bei Chatman (1980), 101-107, allerdings räumt er ein: „,...) there remain important differences between verbal and cinematic story-space. (...) verbal narratives can be completely nonscenic, ,nowhere in particular', transpiring in a realm of ideas rather than place. The movies have difficulty evoking this kind of nonplace.“" Ebd., 106. Hellwig (1964), 33 spricht von „Horizont“ statt Großaufnabme und von „Nahsicht" statt Nahaufnabme.

209 Dennerlein (2009), 147. Grundsätzlich sind der Wahrnehmungsperspektive in fiktionalen Texten keine natürlichen Grenzen gesetzt. Vgl. Martinez/Scheffel (52003), 63. Werden natürliche Grenzen überschritten, gilt dies allerdings als ein besonderes Charakteristikum des literarischen Textes.

210 Geräusche und Gerüche werden mitunter auch räumlich erinnert, d. h. mit bestimmten Räumen verbunden (z. B. Weihnachtsmarkt, Blumenwiese) und können somit räumliche Strukturen evozieren. In dieser Hinsicht wäre auch ein gustatives Raumverständnis („Kulinarische Landkarte“) denkbar. Laut Faure (1990), 226 wurde in der Stadt Rom gegen den schlechten Geruch mit Olivenholz, Duftwässern, Destillaten aus der Kolokasia, keltischer Narde, Safran geräuchert. Augustus und Tiberius ließen Tonnen von Weihrauch und Aromata zu Ehren der Götter und toter Angehöriger verbrennen oder Safranpuder verstreuen, um die Theater und Amphitheater mit Wohlgeruch zu erfüllen, und stifteten den Gymnasien und öffentlichen Bädern duftende Öle. Vgl. Faure (1990), 231 mit entsprechenden Textbelegen. In die antike Dichtung haben aber diese markanten Gerüche laut der Untersuchung von Lilja (1972) nicht Einzug gehalten. Trotz einer breit angelegten Untersuchung muss Lilja feststellen, dass Gerüche ausnehmend selten erwähnt werden. Von den antiken Dichtern waren ihren Ergebnissen zufolge überhaupt nur Pindar, Aischylos, Aristophanes, Plautus, Catull, Horaz und Martial für gute bzw. schlechte Gerüche 
kann ebenso wie der visuelle über die materielle Beschaffenheit Auskunft geben. ${ }^{211}$ Der Einsatz verschiedener Sinneseindrücke erzeugt ein besonders intensives, authentisches und unmittelbares Raumerleben und somit eine sehr konkrete räumliche Vorstellung. ${ }^{212}$

Der Einsatz dieser Sinne dient jedoch ebenfalls der Veranschaulichung räumlicher Strukturen. Wird beschrieben, wie intensiv Geruchs- oder Schallquellen eingeschätzt werden, kann der Abstand zwischen Geruchs- oder Geräuschquelle und Standort der Wahrnehmungsinstanz ${ }^{213}$ abgeschätzt werden: „If a character hears a low buzz, it is still a certain distance from the speakers. If it can understand word for word what is being said, then it is situated much nearer, in the same room, for instance, or behind a screen. A church clock sounding in the distance increases the space; suddenly perceived whispering points to the proximity of the whisperer." 214 Die Erwähnung olfaktorischer, auditiver oder haptischer Wahrnehmungseindrücke erlaubt auch deshalb Aussagen über räumliche Relationen zwischen der Wahrnehmungsinstanz und dem Wahrgenommenen, da sich die fünf Sinne in körperferne und körpernahe Wahrnehmungsformen differenzieren lassen. Zu den körperfernen Sinnen gehört neben dem Sehen das Hören. Aus großer Distanz heraus kann die Figur Dinge betrachten und entsprechende Geräusche wahrnehmen. ${ }^{215}$ Auditive und olfaktorische Eindrücke können sich wiederum dort einstellen, wo dem Visuellen Grenzen gesetzt sind. So kann eine Wahrnehmungsinstanz Geräusche etwa durch eine Wand hindurch hören, die ihr Aufschluss über die räumliche Beschaffenheit einer angrenzenden räumlichen Gegebenheit erlauben, obwohl sich der Nebenraum einer visuellen Wahrnehmung entzieht. Der taktile Sinn erschafft dagegen eher kleine, intime räumliche Umgebungen, die ,in der leibliche[n] Beziehung (...) auf die engste Nähe gerichtet“"216 ist. Denn um Objekte

empfänglich. Eine summarische Zusammenstellung der Behandlung von Düften in verschiedenen römischen Gattungen ebd., 222-225.

211 Vgl. Bal (32009), 136.

212 Vgl. Jäger (1998), 24; Würzbach (2001), 16. Literarische Räume, die mit einem besonders breiten Spektrum an aufnahmefähigen Sinnen gestaltet werden, gelten als eine typische Entwicklung der Moderne, vgl. Bal (32009), 135.

213 Der konkrete Standort der Wahrnehmungsinstanz wird bei den olfaktorischen und auditiven Wahrnehmungseindrücken seltener explizit bezeichnet. Oftmals wird lediglich die Anwesenheit der Wahrnehmungsinstanz im gleichen Raum vorausgesetzt, vgl. Dennerlein (2009), 153.

214 Bal (32009), 136. Sie schreibt dagegen dem Geruch keine raumbeschreibende Funktion zu: „Smell can contribute to the characterization of space but less obviously to its experience qua space."

215 Vgl. Jäger (1998), 44-46.

216 Jäger (1998), 40, der auch den Geschmackssinn einbezieht. Vgl. dagegen Bal (32009), 136: „Taste is rarely relevant in this context." Wegen seiner unmittelbaren Körperlichkeit bei der Wahrnehmung räumlicher Strukturen wird der Tastsinn - wie auch der gustative - im Gegensatz zum visuellen und auditiven Wahrnehmungsmodus als besonders subjektiv eingestuft. Diese Gruppenbildung stimmt mit Aristot. eth. Eud. 1230 b-1231 a überein. Hiernach soll sich der Besonnene gegenüber den Geschmacks- und Tasteindrücken, die der Mensch mit den Tieren teile, seine Be- 
anfassen zu können, muss die Wahrnehmungsinstanz ihnen mindestens auf Armeslänge nahe kommen. ${ }^{217}$

\section{Bewegung}

„Raum ist (...) keine bloße Form der Anschauung, sondern Ergebnis der Bewegung eigener und fremder Körper im Raum, der Erfahrbarkeit von Räumlichkeit." 218 Wenn die figurale Wahrnehmungsinstanz sich folglich selbst in Bewegung setzt, entsteht eine literarische Raumwiedergabe, die dem Filmeffekt Vergleichbares hat, ${ }^{219}$ denn sie ermöglicht zum einen die Darstellung eines mehrdimensionalen Raumerlebens, da zu der sagittalen Achse des Voranschreitens gleichzeitig auf vertikaler und horizontaler Ebene eine räumliche Umgebung veranschaulicht werden kann. Zum anderen ergeben sich durch das Voranschreiten der Wahrnehmungsinstanz notwendigerweise Raumveränderungen. ${ }^{220}$ Die Wahrnehmungsinstanz kann sich fernen Objekten annähern und diese daher genauer wahrnehmen (Zoom). ${ }^{221}$ Die räumliche Umgebung ist nicht mehr nur eine passiv-rezeptive Erfahrung, sondern gleichzeitig ein aktives, exploratives Ausgreifen der Figuren. ${ }^{222}$

sonnenheit erhalten. Visuellen, auditiven und olfaktorischen Reizen zu erliegen, gilt dagegen nicht als unbesonnen. Vgl. auch Lucr. 4, 216-705. Dazu Bailey (1972), Vol. 3, 1206: „(...) except in the primary sensation of touch and in it of taste, where there is direct contact between object and percipient $(\ldots)$.“

217 Vgl. Bal (32009), 136: „If a character feels walls on all sides, then it is confined in a very small space."

218 Bachmann-Medick (2009), 259 im Anschluss an Böhme.

219 Bal (32009), 135. Zur Mobilität der Wahrnehmungsinstanz vgl. Dennerlein (2009), 153-155.

220 Vgl. Jäger (1998), 42. Durch die Veränderung der Position der Wahrnehmungsinstanz wird die Subjektivität der Relation bier-dort in besonderer Weise veranschaulicht. Fitter (1995), 41 über Theokrit: „,[T]he assiduous naturalism - the accurately reported positioning of the landmarks along the eight kilometre walk to Phrasidamus' farm - and the correct natural history (...) embed a paradisal tonality in the closely mapped familiar world.“

221 Vgl. zum Zoom-Effekt durch Bewegung Fitter (1995), 34: „The Homeric eye is fine-tuned to the transformation of appearances of movement." Er weist auf einen bemerkenswerten Einsatz einer derartigen Wiedergabetechnik in der Odyssee hin. Aus einiger Entfernung vom Meer sehen die Berge auf der Insel der Phaiaken aus Odysseus' Perspektive wie ein Schild aus. Später gelangt er an die Grenze dieser Insel, den Strand. Am Strand finden einige Ereignisse statt, die auch den weiteren Bereich des Strandes räumlich klarer hervortreten lassen. Dort wird Odysseus in Form der oben erwähnten Wegbeschreibung über die räumliche Fortsetzung hinter dem Bereich des Strandes informiert, bevor er dann selbst diesen Weg beschreitet und die räumliche Umgebung wahrnimmt. Letztlich steht er vor dem Haus des Alkinoos, dessen Äußeres und Inneres er in kleinen räumlichen Details betrachtet, bevor er schließlich dessen Grenž, die eherne Schwelle, übertritt. Vgl. Hom. Od. 5, 278-281; 7, 82-84.

222 Jäger (1998), 229. Vgl. auch Scheerer, s.v. Sinne, die, in: HWdPh (1995), Bd. 9, 831: „Als ,Teil‘ oder ,Vermögen' der Seele ist die Wahrnehmung [laut Aristoteles, Anm. d. Verf.] Mensch und Tier gemeinsam (...) Als ,leidendes', passives Vermögen wird sie von dem aktiven Bewegungs- und Strebungsvermögen unterschieden (...).“ Generell zur Passivität der Wahrnehmung nach aristotelischem Verständnis: „Die Gegenstände aller S. [inne] treten von außen an das Organ heran und 
Durch die Eigenbewegung der Wahrnehmungsinstanz entsteht auch aus disparaten Bereichen, die sich einer Gesamtschau von einem festen Standort aus entziehen, ein räumliches Kontinuum. Gleichzeitig wird durch die Eigenbewegung der Abstand zwischen zwei Bereichen vermittelt. Er kann dabei auch ohne metrische Angaben implizit über die subjektiven, körperlichen Zustände einer Figur oder die von ihr benötigten Zeit wiedergegeben werden. ${ }^{223}$ Auch die Form der Bewegung, etwa das Tempo oder die Fortbewegungsmittel, lassen Entfernungen disparater räumlicher Gegebenheiten vorstellbar werden. Zudem haben die verschiedenen Bewegungstempi (z. B. Schlendern, Rennen, Reiten) auf das räumliche Erleben der Wahrnehmungsinstanz insofern Einfluss, als sie Auswirkungen auf die räumliche Antizipation, die Genauigkeit der Beschreibung und das Erleben der Zeit haben. ${ }^{224}$

Eine Wiedergabe des Raumes als erzählte Wahrnehmung gilt als recht eindeutiges Indiz einer intendierten Subjektivität bzw. Individualisierung der Darstellung. ${ }^{225}$ Die Offenlegung einer derartigen Intention ist für die Untersuchung eines autoren- und gattungsübergreifenden Raumschemas Großstadt nicht uninteressant, denn durch Gemeinsamkeiten im Beobachteten, also in der Selektion räumlicher Eigenschaften, lassen sich gerade hier recht eindeutig Alleinstellungsmerkmale für den literarischen Raum Großstadt herausarbeiten.

\subsection{Zusammenfassung}

Anhand welcher gestalterischen Mittel ein Leser zu einer Vorstellung von einer räumlichen Physis gelangen kann, wurde in den vorangegangenen Abschnitten vorgeführt. Dreidimensionale Anschaulichkeit und innere Strukturierung werden durch einen kontrastreichen Einsatz von lexikalischen und grammatikalischen Mitteln erzeugt. Anschaulichkeit ist zwar vor allem ein stilistisches Merkmal, sie verschafft aber der räumlichen Gegebenheit in einer besonderen Weise Präsenz̧ da die erzählerische Ausgestaltung eines literarischen Raumes grundsätzlich optional ist. Ihre Veranschaulichung kann deswegen berechtigterweise als Indiz für die Relevanz der räumlichen Gegebenheit angeführt werden.

bewirken dort eine qualitative Änderung ( $\alpha \lambda \lambda$ oí $\omega \sigma \iota \varsigma)$. Dies gilt auch für das Sehen; die Emissions- bzw. Sehstrahltheorie ist falsch“, ebd., 832.

223 Vgl. dazu Friedländer (1969), 5.

224 Vgl. Bal (32009), 140: „From a fast train, the traveller does not see the trees separately, but as one long, blurred line." In der Literatur der Moderne wird die Technisierung der Bewegung (Eisenbahn, Auto) häufig verarbeitet und meist als subjektiver Erfahrungszuwachs gewertet. Die Fortbewegungsmittel ermöglichen grundsätzlich auch die Einnahme unterschiedlicher Perspektiven auf den Wahrnehmungsbereich auf Augenböbe, von unten, als auch von oben.

225 Vgl. zur Individualisierung der Beschreibung in antiker Literatur Friedländer (1969), 14. Vgl. Martinez/Scheffel (52003), 63, Wolf, W., s.v. Fokalisierung, in: Nünning (32004), 191. 
Daneben kann die Wahl einer Darstellungstechnik als gewichtiges Indiz dienen, welchen Stellenwert der Autor einem Gegenstand zusprechen wollte. Bei den Darstellungstechniken der Beschreibung und der erzählten Wahrnehmung wird ein Gegenstand in den Mittelpunkt der Betrachtung gerückt, dem durch diese ausführliche Präsentation eine Bedeutung über die Erzählzeit zugeschrieben wird. Bei der Darstellungstechnik Erzählen von Ereignissen ergibt sich die Erwähnung eines Raumes zwar zunächst aus der Sache, über die Relevanz des Raumes entscheidet hier der Grad der Anschaulichkeit.

Da eine literarische Großstadt aufgrund ihrer Größe nicht im eigentlichen Sinne Schauplatz eines konkreten Ereignisses, Gegenstand einer Beschreibung oder Wahrnehmung sein kann, ist bei der Frage nach der Anschaulichkeit und Präsenz dieses Makroraumes grundsätzlich von Wichtigkeit, wie bedeutend die Inklusion des jeweiligen Schauplatzes oder Raumausschnittes in die Makrostrukturen der Großstadt wirklich ist. In welcher Art und Weise spielen dreidimensionale und strukturelle Eigenschaften des Makroraums in die direkten Ereignisse, also den unmittelbaren Lebenszusammenhang, hinein? Beschränkt sich die Darstellung der literarischen Großstadt auf eine Summe von wechselnden unverbundenen Einzelschauplätzen oder ergibt sich eine übergeordnete Struktur der Großstadt? Gibt es Indizien, dass die Wiedergabe eines Raumausschnittes aus der Perspektive einer einzelnen Figur repräsentativ für einen übergeordneten Raum ist, oder werden sogar entsprechende explizite Hinweise dazu gegeben? Begeben sich Wahrnehmungsinstanzen zu Standorten, in denen sich ihnen ein unverstellter Blick auf die dreidimensionale Ausdehnung, Begrenzung und innere Struktur des Makroraumes bietet oder bahnen sie sich einen, Weg ${ }^{6}$ durch die literarische Großstadt hindurch? Nur wenn sich aus dem Zusammenspiel verschiedener raumbezogener Informationen räumliche Makrostrukturen identifizieren lassen bzw. explizit ein direkter Zusammenhang vom gewählten Ausschnitt zum Makroraum gezogen wird, ist es berechtigt, die entsprechenden Texte als, Großstadttexte` zu bezeichnen. 


\section{Der literarische Raum Großstadt in der augusteischen und kaiserzeitlichen Dichtung}

Dem gesamten Cuvre des Martial oder Juvenal wie auch den augusteischen Elegikern wird in literaturwissenschaftlichen Handbüchern gleichermaßen bescheinigt, dass sie in einem großstädtischen Kontext stehen. Dieser Kontext manifestiert sich z. B. darin, dass eine Figur einen Beruf ausübt, der auf eine differenzierte Arbeitsteilung eines Lebensumfeldes schließen lässt. Er kann ebenso durch Zugangsmöglichkeiten zu bestimmten Lebensgütern intendiert sein, deren Erwerb einen entsprechenden Umschlagplatz von Waren notwendigerweise voraussetzt. Ein so verstandener großstädtischer Kontext bedeutet jedoch nicht zwingend, dass die Großstadt auch in ihrer Physis ausgestaltet wird.

Wie ein Einzug des Raumes Großstadt in die Literatur in basaler Weise feststellbar ist, wurde anhand der Vorschläge Mahlers (1999) im Abschnitt 2.1 dargelegt. Aus dieser Art der Sichtung ergibt sich die Auswahl an Texten und Textpassagen augusteischer und kaiserzeitlicher Dichtung, die in dem nun folgenden Kapitel hinsichtlich einer räumlichen Ausgestaltung untersucht werden sollen. Bei den im Folgenden näher betrachteten Texten handelt es sich somit stets um solche Passagen, in denen sich bereits eine ,Konstitutionsisotopie einer antiken Großstadt (urbs Roma) finden lässt. Sie enthalten in unterschiedlicher Dichte meist eine, Gat- 
Die Vielfalt räumlicher Inseln

tungsbezeichnung' (urbs), das 'Toponym‘ (Roma) oder entsprechende Referenzen auf ,Merk- und Wahrzeichen'bzw. ,typisch städtische Teilelemente‘.

Ziel des Kapitels ist es zu zeigen, ob überhaupt und vor allem wie die Großstadt in ihrer Physis - in ihrer Ausdehnung, ihrer Begrenzung und ihrer inneren Struktur - in römischer Dichtung wiedergegeben wurde.

\subsection{Die Vielfalt räumlicher Inseln}

Die erste ausführlichere Konstitutionsisotopie eines großstädtischen Raumes römischer Dichtung findet sich - womöglich ein wenig überraschend - in einer längeren Passage des plautinischen Curculio. ${ }^{226}$ Überraschen mag es deswegen, da der eigentliche Handlungsschauplatz dieser Komödie Epidaurus ist. 227 Mitten im Stück jedoch, in einer Parabase zum Auftakt des vierten Aktes, wird die eigentliche Handlung für zwanzig Verse unvermittelt unterbrochen. ${ }^{228}$ Während man als Zuschauer auf die Rückkehr des Protagonisten wartet, empfiehlt ein Choragus dem Publikum einstweilen Bereiche innerhalb der Großstadt Rom ${ }^{229}$, an denen man ohne langes Suchen zwielichtigen Gestalten begegnen kann. ${ }^{230}$ Den Grund

226 Vgl. Schmitzer (1999) [ohne Paginierung].

227 Plaut. Curc. 466-485. Zum Handlungsschauplatz vgl. Fantham (1973), 175 f., 202.

228 Diese ungewöhnliche und in ihrer Länge einzigartige Störung der Illusionsbildung hat die Frage herausgefordert, ob mit dieser Passage eine Interpolation vorliegt. Collart (1962), 10 weist darauf hin, dass die Echtheit dieser Passage zwar umstritten ist, jedoch keine objektiven Kriterien vorliegen. Vgl. auch Zwierlein (1990), 253-265, bes. 254: „ein Unikum im gesamten antiken Drama“ und 260: „Der Kunstgriff, durch den Monolog eines Kostümverleihers das Zeitintervall eines Zwischenaktes ausfüllen zu lassen, wirkt so originell, dass man ihn von vornherein nicht einem Bearbeiter zutraut, der nach unseren bisherigen Erfahrungen gerade im Sinne des Gewohnten, Alltäglichen eingreift, also eine Vereinheitlichung aller Szenenübergänge erstrebt und die Vielfalt der Variationen, die der Dichter dem lebendigen Leben abgeschaut hat, in eine schematische Gleichförmigkeit zu zwingen sucht“ und Blänsdorf (1978), 187 f.: „ganz gelegentlich mag die Neue Komödie Reste einer Parabase eingeschoben haben, wie den Auftritt des Kostümverleihers im ,Curculio' (IV 1). Doch ein neues Bewusstsein von künstlerischer Geschlossenheit erforderte, alles auszuschneiden, was die szenische Illusion sprengte.“

229 Das Toponym Roma oder die Gattungsbezeichnung urbs werden in diesem Abschnitt nicht benutzt, jedoch verweisen zahlreiche topographische Merk- und Wahrzeichen unmissverständlich metonymisch auf diesen Raum.

230 Plaut. Curc. 470-485: qui peïurum conuenire nolt hominem ito in comitium;/ qui mendacem et gloriosum, apud Cloacinae sacrum,/ dites, damnosos maritos sub basilica quaerito./ ibidem erunt scorta exoleta quique stipulari solent;/ symbolarum conlatores apud forum piscarium./ in foro infumo boni bomines atque dites ambulant; in medio propter canalem, ibi ostentatores meri;/ confidentes garrulique et malivoli supra lacum,/ qui alteri de nibilo audacter dicunt contumeliam/ et qui ipsi sat habent quod in se possit nere dicier./ sub ueteribus, ibi sunt qui dant quique accipiunt faenore./ pone aedem Castoris, ibi sunt subito quibu' credas male./ in Tusco vico, ibi sunt homines qui ipsi sese uenditant./ in Velabro uel pistorem uel lanium uel haruspicem/ uel qui ipsi uortant uel qui aliis ubi uorsentur praebeant./ [dites, damnosos maritos apud Leucadiam/ Oppiam.]. 
für diese überraschende Orientierungshilfe stellt der Kostümverleiher seinen Ausführungen voran: Sie soll dem Publikum eine lange Suche sparen. ${ }^{231}$

Die städtische Landschaft wird in dieser Empfehlung vielgestaltig beschrieben: Sie umfasst öffentliche Gebäude mit unterschiedlichen Funktionen, darunter Heiligtümer und Tempel, Plätze, ganze Viertel, einen Kanal und einen See, kurzum: zahlreiche mehr oder weniger klar umgrenzte räumliche Teilelemente unterschiedlicher Größe und Volumens. Diese bauliche Vielfalt wird durch eine Vielfalt an Menschen überboten: In den jeweiligen Bereichen lassen sich mehrere, unterschiedliche Menschengruppen antreffen. Da sie dabei als anonym handelnde, kollektive Akteure präsentiert werden, sind sie demzufolge Bestandteil der Raumbeschreibung.

Die Varianz der Präpositionalphrasen (apud, in, propter, pone, sub ...), mit denen die einzelnen Menschengruppen zu den städtischen Teilelementen positioniert werden, vermittelt für deren jeweiligen ,Eigenort' und die räumliche Umgebung bereits einen recht anschaulichen Raumeindruck. ${ }^{232}$ Viele Positionierungen werden über ,absolute Referenzen', also unabhängig von einem bestimmten Betrachterstandort präsentiert ${ }^{233}$, und wirken daher besonders realistisch. Die Anschaulichkeit einzelner Bereiche wird darüber hinaus durch ihre Unterteilung in weitere Zonen erzeugt. ${ }^{234}$

Was die Gestaltung des Gesamtraumes jedoch betrifft, so ist in dieser Passage jeder Bereich zwar Bestandteil des literarischen Raumes urbs Roma (,Inklusion'), bleibt jedoch strukturell eine ,Insel'. Denn eine Beschreibung der räumlichen Lagebeziehungen untereinander fehlt. ${ }^{235}$ Dadurch ergibt sich als Eigenschaft der räumlichen Physis vor allem der Eindruck einer Vielfalt als eine innere Struktur des Makro-

231 Plaut. Curc. 467 f.: commostrabo quo in quemque hominem facile inueniatis loco, / ne nimio opere sumat operam si quem conuentum uelit, (...).

232 Die Verwendung der Präposition sub vermittelt zusätzlich einen räumlichen Eindruck auf vertikaler Achse, da sie den Aufenthaltsort einer Menschengruppe ,,in unmittelbarer Nähe eines höher ragenden Gegenstandes“ bestimmt. Georges (1969), Bd. 2, s.v. sub, I A 2), Sp. 2839. Vgl. Plaut. Curc. 472: sub basilica, ebd., 480: sub neteribus.

233 Absolute Referenzen sind alle topologischen Präpositionalphrasen (in, apud, propter) und die intrinsischen wie sub basilica oder sub veteribus. Auch pone (...) aedem ist als Ortsangabe intrinsisch zu verstehen, da ein römischer Tempel eine standortunabhängig bestimmbare Rückseite hat. Als standortabhängige Präpositionalphrasen könnten nur in foro infumo und supra lacum gedeutet werden. Aus allem ergibt sich, dass ein Sprecherstandort nicht bestimmt werden muss. Vgl. dagegen Überlegungen zum Standort des Choragus bei Schmitzer (1999) [ohne Paginierung] und Schmitzer (2001), 525.

234 Vgl. Plaut. Curc. 475 f.: in foro infumo boni homines atque dites ambulant;/ in medio propter canalem, ibi ostentatores meri.

235 Schäfer (2001), 184. Vgl. Lefèvre (1991), bes. 100 f. und Wright (1981), ad loc. [ohne Paginierung]. „Here the Choragus takes the audience on a satirical tour of the central area of Republican Rome. (...) the second plan (...) shows how strictly geographical the Choragus' ,tour " is." Ein räumlicher Zusammenhang der verschiedenen Merkzeichen in Form einer „,tour“ entspricht m. E. nicht der Textgrundlage. Probleme bestehen auch mit der Identifizierung einiger Gebäude. 
raumes. Auf seine Ausdehnung lässt sich indirekt aus der Inklusion aller dieser Inseln schließen, wie auch aus dem Sprechanlass selbst, nämlich dem Zuhörer eine Orientierung geben zu müssen, um ihm eine lange Suche zu ersparen. Denn dieser erhält seine Berechtigung allein, wenn der Gesamtraum größer als das in der Beschreibung präsentierte Areal vorzustellen ist bzw. eine relative Unübersichtlichkeit herrscht. Da jedoch alle genannten Bereiche in einer potentiellen Erreichbarkeit für jeden Zuschauer liegen, bleibt die Ausarbeitung dieses räumlichen Merkmals in dieser Passage recht vage.

Auch im CEuvre Catulls finden sich bereits Beispiele, in denen in einiger Dichte Referenzen auf typische städtische Teilelemente zu finden sind, wie im carmen 55, das von der vergeblichen Suche des Sprechers nach seinem Freund Camerinus handelt. ${ }^{236}$ Dazu zählt er im ersten Teil des Gedichtes diejenigen Orte auf, an denen er bereits Ausschau nach seinem Freund gehalten hat:

\footnotetext{
te Campo quaesiuimus minore,

te in Circo, te in omnibus libellis,

5 te in templo summi Iouis sacrato.

in Magni simul ambulatione

femellas omnes, amice, prendi,

quas uultu vidi tamen sereno. ${ }^{237}$
}

In diesem Gedicht findet sich zwar keine explizite Referenz auf die urbs Roma, aber mittels zweier topographischer Merk- und Wahrzeichen, des Jupiter-Tempels (v. 5) und vor allem der Portikus des Pompeius (v. 6) lässt sich auf sie als literarischen Raum schließen. Auch werden typische städtische Teilelemente benannt: ein kleinerer Platz innerhalb der Stadt (v. 3), ein Circus (v. 4) und Buchläden (v. 4).238 Die Varianz der Bausubstanz, deren unterschiedlicher Umfang der jeweiligen Eigenorte auffällig ist, charakterisiert in dieser Passage den literarischen Raum zweifelsfrei als einen städtischen.

Der Sprecher reiht verschiedene Ortsangaben, die durch die Anapher (te) jeweils von einander abgesetzt sind, katalogartig aneinander. Zu ihrer Positionierung in-

236 Die Suche nach einer Person in einer städtischen Landschaft findet sich verschiedentlich in der römischen Komödie, vgl. Plaut. Ep. 195-200; 666-674; 719 f. Ter. Heaut. 585-589 und 805-807; Ter. Ad. 713-718.

237 Catull. 55, 3-8.

238 Dass die städtischen Teilelemente auch als Anspielungen auf konkrete topographische Merkzeichen im realen Raum der Stadt Rom verstanden werden sollen, zeigt der Herausgeber des Textes durch die Großschreibung an. Im Falle des campus ist allerdings eine genaue Lokalisierung unklar. Im Falle der Buchläden, auf die hier mittels eines typischen Gegenstandes, nämlich der Bücher, metonymisch verwiesen wäre, ist der Wortgebrauch umstritten. Vgl. dazu Kroll ( ${ }^{71989)}$, 97 und Fordyce (1987). Beide sind für das Verständnis von „Buchläden“, dagegen Ellis (1979), 189 f. In der Ausgabe von Bardon (1973) wurde libellis zu ligellis emendiert. 
nerhalb des Makroraums werden absolute Referenzen verwendet, die aber weniger variantenreich als in der plautinischen Passage gestaltet sind. ${ }^{239}$ Anschaulicher dargestellt wird ein einziger Eigenort, nämlich die Säulenhalle des Pompeius. Der Sprecher selektiert an diesem topographischen Merkzeichen keine architektonischen Details, nennt aber Personen, die sich typischerweise dort aufhalten. Sodann berichtet er davon, wie er dort den verschiedenen Frauen ins Gesicht schaut und nach ihrem jeweiligen Gesichtsausdruck auswählt, um sie auf den Freund anzusprechen. ${ }^{240}$ Der Eigenort der Portikus wird damit zu einem ,Kontaktbereich“ mit Unbekannten und einem ,Schauplatz' seiner Suche ausgestaltet, während die anderen Bereiche allein in ihrer räumlichen Existenz innerhalb des literarischen Raums als ,Ereignisregion' akzentuiert bleiben.

Obwohl in diesem Gedicht mit der Darstellungstechnik des ,Erzählens von Ereignissen' das Ereignis einer Suche innerhalb eines Makroraums erzählt wird, enthält das carmen nur eine äußerst basale Veranschaulichung der Physis des literarischen Raumes selbst. Seine innere Struktur und die Ausdehnung sind auf die Inklusion einer vielfältigen städtischen Bausubstanz, folglich der Existenz verschiedener Inseln, beschränkt. Räumliche Beziehungen und Strukturen wie etwa Entfernungen einzelner Bereiche zueinander oder, ob der Sprecher sie hintereinander abgeschritten oder ob er sie von einem einzigen Standort aus angelaufen hat, wird aus der Darstellung nicht ersichtlich. Auch Grenzen des Raumes werden nicht erwähnt. Der Sprechanlass dieses carmen, die vergebliche Suche und die in diesem Sinne formulierte Bitte um Orientierung, weisen jedoch den gesamten literarischen Raum als größer aus, als er durch die explizit genannten Bereiche dargestellt wurde. Die räumliche Ausdehnung des Makroraumes ist demzufolge zwar wie eine relative Unübersichtlichkeit eine entscheidende Voraussetzung für den Inhalt des Gedichtes, erzählt wird aber allein von der Varianz einer inneren Struktur.

Die wohl prominenteste und umfangreichste literarische Orientierungshilfe für den literarischen Raum urbs Roma findet sich im ersten Buch der Ars amatoria Ovids. In einer längeren Passage (v. 67-262)241 soll der junge Leser unterrichtet werden, wo sich inner- und außerhalb der urbs Roma Mädchen zahlreich einfinden (frequens quo sit disce puella loco, v. 50). Gleich in einem ersten Abschnitt stellt der Sprecher in sehr dichter Folge verschiedene topographische Merk- und Wahrzei-

239 Es handelt sich jeweils um topologische Ortsangaben mithilfe einer eingeleiteten Präpositionalphrase durch in oder des Ablativus loci.

240 Von den Frauen werden Gesichtsausdrücke unterschieden (visuell), die Antwort einer Frau in direkter Rede wiedergegeben (akustisch) und der Fokus verengt auf die Brust einer Frau, die sie ihm als Antwort auf die Frage nach dem Aufenthaltsort des Freundes entgegenstreckt (Zoom). Catull. 55, 12: , en bic in roseis latet papillis. '

241 Einteilung nach Hollis (1991), 43. 
chen innerhalb des literarischen Raumes urbs Roma vor (v. 67-88). ${ }^{242}$ In einem ersten Textausschnitt werden einem mit $t u$ angesprochenen Gegenüber gleich vier Portikus als Option genannt, unter denen er sich schlendernd aufhalten soll. ${ }^{243}$

tu modo Pompeia lentus spatiare sub umbra,
cum sol Herculei terga leonis adit,
aut ubi muneribus nati sua munera mater
addidit, externo marmore diues opus.
nec tibi uitetur quae priscis sparsa tabellis
porticus auctoris Linia nomen habet,
quaque parare necem miseris patruelibus ausae
Belides et stricto stat ferus ense pater.

Die Aufmerksamkeit richtet sich in diesem Ausschnitt auf ein- und denselben Gebäudetypus. Diese Systematik, von Gebäudetypen, nicht von einzelnen Vierteln o. ä. auszugehen, wird in der gesamten Passage (v. 67-262) beibehalten. Dabei verleiht bereits diese Häufung von öffentlichen Gebäuden dem damit beschriebenen Gesamtraum einen außerordentlich großstädtischen Charakter. Für seine Anschaulichkeit bedeutet diese Vorgehensweise aber, dass wiederum einzelne Inseln benannt werden ${ }^{245}$, die miteinander unverbunden bleiben. Wo und auf welchen Wegen sie zu finden sind, wird innerhalb der literarischen Fiktion als Wissen bei dem angesprochenen Leser vorausgesetzt.

Wenn sich daher zwar diese Orientierungshilfe darauf beschränkt, Aufenthaltsorte von Mädchen lediglich zu benennen, richtet sich die Aufmerksamkeit des Sprechers jedoch gerade in diesem ersten Ausschnitt auffälliger Weise nicht auf die Beschreibung der Menschen, sondern - im Gegensatz zum carmen 55 Catulls oder der Parabase des plautinischen Curculio - auf die Oberflächengestalt der Gebäude, das Figurenprogramm oder auf räumliche Nähe der Gebäude untereinander. So werden an zwei Portikus visuell wahrnehmbare architektonische Details erwähnt oder im Fall der Portikus Octavia ihre Stiftungsgeschichte mit der eines benachbarten Gebäudes in Verbindung gebracht ${ }^{246}$; auch die Präpositionalphrase sub umbra (v. 67) evoziert einen räumlichen Eindruck auf vertikaler Achse für den Leser, die

242 Entsprechende Referenzen, die den literarischen Raum explizit als urbs Roma ausweisen, finden sich unmittelbar vorher in den Versen 55 und 60.

243 Die Porticus sind - auch durch Anspielungen auf ihre Eigennamen - als topographische Merkund Wahrzeichen eines literarischen Raumes urbs Roma leicht zu identifizieren.

244 Ov. ars 1, 67-74.

245 Die Positionierung ist für den gesamten Abschnitt trotz des Einsatzes von Deiktika ([ibi], ubi, v. 69; [ea], quae, v. 71; [ea], qua, v. 73) auf ein absolutes Referenzsystem bezogen.

246 Vgl. zu den Schwierigkeiten mit der ovidischen Chronologie der Bauzeiten des Marcellustheaters und der Porticus Octavia Labate (1984), 82-84. 
Handlungsanweisung lentus spatiare (v. 67) auf der sagittalen. ${ }^{247}$ Damit kommt der räumlichen Beschreibung deutlich mehr Gewicht zu als es der eigentliche Erzählgegenstand erfordert. ${ }^{248}$ Im Gegensatz dazu fehlen über die allgemeine Information hinaus, dass der Leser dort Frauen finde, Hinweise auf erwartbare, da typische Ereignisse oder Charakterisierungen der Personengruppen, die einen jungen Mann motivieren, der Empfehlung des Sprechers Folge zu leisten und die vorgeblichen Kontaktbereiche aufzusuchen. ${ }^{249}$ Die Fokussierung auf das Räumliche und die Materialität ist in diesem kurzen Abschnitt besonders auffällig, auch im Kontrast zu der sich anschließenden Passage. Folgend werden nämlich städtische Teilelemente gerade als Orte einer reizvollen Begegnung mit jungen Frauen empfohlen:

$$
\begin{aligned}
& \text { nec fuge linigerae Memphitica templa inuencae: } \\
& \text { multas illa facit, quod fuit ipsa Ioui. } \\
& \text { et fora conueniunt (quis credere possit?) amori, }
\end{aligned}
$$

247 Dieser Raumeindruck lässt sich auch auf die weiteren Portikus übertragen, da für sie die gleiche Handlungsanweisung gilt.

248 Das Urteil Rudds (1976) scheint mir daher unzutreffend: „(...) it is commended not for its columns of giallo antico nor for its impressive statuary, but simply because it provides an excellent hunting-ground for young men on the loose." Rudd (1976), 13 über die Danaiden-Porticus beim Tempel des Apoll. Vgl. zu den anderen Portikus ebd., 13 f. Das Urteil Rudds findet sich verschiedentlich in der Literatur. Vgl. Boyle (2003), 176: „Ovid takes to a new level the eroticisation of Roman space by such poets as Catullus and Propertius (...) Ovid not only eroticizes these places by celebrating them as appropriate venues for picking up girls, but he describes them against the ideological grain by emphasizing the erotic semiotics immanent in the monuments and sites.“, auch Welch (2005), 90. Diese gesamte Passage (v. 67-88) stand schon verschiedentlich im Mittelpunkt des Interesses, vor allem im Hinblick auf die Frage, wie die hier genannten Wahrzeichen augusteischer Baupolitik als Kontaktbereiche für junge Männer und Frauen womöglich diskreditiert bzw. nicht im Sinne eines augusteischen Bildprogramms kontextualisiert werden. Vgl. Holzberg (1999), 62-64, Miller (2007), 151-156, auch Boyle (2003), 42 f., 176 f. Vgl. auch Ov. ars 3, 387 f. Sinnvoller wäre es m. E. das - vor allem im Gegensatz zu späteren Passagen - auffällige Anzitieren von architektonischen Details an diesen Stellen für eine Interpretation im Sinne der eigentlichen Aussageabsicht (womöglich über eine literarische Anspielung hinaus, die hier zweifellos vorliegt), fruchtbar zu machen. Boyle (2003), 177: „The marble revetments or constituents of various buildings are noted (...), but the political semiotics of the revetment $(. .$.$) are cheekily pushed aside in favour of the marble's role in creating a glamorous back-$ drop for sexual encounters." Zur Funktion des Marmors in der augusteischen Literatur vgl. allgemein Edwards (1996), 102-105, 127. Zur literarischen Erotisierung augusteischer Monumente Edwards (1996), 23-25.

249 Vgl. dagegen Ov. ars 3, 387 f.: at licet et prodest Pompeias ire per umbras,/ Virginis aetheriis cum caput ardet equis; hier ist die Erwähnung der Portikus mit ihrer Funktion als Schutz vor der sommerlichen Hitze motiviert. Vgl. darüber hinaus Ov. ars 3, 389-396, wo bei der Darstellung der Gebäude visuelle, olfaktorische und taktile Merkmale überwiegen: Visite laurigero sacrata Palatia Phoebo/ (ille Paraetonicas mersit in alta rates)/ quaeque soror coniunxque ducis monimenta pararunt/ naualique gener cinctus honore caput,/ wisite turicremas uaccae Memphitidos aras,/ wisite conspicuis terna theatra locis./ spectentur tepido maculosae sanguine barenae/ metaque feruenti circumeunda rota. 
80

\author{
flammaque in arguto saepe reperta foro. \\ subdita qua Veneris facto de marmore templo \\ Appias expressis aera pulsat aquis, \\ illo saepe loco capitur consultus Amori, \\ quique aliis cauit, non cauet ipse sibi; (...).250
}

In diesem Abschnitt verflicht der Sprecher die jeweilige räumliche Gegebenheit mit einem beinahe regelhaften (saepe, v. 80) ,amourösen“ Ereignis: In räumlicher Nähe zum Isis-Tempel werden Mädchen zu willigen Geliebten. ${ }^{251}$ Auf den Foren wird das erwartbare kompetente Handeln eines Anwalts mit der Handlungsunfähigkeit eines Verliebten ${ }^{252}$ kontrastiert: Der entflammte Anwalt kann sich selbst nicht mehr verteidigen, wäre statt eines patronus lieber Klient.

Aber auch die räumliche Ausgestaltung dieses regelhaften, mirakulösen Ereignisses wird in diesem Abschnitt sorgfältig ausgearbeitet und hinterlässt beim Leser einen sowohl akustischen als auch visuellen Raumeindruck. Der Ausfall des Anwalts findet nämlich an einem vertikal akzentuierten Brunnen (pulsat aera, v. 82) und bei-d. h. in unmittelbarer Sichtweite - einem Venustempel statt, wie zweimalig betont wird. ${ }^{253}$ Räumlich wird das Ereignis somit in eine Gesamtanlage von drei aufeinander bezogenen Gegebenheiten (Forum, Brunnen, Tempel) eingebettet. Die sinnlichen Eigenschaften der Ereignisregion stehen dabei auffallend im Widerspruch zu den Möglichkeiten des verliebten Anwalts: In der akustisch akzentuierten Umgebung, auf dem wortreichen Forum und in Nähe eines kräftig sprudelnden Brunnens, fehlen dem Anwalt die Worte.

An räumlicher Anschaulichkeit übertrifft diese Ausgestaltung die bisherigen Beispiele $^{254}$, da sie zeigt, wie eine mehrdimensionale und multisensuelle Ausarbeitung

250 Ov. ars 1, 77-84.

251 Ov. ars 1, 77 f.: nec fuge linigerae Memphitica templa iunencae:/ multas illa facit, quod fuit ipsa Ioui.

252 Dazu Labate (1984), 85-89 und Neumeister (1991), 97 f.

253 Ov. ars 1, 79-88: et fora conueniunt (quis credere possit?) amori,/ flammaque in arguto saepe reperta foro./ subdita qua Veneris facto de marmore templo/ Appias expressis aera pulsat aquis,/ illo saepe loco capitur consultus Amori,/ quique aliis cauit, non cauet ipse sibi;/ illo saepe loco desunt sua uerba diserto,/ resque nouae ueniunt, causaque agenda sua est./ bunc Venus e templis, quae sunt confinia, ridet, / qui modo patronus, nunc cupit esse cliens. Die Doppelbödigkeit der Formulierungen aus der juristischen Fachsprache ab v. 83 (vgl. dazu Hollis (1991), 49) erstreckt sich m. E. auch auf die Formulierung expressis aquis in v. 82. Zur erotisierenden Deutung vgl. Boyle (2003), $176 \mathrm{f}$.

254 Vom Aufbau dieser Passage her sind trotz genannter Unterschiede auch viele Ähnlichkeiten mit dem Gedicht Catulls zu entdecken. In beiden Fällen beginnt der Sprecher mit einem Katalog räumlicher Gegebenheiten, am Ende werden jeweils ein Bereich, nämlich die Portikus bei Catull oder das Forum bei Ovid, stärker als städtischer Kontaktbereich ausgearbeitet. Der Status eines Kontaktbereichs kommt zwar inhaltlich allen in der ars aufgeführten räumlichen Gegebenheiten zu, jedoch wird erst das Forum als solcher auch dargestellt. In allen drei Fällen, bei Plautus, Catull und Ovid, werden innerhalb des städtischen Bereichs öffentliche Kontaktbereiche beschrieben, in denen es dem Adressaten oder dem Sprecher möglich ist oder war, ihm Unbekannte zu 
von den römischen Autoren sinnstiftend eingesetzt wird. In Bezug auf den Gesamtraum aber bleibt diese Platzanlage - wie auch die Ereignisregionen in den nachfolgenden Passagen, dem Theater, dem Circus, dem Triumphzug und einem Gastmahl in einem nicht näher spezifizierten Innenraum - stets unverbundene Inseln. ${ }^{255}$ Deren anschauliche Ausgestaltung und die Quantität an Gebäuden und Plätzen lässt jedoch aus der Vielfalt an Inseln eine variantenreiche innere Struktur und auch eine beträchtliche räumliche Ausdehnung zu einer notwendigen Bedingung werden.

Im Gegensatz zu dieser Varianz an städtischer Bausubstanz steht im Epigramm des kaiserzeitlichen Dichters Martials (7, 73) vor allem ein typisches städtisches Teilelement im Mittelpunkt: eine domus.

1 Esquiliis domus est, domus est tibi colle Dianae,

et tua patricius culmina vicus habet;

binc viduae Cybeles, illinc sacraria Vestae,

inde novum, veterem prospicis inde Iovem.

5 dic ubi conveniam, dic qua te parte requiram:

quisquis ubique habitat, Maxime, nusquam habitat. ${ }^{256}$

An städtebaulicher Substanz sind in diesem Epigramm drei Häuser, darüber hinaus aber auch eine Straße und vier Tempel versammelt. Die Positionierung der im Mittelpunkt stehenden domus beschränkt sich allerdings nicht mehr nur auf eine einfache Inklusion in den Gesamtraum: Jeweils weiträumigere, diffus begrenzte Bereiche (Esquiliis; colle Dianae, patricius ... vicus, v. 1 f.) umschließen wiederum die klar umgrenzten Gebäude (domus, v. 1), also kleinere Eigenorte, in denen wiederum der Aufenthaltsort des Freundes Maximus vermutet wird. Durch diese hierarchische Inklusion wird die Lage der einzelnen räumlichen Gegebenheiten zueinander anschaulicher gestaltet als beispielsweise im weiter oben vorgeführten carmen des Catull. Gleichzeitig wird aber auch - durch die Wahl weiträumiger Areale als umfassendere Eigenorte - die Disparatheit der möglichen Standorte des Maximus als eine innere Struktur des Gesamtraumes herausgearbeitet. ${ }^{257}$ So beklagt sich der

treffen. Das Treffen von Unbekannten setzt eine gewisse Anzahl von Einwohnern voraus und berührt damit ein räumliches Merkmal, das in Abschnitt 3.5.2 untersucht werden soll.

255 Auch in den nachfolgenden Passagen werden räumliche Eigenschaften mit zu antizipierenden Ereignissen verknüpft. Es handelt sich entsprechend der literarischen Fiktion bei dem als regelhaft präsentiertem Verhalten von Frauen und Männern um stabile Eigenschaften der jeweiligen Inseln.

256 Mart. 7, 73.

257 Von der äußeren Form des Gedichtes her, nämlich durch die Wortstellung, rahmen die Positionierungen die anaphorisch wiederholten Referenzen auf Gebäude (domus est, domus est, v. 1) ein. Ebenso rahmt im zweiten Vers die Lokalisation (patricius ... vicus, v. 2) das dritte Gebäude ein. 
Sprecher darüber, dass er seinen Freund Maximus nicht antreffen kann (dic ubi conveniam, dic qua te parte requiram, v. 5), jedoch nicht, weil Maximus sich absichtlich dem Sprecher entzieht - wie in der Konstellation in Catulls carmen 55 -, sondern weil Maximus über den Makroraum verstreut ${ }^{258}$ mehrere Häuser besitzt.

Neben der Lage der domus auf horizontaler Achse wird für alle drei möglichen Aufenthaltsbereiche auch eine vertikale Achse herausgearbeitet: Die beiden domus werden im ersten Vers auf Erhebungen positioniert, im zweiten Vers referiert die Metonymie culmina implizit auf ein drittes Haus. ${ }^{259}$ Diese erhöhte Lage wird in den folgenden drei Versen weiter räumlich gestaltet. Denn in den Mittelpunkt rücken Aussichten aus diesen drei Gebäuden ${ }^{260}$, die jeweils auf Tempel gehen. ${ }^{261}$ Die Ausblicke gehen in vier unterschiedliche Richtungen, auf die über deiktische Referenzen hinc, illinc, inde, inde verwiesen wird. Folglich wird eine ,Wahrnehmungsinstanz' in den jeweiligen Häusern positioniert und es entsteht neben einem ,Ereignisbereich“ auch ein ,Wahrnehmungsbereich', d.h. der Eigenort domus wird jeweils um das als Ausblick hinzukommende Gebiet erweitert. ${ }^{262}$

Das gesamte Epigramm ist dominant räumlich angelegt. Es wird kein Ereignis erzählt, kein Kontaktbereich ausgestaltet, sondern allein die räumliche disparate Positionierung von Gebäuden innerhalb des Makroraumes durch entsprechende Ortsangaben und eine jeweils dazugehörige weitere Umgebung durch die Wiedergabe ihres Ausblicks beschrieben. Es sind daher die räumlichen Eigenschaften

Durch Stellung im Vers werden gerade die unterschiedlichen Positionen voneinander getrennt, was man als eine Abbildung der Entfernung interpretieren könnte.

258 Um eine präzise, sprich realitätsnahe Positionierung der Wohngebäude innerhalb des literarischen Raums urbs Roma wird sich nicht bemüht. Dies macht die Größe der Eigenorte (Hügel) deutlich. Die Lokalisierung der domus erfolgt in ,zonal fingierten Handlungszonen'. Zum Begriff fingierte Handlungszone vgl. Piatti (2008), 136 f. Zum Begriff zonal vgl. Glossar.

259 Galán Vioque (2002), 416 weist darauf hin, dass als übliche Metonymie für ein Haus tectum gebraucht wird.

260 Vgl. dazu die Diskussion verschiedener Forschungsbeiträge und weitere Literaturhinweise bei Galán Vioque (2002), 416 f.

261 Die Tempel liegen für den mit der Topographie Roms Vertrauten ebenfalls auf innerstädtischen Hügeln. Vgl. zu den Lokalisierungsversuchen Galán Vioque (2002), 471 f.

262 Die visuell vermittelte Verbindung lässt zwischen den jeweiligen beiden Bereichen ein räumliches Kontinuum entstehen. Die räumliche Distanz zwischen ihnen wird subjektiv über die visuelle Fähigkeit des Angesprochenen (prospicis, v. 4) bestimmt. Vergleichbar auch Ov. Pont. 1, 8, 35-38: nunc fora, nunc aedes, nunc marmore tecta theatra,/ nunc subit aequata porticus omnis humo./ gramina nunc Campi pulchros spectantis in hortos,/ stagnaque et euripi Virgineusque liquor. Hier werden acht verschiedene städtische Teilelemente aufgezählt, die durch den Eigenname Virgineus auf die urbs Roma verweisen. Der Herausgeber zeigt durch die Großschreibung von campus, dass er auch dieses städtische Teilelement ebenfalls als topographisches Merkzeichen verstanden wissen will. Die Bausubstanz ist variantenreich, z. T. werden einzelne architektonische Details hervorgehoben, und sie sind auf jeden Fall typisch städtisch (Forum, Tempel, Theater, Portikus, Gärten). Die Bereiche sind untereinander unverbunden. Allein der Hinweis spectantis stellt eine räumliche Relation zwischen dem campus und den Gärten her, deren Entfernung über die visuelle Wahrnehmungsfähigkeit beschrieben wird. Vgl. Ov. trist. 1, 3, 29 f. 
eines Makroraumes ${ }^{263}$, die in diesem Abschnitt im Zentrum stehen, nämlich die Entfernungen und Höhenunterschiede zwischen einzelnen Bereichen.

\section{Zusammenfassung}

In allen vorgeführten Beispielen römischer Dichtung von der römischen Komödie bis zum kaiserzeitlichen Epigramm werden einzelne Bereiche und Merkzeichen in einem größeren Raum lokalisiert (Inklusion). Die Verwendung von topographischen Wahr- und Merkzeichen und typischen Teilelementen weist den sie umfassenden Raum als urbs Roma aus. Jedoch werden die räumlichen Relationen untereinander nicht kenntlich gemacht. Es handelt sich strukturell um Inseln, die von sehr unterschiedlicher räumlicher Ausdehnung sind und auch unterschiedlich stark ausgestaltet werden. Sie werden benannt, architektonische Details an ihnen erwähnt, sie werden als Kontaktbereich präsentiert oder mehrere Bereiche werden als ein ,räumliches Ensemble gestaltet und sogar multisensuell und mehrdimensional ausgearbeitet. Die räumlichen Strukturen, die sich für diese einzelnen Bereiche erkennen lassen, gehen damit über eine obligatorische Verortung der Handlung hinaus und müssen in eine Gesamtinterpretation einbezogen werden.

Für die Ausgestaltung eines literarischen Makroraums ist die Inklusion allerdings ein sehr einfaches Darstellungsverfahren. ${ }^{264}$ Die Vielfalt der Inseln weist vor allen Dingen auf eine variantenreiche innere Struktur der literarischen Großstadt. Vage bleibt die Vorstellung ihrer räumlichen Ausdehnung und ihrer Begrenzung. Nur für denjenigen Leser, der die Lagebeziehungen der topographischen Merk- und Wahrzeichen aus eigener Anschauung kennt, entsteht ein räumlicher Gesamteindruck. Die jeweiligen Eigenorte der typischen Teilelemente und ihre Summe setzen zwar eine z. T. erhebliche Bebauungsfläche voraus. Von einer ersten Veranschaulichung räumlicher Ausdehnung kann man jedoch allein bei der Darstellung räumlicher Relationen sprechen, die sich der hierarchischen Inklusion bedient.

Zur Vorstellung, dass der literarische Raum eine größere Siedlung sei, trägt daher in diesen Beispielen vor allem der inhaltliche Zusammenhang bei, nämlich, dass eine Orientierung gegeben oder um eine Aufklärung des aktuellen Standortes gebeten wird. Die Notwendigkeit der Orientierung von aktiv-explorativen Figuren zeigt implizit, dass dieser literarische Raum jeweils von dem Einzelnen nicht von einem ,festen Standort ${ }^{6}$ aus zu überblicken ist, dass er folglich um ein unbekanntes Vielfaches über die in der Dichtung vorgenommene Präsentation hinausgeht. Erst damit werden eine gewisse Ausdehnung und die Unübersichtlichkeit als Merkmal einer inneren Struktur zu einer notwendigen Voraussetzung der Illusionsbildung, wenn auch die jeweilige Erreichbarkeit der Inseln von einem explizit nie genann-

263 Durch topographische Merk- und Wahrzeichen wie den Esquilin, den vicus patricius und die verschiedenen Tempel ist der literarische Raum als urbs Roma identifizierbar.

264 Tauscht man die typischen städtischen Teilelemente (Straße, Wohnhaus, Theater, Circus, Porticus) mit anderen zum Beispiel ländlichen (Baum, Wiese, Stall) aus, so entsteht eine bukolische Landschaft. 
ten Sprecherstandort aus nicht zur Vorstellung eines besonders weitläufigen Areals beiträgt.

\subsection{Wege durch den Raum}

Das Beschreiben von Wegstrecken ist eine Darstellungstechnik narrativer Texte, die es dem Autor ermöglicht, die Lage einzelner Bereiche in einem räumlichen Zusammenhang zu präsentieren, wenn sich diese nicht mehr von einem festen Standort aus erfassen lassen. ${ }^{265}$

Wegbeschreibungen sind daher für jeden Makroraum eine naheliegende Darstellungsweise. In der römischen Literatur findet sich eine derartige Wegbeschreibung auch durch einen städtischen Raum. Der in der Komödie Adelphoe beschriebene ,Weg' führt allerdings nicht durch einen literarischen Raum urbs Roma, sondern entsprechend der Illusionsbildung dieser Komödie durch die Stadt Athen. ${ }^{266}$ Als eine Kontrastfolie zu den im Anschluss präsentierten, raren Beispielen einer innerstädtischen Wegbeschreibung durch eine urbs Roma aus der augusteischen und kaiserzeitlichen Dichtung soll an dieser Textpassage das Potential dieser Darstellungstechnik verdeutlicht werden, das der römische Autor Terenz für sein Werk zu nutzen wusste.

In der Komödie Adelphoe beschreibt ein Sklave namens Syrus einen Weg durch einen zweifelsfrei städtischen Raum zu dem Zweck, dass der Protagonist Demea den (angeblichen) Aufenthaltsort seines Bruders Micio findet.

\section{SY. nostin porticum apud macellum hanc deorsum? DE. quidni noverim?}

375 SY. praeterito hac recta platea sursum: ubi eo veneris,

clivo' deorsum vorsum est: hac te praecipitato. postea

est ad hanc manum sacellum: ibi angiportum propter est.

DE. quodnam? SY. illi[c] ubi etiam caprificu' magna est. DE. novi. SY. hac pergito.

DE. id quidem angiportum non est pervium. SY. verum hercle. vah

265 Lynch (1975), 65-70. Wege verbinden einzelne Inseln als Anfangs- und Endpunkte eines Weges zu einem räumlichen Kontinuum. Bereiche sind entlang eines Weges angeordnet, kommen nach und nach in Sicht. Entlang eines Weges werden Lagebeziehungen - die innere Struktur eines Makroraumes - ersichtlich, durch das Abschreiten der einzelnen Bereiche werden eine räumliche Ausdehnung und die räumlichen Grenzen vermittelt. Wege bringen eine Struktur in einen größeren Raum und halten ihn gleichzeitig zusammen.

266 Es ist nicht unversucht geblieben, diese Wegstrecke sowohl mit der Topographie des zeitgenössischen Athens als auch Roms in Verbindung zu bringen. Zur Diskussion vgl. Gilula (1991). Konkrete topographische Merk- und Wahrzeichen fehlen in der Wegbeschreibung jedoch. Es werden vielmehr eine Reihe von typischen städtischen Teilelementen, eine Portikus, ein Fleischmarkt, verschiedene Straßen, Heiligtümer, Stadttore und zwei Werkstätten genannt. Damit ist die Wegstrecke als eine (unspezifisch) innerstädtische ausgewiesen. Generell zur Spiegelung römischer Lebenswelt in der Komödie vgl. Leigh (2004), bes. 6-20. 
380 censen hominem me esse? erravi: in porticum rursum redi:

sane hac multo propius ibis et minor est erratio.

scin Cratini hui(u)s ditis aedis? DE. scio. SY. ubi eas praeterieris,

ad sinistram hac recta platea, ubi ad Dianae veneris,

ito ad dextram; priu' quam ad portam venias, apud ipsum lacum

385

est pistrilla et exadvorsum fabrica: ibist. ${ }^{267}$

Diese Wegbeschreibung setzt nicht unmittelbar am Schauplatz der Komödie ein, sondern an einem innerstädtischen Merkzeichen, einer Portikus, die sich in einem anderen Bereich innerhalb der Stadt befindet. Diesen Ausgangspunkt beschreibt der Sklave daher ausführlich. Unverkennbar sei dieser durch die Nähe des ersten Merkzeichens, einer Portikus, zu einer weiteren räumlichen Gegebenheit, die mit einer deiktischen Referenz (banc deorsum, v. 573) noch näher spezifiziert wird. Durch die Überschneidung mehrerer räumlicher Umgebungen wirkt diese Art der Positionierung realistisch. Zudem vergewissert sich der Sklave über die Bekanntheit des Merkzeichens bei seinem Gesprächspartner. ${ }^{268}$ Von der als erstes visuelles Merkzeichen fungierenden Portikus beschreibt der Sklave dann den Verlauf einer Straße und fügt als eine topographische Information den körperlich erfahrbaren Anstieg und Abfall des Geländes auf sagittaler Achse hinzu. ${ }^{269}$

Dieser Straße soll Demea folgen, bis er zu einem weiteren, visuell wahrnehmbaren Merkzeichen - einem kleinen Heiligtum - kommt. Erneut wird auch dieses Merkzeichen durch eine standortabbängige Referenz (ad banc manum, v. 576) lokalisiert. Wichtig ist: Das Merkzeichen wird allein deswegen selektiert, weil in dessen räumlicher Umgebung eine Richtungsänderung vorgenommen werden soll. Die Kontinuität des Weges auf sagittaler Achse wird an dieser Stelle unterbrochen: Es kreuzt ein Weg, eine kleinere Straße in der Nähe (angiportum propter est, v. 576), der Demea nun folgen soll.

Dieses Prinzip der Orientierung lässt sich in der gesamten Wegbeschreibung erkennen: An visuellen Merkmalen erkennbare Merkzeichen innerhalb des städtischen Raumes werden herausgehoben, wenn sie als Orientierungspunkte dienen sollen, um innerhalb eines Straßennetzes den Verlauf des konkreten Weges zu beschreiben ${ }^{270}$; sie sind entweder in ihrer Position bekannt oder ihre Position wird durch die Überschneidung von verschiedenen räumlichen Umgebungen kommu-

267 Ter. Ad. 573-585.

268 Laut Donat weist die Formulierung hanc deorsum darauf, dass sich nicht nur eine Portikus auf diesem Platz befindet. Vgl. Martin (1976), 187.

269 Vgl. Sloman (21968), 100: „clivos deorsum vorsum est, (...) there is a slope right down in front of you."

270 Vgl. Ter. Ad. 581-583: scin Cratini hui(u)s ditis aedis? DE. scio. SY. ubi eas praeterieris, / ad sinistram hac recta platea, ubi ad Dianae veneris,/ ito ad dextram. Vgl. auch Kauer (21964), 96: „Die sechsmalige Wiederholung von hac gibt der Beschreibung des Weges (...) eine individuelle Färbung.“ 
niziert. ${ }^{271}$ Auch der Zielpunkt wird durch die Überschneidung räumlicher Umgebungen von vier Merkzeichen markiert: vor einem Tor, durch den der Weg durchgeht, befindet sich bei einem Wasserbecken ${ }^{272}$ ein Backhaus und gegenüber eine Werkstatt.

Die innere Struktur dieses literarischen Raumes beruht bei dieser Darstellungstechnik nicht mehr nur in der Inklusion aller genannten Bereiche, sondern es sind nun auch eine relative Struktur und Abstände untereinander angedeutet. Die konkrete Länge der zurückgelegten Wegstrecke bleibt zwar unbekannt, jedoch wird innerhalb dieses Weges die Grenze der Siedlung (ad portam, v. 584) von einem wohl zentralen innerstädtischen Ort aus (porticum apud macellum, v. 573) erreicht. Eine gewisse, wenn auch nicht unbedingt großstädtische räumliche Ausdehnung ist eine notwendige Voraussetzung für eine derartige Wegbeschreibung, die durch die Fülle an Merkzeichen und Richtungsänderungen ${ }^{273}$ über das Genannte hinaus ein Vielfaches an Wegen und baulicher Substanz voraussetzt. Diese unübersichtliche Multiplizität der Wege kommt auch direkt innerhalb der Passage zur Sprache: Syrus unterläuft bei seiner Wegbeschreibung ein Fehler, und Demea gibt zu verstehen, dass er weiß, dass eine kleine Seitenstraße, in die er laut der Beschreibung einbiegen soll, eine Sackgasse ist (id quidem angiportum non est pervium, v. 582). Syrus bietet daraufhin eine neue, gänzlich andere Wegstrecke an, bei dem er die Gefahr des Verlaufens als geringer einschätzt (minor est erratio, v. 580).

Diese literarisierte Wegbeschreibung entspricht recht genau einer realistischen Raumwahrnehmung des Menschen, wie sie auch für die römische Raumerfassung nachgewiesen wurde. ${ }^{274}$ In den Forschungsberichten I und II wurde bereits darauf hingewiesen, dass eine vergleichbare ausführliche Wegbeschreibung, mit der man das Kennenlernen des literarischen Raumes urbs Roma nachverfolgen könnte, in die römische Dichtung kaum Einzug gehalten hat. Die seltenen Beispiele, die vorgeben, Wegbeschreibungen durch einen literarischen Raum urbs Roma zu sein, verfolgen andere Darstellungsziele, wie anhand von zwei Beispielen gezeigt werden soll.

Vordergründig als eine Wegbeschreibung gibt sich beispielsweise das Epigramm 1, 70 des kaiserzeitlichen Dichters Martials. In ihm erklärt der Sprecher einem Ge-

271 Die Überschneidung der räumlichen Umgebungen dient dazu, die Lokalisation der Merkzeichen zu präzisieren. Gleichzeitig wird dadurch auch eine aufeinander bezogene Bebauungssitutation präsentiert.

272 Vgl. dazu Martin (1976), 188.

273 Die Häufigkeit der Richtungsänderung weist auf ein verzweigtes Straßennetz. Nicht alle Wege werden bis zu ihrem Ende beschritten. Vgl. Sloman (21968), 101: „portam showing that Demea was to go to the very extremity of the city“, und Martin (1976), 188: „Syrus intends Demea to have a long walk."

274 Vgl. Brodersen (1995), 245. Zur menschlichen Raumwahrnehmung vgl. Abschnitt 2.2.1. 
dichtband ${ }^{275}$ den Weg zu seinem Patron, da er selbst die morgendliche salutatio nicht auf sich nehmen will. ${ }^{276}$ Bereits von der Sprechsituation her ist die Fiktionalität der Wegbeschreibung für den Leser sehr viel deutlicher markiert als in der terenzischen Komödie.

Quaeris iter, dicam. Vicinum Castora canae

transibis Vestae virgineamque domum;

5 inde sacro veneranda petes Palatia clivo,

plurima qua summi fulget imago ducis.

nec te detineat miri radiata colossi

quae Rhodium moles vincere gaudet opus.

flecte vias hac qua madidi sunt tecta Lyaei

10 et Cybeles picto stat Corybante tholus.

protinus a laeva clari tibi fronte Penates

atriaque excelsae sunt adeunda domus.

banc pete: (...). 277

Beschrieben wird ein alltäglicher Weg des Sprechers. Als Ausgangspunkt wählt er jedoch - wie in der Wegbeschreibung in Terenz' Adelphoe - nicht den gegenwärtigen Standort, sondern einen Bereich innerhalb der urbs Roma. Mithilfe einer einzigen topologischen Relation zweier räumlicher Gegebenheiten (vicinum, v. 3) wird dieser allerdings recht vage lokalisiert. Eine Vergewisserung, ob das Buch diese Stelle kenne, ist innerhalb dieser literarischen Fiktion nicht notwendig; die Kenntnis der beiden Merkzeichen und ihre Lage setzt der Sprecher voraus.

Von diesem Ausgangspunkt an muss der Sprecher jedoch - gemäß der Illusionsbildung für den Leser - den Weg beschreiben. Eine Richtungsangabe transibis (v. 4) erschließt ein räumliches Areal an der Straßenseite und erzeugt eine minimale räumliche Anschaulichkeit, auch wenn offen bleibt, ob es zur linken oder rechten Seite liegt. Die im Folgenden aufgeführten Merkzeichen befinden sich innerhalb des weiträumigen, diffus umgrenzten Bereichs des Palatin (qua, v. 6), also wohl in relativer Nähe zueinander. Ihre Selektion dient jedoch in diesem Epigramm nie dazu, eine Richtungsänderung anzuzeigen, sie kommen entlang des Weges vielmehr nach und nach in den Blick. ${ }^{278}$ Allein eine einzige und zudem recht vage Angabe zur Richtungsänderung (flecte vias, v. 9) verweist auf den Verlauf einer weiteren Straße. Auch Überschneidungen mit anderen räumlichen Umgebungen

275 Wenn im Folgenden des Häufigeren von einem Buch als Figur die Rede sein wird, ist die typische Buchform der römischen Antike, eine Rolle aus Papyrus, gemeint.

276 Vgl. dazu Hor. epist. 1, 20, Ov. trist. 1, 1 und Abschnitt 4.2.2.

277 Mart. 1, 70, 3-13.

278 Vgl. Mart. 1, 70, 5: inde (...) petes Palatia clivo; Mart. 1, 70, 9: flecte vias hac qua (...) sunt tecta (...); in einem einzigen Fall sind sie deiktisch, vgl. Mart. 1, 70, 11: protinus a laeva clari (...) fronte Penates. 
oder Relationen zueinander bleiben ungenannt. ${ }^{279}$ Das Ziel des Weges, die domus (v. 4) des Patrons, ist ebenso weniger an ihrer räumlichen Umgebung, als durch sich selbst erkennbar. Insgesamt vier Verse verwendet der Sprecher auf die Beschreibung des Hauses, dessen vertikale und sagittale Achse er räumlich akzentuiert: Das Haus ragt hoch heraus und seine Tür ist weit geöffnet. ${ }^{280}$

Zwischen dem Ausgangspunkt und dem Bereich des Palatin wird weder architektonisch noch durch sensuelle Eigenschaften über einen Übergang, eine strukturierende Grenze berichtet. Auffällig ist aber, dass durchaus zahlreiche visuelle Eindrücke in die Wegbeschreibung eingearbeitet sind, die über die notwendige Beschreibung eines Merkzeichens hinausgehen. ${ }^{281}$ Die in drei Versen geschilderten Licht- und Glanzeffekte, die von einigen Bildnissen des Kaisers auf dem Palatin ausgehen, retardieren geradezu die Wegbeschreibung und lenken vom dem vordergründigen Erzählgegenstand ab. Der Sprecher nutzt diese Beschreibung sodann auch als Mahnung an sein Buch, hier nicht zu verweilen (nec te detineat, v. 7). Für die Wegbeschreibung selektiert werden vorrangig Gebäude, die einer Gottheit geweiht sind, oder Merkzeichen, die auf einen gewaltigen Herrscher verweisen. Bei dieser Auswahl fällt auf, dass ihnen allen eine gemeinsame Funktion, nämlich für den Kult, zukommt, sie jedoch kaum realistisch als Orientierung gebende Merkzeichen eingesetzt sind. ${ }^{282}$ Recht offensichtlich ist daher, dass die gesamte Wegbeschreibung nicht einer realitätsnahen Orientierungshilfe innerhalb eines komplexen Raumes dienen soll. Die visuell akzentuierten Merkzeichen mit ihren Lichtund Glanzeffekten ${ }^{283}$ werden vielmehr selektiert, um die besondere Aura ${ }^{284}$ des Weges herauszustellen. Hierzu gehört auch die Akzentuierung der Vertikalen bei den einzelnen räumlichen Gegebenheiten. ${ }^{285}$ Mit der Beschreibung des Weges wird zwar ein Raum mit einer spezifischen Atmosphäre ${ }^{286}$ in den Mittelpunkt gestellt, sie dient aber - neben reichen literarischen Anspielungen - wohl vor allem einer indirekten Charakterisierung des Patrons, dessen soziale Distanz zu dem

279 Vgl. Mart. 1, 70, 9 f.: flecte nias hac qua madidi sunt tecta Lyaei/ et Cybeles picto stat Corybante tholus. Eine räumliche Relation der beiden Merkzeichen wird nicht genauer bezeichnet.

280 Vgl. Mart. 1, 70, 12: atriaque excelsae sunt adeunda domus und Mart. 1, 70, 14: nulla magis toto ianua poste patet.

281 Vgl. Mart. 1, 70, 6: plurima (...) fulget imago; Mart. 1, 70, 7: miri radiata colossi; Mart. 1, 70, 10: picto (...) Corybante tholus; Mart. 1, 70, 11: clari (...) Penates; evtl. auch Mart. 1, 70, 9: madidi sunt tecta Lyaei.

282 Auch die Bezeichnung sacro clivo (Mart. 1, 70, 5) findet sich nur hier, vgl. Howell (1980), 267. Vgl. ebenfalls Mart. 1, 70, 5: veneranda Palatia.

283 Vgl. Mart. 1, 70, 6: fulget imago ducis; Mart. 1, 70, 7: radiata colossi; Mart. 1, 70, 11: clari (...) Penates.

$284 \mathrm{Zu}$ Aura vgl. Böhme (1995), 25-28.

285 Vgl. der ansteigende Weg zum Palatin (clivus, v. 5), der Vergleich mit dem Koloss von Rhodos (v. 7 f.). Von den Gebäuden wird die Bedachung (tecta ... tholus, v. 9 f.) herausgehoben, explizit: excelsae domus, v. 12.

286 Zur Atmosphäre auf Grundlage von Materialästhetik vgl. Böhme (1995), 55-56. 
dichtenden Klient über die räumlichen Merkmale seiner Umgebung veranschaulicht werden soll. ${ }^{287}$

Eine Konstitutionsisotopie Großstadt wäre diesem Epigramm trotz der topographischen Merk- und Wahrzeichen nicht zu bescheinigen. Der alltägliche Weg führt zwar explizit durch einen als urbs Roma zu identifizierenden Raum, dieser wird aber entlang von einer Reihe von Mirabilia beschrieben und nicht entlang von städtischen Teilelementen.

Als literarisches Vorbild für dieses Epigramm Martials hat wohl die Elegie 3, 1 aus den Tristia des augusteischen Dichters Ovid gedient. ${ }^{288}$ In dieser Elegie wird aber keine Wegstrecke beschrieben, sondern von einem einheimischen Führer und seinem ortsfremden Begleiter gemeinsam abgeschritten. Damit handelt es sich nicht mehr um eine Wegbeschreibung, sondern vielmehr um die erzählte Wahrnehmung einer Stadtführung. Gemäß der narratologischen Theorie zeigt die Wahl dieser Darstellungstechnik die besondere Relevanz der Raumbeschreibung, da durch diese Technik dem Raum eine besondere Erlebnishaftigkeit für die wahrnehmende Figur zugeschrieben wird. ${ }^{289}$

Die Tristie 3, 1 beginnt szenisch mit einer direkt geäußerten, energischen Bitte eines Buches um Orientierung. Das hier personifiziert vorgestellte dritte Elegienbuch ist nach Rom gereist, es ist fremd im literarischen Raum urbs Roma, den es im ersten Vers der Exilelegie gerade betritt:

$1 \quad$ Missus in banc venio timide liber exulis urbem: da placidam fesso, lector amice, manum,290

Die Aufforderung zum taktilen Kontakt ( $d a$..., lector amice, manum) zieht den als Freund angeredeten Leser vom ersten Vers an in die (zeit ${ }^{291}$-)räumliche Unmittelbarkeit der Elegie hinein. Damit entsteht - gemäß der Illusionsbildung des Lesers - zwischen Buch und Leser ein auf engste Körperlichkeit bezogener, kleiner Raum. Gleichzeitig signalisiert diese Exposition der Gesprächssituation den fiktionalen Charakter dieser Tristie. Die sich in den folgenden Versen anschließende

287 Am deutlichsten in Mart. 1, 70, 13-15: ne metuas fastus limenque superbum:/ nulla magis toto ianua poste patet, / nec propior quam Phoebus amet doctaeque sorores. Zu den limina superba vgl. auch Hor. epod. 2, $7 \mathrm{f}$. Eine eingehende Untersuchung könnte auch zahlreiche literarische Anspielungen offenlegen, die den Sprecher als poeta doctus empfehlen. Auffällig sind raumstrukturelle Gemeinsamkeiten mit Verg. Aen. 8, 337-361; Ov. Pont. 4, 5 und Ov. trist. 3, 1. Vestae canae ist eine direkte Anspielung auf Verg. Aen. 5, 744. Weitere intertextuelle Bezüge Ov. trist. 3, 1, 31 f.; 3, 7, 1 f., Pont. 4, 5, 1. Generell zur literarischen vermittelten Distanz zwischen Poet und Patron vgl. Greg Woolf, The City of Letters, in: Edwards/Woolf (2003), 203-221.

288 Vgl. dazu Geyssen (1999).

289 Vgl. Abschnitt 2.2.3.3.

290 Ov. trist. 3, 1, $1 \mathrm{f}$.

291 Vgl. auch das präsentische Erzähltempus (venio, v. 1). 
Schilderung der Vorgeschichte des Buches in direkter Rede, nämlich seine weite Reise aus einem ,Fernraum' und sein - vor Erschöpfung - hinkendes Versmaß werden in einer raffinierten Dramatik mit den literarischen Konventionen eines Eingangsgedichtes verwoben. ${ }^{292}$ Das Buch ist als Ortsfremder damit eingeführt und auf die Führung Ortskundiger notwendigerweise angewiesen.

dicite, lectores, si non grave, qua sit eundum, quasque petam sedes hospes in urbe liber. ${ }^{293}$

Das Buch bittet um Unterstützung bei der Suche nach Unterkünften (quas ... sedes, v. 20). Die Aufforderung richtet sich demzufolge an ,ideale Leser' (lectores, v. 19), die als Einheimische vorgestellt werden. Was folgt, ist jedoch keine Wegbeschreibung zu potentiellen Herbergen, sondern eine Ortsführung, und zwar von einem namenlos bleibenden lector, die das unmittelbare Kennenlernen des literarischen Raumes auch für den tatsächlichen Leser nachverfolgen lässt.

25

30

\author{
duc age, namque sequar, quamvis terraque marique \\ longinquo referam lassus ab orbe pedem. \\ parnit, et ducens, haec sunt fora Caesaris, 'inquit, \\ ,haec est a sacris quae via nomen habet, \\ bic locus est Vestae, qui Pallada servat et ignem, \\ baec fuit antiqui regia parua Numae." \\ inde petens dextram ,porta est" ait ,ista Palati, \\ bic Stator, hoc primum condita Roma loco est." \\ singula dum miror, (....). ${ }^{294}$
}

Der einheimische lector beginnt mit der Vorstellung der räumlichen Umgebung recht unmittelbar mit einem summarischen haec sunt fora Caesaris (v. 27). Er zählt des Weiteren eine Straße, den Bereich des Vesta-Tempels, die Regia, den Hügel Palatin und ein Tor auf. ${ }^{295}$ Die in dieser Passage in direkter Rede wiedergegebene

292 Das Buch stellt sich vor, gibt Auskunft über seinen Inhalt, seinen Dichter und seine Herkunft, entschuldigt Aussehen und sprachlichen Stil. Den Inhalt verdankt es den Lebensumständen des Dichters, das hinkende Metrum der zurückgelegten langen Wegstrecke und die sprachlichen Schnitzer seiner Herkunft: einem barbarischen Land. Vgl. Ov. trist. 3, 1, 17 f.: siqua videbuntur casu non dicta Latine,/ in qua scribebat, barbara terra fuit. Zur Gestalt des Buches vgl. Newlands (1997), 60-63.

293 Ov. trist. 3, 1, $19 \mathrm{f}$.

294 Ov. trist. 3, 1, 25-33.

295 Neumeister (1991), 109 nimmt als Schauplatz des Treffens von Buch und Lektor das Argiletum und die dortigen Buchhandlungen an. Dies ist durchaus eine attraktive Erklärung, zumal die Stadtführung recht plötzlich mit den Caesarforen, also in der Innenstadt, beginnt. Jedoch fehlt eine entsprechende räumliche Referenz im Text. Betont verweist das Buch auf seine momentane körperliche Erschöpfung aufgrund der langen Wegstrecke, den es hinter sich habe. Dies zeigt 
Führung reiht folglich die verschiedenen topographischen Merkzeichen mittels eines wiederholten, anaphorisch gestellten Demonstrativpronomens ( haec ... haec ... hic ... haec ... hic ... hoc) lediglich aneinander. Unmissverständlich wird damit der Schauplatz urbs zwar als urbs Roma markiert und aus ihrer Abfolge im Text ergibt sich wohl die Abbildung einer räumlichen Reihenfolge auf dem gemeinsamen Weg. Offen bleibt aber gänzlich, ob die Figuren auf diese Merkzeichen zu, über sie hinweg oder an ihnen vorbei gehen. Auf das Abschreiten eines Weges deutet neben der vorangestellten Aufforderung duc age, namque sequar (v. 25) eine einzige Richtungsänderung hin: Als Bewegung und damit räumlich ausgreifende Geste wird eine standortabhängige Seitwärtswendung des Stadtführers benannt, als nach der Regia - der Illusionsbildung für den Leser zufolge - der Palatin in den Blick gerät: inde petens dextram (...) ait (v. 31). Implizit wird hiermit der Verlauf einer weiteren Straße angedeutet, die nicht weiter abgeschritten wird.

Durch die ausschließliche Verwendung des Demonstrativpronomens lässt der lector dux den unkundigen Leser über die Lage der genannten Merkzeichen gänzlich im Unklaren. ${ }^{296}$ Allein einem Leser, der die stadtrömische Topographie vor Augen hat, kann die Reihenfolge, in der die Merkzeichen genannt werden, auch die Abbildung eines Weges sein. ${ }^{297}$

Der im Text präsentierte literarische Raum urbs Roma wirkt durch die dichte Folge verschiedener topographischer Referenzen, die sich vor allem auf Plätze, aber auch auf eine Straße, Gebäude, darunter Tempel, und ein Tor beziehen, vielfältiger und daher auch städtischer als der literarische Raum in Martials eben besprochenem Epigramm 1, 70. Durch die gewählte Darstellungstechnik der erzählten Wahrnehmung - noch dazu in Bewegung - stellt es sich als ein doch recht überschaubares Areal dar. Dieser räumliche Eindruck wird vor allem dadurch erzeugt, dass die einzelnen Stationen in wörtlicher Rede, also im zeitdeckenden Erzählen, wiedergegeben werden, ohne dass minimale Anzeichen einer Bewegung dorthin

m. E. vor allem, dass sich das Buch noch nicht lange in der urbs Roma aufhält. Folgt man dem Rekonstruktionsvorschlag Neumeisters, der sich nicht aus der Textgrundlage ergibt, sondern einen einheimischen Leser voraussetzt, der mit der genauen räumlichen Struktur Roms bestens vertraut ist, sehen Buch und Einheimischer vom Argiletum kommend die Außenfassade des Forums und betreten nicht die Platzanlage. Literaturhinweise auf weitere Rekonstruktionsversuche der Route bei Miller (2002), 131, Anm. 4. Klodt (1998), 1-28 und Schmitzer (2001), 529, Anm. 50 wollen fora nicht als einen poetischen Plural verstehen, sondern auf das Caesar- und Augustus-Forum beziehen.

296 Naheliegend ist, dass alle Merkzeichen auf einer einzigen Seite des Weges liegen. Neumeister (1991) bietet für den einmaligen Wechsel des Demonstrativpronomens von bic zu iste im Vers 31 eine überzeugende räumliche Erklärung und übersetzt es mit „auf deiner Seite“. Vgl. Neumeister (1991), 113 und 300, Anm. 10. Diese Varianz erschließt damit einmalig den Raum auf der anderen Seite des Weges.

297 Vgl. Neumeister (1991), 112-117, eine Karte 110. 
gegeben werden. ${ }^{298}$ Anders betrachtet: Nähme man Darstellungstechnik und die tatsächliche topographische Lage der Merkzeichen im realen Georaum ernst, entstünde für einen ortskundigen Leser durch die dichte Folge der aller weiterer Informationen entblößten Merkzeichen doch der zeitliche Eindruck einer tour de force, womit die Bezeichnung, Stadtspaziergang', mit der diese Elegie häufiger etikettiert wird, alles andere als passend wirkt. ${ }^{299}$ In der im Text gewählten Präsentation der Wegstrecke liegt für einen ortskundigen Leser viel eher komisches Potential. ${ }^{300}$ Denn die Reaktion des ortsfremden Buches auf das erstmalige Erleben des literarischen Raumes, das jedes Merk- und Wahrzeichen einzeln achtunggebietend bestaunt (singula miror, v. 33), steht im (komischen) Widerspruch zu dem hastigen Abschreiten.

In den folgenden Versen der Elegie rücken innerhalb des weiträumigen Bereichs des Palatins zwei Gebäude in den Mittelpunkt: das Haus des Augustus und der Tempel des Apollon Palatinus. Die räumlichen Umgebungen dieser beiden exponierten räumlichen Gegebenheiten werden nicht beschrieben wie auch ihre Relationen zueinander (inde, v. 59) unbekannt bleiben. Verbunden sind die beiden Inseln strukturell allein über den Weg, den das Buch und sein Begleiter zwischen ihnen zurücklegen.

Die Relevanz des räumlichen Erlebens für die Figur des Buches enthüllt sich in diesem Abschnitt der Elegie. Nach dem Haus des Augustus ${ }^{301}$ ist die bibliotheca

298 Wäre diese Rede nicht explizit eingeführt als Wegbeschreibung (duc age, namque sequar, v. 25), stellte sich durch die Wiedergabe eher der Eindruck ein, die beiden Figuren nähmen den Raum von einem erhöhten Standpunkt aus wahr.

299 Man hat diese vom Buch und seinem unbekannten römischen Begleiter zurückgelegte Wegstrecke in die Reihe der berühmten Stadtspaziergänge eingereiht, ein Motiv, das in der augusteischen Literatur als verbreitet gilt. Die Grundlagen dieser Etikettierung überzeugen jedoch nicht, da von einer erzählten Bewegung - mit Ausnahme der Passage im 8. Buch von Vergils Aeneis - in den Beispielen nicht die Rede sein kann. Einen Zusammenhang zwischen dem Spaziergang in der Aeneis und in der Tristie 3, 1 sieht Edwards (1996), 120. Unklar und sehr allgemein Miller (2002), 131: „somewhat in the manner of Propertius 4 and Ovid's Fasti.“

300 Zur Komik in den Tristien vgl. Amann (2006). Für den entsprechenden Abschnitt nennt er als komisches Element jedoch lediglich die Vermenschlichung des Gedichtbandes, das ,als weitgereister Tourist in den Genuss eines Stadtrundganges kommt." Vgl. ebd., 134. Eine ironische Lesart sieht Edwards (1996), 120 erst in der Beschreibung des Hauses des Augustus in Anlehnung an die Beschreibung des Hauses des Euander in der vergilischen Vorlage. Dazu auch Miller (2002), 132-137 und Newlands (1997), $66 \mathrm{f}$.

301 Von dem Haus des Augustus ist es allein die Grenze des Hauses, nämlich die räumliche Umgebung der Tür, die näher teleskopiert wird. Der Anblick des Gebäudes, über dessen Bewohner sich das Buch durch Nachfrage beim Einheimischen Klarheit verschafft, bringt es auf das Schicksal seines Dichters zurück. Die emotionale Wirkung, die der Ort auf das Buch ausübt, deckt sich mit den Gefühlen gegenüber dem Bewohner. Nach einer gebetsartigen Apostrophe an Augustus (Ov. trist. 3, 1, 49-52) benennt das Buch seine Emotionen in autonomer direkter Rede und wendet sich in einer abschließenden Apostrophe an das Haus selbst. Vgl. Ov. trist. 3, 1, 53-58: vereorque locum vereorque potentem, / et quatitur trepido littera nostra metu./ aspicis exsangui chartam pallere colore?/ aspicis alternos intremuisse pedes? / quandocumque, precor, nostro placere parenti/ isdem et sub dominis aspiciare domus! Im Gegensatz zum Epigramm Martials $(1,70)$ wird an dieser Stelle 
Palatina als eine mögliche Unterkunft für das Buch der erste Zielpunkt des gemeinsamen Weges. ${ }^{302}$ Der Eintritt in den Tempelbezirk des Apollon, dem diese Bibliothek angegliedert ist, geht im Gegensatz zu der vorangehenden Stadtführung mit der Wiedergabe eines dreidimensionalen Raumeindrucks einher:

60

inde tenore pari gradibus sublimia celsis
ducor ad intonsi candida templa dei,
signa peregrinis ubi sunt alterna columnis,
Belides et stricto barbarus ense pater,
quaeque viri docto veteres cepere novique
pectore, lecturis inspicienda patent. 303

Das Buch wird eine Treppe mit hohen Stufen (gradibus ... celsis, v. 59) zu einem erhabenen (sublimia, v. 59) Tempel heraufgeführt. Dabei nimmt das Buch Standbilder und Säulen im Wechsel auf beiden Seiten wahr, beide räumlichen Gegebenheiten haben zudem eine, intrinsische ${ }^{604}$ vertikale Achse. Die Selektion architektonischer Details richtet den Fokus auf Lichteffekte (candida, v. 60) und auf Fremdländisches (peregrinus .../ barbarus, 61 f.). ${ }^{305}$ Nach diesem vorrangig vertikalen und horizontalen Raumeindruck wird auch die sagittale Achse akzentuiert: Der Raum steht der Wahrnehmungsinstanz zum Eintritt offen (inspicienda patent, v. 34). Mit einer aufwendigen räumlichen Ausgestaltung wird dieses Merkzeichen als potentielle neue räumliche Umgebung für das Buch herausgehoben. Daneben wird der Ort auch als ein Kontaktbereich präsentiert: Das Buch erkundigt sich bei einem Wächter wie ein (normaler) Besucher nach Büchern seines Dichters, die es dort aber nicht gibt. Es selbst wird aufgefordert, diese potentielle Unterkunft zu verlassen (e sedibus illis/ ... iussit abire ..., v. 67 f.). Das Betreten des Gebäudes ist damit für das Buch gescheitert. ${ }^{306}$

herausgearbeitet, wie eine einschüchternde Wirkung von den limina superba ausgeht. Das Haus des Augustus ist in dieser Passage im Gegensatz zum Haus des Patrons im Epigramm Martials dominant als ein unzugänglicher Raum (inaccessible frame) gestaltet.

302 Vgl. Geyssen (1999), 732. Holzberg (1999), 66 weist darauf hin, dass die Erwähnung des Danaidenporticus in v. 62 ein fast wörtliches Zitat aus Ov. ars 1,74 und damit an dieser Stelle dem Eintritt in die Bibliothek - ein verwegenes Selbstzitat ist. Newlands (1997), 68 weist auf das epische Versmaß hin. Newlands (1997), 66 sieht dagegen als Höhepunkt der Tristie die Station vor dem Haus des Augustus.

303 Ov. trist. 3, 1, 59-64.

304 Vgl. zum intrinsischen Referenzsystem Grabowski (1999), 99-116.

305 Durch diese Selektion sollen womöglich Entsprechungen und Unterschiede zwischen der Figur des Buches und der von ihm betretenen räumlichen Gegebenheit herausgestellt werden. Vgl. auch Newlands (1997), 68-70.

306 Miller (2002), 138: „The all-inclusiveness of Augustus' library (vgl. quaeque viri docto veteres cepere novique/ pectore, lecturis inspicienda patent. v. $63 \mathrm{f}$., Anm. d. Verf.) points up the injustice of the Ovidian exclusion. (...) Ovid's personified book represents the other side of the temple library's 
An dieser Station wird exemplarisch der im weiteren Verlauf der Elegie wiederholte Versuch gezeigt, in eine - jeweils in einem Tempelbezirk befindliche - Bibliothek aufgenommen zu werden (altera templa peto, v. 69; nec ... atria Libertas tangere passa sua est, v. 71 f.). ${ }^{307}$ Alle diese räumlichen Gegebenheiten werden aber für das Buch denselben Status wie die Bibliothek auf dem Palatin haben: Sie bleiben ,unzugängliche Räume' (inaccessible frames). ${ }^{308}$

Die Stadtführung in der Tristie 1, 3 führt über zahlreiche Bereiche und an vielen Merkzeichen unterschiedlicher Größe vorbei. Die Selektion ausgewiesen großstädtischer Teilelemente - wie die Bibliotheken - und die Erwähnung architektonischer Details vermittelt stärker als im Epigramm 1, 70 Martials eine Vorstellung von deren jeweiligem Eigenort und setzt damit auch eine entsprechende räumliche Umgebung voraus. Gerade auch die zu Beginn der Elegie in Szene gesetzte Orientierungslosigkeit des Buches, die Suche nach einem Einheimischen, sowie die Bereitschaft, trotz eigener großer Erschöpfung dem Stadtführer bedingungslos zu folgen, lassen in der Illusionsbildung des Lesers einen vor dem Buch liegenden literarischen Raum ${ }^{309}$ entstehen, der sich dem Überblick durch einen Ortsfremden (hospes ... liber, v. 20) entzieht. Zu dieser Unübersichtlichkeit als innerer Struktur tritt auch eine relative Ausdehnung des literarischen Gesamtraumes, wenn zum Ende der Tristie hin betont wird, dass der im Text abgebildete Raum nur ein Teil eines noch viel größeren Areals ist. ${ }^{310}$ Die Darstellungstechnik der erzählten Wahrnehmung jedoch nutzt der Autor nicht, um für einen unvoreingenommenen

door, the discard's perspective." Zur Anspielung auf das elegische paraklausithyron-Motiv vgl. Newlands (1997), 70.

307 Dieses Vorhaben wird nachfolgend summarisch aus der Perspektive des Buches wiedergegeben. Die einzelnen räumlichen Inseln - verschiedene Bibliotheken - werden durch das Hingehen des Buches miteinander verbunden und so in Form einer Aneinanderreihung auf einer Strecke abgebildet, räumliche Distanzen zwischen den Bereichen werden aber nicht genannt.

308 Dass es sich um unzugängliche Räume handelt, wird mithilfe des haptischen Sensus herausgearbeitet: das Buch darf die Bibliothek mit seinen (Vers-)Füßen nicht betreten, es darf sie nicht einmal berübren. Vgl. Ov. trist. 3, 1, 69-72: altera templa peto, vicino iuncta theatro:/ haec quoque erant pedibus non adeunda meis./ nec me, quae doctis patuerunt prima libellis, / atria Libertas tangere passa sua est.

309 Vgl. Ov. trist. 3, 1, 25 f.: duc age, namque sequar, quamvis terraque marique/ longinquo referam lassus ab orbe pedem.

310 Vgl. Ov. trist. 3, 1, 79 f.: interea, quoniam statio mibi publica clausa est,/ privato liceat delituisse loco. Neben dem summarisch gefassten öffentlichen Teil des literarischen Raumes (publica, v. 79) wird im vorletzten Distichon die räumliche Ausdehnung um einen ebenfalls summarisch gefassten privaten Teil (privato, v. 80) erweitert. Zur Veranschaulichung der Ausdehnung des literarischen Raumes trägt somit auch die abschließende Referenz auf potentielle weitere Räume bei, die von dem Buch während der Elegie zwar nicht mehr betreten oder angelaufen werden, die aber gleichberechtigt den abgeschrittenen Bereichen gegenübergestellt werden. Vgl. Luck (1977), 172: „Ovid rechnet also damit, daß es [d.h. das Buch, Anm. d. Verf.] in den Buchhandel kommt, er schickt aber kein Exemplar an die öffentlichen Bibliotheken." Dass es sich hier um zahlreiche Bereiche innerhalb der literarischen urbs Roma handelt, zeigt das folgende Distichon. Vgl. Ov. trist. 3, 1, $81 \mathrm{f} .:$ vos quoque, si fas est, confusa pudore repulsae/ sumite plebeiae carmina nostra manus. Diese Bereiche wird das Buch vollends betreten können (delituisse, v. 80). 
Leser einen räumlichen Eindruck zu erzeugen. Als idealer Leser ist ein Einheimischer vorgestellt, der das komische Potential der präsentierten Stadtführung erkennt und in der räumlichen Gestaltung das Spiel mit der Intention und Konvention von Eingangs- und Widmungsgedichten bemerkt. ${ }^{311}$

Ausführliche Wegbeschreibungen wurden als Darstellungsform des literarischen Makroraums urbs Roma nicht gewählt. Als eine äußerst reduzierte Form einer Wegbeschreibung mögen allerdings Adressenangaben ${ }^{312}$ gelten, die bemerkenswerterweise Einzug in die römische Dichtung gehalten haben. Für eine Adressenangabe wird eine räumliche Insel recht präzise ausgestaltet. Auch daraus kann sich eine Vorstellung über die innere Struktur und Ausdehnung eines Makroraums ergeben. Mit Martials Epigramm 1, 2, 7 f. erhält der angesprochene Leser beispielsweise eine Angabe, wo er Bücher des Sprechers in einer handlichen Ausgabe erwerben kann: libertum docti Lucensis quaere Secundum/ limina post Pacis Palladiumque forum. Genannt werden der Name des Geschäftsinhabers und eine Positionsbeschreibung des Ladens mithilfe eines absoluten Referenzsystems. ${ }^{313}$ Entsprechend der hier vorliegenden Illusionsbildung ermöglicht die Kenntnis dieser räumlichen Koordinaten, dass der Angeredete zuverlässig in einer um einen Buchladen und einer räumlichen Umgebung von einem Tempelbezirk und einem Forum vielfach multiplizierten literarischen Großstadt die gewünschte Ware erlangt. Aus dem Inneren der urbs Roma heraus ist dem unwissenden Einzelnen eine Orientierung allein durch diese konkreten Hilfestellungen möglich. Durch die innere Logik einer so gestalteten Adressenangabe wird die relative Unübersichtlichkeit, aber auch die Ausdehnung des literarischen Raumes in Ansätzen vorstellbar. Auf beide räumliche Merkmale bezieht sich die im Epigramm direkt vorangestellte Begründung: $\mathrm{Ne}$ (...) erres/ urbe vagus tota, me duce certus eris. 314

\section{Zusammenfassung}

Wege entlang von innerstädtischen Merkzeichen verleihen dem Makroraum eine innere Struktur. Aus disparaten Inseln entsteht ein ,räumliches Kontinuum', auch

311 Vgl. dazu auch Abschnitt 4.2.2.

312 Belegstellen für weitere Adressenangaben: Hor. ars 32 f.: Aemilium circa ludum faber imus et unguis/ exprimet et mollis imitabitur aere capillos. Mart. 1, 117, 8-12: quod quaeris propius petas licebit./ Argi nempe soles subire Letum:/ contra Caesaris est forum taberna/ scriptis postibus binc et inde totis, / omnis ut cito perlegas poetas. Der Sprecher gibt hier auch noch weitere Anhaltspunkte, nämlich die optische Außenansicht des Ladens. Vgl. auch Neumeister (1991), 107 f.; Mart. 4, 18, 1: qua vicina pluit Vipsanis porta columnis; 5, 22, 3 f.; Stat. silv. 1, 1, 84 f.: equus (...) qui contra templa Diones/ Caesarei stat sede fori.

313 Mart. 1, 2, 7 f. Die Adresse wird durch den Namen des Ladenbesitzers eindeutig. Die Verwendung der raumreferentiellen Ausdrücke ist jeweils standortunabhängig, da ich davon ausgehe, dass auch das Templum Pacis eine intrinsische Rückseite hat.

314 Mart. 1, 2, 5 f. Vgl. auch Mart. 1, 70. 
wenn die einzelnen Stationen weiterhin kumulativ aufgezählt werden. Die Abfolge ihrer Nennung bildet ihre räumlichen Verhältnisse wie Nachbarschaften oder Entfernungen in elementarer Weise ab. Durch die Angabe von Richtungsänderungen wird zudem ein Areal angedeutet, das über das beschriebene hinausgeht, in dem es für den Einzelnen zu navigieren ${ }^{315}$ gilt. Die Darstellungstechnik der Wegbeschreibung und der erzählten Wahrnehmung in Bewegung machen besonders deutlich, dass der literarische Raum um weitere Gebiete ergänzt werden soll.

Anhand der Wegbeschreibung innerhalb der Komödie des Terenz konnte das Potential der Darstellungstechnik für einen städtischen Makroraum gezeigt werden. Dass sie für die römische Metropole in der Dichtung nicht genutzt wurde, ist hinlänglich bekannt. Der direkte Vergleich legt jedoch offen, dass es dem kaiserzeitlichen und augusteischen Dichter zu keinem Zeitpunkt um eine möglichst realitätsnahe Beschreibung gegangen ist, sondern das imaginierte Abschreiten eines Weges, die Selektion der ästhetisch akzentuierten Merkzeichen, kurz, die Darstellung des literarischen Raumes überdeutlich einer anderen Aussageabsicht untergeordnet wurde. Die multisensuelle räumliche Darstellung muss demzufolge in eine Gesamtinterpretation dieser Gedichte einbezogen werden. Gerade durch die Wahl der Darstellungstechnik der räumlichen Beschreibung und der erzählten Wahrnehmung wird in diesen Beispielen die Literarisierung des Raumes evident.

315 Navigationshilfen sind typischerweise mit Makroräumen verbunden. Vgl. die Orientierungshilfen in Form einer Wegbeschreibung in Hom. Od. für Odysseus durch die Stadt der Phaiaken durch Nausikaa (Hom. Od. 6, 262-307) und die konkrete Führung durch Athene (Hom. Od. 7, 28-77), Kirke weist Odysseus den Weg zur Unterwelt (Hom. Od. 10, 505-515). Die Darstellung einer Orientierungslosigkeit findet sich beispielsweise auch in den Anfangsfragmenten des Romans Satyricon von Petron. Der Protagonist befindet sich bereits innerhalb einer ihm unbekannten civitas $(8,2)$ und findet nicht mehr den Weg zu seiner Herberge zurück. Er bewegt sich im Kreis (itaque quocumque ieram, eodem revertebar, donec et cursu fatigatus et sudore iam madens accedo aniculam quandam (...). Petron. 6, 4). Zur Führung vertraut er sich einer alten Frau an, die ihn aber in ein Bordell führt. Dort trifft er auf seinen Weggefährten, der sich ebenfalls in der Stadt verlaufen hat (Petron. 8). Wie die beiden zu ihrer Herberge zurückgelangen, ist den Fragmenten nicht zu entnehmen. Breitenstein (2009), 92 mutmaßt - leider ohne Belege -, das Motiv „erfolglos in der Stadt umherzuirren und sich durch wunderbare Fügung an unerwartetem Ort wiederzufinden, könnte aus der Komödie stammen." Unklar bleibt in ihren Ausführungen leider auch, in welcher Weise sich das Motiv bereits im griechischen Roman findet. Zum möglichen Vergleich der Großstadt mit einem Labyrinth in Iuv. 3, 25, vgl. Braund (1996), 178. 


\subsection{Formen der Ausdehnung. Die Größe einer literarischen Großstadt}

Eine physische Eigenschaft, die der literarischen urbs Roma wiederholt zugeschrieben wird, betrifft ihre besondere Ausdehnung. Finden sich doch entsprechende Attribuierungen, etwa Wortverbindungen von Roma/urbs magna bis hin zu Romal urbs maxima reichlich in der augusteischen und kaiserzeitlichen Dichtung.

Im Folgenden sollen Texte vorgestellt werden, die diese räumliche Eigenschaft veranschaulichen und ausgestalten. Wie in den beiden vorangehenden Abschnitten dargestellt, trägt zwar bereits die Unterteilung des Gesamtraumes in mehrere einzelne Bereiche zu einer ersten Abbildung einer räumlichen Ausdehnung bei. Anschaulicher wird die Ausdehnung eines Makroraumes jedoch, wenn Entfernungen zwischen den einzelnen Bereichen benannt (3.3.1) oder die Bewegung von Figuren zwischen den Bereichen (3.3.2) beschrieben werden. Am Ende dieses Abschnittes (3.3.3) wird die auffallend häufige direkte Attribuierung Roms mit magna anhand einiger Textstellen hinsichtlich ihres Bezugs auf eine konkrete physische Eigenschaft zu problematisieren sein.

\subsubsection{Zu weit. Entfernungen in einer literarischen Großstadt}

In der Satire 1, 9 des Horaz befindet sich der Sprecher auf offener Straße, die als ,Bewegungsbereich“ der Schauplatz dieser Satire ist. Durch die Begegnung mit einem aufdringlichen Anonymus und weiteren Figuren ist diese zudem als ein Kontaktbereich gestaltet. Bereits der erste Vers enthält mit einer topologischen Lokalisation Ibam forte via sacra einen impliziten Hinweis auf die urbs Roma, die während der gesamten Satire zwar nicht explizit, aber mit der Gattungsbezeichnung (urbem, v. 13) benannt wird. Andere topographische Merk- und Wahrzeichen wie der Tiber (v. 17), die Gärten Caesars (v. 17) oder der Tempelbezirk der Vesta (ad Vestae, v. 35) werden im Verlauf der Satire erwähnt und erhöhen den „Wiedererkennungswert" 316 des literarischen Raums.

Der Schauplatz der Satire, die innerstädtische ${ }^{317}$ Straße sacra via, wird räumlich kaum ausgestaltet. ${ }^{318}$ Als einzige Station der zurückgelegten Wegstrecke wird der

316 Piatti (2008), 16. Weitere innerstädtische räumliche Gegebenheiten ergeben sich metonymisch aus den erwähnten typischen Handlungen: Der räumliche Bereich des Forums (vgl. Hor. sat. 1, 9, 36 f.: et casu tum respondere vadato/ debebat, quod ni fecisset, perdere litem, und ebd., Hor. sat. 1, 9, 3743. $\mathrm{Zu}$ den juristischen Termini technici vgl. Fedeli (1994), 495), das Haus des Maecenas (Hor. sat. 1, 9, 57 f.: muneribus servos corrumpam; non, hodie si/ exclusus fuero, desistam.). Vorschläge zum Bezug auf den Georaum, auch über die erwähnten topographischen Merkzeichen hinaus bietet Schmitzer (1994).

317 Von den in dieser Satire erwähnten Teilelementen zeichnen vor allem verschiedene Straßentypen den Raum als städtisch aus, da sie auf ein differenziertes Straßennetz schließen lassen. Vgl. Hor. sat. 1, 9, 1: via; 13: vicos und 59: in triviis. Viae waren üblicherweise so breit, dass zweispuriger Wagenverkehr - also in beide Richtungen - möglich war. Vgl. Kolb (2005), 161. Die Erwähnung 
Tempelbezirk der Vesta lediglich genannt (ventum erat ad Vestae, v. 35). Durch ein erzähltes Ereignis erschließt sich in seiner unmittelbaren Nähe ein weiterer Bereich: Der Begleiter wird zu einem Gerichtstermin gerufen, dem er in Begleitung des Sprechers unverzüglich nachkommen kann. ${ }^{319}$

Von den in der Satire erwähnten räumlichen Gegebenheiten wird nur ein Bruchteil von den Figuren abgeschritten. Deren Erwähnung aber leistet einen zentralen Beitrag zur Veranschaulichung der Ausdehnung des literarischen Gesamtraums. Der Sprecher nennt seinem Begleiter auf dessen Ankündigung hin, ihm überall hin folgen zu wollen, als Ziel seines Weges ein Privathaus ${ }^{320}$, das in einiger Entfernung zu seinem gegenwärtigen Standort liegt:

16 ,(...) persequar binc quo nunc iter est tibi. ', nil opus est te

circumagi: quendam volo visere non tibi notum;

trans Tiberim longe cubat is prope Caesaris hortos. '

,nil habeo quod agam et non sum piger: usque sequar te. ${ }^{321}$

Das Privathaus befindet sich laut der Ortsbestimmung jenseits des Tibers, in Nähe der Gärten Cäsars. Dass es sich bei dieser standortabhängigen Positionierung lediglich um eine ungefähre Positionierung handelt, ist an dem jeweiligen weiträumigen Eigenort beider räumlicher Gegebenheiten ersichtlich, aus der sich eine recht großräumige Umgebung ergibt, in der das Haus des Freundes liegen kann. Dem Sprecher liegt auch nichts an einer genauen Aufklärung des Standortes (quendam ... non tibi notum, v. 17), sondern es geht ihm um den Hinweis, dass sich

der Straßen über den konkreten Schauplatz hinaus (vicos, v. 13) entspringt jedoch nicht der unmittelbaren Wahrnehmung der beiden Spaziergänger. Denn ein Verb der Wahrnehmung, das dieses Ereignis anzeigte, fehlt in diesem Zusammenhang. Demzufolge gibt der Begleiter ein allgemeines Wissen über den literarischen Raum wieder, wie es auch die allgemeinbleibende Aussage (urbem laudaret, v. 13) nahelegt. Vgl. dagegen Fedeli (1994), 489: „I vici sono le vie secondarie che confluiv ano nella via Sacra."

318 In ihrer Länge ist die Wegstrecke allein von der Textgrundlage her nicht vorstellbar. Denn die verschiedenen Bewegungstempi, in denen die beiden Figuren unterwegs sind, geben kaum über die zurückgelegte Entfernung Auskunft. Vgl. Hor. sat. 1, 9, 8 f.: discedere quaerens/ ire modo ocius, interdum consistere. Ebenfalls dient die Nennung der Uhrzeit eher dem Hinweis, dass zufällig die übliche Zeit der für den Fortgang des Geschehens relevanten Gerichtstermine gekommen ist. Sie dient als Indiz einer bereits hinter sich gelassenen Wegstrecke. Vgl. Fedeli (1994), $495 \mathrm{zu}$ ebd., 35 f.: quarta iam parte diei/ praeterita.

$319 \mathrm{Zu}$ einer weiteren räumlichen Veranschaulichung des Bewegungsbereichs tragen einzelne Figuren bei, die den beiden entgegenkommen (Hor. sat. 1, 9, 60 f.: ecce Fuscus Aristius occurrit, Hor. sat. 1, 9, 74 f.: venit obvius .../ adversarius), und eine Gruppe von Menschen unbekannter Zahl, die zum Abschluss der Satire sich aus verschiedenen Richtungen kommend einfindet (Hor. sat. 1, 9, 78: undique concursus).

320 Auf das Haus wird metonymisch über den intentionalen Zustand des Liegens (Hor. sat. 1, 9, 18 : cubat) referiert.

321 Hor. sat. 1, 9, 16-19. 
der Zielort weit jenseits des Tiber befindet (trans Tiberim longe, v. 18). Genau diese Tatsache soll der Beendigung des gemeinsamen Weges dienen. ${ }^{322}$ Jedoch reagiert das Gegenüber unerwartet: Zwar teilt der Anonymus die Einschätzung, dass es sich um eine stattliche Entfernung handelt. Jedoch erklärt er sich - für den Sprecher überraschend - zu dem damit verbundenen körperlich-zeitlichen Einsatz bereit: Er habe Zeit und sei bereit, diese Wegstrecke auf sich zu nehmen (,nil habeo quod agam et non sum piger: usque sequar te.', v. 19).

Die Distanz innerhalb des hier präsentierten literarischen Raumes urbs Roma ist demzufolge entsprechend den Regeln der erzählten Welt objektiv weit. Die Vermessung der Wegstrecke liegt als körperlich-sinnliche Erfahrung bei beiden Figuren bereits vor. Obwohl sie einem Fußgänger nicht umstandslos zumutbar ist, entspricht sie dennoch nur einem Radius innerhalb des literarischen Raumes, nicht der Ausdehnung des Gesamtraumes.

Derartige Entfernungen zwischen einzelnen Bereichen werden dem literarischen Raum urbs Roma auch in den Epigrammen Martials zugeschrieben. Ein der horazischen Satire 1, 9 inhaltlich nahestehendes Beispiel ist das Epigramm 1, 117. Ein Sprecher versucht hier ebenfalls sich eines Bekannten zu erwehren, indem er ihn auf die enormen Entfernungen zwischen ihren beiden Wohnorten aufmerksam macht.

Zu Beginn des Epigramms führt der Sprecher in die Situation ein: Er trifft einen hier angeredeten Lupercus häufiger (Occurris quotiens, Luperce, v. 1), der ihm angekündigt hat, einen Diener vorbeizuschicken, um sich von ihm ein Buch auszuleihen. Von diesem Vorhaben versucht ihn der Sprecher abzuhalten:

$5 \quad$ Non est quod puerum, Luperce, vexes.

longum est, si velit ad Pirum venire,

et scalis habito tribus sed altis.

quod quaeris propius petas licebit.

Argi nempe soles subire Letum:

10 contra Caesaris est forum taberna

scriptis postibus binc et inde totis,

omnis ut cito perlegas poetas.

(...) Nec roges Atrectum -

hoc nomen dominus gerit tabernae - : (...)..$^{323}$

An den topographischen Merkzeichen (Argi ... Letum, v. 9; Caesaris ... forum, v. 10) wird der literarische Raum als urbs Roma erkennbar. Die städtische Landschaft

322 Laut Fedeli (194), 490 ist das Verbum circumagi mit der Vorstellung eines weiten Fußweges verbunden.

323 Mart. 1, 117, 5-14. 
besteht in diesem Epigramm aus zwei Straßen, einem Wohnkomplex (insula) mit mindestens drei Etagen, einem wohl innerstädtischen Merkzeichen, das „Birnbaum“"324 genannt wird, dem Caesar-Forum und einem Buchladen. Für die jeweilige Positionierung der drei Bereiche innerhalb der literarischen Großstadt wird ein absolutes Referenzsystem eingesetzt, jedoch in unterschiedlicher Präzision:325 Über die Lage des Aufenthaltsorts des namentlich angesprochenen Lupercus werden keinerlei Angaben gemacht; der Aufenthaltsort des Sprechers dagegen wird in der räumlichen Umgebung des „Birnbaums“ positioniert (ad Pirum, v. 6); weit realistischer ${ }^{326}$ aber wirkt die Positionierung des Bücherladens, der sich an einer namentlich genannten Straße gegenüber dem Caesarforum befindet und dessen Gebäude von außen durch entsprechende Reklame identifizierbar ist. ${ }^{327}$

Die Entfernung zwischen dem Aufenthaltsort des Lupercus und dem des Sprechers wird explizit als weit bezeichnet (longum est, v. 6).328 Über diese direkte Attribuierung hinaus wird die Wegstrecke auch als unzumutbare körperliche Anstrengung für den Laufjungen charakterisiert (puerum ... vexes, v. 5) ${ }^{329}$ und um eine vertikale Eigenschaft ergänzt: Zu dem Aufenthaltsort des Sprechers führen drei hohe Treppen (et scalis habito tribus sed altis, v. 7). Die Entfernung zwischen dem Aufenthaltsort des Lupercus und dem Buchladen dagegen wird sowohl explizit als näher bezeichnet (propius, v. 8), als sich dieser auch dadurch empfiehlt, dass der angesprochene Lupercus dort regelmäßig vorbeikommt (Argi nempe soles subire Letum, v. 9).

Diesem Epigramm zufolge ist das Überwinden von Distanzen innerhalb der urbs Roma eine selbstverständliche Erfahrung. Jedoch unterscheidet der Sprecher zwischen körperlich zumutbaren und unzumutbaren Entfernungen.

Im Epigramm 2, 5 Martials wird ebenfalls und zudem mit großem Nachdruck auf die erheblichen Distanzen zwischen zwei Bereichen hingewiesen.

1

Ne valeam, si non totis, Deciane, diebus

et tecum totis noctibus esse velim.

sed duo sunt quae nos disiungunt milia passum:

quattuor haec fiunt, cum rediturus eam.

324 Vgl. dazu Neumeister (1991), 40.

325 Der Aufenthaltsort des Sprechers ist nur vage lokalisierbar. Dies fügt sich recht gut zur Absicht des Sprechers, sein Gegenüber von einem Besuch abzuhalten.

326 Vgl. dazu Abschnitt 2.2.2.2.

327 Vgl. Howell (1980), 349.

$328 \mathrm{Ob}$ die räumliche Beschreibung und Einschätzung innerhalb der literarischen Kommunikation von Anderen geteilt wird oder ob sie eine Übertreibung darstellen soll, bleibt von der Textgrundlage her offen. Im Gegensatz zur imaginierten Sprechsituation in der Satire 1, 9 des Horaz, in der Einvernehmen über die räumliche Entfernung herrscht, wird die Einschätzung hier von keiner weiteren Figur bestätigt.

329 Vgl. Howell (1980), 349: ,,vexes: ,troublec, ,bother', a colloquial usage.“ 


\author{
saepe domi non es, cum sis quoque, saepe negaris: \\ vel tantum causis vel tibi saepe vacas. \\ te tamen ut videam, duo milia non piget ire; \\ ut te non videam, quattuor ire piget. 330
}

Es ergeben sich jedoch einige Probleme bei der Identifizierung des literarischen Raums. Dass die Ereignisse innerhalb der literarischen urbs Roma stattfinden, ist durch keine Referenz eindeutig zu belegen. Auch wird kaum ein zwingend städtischer Raum durch etwaige typische Teilelemente vorausgesetzt. Allein die als möglich hingestellte Tätigkeit des angeredeten Decianus (v. 1), dass er sich nämlich mit Rechtsfällen beschäftige ${ }^{331}$, verweist auf ein städtisches Lebensumfeld. Fest steht jedoch, dass beide Bereiche zu einem räumlichen Kontinuum gehören, da es eine verbindende Wegstrecke zwischen ihnen gibt und da das Überschreiten von räumlichen Grenzen nicht angezeigt ist. Zudem ist der Sprecher bereit, diese Wegstrecke täglich zurückzulegen, um mit dem angeredeten Decianus zusammen zu sein, wie er zu Beginn des Epigramms zu verstehen gibt.

Die Angabe der Distanz erfolgt an dieser Stelle sogar mittels einer metrischen Angabe (duo sunt ... milia passum, v. 3). Weit entfernt ist dieser Ort zwar weiterhin allein aus der Sicht des Sprechers, durch das wiederholte Insistieren auf die räumliche Distanz bei einem Hin- und Rückweg wird jedoch ersichtlich, dass er innerhalb der literarischen Kommunikation mit einer Zustimmung rechnet, diese Strecke als lang kennzeichnen zu dürfen. ${ }^{332}$ Zudem führt er die räumliche Distanz, die er bereit ist, für den hier angeredeten Decianus täglich zu überwinden, dominant als Zeichen seiner Freundschaft an. Die Entfernung ist somit eine Last, die aber für ihn zumutbar wäre, wenn der Weg nicht vergeblich wäre.

Der völlige Verzicht auf stadtrömische, ja sogar explizit städtische Referenzen führt zu der Vermutung, dass die hier im Mittelpunkt stehende Entfernung zwischen zwei Bereichen, die zwar für einen Fußgänger kaum zumutbar ist, aber täglich zurückzulegen ist, wohl bereits als ein Alleinstellungsmerkmal des literarischen Raumes urbs Roma in römischer Dichtung verstanden wurde. Es wäre in diesem Epigramm das einzige Indiz, dass es sich hier um den literarischen Raum urbs Roma handeln soll.

Für diese Vermutung, dass räumliche Entfernungen zwischen Figuren, die dennoch in einer sozialen Verbindung miteinander stehen, ein typisches Merkmal der

330 Mart. 2, 5.

331 Der Beruf des Rechtsanwalts steht in vielen literarischen Beispielen exemplarisch für den Städter, vgl. Hor. sat. 1, 1, 9 f. Als explizite Referenz auf eine räumliche Gegebenheit ist - kaum eindeutig - domus (Mart. 2, 5, 5) zu werten.

332 Mart. 2, 5, 2 f. Zur Berechnung der Wegstrecke vgl. Williams (2004), 38 f. Ob die Einschätzung, eine derartige Wegstrecke als lang zu bezeichnen, wirklich geteilt wird, bleibt innerhalb des Epigramms offen. 
literarischen urbs Roma sind, spricht neben den aufgezeigten Beispielen noch eine weitere Beobachtung: Im Zusammenhang mit dem literarischen Raum urbs Roma wird räumliche Nähe und Nachbarschaft - wie sie ja aus der römischen Komödie durchaus als Schauplatz vertraut ist - auffallend selten ausgestaltet und thematisiert, obwohl es zur Darstellung gerade alltäglicher Abläufe naheliegender wäre, ein nachbarschaftliches räumliches Ensemble in den Mittelpunkt zu stellen.

In diesem Zusammenhang ist ein Epigramm Martials $(1,86)$ ein bemerkenswertes Beispiel. In ihm wird die räumliche Nähe und Nachbarschaft zweier Figuren gar zum Ausgangspunkt eines Paradoxons.

1 Vicinus meus est manuque tangi

de nostris Novius potest fenestris.

quis non invideat mibi putetque

horis omnibus esse me beatum,

5 iuncto cui liceat frui sodale? (...)

non convivere, nec videre saltem,

non audire licet, nec urbe tota

quisquam est tam prope tam proculque nobis.

Migrandum est mihi longius vel illi (...). ${ }^{333}$

Durch die Gattungsbezeichnung urbs (v. 9) ist der räumliche Hintergrund dieses Epigramms als großstädtisch ausgegeben. Der genaue Schauplatz, ein Wohnhaus, in dem der Sprecher und ein gewisser Novius wohnen, wird jedoch nicht näher lokalisiert.

Das Epigramm beginnt ebenfalls mit der Benennung von zwei räumlichen Koordinaten, nämlich zwei Fenstern, deren Abstand mittels des Einsatzes des taktilen Sinnes als besonders nah gekennzeichnet ist (manuque tangi/ de nostris ... potest fenestris, v. 1 f.). ${ }^{334}$ Die erste Pointe 335 des Epigramms liegt nun darin, dass der Sprecher seinen Nachbarn trotz dieser ausgewiesenen räumlichen Nähe nicht nur nicht trifft, sondern ihn sogar weder sieht noch hört. Die über den taktilen Sinn vermittelte potentielle räumliche Nähe steht im Gegensatz zu einer tatsächlichen - über den visuellen und auditiven Sinn vermittelten - räumlichen Entfernung: Novius ist für den Sprecher selbst über diese Fernsinne nicht wahrnehmbar. Aus dieser paradoxen räumlichen Situation schließt der Sprecher, dass er selbst oder sein Nachbar den Standort innerhalb des literarischen Raumes wechseln muss.

333 Mart. 1, 86, 1-5; 8-11.

334 In welcher Weise diese Fenster zueinander liegen, ob unter-, nebeneinander oder gegenüber, wird nicht gesagt, allerdings deutet inquilinus (v. 12) daraufhin, dass beide Nachbarn im gleichen Mietshaus sind. Vgl. zum Fern- und Nahsinn auch Stat. silv. 1, 3, 30 f.: datur hic transmittere uisus/ et uoces et paene manus.

335 So auch Neumeister (1991), 41: „Damit [d. h. mit Vers 10, Anm. d. Verf.] könnte das Epigramm schließen; das Oxymoron wäre als Schlusspointe gut geeignet.“ 
Die räumliche Ausgestaltung und damit die Betonung der Tatsache, dass die hier vorgeführte Begebenheit in allernächster Nachbarschaft spielt, macht darauf aufmerksam, dass in der innerliterarischen Kommunikation das Auseinanderliegen von Gegenden innerhalb der literarischen urbs Roma als ein selbstverständliches Charakteristikum angesehen wird. 336 Wenn dieses Beispiel also ein Ausnahmezeugnis ist, und die räumliche Konstellation auch als ein solches beschrieben wird, fügt sich dieses Epigramm recht gut zu der Vermutung, dass das Auseinanderliegen einzelner Bereiche, die täglich zu erreichen sind, als ein Alleinstellungsmerkmal der literarischen urbs Roma anzusehen wird.

\section{Zusammenfassung}

Große Entfernungen innerbalb des Raumes urbs Roma zurückzulegen, gehört zu den Selbstverständlichkeiten, die seine literarischen Bewohner auf sich nehmen. Die Vermessung dieser Entfernungen wird von ihnen selten metrisch angegeben, sondern sehr viel häufiger als eine körperlich-sinnliche Erfahrung kommuniziert. Die Figuren kennen den zeitlichen und körperlichen Einsatz, der mit dem Überwinden dieser Distanzen verbunden ist, und nennen es eine körperliche Quälerei. Sie unterscheiden daher zwischen zumutbaren und unzumutbaren Entfernungen. Dass man jedoch überhaupt über einen so weit gespannten Raum soziale Kontakte pflegt oder seinen Verpflichtungen nachkommt, wird von keiner Figur infrage gestellt. Im Gegenteil: Das Überwinden von räumlichen Distanzen gilt als Normalität. Dies konnte in unterschiedlichen Gattungen der römischen Dichtung gezeigt werden.

In allen Beispielen liegen die Anfangs- und Zielpunkte nicht an den Grenzen oder außerhalb des literarischen Raumes. Die Entfernungen, die es zu überwinden gilt, sind Wegstrecken innerhalb der urbs Roma. Die Ausdehnung dieses literarischen Raumes geht somit gemäß der Illusionsbildung für den Leser über die genannten Distanzen hinaus. Wie die räumlich ausgreifenden Bewegungen der Figuren zu ihrem unmittelbarem Lebensalltag gehören, so stellt die enorme flächige Ausdehnung ein markantes Merkmal des literarischen Raumes urbs Roma dar.

336 Weitere Hinweise auf Entfernungen in der literarischen urbs Roma: Hor. epist. 2, 2, 70: intervalla vides humane commoda; Hor. epist. 1, 7, 48 f.: dum redit atque foro nimium distare Carinas/ iam grandis natu queritur, (...). In Martials Epigramm 1, 108 wird ebenfalls zunächst eine Wegstrecke zwischen zwei Orten innerhalb des literarischen Raumes urbs Roma abgesteckt: Ein im Epigramm angeredeter Gallus wohnt in einem Haus jenseits des Tibers, der Sprecher selbst in einer Dachkammer. Die dazwischen liegende Wegstrecke hat der Sprecher schon häufiger zurückgelegt. Hyperbolisch bezeichnet er sie als Wanderung. Vgl. Mart. 1, 108, 5: migrandum est, ut mane domi te, Galle, salutem. Dazu Howell (1980), 332: „migrandum: here in the sense ,make a long journey““. In Mart. 10, 20 (19) wird eine geringe körperliche Anstrengung zwischen zwei Bereichen innerhalb der urbs Roma für erwähnenswert gehalten: $i$ perfer: brevis est labor peractae/ altum vincere tramitem Suburae (v. 4 f.). Räumliche Nähe vgl. Ov. trist. 1, 3, 29 f. 


\subsubsection{Mobilität als Lebensform. Bewegungsbereich Großstadt}

saepe nagos ultra limina ferte pedes

Ov. ars 3, 418

Die Figuren haben Erfahrungen mit der räumlichen Ausdehnung innerhalb der literarischen urbs Roma und wissen, welche Distanzen mitunter zu überwinden sind. In vielen Passagen der römischen Dichtung wird überdies der Mobilität der Figuren eine erhöhte Aufmerksamkeit geschenkt. In Martials Epigramm 8, 44 wird der Alltag eines senex Titullus in rastloser Bewegung skizziert.

(...) tu, miser Titulle, (...),

(...) omne limen conteris salutator

5 et mane sudas urbis osculis udus,

foroque triplici sparsus ante equos omnis

aedemque Martis et colosson Augusti

curris per omnis tertiasque quintasque. ${ }^{337}$

Die räumliche Umgebung des Titullus ist durch die Gattungsbezeichnung urbs (v. 4) als städtisch gekennzeichnet. Die städtische Landschaft besteht in diesem Epigramm aus einer ungenannten Zahl an Häusern, auf die metonymisch über ihre räumliche Grenze limen verwiesen wird. Des Weiteren werden drei Fora, zahlreiche Reiterstatuen ${ }^{338}$, ein Marstempel und eine Kolossalstatue genannt. Durch die entsprechenden Eigennamen werden sie als topographische Merk- und Wahrzeichen identifizierbar. Die einzelnen Bereiche werden durch die Bewegung des Titullus in einem räumlichen Kontinuum präsentiert. Die Summe der auf diesem Weg aufgesuchten Punkte (omne limen, v. 4) ebenso wie die Lage zueinander bleibt jedoch unbekannt. 339

Im ersten Tagesabschnitt (v. 3-5) werden die von Titullus aufgesuchten Bereiche (limen, v. 4) als Kontaktbereiche vorgestellt. Zum einen betritt Titullus aktiv und häufig die Schwellen ${ }^{340}$, zum anderen kommt es mit zahlreichen anderen zu einem taktilen, körpernahen Kontakt (urbis osculis, v. 5). Beides führt zu körperlichen

337 Mart. 8, 44, 3-8.

338 Vgl. zur Diskussion von equos Schöffel (2001), 384 und Anm. 2.

339 Schöffel (2001), 382 f. sieht im generischen Singular von omne limen die „hektische Wahllosigkeit“ der Betätigung hervorgehoben.

340 Selektiert wird damit keine Situation körperlichen Stillstandes wie sie etwa im Inneren des Hauses eintreten müsste. Schöffel (2001), 380 versteht limen nicht metonymisch, sondern übertragen im Sinne von ,Klinken putzen' und konkret in dem Sinne, dass Titullus kein Eintritt in die Häuser gewehrt wird, er vielmehr „(wie ein unterwürfiger Bittsteller) auf der Schwelle abgefertigt“ wird. Dagegen spricht aber wohl - wie er selbst ad loc. festhält - die Tatsache, dass Küssen stets als Gunsterweis zu verstehen ist. Da Titullus nass vor Küssen der gesamten Großstadt ist, zeigt der Verweis auf limina m. E. vielmehr, dass es sich um viele Orte handeln muss, die er besucht. 
Reaktionen: Sein Schwitzen und die Nässe, die die beherzten Küsse auf seinem Körper hinterlassen, vermitteln in deutlicher Überzeichnung eine körperlich-sinnliche Erfahrung der enormen Summe der aufgesuchten Bereiche.

Zur Darstellung eines zweiten Tagesabschnittes (v. 6-8) wird ein größerer, innerstädtischer Bereich genauer ausgestaltet. Titullus befindet sich gleichzeitig (sparsus, v. 6) ${ }^{341}$ auf drei Foren, wobei er sich in großer Eile vor (ante, v. 6) Reiterstatuen, dem Marstempel und einer Kolossalstatue bewegt. Von einer Tätigkeit, der er dabei nachgeht, oder Kontakten wird nicht gesprochen. Dominant steht weiterhin sein In-Bewegung-Sein im Vordergrund.

Die Verdreifachung des Forums weist - zusammen mit der Charakterisierung der Figur als sparsus - auf eine flächige Ausdehnung dieses Bereichs hin. Durch die intrinsische Raumachse der sich auf den Foren befindlichen räumlichen Gegebenheiten - vor allem der Statuen - kommt es gleichfalls zu einer vertikalen Akzentuierung. Diese genaue Positionierung ${ }^{342}$ des Bewegungsbereichs dient einer Herausarbeitung visueller Gegensätze zwischen Figur und räumlicher Umgebung: Zum einen werden damit die Größenverhältnisse von Titullus und den Statuen kontrastiert, ${ }^{343}$ zum anderen entsteht ein Gegensatz zwischen dem statischen und massiven Charakter der räumlichen Gegebenheiten und der ausgreifenden unablässigen Bewegung des Titulus. Diese Kontraste zwischen Raumgestaltung und Figur tragen dazu bei, das Verhalten der Figur in besonderer Weise zu karikieren. ${ }^{344}$

Das präsentische Tempus beschreibt diese Vorgänge als wiederholte Ereignisse. Diese wenigen Verse zeigen daher einen typischen Tagesverlauf (mane, v. 5; tertiasque quintasque, v. 8) des angesprochenen Titullus, dessen herausgestellte Tätigkeit in einer unablässigen Eigenbewegung (conteris, v. 4; curris, v. 8) innerhalb eines offenen Raumes besteht. Andere Tätigkeiten, die diese Bewegung rechtfertigen würden, werden an keiner Stelle genannt. ${ }^{345}$ Alltag in der literarischen urbs Roma

341 Zum Verständnis von sparsus vgl. die Diskussion bei Schöffel (2001), 383 und OLD (1992), s.v. spargo, 5 c, 1797: ,to send (a single person or thing) to numerous places in turn, send hither and thither."

342 Die Positionierung erfolgt zum einen über das topologische Referenzsystem der Inklusion mittels des Ablativus loci (foroque triplici, v. 6), zum anderen über das intrinsische Referenzsystem mittels der Präpositionalphrase mit ante (ante equos ... aedemque Martis et colosson Augusti, v. $6 \mathrm{f}$.). Als intrinsisch gilt das Referenzsystem hier, da Statuen und Tempel eine intrinsische Vorderseite haben.

343 Schöffels (2001), 380 Interpretation, das Deminutiv diene der ,adäquaten Illustration seines Charakters", fügt sich in meinen Vorschlag bestens ein.

344 Schöffel (2001), 384 weist auf die Bedeutung dieser Statuen hin: Reiterstatuen genießen das denkbar größte Prestige. Daraus ergibt sich eine dritte Ebene der Inkongruenz zwischen Figur und Raumgestaltung, nämlich die der gesellschaftlichen Hierarchisierung. Die Mobilität ist nach Ansicht des Sprechers kein Indiz seiner Unabhängigkeit. Im Gegenteil, er fordert Titullus dazu auf, sein Leben endlich in Ruhe und Genügsamkeit zu genießen. Vgl. Schöffel (2002), 381.

345 Die temporale Formulierung currere per verstärkt den Eindruck der unablässigen Bewegung. Vgl. dazu Schöffel (2001), 384 f. Parodierend stützt den Bewegungsreichtum in diesem Epigramm 
bedeutet für den senex Titullus das In-Bewegung-Sein innerhalb eines ausgedehnten Raumes.

Die Anzahl der städtischen Teilelemente, die räumliche Ausgestaltung des einen weiträumigen innerstädtischen Bereichs geben Aufschluss über die innere Struktur des literarischen Raums. Die Bewegung des Titullus und seine körperlichen Reaktionen legen aber das Hauptaugenmerk auf die Abstände aller dieser Bereiche untereinander, die es im Alltagsleben zu überwinden gilt. In ihrer Summe, in der die Orte der sozialen Kontakte über den Makroraum verstreut liegen und deswegen von Titullus angelaufen werden müssen, zeigen sie ihre disparate Lage innerhalb eines ausgedehnten Makroraums.

Bei dem kaiserzeitlichen Autor Juvenal findet sich in der ersten Satire eine äußerst reduzierte Darstellung davon, wie die sozialen Verpflichtungen über den Raum hin verteilt sind und damit der Alltag der Figuren wesentlich durch das eigene InBewegung-Sein bestimmt wird.

Ipse dies pulchro distinguitur ordine rerum:

sportula, deinde forum iurisque peritus Apollo

atque triumphales, inter quas ausus habere

130 nescioquis titulos Aegyptius atque Arabarches,

cuius ad effigiem non tantum meiere fas est.

vestibulis abeunt veteres lassique clientes

votaque deponunt, quanquam longissima cenae

spes homini; caules miseris atque ignis emendus. ${ }^{346}$

Die Ereignisse eines gesamten Tages (dies, v. 127) werden in einem Katalog präsentiert, in dem lediglich räumliche Gegebenheiten unterschiedlicher Größe ohne Hinweis auf topologische Beziehungen nebeneinander gestellt werden. Die Passage ist ohne Vorkenntnisse in dieser Verdichtung kaum verständlich. Der Sprecher nennt die sportula, also ein Körbchen ${ }^{347}$, folgend das Forum, eine Statue des Apollon und Triumphalstatuen. Unter den Triumphalstatuen unbekannter Menge wird einer von ihnen besondere Aufmerksamkeit in zweieinhalb Versen geschenkt. ${ }^{348}$

auch die Wahl des Metrums: ein Hinkjambus. Schöffel (2001), 380 begründet die Wahl des Versmaßes allerdings mit dem skoptischen Charakter dieses Epigramms, womit vor allem „die Perversion dieser popularphilosophischen Konzeption [d. b. die vita vera, Anm. d. Verf.] aufgezeigt wird".

346 Iuv. 1, 127-134.

347 Zur Sportula vgl. Rolf Hurschmann, s.v. Sportula, in: DNP (2001), Bd. 11, Sp. 857. In den Versen Iuv. 1, 95-125 wurden in einer längeren Passage die Ereignisse bei der salutatio beschrieben. Vgl. dazu ausführlich Abschnitt 3.5.2.2.

348 Der räumlich am weitesten ausgestaltete Bereich ist damit in dieser Passage das Forum. Es ist der räumliche Wendepunkt der täglichen Wegstrecke und damit auch der Mittelpunkt des Tages. Das Forum wird als Bereich juristischer Tätigkeiten ausgewiesen. Die Statue des Apollon ist iuris 
Daran anschließend werden Vorhallen, ebenfalls unbekannter Anzahl, genannt, die als Grenzbereiche metonymisch auf Wohnhäuser verweisen. Diese werden als einziger Bereich zu einem Kontaktbereich ausgestaltet: Nach langem Warten verlassen (abeunt, v. 132) die hier versammelten Klienten sie und kehren nach Hause zurück. Allein diese letzte Station ist Ausgangspunkt einer expliziten Bewegung, mit der sich die Figuren zurück an den Anfangspunkt ihres alltäglichen Weges begeben. Es ist die letzte, exemplarische Bewegung auf einem Weg, der über alle vorher genannten räumlichen Gegebenheiten geführt hat. ${ }^{349}$ Daraus erklärt sich der körperliche Zustand der Klienten, nämlich ihre Erschöpfung (lassi, v. 132).

Gleichzeitig verbindet die Bewegung alle Bereiche zu einem räumlichen Kontinuum von einiger Größe, das zum Erzählzeitpunkt von allen Figuren durchschritten worden ist. Das Durchlaufen der Stationen gehört auch in diesem literarischen Raum zum Alltag ${ }^{350}$. Die Beschreibung dieses Alltagsgeschehens durch kollektiv und anonym handelnde Akteure macht die Bewegung der Figuren, ihr Überwinden von Distanzen zu einer Eigenschaft des literarischen Raumes, die seine vari-

peritus (v. 128), da sie Zeuge vieler Verhandlungen geworden ist. Vgl. Braund (1996), 103. (Eine Anspielung auf Mart. 2, 64, 8 und Hor. sat. 1, 9, 77.) Der Sprecher äußert sich ebenfalls zu rechtlichen Fragen (fas est, v. 131). Durch die Nennung zahlreicher Triumphalstatuen, die hier personifiziert lediglich mit triumphalis bezeichnet werden, wird - wie in Mart. 8, 44 - mit deren intrinsischer Achse die Vertikale herausgestellt. Der Sprecher selektiert auf Augenböhe (vgl. Rekonstruktion bei Gowing (2005), 141) die Aufschrift eines Standbildes, das einen Mann ägyptischer Herkunft zeigt. Titullus ist also deutlich kleiner. Gegen die räumlich dargestellte Überhöhung eines (ausländischen) Menschen setzt sich der Sprecher zur Wehr, indem er eine rechtliche Option nennt, den Unterschied zwischen eigener Beweglichkeit und Statik des Standbildes zu nutzen. Womöglich veranschaulicht der indirekt herausgearbeitete Größenunterschied die unterschiedliche gesellschaftliche Wertschätzung zwischen den sich dort und später in den Vorhallen einfindenden Klienten und den Anderen, nämlich denen, die auf Statuen abgebildet werden. Seiner Verachtung für dieses Standbild verleiht der Sprecher nicht nur durch den Zusatz des Indefinitpronomens nescioquis Ausdruck, sondern vor allem durch die von ihm formulierte Erlaubnis, diese nach heiligem Recht (!) verunreinigen zu dürfen. Die Formulierung fas est gibt feierlich zu verstehen, dass es sich bei der Erlaubnis nach Meinung des Sprechers entsprechend einem göttlichen Gebot und sittlichem Gefühl um pflichtgemäßes Tun handelt. Urinieren an der Statue einer Göttin wird an einer anderen Stelle in den Satiren als anstößiges Verhalten von Frauen gewertet. Vgl. Iuv. 6, 309 f. Vgl. auch Pers. 1, 107-114 und Kißel (1990), 259 f. Aus ästhetischen, hygienischen und vor allem sakralen Gründen war es nicht erlaubt, Tempelbezirke, Gräber oder Statuen des Kaisers mit Fäkalien zu verunreinigen. Vgl. auch die Interpretation Larmour (2007), 175, 182 f., im Sinne Kristevas „figure of the ,deject““. Dass die Statue als Fremdkörper empfunden wird, zeigt sich nach Larmour (2007), 182 auch auf sprachlicher Ebene: „The foreign word Arabaches (tax official) intrudes into the midst of the Latin sentence just as the bust of the Egyptian intrudes into the ranks of sculptured Romans." Es handelt sich allerdings um ein Wort, das bereits Cicero gegenüber Pompeius verwendet hat. Vgl. ebd. und Braund (1996), 103.

349 Die kreisförmige Anordnung veranschaulicht die Nutzlosigkeit ihrer tagtäglichen Wegstrecke räumlich.

350 Durch die Anlage der Argumentation (Ipse dies pulcbro distinguitur ordine rerum, v. 127) bleibt es unmissverständlich, dass das Aufsuchen der Bereiche innerhalb eines Tages zu bewältigen ist. 
antenreiche inneren Struktur zeigt, aber vor allem seine räumliche Ausdehnung betont.

Im Gegensatz zu dieser sehr verdichteten Darstellung von Bewegungspfaden (Wegen) durch die Stadt werden in anderen Textpassagen der römischen Dichtung auch über die Bewegungsbereiche an sich, also den Raum zwischen den einzelnen Stationen, räumliche Informationen vergeben. Ein derartiges Beispiel findet sich in der Satire 2, 6 des Horaz, deren Schauplatz ein Landgut ist, auf das sich der Sprecher zurückgezogen hat und dessen Lebensbedingungen er genießt. ${ }^{351}$ Dort beginnt er über sein Leben in der Stadt zu berichten und wählt sie auf einer zweiten Erzählebene zum Gegenstand seiner Dichtung (carminis, v. 22). ${ }^{352}$ Mit dem Toponym Roma (v. 23) benennt er den allgemeinen Schauplatz des eingeschobenen carmen. Einige topographische Merk- und Wahrzeichen wie auch städtische Teilelemente tauchen darüber hinaus in der gesamten Passage (v. 18-59) auf: Als nähere räumliche Umgebungen des Sprechers werden explizit der Esquilin (atras ... Esquilias, v. 32 f.), das (Mars-)Feld (in campo, v. 49) und ein ,mobiles Objekt', nämlich ein Wagen (raeda, v. 42), genannt, implizit ein Theater (ludos spectaverat, v. 48). Erwähnt werden weiterhin das Puteal (v. 36), die Rostra und Straßenkreuzungen (a rostris ... per compita, v. 50), deren genaue Lage zum Sprecherstandpunkt offen bleibt. Aus den Tätigkeiten lassen sich implizit weitere räumliche Umgebungen erschließen. ${ }^{353}$ Die literarische Landschaft ist dementsprechend als städtische und von ihrer inneren Struktur her als variantenreich ausgewiesen. Gleich an prominent erster Stelle geht der Sprecher allerdings auf die Wegstrecken ein, die er innerhalb des Raumes alltäglich zurücklegen muss:

Matutine pater, seu Iane libentius audis, unde homines operum primos vitaeque labores

instituunt - sic dis placitum -, tu carminis esto

principium. Romae sponsorem me rapis: ,eia,

351 Hor. sat. 2, 6, 1-17; 60-117.

352 Strukturell ist die literarische urbs Roma ein raum-zeitlich getrennter Fernraum (spatio-temporally distant frame), auf der zweiten Erzählebene wird sie aber zur räumlichen Umgebung des Sprechers (provisional spatio-temporally distant frame).

353 So wird die erste Station des Weges, das Forum, im literarischen Raum durch die Rollenidentität (sponsorem me rapis, v. 23) angekündigt und durch das Vollziehen einer typischen Handlung (postmodo ... locuto, v. 27) als Umgebung vorausgesetzt. Im Folgenden der Satire benennt der Sprecher als weitere Tätigkeiten eine Fahrt mit dem Wagen, den Besuch von Spielen und das eigene Ballspiel. Vgl. Hor. sat. 2, 6, 41-51: Maecenas me coepit habere suorum/ in numero, dumtaxat ad hoc, quem tollere raeda/ vellet iter faciens (...)/ ludos spectaverat, una/ luserat in campo: (...)/ frigidus a rostris manat per compita rumor:/ quicumque obvius est, me consulit. Sie werden ebenfalls auf disparate unverbundene Bereiche verteilt. Die Tätigkeiten fallen in einen privaten Bereich, werden vom Sprecher aber nicht als solcher empfunden. Er sieht sich beständig einer größeren Öffentlichkeit ausgesetzt. Vgl. Hor. sat. 2, 6, 47 f.: per totum hoc tempus subiectior in diem et horam/ invidiae noster. 
ne prior officio quisquam respondeat, urge.
25 sive aquilo radit terras seu bruma nivalem interiore diem gyro trabit, ire necesse est. Postmodo quod mi obsit certe certumque locuto luctandum in turba et facienda iniuria tardis. ,quid tibi vis, insane?' et, quam rem agis?' inprobus urget

30 iratis precibus, ,tu pulses omne quod obstat, ad Maecenatem memori si mente recurras.

\section{(...) at simul atras}

ventum est Esquilias, aliena negotia centum per caput et circa saliunt latus. 354

Am Beginn des in die Satire 2, 6 eingeschobenen carmen steht ein Götteranruf, der zugleich auf den Beginn eines üblichen Tages überleiten soll. Der Gott Ianus wird als der Gott des anbrechenden Tages, und - allein an dieser Stelle - als Urheber des mühsamen Tagewerks der Menschen angerufen. Der Zuständigkeitsbereich des Gottes bezieht sich dieser Anrufung gemäß auf die allgemeinen Herausforderungen aller Menschen, die im literarischen Raum leben. Der Gott wird gleichzeitig als der erste Kontakt des Tages vorgestellt. Er drängt den Sprecher in direkter Anrede (,eia ... urge', v. 23 f.) zur Eile und weist ihn auf seine Verpflichtungen hin. Am Beginn des Tages steht ein gewaltsames Ziehen des Gottes, das den Sprecher gegen seinen Widerstand zur Bewegung zwingt (me rapis, v. 23). Der Widerstand des Sprechers spiegelt sich in dem unpersönlichen Ausdruck ire necesse est (v. 26) wie auch in der passivem Formulierung ventum est (v. 33) ${ }^{355}$, die seine Bewegung als geboten und unerlässlich charakterisieren.

Sorgfalt verwendet wird in diesem Abschnitt darüber hinaus auf die körperlichsinnliche Erfahrung des Bewegungsbereiches zwischen den Stationen. Im Zusammenhang mit einer ersten zurückzulegenden Wegstrecke ${ }^{356}$ wird erstens auf wechselnde Licht- und Wetterverhältnisse verwiesen. Mit dem Hinweis auf diese natürlichen Unwägbarkeiten wird ein nach oben offener Raum akzentuiert. Eine derartige körperlich-sinnliche Erfahrung legt gleichzeitig nahe, dass die unter freiem Himmel zurückzulegende Wegstrecke von einiger Länge ist. Zwischen den beiden nachfolgenden Stationen, also zwischen Gericht und Esquilin, wird zweitens das Passieren einer Straße beschrieben, bei dem es zu handfesten taktilen und einer

354 Hor. sat. 2, 6, 20-34.

355 Vgl. Fedeli (1994), 485 zur Formulierung ventum erat in Hor. sat. 1, 9, 35: „l'impersonale (...) appare sorprendente: si capisce, però, che in tal modo Orazio evita di unirsi al seccatore con un ,noi' associativo."

356 Der genaue Ort dieser Unterredung bleibt zwar referenzlos, aber als Ausgangspunkt des Weges liegt tageszeitenbedingt das Wohnhaus des Sprechers nahe. Das Wohnhaus liegt der Illusionsbildung für den Leser gemäß auf dem Esquilin, vgl. Hor. sat. 2, 6, 31: recurras. 
verbalen Auseinandersetzungen kommt. ${ }^{357}$ Der Sprecher selbst bezeichnet seine eigene Fortbewegung als einen unvermeidlichen Ringkampf (luctandum, v. 28).

Die Begegnung mit einer widerständigen Gruppe von Menschen unbekannter Größe (turba, v. 28) akzentuiert den zweiten Bewegungsbereich als einen öffentlichen Raum, zudem multipliziert sie die dargestellte eigene Bewegung auf eine unbestimmte Anzahl und macht die kollektive Bewegung in dieser Passage zu einem eindrücklichen Kennzeichen der literarischen urbs Roma.

Die im Präsens gehaltenen Ausführungen beschreiben sich wiederholende, alltägliche Abläufe. Eine allgemeine Bewegung aller Bewohner und ein gleichsam gottgegebener Zwang zur Bewegung kennzeichnen die Lebensumstände, dem der Sprecher mit Widerwillen begegnet. ${ }^{358}$ Die körperlich-sinnliche Erfahrung eines offenen und öffentlichen Bewegungsbereichs rückt das Erlebnis der eigenen Bewegung innerhalb der literarischen Großstadt in den Mittelpunkt.

Eine derart körperlich-sinnliche Erfahrung eines Bewegungsbereichs bietet auch der kaiserzeitliche Autor Martial im Epigramm 12, 29 (26).

1 Sexagena teras cum limina mane senator,

esse tibi videor desidiosus eques,

quod non a prima discurram luce per urbem

et referam lassus basia mille domum. (...)

$7 \quad$ at mibi, quem cogis medios abrumpere somnos

et matutinum ferre patique lutum,

quid petitur? Rupta cum pes vagus exit aluta

10 et subitus crassae decidit imber aquae

nec venit ablatis clamatus verna lacernis,

accedit gelidam servus ad auriculam,

et ,Rogat ut secum cenes Laetorius' inquit. 359

357 Weitere Ausführungen zu dieser Passage in Abschnitt 3.5.2.3.

358 Beschwerlichkeiten des Lebens im literarischen Raum urbs Roma liegen diesem Abschnitt zufolge im persönlichen Ausgeliefertsein eines fremdbestimmten Termindrucks. Gestaltet wird die Übermacht in dieser Passage zwar vor allem durch die drängende Aufforderung eines Gottes, der auf persönliche Anliegen keine Rücksicht nimmt. Diese Aussageabsicht wird aber auch durch den Verweis auf die Wetterverhältnisse in subtiler Weise unterstützt: Wie die Wintersonnenwende keine Rücksicht auf den anbrechenden Tag nimmt, so gibt es auch für den Städter kein Entkommen aus diesem festgelegten alltäglichen Rhythmus in der Stadt. Vgl. Kießling/Heinze (1959), 303: „wie der Mensch, so sträubt sich zu dieser Zeit auch das Gestirn des Tages, seine Bahn anzutreten.“ Fedeli (1994), Tom. 2.2, 706: „ma qui siamo in presenza di una metaphora tratta dalla corsa dei cocchi: il giorno è simile a un carro, il cielo all'arena del circo, le stagioni ai cavalli, che nell'arena celeste tirano il cocchio del giorno in giri ora più larghi ora più stretti." $\mathrm{Zu}$ den verschiedenen Aspekte, die dem Sprecher das Leben in der Stadt als negativ erscheinen lassen, vgl. summarisch Hor. sat. 2, 6, 18 f.: nec mala me ambitio perdit nec plumbeus auster/ autumnusque gravis, Libitinae quaestus acerbae.

359 Mart. 12, 29 (26), 1-4, 7-13. 
Im Mittelpunkt des Epigramms steht der Vergleich der Lebensbedingungen eines Senators (v. 1) und eines Ritters (v. 2), deren Chancen gegenübergestellt werden. Ihre Rollenidentität verweist bereits auf einen städtischen Raum. ${ }^{360}$ Die Gattungsbezeichnung urbs (v. 3) lässt den vorliegenden Schauplatz erkennen, weitere Referenzen auf topographische Merkzeichen oder städtische Teilelemente fehlen. Auf eine bauliche Substanz weisen allein sechzig limina, die als metonymische Referenz auf die entsprechenden Wohnhäuser verstanden werden sollen. Implizit übermittelt die Summe mille basia eine Vorstellung von zahlreichen körperlichen Kontakten.

In den Versen 1-3 wird die Summe (sexagena, v. 1; mille, v. 4) der Stationen genannt, die an einem Morgen von dem Senator tatsächlich, von dem Ritter dagegen gerade nicht angelaufen werden. ${ }^{361}$ Ihre Lage zueinander bleibt unbekannt. Im Mittelpunkt dieses Epigramms steht nicht eine variantenreiche innere Struktur mit verschiedenen Bereichen und einer vielfältigen Bausubstanz, sondern die Bewegung innerhalb des Raumes, die alltäglich am frühen Morgen beginnt und die sich nach den Erfahrungen des Sprechers für ihn zu einem körperlich-sinnlichen Negativerlebnis ausdehnen: Unter Zwang wird der Schlaf abgebrochen, unmittelbar anschließend betritt er den offenen Raum der Straße, auf die hier mittels ihrer materiellen Beschaffenheit (lutum, v. 8) verwiesen wird. Seine nun einsetzende unablässige Bewegung auf der Straße wird in dem Attribut vagus (v. 9) zusammengefasst. $^{362}$

Anschaulich wird der nach oben offene Raum der Straße dargestellt, den der Sprecher vor allem auf vertikaler Ebene als körperlich-sinnliches Erlebnis wiedergibt: An den Füßen tritt der Zeh aus dem zerrissenen Schuh heraus (rupta ... aluta, v. 9) und von oben her stürzt Regen in dicken Tropfen auf ihn nieder (crassae decidit imber aquae, v. 10), seine Ohren sind eiskalt (gelidam ... auriculam, v. 12). Zu diesen äußeren Umständen wie Temperatur, Nässe und Feuchtigkeit, die auf den Körper der Wahrnehmungsinstanz einwirken, kommt das Gefühl der Schutzlosigkeit gegenüber diesen Unwägbarkeiten hinzu: Der Diener mit seinem Mantel kommt nicht zu ihm (nec venit, v. 11). Er befindet sich nicht in seinem Bewegungs- und Wahrnehmungsbereich, denn sein Rufen erreicht ihn nicht. ${ }^{363}$ Neben dieser auf

360 Der Gegenstand des Epigramms, eine asymmetrische Beziehung zwischen Patron und Klient, findet sich verschiedentlich in den Epigrammen Martials, allerdings werden in der Regel konkrete Beispiele wie Geld, Geschenke, Kleidung oder Zugang zu exklusiven Einladungen und entsprechenden Lebensmitteln dazu einander gegenübergestellt. Vgl. z. B. Mart. 2, 16; 2, 37; 2, 43; 3,$60 ; 4,40 ; 4,61 ; 6,82 ; 7,92 ; 9,2 ; 10,11 ; 12,36 ; 12,53$; Iuv. 1, $94 \mathrm{f}$.

361 Dass sich der Ritter explizit nicht am frühen Morgen aufmacht, setzt, um sich als bewusste Entscheidung zu legitimieren, eine entsprechende räumliche Möglichkeit voraus, auch wenn mit der Formulierung mille basia an sich sicherlich eine Überzeichnung gewollt ist.

362 Vgl. Mart. 4, 78, 3 discurris tota vagus urbe und Watson (1993), 145 zu Mart. 12, 18, 5 vagum: ,always on the move'.

363 In Kontrast dazu rückt auf engste körperliche Nähe der Sklave des Antagonisten (accedit ... ad auriculam, v. 12), der ihm auf dem Weg begegnet. 
engste Körperlichkeit beschriebenen Wahrnehmung tritt als Ergebnis der Mobilität eine weitere körperliche Erfahrung hinzu, die vom Sprecher bereits am Beginn des Epigramms als allgemeines Wissen festgehalten wurde: Erschöpfung (lassus, v. 4).

Das Hin- und Herrennen durch einen keinen Schutz bietenden, nach oben offenen Stadtraum (discurram ... per urbem, v. 3) wird als Normalität angesehen. Derjenige, der sich dieser Mobilität entzieht, wird als desidiosus (v. 2) bezeichnet und gerät in eine Verteidigungsposition. Der Sprecher dieses Epigramms reflektiert über diese Selbstverständlichkeit und kalkuliert, welcher Nutzen damit für den Einzelnen, und im speziellen für ihn, verbunden ist. Er stellt ihn dem körperlichen Einsatz gegenüber, den er als sinnlich wiedergegebenen Bewegungsbereichs räumlich gestaltet hat.

Die alltägliche Mobilität aller Figuren ist in diesen Beispielen ein Kennzeichen des literarischen Raums urbs Roma. Dieses Merkmal, dass die Mobilität im literarischen Raum selbstverständlich ist, wird in einem anderen Epigramm Martials, 7, 39, auf die Spitze getrieben:

\section{Discursus varios vagumque mane \\ et fastus et have potentiorum \\ cum perferre patique iam negaret, \\ coepit fingere Caelius podagram. ${ }^{364}$}

Die hier dargestellte Figur des Caelius verweigert sich dem Rennen. Jedoch im Gegensatz zum Epigramm 12, 26 (29) kann sie sich dem nicht einfach entziehen, sondern täuscht eine Krankheit, nämlich eine Fußgicht, vor. Es zeigt sich daran sehr eindrücklich, in welcher Bindung an das Laufen der Mensch in diesem literarischen Raum lebt. Der Raum selbst wird in diesem Epigramm nicht benannt. Als großstädtisch wäre er allein ausgewiesen, wenn es nach den vorangegangenen Ausführungen plausibel scheint, dass eine tägliche und allgemeine Bewegung der Bevölkerung ein Alleinstellungsmerkmal einer literarischen urbs Roma ist. 365

\subsubsection{Ländliche Bewegungsarmut}

Dass Bewegung durch den literarischen Raum eine prominente Darstellungsform gerade der urbs Roma in der römischen Dichtung ist, beweist sich auch bei einem Blick auf denjenigen literarischen Raum, der gern der Stadt gegenübergestellt wird,

364 Mart. 7, 39, 1-4.

365 Die Anspielung auf eine morgendliche Bewegung durch den Raum und das Grüßen von Höherstehenden verweist auf den Klientendienst. Der Klient verweist allerdings in seiner Rollenidentität nicht automatisch auf die Stadt, da dieser Dienst auch außerhalb von Rom und einem städtischen Kontext praktiziert wird. Vgl. Mart. 3, 58, 33 und Galán Vioque (2002), 258. Möchte man das Epigramm 7, 39 in einem literarischen Raum urbs Roma lokalisieren, bliebe allein die typische Handlung des vielen Laufens als Indiz. 
dem Land. ${ }^{366}$ Häufig wird der eine dieser beiden in der römischen Dichtung als Schauplatz und der andere als raum-zeitlich getrennter Fernraum (spatio-temporally distant space) gestaltet und Unterschiede im räumlichen Erleben herausgearbeitet. Eine derartige Kontrastierung findet sich im Epigramm 12, 18 Martials.

1 Dum tu forsitan inquietus erras clamosa, Iuvenalis, in Subura aut collem dominae teris Dianae; dum per limina te potentiorum

5 sudatrix toga ventilat vagumque maior Caelius et minor fatigant: me (...) accepit mea rusticumque fecit (...) Bilbilis (...).

10 Hic (...)

13 ingenti fruor inproboque somno quem nec tertia saepe rumpit hora,

15 et totum mibi nunc repono quidquid ter denos vigilaveram per annos. ${ }^{367}$

Der Sprecher dieses Epigramms befindet sich in einer nach eigenen Aussagen ländlichen Umgebung (rusticumque fecit ... Bilbilis, v. 8 f.), dem Schauplatz des Epigramms. ${ }^{368}$ Sein angesprochenes Gegenüber, Iuvenalis, befindet sich zeitgleich (dum, v. 1 und 4) in der Stadt, die hier als räumlich getrennter Fernraum (spatio distant frame) eingeführt ist. Dieser Fernraum steht im Mittelpunkt der ersten Hälfte des Epigramms. Er ist nicht durch ein entsprechendes Toponym oder eine Gattungsbezeichnung näher bezeichnet, aber topographische Merk- und Wahrzeichen verweisen auf den Raum urbs Roma. Selektiert werden ein akustisch akzentuiertes (clamosa, v. 2) Stadtviertel und drei Hügel samt Schwellen, die metonymisch auf Wohnhäuser verweisen. Die Auswahl fällt somit auf weiträumigere, diffus abgegrenzte Bereiche und rückt vor allem ein topographisches Gelände in den Mittelpunkt. Der literarische Raum urbs Roma wird in disparate Inseln untergliedert, die miteinander unverbunden bleiben. Mithilfe dieser Raumaufteilung werden Optionen einer Tätigkeit gezeigt, denen Iuvenalis an jeweils verschiedenen Orten innerhalb der literarischen urbs Roma nachgehen könnte. An allen Teilorten wird als Tätigkeit eine vergleichbare unruhige und unablässige Bewegung des Iuvenalis vorausgesetzt, die in der Art ihres räumlichen Ausgreifens (inquietus erras, v. 1) bereits

366 Vgl. Abschnitt 1.3.

367 Mart. 12, 18, 1-10; 13-16.

368 Es handelt sich bei dieser Raumgestaltung eindeutig um einen literarischen Raum. Der historische Ort Bilbilis hatte einige regionale Bedeutung und eher kleinstädtischen Charakter. Vgl. Sullivan (1991), 179-184. 
einen Bewegungsbereich von einiger Größe voraussetzt. Die Variation der Tätigkeiten liegt vor allem in der Art und Weise der jeweiligen Bewegung, in Kontakt mit anderen tritt er nicht. Die ersten beiden Bereiche werden mit dem aktiven Agieren des Iuvenalis verknüpft, das einmal ziellos (inquietus erras - in Subura, v. 1 f.), einmal zielgerichtet (collem Dianae - teris, v. 3) wirkt. Im zweiten Satz werden die jeweiligen Bereiche mit einem (passiven) Reagieren verbunden: per limina potentiorum (v. 4) - te toga ventilat (v. 4 f.), vagum (v. 5) - maior Caelius et minor fatigant (v. 6). ${ }^{369}$ Die räumliche Präsentation könnte zudem als eine zeitliche Abbildung interpretiert werden. Kennzeichnen die ersten beiden Tätigkeiten noch eine starke körperliche Unruhe (inquietus erras, v. 1, vagum, v. 5), so beschreiben die folgenden daraus resultierende körperliche Reaktionen (sudatrix, v. 5; fatigant, v. 6). ${ }^{370}$

Dieser eindringlichen Darstellung der unruhigen, bewegungsreichen und raumausgreifenden Tätigkeiten in der Großstadt wird im zweiten Teil des Epigramms das beschauliche Leben auf dem Lande gegenübergestellt. Dieses ist zunächst durch eine nahezu völlige und lang anhaltende Bewegungslosigkeit des Sprechers gekennzeichnet: Er gibt sich einem außerordentlichen und übermäßigen Schlaf hin (fruor ... somno, v. 13). ${ }^{371}$ Die weiteren Ereignisse finden im Inneren eines Hauses statt. Hier werden Andere für den Sprecher tätig. ${ }^{372}$ Die besondere Akzentuierung des Innenraumes als Kontaktbereich weist auf einen begrenzten Bewegungsradius des Sprechers ${ }^{373}$ und steht im deutlichen Kontrast zum offenen Raum der literarischen urbs Roma, in dem sich Iuvenalis unbegrenzt bewegt. ${ }^{374}$

369 Der Wechsel von Aktion zur Rezeption kann als Abbildung der körperlichen Erschöpfung verstanden werden.

370 Das Attribut sudatrix bezieht sich auf toga, ist also vom Träger auf das Kleidungsstück übertragen worden (Enallage). Watson (2003), 145 versteht es auch als „, which makes one sweat' (...) or ,habitually sweating'““.

371 Auffallend ist die Betonung des Exzesses beim Schlafen. Exzessive Handlungen werden in der Regel mit dem Leben in der Stadt assoziiert. Vgl. Watson (2003), 144. Vgl. ebd., 145 zum Verständnis von inquietus: „Also suggested is the sense of ,lacking sleep“ (...) Bilbilis posed no such problems. “ Zu ingens vgl. Bowie (1993), 106: ,ingens is applied to the degree or intensity of physical phenomena and their sounds (winds, hail, storms etc.)."

372 Vgl. Mart. 12, 18, 17-25: Ignota est toga, sed datur petentil rupta proxima vestis a cathedra./ surgentem focus excipit superba/ vicini strue cultus iliceti, / multa vilica quem coronat olla. Im Gegensatz dazu ist die räumliche Umgebung des Iuvenalis konsequent als offener Raum konzipiert. Limina bezeichnet demzufolge pointiert die räumliche Umgebung der Grenze zwischen Innen- und Außenraum, nicht den Innenraum selbst.

373 Der Sprecher selbst verlässt das Haus nicht. Über die nähere Umgebung des literarischen Raumes rus wird der Leser durch den Eintritt anderer in den Schauplatz informiert, etwa der Eintritt eines Jägers, der in seiner Rollenidentität auf einen Wald in näherer Umgebung verweist. Vgl. Mart. 12, 18, 22-25. venator sequitur, sed ille quem tu/ secreta cupias habere silva;/ dispensat pueris rogatque longos/ levis ponere vilicus capillos. Ein expliziter Verweis auf den Wald findet sich in Mart. 12, 18, 20: vicini strue ... iliceti. Zum Verständnis von venator sequitur vgl. Watson (2003), 149: „, next a hunter arrives“ und Mart. 1, 49, 29, gegen Barié (1999), 1412: „Ein Jäger begleitet mich: der jung, hübsch und dem Herrn gefügig ist.“ Der Jäger kommt als Gast zum Abendessen. „The absence of companions other than the vilica, venator, vilicus emphasises M[artial]'s release from the social 
Auch in Horazens Satire 2, 6 lassen sich im Hinblick auf die unterschiedlich ausgreifenden Bewegungsradien derselben Figur vergleichbare Unterschiede in den jeweiligen literarischen Räumen rus und urbs ausmachen. Im Gegensatz zum deutlich herausgearbeiteten Bewegungszwang im offenen Raum der urbs Roma sind die Tätigkeiten, die der Sprecher für das Landleben antizipiert, auffallend bewegungsarm:

60 o rus, quando (...) licebit

nunc veterum libris, nunc somno et inertibus horis

ducere sollicitae iucunda oblivia vitae?

o quando faba (...)

uncta satis pingui ponentur holuscula lardo?

65 o noctes cenaeque deum, quibus ipse meique

ante Larem proprium vescor vernasque procacis

pasco libatis dapibus. ${ }^{375}$

In dieser Emphase verbindet der Sprecher mit dem literarischen Raum rus Tätigkeiten wie Lesen und Schlafen, also räumlich kaum ausgreifende Tätigkeiten der Muße (inertibus horis, v. 61). ${ }^{376}$ Des Weiteren beschwört er abendliche Gastmähler und dabei besonders Speisen, die ihm vorgesetzt werden (ponentur, v. 64). Die Wünsche verweisen allesamt auf einen privaten Innenraum eines Landhauses und erfordern wenig Eigen-Bewegung. ${ }^{377}$ Die cena dient als Anlass von Gesprächen unter Vertrauten. Räumlich befindet sich dieser Kontaktbereich deutlich im Inneren des Hauses, genauer in der unmittelbaren räumlichen Umgebung eines Tisches (ante Larem proprium, v. 66). Auch diese räumliche Präsentation charakterisiert das Landleben vor allem als eine Existenz auf beschränktem Raum.

Die Beobachtung zur geringen Raumnahme des Sprechers deckt sich auch mit den Beschreibungen der räumlichen Umgebung des Landhauses, mit denen die Satire 2, 6 einsetzt:

obligations incumbent on the cliens in Rome." Zur Erotisierung des Zusammenseins vgl. Watson (2003), $149 \mathrm{f}$.

374 Hastige und räumlich ausgreifende Eigenbewegungen werden auch in anderen Bereichen des Landlebens nicht dargestellt: Seine Landarbeit kennzeichnet er in Form eines Oxymoron. Vgl. Mart. 12, 18, 7-11: me (...)/ accepit mea rusticumque fecit/ auro Bilbilis et superba ferro./ Hic pigri colimus labore dulcil Boterdum Plateamque (...). Vgl. dagegen Hor. sat. 1, 9, 19 über die Bereitschaft, große Entfernungen in der urbs Roma auf sich zu nehmen: non sum piger. Zum literarischen Spiel mit der Bedeutung von colere vgl. Bowie (1993), 105.

375 Hor. sat. 2, 6, 60-67.

376 Im Gegensatz zum Klienten als typischen Städter, bezeichnen sich die Figuren auf dem Land zwar als rusticus, gehen aber vor allem Tätigkeiten des städtischen otium nach.

377 Als einzige Bewegung wird nur das Füttern (sic!) der Haussklaven genannt. Vgl. Hor. sat. 2, 6, 66 f.: (...) vernasque procacis/ pasco libatis dapibus. 
1 Hoc erat in votis: modus agri non ita magnus,

bortus ubi et tecto vicinus ingis aquae fons

et paulum silvae super his foret. auctius atque

di melius fecere. bene est. nil amplius oro, (...). ${ }^{378}$

Die Satire beginnt mit der Darstellung eines Wunschortes, eines nicht bestehenden Raumes (frame with a non-factual status). Als Teilelemente dieses literarischen Raumes rus werden ein freies Feld ${ }^{379}$, ein Garten, ein Haus, eine Quelle und ein Wald genannt. Das Feld soll wunschgemäß nicht allzu groß sein. Auf diesem Gebiet (ubi, v. 2) soll sich ein Garten und eine Wasserquelle befinden, die in räumlicher Nähe zum Haus liegen sollte. Hinter dieser Gesamtanlage sollte ein Wald anschließen (super, v. 3).

Diese Wünsche wurden von den tatsächlichen räumlichen Gegebenheiten übertroffen und der Sprecher bezeichnet sich als mehr als zufriedengestellt. Über die genaueren Verhältnisse des Schauplatzes wird der Leser jedoch nicht aufgeklärt. Da der Sprecher ihn aber im Folgenden summarisch mit arx (v. 16) bezeichnet und darüber hinaus allein den Innenraum des Landhauses zum Kontaktbereich ausgestaltet, dominiert weiterhin der Eindruck eines eher kleinen, räumlich beschränkten und überschaubaren ${ }^{380}$ Anwesens. Ein Abmessen des Schauplatzes qua eigener Bewegung oder eine Bewegung $\mathrm{zu}$ anderen Bereichen innerhalb des Raums rus werden nicht realisiert.

Dem Bewegungsreichtum im literarischen Raum urbs Roma wird in beiden ausgewählten Beispielen die Bewegungsarmut auf dem Land gegenübergestellt. Zur räumlichen Gestaltung des literarischen Raums rus werden einzelne Ereignisbereiche selektiert, die auf Innenräume verweisen und als überschaubare und persönliche Kontaktbereiche gekennzeichnet sind. Er wird damit als ein klar umgrenztes Gebiet ${ }^{381}$ gestaltet, das auf die villa und ihre unmittelbare Umgebung

378 Hor. sat. 2, 6, 1-4.

379 Vgl. Georges (1969), Bd. 1, s.v. ager, I a), Sp. 242: „(...) im G[e]g[en]s[a]tz zu Plätzen, die von Häusern od[er] Wald schon bedeckt sind, das Feld; (...) im G[e]g[en]s[a]tz zur Stadt, das flache Land“.

380 Vgl. auch Hor. sat. 2, 6, 8 f.: si veneror stultus nibil horum ,o si angulus ille/ proximus accedat, qui nunc denormat agellum!'; Iuv. 3, 226-231: bortulus bic puteusque brevis nec reste movendus/ in tenues plantas facili diffunditur haustu./ vive bidentis amans et culti vilicus hortil unde epulum possis centum dare Pythagoreis. / est aliquid, quocunque loco, quocunque recessu, / unius sese dominum fecisse lacertae.

381 Vgl. Verg. ecl. 1, 46 f.: rura (...) tibi magna satis; Hor. carm. 2, 16, 37: parva rura; Hor. carm. 2, 18, 14: satis beatus unicis Sabinis; Mart. 10, 96 [explizit v. 5: res parva]; Mart. 12, 31, 8: parva regna; Mart. 12, 57, 1: parva rura; Stat. silv. 4, 5, 1: Parvi beatus ruris honoribus. Die Darstellung von Innenräumen ist nicht nur auf den literarischen Raum rus beschränkt. Es finden sich in der augusteischen und frühkaiserzeitlichen Dichtung zahlreiche Belege über abendliche cenae, über den Besuch von Badeanstalten usw., die innerhalb eines literarischen Raums urbs Roma lokalisiert werden. 
beschränkt ist. Im Gegensatz zum literarischen Raum urbs bleiben Hinweise auf ein Wegenetz oder die Darstellung von ausgreifenden Bewegungen von Figuren selten. ${ }^{382}$ Gerade der literarische Raum rus wird folglich in Absetzung zur literarischen urbs Roma überraschenderweise kaum als ein zusammenhängender, weiträumiger oder offener Raum gestaltet.

\subsubsection{Tempo Großstadt. Schnelle und langsame Bewegungen in der Stadt}

In vielen Beispielen wurde bereits ersichtlich, dass die Figuren innerhalb der literarischen urbs Roma in der Regel zu Fuß unterwegs sind. Textpassagen, in denen Menschen wahrgenommen werden, die auf einem Pferd reiten oder in einer Sänfte getragen werden, sind äußerst selten und es sind dann auch meist „die Anderen“, nicht der Sprecher selbst. 383 Nimmt man die Verben der Bewegungen etwas ge-

382 Wege verbinden meist die Stadt mit dem Land. Vgl. Verg. ecl. 8, 68; Verg. ecl. 9, 62; Hor. sat. 2, 6, 99 f.: ambo propositum peragunt iter, urbis aventes/ moenia nocturni subrepere. Hor. epist. 1, 13. Prop. 2, 32, 2-6; Prop. 4, 7, 84: quod currens nector ab urbe legat, Tib. 1, 7, 61 f.: Te canet agricola, a magna cum venerit urbe/ servus inoffensum rettuleritque pedem.; Ov. trist. 1, 1, 127 f.: longa via est, propera: nobis habitabitur orbis/ ultimus, a terra terra remota mea.; Ov. trist. 1, 3, 61 f.: denique ,quid propero? Scythia est, quo mittimur,' inquam,/ ,Roma relinquenda est. utraque iusta mora est.' Eine Bewegung vom Land in die Stadt: vgl. Hor. sat. 1, 1, 11 f.: ille, datis vadibus qui rure extractus in urbem est,/ solos felicis viventis clamat in urbe. In Stat. silv. 4, 4, 1-7 beschreibt der Sprecher in seinem Brief den Weg zu einem Freund und empfiehlt eine zweite Straße neben der via Appia. Ov. fast. 3, 667-672: In myth-historischer Vergangenheit bringt Anna Perenna Kuchen in die Stadt, der noch warm ist. Folglich wird eine implizite Entfernungsangabe gegeben. Ov. fast. 6, 785 f.: Ecce suburbana rediens male sobrius aede/ ad stellas aliquis talia verba iacit. Eine ausgreifende Bewegung stellt neben den Itinerar Hor. sat. 1, 5 auch Hor. epist. 1, 4, 2-5: quid nunc te dicam facere in regione Pedana?/ scribere quod Cassi Parmensis opuscula vincat/ an tacitum silvas inter reptare salubris/ curantem quidquid dignum sapiente bonoque est? oder Verg. ecl. 2, 12 f.: tua dum vestigia lustro/ sole sub ardenti. Eine genaue Lokalisierung außerhalb der Stadt: Mart. 1, 12, 1-4: Itur ad Herculei gelidas qua Tiburis arces/ canaque sulphureis Albula fumat aquis,/ rura nemusque sacrum dilectaque ingera Musis/ signat vicina quartus ab urbe lapis dar. In Mart. 10, 104 bietet der Sprecher seiner Buchrolle eine Reisebeschreibung von Rom ins spanische Bilbilis. Darin wird auch eine Entfernungsangabe zwischen Tarraco und Bilbilis benannt. Vgl. Mart. 10, 104, 4-7: Hispanae pete Tarraconis arces:/ illinc te rota tollet et citatus/ altam Bilbilin .../ quinto forsitan essedo videbis.

383 Sänften als Transportmittel und gleichzeitig als Statussymbol vgl. Ov. ars 1, 487 f., Mart. 4, 51; 4, 78; 6, 77; 6, 84; 7, 76, Iuv. 1, 32 f. In Hor. sat. 2, 6, $42-46$ ist davon die Rede, dass der Sprecher von Maecenas in einem Reisewagen mitgenommen wird, um mit ihm zu plaudern. Als räumliche Umgebung dieser Fahrt muss die Stadt angenommen werden, da kein räumlicher Wechsel angezeigt wird, auch wenn das Fahren mit dem Wagen tagsüber unüblich bzw. verboten ist. In Hor. epist. 1, 7, $77 \mathrm{f}$. wird ein Städter zu einem ländlichen Fest auf einem Wagen mitgenommen, wobei er im Vorbeifahren die räumliche Umgebung lobt: inpositus mannis arvum caelumque Sabinum/ non cessat laudare. Die Reisegesellschaft auf einem Wagen in Hor. sat. 1, 5, 86 ist nur außerhalb Roms unterwegs. In Mart. 11, 98, 11 f. werden Optionen für eine Rettung vor basiatores durchgesprochen, dabei wird auch eine Sänfte oder ein Sessel erwähnt, allerdings nicht wegen ihrer Schnelligkeit, sondern wegen ihrer festen Begrenzung: lectica nec te tuta pelle veloque,/ nec vindicabit sella saepius clusa. Ein junger Mann auf einem Wagen in Iuv. 1, 60-62. 
nauer in Augenschein, so fällt auf, dass die Geschwindigkeiten der Figuren nicht einheitlich sind, dass aber eine Tendenz zur zügigen Bewegung zu beobachten ist. In der Satire 2, 6 wurde beispielsweise die Geschwindigkeit des Sprechers von einem Passanten als eilig bezeichnet (recurras, v. 31). Dieser Hinweis ist ein Indiz dafür, dass die vom Sprecher zu bewältigenden Distanzen von einiger Länge sind, dass er aber gleichzeitig auch unter Zeitdruck steht. Von einem derartigen Zeitkorsett berichtet er auch gleich zu Beginn seiner Ausführungen: Der Arbeitstag beginnt sehr früh am Morgen. Die direkte Aufforderung des Gottes (,eia ... urge", v. 23 f.) und der Hinweis auf die Konkurrenz (ne prior, v. 24) zeigt, dass die Zeit, um zu dem entsprechenden Bereich innerhalb der urbs Roma zu gelangen, als knapp eingeschätzt wird, und dass er sich dem nicht entziehen kann. Die Zeitnot wird also dadurch verursacht, dass eine persönliche Anwesenheit zu einer bestimmten Zeit an einem bestimmten Ort vorausgesetzt wird. Dies macht eine zügige Bewegung notwendig. ${ }^{384}$

Die Entfernungen verursachen demnach die Bewegungen durch den literarischen Raum urbs Roma, die Vielzahl der anzulaufenden Stationen die ununterbrochene Bewegung, die rasche Bewegung erklärt sich aber mit den Konkurrenzsituationen, durch die die Anwesenheit im richtigen Bereich zur richtigen Zeitpunkt ${ }^{385}$ als Vorteil angesehen wird. Ob das Zuspätkommen ein Ereignis ist, das ausschließlich innerhalb des Makroraums urbs Roma eintritt, wäre eine sich hieran anschließende Frage.

Die dem Einzelnen zur Verfügung stehende Zeit ist ein wichtiges Unterscheidungsmerkmal zwischen schnelleren und langsameren Bewegungen in der Stadt. Beide Tempi lassen sich für den literarischen Raum Großstadt beobachten. ${ }^{386}$

384 Eine Zeitersparnis bringt eine schnelle Fortbewegung vor allem dann, wenn längere Strecken in kürzerer Zeit zurückgelegt werden sollen.

385 Die Bewegung durch den literarischen Raum als Wettrennen: Iuv. 1, 102: sed libertinus prior est:. ,prior' inquit ,ego adsum'; vgl. auch Iuv. 3, 81 f.: me prior ille/ signabit fultusque toro meliore recumbet, ebd., 126-131. Mart. 10, 10, 7 f.: lecticam sellamve sequar? nec ferre recusas,/ per medium pugnas et prior isse lutum. In der ars amatoria Ovids (Ov. ars 2, 226-236) wird der Liebhaber zum schnellen Lauf in der Stadt aufgefordert, um seine officia gegenüber der domina zu erledigen. Vgl. Ov. ars 2, $225 \mathrm{f}$ : occurras aliquo tibi dixerit: omnia differ;/ curre, nec inceptum turba moretur iter. Dazu Janka (1997), 196: „Die asyndetischen Kurzsätze (...) untermalen die Eile und Kurzatmigkeit des (...) Liebhabers.“ Die officia werden im Anschluss mit dem Kriegsdienst verglichen (Ov. ars 2, 233), ähneln aber von ihrer räumlichen Einbindung her (Forum, Wohnhaus) eher dem Klientendienst, vgl. auch Janka (1997), $194 \mathrm{f}$. Bemerkenswert ist, dass im Zusammenhang mit der Dienstfertigkeit des Liebhabers das Verlassen der urbs durchgespielt wird, gerade um seine Bereitschaft zu prüfen, besonders lange Wegstrecken zurückzulegen, um zur domina zu gelangen. Ov. ars 2, 229 f.: rure erit et dicet uenias; Amor odit inertes:/ si rota defuerit, tu pede carpe niam. Vgl. auch eine ausführliche Reflexion einer nächtlichen Wanderung nach Tibur Prop. 3, 16.

386 Der Zusammenhang zwischen der zur Verfügung stehenden Zeit und dem Spazierengehen wird in Mart. 5, 20, 1-4; 8-10 explizit formuliert: Si tecum mibi, care Martialis, / securis liceat frui diebus, / si disponere tempus otiosum/ et verae pariter vacare vitae:/ (...) gestatio, fabulae, libelli, / campus, 
Jedoch werden spaziergängerische, also langsame Stadterfahrungen nur vereinzelt präsentiert und stets als ein Ausnahmeereignis oder eine Absetzung von dem Üblichen bewertet. ${ }^{387}$

In Martials Epigramm 3, 20 fragt sich ein Sprecher, womit ein ihm befreundeter Dichter gerade wohl seine Zeit verbringe. Er stellt verschiedene Möglichkeiten einer Beschäftigung als Optionen vor. Die ersten haben mit einer im weiteren Sinn schriftstellerischen Tätigkeit zu tun, die letzten mit möglichen Aufenthaltsorten, die außerbalb der Stadt liegen. Im Mittelteil aber nennt der Sprecher mögliche Aufenthaltsorte, die mittels der benannten topographischen Merk- und Wahrzeichen auf die urbs Roma verweisen ${ }^{388}$ :

10 hinc si recessit, porticum terit templi

an spatia carpit lentus Argonautarum?

an delicatae sole rursus Europae

inter tepentes post meridie buxos

sedet ambulatve liber acribus curis?

15 Titine thermis an lavatur Agrippae

an inpudici balneo Tigillini? 389

Auch in diesem Epigramm werden verschiedene Inseln innerhalb der urbs Roma als Aufenthaltsorte zur Option gestellt. Sie stellen eine Wahl dar, die Canius Rufus hat. Über ihre Relationen zueinander ist nichts bekannt, jedoch sind sie von sei-

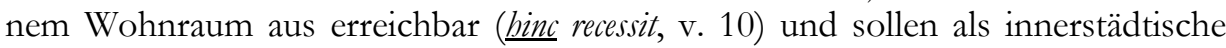
Rückzugsorte (recessit, v. 10) verstanden werden. Bei den Bereichen handelt sich vorrangig um klar umgrenzte räumliche Gegebenheiten: verschiedene Portikus, ein Gebiet zwischen Buchsbaumhecken, Thermen und Bäder, die den literarischen Raum auch gleichzeitig als städtisch auszeichnen. Sie werden in dieser Passage aufgezählt und - wie im Epigramm 12, 18 - jeweils ausdrücklich mit entsprechenden Bewegungen des Canius Rufus in Beziehung gesetzt. Alle Verben

porticus, umbra, Virgo, thermae, / haec essent loca semper, hi labores. In der augusteischen Literatur wird die langsame Bewegung in räumlich umgrenzten Kontaktbereichen des Öfteren erotisiert: Prop. 2, 32, 7-16; 4, 8, 75 f.; Ov. ars 1, 67; 1, 491-498; 3, 387 f.; rem. 627 f.; trist. 2, 285 f. Vgl. auch Catull. $55,6-12$.

387 Vgl. Hor. sat. 1, 6, 128 f.: haec est/ vita solutorum misera ambitione gravique. (Vgl. ausführlicher in Abschnitt 4.3). In der Satire 1, 9, 1 f. des Horaz ist die Geschwindigkeit nur indirekt zu erschlieBen. Da der Sprecher beim Gehen nachdenkt, ist mit einer langsamen Bewegung zu rechnen: Ibam forte via sacra, sicut meus est mos, / nescio quid meditans nugarum, totus in illis. Das Metrum suggeriert ebenfalls ein gemäßigtes Tempo. Mart. 2, 57, 1 f.: Hic quem videtis gressibus vagis lentum,/ amethystinatus media qui secat Saepta, (...). Mart. 9, 59, 1 f.: In Saeptis Mamurra diu multumque vagatus,/ bic ubi Roma suas aurea vexat opes.

388 Die Markierung des Ortswechsels mit rure (v. 17) weist den vorherigen als urbs aus.

389 Vgl. Mart. 3, 20, 10-16. 
deuten auf eine wenig ausgreifende Bewegung hin ${ }^{390}$, die durch das Attribut lentus (v. 11) einmal direkt charakterisiert wird. Das Verb sedet (v. 14) gibt sogar einen Bewegungsstillstand zu erkennen. Die Ausdehnung wirkt zum einen durch die Positionierung in geschlossenen Bereichen überschaubar, wird zum anderen aber durch den geringen Bewegungsumfang des Canius Rufus noch unterstrichen. Dass diese Art der Beschäftigungen eine Ausnahme von üblichen Umständen ist, wird in dem Epigramm jedoch betont (liber acribus curis, v. 14).

\section{Zusammenfassung}

Das Überwinden von Distanzen zwischen Orten eines Alltagsgeschehens führt zu zahlreichen Bewegungsanlässen für die Figuren innerhalb der literarischen urbs Roma. Bewegungen innerhalb des literarischen Raums sind dabei nicht an ein besonderes, einmaliges Ereignis gebunden, sondern die Mobilität bestimmt den Tagesablauf ${ }^{391}$ einer großen Anzahl der literarischen Figuren wesentlich: Die Einteilung des Tages wird als eine räumliche Verteilung einer Figur über einen aus mehreren Bereichen bestehenden Raum gestaltet, die in einer festgelegten Reihenfolge abgeschritten werden müssen. Diese allgemeine Mobilität ist ein Kennzeichen des literarischen Raums.

Durch das Ablaufen einzelner Bereiche entsteht ein umfassenderes räumliches Kontinuum von einiger Ausdehnung. Die Figuren stoßen jedoch nicht an die Grenzen des Raumes. Die eigentliche Ausdehnung des literarischen Raumes urbs Roma geht über diese individuellen Bewegungen im Raum stets hinaus.

Das Erlebnis der eigenen Mobilität besteht aus der körperlich-sinnlichen Wahrnehmung eines nach oben offenen Raumes, in dem Unwägbarkeiten wie nachteilige Wetter- und wechselnde Lichtverhältnisse ${ }^{392}$ wahrgenommen werden. Es besteht auch in der Wahrnehmung eines öffentlichen Raumes, in dem sie auf andere Figuren treffen, die ebenfalls in Bewegung sind. ${ }^{393}$

390 Vgl. zu porticum terit auch Mart. 2, 11, 2: quod ambulator porticum terit seram. Vgl. dagegen Ov. ars 1, 491-496 mit unterschiedlichen Tempi in einer Säulenhalle.

391 Weitere Darstellungen von Tagesabläufen in der literarischen urbs Roma: Vgl. Mart. 8, 44; Mart. 10, 56; Mart. 12, 29; Iuv. 3.

392 Nachteilige Wetterverhältnisse werden im literarischen Raum der urbs Roma häufiger thematisiert. Vgl. Hor. sat. 2, 6, 19; Hor. sat. 2, 5, 39 f., Mart. 10, 82, 3 f.: stridentesque feram flatus aquilonis iniquil et patiar nimbos excipiamque nives.; Mart. 12, 29, 10: et subitus crassae decidit imber aquae; Iuv. 5, 22 f.: illo tempore quo se/ frigida circumagunt pigri serraca Bootae.; Iuv. 5, 78 f.: fremeret saeva cum grandine vernus/ Iupiter et multo stillaret paenula nimbo. Zum allgemeinen Zusammenhang zwischen langen Wegstrecken (einer Reise außerhalb der urbs) und Wetterverhältnissen vgl. auch Ov. ars 2, 230232: si rota defuerit, tu pede carpe uiam./ nec graue te tempus sitiensque Canicula tardet/ nec uia per iactas candida facta niues, ebd., 230-232. Tib. 1, 4, 41 f.: Neu comes ire neges, quamvis via longa paretur/ Et Canis arenti torreat arva siti. Wetterverhältnisse im Zusammenhang mit den militia (amoris): vgl. Ov. am. 1, 9, 11-16.

393 Laufen durch die urbs: In Hor. sat. 2, 6, 50-53 laufen dem Sprecher dieser Satire verschiedene Menschen entgegen, die Neuigkeiten von ihm erhalten wollen. In Iuv. 6, 398-402 rennt eine Frau durch die Stadt, um an Gesprächen über die Tagespolitik teilzunehmen: Sed cantet potius 
Im Zeitkorsett sich täglich wiederholender Abläufe sind die Figuren in unterschiedlichen Geschwindigkeiten unterwegs. Das zeitige Aufstehen ${ }^{394}$ und das zügige Tempo einiger Figuren erklärt sich aus dem Gefühl, bei dem Alltagsgeschehen einem Konkurrenzdruck ausgesetzt zu sein.

\subsubsection{Qualitätssprung. Die große Stadt - Die Großstadt}

bic, ubi nunc urbs est, tum locus urbis erat.

Ov. fast. 2, 280

Dass Rom eine große Stadt sei, wird wiederholt in der Dichtung geäußert. ${ }^{395}$ Generell darf man die Attribuierung Roms mit magna jedoch nicht einfach als eine explizite Referenz auf deren räumliche Ausdehnung werten. Denn häufig bezeichnet dieses Attribut die ihr zugestandene Bedeutung für das römische Imperium und den Erdkreis.

So heißt es in dem zum Jahre 17 v. Chr. aufgeführten carmen saeculare des Dichters Horaz: alme Sol, curru nitido diem quil promis et celas aliusque et idem/ nasceris, possis nihil urbe Romal visere maius. ${ }^{396}$ Diese Verse wurden so interpretiert, dass hier dem Wunsch nach Größe im Sinne von Erhabenheit und Einzigartigkeit Roms in Raum und Zeit Ausdruck verliehen wird. ${ }^{397}$ Entsprechend einer derartigen Aussageintention ist nicht davon auszugehen, dass hier auf das besonders großflächige Siedlungsareal der Metropole hingewiesen werden soll. Auffällig an der hier gewählten Formulierung ist allerdings, dass die Größe Roms nicht gewusst, geahnt oder gefühlt, sondern dass dieser Qualitätssprung gesehen (visere) werden soll, also gemäß der Illusionsbildung für den Leser visuell aus der von Sol eingenommenen Vogelperspektive (birds-eye view) wahrnehmbar ist. ${ }^{398}$

quam totam pervolet urbem/ audax et coetus possit quae ferre virorum/ cumque paludatis ducibus praesente marito/ ipsa loqui recta facie siccisque mamillis./ haec eadem novit quid toto fiat in orbe (...). Mart. 4, 78, 16: Condita cum tibi sit iam sexagensima messis/ et facies multo splendeat alba pilo,/ discurris tota vagus urbe, nec ulla cathedra est/ cui non mane feras inrequietus, Have;// et sine te nulli fas est prodire tribuno, / nec caret officio consul uterque tuo/ (...).

394 Der frühe Aufbruch: Mart. 12, 29, 7-9: at mibi, quem cogis medios abrumpere somnos/ et matutinum ferre patique lutum./ quid petitur?; Iuv. 5, 19 f.: habet Trebius propter quod rumpere somnum/ debeat et ligulas dimittere. Vgl. dagegen Pers. 3, 1-4.

395 Vgl. Ov. trist. 1, 1, 59 f.: nec te, quod venias magnam peregrinus in urbem,/ ignotum populo posse venire puta. Ov. Pont. 4, 5, 20: et minui magnae non sinet urbis opes. Mart. 7, 96, 2: cui genus et nomen maxima Roma dedit.

396 Hor. carm. saec. 9-12.

397 Vgl. Cancik (1996), $109 \mathrm{f}$.

398 Vgl. auch Mart. 5, 19, 5: pulchrior et maior quo sub duce Martia Roma? Auch hier changiert das Attribut maior zwischen ,weit ausgedehnt' und ,erhaben'. Mart. 8, 55 (56), 1 f.: Temporibus nostris aetas cum cedat avorum/ creverit et maior cum duce Roma suo bezieht sich wohl auf die Vergrößerung des 
In der erste Ekloge Vergils versucht ein Hirte namens Tityrus die Unterschiede zwischen der urbs Roma und den ihm bekannten Landstädten mit einem Größenvergleich zu beschreiben.

Vrbem quam dicunt Romam, Meliboee, putaui

20

stultus ego buic nostrae similem, quo saepe solemus

pastores ouium teneros depellere fetus.

sic canibus catulos similis, sic matribus haedos

noram, sic paruis componere magna solebam.

uerum baec tantum alias inter caput extulit urbes

25

quantum lenta solent inter wiburna cupressi. ${ }^{399}$

Der erste Vergleichsgegenstand entstammt dem Bereich der Fauna. Diese Anlage des Vergleichs zwischen Jungtieren und ausgewachsenen Tieren hat sich jedoch laut Tityrus zur Veranschaulichung des Unterschieds zwischen der urbs Roma und einer urbs nostra als wenig geeignet erwiesen. Die urbs Roma ist keiner Stadt ähnlich, sie erhebt ihr caput 400 über andere Städte, wie eine schlanke Zypresse ihre Baumkrone über vor sich hin kriechende Wandelröschen. ${ }^{401}$ Der Hirte bringt mit diesem Vergleich zum Ausdruck, dass natürliche Maßstäbe eines Vergleiches zwischen Groß und Klein in Bezug auf die urbs Roma nicht funktionieren. Rom ist nicht nur eine größere Stadt als die Städte, die er als Bewohner einer ländlichen Welt, aber mit Kontakt zu nahen Landstädten, im Kopf hat (sic paruis componere magna solebam, v. 23). Diese urbs sprengt vielmehr die vorher bekannten Maßstäbe. Sie ist nicht nur eine andere größere Stadt, sondern von anderer Art. Es ist der Sprung von der Quantität in eine andere Qualität, die sich in der Bewunderung des Tityrus ausdrückt. ${ }^{402}$ Eine weitergehende Beschreibung dieser Stadterfahrung, die sich aus eigenem Erleben speist, ist innerhalb der eng gesetzten Gattungskonventionen der Bukolik nicht vorgesehen.

Selbstverständlich sind die hier kommunizierten räumlichen Vergleiche funktionalisiert. Wird die urbs Roma mit dem Vergleich aus dem Bereich der Flora nicht auf einer flächigen, sondern vertikalen Achse mit anderen Städten verglichen, geht es wohl nicht darum auszudrücken, dass Rom höher als andere Städte gebaut ist,

Imperium Romanum. Vgl. Schöffel (2002), 474. Mart. 7, 96, 2: cui genus et nomen maxima Roma dedit.

399 Verg. ecl. 1, 19-25.

400 Die Wortgruppe caput extollere ist anspielungsreich. In Beziehung zum ländlichen Schauplatz ist mit caput sicher, Wipfel' gemeint.

401 Vgl. Clausen (1994), 43.

402 Wenn er auch ein Mensch des Landes bleibt und dahin zurückgekehrt ist, hat er die Andersartigkeit dieser Großstadt nicht als beängstigende Verunsicherung der eigenen Welt erlebt, sondern durch einen Wissenszuwachs (stultus putavi) seine gewohnte Vorstellungen überwunden (solebam, / verum ...). 
sondern die Herausarbeitung der vertikalen Achse dient der Charakterisierung einer räumlichen Umgebung eines hierarchisch höherstehenden Gott-Herrschers, den der Hirte dort getroffen hat. 403

Ein naheliegender Kunstgriff, eine gegenwärtige enorme Ausdehnung einer Großstadt zu veranschaulichen, wäre ein Vergleich mit ihren einstigen Ausmaßen. Auch derartige Vergleiche finden sich vielfach in der Dichtung der augusteischen Literatur.

Mit einem Vergleich zwischen dem Schauplatz und einem zeitlich getrennten Fernraum (temporally distant frame), der das Areal in den Anfängen der Siedlung darstellt, beginnt die Elegie 4, 1 des Properz.

,hoc quodcumque uides, hospes, qua $[m]$ maxima Roma est,
ante Phrygem Aenean collis et herba fuit;
atque ubi Nauali stant sacra Palatia Phoebo,
Euandri profugae concubuere boues.
fictilibus creuere deis haec aurea templa,
nec fuit opprobrio facta sine arte casa;
Tarpeiusque pater nuda de rupe tonabat
et Tiberis nostris aduena bubus erat.
qua gradibus domus ista Remi se sustulit, olim

403 Die Frage nach dem Wesen des Gottes beantwortet Tityrus mit einem Verweis auf die Wirkungsstätte des Gottes. Vgl. Verg. ecl. 1, 18: sed tamen iste deus qui sit, da, Tityre, nobis. Die Formulierung in Verg. ecl. 1, 26: Et quae tanta fuit Romam tibi causa uidendi? setzt wiederum Gott und Stadt gleich, denn Tityrus berichtet über seine Vorhaben in der Stadt und schließt damit die abweichende' Beantwortung der Frage nach dem Gott. Vgl. Servius zu Vers 19: VRBEM QVAM DICVNT ROMAM quaeritur, cur de Caesare interrogatus, Romam describat. et aut simplicitate utitur rustica, ut ordinem narrationis plenum non teneat, sed per longas ambages ad interrogata descendat: aut certe quia nullus, qui continetur, est sine ea re, quae continet, nec potest ulla persona esse sine loco: unde necesse habuit interrogatus de Caesare locum describere, in quo eum viderat. Die Stadt Rom wird mit einseitig positiven semantischen Wertungen wie Freiheit (vgl. Verg. ecl. 1, 27), Gottgegenwärtigkeit (vgl. Verg. ecl. 1, 40 f.: licebat/ nec tam praesentis alibi cognoscere divos. und 42 f.) und Gnade (vgl. Verg. ecl. 1, 44 f.) in Zusammenhang gebracht. Hierin unterscheidet sich die Darstellung der Stadt Rom von anderen städtischen Siedlungen, die den Hirten jeweils bekannt sind: nicht nur in Größe und Bedeutung, sondern auch in der ihr entgegengebrachten Wertschätzung. Vgl. auch Coleman (1977), 77: solemus (20) (...) solebam (23) (...) solent (25) „emphasize by contrast the uniqueness of Rome.“ Dagegen Skoie (2006), 305. Ihr Ziel ist es, ausgehend von der Dichotomie Stadt-Land aufzuzeigen, dass die Stadt in den Eklogen keine simple Negativfolie zum Land ist. Damit trifft sie sicher einen wichtigen Punkt, differenziert aber $\mathrm{m}$. E. nicht ausreichend zwischen der besonders positiven Konnotation Roms und der anderer Städte. Skoie verallgemeinert ebenso, dass Städte sich durchaus in Sichtweite der Hirten befinden, es verbindende Wege gebe usw. Diese relative Entfernung trifft auf die nicht namentlich genannten Städte zu, in Bezug auf Rom aber wird gerade die lange Abwesenheit betont. Die Abwesenheit des Tityrus versetzt die Umgebung in Trauer, vgl. Verg. ecl. 1, 38 f.: ipsae te, Tityre, pinus,/ ipsi te fontes, ipsa haec arbusta nocabant. Zur Unvereinbarkeit der Gattung Bukolik und der Beschreibung der Stadt vgl. Calp. ecl. 7. 
10

15 unus erat fratrum maxima regna focus.

Curia, praetexto quae nunc nitet alta senatu, pellitos habuit, rustica corda, Patres.

bucina cogebat priscos ad nerba Quiritis:

centum illi in prato saepe senatus erat.

nec sinuosa cauo pendebant uela theatro,

pulpita sollemnis non oluere crocos. ${ }^{4} 404$

Mit einer expliziten Referenz bezeichnet der Sprecher in Properzens Elegie 4, 1 den vor ihm liegenden literarischen Raum als Roma und weist einen Fremden (hospes, v. 1) auf Veränderungen im Stadtbild hin. ${ }^{405}$ Rom ist im Auge des heutigen Betrachters, des Sprechers wie des hospes, eine besondere, eine besonders große Stadt. Vor der Ankunft des Aeneas, so erklärt der historisch Versierte, war hier vieles anders, sah man eine Landschaft aus Hügeln und Gras. Der gegenwärtige Anblick der Stadt verrät nichts mehr von den Anfängen der Siedlung: Auf die heutige Bebauung wird in den Bereichen des Palatin, des tarpejischen Felsens und des Forums verwiesen. Auf eine räumliche Vergrößerung wird - akzentuiert auch auf vertikaler Achse - im Zusammenhang mit dem Eigenort der Hütte des Romulus insistiert (gradibus domus ista ... se sustulit, olim/ unus erat ... maxima regna focus, v. 9 f.), wohl aber auch in Bezug auf eine Expansion des städtischen Areals (Tiberis ... aduena erat, v. 8).406

Neben dem flächigen Ausbau weist der Sprecher auf visuelle Veränderungen einzelner Bereiche hin: goldene Tempel statt tönerne Götterbilder, eine von den Togen strahlende Curie statt bäuerlicher Fellumhänge der Senatoren, Sonnensegel für das Theater. Ebenfalls weist er auf eine akustische als auch eine olfaktorische Veränderung hin: Das Horn ruft heutzutage nicht mehr zur Versammlung und die Bühne des Theaters riecht nach Safran.

404 Prop. 4, 1, 1-16.

405 Vgl. Rea (2007), 103-123, bes. 106-113. Stahl (1985), 255 nennt als Standort den Palatin: ,,placing him on the Palatine Hill, i.e., on the site of Augustus' residence - the viewpoint of Augustus in the most literal way - not far from the Temple of the Actian Apollo celebrated in 4.6." Vgl. dagegen Schmitzer (2001), 526: „Properz evoziert in der Tat auf den ersten Blick die Atmosphäre einer Fremdenführung, (...) aber daraus ergibt sich weder die Abfolge eines Rundgangs noch ein Standpunkt für den Panoramablick.“"

406 Diese Textpassage ist in ihrer Bedeutung umstritten, vgl. ausführlich dazu Hutchinson (2006), 63. Die neue Textausgabe von Heyworth (2007) emendiert: Tiberis nostris aduena murus erat. Hinsichtlich der Raumgestaltung fällt eher die Privilegierung einer vertikalen Achse auf. In der Gegenüberstellung von früher und jetzt, werden in dieser Passage der Gegenwart vorrangig räumlich aufstrebende Bewegungen (creuere, se sustulit) resp. höherliegende Bereiche zugeordnet. (Schilderungen der Gegenwart: v. 5: fictilibus crenere deis haec aurea templa; v. 9: qua gradibus domus ista Remi se sustulit olim; v. 11: Curia, praetexto quae nunc nitet alta senatu.; Vergleich Gegenwart und Vergangenheit: v. 3 f.: atque ubi Nauali stant sacra Palatia Phoebo,/ Euandri profugae concubuere boues.; Vergangenheit: v. 7: Tarpeiusque pater nuda de rupe tonabat. 
In der aparten Kombination visueller, akustischer und olfaktorischer Sinnlichkeit wird dem Fremden der Schauplatz Großstadt als Ort des Neuen anhand der Veränderung typischer römischer „Erinnerungsorte“407 vor Augen geführt. Durch den Kontrast mit einer Vergangenheit - aus der im visuellen Gedächtnis vor allem Rinder, Gras, Hügel und bescheidene Bauten verankert sind - gewinnt in dieser Elegie der moderne Mythos der urbs Roma an ästhetischer Strahlkraft: Durch die vergleichende Aufzählung verschiedener Teilelemente entsteht der Eindruck einer nun geordneten Bebauung. Verleihen diese zahlreichen Tempel und vor allem die Theater dem Raum auch einen städtischen Charakter, so ist in dieser Elegie die Gestaltung der urbs Roma als eine sakrale Landschaft vorherrschend. ${ }^{408}$

In Fall der Elegie 4, 1 handelt es sich um einen für seine Gegenwart begeisterten Betrachter, ${ }^{409}$ der die Erinnerung an eine Vergangenheit als Kontrast für die enormen Errungenschaften der Gegenwart nutzt. Herausgestellt wird vor allem die visuelle Veränderung der Großstadt, ihr Ausbau, Umbau und Glanz. Diese Affirmation des Modernisierungsprozesses und der Zugewinn für die Wahrnehmungssensibilität werden aber nicht in einem Vergleich mit einer jüngeren Vergangenheit präsentiert, sondern mit dem zeitlich zur Gegenwart wohl am weitesten getrennten Fernraum (temporally distant frame), dem schlichten Gelände in seinen ländlich-bukolischen Anfängen. Einen geeigneten Vergleichspunkt, um eine besondere Ausdehnung einer Siedlung zu veranschaulichen, bietet dieser Zeitpunkt der räumlichen Kontrastierung daher kaum. ${ }^{410}$

In der Elegie Tibulls 2, 5 stellt der Sprecher ebenfalls in einer Retrospektive die ursprüngliche arkadische Umgebung des Siedlungsgebietes vor. ${ }^{411}$ Diese arkadi-

407 Vgl. zu stadtrömischen „Erinnerungsorten“ ausführlich Edwards (1996), 41 f. Die Bedeutung für die römische Identität unterstreicht auch Welch (2005), 23, zur Identifizierung der Merkzeichen in der stadtrömischen Topographie vgl. ebd., 169. Zur Rezeption dieser memorialen Wahrnehmung in der Neuzeit vgl. Vout (2007), 304 f. Zum Begriff Erinnerungsorte vgl. Nünning (42008), 385.

408 Vgl. Hutchinson (2006), 64: „dominating theme of religion“.

409 Im ersten Teil fehlen gegenwartskritische Betrachtungen oder Themen des Niedergangs. Rea (2007), 106-109 legt Anspielungen auf eine gewaltsame Vergangenheit in dieser und der folgenden (Prop. 4, 1, 11-38; dazu ebd., 111-113) Passage offen, deutet dies als eine Darstellung einer bis in die Gegenwart des Properz reichenden Kontinuität. Vgl. auch Glaser (2005). Zur Mehrstimmigkeit in der Elegie 4, 1 - besonders durch die später eingeführte Figur des Horos - vgl. Welch (2005), 19-34.

410 Vgl. dagegen Stahl (1985), 255: „(...) the huge contemporary city (maxima Roma) (...).“ Das Attribut maxima wird aber in relativ kurzem Abstand sowohl der Roma (v. 1) als auch den regna des Romulus (v. 10) zugeschrieben.

411 Vgl. Tib. 2, 5, 23-34. Folgende räumliche Gegebenheiten werden selektiert: Romulus aeternae nondum firmaverat urbis/ Moenia, (...),/ Sed tunc pascebant berbosa Palatia vaccae/ Et stabant bumiles in Iovis arce casae./ (...) illic suberat Pan ilicis umbrae/(...) / Pendebatque (...) in arbore (...)/ (...) fistula (...)/ At qua Velabri regio patet, ire solebat/ (...) per vada linter aqua. Außer den moenia urbis tauchen keine städtischen Teilelemente in dieser Passage auf. Allein die beiden Eigennamen verweisen 
sche Umgebung wird zum zeitweiligen Schauplatz der Elegie. In der Prophezeiung einer Seherin wird von diesem Schauplatz aus auf die ausnehmende Größe der künftigen Siedlung hingewiesen:

Auf dem Weideland, den sieben Hügeln, und damit dem Nahrungslieferant der Tiere wird der Prophezeiung zufolge nicht nur die künftige Siedlung einer urbs entstehen, sondern einer magna urbs, einer besonders großen Stadt. ${ }^{413}$ Diese enorme Entwicklung wird nicht in Form eines zeitlichen Rückgriffs dargestellt, sondern in Form einer prophetischen Vorhersage, die sich an eine indigene Tierwelt, nämlich Rinder in bukolisch-bäuerlicher Umgebung, richtet. ${ }^{414}$ Die große urbs Roma ist erst eine künftige Siedlung, ein noch nicht bestehender Raum (non-factual frame). Das Siedlungsareal wird sich auf einem Gebiet von sieben Hügeln erstrecken. ${ }^{415}$ Die Größe, die die spätere Großstadt erhalten soll, zeichnet sich in dieser Elegie aber in erster Linie durch eine göttliche Vorsehung aus und - wie der Fortgang der Elegie hervorhebt - durch ihre Bedeutung als Herrscherin über eine urbar gemachte Welt. ${ }^{416}$ Die Größe der literarischen urbs Roma bezieht sich demzufolge ebenfalls nicht eindeutig auf eine konkrete räumliche Ausdehnung einer städtischen Siedlung, sondern auf ihre Bedeutung als Hauptstadt eines gewaltigen Reiches.

auf größere Bereiche innerhalb des städtischen Areals der urbs Roma. Der Vergleich einer Gegenwart im Kontrast zu einer weit zurückliegenden vorwiegend bukolisch gestalteten Vergangenheit findet sich gelegentlich in der augusteischen Dichtung. Vgl. Ov. fast. 6, 395-416.

412 Tib. 2, 5, $55 \mathrm{f}$.

413 Vgl. Murgatroyd (1994), 202: „Magnae here encompass any or all of the following: ,large in size', ,of importance/consequence', ,famous', ,powerful', ,splendid', ,outstanding', and ,proud'. “

414 Die Apostrophe an Rinder, in der sie zudem dazu angetrieben werden, den ihnen verbleibenden Zeitraum noch zum Weiden zu nutzen (dum licet, v. 56.), wirken im Hinblick auf die anvisierte Zeitspanne übertrieben und sind womöglich als ein Indiz für Ironie zu werten.

415 In der Elegie überwiegt die Schilderung des Siedlungsplatzes von Rom, bevor Aeneas dorthin kam. Vgl. Tib. 2, 5, 23-38. Motivisch verwandt sind Prop. 4, 1 und Tib. 2, 5, 1-18 mit Verg. Aen. 8, 306-368. Zu Vergil, Properz vgl. Weeber (1978), Edwards (1996), 31-43 und Rea (2007), 105 f.; zu Tibull und Vergil vgl. Rea (2007), 85-102; zu Vergil und Ov. trist. 3, 1 vgl. Edwards (1996), 120. In der Tat teilen sie Referenzen auf wichtige Merk- und Wahrzeichen auf die urbs Roma. Es fehlt bei Tibull und Properz jedoch jeglicher Hinweis auf eine Bewegung durch das Gelände, weswegen Begriffe wie Stadtführung oder tour für diese Beispiele unzutreffend sind. Vgl. Amann (2006), 134: ,poetischer Stadtrundgang“; Rea (2007), 105: ,, a visitor to Rome is given a monumental tour of the city“. Vgl. aber auch Ov. fast. 5, 93 f.: hic, ubi nunc Roma est, orbis caput, arbor et herbae/ et paucae pecudes et casa rara fuit, der im Zusammenhang mit den Unterschieden einer Gegenwart und Vergangenheit das gegenwärtige Rom in seiner Bedeutung hervorhebt.

416 Vgl. Tib. 2, 5, 57 f.: Roma, tuum nomen terris fatale regendis, / Qua sua de caelo prospicit arva Ceres, (...). 
Für die Ausgestaltung einer räumlichen Ausdehnung der literarischen urbs Roma erweisen sich die Passagen, in denen eine maxima urbs mit zeitlichen oder räumlichen Kontrasträumen verglichen wird, bemerkenswerter Weise gerade als wenig aussagekräftig. Die hier explizite lexikalische Dimensionierung einer Größe Roms wie auch die ihrer Bauwerke beschreibt nicht die Physis eines konkreten Raumes, sondern gehört in ein elaboriertes symbolisches Netzwerk, mit dem auf Strukturen einer gesellschaftlichen Ordnung für die Stadt oder das Imperium verwiesen wird. 417

\subsubsection{Auswertung}

Die Relevanz der Ausdehnung als ein räumliches Merkmal der literarischen urbs Roma zeigt sich in ihrer Ausgestaltung in der augusteischen und kaiserzeitlichen Dichtung. So bestimmt diese räumliche Eigenschaft das Leben seiner literarischen Bewohner erheblich. Distanzen zu überwinden ist eine Erfahrung, über die häufig in der Dichtung reflektiert wird. Die literarische Figuren teilen diese Erfahrung miteinander und bewerten sie ähnlich: sie empfinden es als eine körperliche Strapaze und unterscheiden zwischen zumutbaren und unzumutbaren Entfernungen. Über weite Distanzen hinweg enge soziale Kontakte zu pflegen, wird jedoch auch als eine Selbstverständlichkeit beschrieben. Das Hinnehmen von langen Wegstrecken gehört zu einer Alltagserfahrung der literarischen Figuren. Wie stark das In-Bewegung-Sein typischerweise mit der urbs Roma verbunden ist, zeigt sich im Vergleich mit dem Kontrastraum rus. Die allgemeine Mobilität ist ein Kennzeichen des literarischen Makroraums urbs Roma.

In der Raumforschung der Moderne hat man das emanzipatorische Moment an der eigenständigen Bewegung herausgestellt. ${ }^{418}$ In der augusteischen und kaiserzeitlichen Dichtung scheint sich eine Emanzipation jedoch gerade in der Segregation in Räume außerhalb der Stadt und in räumlicher Grenzziehung auszudrücken. Als privilegiert oder auch eskapistisch werden des Weiteren diejenigen Figuren eingestuft, die sich langsam bewegen, in einer Bewegungslosigkeit verharren oder sich der Mobilität anderweitig entziehen. Die besondere Ausdehnung der Stadt stellt in der literarischen Fiktion somit keinen Frei- oder Emanzipationsraum dar. Im Gegenteil: Die eigene Mobilität wird von den Figuren gerade nicht als ein Zeichen von persönlicher Unabhängigkeit gewertet.

Ein Grund dafür liegt darin, dass die Bewegungsanlässe in der Regel ziel- und zweckgebunden sind. Die Figuren fühlen sich dazu angehalten, innerhalb eines Tages eine Wegstrecke in einer z. T. festgelegten Reihenfolge von Wirkungsfeldern zurückzulegen. Aufgrund dieser Vorgaben entsteht ein Zeitkorsett, welches

417 Vgl. Döpp (2003), Purcell (21996), 785 f.; Purcell (22000), 405 f., 410 f. Zu Strategien, um die Einzigartigkeit Roms herauszustreichen, vgl. Edwards (1996), 96-101, bes. als Surrogat des Imperiums (Bevölkerung, Baumaterial, Lebensmittel) 99-100.

418 Vgl. Würzbach (2001), 121. 
die Figuren zur Eile treibt und ihnen auch eine erhöhte Geschwindigkeit aufzwingt. Es ist womöglich der einzige Raum in der römischen Dichtung, in dem so viele Figuren unter dem Eindruck stehen, zu spät kommen zu können.

Zum exemplarischen Städter, in dessen Lebenszusammenhang das räumliche Merkmal der Ausdehnung und die sich daraus ergebene unablässige Bewegung unmittelbar hineinspielt, wird der Klient. ${ }^{419}$ In der überwiegenden Zahl stehen die täglichen Bewegungsanlässe im Zusammenhang mit den officia, die ein Klient seinem Patron gegenüber abzuleisten hat. Es kommt damit auch zu einer einseitigen Selektion bestimmter städtischer Bereiche, die als „Stätten öffentlichen Lebens $^{\text {" } 420}$, d. h. Stätten des Klientendienstes, klassifizierbar sind. Die sich in vielen Dichtungen wiederholende innere Struktur des literarischen Raums urbs Roma ist dieser sozialen Perspektive geschuldet.

Sind soziale Verpflichtungen zwar häufige Bewegungsanlässe, wird der Makroraum nicht in erster Linie als ein sozialer Raum präsentiert. Auffälliger Weise werden die Interaktionen oder Tätigkeiten an den einzelnen Bereichen z. T. nur sehr reduziert wiedergeben. Stattdessen wird die Mobilität selbst zu einem körperlichsinnlichen Erlebnis ausgestaltet. Der Bewegungsbereich tritt als offener und öffentlicher Raum in den Vordergrund der Präsentation, der die Figuren mit Unwägbarkeiten, wie wechselnden Wetter- und Lichtverhältnissen, oder mit anderen Figuren, die ebenfalls in Bewegung sind, konfrontiert.

Darüber hinaus gerät die räumliche Ausdehnung zu einer subjektiven, vom Körper ausgehenden, sinnlichen Erfahrung, die am eigenen Körper erlebt oder an Anderen beobachtet wird. Aufgrund der ständigen Bewegung zeigen die Figuren nach dieser längeren Anstrengung körperliche Reaktionen wie Schwitzen und Erschöpfung, die als allgemeines Kennzeichen der Stadtbewohner kommuniziert werden. ${ }^{421}$

Mit diesem Fokus auf die Distanzen, die Mobilität seiner Bewohner und das körperliche Erlebnis wird der Raum in besonderer Weise als ein ausgedehntes Areal gestaltet. Diese Wechselbeziehung zwischen räumlicher Ausdehnung und notwendiger Mobilität reiht die literarische urbs Roma in die Gruppe der Makroräume

419 Die Figur des Klienten wird zum exemplarischen Städter wie die Figur des Hirten zum exemplarischen Bewohner der unbebauten Natur wird. Selbstverständlich finden sich in allen literarischen Räumen auch weitere Figuren.

420 Schöffel (2001), 383.

421 Körperliche Erschöpfung aufgrund der Bewegung: Vgl. Mart. 3, 36, 5 f.: lassus ut in thermas decuma vel serius horal te sequar Agrippae; Mart. 4, 88, 4: sexta [hora, Anm.d. Verf.] quies lassis; Mart. 10, 56, 8: qui sanet ruptos dic mibi, Galle, quis est?; 10, 82, 7: parce, precor, fesso vanosque remitte labores; Mart. 12, 29(26), 3 f.: quod non a prima discurram luce per urbem/ et referam lassus basia mille domum.; Stat. silv. 4, 8, 55: fessam (...) crebrisque laboribus urbem. Iuv. 1, 132: vestibulis abeunt veteres lassique clientes. Mart. 1, 55, 14: vivat et urbanis albus in officiis; Mart. 10, 12, 9-12: et venies albis non adgnoscendus amicis/ livebitque tuis pallida turba genis./ sed via quem dederit rapiet cito Roma colorem, / Niliaco redeas th licet ore niger. Mart. 12, 68; Mart. 10, 74, 1-6, 12. Aufschlussreich wäre ein Vergleich mit der Figur des servus currens aus der römischen Komödie, vgl. Fraenkel (1972), 123-127. 
ein. Das bedeutet: Diese literarischen Texte teilen trotz ihrer Kürze die Präsentation einer räumlichen Struktur mit denjenigen Dichtungen, die ebenfalls große Räume darstellen, wie Itinerarien oder Seefahrer-Epen. ${ }^{422}$ Im Gegensatz zu ihnen greifen die Figuren allerdings nicht auf Beförderungsmittel zurück, sondern sie durchschreiten den Makroraum zu Fuß. Ihre Erlebnisse werden des Weiteren nicht als einmalige Ereignisse in, an oder bei räumlichen Gegebenheiten präsentiert, sondern es wird vorgegeben, ein Alltagsgeschehen widerzuspiegeln. Zudem gilt die Aufmerksamkeit der Bewegung zwischen den Bereichen, also dem Mobilitätsverhalten der Figuren.

Es ist durchaus bemerkenswert, dass das Durchqueren des Raumes für die Darstellung eines alltäglichen Geschehens gewählt wurde, da doch das Beieinanderliegen der Bereiche, in denen eine Figur agiert, für die Darstellung eines Alltags naheliegender gewesen wäre. Es wäre doch denkbar gewesen, eine einzelne Straße oder zwei nachbarschaftliche Häuser als räumliche Exemplare städtischen Wohnens herauszugreifen, wie es z. B. in der römischen Komödie geschieht. Gerade die gewählte Darstellungsform weist somit den literarischen Raum urbs Roma deutlich als einen Makroraum aus.

Der Raum wird von innen heraus in seiner flächigen Ausdehnung gestaltet, in den Bewegungen der Figuren und in den von ihnen zurückzulegenden Entfernungen. Bisweilen nach metrisch genauen, in der Regel jedoch nach subjektiven Entfernungsmaßstäben und unter Vernachlässigung genauer Winkelangaben wird ein Weg durch den literarischen Raum gebahnt, wird der Makroraum von ihnen durchschritten. Die Darstellungsweise betont, dass der literarische Raum von seiner inneren Struktur her aus sehr disparaten Bereichen besteht, die durch die Bewegung der Figuren zu einem räumlichen Kontinuum verbunden werden. Bisweilen entstehen durch die Bewegungen auch Wegestrukturen wie Rund- bzw. Hin- und Rückwege. An die Grenzen des Raumes stoßen die Figuren aber dabei nie. Die eigentliche Ausdehnung des literarischen Raumes urbs Roma geht über die individuelle Bewegung stets hinaus.

422 Vgl. Hor. sat. 1, 1, 29-35: perfidus bic caupo, miles nautaeque, per omne/ audaces mare qui currunt, hac mente laborem/ sese ferre, senes ut in otia tuta recedant, / aiunt, cum sibi sint congesta cibaria: sicut/ parvola nam exemplo est - magni formica laboris/ ore trabit quodcumque potest atque addit acervo/ quem struit, hand ignara ac non incauta futuri und Hor. epist. 1, 1, 45 f.: inpiger extremos curris mercator ad Indos, / per mare pauperiem fugiens, per saxa, per ignes: (...). 


\subsection{Formen der Begrenzung und des Übergangs. Räumliche Vereinnahmungen einer literarischen Großstadt}

Wo endet der literarische Raum urbs Roma? Wie sind seine Grenzen gestaltet? Trotz der körperlich-sinnlichen Erfahrung enormer Entfernungen innerhalb des literarischen Raums werden seine Grenzen nicht erreicht. Wenn nicht in einer aktiv-explorativen Bewegung, so werden sie womöglich in einer passiv-rezeptiven Gesamtschau von einem festen Standort aus festgehalten (3.4.1). Nach antiker Vorstellung haben Städte klare Grenzen, die sich architektonisch sichtbar als Mauern oder Grenzsteine konstituieren. ${ }^{423}$ Aber auch natürliche Schranken wie Flussufer, Berge oder Wege können als Umrisslinien und Unterbrechung eines räumlichen Zusammenhangs bewertet werden. Durch solche architektonischen oder natürlichen Manifestationen wird eine Begrenzung definiert, Unterschiede in den räumlichen Merkmalen zwischen Innen und Außen werden dort bestimmbar. Im folgenden Abschnitt sollen Textpassagen vorgestellt werden, in denen Grenzbereiche der literarischen urbs Roma in den Blick genommen werden. Gibt es eine klar markierte Grenze (3.4.2), an der die Großstadt endet, oder läuft sie in Zonen des Übergangs aus (3.4.3)? Außen und Innen wären dann in Form eines breiteren Saumes aneinandergefügt. ${ }^{424} \mathrm{Je}$ nach Gestaltung dieser Übergangszonen grenzt sich ein Raum markant oder diffus von einem anderen ab und seine Grenzen gelten als mehr oder weniger überwindbar (3.4.4).

\subsubsection{Aussichtspunkte. Panoramablick auf den Großstadtraum}

Die Stadt, insbesondere die Großstadt, gilt nach neuzeitlichem Verständnis als eine Siedlungsform, die sich nicht zuletzt aufgrund ihrer besonderen Ausdehnung der visuellen Gesamtansicht eines Einzelnen aus dem Inneren heraus entzieht. In den Anfängen moderner literarischer Großstadtwahrnehmungen griff man daher auf einen Kunstgriff zurück: Der fiktive Betrachter stand auf einem erhöhten Aussichtspunkt, einem Turm, einer Anhöhe, oder schaute aus einem Dachfenster heraus, von wo er sich einen Überblick über die Ausdehnung des Gebiets und seiner Grenzen verschaffen konnte. ${ }^{425}$

Diese Form des Panoramablicks ist zwar für die Stadt Rom in der Vedutenmalerei der Renaissance oder als wichtige Kulturtechnik des modernen Tourismus etabliert ${ }^{426}$, in römischer Dichtung findet sich aber diese Perspektive eines einzelnen

423 Vgl. Hans Jörg Nissen, s.v. Städtebau, in: DNP (2001), Bd. 11, 903.

424 Vgl. dazu Lynch (1975), 61.

425 Vgl. Corbineau-Hoffmann (2003), 13-32, bes. 13 f. und 40; Daemmrich (1987), 297.

426 Vout bespricht in ihrem Beitrag „Sizing up Rome“, in: Larmour/Spencer (2007), 295-322, schriftliche Zeugnisse und bildliche Artefakte, die von der Antike bis in die Moderne hinein die Perspektive des Panoramablicks auf Rom von einem Berg aus wählen, um damit den Ort und 
Betrachters vergleichsweise selten. Dies ist insofern überraschend, als die Darstellungstechnik, ein größeres Gebiet von einer Erhebung aus zu überschauen, sich bereits in den homerischen Epen nachweisen lässt ${ }^{427}$ und beispielsweise im ersten Buch des vergilischen Epos auch die Stadt Karthago von einem Hügel aus betrachtet wird. ${ }^{428}$ Im Buch 8 desselben Werkes wird gegen Ende des berühmten Spazierganges das arkadische Gelände des künftigen Roms, das Forum Romanum, auch von oben - oder genauer - während des Aufstiegs auf den Palatin kurz in den Blick genommen. ${ }^{429}$ In panegyrischen oder mythologisch-religiösen Zusammenhängen findet sich ebenfalls eine von oben eingenommene Perspektive: ${ }^{430}$ In Ovids Elegie trist. 1, 5 schaut die urbs Roma - die als domus des Sprechers bezeichnet wird - selbst von allen (!) ihren sieben Hügeln gleichzeitig herab. Dabei überschaut sie aber nicht die sich zu ihren Füßen ausbreitende Siedlung, also sich selbst, sondern die sich ringsum ausgebreitete gesamte Welt. ${ }^{431}$

Das Fehlen einer derartigen Darstellung für eine literarische urbs Roma wird umso erstaunlicher, als des Häufigeren auch die Hügel der urbs Roma als markantes Merkzeichen erwähnt werden und davon berichtet wird, dass der jeweilige Sprecher oder andere Figuren unterwegs zu einem dieser Hügel sind und diesen besteigen. ${ }^{432}$ Diese Figuren schauen jedoch nie von dort herab. ${ }^{433}$

dessen Sehenswürdigkeiten zu vermitteln, pointiert ebd., 321: „Rome has a heritage of being viewed from her hills.“ In Anm. * (ebd., 295) kündigt sie ein neues Projekt zum Thema „Rome and her hills" an. Ihren Beitrag versteht sie als eine erste Sondierung des Forschungsfeldes.

427 Vgl. Abschnitt 2.2.3.3, Fn. 197.

428 Erst nachdem sich Aeneas und Achates einen Überblick über Karthago verschafft haben, begeben sie sich mitten in die Stadt. Vgl. Verg. Aen. 1, 419-440, bes. 419 f. und 440: iamque ascendebant collem, qui plurimus urbil imminet aduersasque aspectat desuper arces. (...) per medios, miscetque viris neque cernitur ulli.

429 Verg. Aen. 8, 359-36: talibus inter se dictis ad tecta subibant/ pauperis Euandri, passimque armenta uidebant/Romanoque foro et lautis mugire Carinis. Bemerkenswert ist dabei die Formulierung videbant (...) mugire, die visuelle und akustische Wahrnehmung verknüpft.

430 Vgl. Hor. carm. saec. 9-12 (Sol); Lucan. 1, 195-198 (Jupiter); Rut. Nam. 197 f.; Claud. 28, 529-31.

431 Vgl. Ov. trist. 1, 5, 67; 69 f.: nec mibi Dulichium domus est Ithaceve Samosve, (...)/ sed quae de septem totum circumspicit orbem/ montibus, inperii Roma deumque locus. Vgl. auch Ov. trist. 3, 7, 51 f. Die visuell vermittelte räumliche Konstellation unterscheidet zwei Bereiche auf einer vertikalen Achse: zum einen die personifizierte Roma (oben) und zum anderen der Erdkreis (unten). Mithilfe dieser räumlichen Konstellation und der dadurch ermöglichten Perspektive wird die politische wie religiöse Strahlkraft der Heimatstadt des Sprechers für das Imperium Romanum symbolisiert. Die räumliche Konstellation dient dem Hinweis auf ihre Bedeutung. Vgl. Luck (1977), 57: „Der Gedanke, dass Rom (...) die ganze Welt überschaut, ist bezeichnend für das Lebensgefühl augusteischer Zeit." Die Personifizierung Roms erweist sich allerdings für eine räumliche Vorstellung der Ausdehnung als ungeeignet, wenn der Erdkreis zu einem eher überschaubaren Gebiet zusammenschrumpft. Vgl. weiter Ov. fast. 1, 85 f., Prop. 3, 11, 57, auch pointiert Claud. 28, 40 f.: nulloque magis se colle potestas/ aestimat. Gemeint ist der Palatin. Generell auch Edwards/Woolf (2003), 3 mit weiterführender Literatur.

432 Hor. epist. 2, 2, 68 f.; Ov. trist. 1, 1, 69 f.: forsitan expectes, an in alta Palatia missum/ scandere te iubeam Caesareamque domum; Ov. Pont. 2, 1, 57 f.: te quoque victorem Tarpeias scandere in arces/ laeta coronatis 
In der Verwirklichung einer derartigen Perspektive stellt somit das Epigramm 4, 64 Martials ein Ausnahmezeugnis dar. Dieses Epigramm ist in erster Linie die Beschreibung der besonderen Lage eines Gebäudes, einer domus (v. 25), auf dem Ianiculus (longo Ianiculi iugo recumbunt, v. 3). Dieser Standort wird in den ersten zehn Versen ausgiebig gelobt. Die wiederholte Akzentuierung der räumlichen Vertikalen ${ }^{434}$ und der zusätzliche Einsatz des Kontrastpaares klar-dunstig ${ }^{435}$ tragen dazu

Roma videbit equis; Mart. 4, 78, 7: et sacro decies repetis Palatia clivo; Mart. 10, 56, 2: et per Aventinum ter quater ire tuum.; Iuv. 5, 78 f. Vout bezeichnet Rom als „, the city of hills' par excellence“, 297. Selten findet sich, dass Figuren von den oberen Rängen des Theaters herabschauen. Vgl. Calp. ecl. 7.: Der Hirte Korydon vergleicht den Blick von den oberen Rängen zunächst mit dem Blick auf ein Tal. Vgl. Calp. ecl. 7, 30-34: qualiter haec patulum concedit vallis in orbem/ et sinuata latus resupinis undique silvis/ inter continuos curvatur concava montes, / sic ibi planitiem curvae sinus ambit harenae/ et geminis medium se molibus alligat ovum. Auf die Frage des Gesprächspartners Lykotas, ob er auch den Kaiser (venerandum numen, Calp. ecl. 7, 76) während der Festspiele gesehen habe, antwortet der Hirte mit Verweis auf seinen Sitzplatz in den oberen Rängen. Vgl. Calp. ecl. 7, 82-84: utcumque tamen conspeximus ipsum/ longius; ac, nisi me visus decepit, in uno/ et Martis vultus et Apollinis esse putatur. Vgl. dagegen Ov. am. 2, 7 den Blick im Theater von unten nach oben.

Mart. 1, 108, 3 erwähnt den Blick auf Lorbeerbäume, nicht aber auf eine bauliche Anlage, ebenso Mart. 7, 73, 4. In Mart. 3, 58, 45 f. wird ein Turm in der Peripherie Roms erwähnt, von dem der im Gedicht angesprochene Bassus auf Lorbeerbäume hinuntersieht: At tu sub urbe possides famem mundam/ et turre ab alta prospicis meras laurus.

$433 \mathrm{Ob}$ die fehlende, aber so naheliegende Realisierung eines Blickes von oben auf die Stadt einer kulturellen Konvention unterliegt, etwa dass diese Blickinszenierung nur göttlichen oder gottgleichen Geschöpfen zugestanden wird oder im Sinne eines Feldherrnblicks als beherrschende, unterwerfende Blickinszenierung verstanden wurde, könnte nur eine Studie verdeutlichen, die die Anwendung dieser Darstellungstechnik in der römischen Literatur vergleichend auswertet. Vout (2007), 321 resümiert ihre diachrone Untersuchung: „At that moment, the visitor becomes king or pretends (s)he ,plays god', captures the city's complexity in a single frame or portrait.“ Vgl. George (1974), 127: „The picture of generals viewing the terrain from a vantage point is conventional in historiography and epic, and doubtless too in real life." Vgl. Sil. 12, 567-573: Hannibal betrachtet von einem erhöhten Standpunkt (celsis adstans in collibus, v. 567) die Stadt. Diese Betrachtung wird bereits als Eindringen gedeutet. Vgl. intrat/ urbem oculis discitque locos, v. $567 \mathrm{f}$. und ac legeret uisu cuncta et penetraret in omnes/ spectando partes, v. $569 \mathrm{f}$. und spectata ductor satiatus pectora Roma, v. 573. Bei Lucan. 3, 87-98 betrachtet Caesar Rom von oben und spricht zu den Mauern. Über seinen Standpunkt heißt es: excelsa de rupe procul iam conspicit urbem/Arctoi toto non visam tempore belli/ miratusque suae sic fatur moenia Romae (Lucan. 3, 88-90). Vgl. dazu Hunink (1992), 72: „We get an image of Caesar ante portas, the victorious general approaching a town he intends to conquer." Vgl. auch Petron. 122, 155-155. Allerdings müsste diese Blickinszenierung als visuelle Inbesitznahme um die Blickinszenierung der Götter oder von gottgleichen Geschöpfen erweitert werden. Diese geht bis in die homerischen Epen zurück, vgl. Hellwig (1964), 26-28, 88-92. In lateinischer Dichtung z. B. Verg. Aen. 11, 836-840.

434 Vgl. Neumeister (1991), 216, der darauf hinweist, dass die Verwendung recumbere nicht ohne Absicht an „das Sich-Hinlagern eines Zechers beim convivium“ erinnern soll und „eine Atmosphäre entspannten Genießens (...) angedeutet werden“ soll. Räumlich verglichen ergäbe sich aus diesem Bild m. E., dass die domus aus ihrer Umgebung herausgehoben wird, dass nämlich die sich auf einem Berg lagernde domus über den Boden erhoben bleibt wie auch ein sich auf einer Kline lagernder Gast. Zur Gestaltung von Ausblicken in römischen Landhäusern (auch vom Triclinium aus) und zum Kult des schönen Ausblicks in römischer Villenarchitektur vgl. Schneider (1995), 76-85. Vgl. Mart. 10, 51, 8-10 über den Ausblick von einer Kline in einer Villa in Anxur: 
bei, das Gebäudes und die unmittelbare Nachbarschaft seiner weiteren Umgebung räumlich und visuell zu entheben.

Im Vers 11 (binc) ${ }^{436}$ wechselt der Sprecher jedoch seine Perspektive und kontrastiert damit indirekt den geringen Umfang des Grundstücks (pauca ingera, v. 1 und v. 36) mit einer gewaltigen Aussicht, die sich von dort aus dem Betrachter bietet. Das Grundstück wird zum Standort, von wo aus er einen Wahrnehmungsbereich, seine Aussicht, beschreibt:

Hinc septem dominos videre montis

et totam licet aestimare Romam,

Albanos quoque Tusculosque colles

et quodcumque iacet sub urbe frigus,

15 Fidenas veteres brevesque Rubras,

et quod virgineo cruore gaudet

Annae pomiferum nemus Perennae.

Illinc Flaminiae Salariaeque

gestator patet essedo tacente,

20 ne blando rota sit molesta somno,

quem nec rumpere nauticum celeuma

nec clamor valet helciariorum,

cum sit tam prope Mulvius sacrumque

lapsae per Tiberim volent carinae. ${ }^{437}$

Die Aussicht (videre, v. 11) von diesem Standort ist enorm: Der Sprecher gibt an, von dort Rom als Ganzes in seiner Ausdehnung abschätzen zu können (totam ... aestimare Romam, v. 12) ${ }^{438}$ und hebt aus dem innerstädtischen Bereich summarisch

[O] (...) aequoreis splendidus Anxur aquis, / et non unius spectator lectulus undae, / qui videt binc puppes fluminis, inde maris! oder Ov. met. 8, 574.

435 Vgl. zum Kontrast klar-dunstig, Mart. 4, 64, 5-10: et planus modico tumore vertex/ caelo perfruitur sereniore/ et curvas nebula tegente valles/ solus luce nitet peculiari:/ puris leniter admoventur astris/ celsae culmina delicata villae. Neumeister (1991), 218 deutet den Kontrast zwischen Hügel und Tal als Entgegensetzung von Tag und Nacht. Ich meine, es handelt sich eher um einen Vergleich, der darauf abzielt, die beiden Bereiche in ihren Sphären sowohl tags als auch nachts zu trennen.

436 Vgl. Moreno Soldevila (2006), 439: „The adverb introduces a change of perspective: lines 11-17 offer a panoramic view." Vgl. Maselli (1995), 53. Gegen die Übersetzung von binc bei Barié (1999), 301 als ,von der einen Seite.

437 Mart. 4, 64, 11-24.

438 Vgl. Moreno Soldevila (2006), 440: „the literal meaning [von aestimare, Anm. d. Verf.] is to measure extension, and visually ,to take in ' (...) from this retreat (...) one can love and enjoy the Urbs." Vgl. auch Neumeister (1991), 215. Er erklärt dazu ebd., 218: „Auffällig ist der Wechsel des Verbs [gemeint ist von videre zu aestimare, Anm.d. Verf.]; auch, daß in diesem Zusammenhang, aestimare gebraucht wird. Das Verb hat die Grundbedeutung ,den Wert von etwas abschätzen`. Das scheint mir eine ganz bestimmte Interpretation nahezulegen: Erst von dieser erhöhten Warte dieses Landhauses aus und aus der Distanz, die es (physisch und psychisch) zum Betrieb der 
die sieben Hügel als beherrschende Merkzeichen (dominos, v. 11) heraus. ${ }^{439}$ Mehr über die innere Struktur der Großstadt erfährt der Leser nicht. Als weitere Merkzeichen werden andere Hügel (colles, v. 13), zwei Siedlungen und ein Hain selektiert, deren Lage über ihre topographischen Bezeichnungen, aber vor allem durch die summarische Positionierung sub urbe (v. 14) bereits als Peripherie bzw. außerstädtischer Bereich gekennzeichnet wird. Ebenso gehören zwei Straßen, der Tiber und die Mulvische Brücke in diese Landschaft. Dass diese ebenfalls zum außerstädtischen resp. peripheren Bereich der Stadt gerechnet werden, wird durch die typischen Handlungen der Reise auf dem Wagen und auf dem Schiff akzentuiert. Aufgrund der intrinsischen horizontalen Ausdehnung der Straßen und des Flusses wird für den topographisch Kundigen mit ihrer Erwähnung eine räumliche Verbindung zur städtischen Siedlung Rom hergestellt.

Was die Ausdehnung der literarischen urbs Roma anbelangt, wird sie bei diesem literarischen Panoramablick als eine Zone von weiteren dargestellt. Ihre räumliche Ausdehnung ist folglich nicht unbegrenzt. Im Gegensatz zur Veranschaulichung der anderen räumlichen Gegebenheiten erhält die urbs Roma durch die Erwähnung der Berge in diesem Epigramm eine differenziertere Gestalt, jedoch handelt es sich um eine recht summarische und wenig anschauliche Beschreibung, die die Illusion der Weite des gesamten Ausblicks nicht stört. Architektonisch manifestierte Grenzen des literarischen Raumes urbs Roma, im Sinne der Mauern der Stadt, werden nicht benannt. Allein der Tiber (v. 24) als natürliche Grenze und die Mulvische Brücke (v. 23) ${ }^{440}$, die zum Schluss der visuellen Panoramafahrt erwähnt werden, können als Referenzen auf den Übergang zwischen städtischem Ballungsraum und ländlicher Zersiedelung gewertet werden. Der erhabene Ausblick greift aber vor allem auf den unbegrenzten Raum außerhalb Roms aus und gewährt eine unverstellte Aussicht auf einzelne Sommerrefugien und Ausflugsziele vornehmer

Hauptstadt herstellt, kann man Rom und alles, wofür es steht, richtig bewerten. Der antike Leser fühlte sich hier wahrscheinlich sofort an Lukrezens ,hochragende heitere Bezirke' (edita sapientium templa serena) erinnert, von denen die Weisen auf das ziellose Leben und sinnlose Streben der übrigen Menschheit herabschauen." Dagegen ThLL (1900), 1. s.v. aestimo II, 2, Sp. 1103, de quantitate et mensura: mensuram, distantiam, sim. 42-60, bes. $52 \mathrm{f}$.

439 In dem Verständnis von dominus unterscheide ich mich von Neumeister (1991), 218 und Barié (1999), die einstimmig für ein Verständnis im Sinne von ,(welt-)beherrschend‘ plädieren. Was oder wen die Berge beherrschen wird nicht gesagt. Eine adjektivische Verwendung von dominus findet sich zuerst bei Prop. 3, 9, 23. Vgl. Fedeli (1985), 317. In der Tat wird es häufig direkt auf Rom bezogen, auch bei Mart. 3, 1, 5; 9, 64, 4; 12, 21, 9. Vgl. ThLL (1909-1934), 5.1. s.v. dominus, Sp. 1941, 31-55, bes. 37. Vgl. Ov. am. 2, 14, 16; Ov. rem. 291; Ov. Pont. 4, 5, 7; Calp. ecl. 4, 161.

440 Für den mit der Infrastruktur vertrauten Leser gehören die Mulvische Brücke und weitgehend der Tiber nicht mehr dem innerstädtischen Bereich an. Sie markieren Grenzen der Stadt. Vgl. Neumeister (1991), 15; Favro (1993), 238; Kolb (22002), 404, Abb. 65. In diesem Epigramm wird dieser Sachverhalt über die Berufe der Menschen (Seeleute, Treidler) nahegelegt. Die Mulvische Brücke markiert in dieser landschaftlichen Aufnahme für den vertrauten Leser sogar den Knotenpunkt zwischen Via Flaminia und Tiber, die im Norden zusammentreffen. Vgl. Moreno Soldevila (2006), 445. 
Römer. Diese werden als solche wiederum nur minimal charakterisiert (frigus, v. 14) und zudem lediglich aufgezählt. Bei der Darstellungsform der Aufzählung wird eine Anordnung der einzelnen Orte zueinander vernachlässigt. Allein die deiktischen Referenzen binc und illinc (v. 11 und 18) ordnen die Sommerrefugien und die Verkehrswege zwei verschiedenen Blickrichtungen zu. Zu einer Vorstellung über die Ausdehnung der vielgestaltigen Landschaft aus Bergketten, Siedlungen, einem Hain, einer Brücke, einem Fluss und mobilen Objekten, wie einem Wagen und Schiffen, gelangt der Leser allein über die eine Positionierung in der Nähe der Stadt (Rom) (sub urbe, v. 14). Aus dem Radius, der eine derartige Positionierung aufgrund des Eigenortes der urbs Roma umfassen kann, lässt sich folglich auch für den Leser, der einer genauen topographischen Lage unkundig ist ${ }^{441}$, eine enorme Ausdehnung von einigen Kilometern vorstellen.

Im zweiten Teil (illinc, v. 18) werden anstelle einer Großaufnahme kleinere Details, Menschen und mobile Objekte, näher teleskopiert (Zoom). Neben der Veränderung der Blickinszenierung steht nun auch nicht mehr ein unbelebtes Landschaftspanorama im Mittelpunkt, sondern ein Verkehrsnetz und die Verrichtung von Arbeiten, die im Zusammenhang mit der Versorgung einer Großstadt gesehen werden können: Die Wahrnehmungsinstanz nimmt auf den beiden Ausfallstraßen jeweils einen Reisenden auf einem Wagen wahr, des Weiteren sieht sie auf dem Tiber Schiffe, Seeleute und Treidler und wählt durch den Hinweis auf die Brücke einen markanten Punkt, an dem sich der Wasser- und der Landweg kreuzen. In weiterer Absetzung zum ersten Teil kontrastiert sie die vormals wiedergegebene weit ausgreifende visuelle Wahrnehmung auf das Umland mit einer eingeschränkten auditiven Wahrnehmung. Die sich vor ihren Augen unter großen Anstrengungen abspielenden alltäglichen ${ }^{42}$ Ereignisse werden - der Wahrnehmung des Sprechers gemäß - geräuschlos verrichtet. Der Reisewagen bewegt sich schweigend fort (essedo tacente, v. 19) und auch die Kommandos der Schiffer und Rufe der Treidler nimmt er von seinem Standort aus akustisch nicht wahr, obwohl diese laut (rota molesta ... celeuma ... clamor, v. 20-22) sind und die Schiffe zügig fahren (volent, v. 24). ${ }^{443}$ Das Nicht-Wahrnehmen dieser räumlich ausgreifenden Betriebsamkeit wird in besonderer Weise akzentuiert, da sich die Ereignisse in erklärter Nähe der Wahrnehmungsinstanz (cum sit tam prope Mulvius, v. 23) abspielen. Wiederholt wird selbst ein gedämpftes Hören einer Arbeitswelt, die zweifellos seine

441 Zur Diskussion der genauen geographischen Lage und der genauen Lage des Standortes vgl. Neumeister (1991), 216 f. mit Karte. Weitere Literaturhinweise bei Galán Vioque (2002), 137.

442 Der Modus der Beschreibung wird trotz der Wiedergabe von Ereignissen m. E. nicht unterbrochen, da es sich um alltäglich wiederkehrende Ereignisse handelt. Der Sprecher macht keinen Unterschied zwischen der Mitteilung von den stabilen Merkzeichen des Landschaftsbildes im ersten Abschnitt und der Wiedergabe von Ereignissen an den mobilen Objekten.

443 Schnelle Schiffe auf dem Tiber auch in Prop. 1, 14, 3 f. In Ov. trist. 4, 1, 7-10 vergleicht der exilierte Sprecher seinen eigenen Gesang mit dem der körperlich schwer arbeitenden Treidler und Schiffer. 
unmittelbare Umgebung als großstädtisch auszeichnet, von diesem Standort aus zurückgewiesen (ne blando ... sit ... somno,/ quem nec rumpere ... / ... cum sit tam prope ..., v. 20-23).

Diese besondere Hervorhebung, nämlich, dass es sich allein um eine visuelle und nicht audiovisuelle Wahrnehmung handelt, weist auf die besondere räumliche Gestaltung des Stadt-Landgutes (Hoc rus, seu potius domus vocanda est, v. 25) ${ }^{444}$ hin: Trotz seiner Nähe zur Stadt ist es in deren multisensorische Wahrnehmung nicht eingebunden. Die domus des Martialis liegt in einem Grenzbereich zwischen Stadt und Land, ist ein rus in urbe. Die Betonung der besonderen Abgelegenheit in einer ja ausgewiesenen städtischen Umgebung wird neben der bereits erwähnten Akzentuierung der Vertikalen und der fehlenden auditiven Wahrnehmung auch über den Vergleich mit den Gärten der Hesperiden verstärkt, die sich nach römischer Vorstellung an den Grenzen der bewohnten Welt befanden. ${ }^{445}$ Zur räumlichen Entrückung des Landgutes tragen auch die weiteren mythologischen Vergleiche mit Molorchos und vor allem Alkinoos bei, deren Aufenthaltsorte auch an den Rändern der Welt angesiedelt sind, auch wenn der Vergleich in erster Linie doch der Umschreibung der besonderen herzlichen Gastlichkeit des Hausherrn dient. Trotz des als kleinen, sehr privaten Rückzugsraum ausgestalteten Standortes (Iuli ingera pauca Martialis, v. 1; v. 36; Hoc rus .../ commendat dominus, v. 25 f.) entspricht gerade der großzügige Ausblick auf Orte der Sommerrefugien (Illinc ... patet, v. 18 f.) wie auf die geräuschlose Versorgung einer Großstadt der Großzügigkeit des Gastgebers ([erg. hoc rus] comi patet hospitalitate, v. 28).

Die Ausdehnung, innere Struktur und Begrenzung der urbs Roma wird in diesem Epigramm von einem festen, erhöhten Standort, also in der Perspektive eines Panoramablicks, nur indirekt beschrieben. Neben der Inklusion von sieben Hügeln in das mit dem Toponym Roma bezeichnete Stadtgebiet selbst wird erst im zweiten Teil der Beschreibung eine Wege-Struktur der Peripherie, Verkehrsadern und Transportobjekte, in den Mittelpunkt gerückt, die durch alltägliche Handlungen und einer normalerweise zu antizipierenden Lautstärke die urbs als eine Großstadt veranschaulichen. Im Mittelpunkt dieses Epigrammes steht jedoch nicht deren Wahrnehmung, sondern die domus des Iulius Martialis, die sich in ihrer geringen Größe, ihrer erhabenen Position und ihrer besonderen Versorgungsleistung auszeichnet.

Diese hinsichtlich ihres Ausblicks so besondere domus wird auch in späteren Büchern Martials erneut erwähnt. 446 Im Epigramm 7, 17 wendet sich der Sprecher in

444 Zur Bezeichnung domus vgl. Moreno Soldevilla (2006), 446 mit Parallelstellen. In den Epigrammen Martials wird domus häufig zur Bezeichnung für ein Stadthaus verwendet. Vgl. u. a. Mart. 8, $68,4$.

445 Vgl. auch Vout (2007), 299: „(...) the word ,recessus‘ infers a sense of distance or withdrawal as though disengagement aids familiarity."

446 Das räumliche Paradoxon rus in urbe findet sich in weiteren Epigrammen Martials, vgl. Mart. 12, 57, 18-25. Hier geht der Ausblick allerdings auf die Berge und eben nicht auf die Stadt. Vgl. 
einer Apostrophe an die personifizierte Bibliothek innerhalb der domus und bittet um Aufnahme einer korrigierten Fassung seiner sieben Bücher: Ruris bibliotheca delicati,/ vicinam videt unde lector urbem,/ inter carmina sanctiora si quis (...) (v. 1-3). Als erstes Merkmal dieses Innenraumes wird die Aussicht des Lesers auf die nahe Stadt durch die mehrfache Alliteration und das Hyperbaton auf stilistischer Ebene herausgehoben. Die Nähe der Bibliothek und damit der domus zur Stadt wird in diesem Epigramm explizit erwähnt, jedoch strukturell in Schauplatz und Nebenraum getrennt. Ein Ausblick auf Rom wird folglich auch an dieser Stelle als etwas Besonderes herausgehoben. In ihrer Räumlichkeit beschrieben wird die Großstadt aber nicht.

\subsubsection{Natürliche und architektonische Grenzen. Mauern, Flussläufe und Grenzsteine}

In der augusteischen und kaiserzeitlichen Dichtung ist der Mauerring ein zentrales und markantes Teilelement für eine Stadt. ${ }^{447}$ Auch in Ovids Elegie trist. 4, 3 werden Mauern als genau dasjenige Orientierungsmerkmal genannt, an dem die in dieser Elegie angesprochenen Sternbilder Großer und Kleiner Bär den literarischen Raum der urbs Roma von ihrer Position aus erkennen können.

Magna minorque ferae, (...),
3 omnia cum summo positae videatis in axe, (...),
5 aetheriamque suis cingens amplexibus arcem
vester ab intacta circulus extet humo,

Mart. 12, 57, 20: cui plana summos despicit domus montis. Vgl. auch Hor. epist. 1, 10, 23: laudaturque domus, longos quae prospicit agros. Hor. carm. 3, 29, 6-12; Stat. silv. 2, 2, 72-97.

447 Mauern als typisches Teilelement einer Stadt: vgl. Verg. Aen. 1, 423; Verg. Aen. 2, 233, 290, 298; Hor. carm. 1, 7, 3; Hor. carm. 1, 18, 2; Hor. carm. 3, 17, 6; Hor. epist. 1, 30; Hor. sat. 1, 5, 97; Hor. ars 208 f.; Prop. 4, 1, 125 f. (Geburtsort des Properz), unklar ist dagegen der Bezug von Prop. 4, 1, 65: scandentis quisquis cernit de uallibus arces, / ingenio muros aestimet ille meo!, vgl. Hutchinson (2006), 73. Für einen Verweis auf Rom spricht sich Sandbach (1962), 272 aus: „Of course Propertius did not boast that Rome got its importance from him; his hope is that people will judge the value, understand the meaning and importance, of the buildings of Rome through the accounts he will write of them. “; Ov. am. 3, 15, 10 (Sulmo); Ov. Pont. 1, 8, 11 (Tomi), Ov. Pont. 2, 1, 24; Ov. Pont. 2, 1, 37 f. und 51 f. (Mauern barbarischer oppida). Iuv. 6, 83; Iuv. 15, 28. Die Tradition der Mauern als Kennzeichen einer Stadt findet sich bereits in griechischer Literatur. Vgl. Hom. Il. 19, 514 f. Zu der zentralen Rolle der moenia Romae im Epos Punica des Silius Italicus, vgl. v. Albrecht (1964), 24-46, bes. 34. Im dritten Buch aus Lucans Epos Bellum civile findet sich eine Passage, die die Ankunft und den Aufenthalt Caesars in Rom (!) beschreibt, vgl. Lucan. 3, 88-168; 299. Von einem erhöhten Standpunkt aus betrachtet er die Stadt. Lucan. 3, 88-92: conspicit urbem/ Arctoi toto non visam tempore belli/ miratusque suae sic fatur moenia Romae:/ ,tene, deum sedes, non ullo Marte coactil deseruere viri? (...): Caesar nimmt visuell einerseits die Grenzen der Siedlung wahr und andererseits, dass sie leer ist. Vgl. aber Hunink (1992), 73: „(...) moenia is probably used here in a more general way, as a symbol for a city as a whole." mit weiteren Belegstellen. 


\section{aspicite illa, precor, quae non bene moenia quondam \\ dicitur Iliades transiluisse Remus, inque meam nitidos dominam convertite vultus, sitque memor nostri necne, referte mibi. ${ }^{448}$}

Aufgrund ihres erhöhten Standpunkts (summo ... in axe, v. 3; vester ab intacta circulus extet humo, v. 6) und der guten Sichtverhältnisse (omnia ... videatis, v. 3) bittet der elegische Sprecher, der des Nachts aus Sehnsucht nach seiner Frau nicht schlafen kann, die beiden Sternbilder, sich zu den Mauern Roms und zu der Gattin zu wenden (aspicite illa ... moenia, v. 7; inque meam nitidos dominam convertite vultus, v. 9). Die Mauern werden explizit benannt. Statt auf ihr gegenwärtiges Aussehen verweist der Sprecher aber auf den myth-historischen Umstand, dass Remus sie einst überspringen wollte. Ihre architektonischen Merkmale, Relationen zu anderen räumlichen Gegebenheiten oder weitere topographische Orientierungspunkte einer inneren Struktur, die die Mauern und ihre Siedlung urbs Roma für die Sternbilder überhaupt erst erkennbar werden lässt, nennt der Sprecher dagegen nicht. ${ }^{449}$ Vergleichbare Beobachtungen lassen sich häufiger machen: Die Mauern der urbs Roma werden zwar verschiedentlich in der augusteischen und kaiserzeitlichen Dichtung erwähnt, allerdings in der Hauptsache im Zusammenhang mit dem Gründungsmythos von Romulus und Remus oder einem inhaltlich verwandten, in myth-historischer Vorzeit stattfindenden Ereignis, wie z. B. in der Textpassage aus den Georgika Vergils. ${ }^{450}$

\section{hanc olim ueteres uitam coluere Sabini,}

hanc Remus et frater; sic fortis Etruria crenit

scilicet et rerum facta est pulcherrima Roma,

535 septemque una sibi muro circumdedit arces. ${ }^{451}$

448 Ov. trist. 4, 3, 1, 3, 5-10.

449 Die visuelle Verdichtung von dem unendlichen Raum (omnia) über die Mauern Roms (moenia) bis hin zu dem Anblick eines Menschen (inque meam ... dominam) (Zoom) inszeniert im räumlich-bildkünstlerischen Sinn die besondere Wertschätzung der Ehefrau, an einer eigentlichen Orientierung ist dem Sprecher nicht gelegen. Die Nennung der Mauern ist eine implizite Referenz auf die urbs Roma. Die damit verbundene mythologische Anspielung auf den fatalen Mauersprung des Remus weist auch auf die Unüberwindlichkeit der Trennung zwischen dem Sprecher und seiner Gattin hin. Der außergewöhnliche Standpunkt der Sternbilder auf ihrer vertikalen Achse und die damit entstehende Perspektive vermittelt implizit die räumliche Entfernung zwischen den beiden. In dieser Passage wird zwar eine so genannte Vogelperspektive (bird's-eye-view) verwirklicht, aber nicht im Hinblick auf eine detaillierte Wahrnehmung eines literarischen Raumes urbs Roma verwandt.

450 Vgl. Prop. 4, 1, 55-58: optima nutricum nostris lupa Martia rebus,/ qualia creuerunt moenia lacte tuo!/ moenia namque pio coner disponere uersu:/ ei mibi, quod nostro est paruus in ore sonus!; Vgl. auch Tib. 2, 5, 23 f.; Prop. 4, 4, 9 und 13: quid tum Roma fuit,(...)/ (...)/ murus erant montes: (...). (Vgl. dazu Hutchinson (2006), 121: ,a neat and contemptuous phrase.“); Stat. silv. 1, 2, 191-193.

451 Verg. georg. 2, 532-535. 
Das von den Mauern umschlossene Gebiet wird summarisch mit septem arces zusammengefasst, die Mauer selbst wird nicht näher betrachtet. Wenn aus den vielen möglichen städtischen Teilelementen die Mauer in der Dichtung benannt wird, bezeichnet sie demzufolge selten die gegenwärtige Grenze der literarischen urbs Roma. Es fehlen Hinweise auf ihre Materialität, also visuell oder haptisch vermittelte Details. ${ }^{452}$ Als Ereigniszone, Wahrnehmungsbereich oder als Schauplatz wird die räumliche Umgebung einer Mauer innerhalb der literarischen urbs Roma nicht ausgestaltet. ${ }^{453}$

Der Tiber, markantes topographisches Merk- und Wahrzeichen bis in die Gegenwart, wird ebenfalls allein in einer myth-historischen Vorzeit als eine natürliche Grenze der urbs Roma gewertet. ${ }^{454}$ Bisweilen werden zwar außerstädtische Abschnitte des Tibers erwähnt, sie dienen aber allein einer Positionierung weiterer räumlicher Gegebenheiten. Aussagen über den Tiber selbst werden dabei nicht getroffen. Als Grenze oder als ein Übergangsgebiet zwischen einem Innen- und Außenbereich der urbs Roma wird er nicht präsentiert. ${ }^{455}$ Verbreiteter dagegen ist, den Fluss als topographisches Merk- und Wahrzeichen innerbalb der Siedlung zu lokalisieren, an oder in dem als typisch dargestellte Handlungen von Bewohnern vollzogen werden. ${ }^{456}$ So verstanden dient er verschiedentlich als implizite Referenz

452 Selten werden die Mauern der urbs Roma als gegenwärtig wahrgenommen beschrieben: Verg. Aen. 8, 714 f.: at Caesar, triplici inuectus Romana triumpho / moenia, (...); Stat. silv. 3, 5, 76 f.: at binc magnae tractus imitantia Romae / quae Capys aduvectis implenit moenia Teucris. (Roms Mauern dienen als Vergleich); Stat. silv. 4, 4, 14: ardua iam densae rarescunt moenia Romae. Mart. 10, 103, 9: moenia dum colimus dominae pulcherrima Romae. (Vgl. dagegen Damschen/Heil (2004), 363: „In nur zwei Versen kontrastiert Martial (...) das einfache Leben (...) mit dem üppigen Leben in den prachtvollen Gebäuden - mit moenia sind nicht etwa die die Stadt umgebenden Befestigungsmauern gemeint der Großstadt."). Innerhalb der fabula über die Stadt- und Landmaus markiert das Erreichen der Mauern das Erreichen des Stadtgebiets. Vgl. Hor. sat. 2, 6, 99 f.: ambo propositum peragunt iter, urbis aventes/ moenia nocturni subrepere. In der Mehrzahl der Textbelege handelt es sich folglich stets um eine implizite Referenz auf die urbs Roma. Zur metonymischen Verwendung von moenia für die gesamte städtische Siedlung vgl. ThLL 8 (1936-1966), s.v. moenia, B 1, Sp. 1327, 59 ff.

$453 \mathrm{Zu}$ der zentralen Rolle der moenia Romae im Epos Punica des Silius Italicus, vgl. v. Albrecht (1964), 24-46, bes. 34. Im 12. Buch wird der Erkundungsritt Hannibals vor den Mauern Roms ausgestaltet. Vgl. Sil. 12, 563-567. Die Bewohner der Stadt hören Hannibal: sowohl das Schlagen der Hufe (563 f.) als auch sein Rütteln an den Toren (565 f.).

454 Tiber als einstige Grenze: Iuv. 8, 265: imperii fines Tiberinum virgo natavit, Prop. 4, 1, 8: Tiberis ... aduena erat. Prop. 4, 10, 25: necdum ultra Tiberim belli sonus; Ov. fast. 5, 639-642. In Verg. Aen. 9-11 fungiert der Tiber als Grenze des trojanischen Lagers, vgl. Wulfram (2010), 15.

455 Vgl. Stat. silv. 5, 2, 113-116; Lucan. 1, 175; Ov. fast. 4, 291 f.; Ov. fast. 4, 337; Treibende Leichen auf dem Tiber: Lucan. 2, 209-220; Wohnen in der Nähe des Tibers: Hor. carm. 2, 3, 18; Prop. 1, 14, 1; Mart. 10, 85; Stat. silv. 4, 4, 1-7.

456 Prop. 4, 2, 7-10; Hor. carm. 1, 8, 8; Hor. carm. 3, 12, 7; Hor. sat. 2, 1, 8; Hor. sat. 2, 3, 292; Hor. epist. 1, 11, 19; Ov. fast. 5, 655 f.; Ov. fast. 6, 237-240; Pers. 2, 15; Lucan. 2, 216; Iuv. 6, 523. Fische aus dem Tiber wurden innerhalb des Stadtgebietes gefangen: vgl. Hor. sat. 2, 2, 31 und 120 f.; Iuv. 5, 104. Sehr selten wird dem Tiber die Funktion einer innerstädtischen Grenze zuge- 
auf die urbs Roma selbst. ${ }^{457}$ Für die Frage nach einer Begrenzung oder nach Zonen des Übergangs bietet seine Erwähnung aber keine aussagekräftigen Beispiele.

Gegen die nun naheliegende Ansicht, man hätte aufgrund der besonderen Größe Roms Grenzen dieser Siedlung gar nicht ausmachen können ${ }^{458}$, und daher fänden sie auch folglich in der Dichtung keinen Niederschlag, spricht allerdings die räumliche Präsentation der urbs Roma im bereits besprochenen Epigramm Martials 4, 64. Der Sprecher kann dort von der erhöht gelegenen domus des Iulius Martialis aus - so heißt es - die urbs Roma als Ganzes abschätzen (totam licet aestimare Romam, v. 12). Ferner zählt er sogar Orte auf, die nicht mehr zur Stadt gehören, sondern sich in ausgewiesener Nähe der Stadt (sub urbe, v. 14) befinden. Umrisslinien der Stadt, die explizit Grenzen der urbs Roma ausmachen könnten, nennt er zwar dabei nicht. Deutlich wird aber, dass für ihn ein Unterschied zwischen der urbs und den Siedlungen, die er sub urbe lokalisiert, durchaus besteht, wenn er ihn auch nicht benennt. Des Weiteren spielen Bewegungen von Figuren zwischen der urbs Roma und außerstädtischen Zonen in der augusteischen und kaiserzeitlichen Dichtung durchaus häufig eine Rolle, und räumliche Unterschiede zwischen dem Ausgangsund Endpunkt dieser Bewegung werden dabei kontrastreich gegenübergestellt. Diese literarischen Tatsachen zeigen explizit und implizit, dass die literarische urbs Roma in der Vorstellung der Dichtung durchaus begrenzt ist.

Die fehlende Benennung einer natürlichen oder architektonisch manifestierten Grenze einer als gegenwärtig dargestellten urbs Roma in der augusteischen und kaiserzeitlichen Dichtung bleibt m. E. auffallend. ${ }^{459}$ Eine Begründung dafür bietet

schrieben: Hor. sat. 1, 9, 18: trans Tiberim; Iuv. 14, 202: Tiberim ultra; Ov. fast. 3, 519 f.: Campo,/ quem Tiberis curvis in latus urget aquis; Stat. silv. 4, 4, 5-7: continuo dextras flaui pete Thybridis oras, / Lydia qua penitus stagnum nauale coercet/ ripa suburbanisque nadum praetexitur hortis.

457 Vgl. Verg. georg. 1, 499; Hor. epist. 1, 11, 4; Prop. 4, 10, 25; Stat. silv. 2, 7, 45; Stat. silv. 3, 5, $112 \mathrm{f}$. Häufig auch in der Gegenüberstellung mit anderen Flüssen: Prop. 2, 33, 20 [Nil und Tiber]; Prop. 3, 11, 42 [Nil und Tiber]; Mart. 10, 7, 9 [Rhein und Tiber]; Stat. silv. 4, 3, 112 f. [Tiber und Lukriner See]; Iuv. 3, 62 [Orontes und Tiber].

458 So Edwards (1998).

459 Im Zusammenhang mit anderen Siedlungen wird eine durch eine Mauer umschlossene Siedlung durchaus dichterisch dargestellt. So findet sich in der Tristie 5, 10 Ovids die Darstellung des Aufenthaltsortes des Sprechers. Es fehlen in diesem Beispiel ein entsprechendes Toponym oder eine Gattungsbezeichnung, die die Siedlung näher spezifizieren würde. Allerdings weisen die im Laufe der Elegie genannten Teilelemente ihn minimal als städtisch aus. Diese Siedlung ist als Aufenthaltsort, wie so häufig in der Exildichtung Ovids, zu einem Kontrastraum des räumlichen Fernraums (spatio distant frame) urbs Roma ausgestaltet. Explizit formuliert dies der Sprecher am Ende seiner Ausführungen (Ov. trist. 5, 10, 49 f.): merui tamen urbe carere, / non merui tali forsitan esse loco. Abgrenzungen zwischen Innen und Außen sind für diese Siedlung deutlich gestaltet. Ov. trist. 5, 10, 15-24: innumerae circa gentes fera bella minantur, / (...) / nil extra tutum est: tumulus defenditur ipse/ moenibus exiguis ingenioque loci./ cum minime credas, ut aves, densissimus hostis / advolat, (...)/ saepe intra muros clausis venientia portis/ per medias legimus noxia tela vias./ est igitur rarus, rus qui colere andeat, isque/ hac arat infelix, hac tenet arma manu. Die Siedlung ist durch eine Mauer und ihre natürliche (!) Topographie (ingenio loci) begrenzt. Außerbalb ist die Siedlung von Feinden umringt. Landarbeit 
die Dichtung nicht. Dieses Negativergebnis könnte jedoch als ein räumliches Charakteristikum des literarischen Raumes der urbs Roma gewertet werden. Womöglich soll die Ausdehnung der literarischen urbs Roma gerade nicht auf eine fassbare Größe gebracht werden; womöglich soll sie gerade nicht wie jede typische antike Stadt begrenzt sein. Diese Annahme, dass eine natürliche wie auch architektonisch manifestierte Grenze für eine gegenwärtige urbs Roma absichtsvoll unerwähnt bleibt, könnte durch das folgende Beispiel plausibilisiert werden.

Im zweiten Buch der Fasten Ovids wird das Fest des Gottes Terminus, die Terminalia, beschrieben. ${ }^{460}$ Terminus' Zuständigkeitsbereich sind die Grenzen zwischen den Gebieten und demzufolge die Begrenzung einer räumlichen Ausdehnung. Wie sein Fest auf dem Lande zwischen Grenznachbarn begangen wird, ist Gegenstand eines ersten Abschnitts461: Terminus ist als Stein oder als Pfahl in die Erde eingegraben, Anwohner beider Gebiete kommen an ihm zusammen und vollziehen gemeinsam den Ritus.

Die prinzipielle Unverrückbarkeit des Gottes Terminus und damit der Grenze wird in einem weiteren Abschnitt ${ }^{462}$ anhand eines Ereignisses erläutert, das sich auf dem Kapitol, also in einem Bereich innerhalb der urbs Roma, zutrug: Als auf dem Kapitol für die Errichtung des Jupiter-Tempels alle Bebauung weichen musste, so der Sprecher, wurde allein der als Terminus identifizierte Grenzstein nicht verrückt. Der Sprecher macht darauf aufmerksam, dass beide Gottheiten den Tempel teilen und dass auch in der Sprechergegenwart noch eine architektonische Besonderheit am Jupiter-Tempel auf diesen Umstand hinweist. ${ }^{463}$

Der als Grenzstein oder -pfahl sich materialisierende Terminus ist nach Meinung des Sprechers ein alter, verehrungswürdiger Gott, dessen Zuständigkeitsbereich eine hohe Anerkennung genießt und dessen Missachtung verheerende Folgen für das Zusammenleben der Menschen mit sich bringt. In einem letzten Abschnitt kommt der Sprecher nun auf eine Kulthandlung zu sprechen, die in der Nähe der urbs Roma lokalisiert ist.

dort zu verrichten, ist daher ein Zeichen von kriegerischer Tapferkeit. Innerhalb der Siedlung finden sich trotz geschlossener Tore mitten auf den Straßen Pfeile, die die Nähe der Feinde implizit beschreiben. Die Mauer hat hier die deutliche Funktion, zwei Bereiche, denen jeweils das Merkmal zivilisiert bzw. unzivilisiert zugeordnet ist, voneinander abzugrenzen. Diese Art der Abgrenzung findet sich für die literarische urbs Roma nicht. Es wird vielmehr ihr umfassender Charakter herausgehoben. In Ov. fast. 2, 549 f. wird ein Unterschied zwischen Innen und Außen in mythhistorischer Zeit versetzt gestaltet, wenn der Sprecher daran erinnert, dass Brandgeruch von den im umliegenden Gebiet abgehaltenen Leichenfeiern innerhalb der urbs Roma wahrnehmbar war.

460 Ov. fast. 2, 639-684.

461 Ov. fast. 2, 643-666.

462

Ov. fast. 2, 667-672.

463 Vgl. Ov. fast. 2, 669-672: Terminus (...) invictus in aede/ restitit et magno cum Iove templa tenet./ nunc quoque, se supra ne quid nisi sidera cernat, / exiguum templi tecta foramen habent. 
680

\author{
est via quae populum Laurentes ducit in agros, \\ quondam Dardanio regna petita duci: \\ illa lanigeri pecoris tibi, Termine, fibris \\ sacra videt fieri sextus ab Urbe lapis. \\ gentibus est aliis tellus data limite certo: \\ Romanae spatium est Urbis et orbis idem. ${ }^{464}$
}

An der Straße, die von der urbs Roma Richtung Laurentum führt, wird an einem Grenzstein dem Gott Terminus geopfert. Nachbarn, die an diesem Grenzstein zusammenkommen, werden nicht genannt, sie sind aber implizit durch den Vollzug des Ritus vorausgesetzt. Die Beschreibung der räumlichen Umgebung des Grenzsteins ist somit - entgegen der Erwartungen aus den vorher beschriebenen Riten nicht zu einem Kontaktbereich zwischen Nachbarn ausgestaltet, vielmehr wird aus der Perspektive des Terminus berichtet, wie er das Opfern eines Tieres wahrnimmt (videt, v. 682). Undeutlich bleibt, um wessen Grenzstein es sich überhaupt handelt.

Betrachtet man diese Passage unter dem Gesichtspunkt ihrer räumlichen Gestaltung, so ist indes eine Annahme möglich. Im ersten Distichon wird der Bereich genannt, auf den die Straße zuläuft: das Gebiet der Laurenter. Die metrische Lokalisierung sextus ab Urbe lapis (v. 682) nennt im zweiten Distichon denjenigen Bereich, von dem die Straße herführt: urbs Roma. Von dieser räumlichen Gestaltung her ist wohl Einigkeit darüber zu erzielen, dass die räumliche Umgebung des Steines eine Grenzmarkierung zwischen Laurentum und der urbs Roma darstellen soll. Dies wird jedoch explizit nicht gesagt. ${ }^{465}$

Das dritte Distichon (v. 683 f.) bildet den Abschluss der gesamten TerminusPassage. Gegenübergestellt werden nun überraschenderweise zum einen generell Gebiete anderer Völker (tellus, v. 683) und zum anderen speziell die räumliche Ausdehnung der urbs Roma (spatium, v. 684). Gebiete anderer Völker seien jeweils begrenzt, die Grenzen der urbs Roma sind jedoch mit der, wenn man so will, nächsthöheren räumlichen Kategorie, nämlich dem Erdkreis, identisch. Anders als durch den vorangegangenen Duktus der Passage zu erwarten gewesen wäre ${ }^{466}$, gibt es für die urbs Roma laut dem Sprecher keinen architektonisch manifestierten Grenzstein.

464 Ov. fast. 2, 679-684.

465 Der Sprecher verweist im ersten Distichon auf ein Ereignis in einer myth-historischen Vergangenheit, als der Anführer der Trojaner das Gebiet der Laurenter aufsuchte. Die Formulierung Dardanio regna petita duci lässt offen, ob hier lediglich auf die Ankunft des Aeneas in Laurentum angespielt werden soll oder auf das Besitzstreben eines fremden Volkes. Das erhielte im Kontext dieser Passage eine ausgesprochen negative Note. Der Ausgang dieses Ereignisses wird nicht erwähnt.

466 Vgl. Ov. fast. 2, 659 f. ,tu populos urbesque et regna ingentia finis:/ omnis erit sine te litigiosus ager. 
Wie bereits in der ersten Ekloge Vergils (vgl. Abschnitt 3.3.2.2) findet sich in dieser Passage erneut der Gedanke, dass der urbs Roma eine Ausnahmestellung zukommt. Erneut wird dazu nicht unmittelbar miteinander Vergleichbares gegenübergestellt. In den Versen aus den Fasten werden das Gebiet des Erdkreises, das Territorium eines Volkes und das Areal einer Stadt miteinander verglichen. Explizit bezieht sich der Vergleichspunkt auf die Ausdehnung bzw. Begrenzung der Stadt (spatium, v. 684). Mit Nachdruck wird hier folglich der Gedanke der Ausnahmestellung der urbs Roma an ihre räumliche Ausdehnung gebunden. ${ }^{467}$

Der Gedanke, das urbs und orbis miteinander identisch seien, findet sich verschiedentlich in der augusteischen Dichtung bei Properz und Ovid ${ }^{468}$, so dass sich hier plausibilisieren ließe, wieso architektonisch manifestierte oder natürliche Grenzen einer gegenwärtigen literarischen urbs Roma gerade nicht in einer Beschreibung oder als räumliche Ereigniszone präsentiert werden.

\subsubsection{Grenzbereiche. Anzeichen der Verstädterung}

Der erste oder auch letzte Blick eines Reisenden auf eine große Stadt ist aus den Beschreibungen der deutschen Reiseliteratur eine bekannte Darstellungsweise für

467 Damit wird anders als in der ersten Ekloge Vergils der Vergleich nicht auf vertikaler Achse, sondern auf horizontaler geführt.

468 Vgl. Prop. 3, 11, 57; Ov. ars 1, 174 (hier: orbis in Vrbe fuit), zu weiteren Belegen vgl. Bömer (1957), Bd. 2, 131 f., Edwards (1996), 99 f. und Nicolet (1988), 127. Verwandt in der Aussage auch Verg. Aen. 1, $278 \mathrm{f}$.: his ego nec metas rerum nec tempora pono:/ imperium sine fine dedi. Vgl. dazu Döpp (2003), 33. Unmittelbar zuvor werden die von Romulus gebauten Mauern genannt. Vgl. Verg. Aen. 1, 276 f.: Romulus excipiet gentem et Mauortia condet/ moenia Romanosque suo de nomine dicet. Generell zur hyperbolischen Raumstruktur der Aeneis Hardie (1986), 267-285 für die vertikale Raumachse, zur Darstellung römischer Expansion auf dem Schild des Aeneas und der grundlegenden Assoziation von urbs und orbis ebd., 364-366. Die Passage Ov. fast. 2, 683 f. zitiert er als Zusammenfassung der Interpretation des Schildes als ,apophtegmatic words“ (ebd., 366). Zur Identifizierung der Grenzen der Stadt mit den Grenzen des Imperiums bemerkt er (ebd., 365.): „The Roman imperial sense that the city reaches out to the limits of the universe is only partially adequate to the real historical growth of the empire; the extravagance of such formulations points to a far more widespread mythical or mystical equation to the city with the universe, which has no essential link with empirical reality. In many societies the human city is planned as an imitation of the wider cosmos." So versteht Bréguet (1969), 149 auch Ov. fast. 2, 683 f. und Verg. Aen. 1, 278 f. nicht im eigentlichen räumlichen, sondern im übertragenen Sinne. „Les limites de la ville, c'est-à-dire de sa puissance, se confondent avec celles de l'empire." Romm (1992), 121 f. zitiert die Ovid-Passage aus den Fasten als ,geographic keynote“, die pointiert die Behauptung der bedeutendsten kaiserzeitlichen Geographen zum Ausdruck bringt, die Grenzen der Welt wären durch die Ausdehnung des Imperium erreicht. Dahinter stehe die räumliche Vorstellung eines „, island oikumene- concept, during a time when it seemed that the earth would soon be consolidated into a single city-state." Romm versteht demzufolge urbs in dieser Passage im Sinne von civitas/ródı५. Soweit ich sehe, wird der konkrete Kontext der Passage aus Ovids Fasten in den Argumentationen nicht berücksichtigt. 
derartige Siedlungen. ${ }^{469}$ Mit der Eigenbewegung einer Figur kann nicht nur der Ausdehnung einer Stadt, sondern deren Grenzen oder Übergängen eine besondere Aufmerksamkeit geschenkt werden.

Literarische Itinerarien, wie die in der Satire 1, 5 des Horaz beschriebene Reise nach Brundisium, führen von der urbs Roma weg, beschrieben wird aber eine Zone des Übergangs als Wahrnehmungsbereich nicht. ${ }^{470}$ Auch werfen die Figuren kaum

469 Vgl. z. B. Joseph von Eichendorff, Aus dem Leben eines Taugenichts, Kap. 7: „Unterwegs erfuhr ich, dass ich ein paar Meilen von Rom wäre. Da erschrak ich ordentlich vor Freude. (...) die Stadt stieg immer deutlicher und prächtiger vor mir herauf, und die hohen Burgen und Tore und goldenen Kuppeln glänzten so herrlich im hellen Mondschein, als ständen die Engel in goldenen Gewändern auf den Zinnen und sängen durch die stille Nacht herüber. So zog ich denn endlich, erst an kleinen Häusern vorbei, dann durch ein prächtiges Tor in die berühmte Stadt Rom hinein." Einen Weg vom Forum durch das Esquilinische Tor hinaus aus der Stadt imaginiert Purcell (1987), 187-189.

470 Der Abschiedshymnus des Rutilius Claudius Namatianus in de reditu suo besingt Roma als Göttin. Bereits in den Anfangsversen wird Rom personifiziert dargestellt. Ihre räumliche Ausdehnung als Herrin der Welt (regina ... mundi, v. 48) umfasst auch weiträumige Bereiche wie die Wüste Libyien und das nordische Eis, deren Überwinden als Zeichen der Grenzenlosigkeit angesehen wird. In diesem Zusammenhang wird nicht die urbs mit dem Erdkreis, sondern der Erdkreis mit der urbs gleichgesetzt: Vgl. Rut. Nam. 57-62; 66: volitur ipse tibi, qui continet omnia, Phoebus/ eque tuis ortos in tua condit equos. / te non flammigeris Libye tardavit arenis; / non armata suo reppulit ursa gelu:/ quantum vitalis natura tetendit in axes, / tantum virtuti pervia terrae tuae./ (...) urbem fecisti, quod prius orbis erat. In einem späteren Abschnitt werden Gebäude der Stadt nach Typen aufgezählt (Rut. Nam. 93-114): Als visuell auffällig nennt er vor allem räumlich klar begrenzte städtische Teilelemente: trophäengeschmückte Gebäude, blitzende Tempel, hoch liegende Aquädukte, hoch aufragende Thermen und von Säulengängen umgebene Gärten. Im Zusammenhang mit dem Wasserreichtum der Stadt erwähnt er zweimal die Mauern, die im Sinne einer pars pro toto das gesamte Stadtgebiet meinen: intercepta tuis conduntur flumina muris, v. 101; tota (...) nativo moenia fonte sonant, v. 104. Als akustisches Merkmal nennt er die Geräusche der zahlreichen Wasseradern und den Gesang von Vögeln in den Gärten. Die Zahl und die Größe der Gebäude werden nach dem rhetorischen Muster der laus urbium dargestellt. Vgl. Classen (1986), 28. Die Beschreibung der Stadt oder genauer die Aufzählung ihres Inventars wird nicht von einem erkennbaren Wahrnehmungsstandpunkt aus beschrieben. Wenn er behauptet, bei dem Umherschweifen mit den Augen von ihnen geblendet zu werden, wird dies als Wissen, und nicht als Wahrnehmung erzählt. Vgl. Rut. Nam. 93-95: Percensere labor densis decora alta trophaeis,/ ut si quis stellas pernumerare velit/ confunduntque vagos delubra micantia visus. Von dem Bewegungsbereich zwischen urbs und Hafen (Rut. Nam. 165-178) werden keine räumlichen Details erwähnt, sondern allein seine Begleitung. Deutlich wird aber, dass das Gebiet der urbs Roma bereits vor Erreichen der Schiffe länger verlassen worden ist: iamque aliis Romam redeuntibus baeret eunit/ Rufus (v. 167 f.); invitum tristis tandem remeare coegi (v. 178). Als sich die Weiterfahrt am Hafen verzögert, gibt der Sprecher eindrucksvoll seine (z. T. eingeschränkte!) audiovisuelle Wahrnehmung der nahen Stadt wieder. Vgl. Rut. Nam. 189-204: Respectare iuvat vicinam saepius urbem/ et montes visu deficiente sequi;/quaque duces oculi grata regione fruuntur,/ dum se quod cupiunt cernere posse putant./ Nec locus ille mibi cognoscitur indice fumo,/ qui dominas arces et caput orbis habet/ (...) sed caeli plaga candidior tractusque serenus/ signat septenis culmina clara iugis./ (...) Saepius attonitae resonant circensibus aures; / nuntiat accensus plena theatra favor; / pulsato notae redduntur ab aethere voces, / vel quia perveniunt vel quia fingit amor. Er selektiert von der urbs Roma die Berge (montes, v. 190) und die sieben Hügel (septenis culmina ... ingis, v. 197), die Burg - auf dem Kapitol - (arces et caput orbis, v. 194). Akustisch nimmt er die Circusspiele (circensibus, v. 201) 
einen Blick auf die hinter sich gelassene Stadt zurück. ${ }^{471}$ So nennt der Sprecher der Satire 1, 5 Roma lediglich als Ausgangspunkt seiner Reise, wobei das Attribut magna (v. 1), das der urbs Roma in diesem Zusammenhang zugesprochen wird, in einem wenig spezifischen Gegensatz zu den im Laufe der Reise aufgesuchten Kleinstädten steht. ${ }^{472}$

Trotz zahlreicher Bewegungen zwischen städtischen und nicht-städtischen Bereichen findet eine Vermittlung von diffusen Zonen einer städtischen Peripherie und des Übergangs kaum statt. In der Elegie 3, 16 des Properz überlegt der Sprecher, ob er mitten in der Nacht die Wegstrecke nach Tibur auf sich nehmen soll. Er hat soeben einen Brief seiner domina erhalten, die ihn auffordert, unverzüglich dorthin zu kommen. Der Schauplatz der vorgetragenen Überlegungen ist nur als Ausgangspunkt gekennzeichnet: Zwischen ihm und Tibur liegt eine Wegstrecke, die der Sprecher zurücklegen muss. Sie steht im Mittelpunkt der Elegie, genauer gesagt ein Ereignis, das den Sprecher erwarten könnte, nämlich die Begegnung mit einem nächtlichen Feind (nocturno hoste, v. 8), der handgreiflich wird (audaces in mea membra manus, v. 6). Die Wegstrecke steht in dieser Elegie also zwar im Mittelpunkt, aber sie ist als ein nicht bestehender Raum (frame with a non-factual status) gestaltet.

Von dieser Wegstrecke werden außer möglichen Kontakten die Beschaffenheit des Bodens und die Lichtverhältnisse als räumliche Merkmale präsentiert. Recht ausführlich imaginiert der Sprecher eine Gruppe von Begleitern, die sich vor allem als Lichtquellen - Mond, Sterne und einen Fackel schwenkenden Amor - auszeichnen. ${ }^{473}$ Durch diese Schutzmannschaft wird er vor holprigen Stellen gewarnt sein, und auch aggressive Hunde und Meuchler werden sich zurückziehen. Der Sprecher antizipiert für eine außerstädtische, nächtliche Wegstrecke folglich vor allem Gefahren für den eigenen Leib, die ihn zögern lassen, der an ihn gestellten Aufforderung nachzukommen. ${ }^{474}$ In einem dritten Teil (v. 21-30) trägt er in Anbe-

und volle Theater (plena theatra, v. 201) wahr. Diese Geräusche sind ihm bereits bekannt (notae ... voces, v. 203).

471 Vgl. Hor. sat. 1, 5, 1 f.: Egressum magna me accepit Aricia Roma/ hospitio modico. Vergleichbar auch die Abschiedselegie Prop. 3, 21, 15, in der sich der Sprecher nach Athen aufmacht: Romanae turres et uos ualeatis, amici. Die Bedeutung von turres ist nicht klar, vgl. Fedeli (1985), 321. Rothstein (31966), Bd. 2, 163 schlägt vor, dass es sich auf Hochbauten beziehe.

472 Vgl. Fedeli (1994), 417: „Per di più, giunto al termine della prima trappa, sembra che egli senta il peso del distacco da Roma: la capitale è magna, mentre Arricia, accostata per contrasto a Roma, può solo offrire una modesta ospitalità.“ und Kießling/Heinze (1959), 91: „um den Kontrast mit dem ersten dürftigen Quartier zu schärfen.“

473 Vgl. Prop. 3, 16, 15-17: luna ministrat iter, demonstrant astra salebras, / ipse Amor accensas percutit ante faces, / saeua canum rabies morsus auertit hiantis.

474 In einem übertragenen Verständnis von Grenze und Übergang, also nicht mehr bezogen auf die konkrete Wegstrecke zwischen einer Stadt und einer weiteren Siedlung, sind die Überlegungen zu den Gefahren für den Leib und die Antizipation des eigenen Todes durchaus als Übergang, nämlich zwischen Leben und Tod, interpretierbar. In Mart. 4, 18 wird der Tod eines jungen 
tracht eines möglichen Todes, den diese Unternehmung mit sich bringen könnte, emphatisch den Wunsch vor, wo er bzw. wo er nicht beigesetzt werden möchte: di faciant, mea ne terra locet ossa frequenti,/ qua facit assiduo tramite unlgus iter! ${ }^{475}$ Für den Tag - wenn auch nicht explizit gekennzeichnet - geht der Sprecher folglich von einem enormen Menschenaufkommen auf diesem Weg aus. So werden für die jeweiligen Tageszeiten zwar unterschiedliche Merkmale vorgeführt. Sie gelten allerdings für die gesamte Wegstrecke, ohne dass Eigenheiten für eine Stadtnähe oder -ferne unterschieden würden. ${ }^{476}$ Für die in diesem Abschnitt interessierende Frage nach der Begrenzung der urbs Roma zeigt diese Passage, dass ihre Grenze und darüber hinaus sogar eine weitere Siedlung noch innerhalb einer Nacht und ohne größere Vorbereitungen und Planung erreicht werden kann, jedoch die Wegstrecke als Transitraum zwischen Großstadt und Kleinstadt nicht durch ab- oder zunehmende räumliche Merkmale dargestellt wird. Zonen eines Überganges werden in dieser Passage nicht erkennbar. Durch die fehlende Lokalisierung der antizipierten Ereignisse entsteht vielmehr der Eindruck, dass alle, auch die räumlichen Eigenschaften, für die gesamte Wegstrecke repräsentativ sind.

Besonders markante Stellen des Übergangs zwischen dem Innen und Außen sind Zugangsbereiche zu einer Stadt, etwa Stadttore, Zugangsstraßen oder Hafenanlagen. Werden diese als Zonen beschrieben oder werden in, an oder bei ihnen Ereignisse lokalisiert, könnten räumliche Unterschiede zwischen einem Innen und AuBen dargestellt oder ein Übergang als solcher kenntlich gemacht werden.

Die dritte Satire Juvenals ist als Ganze betrachtet eine Abschiedsszene zwischen einem römischen Bürger namens Umbricius und seinem Freund, dem Ich-Erzähler. Umbricius berichtet in einem längeren Monolog (Iuv. 3, 21-322) über seine Beweggründe, der Großstadt ${ }^{477}$ für immer den Rücken zu kehren. Bevor es dazu kommt, wird jedoch der Schauplatz des Abschiedsgesprächs beschrieben, ein weiträumiger Bereich um ein Stadttor. Durch das Ereignis selbst ist diese räumliche Umgebung bereits als Zone des Übergangs ausgewiesen. Dass sich der Schauplatz dieser Satire in der näheren Umgebung eines Zugangsbereiches zur urbs Roma befindet, wird über das als Eigenname gebrauchte Adjektiv Capena deutlich, der

Mannes durch einen Eiszapfen an einem städtischen Durchgangstor beschrieben. Vgl. auch Prop. 4, 3, 69-72.

475 Prop. 3, 16, $25 \mathrm{f}$.

476 Im Fokus ist die Materialität der Straße selbst: Vgl. Tib. 1, 7, 61 f.; Iuv. 5, 54 f. Vgl. dagegen Ov. Pont. 1, 8, 43 f. über die Lage seines stadtnahen Landguts: nec quos piniferis positos in collibus hortos/ spectat Flaminiae Clodia iuncta viae.

477 Die Gattungsbezeichnung urbs taucht in unmittelbarem Anschluss an die Einleitung in den ersten Versen des Monologs auf (Iuv. 3, 22), das Toponym Roma wird erstmals in Vers 41 verwendet. 
auf eine nach ihr benannte porta der urbs Roma verweist. 478 Darüber hinaus wird der Bereich als Zone des Übergangs dadurch gekennzeichnet, dass der Hausrat des abreisenden Umbricius bei der porta Capena auf Wagen verladen wird. Während dieses Vorganges steigen beide in ein Tal hinab.

10 sed dum tota domus raeda componitur una,
11 substitit ad veteres arcus madidamque Capenam.
$17 \quad$ in vallem Egeriae descendimus et speluncas
dissimiles veris. quanto praesentius esset
numen aquis, viridi si margine cluderet undas
$20 \quad$ herba nec ingenuum violarent marmora tofum.
$12 \quad$ bic, ubi nocturnae Numa constituebat amicae,
nunc sacri fontis nemus et delubra locantur
Iudaeis, quorum cophinus fenumque supellex;
$15 \quad \begin{aligned} & \text { omnis enim populo mercedem pendere iussa est } \\ & 16 \quad \text { arbor et eiectis mendicat silva Camenis. }{ }^{479}\end{aligned}$

Von der porta Capena aus steigen die beiden Freunde in ein Tal hinab, das demzufolge in unmittelbarer Nähe zum Stadttor liegen muss. Der Sprecher nimmt die Umgebung während der eigenen Bewegung in einem Prozess der visuellen Annäherung (Zoom) wahr: Von der Großaufnahme vallem (v. 17) selektiert er zunächst die Gegenwart verschiedener strukturell kleinerer Orte (speluncas, v. 17) und konzentriert sich letztlich auf die Umrandung einer Quelle 480 (undas, v. 19). Es werden in dieser literarischen Raumwiedergabe zahlreiche räumliche Gegebenheiten genannt, die auf eine außerstädtische Landschaft verweisen. ${ }^{481}$ Auf den ersten Blick lassen sich hier Innen und Außen klar voneinander unterscheiden.

Das visuell Wahrgenommene entspricht jedoch nicht den Erwartungen der Wahrnehmungsinstanz. Die Grotten sehen unecht aus, die Quelle ebenso: diese wird nicht von Gras, sondern von Marmor umsäumt. Es handelt sich somit bei genauerer Betrachtung nicht um einen ausgewiesen außerstädtischen Bereich. Vielmehr wird ein Gegensatz zwischen einem erwarteten natürlichem Bewuchs (berba, v. 20) und einer vorgefundenen absichtsvollen Gestaltung (marmora, v. 20) herausgear-

478 Es handelt sich um ein Tor, das in der severianischen Stadtmauer einen Durchgang der via Appia Richtung Capua lässt. Dieses Tor lag bereits in der frühen Kaiserzeit innerhalb der Stadt. Vgl. auch Courtney (1980), 158: „Since the Porta Capena was a loading point, it will have been rather like a modern railway-station (...), with a general market where Jews could peddle their wares." Weitere städtische Teilelemente nennt der Sprecher dieser Satire aber für diese räumliche Umgebung nicht.

479 Iuv. 3, 10-20 [ed. Braund]. Zur Diskussion der Textüberlieferung vgl. Pearce (1992).

$480 \mathrm{Vgl}$. Braund (1996), $176 \mathrm{zu}$ undas: „Often denotes flowing water of springs and rivers (OLD 2)“.

481 Vgl. Braund (1996), 175: „The setting of the poem presents a satiric parody of Plato's Phaedrus and Cicero De legibus (...): a dialogue between two friends walking outside the city walls and halting in a pleasant place." 
beitet, der in dieser Passage nicht als aparter Kontrast, sondern als regelrechter Gewaltakt (violarent, v. 20) empfunden wird.

Im Folgenden werden weitere Bereiche dieses Schauplatzes mit einem zeitlichen Fernraum (temporally distant frame) kontrastiert. Verglichen werden die räumlichen Gegebenheiten zur Zeit des zweiten Königs von Rom, Numa Pompilius (bic, ubi ... Numa constituebat, v. 12), und in der Gegenwart des Sprechers ([bic] nunc, v. 13). Die Erwähnung Numas dient hier nicht nur einer zeitlichen Einordnung in eine myth-historische Vergangenheit. Der Sprecher weist dieses Gebiet explizit als einstigen Kontaktbereich zwischen Numa und der Nymphe Egeria aus. Durch diesen erzählerischen Rückgriff wird die räumliche Umgebung als ein einstmals abgeschiedener, aber auch sakraler Bereich gekennzeichnet. Dem entsprechen auch die genannten typischen Teilelemente der Landschaft: eine Quelle, ein Hain, ein Tempel, Bäume und Wald. Die zeitlich entfernt liegenden Kontrasträume werden in dieser Textpassage nicht durch die Ersetzung ländlicher durch städtische Teilelemente miteinander verglichen. Vielmehr werden die typisch ländlichsakralen Teilelemente ihrer ursprünglichen Bestimmung entzogen bzw. personifiziert: Hain, Quelle und Tempel sind vermietet, jeder Baum zahlt Miete, der Wald bettelt. Anders formuliert: Aus Bäumen sind Mieter, aus einem Wald eine Gruppe von Bettlern, aus dem abgeschiedenen Bereich ein bewohntes Gebiet geworden, in dem sich eine bestimmte Bevölkerungsgruppe, nämlich Juden, mit ihrem Hausrat angesiedelt hat. Wie eine umgekehrte Metamorphose ${ }^{482}$ von einer Landschaft zur Person wird die Veränderung einer einst ländlich-sakralen Landschaft zu einem städtischen Areal der Gegenwart gestaltet. Aus der gesamten Umgebung der porta Capena ist somit bereits eine städtische geworden.

Eine gegenwärtige Begrenzung der urbs Roma wird damit in dieser Passage nicht gestaltet. Vielmehr wird die vollständige Verstädterung einer einstmals natürlichen Umgebung in einer zeitlichen Perspektive konstatiert. Dieser nun genuin städtische Zugangsbereich ist jedoch durch die Eigenorte der vormals ländlichen Teilelemente von erheblicher Ausdehnung. In Bezug auf die Begrenzung der urbs Roma zeigt demzufolge diese Bestandsaufnahme, dass sich Grenzen der urbs Roma weit nach außen verschoben haben und für die Wahrnehmungsinstanz nicht mehr erkennbar sind.

In seiner Raumgestaltung unterliegt dieser Schauplatz einer starken semantischen Bewertung: Er nimmt die Verdrängung eines indigenen Römers, um die es im Folgenden der Satire gehen soll, bereits vorweg. ${ }^{483}$ Die Gestaltung der räumlichen

$482 \mathrm{Zu}$ generellen Anspielungen auf die Metamorphosen Ovids in diesem Abschnitt vgl. Braund (1996), 176. Wichtig vor allem Ov. Met. 3, 157-162 und die Verwandlung der Egeria in eine Quelle bei Ov. Met. 15, 547-551. Egeria ist folglich das numen aquae, das in der zeitlichen Gegenwart des Sprechers nicht von Gras, sondern von Marmor umsäumt wird.

483 Vgl. Courtney (1980), $158 \mathrm{f.:} \mathrm{„(...)} \mathrm{its} \mathrm{literary} \mathrm{point} \mathrm{is} \mathrm{clear.} \mathrm{Juvenal} \mathrm{and} \mathrm{Umbricius} \mathrm{look} \mathrm{for} \mathrm{a}$ non-urban setting for the denunciation of Rome, but the one they find is spoiled by foreigners (...) whose cult has evicted the native goddesses, by greed which profiteers from the sacred, by luxuria which despises simple Roman stone, and in short by lack of respect of Roman tradition 
Umgebung dieses Zugangs soll vom Leser bereits als beispielhafter Ausschnitt für die urbs Roma verstanden werden, die im Folgenden durch die Erzählung des Umbricius betreten und auf einer zweiten Erzählebene zum Schauplatz der Satire wird. 484

In der Satire 1, 8 des Horaz wird der Prozess der Verstädterung eines Gebietes ebenfalls deutlich räumlich gestaltet. Eine Priap-Statue ist in dieser Satire der Sprecher, die sich aufgrund ihres festen Standorts als ausgewiesener Kenner gegenwärtiger und vergangener Verhältnisse ihrer näheren räumlichen Umgebung empfiehlt.

nunc licet Esquiliis habitare salubribus atque

15 aggere in aprico spatiari, quo modo tristes

albis informem spectabant ossibus agrum,

cum mibi non tantum furesque feraeque suetae

bunc vexare locum curae sunt atque labori

quantum carminibus quae versant atque venenis

20 bumanos animos: has nullo perdere possum

nec probibere modo, (...).485

Den Standort, den die Figur in diesen Versen beschreibt, ist der Bereich des Esquilin (v. 14). Früher waren in dieser Gegend, so weiß die Priap-Statue, Begräbnisplätze für Sklaven und ärmere Bevölkerungsgruppen. ${ }^{486}$ Für die Gegenwart weist sie auf eine neue variantenreiche Nutzung und Ausgestaltung des Areals durch Städter hin, das neue Gärten (novis ... in hortis, v. 7), einen Wall (aggere in aprico, v. 15) und auch Wohngebäude umfasst (babitare, v. 14). Durch die Verwendung entsprechender Attribute ist erkennbar, dass es sich bei diesem Prozess aus Sicht der Priap-Statue um eine Aufwertung der Umgebung handelt (nunc Esquiliis habitare salubribus ... / ... quo modo tristes/ ... spectabant, v. 14-16).

Die Priap-Statue beobachtet, dass trotz einer neuen Nutzung des Gebietes der Rückzug der einstigen Nutzer nicht vollständig geschehen ist. Wilde Tiere (ferae, v. 17) und Diebe (fures, v. 17) kehren an den für sie gewohnten Ort zurück. Das ei-

(note the emphatic contrast between nunc and Numa, (...) it will be noted that the satirist cannot refrain from joking at Numa, his symbol of what has to be respected).“ Braund (1996), „(...) lines 17-20 present an antithesis of the natural and the artificial which provides a preview of Umbricius' opening theme, the displacement of simple honourable men like himself by crooks and criminals." Vgl. auch Fredericks (1973).

484 Vgl. dazu auch Larmour (2007).

485 Hor. sat. 1, 8, 14-21.

486 Vgl. Hor. sat. 1, 8, 8-13: buc prius angustis eiecta cadavera cellis/ conservus vili portanda locabat in arca;/ boc miserae plebi stabat commune sepulcrum;/ Pantolabo scurrae Nomentanoque nepotil mille pedes in fronte, trecentos cippus in agrum/ bic dabat, beredes monumentum ne sequeretur. 
gentliche Problem stellen allerdings aus ihrer Sicht Magierinnen dar, die sich nicht aus diesem Gebiet vertreiben lassen (bas nullo perdere possum/ nec probibere, v. 20 f.). In der nun folgenden Erzählung verflicht die Priap-Statue ihre räumliche Umgebung mit einem vor allem akustisch und visuell akzentuierten unheimlichen Ereignis, bei dem es ihr schließlich aus eigener Kraft gelingt, diese zu vertreiben.

Dieser gesamte Bereich lag einst in der Nähe der Stadt, wie seiner Funktion als Begräbnisplatz zu entnehmen ist. Dass er aber auch in der Gegenwart der PriapStatue noch außerhalb der urbs Roma liegt, wird zum Schluss der Satire deutlich. Die beiden Magierinnen laufen, aufgeschreckt durch die Statue, in die Stadt zurück (at illae currere in urbem, v. 47). Die Priap-Statue ist somit Zeuge eines sich allmählich verändernden Bereiches, dessen Verstädterung nicht abgeschlossen ist und der daher räumlich noch nicht der literarischen urbs Roma zugeordnet wird. Die Größe des von der Statue beschriebenen Saumes entspricht der allgemeinen visuellen Wahrnehmungsfähigkeit, die einer anthropomorphen Priap-Statue entsprechend der menschlichen Wahrnehmungsfähigkeit zugesprochen werden kann. Da die einzelnen Teilelemente tendenziell weiträumig sind, überschaut die Statue ein Gebiet von einiger Größe. Dieser Prozess der allmählichen Wandlung und die damit einhergehende Vertreibung der vorhergehenden Nutzer werden von der Priap-Statue wohlwollend beobachtet und sogar durch ihr aktives Eingreifen unterstützt.

Eine derartige Verstädterung des Umlandes und eine sich daraus implizit ergebende Vergrößerung des Stadtgebietes ist auch in anderen Passagen der augusteischen und kaiserzeitlichen Dichtung als eine Tendenz, wenn auch nicht als durchgängige Beobachtung, anzutreffen, so beispielsweise in einigen Epigrammen Martials, die ihren Blick auf umliegende Landgüter richten. ${ }^{487}$ Auffallend ist hier, dass der Prozess für den jeweiligen Sprecher mit der Frage verbunden ist, ob die Versorgung mit Lebensmitteln auf dem Land aus eigenem Anbau möglich ist oder ob die Lebensmittel in der Stadt erworben wurden. ${ }^{488}$ Die Verstädterung ist damit nicht räumlich, sondern in einem übertragenen Sinne als zunehmende Entfremdung

487 Mart. 3, 58, 45-51. Mart. 7, 31. Überwiegend werden jedoch keine Auswirkungen der Stadtnähe auf das Landgut beschrieben: Mart. 1, 85; 5, 1; 5, 35; 7, 49; 8, 61; 10, 58. In der überwiegenden Mehrzahl wird das stadtnahe Landgut als genuin ländlicher Raum gestaltet. Vgl. Ov. Pont. $1,8,41-48$.

488 Vgl. bereits Ov. ars 2, 263-266: dum bene diues ager, cum rami pondere nutant,/ afferat in calatho rustica dona puer/ (rure suburbano poteris tibi dicere missa,/ illa vel in Sacra sint licet empta Via). Mart. 7, 31, 612. Übertragene Vorstellungen zur Verstädterung bzw. Durchlässigkeit von innen nach außen finden sich z. B. bei Iuv. 2, 166-170. Vgl. Braund (1996), 25: „Homosexual practice raging in Rome will spread outwards to infect all parts of the empire." Von einer in diesem Sinne verstandenen Durchlässigkeit wird bei Prop. 2, 32, 47-51 gerade nicht ausgegangen, er macht Unterschiede zwischen innen und außen deutlich: qui quaerit Tatios ueteres durosque Sabinos,/ bic posuit nostra nuper in urbe pedem./ tu prius et fluctus poteris siccare marinos/ (...)/ quam facere, ut nostrae nolint peccare puellae. 
von ländlicher Selbstversorgung und entsprechend wachsender Abhängigkeit von städtischer Versorgung gestaltet.

Pointiert wird eine derartige, übertragene Verstädterung in einem Epigramm des dritten Buches Martials beschrieben, indem die Bewegung einer Figur aus dem städtischen in den nicht-städtischen Bereich an einem Grenzbereich der urbs, nämlich an die Ereigniszone der porta Capena, verlegt wird. Eine Person namens Bassus ist dort auf einem Reisewagen unterwegs, der mit Kohl, Salat, Mangold, Vögeln, Hasen und einem Ferkel beladen ist.

1 Capena grandi porta qua pluit gutta

Phrygiumque Matris Almo qua lavat ferrum,

Horatiorum qua viret sacer campus

et qua pusilli fervet Herculis fanum,

5

Faustine, plena Bassus ibat in reda,

omnis beati copias trabens ruris. (...)

15 Vrbem petebat Bassus? immo rus ibat. 489

In dem ersten Teil des Epigramms 3, 47 werden mit einem viermaligen qua diejenigen Orte eines Bewegungsbereichs markiert, an denen Bassus auf einem Reisewagen voll mit den Gütern eines fruchtbaren Landgutes (beati ... ruris, v. 6) vorbeikam. Es ist die Porta Capena, weiterhin ein kleiner Fluss (Almo, v. 2), eine Grabstätte (sacer campus, v. 3) und schließlich ein kleines Heiligtum (fanum, v. 4). Das einzige ausgewiesen städtische Teilelement ist folglich das Tor, die anderen Teilelemente weisen auf einen außerstädtischen Raum. Auffällig sind in diesem Abschnitt die personifizierten, aktiven Konstruktionen (pluit, lavat, viret, fervet), die den Eindruck einer lebendigen räumlichen Umgebung hervorrufen. Die Relation der verschiedenen Teilbereiche zueinander wird nicht bestimmt. Möglicherweise bildet allerdings die Abfolge ihrer Nennung einen Weg ab, auf dem sich Bassus folglich von einem Tor aus an einem Fluss, Gräbern und einem kleinen Heiligtum vorbei bewegt hat. Damit würde freilich die Pointe dieses Epigramms den aufmerksamen Leser wenig überraschen: Bassus ist auf dem Weg zu seinem Landgut. In der räumlichen Bewegung liegt die Pointe des Epigramms: weg von der Stadt, durch eine lebendige außerstädtische Umgebung, aber mit einer Ladung, die eine ausgewiesen ländliche Handelsware ist. Zeichen der Verstädterung ist es, dass Bassus auf dem Land nicht als Selbstversorger lebt, sondern dies eine Angelegenheit der Stadt geworden ist, diese mithin ihren Geltungsbereich bis dorthin ausgeweitet hat.

Während die beiden ersten Beispiele räumlich einen Prozess der Verstädterung an Grenzbereichen oder in der unmittelbaren Umgebung der literarischen urbs Roma beschreiben, der bereits abgeschlossen oder noch im Vollzug ist, ist der außerstäd-

489 Mart. 3, 47, 1-6, 15. 
tische Raum im Epigramm Martials anhand der typischen Teilelemente für die Erzählgegenwart noch deutlich erkennbar. Im Zentrum der Betrachtung steht jedoch in allen Beispielen jeweils die Ausweitung der urbs. ${ }^{490}$ Deren Grenzen verschieben sich im räumlichen und übertragenen Sinne nach außen. Ihre Grenzen sind demnach nicht exklusiv, sondern erweisen sich von innen nach außen als durchlässig.

\subsubsection{Tiberim defluxit Orontes. Durchlässige Grenzen}

Das Eindringen nicht-städtischer Teilelemente wird an den Grenzen nicht präsentiert. Eine Renaturierung der urbs Roma, durch den Austausch städtischer durch typisch ländliche Teilelemente, findet sich in der augusteischen und kaiserzeitlichen Dichtung nicht. ${ }^{491}$ Es finden sich zwar generelle Feststellungen, dass etwa auf dem Tiber Schiffe fahren ${ }^{492}$ oder Reisende auf den Ausfallstraßen unterwegs sind, wie im Epigramm 4, 64 Martials. Dort nahm der Sprecher sie aber als Vorgänge wahr, die von der Stadt wegführten. Derartige mobile Objekte auf LandstraBen oder Schifffahrtswegen werden weder in ihren räumlichen und materiellen Merkmalen genauer betrachtet, noch werden sie zu einer Ereigniszone. ${ }^{493}$ Die Ankunft eines Schiffes in der urbs Roma etwa wird nicht in einer Hafenszene dargestellt oder die Ankunft eines Reisenden vor einem Stadttor. Hingewiesen wird gelegentlich auf ein allgemeines Eindringen von nicht-römischen also ausländischen Teilelementen, ohne dass dies jedoch an Zonen des Übergangs gestaltet wird. Auf eine Durchlässigkeit einer Grenze von außen nach innen kann folglich nur indirekt aufgrund ihres Vorhandenseins innerhalb der literarischen urbs Roma geschlossen werden.

Für Umbricius, die Figur in der dritten Satire Juvenals, ist wichtigstes Kriterium, die Stadt zu verlassen, eine generelle Überhandnahme an fremdstämmigen Menschen, pointiert von ihm formuliert: die Graeca urbs (v. 61). In drei, dicht hintereinander folgenden Passagen äußert sich Umbricius $\mathrm{zu}$ dieser Inbesitznahme und weist zwar lediglich implizit, aber doch dominant räumlich immer wieder auf die Durchlässigkeit der Grenzen der literarischen urbs Roma von außen nach innen hin.

iam pridem Syrus in Tiberim defluxit Orontes

et linguam et mores et cum tibicine chordas

\footnotetext{
490 Weitere Stellen, in denen die Erweiterung des Stadtgebietes thematisiert wird: Hor. ars 208; Ov. fast. 1, 241.

491 Vgl. Purcell (1987) zum Verständnis von rus in urbe.

492 Schiffe auf dem Tiber: Prop. 1, 14, 1-6; Ov. fast. 4, 293-348.

493 Ein ausgedientes Schiff auf dem Tiber: Mart. 10, 85.
} 


\section{obliquas nec non gentilia tympana secum \\ 65 vexit et ad circum iussas prostare puellas. ${ }^{494}$}

Als topographisches Merk- und Wahrzeichen der urbs Roma wird der Tiber genannt. Er dient als ein Transportweg, der Fremdländisches ${ }^{495}$ mitten ins Zentrum (ad circum, v. 65) bringt. Der Tiber ist somit nicht als eine zu überwindende Grenze der urbs gestaltet, sondern als Route mitten in die urbs Roma hinein. Zu überwindende räumliche Gegebenheiten werden nicht genannt. Im Gegenteil: In Bezug auf die Aufnahme wird in dieser Passage ein Bild gewählt, dass gerade die Vorstellung einer unaufhaltbaren Durchlässigkeit vermittelt. ${ }^{496}$ Der direkte Zufluss des Orontes in den Tiber (in Tiberim defluxit Orontes, v. 62), ein geographisches Paradoxon, hebt die Vorstellungen jeder räumlichen Abgrenzung zwischen Außen und Innen pointiert auf.

In einer Variation wird der unaufhaltsame Zustrom in der folgenden Passage ausgestaltet:

bic alta Sicyone, ast hic Amydone relicta,

70 bic Andro, ille Samo, bic Trallibus aut Alabandis,

Esquilias dictumque petunt a vimine collem,

viscera magnarum domuum dominique futuri. ${ }^{497}$

Beschrieben werden Bewegungen von Fremdstämmigen in die urbs Roma hinein, nicht als Kollektiv, sondern es werden - in epischer Manier ${ }^{498}$ - die Bewegung einzelner Männer (bic ... bic ... hic ... ille ... hic ... petunt, v. 69-71) nachvollzogen, die sich aus verschiedenen Gebieten Griechenlands in die urbs Roma aufgemacht haben. Die Bewegung, deren Ausgangspunkt und Ziel explizit genannt ist, wird in drei Schritten vollzogen: von Städten oder Inseln in Griechenland, also aus Gebieten von einigem Umfang, hinein in ein kleineres Gebiet, nämlich zu explizit genannten Teilbereichen der urbs Roma, zwei Hügeln, dem Esquilin und dem Viminal (dictumque ... a vimine collem, v. 71), bis in das Innere einzelner domus (Zoom). Auch bei dieser sukzessiven Fokussierung kleinerer räumlicher Einheiten werden keinerlei Grenzen oder andere Hindernisse benannt, die es bei dem Eintritt in die urbs Roma oder bei dem Eintritt in die Häuser für sie zu überwinden gilt. Vielmehr wird ihrem Eindringen bis tief in die Stadt pointiert und zugespitzt durch die räumliche Verwendung des Wortes viscera Ausdruck verliehen. Durch die Bewe-

\footnotetext{
494 Iuv. 3, 62-65.

495 Das Fremdländische wird vor allem akustisch akzentuiert. Vgl. Iuv. 3, 63 f.: linguam ... cum tibicine chordas/ ... tympana.

496 Courtney (1980), 164: „Juvenal is putting in a more pictorial form the metaphor often conveyed by fluo". Braund (1996), 185: „A graphic image of the river Orontes flowing into the Tiber“.

497 Iuv. 3, 69-72.

498 Vgl. Braund (1996), 186.
} 
gung der Einwanderer entsteht ein räumliches Kontinuum, das die Orte ihrer Herkunft und die innersten Teile der urbs Roma verbindet.

In einer dritten Passage vergleicht sich Umbricius als indigener Bewohner der Stadt mit den fremdländischen Eindringlingen. Sie sind ihm an Schnelligkeit und Ansehen überlegen:

\section{(...) me prior ille \\ signabit fultusque toro meliore recumbet, advectus Romam quo pruna et cottana vento? \\ usque adeo nibil est quod nostra infantia caelum \\ hausit Aventini baca nutrita Sabina? ${ }^{499}$}

Die kontinuierliche Bewegung von außen in das Zentrum der Stadt wird in dieser dritten Variation durch den Wind (advectus ... vento, v. 83) verursacht, der die Fremden in die Stadt bringt. Dem gegenübergestellt wird der Himmel als statische Größe über der urbs Roma, dessen Luft der Einheimische seit seiner Kindheit atmet. Die Durchlässigkeit der Grenzen von außen nach innen ist mit dem Bild der Luftbewegungen in einem offenen Himmelsraum verbunden, in dem es keinerlei natürliche Widerstände gibt. ${ }^{500}$

Die Konkurrenten vergleicht Umbricius mit der Importware, nämlich der Pflaume und der Feige, sich selbst mit einem regionalen Produkt, der Olive. Jeweils handelt es sich um Gegenstände, die in hoher Stückzahl vertrieben werden. Dem Vergleich zufolge stehen die Fremdstämmigen in der urbs Roma zu den Einheimischen in Konkurrenz wie massenhaft importierte Ware zu regionalen Produkten.

Die explizit genannten Bewegungen weisen in allen drei Abschnitten auf eine Strecke hin, die zwischen einem Bereich außerhalb und innerhalb der urbs Roma zurückgelegt werden muss, ${ }^{501}$ ohne dass jedoch ein natürliches oder architektonisch manifestiertes Hindernis, dass die Fremdländischen zu überwinden haben, erwähnt wird. Insistiert wird dagegen gerade auf eine Durchlässigkeit von außen nach innen, und zwar zu Wasser, zu Land und in der Luft. 502

499 Iuv. 3, 81-85.

500 Mit der Formulierung in caelum iusseris, ibit (Iuv. 3, 78) schließt Umbricius eine Passage ab, in der er zeigt, dass vor allem der fremdstämmige Grieche sich zu allem, auch den unmöglichen Dingen, bereit zeigt. Diese Behauptung stützt er durch einen Hinweis auf den Geburtsort des Daedalus: in summa non Maurus erat neque Sarmata nec Thrax/ qui sumpsit pinnas, mediis sed natus Athenis (v. 79 f.). Gleichzeitig wird damit der Bereich des Himmels als drittes Element neben Erde und Wasser erwähnt und steht lose als weiterer möglicher Zugangsbereich zur Stadt im Raum.

501 In vergleichbarer Weise wird die implizite Durchlässigkeit der Grenzen in Mart. spect. 3 gestaltet. Vgl. Mart. spect. 3, 1-9: Quae tam seposita est, quae gens tam barbara, Caesar, / ex qua spectator non sit in urbe tua? I venit ab Orpheo cultor Rhodopeius Haemo, / venit et (...) Sarmata (...),/ (...)/ festinavit Arabs, festinavere Sabaei,/ (...)/ (...) venere Sicambri.

502 Diese variantenreiche Schilderung der Inbesitznahme Roms durch Fremde wurde verschiedentlich mit derjenigen Trojas zum Zeitpunkt der militärischen Eroberung durch die Grie- 
Von einer implizit dargestellten Durchlässigkeit der Grenzen der urbs Roma von außen nach innen ist es wohl immer dann erlaubt zu sprechen, wenn entsprechend als ausländisch markierte Teilelemente innerhalb der urbs Roma lokalisiert werden, d. h., wenn sie durch räumliche Inklusion vom Gebiet der urbs Roma umschlossen sind. Neben räumlichen Gegebenheiten, etwa Tempeln ${ }^{503}$, finden sich in der augusteischen und kaiserzeitlichen Literatur wohl vor allem Referenzen auf so genannte mobile Objekte wie Lebensmittel, Haushaltswaren, Baustoffe, Kleidung usw. ${ }^{504}$ Die städtische Physis verändert sich jedoch durch eine derartige Durchlässigkeit der Grenzen nicht. Nach Aussage des Umbricius geht damit vor allen das Römische der literarischen urbs Roma verloren.

\subsubsection{Auswertung}

Aufgrund der wenigen Passagen, in denen Grenzen und Grenzbereiche einer literarischen urbs Roma in den Mittelpunkt der augusteischen und kaiserzeitlichen Dichtung rücken, lassen sich generelle Aussagen zur erzählerischen Ausgestaltung nur eingeschränkt machen. Selbstverständlich wird in zahlreichen Raumdarstellungen eine wie auch immer geartete Begrenzung einer urbs Roma vorausgesetzt, vor allem in denjenigen Texten, in denen sich Figuren zwischen ihr und anderen Bereichen bewegen. Die literarische urbs Roma wurde demzufolge in der augusteischen und kaiserzeitlichen Dichtung durchaus als begrenzt vorgestellt. Wird in den Texten jedoch explizit auf Mauern referiert, erfolgt ihre Erwähnung entweder im Zusammenhang mit einer myth-historischen Vergangenheit oder lediglich als implizite Referenz auf das Stadtgebiet der urbs Roma ohne die Veranschaulichung weiterer architektonischer Details. Auffällig bleibt daher durchaus die fehlende Ausgestaltung einer natürlichen und architektonisch manifestierten klaren Grenze

chen verglichen, wie sie beispielsweise im zweiten Buch der Aeneis dargestellt wird. Vgl. Baines (2003). Wichtig ist in diesem Zusammenhang jedoch zu bemerken, dass es sich gemäß der Illusionsbildung dieser Satire nicht um ein einmaliges Ereignis, wie eben die epische Eroberung Trojas, handelt, sondern Umbricius dies als dauerhaften Zustand der urbs Roma beschreibt, und dass bei dieser Inbesitznahme keinerlei Hindernisse, wie etwa Mauern, überwunden oder zerstört werden müssen.

503 Vgl. Prop. 2, 33 a, 3 f.: atque utinam pereant, Nilo quae sacra tepente/ misit matronis Inachis Ausoniis! und 15 f.: an tibi non satis est fuscis Aegyptus alumnis?/ cur tibi tam longa Roma petita uia? über den Kybelekult.

504 Verlässt man die dieser Untersuchung auferlegte Beschränkung auf das Räumlich-Physische zugunsten eines übertragenen Verständnisses von Räumlichkeit, lassen sich für die Frage nach der Durchlässigkeit von Grenzen weitere zahlreiche, fremdländische Objekte innerhalb der urbs Roma und innerhalb der Dichtung selbst ausmachen. Larmour (2007) macht darauf aufmerksam, dass in Juvenals Satiren Überschreitungen von Grenzen sozialer Hierarchie oder einer Geschlechterordnung häufig thematisiert werden. Des Weiteren weist er auf das Eindringen fremder Elemente in die Texte, z. B. anhand von fremdländischer Sprache, hin. 
als Ereigniszone oder Gegenstand einer Beschreibung. ${ }^{505}$ Darin unterscheidet sich die räumliche Darstellung einer urbs Roma auch von denen anderer Stadtschilderungen. So spielt in der homerischen Ilias etwa die städtische, sich architektonisch manifestierende Grenze eine zentrale Rolle. Im 3. Gesang der Ilias werden die Mauern der Stadt sogar zu einem Schauplatz der Handlung, von dem aus sich die Wahrnehmung der Figuren auf das angrenzende Feld, das außerhalb der Stadt liegt, genauer: auf die dort anwesenden Krieger, ausdehnt. ${ }^{506}$

Möglicherweise wurde eine derartige literarische Thematisierung für den literarischen Raum urbs Roma in einer Erzählgegenwart absichtsvoll unterlassen, um ihr in Bezug auf ihre räumliche Ausdehnung einen besonderen Status zuzuweisen. Eine Übersteigerung gerade des räumlichen Merkmals der Ausdehnung schlägt sich nämlich in dem in augusteischer Dichtung verschiedentlich formulierten Gedanken nieder, das urbs und orbis identisch seien. Diese Formulierung zeigt allerdings gleichfalls deutlich, dass der Redegegenstand urbs Roma im Sinne einer materialisierten Großstadt in diesen Textpassagen zusehends in den Hintergrund rückt und die urbs vielmehr als Allegorie für das Imperium umfunktionalisiert wird. ${ }^{507}$

Statt einer Mauer oder anderer Linearelemente rücken einige Texte Zugangsbereiche zur literarischen urbs Roma in den räumlichen Mittelpunkt und werden als Wahrnehmungsbereich und Schauplatz ausgestaltet und ausführlicher in ihrer räumlichen Gestaltung beschrieben. Durch die Wahl der Darstellungstechniken wird den Zugangsbereichen zur literarischen urbs Roma folglich durchaus eine Relevanz zugeschrieben. Neben expliziten Referenzen auf Stadttore verdeutlichen auch die dort lokalisierten Handlungen (Abschied, Begrüßung) dieses Gebiet als Zone des Übergangs. ${ }^{508}$ Die präsentierten räumlichen Merkmale weisen diese Übergangsbereiche als ausgedehnte Areale aus, sind folglich keine kleinen, schwer zugänglichen Engpässe. Eine markante Abgrenzung der literarischen urbs Roma

505 Purcell (1987), 189, dem es darum geht, das Wort rus nicht als Referenz auf eine natürliche Landschaft missverstanden zu wissen, meint: „But it would not, I feel, have occurred to people to say, ,Here is the edge of the continentia aedificia, the rus starts here'. That is not the opposition which was made." Diese Auffassung ist m. E. zutreffend für die Bestimmung von rus, was sich auch in Formulierungen wie rus in urbe spiegelt. Für die urbs selbst wiederum muss eine Zone, die das Verlassen ihrer räumlichen Umgebung bedeutete, kommunizierbar gewesen sein. Mag sie bereits beim Verlassen des Zentrums oder in äußersten Zonen des Übergangs liegen, die Dichtung gibt den Überlandwegen durch entsprechende Referenzen eindeutig außer-städtischen Charakter und bemüht sich gerade nicht um die Darstellung baulicher continentia. Zur continentia als juristischer Terminus zur Bestimmung des Stadtgebietes vgl. Kolb (22002), 406-409.

506 Vgl. auch die Darstellung der Stadt in der römischen Komödie, in der über Figurenberichte Grenzbereiche der Stadt, wie der Hafen, einbezogen werden bzw. die Figuren durch Bewegung die Grenzen des literarischen Raumes erreichen. Vgl. eine Zusammenstellung zum Hafen bei Johnston (1933), 128-130. Eine Zusammenstellung von städtischen Teilelementen, die gleichzeitig Grenzen der Stadt anzeigen, wie porta u. ä. findet sich bei Johnston (1933) leider nicht.

507 Vgl. Döpp (22003), 33.

508 Räumliche Umgebungen von Stadttoren: Ov. fast. 2, 201 f.; 4, 871 f.; 5, 673; 6, 191 f.; Ov. rem. 549-552; Mart. 4, 18; 8, 65. 
von dem nächst angrenzenden Raum wird hier aber nicht dargestellt, wie auch das sukzessive Ab- und Zunehmen bestimmter Eigenschaften nicht präsentiert wird. Vielmehr wird auf zeitlicher Ebene über eine Ausweitung des städtischen Raumes räsoniert. Für die Erzählgegenwart gehören die Bereiche des Übergangs stets zum städtischen Raum. Ihnen kommt entsprechend der Aussageintention sogar bisweilen paradigmatischer Charakter für den Gesamtraum der literarischen urbs Roma $\mathrm{zu}$.

Raumspezifische Merkmale der Grenzbereiche werden somit kaum in einem für die Figuren gegenwärtigen Lebenszusammenhang präsentiert. Dienen diese Orte zwar dem Abschied und der Begrüßung, so werden nicht Szenen des konkreten Auseinandergehens o. ä. ausgestaltet. Auch das Ankommen und Weggehen anderer Personen oder mobiler Objekte wird selten als ein konkretes Alltagsgeschehen dargestellt. Zu beobachten ist eher eine Tendenz zur Literarisierung, beispielsweise durch die Abgabe der Erzählinstanz an eine Priap-Statue (Hor. sat. 1, 8) oder die poetische Metamorphose einer Landschaft (Iuv. 3).

Der anhand von weiträumigen Übergangsbereichen thematisierte, im Vollzug befindliche oder abgeschlossene Prozess einer Verstädterung wird unterschiedlich bewertet: Diese von den Figuren beobachtete räumliche Veränderung wird als eine Aufwertung der Umgebung begrüßt (Hor. sat. 1, 8), in der dritten Satire des Juvenals dagegen werden diesem Vorgang verschiedene Gefahren zugeschrieben. Es finden sich demzufolge in der augusteischen und kaiserzeitlichen Dichtung durchaus differente Erfahrungen und Bewertungen des Verstädterungsprozesses, die gleichzeitig auch als Erfahrung und Bewertung eines Modernisierungsprozesses verstanden werden können.

Implizit und explizit zeigen diese Prozesse eine Durchlässigkeit der Grenzen der literarischen urbs Roma von innen nach außen. Zentral für die Frage nach der Wiedergabe räumlicher Physis ist die Beobachtung, dass die Verstädterung auf den Prozess einer Ausdehnung des literarischen Raumes urbs Roma aufmerksam macht. Die Durchlässigkeit der Grenzen von außen nach innen wird wiederum gerade nicht in, an oder bei räumlichen Grenzbereichen gestaltet. Die Durchlässigkeit in diese Richtung ergibt sich lediglich implizit durch das Vorhandensein von ausländischen, weniger von ländlichen Teilelementen innerhalb des Gebietes der urbs Roma. Wird die Aufnahme raum-fremder Merkmale thematisiert, handelt es sich in der Regel um mobile Objekte, denen ein Einfluss auf die römischen, jedoch nicht städtischen Eigenschaften zugesprochen wird.

Das Ergebnis zur Begrenzung des Makroraumes urbs Roma scheint in diesem Abschnitt womöglich widersprüchlich. Zum einen wird von der Begrenztheit des Raumes in einer Weise ausgegangen, die eine spontane und zügige Bewegung zwischen verschiedenen Räumen vorstellbar werden lässt. Zum anderen wird auf eine Unbegrenztheit des literarischen Raumes insistiert, indem seine räumliche Ausdehnung explizit mit der des Erdkreises gleichgesetzt wird, und der Eindruck entsteht, die Thematisierung seiner Grenze werde absichtlich gemieden. An den 
durchlässigen Punkten des Raumes werden nicht seine Grenzlinien, Unterschiede zwischen Innen und Außen, sondern die genuin städtischen Merkmale und die Ausdehnung derartiger Merkmale herausgestellt.

\subsection{Innere Strukturen. Raumnot in der literarischen Großstadt}

Wie in den Abschnitten 3.1 und 3.2 dargelegt setzt die Summe der als Inseln aufgeführten Eigenorte eine ausgedehnte Bebauungsfläche voraus, gleichzeitig trägt die Unterteilung des Gesamtraumes in mehrere Bereiche zur Darstellung einer variantenreichen inneren Struktur bei. Wiederholt wird der literarische Raum urbs Roma jedoch auch als dicht (densus) charakterisiert und zudem über einen Mangel an Lebensraum geklagt. Damit ist unmissverständlich ein räumliches Merkmal angesprochen, das die Verhältnisse im Inneren des Makroraums auch in seiner räumlichen Situation in den Blick nehmen will.

In einem ersten Abschnitt (3.5.1) werden Textpassagen präsentiert, die diese räumliche Eigenschaft im Zusammenhang mit einer innerstädtischen Bebauungssituation vorführen und anhand der Abstände zwischen einzelnen räumlichen Gegebenheiten ausgestalten. Für die Frage nach einer inneren Struktur des Gesamtraums urbs Roma ist dabei aufschlussreich, ob die an einzelnen Bereichen dargestellte Beengtheit als beispielhaft für ihn bewertet wird.

In einem zweiten Abschnitt (3.5.2) sollen Textbeispiele vorgeführt werden, in denen die für den literarischen Raum urbs Roma so typische, allgemeine Mobilität der Figuren zu Verdichtungen führt. Auch wenn es sich bei einer solchen räumlichen Beengtheit lediglich um vorübergehende Verhältnisse handelt, gehört doch laut Lynch die Selektion von ,intensiv genutzte[n] Zentralpunkte[n]“509, in denen es durch Bewegungen wiederholt und regelmäßig zu Verdichtungserscheinungen kommt, ebenfalls zu den grundlegenden Strukturelementen der menschlichen Stadtwahrnehmung. Um bei Ausgestaltungen eines derartigen transitorischen Raumes von der Darstellung eines sogenannten ,Knoten- und Konzentrationspunkts im Sinne Lynchs sprechen zu können, wird es von Interesse sein, ob diese Konzentrationen als einmalige Ausnahmeereignisse erzählt werden oder ob sie als sich regelmäßig wiederholende Ereignisse beschrieben und als eine dauerhafte Eigenschaft des Makroraums urbs Roma gewertet werden können.

\subsubsection{Dichte Bebauung}

In Martials Epigramm 5, 22 wird die innere Struktur des literarischen Raums urbs Roma in bekannter Weise ausgestaltet: Mehrere topographische Merkzeichen konstituieren die literarische urbs Roma; zwischen diesen innerstädtischen Bereichen liegt eine räumliche Distanz, deren Überwindung aus der Sicht des Sprechers

509 Lynch (1975), 61. 
kaum zumutbar ist (longius, v. 2), über die er aber täglich eine soziale Verpflichtung aufrechterhält:

1

\begin{abstract}
Mane domi nisi te volui meruique videre, sint mibi, Paule, tuae longius Esquiliae. sed Tiburtinae sum proximus accola pilae, qua videt anticum rustica Flora Iovem: 510
\end{abstract}

Auch die hier vorliegende Darstellung der einzelnen Orientierungspunkte findet sich vielfach in der römischen Dichtung ${ }^{511}$ : Um über eine bestimmte Position innerhalb des literarischen Raumes Auskunft zu geben, nennt der Sprecher verschiedene räumliche Gegebenheiten, von denen die eine die andere enthält (Inklusion) oder die sich in einiger Nähe zueinander befinden. Aus den Überschneidungen ihrer räumlichen Umgebungen ergibt sich die realistisch wirkende Positionierung eines genauen Standorts. Gleichzeitig vergeben derartige Beschreibungen auch Informationen über eine jeweilige Bebauungssituation. Denn die in diesem Epigramm gegenübergestellten innerstädtischen Bereiche zeugen von einer unterschiedlichen Dichte an Gebäuden: Dem diffus umgrenzten, weiträumigen Bereich des Esquilin, innerhalb dessen sich eine einzelne domus, der Standort des Paulus (tuae, v. 2), befindet, wird die räumliche Umgebung des Sprechers gegenübergestellt. Durch die Betonung der ausgewiesenen Nähe seines Standorts zu einem Pfeiler (proximus accola pilae, v. 3) und der zusätzlichen Nennung zweier gegenüberliegender Tempel, die den infrage kommenden Bereich auf zwei Seiten begrenzen, wird implizit ein im Vergleich kleinerer Raumausschnitt beschrieben, innerhalb dessen der Sprecherstandort liegt, und damit auch eine enger bebaute und relativ unübersichtliche innere Struktur für diesen Bereich vorausgesetzt. ${ }^{512}$ Der Illusionsbildung dieses Epigramms zufolge hat diese literarische urbs Roma als Ganze, was ihre Bebauungsdichte betrifft, keine durchgehende innere Struktur, sondern umfasst dicht bebaute und weniger dicht bebaute Areale.

510 Mart. 5, 22, 1-4.

511 Diese Passage thematisiert ausschließlich räumliche Verhältnisse: Zunächst wird als Endpunkt einer Wegstrecke ein Gebäude (domi, v. 1) genannt, das innerhalb (Inklusion) des weiträumigen Eigenorts des Esquilin (Esquiliae, v. 2) positioniert wird. Der Ausgangspunkt, der Sprecherstandort, dagegen liegt in unmittelbarer Nähe (proximus, v. 3) zu einem Pfeiler, der wiederum in die räumliche Umgebung zweier Tempel eingebettet ist. Auch diese Merkzeichen werden zueinander in eine räumliche Beziehung gesetzt: Die beiden Tempel liegen sich gegenüber, wobei die Personifikation des einen Tempels als Wahrnehmungsinstanz (qua videt ... rustica Flora, v. 4) zeigt, dass er eine intrinsische Vorderseite hat.

512 Eine genaue Vorstellung der hier präsentierten räumlichen Umgebung ist eng mit der subjektiven Vorstellung des Lesers verbunden. Der Eigenort eines Pfeilers bleibt schwer vorstellbar, womöglich fungiert er als ein spezifisches Merk- und Orientierungszeichen, da er durch seine intrinsische vertikale Achse weithin sichtbar ist. Damit relativiert sich die räumliche Vorstellung dessen, was der Sprecher mit proximus meint. 


\subsubsection{Gefährliche Enge I. Entgrenzungen von innen nach außen}

Das Epigramm Martials 7, 61 widmet sich monothematisch einer inneren Struktur, die - der Illusionsbildung gemäß - der gesamten literarischen urbs Roma (totam ... urbem, v. 1) zukommt.

1

5

10
Abstulerat totam temerarius institor urbem inque suo nullum limine limen erat. iussisti tenuis, Germanice, crescere vicos, et modo quae fuerat semita, facta via est. nulla catenatis pila est praecincta lagonis nec praetor medio cogitur ire luto, stringitur in densa nec caeca novacula turba occupat aut totas nigra popina vias. tonsor, copo, cocus, lanius sua limina servant. nunc Roma est, nuper magna taberna fuit. 513

Als innere Struktur wird eine äußerst beengte Bebauungssituation mit der Feststellung vergegenwärtigt, dass die Grenzen der Häuser (limen, v. 2) sich nach außen verschoben und den Eigenort der Straßen für sich vereinnahmt haben (inque ... nullum limine limen, v. 2). Die Perspektive auf diese innere Struktur ist folglich vom öffentlichen Straßenraum aus: Die angrenzenden Wohn- und Arbeitsgebäude verengen, beschneiden, beseitigen sogar (Abstulerat totam temerarius institor urbem, v. 1) den städtischen Raum.

Eine derartige räumliche Entgrenzung gehört, wie die Tempora von Beginn an zeigen, einer jüngeren Vergangenheit an (nunc ... nuper, v. 10) und ist daher genau genommen die innere Struktur eines zeitlichen Fernraums (temporally distant frame), der in dieser Weise auch einen Kontrastraum zum gegenwärtigen Schauplatz darstellen soll. Die räumlichen Gegensätze werden durch kontrastreiche Gattungsbezeichnungen für Straßentypen und eine entsprechende Attribuierung vor Augen geführt: Die literarische urbs Roma der Vergangenheit enthielt Straßen von geringem Umfang (tenuis vicos, v. 3; semita, v. 4); im literarischen Raum der Gegenwart sind diese schmalen Fußwege zu breiten Fahrwegen (facta via est, v. 4) geworden.

Der Sprecher widmet den einst beengten Verhältnissen einen weiteren Abschnitt (v. 5-8). Mittels vier räumlicher Eindrücke - erneut vom öffentlichen Straßenraum aus gewonnen - werden diese ausgestaltet: Als erstes wird die Außenansicht von Häusern beschrieben: Pfeiler (pila, v. 5), die die Grenze zwischen Häusern und Straße repräsentieren, trugen zur Vergrößerung des Eigenortes der Häuser bei, indem sie mit Weinkrügen behängt wurden (catenatis ... praecincta lagonis, v. 5). Als zweites beschreibt der Sprecher die räumliche Situation auf der Straße: Ein praetor geht in der Mitte der Straße, auf die hier über ihre Beschaffenheit (luto, v. 6) ange-

513 Mart. 7, 61, 1-10. 
spielt wird. Dass der Bewegungsumfang der Figur eingeschränkt ist und sich auf beiden Straßenseiten Bewegungshemmnisse befinden, legt die passive Formulierung und die Akzentuierung der Straßenmitte (medio cogitur ire luto, v. 6) nahe. In der nächsten Szene geht ein Barbier seiner Arbeit auf offener Straße nach. Der Raum, den der Barbier in Anspruch nimmt, wird über seine - wenig ausladende - Handbewegung bei der Benutzung eines Rasiermessers (stringitur, v. 7) angedeutet: Die Bewegung der Hand, an deren Ende das Messer ist, beschreibt seinen maximalen Bewegungsumfang. Das unbekümmerte Ausüben seines Handwerks mit einem Messer wird jedoch als ein Risiko für die anderen eingeschätzt. Denn er teilt sich den zur Verfügung stehenden öffentlichen Straßenraum mit einer anonymen Menschengruppe unbekannter Zahl (in densa ... caeca novacula turba, v. 7). Die räumlichen Abstände innerhalb der Menschenmenge sind so beschaffen, dass man sich auf Armeslänge nahe kommt. Der letzte räumliche Eindruck wird als ein Paradoxon gestaltet: Es heißt, der natürlicherweise größere Eigenort - nämlich der einer via ${ }^{514}$ - ist von einem als kleiner geltenden Eigenort - nämlich dem einer popina - vollständig vereinnahmt worden ${ }^{515}$ (occupat ... totas popina vias, v. 8). Neben dem Ausmaß der Entgrenzung deutet dieses Bild darauf hin, dass der offene StraBenraum nun auch Eigenschaften eines geschlossenen Innenraums aufzeigt.

Die Pointe von Martials Epigramm liegt jedoch gerade darin, dass diese vermittelte innere Struktur den eigentlichen Verhältnissen einer literarischen urbs Roma nicht entspricht. Ein Mangel an öffentlichem Straßenraum kommt einem Raum, der urbs Roma genannt werden soll, explizit nicht zu, sondern stellt, so der Sprecher, geradezu einen Verlust ihres räumlichen Charakters dar. Ihre eigentliche innere Struktur ist in der Gegenwart des Sprechers durch das Eingreifen des direkt angesprochenen Germanicus wieder hergestellt: Die öffentlichen Straßen sind breit und die Grenzen werden gewahrt (sua limina servant, v. 9); stadtrömischer Raum (nunc Roma est, v. 10) ist wieder deutlich erkennbar.

Eine andere Beurteilung dessen, was als innere Struktur dem Gesamtraum urbs Roma zukommt, findet sich in der dritten Satire Juvenals. Der Sprecher dieser Satire, Umbricius, berichtet von einem vergleichbaren Betrachterstandpunkt aus von der räumlichen Situation einer beliebigen Straße in der Großstadt.

Respice nunc alia ac diversa pericula noctis,

quod spatium tectis sublimibus unde cerebrum

270 testa ferit, quoties rimosa et curta fenestris

514 Ich verstehe vias als poetischen Plural.

515 In welcher Form man sich die Raumnahme der Kneipe vorzustellen hat, geht aus dem Text nicht hervor. Galán Vioque (2002), 357 f. denkt auch an eine olfaktorische Okkupation und nennt verschiedene Belegstellen. Der Duktus des Epigramms legt aber m. E. eine konkrete Vereinnahmung der Straße durch Objekte nahe. Handelt es sich nach Ansicht des Sprechers bei den beengten Verhältnissen doch um eine magna taberna. 
vasa cadunt, quanto percussum pondere signent

et laedant silicem. possis ignavus haberi

et subiti casus improvidus, ad cenam si

intestatus eas; adeo tot fata quot illa

275 nocte patent vigiles te praetereunte fenestrae.

ergo optes votumque feras miserabile tecum,

ut sint contentae patulas defundere pelves. ${ }^{516}$

Der räumliche Mittelpunkt dieser Passage besteht aus einem Ensemble, das ebenfalls aus einer Straße besteht, die implizit über das Straßenpflaster (silicem, v. 272) angedeutet ist, und aus Mietshäusern, die implizit durch ihre Grenzen (tectis, v. 269; fenestris, v. 270; fenestrae, v. 275) umschrieben werden. Eine mit ,du' exemplarisch vorgestellte Figur bewegt sich an diesen Gebäuden vorbei (praetereunte, v. 275). Von der Existenz der Gebäude und der strukturell als Nebenraum gestalteten Innenräume der Häuser wird der Stadtgänger durch taktile (cerebrum/ testa ferit, v. 269 f.), visuelle (rimosa et curtal ... vasa cadunt, ... signent/ et laedant, v. 270-272) und akustische (percussum, v. 271) Stimuli multisensuell in Kenntnis gesetzt. Gleichzeitig wird mittels dieser mobilen Objekte die vertikale Achse der Häuser herausgestellt. Ihre Höhe, die explizit als hoch charakterisiert ist (tectis sublimibus, v. 269), wird durch die von den Objekten zurückzulegende Wegstrecke (quod spatium ... unde/ ...ferit, v. 269 f.) und die damit verbundene Wucht ihres Aufpralls (quanto percussum pondere signent/ et laedant silicem, v. 271) noch zusätzlich sensuell veranschaulicht. ${ }^{517}$

Der Abstand, den man auf der Straße zu den Gebäuden einnehmen kann, ist nicht allzu groß518, da es zu großen Überschneidungen der beiden Bereiche kommt. Die Anwohner weiten ihren Wohnraum (Nebenraum) auf die Straße (Schauplatz) aus, insofern sie Gegenstände (mobile Objekte) von den Fenstern aus (fenestrae, v. 275) dorthin entsorgen. Daraus entstehen für die Wahrnehmungsinstanz auf der Straße (te pratereunte, v. 275) unmittelbar Gefahren für den eigenen Körper, den Eigenort des Individuums (cerebrum, v. 269), die sogar als lebensbedrohlich eingeschätzt werden (si/ intestatus eas, v. 273).

Entsprechend dem Duktus dieser Passage stellt diese beispielhaft präsentierte Bebauungssituation eine innere Struktur dar, die vom Leser im Sinne eines pars pro

516 Iuv. 3, 268-277.

517 Auch die Erwähnung der Fenster (vgl. Iuv. 3, 270, 275) ist ein impliziter Hinweis auf die Höhe der Häuser. Vgl. dazu Braund (1996), 221.

518 Ein mögliches Ausweichen des Fußgängers - etwa in die Mitte der Straße - wird nicht in Betracht gezogen. Vielmehr wird ein Passant als unbedacht und unvorbereitet (possis ignavus haberi/ ... improvidus, Iuv. 3, $272 \mathrm{f}$.) bezeichnet, der sich auf diese regelhaften Gefahren nicht durch das Verfassen eines Testaments eingestellt hat. Zu Gefahren, die unmittelbar mit einer Bausubstanz des literarischen Raums urbs Roma verbunden sind, vgl. auch Iuv. 3, 6-9: nam quid tam miserum, tam solum vidimus, ut non/ deterius credas horrere incendia, lapsus/ tectorum assiduos ac mille pericula saevae/ urbis (...). Die andauernden Brände und Einstürze setzen die entsprechende Bebauungsdichte voraus. 
toto auf den gesamten literarischen Raum bezogen werden soll. Denn die Häufigkeit solcher Ereignisse (quoties, v. 270; tot ... quot, v. 273) und die als Resümee zu verstehende Formulierung adeo tot fata quot illa/ nocte patent vigiles te praetereunte fenestrae (v. 274 f.) weisen den gesamten Bewegungsbereich auf horizontaler Achse als beengt, auf sagittaler Achse aber als ausgedehnt aus.

Die dichte Bebauung als eine innere Struktur wird in beiden Textpassagen gleichermaßen an beispielhaften räumlichen Ensembles veranschaulicht, die aus Häuserfronten und Straßen bestehen. Im Mittelpunkt steht die Benutzung des öffentlichen Raumes für Passanten, deren Bewegungsumfang durch die variantenreich dargestellte räumliche Konstellation immer wieder beeinträchtigt ist. In beiden Texten fehlt ein genauerer referentieller Bezug zum Georaum des antiken Roms, womit sich beide Autoren einer genauen Nachprüfbarkeit ihrer räumlichen Ausgestaltung durch einen Leser entziehen. Daraus ergibt sich für sie die Möglichkeit, die Frage, wie repräsentativ die abgebildete innere Struktur für den Gesamtraum ist, so gegensätzlich zu bewerten.

\title{
3.5.1.2 Klangteppich Großstadt. Entgrenzungen von außen nach innen
}

Im Epigramm 12, 57 Martials erklärt der Sprecher, wieso er sich häufig aus der urbs Roma ${ }^{519}$, dem Schauplatz ${ }^{520}$ des Epigramms, auf sein Landgut zurückziehe. Es gebe, so lässt er den direkt angeredeten Sparsus wissen, für den Mittellosen in der Stadt keinen Platz zum Nachdenken oder Ausruhen (Nec cogitandi, Sparse, nec quiescendi/ in urbe locus est pauperi, v. 3 f.). Die Formulierung nec ... locus est evoziert dabei die Vorstellung von einem Mangel an konkretem Raum, mit dem in diesem Fall jedoch nicht ein öffentlicher Transitraum, sondern ein privater Rückzugsort gemeint ist. Von den Gründen für diesen Raummangel berichtet der Sprecher im Folgenden:

\author{
Negant vitam \\ 5 ludi magistri mane, nocte pistores, \\ aerariorum marculi die toto; \\ binc otiosus sordidam quatit mensam \\ Neroniana nummularius massa, \\ illinc palucis malleator Hispanae
}

519 Vgl. Mart. 12, 57, 1 f.: Cur saepe ... parva rura ... / ... petam, quaeris? Die Gattungsbezeichnung urbs wird in diesem Epigramm dreimal verwendet, vgl. Mart. 12, 57, 4, 16 und 21, das Toponym Roma einmal, vgl. Mart. 12, 57, 27. Explizite Referenzen auf topographische Merkzeichen oder städtische Teilelemente finden sich dagegen in diesem Epigramm nicht.

520 Die Verwendung von Deiktika (Mart. 12, 57, 7: binc, Mart. 12, 57, 9: illinc, Mart. 12, 57, 18: ista) für den literarischen Raum urbs Roma weist diesen als Schauplatz dieses Epigramms aus, ebenso wie implizit das intendierte Gespräch mit Sparsus, der sich dem Sprecher zufolge ebenfalls im literarischen Raum urbs Roma aufhält. 
10 tritum nitenti fuste verberat saxum;

nec turba cessat entheata Bellonae, nec fasciato naufragus loquax trunco, a matre doctus nec rogare Indaeus, nec sulphuratae lippus institor mercis.

Numerare pigri damna quis potest somni?

dicet quot aera verberent manus urbis, cum secta Colcho Luna vapulat rhombo. 521

Der Sprecher stellt seine räumliche Umgebung fast ausschließlich in ihrer „hörbaren Gestalt“"522 vor. Trotz der Flüchtigkeit von Geräuschen gehört ihre Alltäglichkeit und Permanenz nach Ansicht des Sprechers zu den festen Eigenschaften seiner räumlichen Umgebung (negant vitam, v. 4). Eine Geräuschkulisse ist dauerhaft gegenwärtig. Je nach Tageszeit unterscheidet die Wahrnehmungsinstanz unterschiedliche Klangfarben (mane - nocte - die toto, v. 5 f.).

In den ersten Versen dieses Textausschnitts identifiziert der Sprecher Stimmen verschiedener Personen und das Geschepper und Geklirre von Werkzeugen: Er nennt zwei Berufsgruppen (magistri, pistores), ohne die von ihnen ausgehenden Geräusche näher zu bezeichnen ${ }^{523}$, und Schmiedehämmer als eine weitere Geräuschquelle. Dieser Aufzählung kann man bereits eine vage räumliche Struktur entnehmen, nämlich dass diese drei Berufsgruppen jeweils Bereiche in relativer Nähe zum Sprecherstandort zur Ausführung ihrer Tätigkeiten in Anspruch nehmen, denn sie sind für ihn akustisch wahrnehmbar. In welcher konkreten Entfernung diese Bereiche liegen, bleibt jedoch offen, da die akustische Wahrnehmung zu den Fernsinnen zählt. Mit der Verwendung des Plurals deutet der Sprecher an, dass sich derartige Bereiche mehrfach in seiner räumlichen Umgebung befinden.

Das Klangerlebnis wird im folgenden Abschnitt (v. 7-14) differenzierter beschrieben, gleichzeitig treten damit weitere Bereiche hervor: Durch die Deiktika hinc und illinc werden zwei Wahrnehmungsbereiche in unterschiedlichen Richtungen angedeutet und mit dem viermaligen nec zusätzliche Geräusche auseinandergehalten. $\mathrm{Zu}$ den realisierten Geräuschen gehören metallene Klänge, die von Metallverarbeitenden erzeugt werden, und unterschiedliche menschliche Laute. Sie qualifizieren diese räumliche Umgebung als ausgewiesen städtisch, zeugen sie doch von einer differenzierten Arbeitsteilung. Die präzisere Beschreibung der Geräuschquellen enthält aber auch räumliche Informationen, nämlich in welchem Abstand sich die Verursacher (Wahrnehmungsbereich) zum Standort der Wahrnehmungsinstanz

521 Mart. 12, 57, 4-17. Zur Klimax des Katalogs vgl. Watson (2003), 155.

522 Böhme (2013), 79. Die Stadtwahrnehmung ist in diesem Epigramm vor allem eine sinnliche Wahrnehmung, architektonische Gebäude werden nicht erwähnt.

${ }_{523} \mathrm{Zu}$ Geräuschen, die von Lehrern verursacht werden, vgl. Mart. 9, 68, 1-4. Über die konkreten Geräusche, die von den Bäckern ausgehen, herrscht keine Klarheit. Vgl. Watson (2003), 152 und Mart. 14, 223. 
befinden: Die selektierten menschlichen Geräusche (loquax, v. 12; rogare, v. 13; institor, v. 14) sind auf die Entfernung hin als nicht besonders laut einzuschätzen. Zudem ist die Wahrnehmungsinstanz in der Lage, sie konkreten Personen zuzuordnen, und nennt visuelle Details (sordidam mensam, v. 7; nitenti fuste, v. 10). Daraus ergibt sich, dass der Standort der Wahrnehmungsinstanz nicht weit von den Schallquellen entfernt vorzustellen ist und sie folglich eine räumlich eingeschränkte, von der inneren Struktur allerdings variantenreich gestaltete Umgebung wahrnimmt. Aus dieser ausgewiesenen Nähe recht vielfältiger Bereiche entsteht der räumliche Eindruck einer enormen Besiedelungsdichte. Mit einer als Adynaton intendierten rhetorischen Frage (Numerare pigri damna quis potest somni?, v. 15) schließt der Sprecher die Beschreibung der Vielfalt an seinem Wahrnehmungsstandort $\mathrm{ab}$ und bündelt die zahlreichen Geräusche in einem Vergleich mit dem Klangerlebnis einer kultischen Massenveranstaltung. 524

Dass diese Geräuschkulisse tatsächlich eine räumlich beengte und nicht nur eine variantenreiche innere Struktur wiedergeben soll, zeigt der anfängliche Hinweis auf die persönliche Raumnot des Sprechers (nec .../ in urbe locus est, v. 3 f.), wegen der er sich zum zeitweiligen Verlassen des literarischen Raums (Cur saepe ... parva rura ... / ... petam, v. 1 f.) genötigt sieht. Zudem wird seine konkrete räumliche Situation an seinem Wahrnehmungsstandort auch noch präziser ausgestaltet:

\section{nos transeuntis risus excitat turbae, \\ 27 et ad cubile est Roma. Taedio fessis \\ dormire quotiens libuit, imus ad villam. 525}

Durch die Erwähnung eines Bettes als typischer Bestandteil eines Schlafraums (ad cubile, v. 27) lässt sich als Standort der Wahrnehmungsinstanz unmissverständlich ein privater Innenraum identifizieren. Von hier aus ist akustisch das Geräusch (risus, v. 26) einer vorüberziehenden anonymen Menschenmenge (transeuntis ... turbae, v. 26) wahrnehmbar. Daraus lässt sich als Nebenraum (secondary frame) ein angrenzender öffentlicher Außenraum, eine Straße, erschließen. Diese sorgfältig strukturierte Unterscheidung zwischen Innen und Außen verdeutlicht die beengte Situation. Denn der Sprecher findet im räumlich getrennten, privaten Innenraum gerade keinen Schutz- bzw. Rückzugsort. Im Gegenteil: Mit dem ausdrucksstarken räumlichen Bild, Rom stehe an seinem Bett (ad cubile est Roma, v. 27), wird die Existenz einer Grenze zwischen öffentlichem und privatem Raum für seinen Standort pointiert negiert. Die Grenzen von außen nach innen erweisen sich als durchlässig. Der Nebenraum dringt bis in die äußerste körperliche Nähe des Sprechers vor.

524 Der akustische Vergleich entspricht in seinem atmosphärischen Klangerlebnis genau dem der vorher genannten Einzelgeräusche und ist absichtsvoll gewählt. Die Geräuschkulisse dieser Kulthandlung besteht ebenfalls aus menschlichen Lauten und metallenen Klängen.

525 Mart. 12, 57, 26-28. 
Die physischen Eigenschaften dieser literarischen urbs Roma, ihre Bebauungsdichte, stellen für den Einzelnen eine Beeinträchtigung dar, die sein Leben wesentlich bestimmen und sogar zu seelischem Verdruss und körperlicher Erschöpfung führen (taedio fessis, v. 27). Will sich der Sprecher ausruhen oder nachdenken ${ }^{526}$, so bleibt ihm als Ausweg nur die zeitweilige Emigration zu den als Fernraum (spatio distant frame) gestalteten parva rura (v. 1), nämlich der Rückzug in seine villa (v. 28). Dass diese Beschreibung der beengten inneren Struktur einem subjektiven Standort innerhalb der literarischen urbs Roma geschuldet ist ${ }^{527}$, lässt der Sprecher jedoch nicht unerwähnt: Dem im Epigramm angesprochenen Sparsus bieten sich nach Meinung des Sprechers andere, sogar gegenteilige Bedingungen. Von dessen innerstädtischem Hügelgrundstück aus genieße dieser nicht nur visuell eine freie Aussicht (cui plana summos despicit domus montis, v. 20), sondern sei auch vor jeder Form einer auditiven Wahrnehmung des literarischen Raumes urbs Roma geschützt. Sein Schlaf und seine Ruhe werden weder nachts noch tagsüber gestört (et in profundo somnus, et quies nullis/ offensa linguis, nec dies nisi admissus, v. 24 f.). Die einzelnen Bereiche des Weinguts, das der Sprecher als regnum bezeichnet (Petilianis delicatus in regnis, v. 19), sind großzügig und bieten sogar mobilen Objekten Bewegungsspielraum (intraque limen latus essedo cursus, v. 23).

Nach Ansicht des Sprechers lässt sich jedoch diese enthobene Wohnumgebung nicht als städtisch klassifizieren. Er bezeichnet sie vielmehr als ein rus in urbe und weist damit explizit für diesen Bereich typische Eigenschaften eines literarischen Raums urbs zurück. Befinden sich beide Bereiche innerhalb des literarischen Gesamtraums, so werden sie doch als Kontrasträume gegenübergestellt, von denen nur dem einen - nämlich dem lauten und dicht bebauten - die Bezeichnung urbs Roma zukommt. 528

Die Ausgestaltung einer dicht bebauten inneren Struktur mittels damit einhergehenden Geräuschbelästigungen wird auch in einem Ausschnitt aus Juvenals dritter Satire gewählt. In Form des iterativen Erzählens berichtet der Protagonist Umbricius von alltäglichen, sich wiederholenden Ereignissen, deretwegen er der literarischen urbs Roma endgültig den Rücken kehren will.

526 Der Schlaf wird in diesem Epigramm besonders akzentuiert: Vgl. Mart. 12, 57, 3: quiescendi; Mart. 12, 57, 15: pigri damna (...) somni?; Mart. 12, 57, 24 f.: in profundo somnus et quies nullis/ offensa linguis; Mart. 12, 57, 26: nos (...) excitat, Mart. 12, 57, 27: ad cubile est Roma; Mart. 12, 57, 28: dormire quotiens libuit.

527 Die subjektive Sichtweise wird bereits durch die Koppelung der Wahrnehmung an eine figurale Wahrnehmungsinstanz signalisiert.

528 Die parva rura werden in diesem Epigramm nicht zum Kontrastraum ausgebaut. Sie böten sich als ein solcher nicht an, da es dem Sprecher eben auch um die beengte innere Struktur der literarischen urbs geht, die er in seinem gewählten Vergleich mit dem großzügigen Bereich des rus in urbe kontrastiert. 
nam quae meritoria somnum

235 admittunt? magnis opibus dormitur in urbe.

inde caput morbi. raedarum transitus arto

vicorum in flexu et stantis convicia mandrae

eripient somnum Druso vitulisque marinis. 529

In den Mietwohnungen (meritoria, v. 234) innerhalb des literarischen Raums urbs Roma (in urbe, v. 235) kann man nicht bzw. nur unter Aufwendung von viel Geld schlafen. ${ }^{530}$ Diese allgemein herrschende Schlaflosigkeit wird auf die Anwesenheit von Geräuschen zurückgeführt, deren Verursacher auf dem öffentlichen Straßenraum (vicorum in flexu, v. 237) lokalisiert werden. Folglich ist auch in dieser Passage die innere Struktur anhand zweier unmittelbar aneinander angrenzender räumlicher Gegebenheiten (Kontakt) ausgestaltet, die erneut nur zonal im Georaum der Metropole verortet sind: Mietwohnungen als Wahrnehmungsstandort und Straßen als Nebenraum (secondary frame). Sie bilden jeweils ein räumliches Ensemble, das entsprechend dem generalisierenden Aussagemodus in unbekannter Zahl innerhalb der literarischen urbs Roma zu finden ist.

Die akustische Wahrnehmung des Nebenraums Straße bleibt in dieser Passage auf die Nacht beschränkt. Als Geräuschquellen werden variantenreich Geräusche von mobilen Objekten ausgemacht: Wagen und Maultiere. Trotz ihrer besonderen Flüchtigkeit zählen sie nach Auskunft des Sprechers zu den festen Eigenschaften des gesamten Makroraums (in urbe, v. 235).

Die in dieser Passage vermittelte innere Struktur der literarischen urbs Roma ist unmissverständlich gestaltet: Die Straßenbiegungen werden als eng attribuiert (arto, v. 236) und auch die Gattungsbezeichnung vicus kennzeichnet eine schmale Straße. ${ }^{531}$ In dieser somit mehrfach akzentuierten Beengtheit werden zudem noch mobile Objekte positioniert, die durch ihren jeweiligen Eigenort geradezu den Eindruck räumlicher Gedrängtheit erzeugen (raedarum transitus .../ ... et stantis convicia mandrae, v. 236 f.).

Die ausschließliche Darstellung des Nebenraums als Transitraum, auf dem sich keine Figuren, sondern lediglich mobile Objekte bewegen, verdeutlicht in besonderer Weise die Beziehungslosigkeit der Wahrnehmungsinstanz zu seiner räumlichen Umgebung. Sie ist für sie kein Bereich sozialer Kontakte, sondern stellt mit ihrer anonymen Geräuschkulisse auf beengtem räumlichen Areal für jeden Be-

529 Iuv. 3, 234-238.

530 Vgl. die Erklärung Braunds (1996), 216, die sich auf den räumlichen Abstand zwischen dem Bereich der Wahrnehmung und dem Nebenraum bezieht: „(...) rich men's houses are large enough to include bedrooms facing inwards, away from noisy street."

531 Das Stehen der Tiere wird von Courtney (1980), 186 ebenfalls auf die räumlichen Umstände zurückgeführt, die eine Bewegung nicht zulassen: ,,in a traffic-jam.“ Enge Straßen für einen literarischen Raum urbs Roma: vgl. Iuv. 6, 78. Dagegen Prop. 3, 14, 29 f.: at nostra ingenti nadit circumdata turba,/ nec digitum angusta est inserwisse uia. 
wohner eine Beeinträchtigung der Lebensumstände dar, die typischerweise zu Erkrankungen führt (inde caput morbi, v. 236). Will man diesen Zuständen entkommen, bleibt einem laut Umbricius nur die dauerhafte Emigration.

Ebenso wie im Epigramm Martials ist jedoch die Wahrnehmung der nächtlichen Geräuschkulisse auch in dieser Passage an eine subjektive Perspektive gebunden. Der in Martial geäußerte Gedanke, dass man in der literarischen urbs Roma als Armer (pauperi, v. 4) nicht schlafen könne, entspricht der Formulierung in der Satire Juvenals, dass man in der Stadt nur mit entsprechendem finanziellen Aufwand schlafen kann (magnis opibus dormitur in urbe, v. 235). Die sich daraus für den Bewohner ergebenden Alternativen sind jedoch in den beiden Passagen unterschiedlich veranschaulicht: Im Epigramm Martials zieht sich der Sprecher bisweilen auf ein Landgut zurück und gleichzeitig verfügt der im Epigramm angesprochene Bekannte Sparsus über ein rus in urbe, das die Eigenschaften der urbs Roma zwar nicht teilt, aber sich innerhalb des literarischen Raums befindet. In der Satire Juvenals werden dagegen derartige Alternativen nicht aufgezeigt. Vielmehr wird Umbricius den literarischen Raum dauerhaft verlassen. Wie der Verweis auf die Abhängigkeit des Schlafens von finanziellen Möglichkeiten nahelegt, gibt es zwar implizit auch innerhalb dieses literarischen Raums Alternativen, veranschaulicht und ausgestaltet werden sie jedoch nicht. Die Imagination des Lesers wird allein für nachteilige räumlich-beengte Bedingungen vereinnahmt.

\subsubsection{Versperrte Sicht. Monumentale Beengtheit}

Räumlich beengte Verhältnisse werden auffälligerweise recht selten durch Referenzen auf topographische Merk- und Wahrzeichen innerhalb des Georaums der römischen Metropole verankert. Eine Ausnahme stellt in diesem Zusammenhang die Silve 1, 1 des Statius dar. Ihre räumliche Gestaltung unterscheidet sich allerdings bereits darin von anderen Darstellungen, dass hier überhaupt eine nähere räumliche Umgebung einbezogen wird. ${ }^{532}$ In der Regel wird nur das Monument selbst, ohne seine räumliche Umgebung beschrieben. Einen allgemeinen räumlichen Eindruck der Statue und ihrer näheren räumlichen Umgebung hält die mit dem Sprecher identische Wahrnehmungsinstanz bereits im ersten Satz fest: Quae superimposito moles geminata colosso/ stat Latium complexa forum? (v. 1 f.). Demgemäß ist der literarische Eigenort (moles) dieser Reiterstatue sowohl auf vertikaler wie auf horizontaler Achse enorm. Ihre Masse verdoppelt sich durch einen oben aufgesetzten Koloss (superimposito geminata colosso). Von der Breite ihrer Aufstellungsfläche

532 Im Fokus steht in der Regel die architektonische Monumentalität des Eigenortes ohne eine weitere räumliche Einbettung. Vgl. Ov. trist. 3, 1 und dazu Abschnitt 3.2. Beschreibungen von Monumenten innerhalb der literarischen urbs Roma: Prop. 2, 31; Ov. fast. 5, 553-598; vgl. Calp. ecl. 7, 23-56. Erwähnt wird hier der tarpeijsche Felsen als räumliche Umgebung, jedoch vorrangig als Höhenvergleich, vgl. Calp. ecl. 7, $23 \mathrm{f}$.: Vidimus in caelum trabibus spectacula textis/ surgere, Tarpeium prope despectantia culmen. Vgl. auch Edwards (1998), 237. 
her umfasst sie die gesamte Platzanlage (complexa forum). ${ }^{533}$ Diese Platzanlage, der Aufstellungsort der „Kolossal“"-statue, wird in ihrer räumlichen Gestaltung genauer beschrieben. ${ }^{534}$

par operi sedes. huic obuia limina pandit

qui fessus bellis (...)

24 primus iter nostris ostendit in aethera diuis, (...)

29 at laterum passus hinc Iulia tecta tuentur,

illinc belligeri sublimis regia Pauli;

terga pater blandoque videt Concordia uultu. ${ }^{535}$

Zur Positionierung der einzelnen Gebäude um das Standbild herum verwendet der Sprecher absolute Referenzen, die sich an der intrinsischen Vorderseite des Reiterstandbildes ausrichten und damit realistisch wirken ${ }^{536}$ : Der Statue gegenüber (buic obuia, v. 22) breitet sich die Schwelle des Caesar-Tempels aus (limina pandit, v. 22). An den beiden Seiten (binc ... illinc, v. 29 f.) und im Rücken (terga, v. 31) stehen die Basiliken und Tempel, die mit wohlwollendem Blick (blando uultu, v. 31) auf die Statue bzw. genauer auf die Flanken des Pferdes (passus, v. 29) ${ }^{537}$ schau-

533 Vgl. dazu Klodt (1998), 31: „Complecti (...) kann eigentlich nur von einem Größeren (...) in Bezug auf etwas Kleines, im Größeren Enthaltenes gesagt werden. Moles complexa forum ist ein Paradoxon, das aber genau den Eindruck wiedergibt, den der neue Koloß auf den Forumsbesucher gemacht haben muss: das Riesendenkmal okkupiert den Platz und erdrückt ihn." Angesichts dieser Ausmaße fragt sich der Sprecher, wie die Statue an ihren Platz gelangt sei (Stat. silv, 1, 2-16). Der Sprecher vergleicht die Größe des Pferdes mit der des trojanischen Pferdes. Dieser Vergleich dient vor allem dazu, Unterschiede zwischen den beiden auszumachen und trägt damit Wesentliches zur Vermittlung einer räumlichen Vorstellung des ihm gegenwärtigen Pferdes bei. Nach Meinung des Sprechers hätte dieses Pferd, das mitten auf dem Forum der literarischen urbs Roma steht, von den Mauern Trojas nicht aufgenommen werden können (bunc neque discissis cepissent Pergama muris, v. 11). Das bedeutet zum einen, die Statue selbst ist in ihren Ausmaßen als überaus gewaltig vorzustellen, zum anderen übertreffen die räumlichen Ausmaße der stadtrömischen Platzanlage die der myth-historischen trojanischen Stadt. Da der Größenvergleich somit zugunsten des vor Ort befindlichen Pferdes ausfällt, wird eine Beglaubigung für ein fiktives Gegenüber nachgereicht. Vgl. Stat. silv. 1, 1, 17 f.: nec ueris maiora putes: par forma decorque,/ par honor.

534 Zur Diskussion möglicher Aufstellungsorte in Rom zur Zeit Domitians vgl. etwa Dewar (2008), 75-83.

535 Stat. silv. 1, 1, 22-24; 29-31.

536 Geht man davon aus, dass eine Reiterstatue eine intrinsische Vorderseite hat, so kann man die Positionierung der Statue als absolut bezeichnen. In einem späteren Abschnitt werden die Hände der Reiterfigur in den Blick genommen, vgl. Stat. silv. 1, 1, 37 f:: dextra uetat pugnas, laenam Tritonia uirgo/ non granat et sectae praetendit colla Medusae. Hier wird wiederum ein deiktisches Referenzsystem gewählt. Die intrinsische Blickrichtung der Reiterstatue ist nun aufgegeben. Die Wahrnehmungsinstanz steht der Reiterstatue gegenüber und nimmt das Schild der Athene von vorn wahr.

537 Vgl. zum Verständnis von laterum passus Vollmer (1971), 221. 
en. ${ }^{338}$ Aus den Grenzen dieser fünf Gebäude ergibt sich die unmittelbare räumliche Umgebung (sedes, v. 22) ${ }^{539}$ der Reiterstatue. Durch die intrinsische Breite der jeweiligen Gebäude entsteht der Eindruck eines nach allen Seiten geschlossenen räumlichen Ensembles, dessen räumlicher Fixpunkt das Standbild ist.

Die Verwendung topographischer Eigennamen und Umschreibungen weist den Standort als das Forum Romanum aus. Die Auswahl aber, drei Tempel und zwei Basiliken, führt gleichzeitig typische Teilelemente vor, deren Eigenorte von ihrem räumlichen Umfang her eine Platzanlage ebenfalls architektonisch dominieren können. ${ }^{540}$ Eine entsprechende Beurteilung liefert auch der Sprecher, dass nämlich eine Auswahl vorgestellt wird, die als unmittelbare räumliche Umgebung die Statue nobilitiert (par operi sedes, v. 22).541 Genau diese Anzahl größerer und bedeutungsvoller räumlicher Gegebenheiten in einer ausgewiesenen räumlichen Nähe zueinander führt aber auch zu dem Eindruck, dass sich die jeweiligen räumlichen Umgebungen mit der der imposanten Reiterstatue stark überschneiden. Dies erzeugt für diesen innerstädtischen Bereich den Eindruck einer geradezu gedrängten, dichten Bebauung.

Dieser subjektive Eindruck des Lesers wird in der Silve auch mittels einer imaginären Nahaufnahme ausgestaltet. Die umliegenden räumlichen Gegebenheiten, die an den Seiten der Statue stehen, werden zu Wahrnehmungsinstanzen (tuentur, v. 29; uidet uultu, v. 31) und nehmen als Wahrnehmungsbereich allein den unteren Teil des gewaltigen Pferdes (laterum passus, v. 29) wahr. ${ }^{542}$ Dieser Blickinszenierung

538 Ich verstehe hier tueri als variatio zu uidet uultu (Stat. silv. 1, 1, 31), prospectare (Stat. silv. 1, 1, 33), aspiciens (Stat. silv. 1, 1,53) und damit ebenfalls als Verb der (visuellen) Wahrnehmung. Vgl. Shackleton Bailey (2003), 33. Er übersetzt tuentur mit „,is surveyed“. Gegen Klodt (1998), 31, die tueri als ,schützen' versteht und das Verständnis von ,sehen` ohne Begründung als unrichtig zurückweist. Vgl. ebd., Anm. 71.

539 Ich verstehe sedes nach OLD (1992), s.v. sedes 8, 1725: „The place or position occupied by anything." Shackleton-Bailey (2003), 33 übersetzt m. E. treffend: „The setting matches the work.“" Gegen Koldt (1996), Anm. 69, die sedes als „Wohnstatt (auch von Göttern)“ oder „Untergrund“ verstanden wissen will.

540 An den umliegenden Gebäuden werden kaum architektonische Details wahrgenommen, sie bleiben demnach auf ihre bauliche Funktion beschränkt. Die Personifizierung der Gebäude trägt dazu bei, die Platzanlage und damit vor allem die Reiterstatue durch die Anwesenheit der Namensgeber zu nobilitieren.

541 Vgl. Vollmer (1971), 219.

542 Die mit dem Sprecher zu identifizierende Wahrnehmungsinstanz behält diese Perspektive von unten während des gesamten Gedichtes ebenfalls bei. Wenn er in den folgenden Abschnitten das Aussehen der Reiterfigur und des Reitpferdes näher beschreibt (Stat. silv. 1, 1, 37-55), wird er von dem erhöht sitzenden Reiter allein Rumpf und Hände visuell in den Blick nehmen, das Pferd dagegen mit allen Gliedmaßen (Kopf, Hals, Sporen und Hufe). Die Gesichtszüge der Reiterfigur werden durch eine weitere Wahrnehmungsinstanz, nämlich die des vergöttlichten Caesar, beschrieben. Vgl. Stat. silv. 1, 1, 23-26: qui [d.h. Caesar, Anm. d. Verf.] fessus bellis adscitae munere prolis/ primus iter nostris ostendit in aethera dinis, / discit et e uultu quantum tu mitior armis, / qui nec in externos facilis saenire furores. Auch die in Stat. silv. 1, 1, 52-54 erwähnte räumliche Gegebenheit betracbtet das Pferd, vgl. dazu Döpp (1996), $323 \mathrm{f}$. 
zufolge sehen die umliegenden Gebäude das Standbild nicht als Ganzes, sondern lediglich einen Ausschnitt. Vier städtische Teilelemente von einigem räumlichen Volumen stehen folglich in so ausgewiesener Nähe zu einem gewaltigen Standbild, da es ihnen die Sicht versperrt. ${ }^{543}$

Gleichzeitig wird aus dieser Blickinszenierung auch offensichtlich, dass die Statue ihre nähere Umgebung weit überragt. Diese vertikale Achse der Reiterstatue wird in einem anschließenden Abschnitt ausgestaltet. ${ }^{544}$ Die Statue selbst wird zu einer potentiellen Wahrnehmungsinstanz, als deren Wahrnehmungsbereich Gebäude auf dem Palatin und der Tempel der Vesta genannt werden. ${ }^{545}$ Dieser Blickinszenierung zufolge kann das Standbild somit über die sie umgrenzenden räumlichen Gegebenheiten hinweg sehen.

543 In zwei weiteren Beispielen, bei denen weitere räumliche Gegebenheiten erwähnt werden, wird ebenfalls die Sichtweite zur Vermittlung eines subjektiven Abstands genutzt, jedoch auch zusätzlich ihre räumliche Nähe explizit hervorgehoben. Vgl. Stat. silv. 1, 1, 53 f.: et pauet aspiciens Ledaeus ab aede propinqual Cyllarus; Klodt (1998), 32 weist auf die Fiktionalität dieser Blickinszenierung hin. Stat. Silv. 1, 1, 75-78: nunc mea felix, / nunc ueneranda palus, cum te prope nosse tuumque/ immortale iubar uicina sede tueri/ concessum.

544 Die vertikale Ausrichtung des Standbildes als Ausdruck seiner besonderen Kolossalität wird gesteigert, indem die jeweiligen Pole dieser Achse, nämlich der ächzende Boden unter ihr und der offene Himmel über ihr, akzentuiert werden. Diese Ausarbeitung der vertikalen Achse drängt die zu Beginn des Gedichtes festgehaltene räumliche Einnahme auf horizontaler Ebene zurück. Bereits im zweiten Satz der Silve zieht der Sprecher die Herkunft der Statue aus dem Himmel in Betracht. Vgl. Stat. silv. 1, 1, 2 f.: caelone peractum/ fluxit opus? Damit wird gleich zu Beginn der Silve der räumliche Bereich oberhalb der Statue benannt und eine räumliche Beziehung auf vertikaler Achse durch die (potentielle) Bewegung geschaffen. Des Weiteren werden die Bereiche unterhalb und oberhalb der Statue zu Kontaktbereichen mit einer myth-historischen Figur (Marcus Curtius) und den vergöttlichten Verwandten ausgestaltet. Vgl. Stat. silv. 1, 1, 66-83 und 94-98. Auf die Darstellung eines Kontaktbereichs zwischen den bei der Einweihung anwesenden Menschen wird dagegen verzichtet. Vgl. Newlands (2002), 67. Diese Darstellung trägt nach Meinung Newlands zu einer majestätischen und quasi göttlichen Isolation der Statue bei. Sie fasst als allgemeinen Eindruck zu dieser Silve zusammen: „Silv. 1, 1 emphasises the isolation of the statue and its remoteness from its viewer.", Newlands (2002), 76. Auf die Positionierung der Statue innerhalb des räumlichen Ensembles und die verschiedenen Blickinszenierungen auf vertikaler Ebene geht sie allerdings im gesamten Abschnitt nicht ein. Bezogen auf eine soziale Distanz, die sich in der Kolossalität des Standbildes ausdrückt, ist ihr mit der Beobachtung einer ,isolation of the statue" sicher Recht zu geben, bezüglich einer räumlichen Distanz weniger. Neben der (ungewöhnlichen!) Einbettung in eine nähere räumliche Umgebung, wird die Perspektive der publica persona in dieser Silve vom Sprecher übernommen. Vgl. dazu, m. E. überzeugend, Hardie (1983), 141: ,(...) he [d.h. der Sprecher der Silve 1, 1, Anm. d. Verf.] appears to identify himself with the people of Rome, on the occasion of the dedication of Domitian's equestrian statue: this identification is conveyed by the words nobis (5) and dicamus (105).“

545 Vgl. Stat. silv. 1, 1, 32-36: ipse autem puro celsum caput aere saeptus/ templa superfulges et prospectare videris,/ an noua contemptis surgant Palatia flammis/ pulchrius, an tacita vigilet face Troicus ignis/ atque exploratas iam laudet Vesta ministras. Klodt (1998), 32 und Anm. 75, weist auf die Fiktionalität des Wahrnehmungsbereiches hin. Die unter Domitian errichteten Neubauten auf dem Palatin waren vom Forum wohl sicher nicht zu sehen. 
Wird eine beengte innere Struktur für einen Bereich innerhalb der literarischen urbs Roma in diesem Text unmissverständlich präsentiert, so ist sie jedoch von dem Sprecher als eine Ausnahmeerscheinung beschrieben, so dass sie auf die Gesamtsituation im literarischen Raums urbs Roma gerade nicht übertragen werden soll.

\section{Zusammenfassung}

In der römischen Dichtung der augusteischen und kaiserzeitlichen Epoche findet sich die mehrdimensionale Ausgestaltung einer dichten Bebauung, jedoch überwiegend anhand von typisch städtischen Teilelementen wie Straßen, Wohn- und Arbeitsgebäuden. Diese werden mit Verweis auf ihre gemeinsame Grenze (Kontakt) als räumliches Ensemble präsentiert und ihre räumliche Beziehung als beengt charakterisiert. Allerdings werden die Abstände zwischen verschiedenen Gebäuden nicht vermessen. Die Ausgestaltung erfolgt einerseits durch unterschiedliche Formen mobiler Objekte, die die Anwohner in den öffentlichen Straßenraum in variantenreicher Form platzieren, und die dort von Passanten multisensuell als Bewegungseinschränkungen und sogar als Gefahren für den menschlichen Körper wahrgenommen werden. Andererseits werden die beengten Verhältnisse als eine auditive Erfahrung ausgestaltet. Die Anwohner sehen sich wegen einer hohen Besiedelungsdichte und einem Transitverkehr einer permanenten und alltäglichen Geräuschkulisse ${ }^{546}$ ausgesetzt, die von einem öffentlichen Außenraum bis in ihre privaten Innenräume eindringt. Die Vielzahl an Lauten und Klängen, die den Standort der Wahrnehmungsinstanz anfüllt, weist auf verschiedene Berufsgruppen und Tätigkeiten, denen innerhalb eines recht kleinen Radius nachgegangen wird. Die Permanenz dieses Klangteppichs, die den Alltag in den beengten Verhältnissen wesentlich prägt, führt zu Erschöpfung und Krankheit der Bewohner, denen als Alternative eine zeitweilige oder dauerhafte Emigration bleibt. Die dichte Bebauung und Besiedlung werden folglich in diesen Passagen als eine charakteristische innere Struktur der literarischen urbs kommuniziert. Denn den innerstädtischen Alternativen, die ebenfalls räumlich beschrieben werden, wird ein städtischer Charakter nicht zugestanden.

Trotz der gedrängten inneren Struktur sind kaum Interaktionen an den jeweiligen Kontaktbereichen zwischen den Figuren ausgestaltet, die sie als deren vertrautes soziales Umfeld präsentieren würden. Die Wahrnehmungsinstanz tritt mit niemandem in eine direkte Interaktion, auch nicht die beobachteten Figuren untereinander. Allgegenwärtig sind dagegen mobile Objekte oder Geräusche der weitgehend anonym bleibenden Anwohner und Passanten, die man passiv über den haptischen Nahsinn oder den akustischen Fernsinn wahrnimmt. Der strukturell als

546 Lärm wird im literarischen Raum urbs Roma häufig wahrgenommen und dient auch seiner Kennzeichnung. Vgl. Verg. ecl. 1, 55; Verg. georg. 3, 435; Hor. carm. 3, 1, 21; 3, 29, 12; Hor. epist. 1, 17, 7; 2, 2, 79; Calp. ecl. 4, 25 f.; Stat. silv. 4, 4, 18 f.: te quoque clamosae quae iam plaga mitior V rbi/ subtrahit?; Mart. 12, 18, 2: clamosa Subura; Iuv. 4, 32 f. Zum Lärm allgemein vgl. Dahlmann (1978). 
Schauplatz oder Nebenraum ${ }^{547}$ konzipierte Straßenraum repräsentiert daher einen öffentlichen Raum, der weitgehend als anonymer Transitraum wahrgenommen wird.

Die variantenreichen Referenzen auf typisch städtische Teilelemente in diesen Textpassagen weisen den dargestellten Raum als einen städtischen aus. Trotz der Nennung des Toponyms Roma bleibt in den meisten Beispielen eine genauere Verortung im Georaum aus. Indem die räumlichen Situationen lediglich zonal eingebettet werden, erhalten die Bereiche einerseits einen exemplarischen Charakter für den Gesamtraum, andererseits wird die dargestellte räumliche Situation von einer genauen Nachprüfbarkeit suspendiert. Damit erweitert sich der Gestaltungsspielraum der Autoren, der sich beispielsweise in einer widersprüchlichen Bewertung spiegelt, ob es sich bei einer beengten inneren Struktur um eine typische Eigenschaft des literarischen Raums urbs Roma handelt oder nicht.

\subsubsection{Densum volgus ${ }^{548}$ - Wahrnehmung der Masse}

Zweimal wird in dichter Folge in der Silve 4, 4 des Statius auf den literarischen Raum urbs Roma referiert und ihm werden dabei zwei Eigenschaften zugeschrieben: Er sei dicht gedrängt (densae, v. 14) und laut (clamosae, v. 18). Beide Merkmale beziehen sich in diesem Falle jedoch weniger auf eine innere bauliche Struktur,

547 Wahrnehmungen von Nebenräumen innerhalb der urbs Roma: Hor. epist. 1, 17, 6-8: si te grata quies et primam somnus in horam/ delectat, si te pulvis strepitusque rotarum, / si laedit caupona, Ferentinum ire iubebo. Der Hinweis auf den Schlaf legt nahe, dass es sich bei den wahrgenommenen Geräuschen der Kneipen und Wagen um nahe Geräusche aus einem Nebenraum (Straße) vom Schauplatz aus (Schlafraum) handelt. Eine vergleichbare räumliche Konstellation in Iuv. 6, 415-417. Mart. 1, 49, 33-36: procul borridus Liburnus et querulus cliens,/ imperia viduarum procul;/ non rumpet altum pallidus somnum reus,/ sed mane totum dormies. Vgl. auch Prop. 2, 19, 5 f.: nulla neque ante tuas orietur rixa fenestras,/ nec tibi clamatae somnus amarus erit. Dagegen eine Wahrnehmung von innen nach außen - wohl als einmaliges Ereignis vorgestellt - in Prop. 3, 10, 23 f., 26: tibia nocturnis succumbat rauca choreis,/ et sint nequitiae libera uerba tuae,/ (...)/ publica nicinae perstrebat aura viae. In Juvenals elfter Satire lädt der satirische Sprecher einen Freund zum gemeinsamen Essen ein. Dieses Vorhaben an einem Festtag kontrastiert er in wenigen Versen mit dem gleichzeitig stattfindenden Großereignis in der Stadt, an dem die Mehrzahl der städtischen Bevölkerung teilnimmt. Vgl. Iuv. 11, 197 f. totam hodie Romam circus capit, et fragor aurem/ percutit. Der Lärm schallt vom Circus herüber, in dem sich ganz Rom an den Festtagen versammelt hat. Diese Erkenntnis entspringt einer akustischen Wahrnehmung, und zwar der sich im Circus entwickelnden Geräuschkulisse. Die Übermacht des Lärmpegels übersteigt seine Schmerzgrenze (au$\mathrm{rem} /$ percutit). Eine Bestimmung der Entfernung zwischen seinem Haus (mit der impliziten Referenz limen, vgl. Iuv. 11, 190) und dem Circus wird zwar nicht veranschaulicht, aber der Sprecher will seinen Aufenthaltsort als einen Rückzugs- resp. Erholungsort verstanden wissen (vgl. Iuv. 11, 183-192). Die Mächtigkeit, mit der der Lärmpegel den eigenen Körper erreicht, lässt allerdings die Vorstellung räumlicher Entfernung nicht zu. Vgl. dagegen die Schilderungen der Lautlosigkeit in Mart. 4, 64.

548 Hor. carm. 2, 13, 32; Mart. 6, 38, 5 f. 
sondern auf eine hohe Bevölkerungsdichte, wie durch das erzählte Ereignis deutlich wird: Rom leert sich (rarescunt, v. 14). 549

ardua iam densae rarescunt moenia Romae.

hos Praeneste sacrum, nemus hos glaciale Dianae

Algidus aut horrens aut Tuscula protegit umbra,

Tiburis hi lucos Anienaque frigora captant.

te quoque clamosae quae iam plaga mitior V rbi

subtrahit? 550

Der Prozess des (jahreszeitlichen ${ }^{551}$ ) Leerens wird als eine räumliche Verteilung der Bevölkerung auf außerhalb der urbs liegende Orte beschrieben: Mittels der sechs Toponyme werden bekannte Sommerfrischen vornehmer Römer benannt ${ }^{552}$, mit der Wiederholung des Demonstrativpronomens (hos, hos, hi) diejenigen Gruppen von Stadtrömern bezeichnet, die von diesen Orten bereits aufgenommen wurden. Trotz des Auszugs unbekannter Größe ist der literarische Raum urbs Roma jedoch nicht leer. Die anhaltende Fülle an Menschen wird in einem akustischen Gesamteindruck, nämlich dem eines hohen Geräuschpegels, gebündelt (clamosae ... V rbi, v. 18). ${ }^{553}$

Die besondere Anzahl an Menschen wird in der augusteischen und kaiserzeitlichen Dichtung wiederholt als ein allgemeines Kennzeichen der urbs Roma erwähnt. ${ }^{554}$ So attestiert der Sprecher in der Ars amatoria Ovids dem literarischen

549 Vgl. auch Coleman (1988), 141: „Rome is densa because she is heavily populated (...) as people migrate to the hills for the summer the population thins out."

550 Vgl. Stat. silv. 4, 4, 14-19.

551 Vgl. Coleman (1988), 141: „St[atius] composes a list of resorts outside Rome so as to persuade Marcellus to join the annual migration."

552 Diese Orte gelten als populäre Urlaubsorte für die römische Oberschicht. Vgl. Coleman (1988), 141: „Martial composes an almost identical list of summer resorts.“ (10, 30, 5-7) und Coleman (1988), 142: „The combination of shade and water creates an ideal summer retreat.“ Ähnlich auch die Aufzählung bei Iuv. 3, 190-193; 14, 86-91.

553 Im Mittelpunkt der Silve stehen im Folgenden die zahlreichen Kontakte, durch die der in dieser Silve Angesprochene in das städtische Leben eingebunden ist. Die urbs Roma ist folglich keineswegs menschenleer. Vgl. Stat. silv. 4, 4, 39-43: certe iam Latiae non miscent iurgia leges/ et pacem piger annus babet messesque reuersae/ dimiscere forum, nec iam tibi turba reorum/ uestibulo querulique rogant exire clientes. / cessat centeni moderatrix iudicis hasta. Zu clamosa vgl. Coleman (1988), 142: „Rome is clamosa like any rowdy city. "Ihre angeführte Parallelstelle bezieht sich allerdings ebenfalls auf die literarische urbs Roma. Auch in Stat. silv. 1, 1, 61-70 besteht die dominante Wahrnehmung des Makroraums in der Wahrnehmung von Geräuschen (strepit pulsu, fragor, sonitus, ut sensit mugire forum). Die Wahrnehmungsinstanz berichtet, dass der anhaltende Lärm bei der Fertigstellung einer Reiterstatue über die sieben Hügel der urbs Roma empor steigt und damit einen Geräuschpegel, der sich beständig dort (magnae Romae) ausgebreitet findet (vaga murmura), übertrifft.

554 Dies spiegelt sich vor allem in der Darstellung literarischer Fernräume (spatio distant frame) wider, die sich durch eine geringe Bevölkerungsdichte auszeichnen. Leere Räume im Gegensatz zur urbs Roma: Hor. epist. 1, 7, 44 f.: mibi iam non regia Roma,/ sed vacuum Tibur placet, Hor. epist. 2, 2, 
Raum allein für die Anzahl an Frauen, also einem Teil der Bevölkerung, eine Vielfalt und Verfügbarkeit, die seiner Meinung nach für jeden aufmerksamen Beobachter (quaerenda est oculis apta puella, v. 44) ein passendes Angebot bereithält.

\author{
tot tibi tamque dabit formosas Roma puellas, \\ ,haec habet" ut dicas ,quicquid in orbe fuit." \\ Gargara quot segetes, quot habet Methymna racemos, \\ aequore quot pisces, fronde teguntur aues, \\ quot caelum stellas, tot habet tua Roma puellas: (...). 555
}

Dem Sprecher zufolge bietet der literarische Raum urbs Roma von der Varianz an Frauen her dem Erdkreis Identisches (quicquid in orbe, v. 56). ${ }^{556}$ Zahlenmäßig (quot, tot) stelle er ein Angebot an Frauen bereit, das ihn mit Orten vergleichbar macht, die für ihren Reichtum - vorrangig an Essbarem - bekannt sind.557 Als Vergleichsorte nennt er diffus umgrenzte Makroräume wie Landschaften ${ }^{558}$, Himmel und Meer. Die Vergleichsinhalte, Saatgut, Trauben, Fische, Vögel, Sterne, sind von ihrem Eigenort her im Verhältnis zu den Bereichen, in denen sie sich finden lassen, ausgesprochen klein. Sie können in sehr hoher Stückzahl, eben ,unzählbar‘, im jeweiligen Makroraum enthalten sein. Durch diesen Vergleich wird die räumliche Vorstellung von der literarischen urbs Roma als einem ausgedehnten Makroraum, mit einem Raum, der über eine ausnehmend hohe Bevölkerungszahl verfügt, kombiniert.

In einer unmittelbar vorangehenden Passage wird genau aufgrund dieser besonderen Konstellation - nämlich dass sich die vielen Frauen in einem vergleichsweise ausgedehnten Areal aufhalten - dem jungen Mann ein Ratschlag gegeben. Dafür greift der Sprecher abermals auf einen Vergleich zurück:

81: vacuas ... Athenas; Ov. trist. 4, 8, 27 f.: sed modo, quos habui, vacuos secedere in hortos, / nunc hominum visu rursus et urbe frui; Ov. Pont. 3, 1, 19 f.: rara, neque haec felix, in apertis eminet arvis/ arbor, et in terra est altera forma maris.; Iuv. 3, 2 f.: laudo ... vacuis quod sedem figere Cumis/ destinet atque unum civem donare Sibyllae; Iuv. 10, 102: vacuis Ulubris.

555 Ov. ars 1, 55-59.

556 Varianz ist ein Merkmal, das laut Hollis (1991), 42 in der augusteischen Literatur den literarischen Räumen Roma und Italia - vor allem in panegyrischer Absicht - häufig zugeschrieben wird.

557 Holzberg (1999), 57 f. sieht in dieser Passage eine Parodie eines Stadtlobs. „Es ist das für das Stadtlob typische Motiv der Autarkie. (...) Frauen [werden] als Inventar präsentiert (...) und mit Saatfeldern, Trauben, Fischen, Vögeln und Sternen verglichen und in verschiedene Typen eingeteilt. Das entspricht der Katalogisierung von Türmen, Brücken, Gebäuden und Straßen.“ Jedoch bliebe es - wenn ich richtig sehe - allein bei der Feststellung, dass die urbs Roma hinsichtlich der Frauen autark ist.

558 Ich verstehe die topographische Referenz Gargara auf die höchste Erhebung des Idagebirges wie die topographische Referenz Methymna auf eine Stadt auf Lesbos als topographisches Merkzeichen eines umfassenderen Bereichs (nämlich das Idagebirge und die Insel Lesbos) im Sinne einer pars pro toto. 
scit bene uenator, ceruis ubi retia tendat; scit bene, qua frendens ualle moretur aper. aucupibus noti frutices; qui sustinet hamos, nouit quae multo pisce natentur aquae. tu quoque, (...)

Das Vorgehen, das dem jungen Mann innerhalb der urbs Roma empfohlen wird, ist mit dem von Jägern, Vogelstellern und Fischern vergleichbar: Auch ihre potentielle Beute bewegt sich in großräumigen Gebieten. ${ }^{560}$ Kenner ihres Fachs werden daher bestimmte Punkte innerhalb dieser Regionen aufsuchen, an denen diese Tiere häufiger anzutreffen sind. ${ }^{561}$ Gerade die Ausdehnung der urbs macht es demnach erforderlich, auf der Suche nach einer passenden puella Kenntnis über deren Aufenthaltsorte zu haben. Ein Kenner des Makroraums - und als ein solcher empfiehlt sich der Sprecher - weiß um diese besonderen Bereiche, an denen sich junge Frauen wiederholt aufhalten, die sie vermehrt ansteuern: frequens quo sit disce puella loco (v. 50). Es sind gewissermaßen spezielle „intensiv genutzte Zentralpunkte ${ }^{652}$, an denen sich Frauen innerhalb der literarischen urbs Roma immer wieder konzentrieren.

\subsubsection{Theater, Circus, Atrium - Städtische Konzentrationspunkte}

Im ersten Buch der Ars amatoria werden derartige Konzentrationspunkte en bloc 563 vorgestellt: neben dem Circus ${ }^{564}$ sind es vor allem Festveranstaltungen ${ }^{565}$, die Theater $^{566}$ und das Gastmahl ${ }^{567}$, die sich nach Meinung des Sprechers für eine Kontakt-

559 Vgl. Ov. ars 1, 45-50.

560 Explizit genannt werden Ov. ars 1, 46: ualle; Ov. ars 1, 48: aquae; implizit verweisen auf größere Bereiche Ov. ars 1, 47: frutices; Ov. ars 1, 45: ceruis.

561 Der Vergleich zwischen den angeführten Berufsgruppen und einem Liebenden ist bereits in der antiken Dichtung etabliert, weswegen Hollis (1991), 41 bemerkt: „Stereotyped illustrations, which may seem dull but contain more than meets the eye." Vgl. dazu Kenney (1970), 386-388, der außer Lukrez vor allem griechische Autoren heranzieht. Dabei geht der Vergleich der Stellen vor allem auf die Handlungen ein. Die räumliche Ausdehnung der Orte (o. ä.) wird bei Kenney nicht verglichen.

562 Lynch (1975), 61.

563 Vgl. Ov. ars 1, 67-252. Im Anschluss folgt die Aufzählung von Orten, die außerhalb der Stadt liegen. Sie fällt bei weitem kürzer aus: Ov. ars 1, 253-262. Der Sprecher benennt den beliebten Badeort Baiae und einen stadtnahen Hain der Diana. Vgl. Ov. ars 1, 259: suburbanae templum nemorale Dianae.

564 Ov. ars 1, 135-170.

565 Ov. ars 1, 171-228.

566 Ov. ars 1, 49-134. In Horazens Darstellung über die Anfänge des antiken Dramas und frühere Theaterveranstaltungen wird erklärt, wieso sich im Laufe der Zeit die Konstruktion der tibia verändern musste. Vgl. Hor. ars 204-207: (...) erat utilis (...)/ nondum spissa nimis complere sedilia flatu;/ 
aufnahme als günstig erweisen. Die Intention der Empfehlung weist die Konzentration an den typisch städtischen Teilelementen als wiederkehrend und sich wiederholend aus, sie ist regelhaft, vorhersehbar.

Die Theater sind derartige Bereiche, die intensiv von Frauen genutzt werden. Dass sie mehrfach innerhalb des literarischen Makroraumes urbs Roma ${ }^{568} \mathrm{zu}$ finden sind, zeigt die Verwendung des Plurals (theatris, v. 89), verortet sind sie dagegen lediglich zonal. Damit wird vor allem der großstädtische Charakter des literarischen Raumes betont.

sed tu praecipue curuis uenare theatris; haec loca sunt uoto fertiliora tuo. (...) ut redit itque frequens longum formica per agmen, granifero solitum cum uehit ore cibum, aut ut apes saltusque suos et olentia nactae pascua per flores et thyma summa uolant, sic ruit ad celebres cultissima femina ludos; copia iudicium saepe morata meum est. spectatum ueniunt, ueniunt spectentur ut ipsae: (....). ${ }^{569}$

Der Sprecher vergleicht in diesem Abschnitt die zügigen Bewegungen der Frauen mit denen von kleinen Insekten, nämlich Ameisen und Bienen (ut redit itque frequens, v. 93; uolant, v. 96; ruit, v. 97). Mit diesem doppelten Vergleich wird die Beschreibung eines innerstädtischen Verdichtungsprozesses auf eine poetische Ebene gehoben: Übergeordneter Aufenthaltsort der Bienen sind Waldtäler (saltus, v. 95) und Weideplätze ( weite Distanz hin zu bestimmten, für sie anziehenden Bereichen überwinden (longum ... per agmen, v. 93570; saltusque ... et ... nactae/ pascua, v. 95 f.) und um sie herumfliegen (per flores et thyma summa, v. 96), so bewegen sich die Frauen auf die

quo sane populus numerabilis, utpote parvos, / et frugi castusque verecundusque coibat. Der vormals schwache Ton der tibia - so der Sprecher - habe damals für eine geringere Zuschauerzahl ausgereicht. Diesen Sachverhalt der Tonstärke und der vormaligen Aufführungsbedingungen veranschaulicht er überraschenderweise nicht im Zusammenhang mit kleineren Maßstäben der Theaterarchitektur, sondern - „nicht eben glücklich“ (Kießling/Heinze (1959), 326) - an für die Akustik sekundären Aspekten wie der Überschaubarkeit der Zuschauerzahlen sowie den ihnen zur Verfügung stehenden Sitzmöglichkeiten. Ov. ars 1, 229-252. Vgl. auch Hor. epist. 1, 5, 28 f.

Dass es sich um den literarischen Raum urbs Roma handelt, zeigen innerhalb des ersten Buches wiederholt das entsprechende Toponym oder die Gattungsbezeichnung. Vgl. z. B. Ov. ars 1, 55 : Roma; 59: Roma; 60: in urbe.

Ov. ars 1, 89 f., 93-99.

Vgl. Hollis (1991), 51 zur Formulierung per agmen: „It seems almost, that he imagined the column as existing independently of the ants which form it, so that they can be said to move along the column." 
Theater zu. Die Zone, die die Ameisen wiederholt ansteuern, wird durch ihr typisches Handeln implizit genannt: Es ist der Ort, an den sie durch Nahrung angelockt werden (granifero solitum cum uehit ore cibum, v. 94).

$\mathrm{Da}$ es sich bei diesen Vorgängen um wiederkehrende, typische Ereignisse handelt, teilen diese räumlichen Fixpunkte die Eigenschaften von Konzentrationspunkten. Dass es an ihnen zu einer räumlichen Verdichtung kommt, muss der Leser in Bezug auf die Insekten aus seinem Weltwissen ergänzen. Die Konzentration von jungen Frauen innerhalb der räumlichen Umgebung von innerstädtischen Theatern wird dagegen in dieser Passage durch entsprechende Substantive und Adjektive festgehalten: Die Bereiche der Theater seien reiche "Jagdgründe“ (baec loca ... uoto fertiliora, v. 90), die hohe Anzahl an jungen Frauen mache die Wahl häufig schwer (copia iudicium saepe morata ... est, v. 98).

Mit diesem zweigeteilten Vergleich gestaltet der Autor gleichzeitig zwei unterschiedliche ,Blickinszenierungen', die auf die gemeinten räumlichen Verhältnisse um die Theater herum übertragen werden sollen: In ,Nahaufnahme ${ }^{6}$ werden die Bewegungen der Ameisen um den Ort ihrer Nahrungsbeschaffung wiedergegeben, denn es werden sehr kleine Details - die Anordnung der Ameisen in einem Zug (longum ... per agmen, v. 93) und ihre Nahrung (cibum, v. 94) - selektiert. Übertragen auf die räumliche Zone um die Theater verdeutlicht dieser Vergleich die hohe Konzentration an Menschen, die in wimmelnder Bewegung sind. ${ }^{571}$ Der Bienenvergleich dagegen bietet eine Großaufnahme. Innerhalb räumlich größerer Weideplätze und Wiesen befinden sich deutlich kleinere Bereiche, Blumen und Thymian (Inklusion), die die Bienen anfliegen. Die größeren Bereiche dieses Vergleichs entsprechen dem gesamten Makroraum urbs Roma, die kleineren den Theatern, wie die Bienen den Frauen, die innerhalb des Makroraumes die Konzentrationspunkte ansteuern.572 Mithilfe dieser poetischen Blickinszenierungen befindet sich der Standort des Sprechers im bildkünstlerischen Sinne sogar außerbalb der literarischen urbs Roma.

Das Phänomen einer intensiven Nutzung des öffentlichen Raums wird in Ovids Ars amatoria, aber auch in den Amores gezielt für das spezielle Anliegen dieser Dichtung vereinnahmt. Der Hinweis auf derartige Konzentrationspunkte ist gleichzeitig mit der konkreten Aufforderung an den Liebenden verbunden, sich aus dem Inneren heraus die Vorteile der räumlichen Konstellation zunutze zu

571 Vgl. dagegen Hollis (1991), 50: „The ants call to mind an unbroken column making purposefully for the theatre." Dagegen spricht m. E. die Akzentuierung einer häufigen Hin- und Herbewegung.

572 Vgl. dagegen Hollis (1991), 51: „(...) the bees add a touch of elegance and perhaps imply that the girl's attention is easily turned from one sight to another." Diese Interpretation entspricht m. E. nicht den Textsignalen. 
machen. ${ }^{573}$ Gerade die mit dem hohen Menschenaufkommen verbundene räumliche Dichte verschafft reizvolle und konkrete Möglichkeiten für die Kontaktaufnahme eines liebeswilligen Mannes. ${ }^{574}$ Aus diesem Grund geraten in den Amores 3, 2 Ovids der Circus und dessen räumliche Verhältnisse auf den Zuschauerrängen in den Blick. Er ist das einzige städtische Teilelement, das in dieser Elegie erwähnt wird ${ }^{575}$, jedoch gilt gerade er als ein ausnehmend großstädtisches Bauwerk. Die als regelhaft kommunizierte räumliche Dichte im Circus gibt der Sprecher an einem sehr kleinen räumlichen Ausschnitt wieder, dem Körperumfang einer puella und ihrem Abstand zu ihren allernächsten Nachbarn auf den Zuschauerrängen.

$$
\text { quid frustra refugis? cogit nos linea iungi; }
$$

baec in lege loci commoda Circus habet.

tu tamen a dextra, quicumque es, parce puellae:

contactu lateris laeditur ista tui.

tu quoque, qui spectas post nos, tua contrahe crura,

si pudor est, rigido nec preme terga genu. ${ }^{576}$

Ein im Circus herrschender eingeschränkter Bewegungsspielraum (cogit, v. 19) ist laut dem Sprecher eine räumliche Gesetzmäßigkeit (in lege loci, v. 20). ${ }^{577}$ Der einem

573 Die Theater bieten als potentielle Kontaktbereiche vor allem die Möglichkeit visueller Beobachtung. Vgl. Ov. ars 1, 99: spectatum ueniunt, ueniunt spectentur ut ipsae. Doppeldeutig werden hiermit die Frauen als Wahrnehmungsinstanz eingeführt (spectatum ueniunt, Ov. ars 1, 99), aber eben ohne dass ihr Wahrnehmungsbereich explizit genannt wird. Gleichzeitig werden sie selbst zu einem Wahrnehmungsbereich (spectentur ut ipsae, Ov. ars 1, 99), ohne dass deren Beobachter wiederum explizit würde. Der haptische Wahrnehmungsmodus der Kontaktaufnahme wird für den Bereich des Theaters allein für ein zukünftiges Handeln angedeutet: Vgl. Ov. ars 1, 89-92: sed tu praecipue curuis nenare theatris;/ haec loca sunt noto fertiliora tuo./ illic innenies quod ames, quod ludere possis, / quodque semel tangas, quodque tenere uelis. In einem späteren Abschnitt flicht der Sprecher eine Begebenheit aus der Frühzeit der Theatervorstellungen ein, den Raub der Sabinerinnen. Dabei stellt er das körperlich-handgreifliche Ereignis des Raubes heraus. Die räumliche Distanz zu den Frauen - nicht das generelle Fehlen räumlicher Dichte! - wird als Nachteil dieses städtischen Teilbereiches erwähnt: Vgl. Ov. ars 1, 136-140: multa capax populi commoda Circus habet./ nil opus est digitis per quos arcana loquaris,/ nec tibi per nutus accipienda nota est;/ proxmius a domina nullo probibente sedeto,/ iunge tuum lateri qua potes usque latus. Der Circus und die Auflösung des Gastmahls (vgl. Ov. ars 1, 603606: at cum discedet mensa conuina remota, / ipsa tibi accessus turba locumque dabit./ insere te turbae, leniterque admotus eunti/ uelle latus digitis et pede tange pedem.) werden gerade wegen der Durchmischung der Geschlechter besonders empfohlen.

574 Vgl. dagegen Prop. 3, 14, 29 f.: at nostra ingenti nadit circumdata turba,/ nec digitum angusta est inservisse via.

575 Durch die vom Herausgeber der Textausgabe gewählte Großschreibung soll er als topographisches Merkzeichen der urbs Roma gekennzeichnet sein.

576 Ov. am. 3, 2, 19-24.

577 Diese Szene im Circus wird in Ovids ars 1, 135-164 ähnlich ausgestaltet. Wiederholt findet sich der Hinweis auf die räumliche Enge als Gesetz des Ortes. Vgl. Ov. ars 1, 136-142: multa capax populi commoda Circus babet. (...) proximus a domina nullo probibente sedeto, / iunge tuum lateri qua potes usque latus. / et bene, quod cogit, si nolis, linea inngi, / quod tibi tangenda est lege puella loci. Ebenfalls findet 
Einzelnen zur Verfügung stehende Raum ist für jeden minimal. Körperlicher Kontakt der Sitznachbarn ist daher nach Ansicht des Sprechers unvermeidbar (nos ... iungi, v. 19). Den Versuch, sich dieser Situation durch einen Standortwechsel zu entziehen, betrachtet er als unnütz (quid frustra refugis?, v. 19).

Entsprechende Einschränkungen beschreibt er für die puella, seine Nachbarin, deren zur Verfügung stehenden Raum er in einer Nahaufnahme wiedergibt: Neben dem Sprecher selbst haben weitere Figuren an ihrer rechten Seite (a dextra, v. 21) und im Rücken (post nos, v. 23) mit ihr allesamt einen direkten taktilen Kontakt (contactu lateris tui, v. 22; contrabe crura, v. 23; preme terga genu, v. 24). Für die Figur, die hinter der puella sitzt, werden sogar zwei Körperpartien selektiert (tua contrabe crura, / ... nec preme terga genu, v. 23 f.), wodurch das sukzessive Ansteigen der $\mathrm{Zu}$ schauerränge veranschaulicht wird. Die räumliche Umklammerung ergibt sich folglich aus einer Konzentration an Menschen in bestehenden architektonischen Verhältnissen.

Da der Sprecher jedoch für seine eigene räumliche Umgebung keine weiteren Einschränkungen beschreibt, bleibt offen, ob es sich bei seinem Hinweis auf die Enge als Gesetz des Ortes tatsächlich um eine gegebene räumliche Konstellation handeln soll. Der übergeordnete erotische Kontext, in dem diese Beobachtung wiedergegeben wird, und die widersprüchlichen Argumente, die der Sprecher für sich selbst und für andere nennt, lassen die Extremsituation für die puella als absichtsvoll herbeigeführt erscheinen. Feststeht: Weniger wird das Erlebnis der Masse, sondern eher der Vorteil einer räumlichen Konstellation als intensiver Kontaktbereich geschildert, der sich für einen Einzelnen aus dem Inneren heraus ergibt. ${ }^{578}$

Die Konzentration von Menschen in innerstädtischen Theatern oder dem Circus wird auch außerhalb der Liebeselegie und -didaktik häufig als allgemeiner Eindruck festgehalten und auch das Forum und die Atrien ${ }^{579}$ der Patrone gelten als typische Konzentrationspunkte. Allerdings erfolgt die Wiedergabe der dort herrschenden räumlichen Bedingungen vorrangig durch entsprechende Attribute oder

sich die Möglichkeit der Kontaktaufnahme durch den Hintermann. Vgl. Ov. ars 1, 157 f.: respice praeterea, post nos quicumque sedebit, / ne premat opposito mollia terga genu.

578 Vgl. dagegen Calp. ecl. 7, 23-29, der den Gesamteindruck eines städtischen Teilelements beschreibt: Vidimus in caelum trabibus spectacula textis/ surgere, Tarpeium prope despectantia culmen;/ emensique gradus et clivos lene iacentes/venimus ad sedes, ubi pulla sordida veste/ inter femineas spectabat turba cathedras. / nam quaecumque patent sub aperto libera caelo, / aut eques aut nivei loca densavere tribuni.

579 Atrien: vgl. Iuv. 1, 95-105, 120; Mart. 10, 10; 10, 74; Verg. georg. 2, 461 f.: si non ingentem foribus domus alta superbis/ mane salutantum totis nomit aedibus undam; Ov. Pont. 4, 4, 27 f.: cernere iam videor rumpi paene atria turba, / et populum laedi deficiente loco, (...). Stat. silv. 4, 4, 41 f.: nec iam tibi turba reorum/ uestibulo querulique rogant exire clientes. Zum Sportplatz vgl. Hor. ars 379-381: ludere qui nescit, campestribus abstinet armis/ indoctusque pilae discive trocbive quiescit,/ ne spissae risum tollant inpune coronae: (...). Auktionator: Hor. ars 419: ut praeco, ad merces turbam qui cogit emendas. 
durch allgemeine visuelle ${ }^{580}$ und haptische ${ }^{581}$, selten auch durch olfaktorische Eindrücke. ${ }^{582}$ Prominent ist die akustische Akzentuierung, ${ }^{583}$ die besonders anschaulich auf eine hohe Konzentration an Menschen verweist. Eine konkretere räumliche Veranschaulichung findet sich jedoch vergleichsweise selten. ${ }^{584}$

Ein wenig überraschen mag womöglich, dass auch die Atrien der Patrone als allgemeine Konzentrationspunkte der literarischen urbs Roma präsentiert werden. Da das römische Patronatswesen sich auf persönliche Beziehungen zwischen Patron und Klient gründet, liegt es nicht von vornherein nahe, dass gerade diese Bereiche als intensiv genutzte Zentralpunkte eines umfassenderen Makroraums herausgestellt werden, auch wenn die Wohnhäuser der Patrone in der augusteischen und kaiserzeitlichen Dichtung als innerstädtische Bereiche präsentiert werden, die auBerordentlich häufig von Figuren als Zielpunkte angelaufen werden. Eine räumliche Veranschaulichung einer derartigen salutatio in, an oder bei den Gebäuden der Patrone ist recht selten. Eine Ausnahme stellt eine sich über 30 Verse erstreckende Passage der ersten Satire Juvenals dar, in der ein entsprechender Andrang auch räumlich präsentiert wird.

580 Theater: vgl. Ov. am. 2, 7, 3 f.: sive ego marmorei respexi summa theatri,/ eligis e multis unde dolere uelis; Ov. ars 1, 99: spectatum ueniunt, ueniunt spectentur ut ipsae; Hor. epist. 2, 1, 60 f.: hos arto stipata theatro/ spectat Roma potens. Das Theater ist wegen Überfüllung eng. Vgl. Kießling/Heinze (1959), 211. Forum: vgl. Lucil. 1145-1147 W (= 1228-1230 M); Hor. epist. 1, 6, 59: differtum transire forum populumque iubebat.

581 Vgl. Mart. 5, 8, 7-9: ,Tandem commodius licet sedere,/ nunc est reddita dignitas equestris;/ turba non premimur, nec inquinamur

582 Zum raumerfüllenden Geruch eines Einzelnen vgl. Mart. 2, 29, 1 f., 5: Rufe, vides illum subsellia prima terentem, / cuius et binc lucet sardonychata manus/ (...), / cuius olet toto pinguis coma Marcelliano (...). Zum Duft im Theater vgl. Prop. 4, 1, 16. Safranregen in visueller Wahrnehmung: Mart. 5, 25, 7 f.: hoc, rogo, non melius quam rubro pulpita nimbo/ spargere et effuso permaduisse croco?

583 Theater: vgl. Ov. trist. 3, 12, 24: proque tribus resonant terna theatra foris. (Vgl. dazu auch Iuv. 6, 68: et vacuo clausoque sonant fora sola theatro.); Ov. trist. 5, 7, 25 f.: carmina quod pleno saltari nostra theatro,/ versibus et plaudi scribis, amice, meis, (...); Mart. 6, 34, 5: quaeque sonant pleno vocesque manusque theatro; Circus: vgl. Mart. 10, 53, 1 f.: Ille ego sum (...), clamosi gloria Circi,/ plausus, Roma, tui deliciaeque breves; Stat. silv. 1, 6, 51 f.: hos inter fremitus nouosque luxus/ spectandi leuis effugit uoluptas. Iuv. 11, 193198, bes. 197 f.: totam hodie Romam circus capit, et fragor aurem/ percutit; Forum: vgl. Hor. sat. 1, 9, 77 f.: clamor utrimque,/ undique concursus. Ov. trist. 3, 12, 18: cedunt verbosi garrula bella fori; Ov. trist. 4, 10, 18: fortia verbosi natus ad arma fori; Mart. 6, 38, 5 f.: iam clamor centumque viri densumque coronal volgus et infanti Iulia tecta placent; Iuv. 13, 135: sed si cuncta vides simili fora plena querela.

584 Vgl. Calp. Ecl. 7. 
suppositus venias ac falso nomine poscas.

agnitus accipies. ${ }^{585}$

Die ersten beiden Verse fassen pointiert die entscheidenden räumlichen Merkmale dieses Konzentrationspunkts zusammen: Im Fokus steht die Sportel, die sich am äußersten Rand einer Türschwelle - durch das Enjambement dramatisch als gerade noch ausgestaltet - befindet (primo/ limine ... sedet, v. 95 f.) und die explizit als klein charakterisiert wird (sportula .../parva, v. 95 f.). Diese Schwelle verweist als Außengrenze auf ein Wohnhaus, in dessen räumlicher Umgebung es zu enormen Verdichtungen gekommen ist. Denn diesem äußerst kleinen Objekt steht eine große, unbestimmte Anzahl von Klienten (turba ... togata, v. 96) in größtmöglicher Nähe gegenüber. Das Bestreben jedes Einzelnen dieser Gruppe ist es, die kleine Sportel unter Einsatz von Gewalt ${ }^{586}$ zu ergreifen (rapienda, v. 96), ihr also auf $A r$ meslänge nahe zu kommen. Dies weist die Szene einerseits als angespannt, andererseits als räumlich höchst beengt aus.

Durch einen Perspektivwechsel wird ein ille zu einem wahrnehmenden Gegenüber dieser Menschenmenge, ${ }^{587}$ in dem er in die räumliche Umgebung jedes Einzelnen tritt und diesem in das Gesicht schaut, um sich zu vergewissern, dass er ihn erkennt (faciem ... inspicit, v. 97; agnitus accipies, v. 99). Dieses Ereignis zeigt, dass es nicht möglich ist, sich einen schnellen Überblick über die Versammelten zu verschaffen. Die Reglementierung durch eine visuelle Vergewisserung erlaubt eine relative Vorstellung von der Anzahl der als turba summarisch bezeichneten Klienten, deren genauer Umfang in der folgenden Passage deutlicher wird.

iubet a praecone vocari

100

ipsos Troingenas, nam vexant limen et ipsi

nobiscum. (...)

sed libertinus prior est: (...)

120

densissima centum

quadrantes lectica petit, sequiturque maritum (...). ${ }^{588}$

Durch die gewaltige Ansammlung von Menschen aller Schichten und einem dicht gedrängten Aufgebot an mobilen Objekten wird die räumliche Umgebung eines beliebigen Wohnhauses eindeutig zu einem innerstädtischen Konzentrationspunkt der literarischen urbs Roma ausgestaltet. Dazu werden aus der versammelten Menschenmasse einzelne Gruppen selektiert, die untereinander um die räumliche Um-

\footnotetext{
585 Iuv. 1, 95-99.

586 Vgl. Braund (1996), 98: „rapienda is a violent word.“

587 Gemeint ist entweder ein dispensator oder der Patron selbst vgl. Courtney (1980), 106; Braund (1996), 98.

588 Iuv. 1, 99-102; $120 \mathrm{f}$.
} 
gebung der Schwelle (limen, v. 100) konkurrieren und dabei in einen körperlichen Kontakt (vexant, v. 100) zueinander treten. ${ }^{589}$ Hierzu gesellt sich ein Verband von Sänften ${ }^{590}$ (densissima, v. 120), die als mobile Objekte durch ihren weitaus größeren Eigenort den Eindruck der Masse, die sich vor der Schwelle ansammelt, nochmals steigert. Gründe für diesen exorbitanten Auflauf werden nicht genannt, wie auch eine genauere Verortung in den Georaum der antiken Metropole fehlt. Das kumulativ ausgestaltete Aufgebot entspricht nach Ansicht des Sprechers einer alltäglichen, normalen Aufwartung in der literarischen urbs Roma und zeigt damit einen typischen innerstädtischen Zielpunkt.

Wenn in, an und bei Theatern, dem Circus und anderen Orten regelhaft hohe Konzentrationen an Menschen verortet werden, werden die Gründe für die Wahl dieser Zielorte in der Regel nicht genannt. Sie ergeben sich wohl aus der Sache selbst. Ebenso auffällig ist, dass diese Konzentrationspunkte selten eindeutig auf den Georaum der antiken Stadt Rom bezogen werden, es sich also verstärkt um fingierte Handlungszonen handelt, an denen dieses räumliche Merkmal der Verdichtung ausgestaltet wird. Gewiss werden in heutigen Textausgaben die Gattungsbezeichnungen circus, theatrum, forum häufig durch Großschreibung als Eigenname markiert, jedoch sind sie für einen Kenner stadtrömischer Topographie nicht eindeutig, da es doch bekanntermaßen mehrere Theater und Fora in der antiken Metropole gab. Konzentrationspunkte der literarischen urbs Roma werden demzufolge als solche zwar typisiert, aber nicht konkretisiert. Sie gelten aber gerade aufgrund ihrer räumlich beengten Eigenschaften und ihrer hohen Menschendichte als eine pars pro toto für den Gesamtraum urbs Roma selbst. ${ }^{591}$

\subsubsection{Gefährliche Enge II. Die Widerständigkeit der Masse}

Verdichtungen durch eine hohe Konzentration von Menschen werden nicht nur in der räumlichen Umgebung von innerstädtischen Zielpunkten verortet. Wieder-

589 Eine Gruppe wird als Troiugenae bezeichnet und ist dadurch als Angehörige vornehmer Familien ausgewiesen. Vgl. Courtney (1980), 106. Eine weitere Gruppe, zu der sich der Sprecher zugehörig fühlt, wird mit nobiscum, v. 101, angedeutet. Eine dritte Gruppe repräsentiert die Figur des Freigelassenen (libertinus, v. 102). Während der ille die Ausgabe der Sportel mit den Amtsträgern beginnen lassen will (,da praetori; da deinde tribuno!'), weist der Freigelassene auf die Tatsache hin, vorher eingetroffen zu sein (prior est). Es gelingt ihm, sich mit Hilfe von Argumenten, nämlich mit dem Hinweis auf seinen Reichtum, durchzusetzen, während ein Erzählerkommentar den libertinus als einen Fremden charakterisiert, der noch kürzlich dem Sklavenstand angehörte. Vgl. Iuv. 1, 101-111: ,da praetori; da deinde tribuno!"/ sed libertinus prior est: ,prior inquit ,ego adsum./ cur timeam dubitemve locum defendere, quamvis/ natus ad Euphraten, (.... \% (...) expectent ergo tribuni;/ vincant divitiae; sacro ne cedat honori/ nuper in hanc urbem pedibus qui venerat albis, (...).

590 Vgl. Braund (1996), 102: „densissima (...) lectica: ,crowds of litters', singular for plural.“

591 In Martials monothematischer Epigrammsammlung de spectaculis werden die Begriffe urbs, amphitheatrum und circus annähernd synonym verwandt. Vgl. Mart. spec. 2, 4; 3, 2; 4, 5. Iuv. 8, 118. Stat. silv. 3, 5, 14-16. Vgl. auch Iuv. 3, 223: Si potes avelli Circensibus, (...). 
holt und in sehr unterschiedlichem Zusammenhang werden derartige Strukturmerkmale auch mit dem offenen Straßenraum in Zusammenhang gebracht. In der Exildichtung Ovids etwa beschreibt der Sprecher an mehreren Stellen Festzüge, die innerhalb der literarischen urbs Roma stattfinden, an denen er allerdings aufgrund seiner Sprechsituation - ein Mann im Exil - nicht in eigener Person teilnehmen kann. Trotzdem schildert er sie mit sorgfältiger Genauigkeit als multisensuelles Erlebnis. ${ }^{592} \mathrm{Im}$ elegischen Brief Epistulae ex Ponto 4, 9 imaginiert er so den Amtsantritt seines Freundes Graecinus als Konsul. Durch wenige, aber eindeutige Referenzen auf topographische Merk- und Wahrzeichen - wie Capitolia (v. 5) und auch durch den Anlass selbst (bis senos fasces quae tibi prima dabit, v. 4) ist der literarische Raum als urbs Roma umgehend identifizierbar. Räumlich vollzieht er eine Wegstrecke von einem ungenannten Punkt aus zum tarpejischen Felsen (v. 29) nach. Im Mittelpunkt seiner Imagination steht allerdings die räumliche Struktur des Festzuges selbst. Die Aufmerksamkeit des Sprechers richtet sich auf zwei Bereiche, die Formierung von Menschen um den Freund Graecinus herum und die Menge von Schaulustigen.

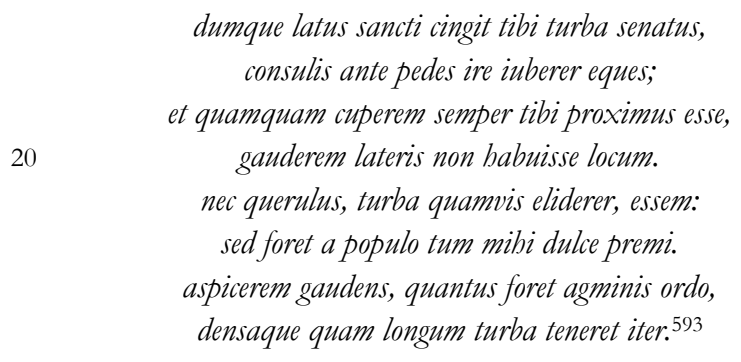

Die Beobachtung an dem Festzug gerät in dieser Passage zu einem dominanten Erlebnis der Masse. Dreimal wird innerhalb weniger Verse auf das hohe Menschenaufkommen hingewiesen (turba, v. 17; 21; 24). Aus dem Festzug selektiert der Sprecher visuell zwei Gruppen, den Senat (senatus, v. 17) und die Ritter (eques, v. 18). In unmittelbarer Nähe des Freundes, in der Gruppe der Ritter, sieht der Sprecher seinen favorisierten Platz. Er beschreibt den dort zur Verfügung stehenden Raum für einen Einzelnen als äußerst klein: Den Körper seines Freundes

592 Vgl. Ov. Pont. 4, 4, 27 f. und 43 f.: cernere iam videor rumpi paene atria turba,/ et populum laedi deficiente loco,/ (...)/ me miserum, turba quod non ego cernar in illa, / nec poterunt istis lumina nostra frui! Vgl. auch Ov. trist. 4, 2, 15 f., indem zum visuellen Eindruck der akustische hinzugenommen wird: Ov. trist. 4, 2, 49 f.: quaque ibis, manibus circumplaudere tuorum, / undique iactato flore tegente vias. Ov. trist. 4, 2, 53 f.: ipse sono plausuque simul fremituque canente/ quadrïngos cernes saepe resistere equos. Eine ausgeprägt visuelle Wahrnehmung findet sich in Ov. Pont. 2, 1. Durch die im Triumphzug getragenen Waffen funkelt das Forum golden. Vgl. Ov. Pont. 2, 1, 40-42: armaque cum telis in strue mixta sua,/ deque tropaeorum, quod sol incenderit, auro/ aurea Romani tecta fuisse fori, (...).

593 Ov. Pont. 4, 9, 17-24. 
sieht er von der Seite und von vorn umschlossen (latus ... cingit tibi turba, v. 17; ante pedes ire iuberer, v. 18). Auch für den Sprecher herrschte dort Platzmangel (lateris non habuisse locum, v. 20). Trotz dieser räumlichen Beengtheit auf horizontaler und sagittaler Achse fokussiert er keine weiteren visuellen Details, beschränkt sich vielmehr auf die Beschreibung des zur Verfügung stehenden Raumes für seinen Freund und sich selbst aus dem Inneren heraus, um den ungeheuren Andrang hervorzuheben.

Der Sprecher nimmt sodann einen imaginierten Standortwechsel vor (21-24): Er sähe sich auch gern inmitten einer weiteren Gruppe, nämlich der schaulustigen Bevölkerung (populo, v. 22). An seinem Bewegungsspielraum verändert sich hier wenig: Erneut dominiert der Eindruck räumlicher Enge, die nicht mehr über visuelle Raumvermessungen, sondern als Erfahrung am eigenen Körper beschrieben wird (turba eliderer, v. 21; a populo premi, v. 22). Seine Nachbarn nimmt er taktil, jedoch nicht als Individuum, sondern immer noch als Masse wahr.

Durch diesen Standortwechsel verändert sich auch die Blickinszenierung auf den wahrgenommenen Festzug: Statt einer Fokussierung auf kleinste räumliche Verhältnisse wird eine Außenansicht als Großaufnahme geboten: Der Sprecher lässt das dichte Gedränge (densa turba, v. 24) derjenigen, die seinen Freund geleiten, an sich vorüberziehen und überblickt nun den vollen Umfang dieser Menschenformation (quantus ... agminis ordo, v. 23; quam longum ... teneret iter, v. 24). Durch die Kombination beider Blickinszenierungen gelingt es, die enorme Dichte in einem großräumigen transitorischen Raum zu gestalten.

Dieser Aufzug an Menschen soll in dieser Elegie wohl als Zeichen einer besonderen Wertschätzung eines außergewöhnlichen städtischen Ereignisses und im Besonderen der Persönlichkeit des Freundes dienen. Der aus dem Alltag herausragende Moment ist eine Ausnahmesituation, die als ein räumliches Erlebnis der Masse gestaltet ist. Die eingeschränkte Wahrnehmungsperspektive des Sprechers, der gemäß der literarischen Fiktion keine Wahrnehmungsinstanz in der literarischen urbs Roma sein kann, wird von ihm offen problematisiert:

35

$$
\begin{aligned}
& \text { bic ego praesentes inter numerarer amicos, } \\
& \text { mitia ius urbis si modo fata darent, } \\
& \text { quaeque mibi sola capitur nunc mente voluptas, } \\
& \text { tunc oculis etiam percipienda foret. } .94
\end{aligned}
$$

Die Irrealität seines Blickwinkels signalisieren die Konjunktive (numerarer, v. 35; darent, v. 36). Nicht durch eigene, direkte Anschauung (oculis, v. 38), sondern allein mit Hilfe der mens (v. 37) kann er die Ereignisse dieses besonderen Tages antizipieren. Daher wahrt er im Sinne dieser literarischen Nicht-Faktualität im entscheidenden Detail auch eine entsprechende Zurückhaltung und formuliert lediglich als

594 Ov. Pont. 4, 9, 35-38. 
Wunsch: spectarem, qualis purpura te tegeret. 595 Seine Imagination geht diesem Duktus zufolge nicht über das Allgemeine hinaus und spiegelt vor allem seine Wünsche für seinen Freund wider. Die Beschreibung des Besonderen, des Festtages, steht genau im Spannungsverhältnis zwischen einer als Wissen präsentierten Standardsituation und einem Ausnahmeereignis. Eine derartige Konzentration an Menschen ist dem Duktus der Elegie folgend kein einmaliges Ausnahmeereignis, aber auch nicht alltäglich.

Verdichtungen auf innerstädtischen Straßen durch ein hohes Menschenaufkommen werden jedoch auch als regelhaft wiederkehrend sowohl in augusteischer als auch in kaiserzeitlicher Dichtung präsentiert. Demgemäß beschreibt der Sprecher der Satire 2, 6 des Horaz eine Wegstrecke vom Forum zum Esquilin, die täglich von ihm zurückzulegen ist. 596

luctandum in turba et facienda iniuria tardis.

,quid tibi vis, insane?" et ,quam rem agis?' inprobus urget

30 iratis precibus, ,tu pulses omne quod obstat,

ad Maecenatem memori si mente recurras. ${ }^{5}{ }^{597}$

Diese Wegstrecke wird als ein widerständiger Bereich präsentiert, dessen innere Struktur sich aus einem hohen Aufkommen von Passanten ergibt (turba, v. 28). Der Sprecher taucht in diese räumliche Struktur mit dem eigentlichen Vorhaben ein, diesen Bereich zügig zu passieren (recurras, v. 31).598 Innerhalb der Menschenmenge beschreibt der Sprecher jedoch enorme Einschränkungen des eigenen Bewegungsspielraums mit der Vielzahl an taktilen Kontakten und bezeichnet das Durchqueren als einen groben Ringkampf, an dem man sich gezwungenermaßen beteiligt (luctandum, v. 28, urget, v. 29, iratis precibus, v. 30; tu pulses, v. 30), da ihm der Weg versperrt ist (omne, quod obstat, v. 30). Indirekt ergibt sich aus dieser Ausgestaltung die innere Struktur, der Abstand, den die Passanten innerhalb dieses Kontaktbereichs zueinander einnehmen: Sie kommen sich auf Armeslänge nahe.

Des Weiteren gibt der Sprecher in autonomer direkter Rede ${ }^{599}$ einen kurzen Gesprächsfetzen wieder, in dem sich ein namenlos bleibender ${ }^{600}$ Grobian (inprobus, v.

595 Ov. Pont. 4, 9, 26.

596 Diese Passage wurde bereits im Abschnitt 3.3.2 unter dem Gesichtspunkt der Ausgestaltung räumlicher Ausdehnung vorgeführt.

597 Hor. sat. 2, 6, 28-31.

598 Die Präpositionalphrase in turba zeigt an, dass dieser Menschenmenge Eigenschaften einer räumlichen Gegebenheit zukommen, da man in sie hineingehen kann.

599 Zur Begrifflichkeit vgl. Martinez/Scheffel (52003), 51, 62.

600 Dieser aus Sicht des Sprechers Unbekannte kennt jedoch den Sprecher. Er weiß, wohin der Sprecher unterwegs ist, nämlich zu Maecenas. Wiederholt klagt der Sprecher in dieser Satire, dass seine Freundschaft zu Maecenas nach seinem Geschmack von zu großem öffentlichem Interesse ist. Diese Asymmetrie der Bekanntschaft bei den Begegnungen im öffentlichen Raum ist hier als ein erster Hinweis gestaltet. Vgl. dazu Kießling/Heinze (1959), 305 f. 
29) über das handfeste Vorgehen des Sprechers beschwert. So unvermittelt, wie diese Figur aufgetaucht ist, scheint sie jedoch auch wieder verschwunden zu sein. ${ }^{001}$ Der Vorwurf bleibt unbeantwortet und die akustisch akzentuierte, flüchtige Begegnung veranschaulicht damit exemplarisch, dass die gesamte Menschenmenge in diesem transitorischen Raum in Bewegung ist. Trotz des Bildes vom Ringkampf besteht folglich innerhalb der turba zwischen den Einzelnen kein Kontakt von Dauer. Im Gegenteil: Gerade der individuellen Eigengeschwindigkeit wird explizit eine Bedeutung zugewiesen, denn Schnelligkeit wird zu einer zentralen Voraussetzung erklärt, um innerhalb dieses Bereichs unausweichlicher Prügel zu entkommen (facienda iniuria tardis, v. 28). ${ }^{602}$ Werden diese Gefahren für den eigenen Körper als für alle Passanten geltende Erfahrungen und als notwendig dargestellt, so bezeichnet der Sprecher sie doch als Unrecht (iniuria, v. 28) und tritt damit zu den Erfordernissen, die diese Straßensituation von ihm abverlangt, in Distanz.

Aufgrund der personengebundenen Perspektive aus dem Inneren heraus bleibt ein genauerer räumlicher Umfang des Bewegungsbereichs diffus. Lediglich durch seinen Anfangs- und Zielpunkt ist er vage begrenzt. Auch einen Anlass für diese Bevölkerungskonzentration nennt der Sprecher nicht, sondern er präsentiert seinen Erlebnisbericht als eine unausweichliche Alltagserscheinung. Das räumliche Merkmal dieser Wegstrecke, nämlich ihre Dichte, gehört dieser literarischen Ausgestaltung nach zu den festen Eigenschaften ihrer inneren Struktur.

Eine vergleichbare, jedoch viel differenziertere Veranschaulichung von Verdichtungen auf einer innerstädtischen Wegstrecke findet sich in der dritten Satire Juvenals. In erzählter Wahrnehmung schildert der Sprecher Umbricius, der hier in der ersten Person Plural und Singular von sich spricht, im iterativen Erzählmodus folgendes:

239 Si vocat officium, (...)

243 nobis properantibus obstat

unda prior; magno populus premit agmine lumbos

245 qui sequitur; ferit bic cubito, ferit assere duro

alter, at bic tignum capiti incutit, ille metretam.

pinguia crura luto, planta mox undique magna

calcor, et in digito clavus mibi militis baeret; (...). ${ }^{603}$

Wenn man in Erfüllung von Verbindlichkeiten (officium, v. 239) eilig zu Fuß in der urbs Roma unterwegs ist (nobis properantibus, v. 243), befindet man sich laut Umbri-

601 Kießling/Heinze (1959), 304 kommentieren diese Begegnung: „Erst bei näherem Hinsehen erkennt der Schimpfende, wen er vor sich hat, den Vertrauten des Maecenas (der also als solcher stadtbekannt ist)." Diese visuelle Perspektive ist im Text aber nicht angelegt.

602 Vgl. Kießling/Heinze (1959), 303 kommentieren tardis: „die ich also überholen will.“

603 Iuv. 3, 239, 243-248. 
cius unmittelbar in einem widerständigen Bewegungsbereich: Auf sagittaler Achse steht (!) einer beliebigen Wahrnehmungsinstanz eine Menschenmenge entgegen, die mit der räumlich diffusen Referenz unda bezeichnet wird. ${ }^{604}$ Es handelt sich dieser Metapher zufolge um eine unspezifische, jedoch wohl übermächtige Masse, deren Eigenbewegung (unda, v. 244) in diesem Bewegungsbereich bereits zum Erliegen gekommen ist (properantibus obstat, v. 243 f.). ${ }^{605}$ In der entgegengesetzten Richtung - der visuellen Wahrnehmung damit entzogen - befindet sich ebenfalls ein Kollektiv von Menschen: Eine formierte, große Volksmenge (magno populus agmine, v. 244) drückt von binten nach. Deren noch anhaltende Bewegung nimmt die Wahrnehmungsinstanz taktil wahr, da sie sich an ihre Lenden presst (premit ... lumbos, v. 244). Auf sagittaler Achse ergibt sich daraus für den Einzelnen eine äuBerst beengte und in gleicher Weise ausweglose räumliche Konstellation: Während im Rücken die Menge ihn vor sich her bewegt, stößt sie ihn auf eine weitere Menschenmenge zu, die ins Stocken geraten ist.

Jedoch auch auf horizontaler und vertikaler Achse zeigt sich der Bewegungsbereich eingeschränkt und widerständig. Von einzelnen Menschen (bic, alter, bic, ille) und den von ihnen transportierten Gegenständen wird die Wahrnehmungsinstanz an verschiedenen Gegenden ihres Körpers traktiert: Einer schlägt mit dem Ellenbogen, ein anderer mit einer harten Stange, einer trifft mit einem Balken ihren Kopf und ein vierter mit einem Tongefäß; ihre Beine strotzen vom Straßendreck, sie wird wiederholt auf den Fuß getreten und hat den Schuhnagel eines Militärs im Zeh. Die verschiedenen taktilen Stöße treffen den gesamten Körper: von der Hüfte aufwärts über den Oberkörper zum Kopf (cubito, v. 245, capiti, v. 246), von den Unterschenkeln abwärts über die Füße zum Zeh (crura, v. 247; calcor ... in digito, v. 248). Der räumliche Abstand zu den anderen ist in diesem Bewegungsbereich folglich auf ein Minimum reduziert ${ }^{606}$ : der Wahrnehmungsbereich fällt nicht nur mit einem Wahrnehmungsstandort und dessen räumlicher Umgebung, sondern mit der Wahrnehmungsinstanz selbst zusammen. In dieser extrem beengten und zugleich äußerst gefahrenträchtigen räumlichen Situation bleibt sie selbst allerdings - im Gegensatz zur Figur aus der eben vorgestellten horazischen Satire völlig passiv und verteidigt ihre räumliche Umgebung nicht.

Über die jeweiligen Gegenstände und Stöße nimmt die Wahrnehmungsinstanz taktil eine äußerst heterogen gestaltete, nächste räumliche Umgebung wahr, visuelle Details dagegen werden nicht selektiert. Es überwiegen vielmehr Referenzen auf

604 Vgl. auch Verg. georg. 2, $461 \mathrm{f}$.

605 Vgl. OLD (1992), 1225, s.v. obsto 2 a: „To be or stand in the way (of), constitute a physical barrier (to), block the path (of)" und Stat. Theb. 8, 350: currus properantibus obstant.

606 Vgl. auch Iuv. 3, 254: scinduntur tunicae sartae modo. Das Zerreißen des Unterkleides weist darauf hin, dass sich das Geschehen in gefährlicher Nähe zum eigenen Körper abspielt. Die Grenzen des Eigenorts werden von allen Seiten wie bei einem „Nahkampf“ mit verschiedenem Geschütz angegriffen, vgl. Schmitz (2000), 212. Zur epischen Kampfmetaphorik in dieser Szene vgl. Braund (1996), 217 und Schmitz (2000), 212-221. 
diffuse Konzentrationen von Menschen, von denen besonders poetisch der Ausdruck unda ist. Durch die Formierung der Menge (magno ... agmine, v. 244) und die eingeschränkte Situation der Wahrnehmungsinstanz entsteht der Eindruck, als ob auch sie gefordert ist, zu einem Teil dieser Masse zu werden und vollständig in sie einzutauchen. Im starken Kontrast zu diesen Anzeichen einer Kollektivierung steht die heterogene taktile Wahrnehmung dieses Transitraumes.

In einem weiteren Abschnitt teilt die Wahrnehmungsinstanz visuelle Beobachtungen mit, jedoch ausnahmslos von mobilen Objekten: Sie beschreibt verschiedene Transportmittel, die sich ebenfalls innerhalb des Bewegungsbereichs befinden.

longa coruscat
255 sarraco veniente abies, atque altera pinum
plaustra vebunt; nutant alte populoque minantur.
nam si procubuit qui saxa Ligustica portat
axis et eversum fudit super agmina montem,
quid superest e corporibus? 607

Fokussiert wird die Ladung dreier Wagen: Zwei von ihnen transportieren Bauholz (abies ... pinum, v. 255), ein weiterer Marmor (saxa Ligustica, v. 257). Von diesen Materialien wird ihr Volumen (longa, v. 254) und ihr Gewicht (nam si procubuit qui saxa ... portat/ axis, v. 257 f.) herausgestellt. Für die Ausgestaltung ihrer jeweiligen räumlichen Umgebung ist relevant, dass sich dieses Transportgut nicht nur raumnehmend durch den Straßenraum hindurch bewegt, sondern sich auch in sich bewegt (coruscat, v. 254; nutant, v. 256). Gerade diese Eigenbewegung stellt nämlich für die Passanten eine Bedrohung von oben dar (alte populoque minantur, v. 256): Von herausfallendem Marmor, der sich wie ein Berg über der Masse ergießt (!) (fudit super agmina, v. 258), wird man womöglich bis zur Unkenntlichkeit zerquetscht (quid superest e corporibus?, v. 259). Die Grenzen des menschlichen Körpers wären damit endgültig überschritten. Der Bewegungsbereich ist mit dem Einbezug der vertikalen Achse nun auf allen Seiten zu einer Gefahrenzone für den eigenen Körper ausgestaltet.

Dass die eingeschränkten Möglichkeiten in einer sozialen Stellung begründet liegen, lässt der Sprecher nicht unerwähnt. Diese Darstellung der ausweglosen unmittelbaren Umklammerung seines Körpers wird mit einem anderen städtischen Transitraum kontrastiert, in dem sich gegenteilige Bedingungen bieten.

turba cedente vehetur

240 dives et ingenti curret super ora Liburna

atque obiter leget aut scribet vel dormiet intus;

607 Iuv. 3, 254-259. 
namque facit somnum clausa lectica fenestra

ante tamen veniet: (...). ${ }^{608}$

Oberhalb der Köpfe (super ora, v. 240) ${ }^{609}$, also von ihrem Bewegungsbereich aus, nimmt die Wahrnehmungsinstanz eine gewaltige Sänfte wahr. Diese Sänfte bewegt sich mühelos und in raschem Tempo (turba cedente vehetur, v. 239; curret, v. 240). ${ }^{610}$ Mit der Bezeichnung der Sänfte als Kriegsschiff (ingenti ... Liburna, v. 240) bleibt die Wahrnehmungsinstanz im poetischen Bild: Es befindet sich auf der als unda (v. 244) bezeichneten Menschenmasse. Die Sänfte bzw. der Getragene entgeht durch diese räumlich enthobene Position dem taktilen Kontakt mit der Masse. Doch der Rückzug geht noch darüber hinaus: Deutlich akzentuiert wird die Sänfte als ein unbetretbarer Raum (inaccessible frame): Ihre Grenzen, die Fenster, sind geschlossen (clausa lectica fenestra, v. 242). Jedoch sind die Vorgänge im Inneren (intus, v. 241) dem Sprecher bekannt. In der Sänfte beschäftigt sich die Figur (dives, v. 240) mit Lesen, Schreiben, Schlafen. Diese Beschäftigungen setzen eine akustisch ungestörte Umgebung - zudem über einen längeren Zeitraum - voraus. Die Figur nimmt folglich über den visuellen, wie auch akustischen Fernsinn nichts von ihrer unter ihr befindlichen räumlichen Umgebung wahr. Auch räumlichen Beschränkungen ist sie nicht ausgesetzt. Die widerständige Menschenmasse weicht ihr aus (turba cedente, v. 239), so dass sie sich zügig oberhalb von ihr fortbewegen kann (curret supra ora, v. 240).

In beiden Bewegungsbereichen - oben und unten - werden Entfernungen innerhalb des literarischen Raumes zurückgelegt. Die Geschwindigkeit der Sänfte wie auch der Hinweis auf die Tätigkeiten, denen die Figur in der Sänfte unterwegs nachgeht, weisen implizit darauf hin, dass es sich um recht große Entfernungen handelt, die von beiden zurückzulegen sind. Die Wegstrecke ist für den Fußgänger und den Getragenen damit identisch. Das Wettrennen innerhalb der literarischen urbs Roma beantwortet die Sänfte jedoch für sich: ante ... veniet (v. 243). Denn die Unterschiede zwischen den beiden Konkurrenten bestehen nicht darin, ob eine Entfernung zurückzulegen ist oder nicht, sondern in den Möglichkeiten, sich einer inneren Struktur der literarischen urbs Roma zu entziehen. Die Verdichtungen im offenen Straßenraum werden in dieser Passage damit zu einem zentralen Merkmal der literarischen urbs erklärt, anhand derer der Erzähler Umbricius die Möglichkeiten seiner Person mit den Chancen der vom Stadtleben Privilegierten gegenüberstellt.

608 Iuv. 3, 239-243.

609 Vgl. OLD (1992), 1273, s.v. os 7: „The face as implying the head“ und Iuv. 6, 43. Braund (1996), 217: „super ora suggests the upturned faces of those less fortunate.“

610 Vgl. Braund (1996), 216 f. Zum gnomischen Futur vgl. Courtney (1980), 187. 


\section{Zusammenfassung}

Die intensive Nutzung von öffentlichem Raum wird anlässlich einmaliger, vom Duktus her herausragender, Ereignisse ebenso beschrieben wie als eine alltägliche Erfahrung innerhalb der literarischen urbs Roma. Dabei tritt neben die direkte Attribuierung und die Wahl von Referenzen auf kollektive Formierungen von Menschen eine lebendige Ausgestaltung räumlicher Dichte.

Eine Lokalisierung derartiger Bewegungsbereiche in einem innerstädtischen Verkehrsnetz der literarischen urbs Roma findet allenfalls vage statt. Es fehlt der Hinweis auf weitere städtische Teilelemente oder topographische Wahr- und Merkzeichen, an denen die Wegstrecken entlangführen. Es handelt sich daher um zonale Schauplätze mit in erster Linie städtischem Charakter. Gründe für die intensive Nutzung, etwa eine besondere Straßenführung oder die Konzentration wichtiger Eigenschaften, werden nicht angeführt. Die vorausgesetzte Bewegung aller Beteiligten charakterisiert diese Bereiche daher jeweils als einen großräumigen Knotenpunkt im Sinne einer intensiven Nutzung durch eine innerstädtische Mobilität. Auffällig ist in diesem Zusammenhang, dass jeder Hinweis auf ein weiterführendes Straßennetz von Haupt- und Nebenstraßen, in dem die Figuren navigieren könnten, fehlt. Für die Wahrnehmungsinstanz ergibt sich die Begegnung mit diesem widerständigen Bewegungsbereich gemäß der Illusionsbildung vielmehr alternativlos und zwingend, der iterative Erzählmodus stellt die Eigenschaften des ,transitorischen Raums` als eine typische innere Struktur dar.

Dargestellt wird der Bewegungsbereich als ein auf mehreren Achsen dichter und widerständiger Raum. Zur räumlichen Vermessung der Dichte - weniger zur Wahrnehmung räumlicher Verdichtung - wird wiederholt die taktile Wahrnehmung genutzt, die Auskunft über die Abstände, den Grad des Widerstands und über Varianz und Heterogenität des Bewegungsbereichs gibt. Der Einzelne befindet sich dabei inmitten einer unbekannten Vielzahl von Menschen, von denen er visuell trotz des geringen Abstands kaum individuelle Merkmale wiedergibt. Trotz ausgewiesener Kontaktbereiche werden keine persönlichen Bindungen unter den Nutzern des öffentlichen Raums sichtbar. Es handelt sich um einen Bereich von vorwiegend anonym handelnden Akteuren, inmitten derer allein über die Gefahren, die sich für das Individuum aus der räumlichen Situation heraus ergeben, reflektiert wird. Im Mittelpunkt steht folglich die Betrachtung und Wahrnehmung eines räumlichen Merkmals in seinem direkten Lebenszusammenhang, das in seinen Eigenschaften als typisch für die innere Struktur einer urbs Roma präsentiert wird.

\subsubsection{Auswertung}

Die Relevanz der Dichte als ein räumliches Merkmal der literarischen urbs Roma zeigt sich an ihrer variantenreichen Ausgestaltung in der augusteischen und kaiser- 
zeitlichen Dichtung, die gattungsübergreifend sowohl an (1) innerstädtischen räumlichen Ensembles als auch (2) durch Konzentrationspunkte veranschaulicht wird. In einem direkten Lebenszusammenhang zeigt sich diese innere Struktur wiederholt als mangelnder Bewegungsfreiraum für Passanten oder fehlende Rückzugsmöglichkeiten für die Anwohner.

(1) Beengte Verhältnisse aufgrund einer städtischen Bebauungssituation treten überwiegend im Zusammenhang mit einem öffentlichen Straßenraum und unmittelbar angrenzenden städtischen Teilelementen - Wohn- und Arbeitsgebäuden ins Bewusstsein, wobei der Straßenraum einerseits als Schauplatz, andererseits aber auch als Nebenraum eines ihm benachbart liegenden Innenraums in den Vordergrund der räumlichen Wahrnehmung rückt. Eine Raumvermessung erfolgt nicht metrisch und auch nicht - wie es vielleicht naheliegender wäre - über den Abstand der auf beiden Seiten die Straße begrenzenden Gebäude. Der für die Figuren zur Verfügung stehende Raum wird vielmehr durch vielfältige Gattungsbezeichnungen von Straßentypen in seinen räumlichen Ausmaßen unterschieden und eine beengte innere Struktur tritt in Form von stehenden und mobilen Objekten als visuell und taktil wahrgenommenes Bewegungshemmnis den Passanten in den Weg. Besonders die körpernahe Raumvermessung erzeugt dabei die Wiedergabe einer beengten inneren Struktur. Eine variantenreiche, aber eben auch dicht bebaute räumliche Umgebung nehmen die Anwohner dagegen vornehmlich auditiv wahr, da sie sich in privaten Innenräumen aufhalten, wo sie der visuellen und taktilen Wahrnehmung des öffentlichen Raums entzogen sind.

Zur Vorstellung einer inneren Struktur führt des Weiteren die Darstellung von Grenzüberschreitungen, wobei sowohl Innenräume auf einen öffentlichen Raum übergreifen als auch öffentlicher Raum in einen privaten Innenraum eindringt. Ähnlich wie bei den Prozessen der Verstädterung an den Grenzen der literarischen urbs Roma (vgl. Abschnitt 3.4.3) werden im Inneren Prozesse seiner Ausdehnung beobachtet, wobei jeweils der Standort des Sprechers derjenige ist, an dem der Verlust an Raum beobachtet wird.

Auffälligerweise werden trotz einer derartigen Beengtheit und durchlässiger Grenzen die ,Ensembles' gerade nicht als ein lebendiger Kontaktbereich ausgestaltet. Die Sprecher bleiben zu ihrer unmittelbaren räumlichen Umgebung eher auf Distanz und nehmen sie sogar als einen anonymen Transitraum wahr. Beschrieben werden vor allem die Auswirkungen dieser Verhältnisse auf die Passanten und Bewohner selbst, die meist derartige Bereiche als Gefahrenzonen einschätzen, mit körperbezogenen Risiken rechnen oder durch die Ruhelosigkeit sich erschöpft fühlen oder sogar erkranken. Die räumliche Enge und eine damit thematisierte Vielheit an Reizen führen für das wahrnehmende Individuum zu einer Überforderung und werden von ihm als ein Fehlen einer körperlichen und persönlichen Abgrenzungsmöglichkeit erlebt. Als Strategien der Bewältigung gelten ihm nur räumliche Alternativen, die sich entsprechend der jeweiligen Fiktion innerhalb und außerhalb der literarischen urbs Roma finden lassen, in finanziellen Möglichkeiten, 
einer temporären Abwesenheit oder auch im Exil bestehen. Als privilegiert werden diejenigen Bewohner angesehen, denen es möglich ist, sich dieser inneren Struktur zu entziehen bzw. denen eine gegenteilige Struktur, ein weiträumiges und sensuell enthobenes Areal zur Verfügung steht. Dennoch ist diese räumliche Dichte nicht allein Kennzeichen einer sozialen Perspektive. Im Zusammenhang mit einem topographischen Merk- und Wahrzeichen diente dieses Merkmal dazu, die räumliche Umgebung zu nobilitieren.

Wird bauliche Dichte somit an kleineren, überschaubaren Bereichen und einer unmittelbaren räumlichen Umgebung vorgeführt, so tragen dennoch in der Regel die zur Wahl gestellten Alternativen, wie auch die konkrete Ausgestaltung der Bereiche, etwa der Einsatz von mobilen Objekten oder einer sich bewegenden Wahrnehmungsinstanz, dazu bei, dass der Leser die präsentierte innere Struktur einer dichten Bebauung auf die gesamte oder doch auf weite Teile der literarischen urbs Roma überträgt.

Text $\ddot{b}$ ergreifend konnte beobachtet werden, dass die jeweilige Bewertung, ob das Merkmal baulicher Dichte dem gesamten literarischen Raum urbs Roma zukomme oder nicht, widersprüchlich ist. Die für diese baulichen Ensembles präsentierten räumlichen Eigenschaften werden als typisch für den Gesamtraum der urbs Roma bezeichnet oder gerade als untypisch zurückgewiesen. Derartige Widersprüche sind nicht auf autoren-, gattungs- oder zeitspezifische Unterschiede zurückzuführen, sie finden sich innerhalb eines Euvres. Bei der Darstellung baulicher Dichte in der literarischen urbs Roma handelt es sich somit um ein Merkmal eines literarisierten Raumes, das dem Gestaltungsspielraum der Autoren große Freiheiten auch zu einer Multiperspektivität lässt, d. h. einer intentionalen Perspektive unterliegt. Hierzu passt auch die Beobachtung, dass es in der Mehrzahl der Texte durch das Fehlen entsprechender Referenzen unmöglich ist, die räumlichen Ensembles in den Georaum der antiken Metropole Rom zu verorten. Räumliche Dichte wird an frei gewählten Schauplätzen und Nebenräumen vorgeführt, für die lediglich eine Inklusion in den Makroraum urbs Roma gilt, es sind poetisierte, fingierte Handlungszonen, Orte der Literatur. Die Auswahl der typisch städtischen Teilelemente wiederum, etwa sehr hohe Wohngebäude mit Fenstern zur Straßenseite oder eine äußerst heterogene - sprich arbeitsteilige - Umgebung eines Wohngebietes, verweisen allemal eindeutig auf eine spezifisch großstädtische Infrastruktur des jeweiligen Bereichs. Der Einsatz transitorischer Ereignisse wie das Vorbeirollen von Wagen oder die Bewegung einer Wahrnehmungsinstanz durch diese Bereiche hindurch erweitert den exemplarisch dargestellten Raum um eine unbekannte Größe. Präsentiert wird mit der Darstellung einer verdichteten inneren Struktur ein ausgeprägt großstädtischer, aber eben weniger stadtrömischer Raum. Trotz der Widersprüchlichkeit der Bewertungen bleibt die bauliche Dichte ein Alleinstellungsmerkmal einer urbs Roma. 
(2) Als ein weiteres charakteristisches Merkmal der literarischen urbs Roma gilt ihre besonders hohe Anzahl von Einwohnern. Dargestellt wird sie räumlich anhand von Bereichen, in denen es zu einer intensiven, simultanen Nutzung kommt.

Zielpunkte, die von den Bewohnern regelmäßig angelaufen werden und in, an oder bei denen es wiederkehrend zu Verdichtungen kommt, sind typisch städtische Teilelemente wie Theater, Circus, Forum, Atrium, also vor allem klar begrenzte räumliche Gegebenheiten. Explizit wird die Konzentration an Einwohnern wiederholt und gattungsübergreifend in einem visuellen, akustischen oder haptischen Gesamteindruck festgehalten, indem derartige Bereiche als vollbesetzt, besonders laut, als räumlich beengt o. ä. attribuiert werden. Eine räumliche Ausgestaltung ihrer inneren Struktur oder der Prozess der Verdichtung findet sich im Gegensatz dazu recht selten.611 Der Einsatz der Darstellungstechniken ,Beschreibung' und ,erzählte Wahrnehmung' zeigt aber, dass in denjenigen Passagen, in denen es zu einer räumlichen Ausgestaltung kommt, gerade dem räumlichen Merkmal der Dichte eine besondere Relevanz zugeschrieben wird. In der literarischen Präsentation ist eine große Variationsbreite - auch innerhalb eines Cuvres - feststellbar. So bietet Ovid sowohl eine personengebundene Perspektive aus dem Inneren heraus, wobei räumliche Abstände körperbezogen vermessen werden, als auch poetische Vergleiche aus dem Landleben und aus der Tierwelt, mit denen es ihm durch verschiedene Blickinszenierungen gelingt, auch den Prozess der Verdichtung darzustellen. Juvenal dagegen nutzt vor allem das Mittel der Kumulation von Menschengruppen und raumnehmenden Objekten, um eine aufs Äußerste verdichtete räumliche Umgebung eines Wohnhauses zu präsentieren. Diese Beispiele lassen erkennen, dass die Vorstellung von einem Konzentrationspunkt im Sinne eines regelmäßig intensiv genutzten Bereiches für den literarischen Raum urbs Roma in der Dichtung vorliegt.

Vor allem veranschaulicht wird die kollektive Nutzung in einem offenen, diffus umgrenzten Raum, der durch typische Handlungen von Figuren implizit als eine Straße identifizierbar ist. Gründe für das erhöhte Menschenaufkommen, etwa eine entsprechende Straßenführung oder die räumliche Nähe zu Bereichen, die für das alltägliche Leben der Einwohner zentral wären, werden nur in Ausnahmefällen genannt, ebenso fehlen Hinweise auf architektonisch manifestierte Begrenzungen - etwa Häuserwände -, oder die Breite der Straße, die als Gründe einer derartigen Verdichtung angeführt werden könnten. Alternative Wege, Nebenwege, Abkürzungen werden nicht vorgestellt. Das Wegenetz, auf das bei einer Orientierung durch den literarischen Raum noch implizit verwiesen wird (vgl. Abschnitt 3.2), existiert in den Darstellungen einer dichten literarischen urbs Roma nicht. Gemäß der Illusionsbildung handelt es sich einerseits um Ausnahmeereignisse, andererseits um eine typische innere Struktur aller öffentlicher Transitbereiche, die von den

611 Die Ausgestaltung einer Konzentration von Menschen findet sich bereits in der römischen Komödie. Vgl. Plaut. Ep. 206-254. Zur Darstellung des Prozesses des Sich-Versammelns in der griechischen Komödie vgl. Barner (22003), 16. 
Bewohnern alltäglich zu durchqueren sind. Durch topographische Referenzen im Georaum der antiken Metropole sind sie nicht verortet. Allenfalls dienen räumlich diffuse topographische Merkzeichen wie Berge oder größere Plätze als vage Anfangs- und Endpunkte der Straßen. Von einer Nachprüfbarkeit sind sie damit suspendiert. Städtischen, weniger stadtrömischen Charakter erhalten diese fingierten Handlungszonen damit vor allem durch die Wahrnehmung einer massenhaften, simultanen Bewegung von Figuren und mobilen Objekten.

Die Perspektive auf diese Bereiche ist aus dem Inneren heraus. Sie sind Bewegungsbereiche einer Wahrnehmungsinstanz. Im Mittelpunkt ihrer Wahrnehmung steht der eigene Bewegungsspielraum, den sie als stark eingeschränkt wahrnimmt. Die geringen Abstände werden neben expliziten Attribuierungen vor allem durch entsprechende Verben angezeigt, die nicht nur auf einen körperlichen Kontakt hinweisen, sondern die Widerstände als grobe Auseinandersetzungen beschreiben. „Ohne Reibungen aneinander vorbeizukommen, (...) elementare Regeln der Höflichkeit" einzuhalten wie auch ,gewisse Techniken des Selbstschutzes"“612 zu entwickeln ist den Figuren dieses literarischen Raums nicht möglich. Der Transitbereich ist dieser Wahrnehmung entsprechend eine Gefahrenzone für das Individuum. Hier zeigen sich Ähnlichkeiten mit der Darstellung anderer verdichteter Räume, wie epischen Kampfschilderungen. ${ }^{613}$ Im Unterschied zu diesen handelt es sich jedoch um alltägliche und sich wiederholende Geschehensabläufe, die zudem aus einer subjektiven Perspektive beschrieben werden. Die Intention der Wahrnehmungsinstanz ist es allein, einen Weg zwischen zwei disparaten Bereichen innerhalb der urbs Roma zurückzulegen, und nicht, sich in eine Auseinandersetzung mit Anderen zu begeben. Die Konfrontation trifft sie in diesem Sinne unvorbereitet und widerwillig. Auch in der Bewertung ist diese Darstellung eher un-militärisch: Eine Wahrnehmungsinstanz bezeichnet die Gewaltanwendungen als Unrecht, eine andere verhält sich sogar passiv.

Trotz des geringen Abstandes und der unmittelbaren körperlichen Auseinandersetzung nimmt die Wahrnehmungsinstanz visuell keine Individuen wahr. Das Gegenüber, dessen Präsenz sie am Körper fühlt, bleibt anonym. Die Figuren fungieren wie mobile Objekte, als räumliche Merkmale und Bewegungshemmnisse eines Transitraums, keines sozialen Raums. Diese innere Struktur entsteht nicht aufgrund von besonderen Anlässen oder zu bestimmten Zeiten. Figuren begeben sich in diese Verdichtung hinein und werden in diese eingebunden. Das Gegenüber, eine kollektive Menge, die sich der Wahrnehmungsinstanz in den Weg stellt, ist ein Gefahrenraum, aber im Sinne der iterativen Erzählung immer vorhanden. Sie selbst wird in der Literatur zu einem typischen, großstädtischen Teilelement. ${ }^{614}$

\footnotetext{
612 Assmann (22008), 161.

613 Vgl. dazu Schmitz (2000), 212-221.

614 Vgl. dazu Chatman (1980), 139: „It makes no sense to treat crowds of walk-ons or extras as characters. (...) they are parts of the (...) setting."
} 



\section{Die Großstadt als erklärter Gegenstand römischer Dichtung}

In der altertumswissenschaftlichen Forschung besteht Einigkeit darüber, dass eine dem heutigen Verständnis entsprechende Großstadt kein Novum der letzten drei Jahrhunderte darstellt. Im Kulturraum der griechisch-römischen Antike gelten Wirtschafts-, Verwaltungs- und Kulturzentren wie Alexandria, Konstantinopel oder Rom als Siedlungen, die sowohl mit den bevölkerungsstatistischen Maßstäben, als auch in struktureller, kultureller und sozialer Hinsicht mit der Vielfalt heutiger moderner Großstädte mithalten konnten. ${ }^{615}$

Die Existenz einer Großstadt bedeutet allerdings nicht, dass nun in ihrem Gravitationszentrum - wie in einem zwingenden, mimetischen Wechselverhältnis - auch literarische Auseinandersetzungen über diesen Lebensraum entstehen müssen. ${ }^{616}$

615 Einen breit angelegten Definitionsversuch von ,Stadt ${ }^{\star}$ unternimmt Kolb (2005), 12-15. Alexandria als politisches, wirtschaftliches und kulturelles Zentrum hatte „bald nach Beginn des 3. Jahrhunderts die Zahl von 100000 Einwohnern überschritten“ und gilt als erste Großstadt der griechischen Welt. Vgl. Kolb (2005), 123-126. Zu Definitionsversuchen von ,Großstadt' in der Moderne vgl. Pfeil (21972), 4-7.

${ }^{616}$ Vgl. auch Traut (1957), 31 zur Entstehung der Großstadt-Literatur in der Moderne: „Eine realistische Großstadtdichtung setzte offenbar nicht nur das Entstehen der Großstadt voraus, sondern eine umfassendere Sicht ihrer Bevölkerung und ein spannungsreicheres, differenzierteres Erlebnis der modernen Welt.“ 
Ein Blick in Überblicksdarstellungen über diejenige Literatur, die in das Bezugsfeld der ersten Großstadt der griechischen Welt, nämlich der Metropole Alexandria, gehört, ${ }^{617}$ lehrt sogar eher das Gegenteil: Denn erstaunlicherweise gilt zwar als besondere literarische Entdeckung dieser Epoche durchaus ein Raum, aber gerade nicht die Stadt, sondern das Land. Womöglich - so wird verschiedentlich vermutet $^{618}$ - schuf Theokrit, der aus Syrakus stammte, aber auch Alexandria kannte, als Archeget seine ländlichen Idyllen ex negativo, als Kontrast zu einer als Überforderung wahrgenommenen großstädtischen Lebensweise. ${ }^{619}$ So wäre die Entdeckung des Ländlichen ein antiurbaner Reflex auf eine neue Erfahrungswelt, eine Art literarische Landflucht des Großstadtdichters. Diese weitverbreitete Deutung der Entdeckung eines Raumes, mit der eine sehr erfolgreiche europäische Gattungsgeschichte begann, ${ }^{620}$ wird jedoch von einigen Forschern auch für eine vereinfachende Erklärung gehalten: Nicht der Tadel an einer negativ empfunde-

617 Hunter (1997), 246: „Von der Dichtung wurde das meiste im 3. Jh. in Alexandria geschrieben oder ist mit Alexandria verbunden." Von der Dichtung des 2. und 1. Jahrhunderts v. Chr. ist sehr wenig erhalten.

618 Vgl. Vischer (1965), 126: „In der Bukolik des Theokrit findet man eine Flucht des Großstadtmenschen vor der übersteigerten Zivilisation seiner Zeit und ein Verlangen nach der verlorenen Einfachheit.“ Kolb (2005), 125 f.: „In Verbindung mit der Großstadt Alexandria wird nun aber auch - wohl zum ersten Mal in der Weltgeschichte - der Lobpreis des Landlebens als Kontrast zur städtischen Lebensweise literarisch formuliert. Zwar treffen wir schon im 4. Jahrhundert bei Xenophon und Platon auf eine negative Bewertung eines bestimmten Typs Stadt, wie ihn Athen verkörpert. (...) Das Bewertungskriterium ist hier jedoch moralisch-politischer Art, während in der bukolischen Dichtung das persönliche Glücksgefühl zum Maßstab erhoben wird. Die dort in Gedichten zum Ausdruck kommende Sehnsucht des hellenistischen Großstädters nach grünen Wiesen (...) bezeichnet die Entdeckung der Natur durch den antiken Menschen; möglich wurde dies wohl nur vor dem Hintergrund einer großstädtischen Zivilisation“. Green (2008), 60 f:: „Theocritus, indeed, presents a virtually new genre, the pastoral or bucolic idyll, a sanitized and idealized version of country matter calculated to appeal to city-based intellectuals and others hankering after the simple life but disinclined to face its harsh realities. In these poems the sun is always shining, and the flocks can seemingly take care of themselves. Mixed in with rustic piping and elegantly bawdy peasant banter is much enthusiastic flattery of Ptolemy: (...) It is essentially city-based.“ Fitter (1995), 40 f.: „Theocritus’ idylls indeed offer ,milieu studies“ (...): his landscapes are always figure-related, always profiled habitat. (...) with Theocritus (...) specificity turns gain, as a ,poetry of place' is born. The Harvest Home (Idyll 7) borrows the device of the bird-catalogue from Homer's Calypso, and the nightingale singing from the thicket is directly Homeric; but the assiduous naturalism - the accurately reported positioning of the landmarks along the eight kilometer to the Phrasidamus' farm - and the correct natural history (the rare tomb-crested lark, and the other birds referred to, seem always to have been resident in Cos) embed a paradisal tonality in the closely mapped familiar world."

619 Reinhardt (1988), 144 stellt fest, dass soziale Probleme des Landlebens, die in der älteren Literatur im Zusammenhang mit einem Stadt-Land-Vergleich durchaus eine Rolle spielten, bei Theokrit ausgeklammert werden.

620 Vgl. Curtius (111993), 191-209, pointiert 195 und 197. Green (1990), 223: „(...) a perennial form of literary and social escapism." 
nen Wirklichkeit, sondern ein antiquarisches Interesse an alten Liedtraditionen könne ebenso zur „Entdeckung des Landlebens“ geführt haben. ${ }^{621}$

Gewiss ist unser Bild von der hellenistischen Literatur bruchstückhaft und durch die Überlieferung verzerrt. ${ }^{622}$ Inwieweit Metropolen schon in hellenistischer Zeit Einzug in die Dichtung hielten, kann nur entsprechend der heutigen Überlieferungslage konstatiert werden. Aus ihr ergibt sich: Ein gewichtiger Gegenstand der Dichtung war die Großstadt auch in den anderen erhaltenen Werken dieser Epoche nicht. ${ }^{623}$ Zwar wählen einzelne Werke bisweilen einen sehr allgemein gehaltenen städtischen Hintergrund wie die Mimiamben des Herodas ${ }^{624}$ oder einen städtischen Schauplatz wie die Komödien Menanders ${ }^{625}$, doch der städtische Raum steht in diesen Werken nicht im Zentrum. ${ }^{626}$ Großstadttexte im Sinne Mahlers ${ }^{627}$

621 Hunter (2003), 491: „(...) the third century saw the creation of at least one new genre in which the construction of nature by art was central. (...) Implicit, then, in this new genre is a literaryhistorical construction analogous to Aristotle's tracing of the origin of tragedy and comedy to less formalized song traditions (...), and it is very difficult to accept any simplistic explanation for the emergence of bucolic in a desire to find relief from the pressures of life in the large conurbations of the Hellenistic world. On the other hand, these poems can, with hindsight, be seen as very significant texts in the history of the imagination of the countryside as a separate space of emotional (...) experience.“ Eine ironische Lesart vertreten Effe/Binder (22001), 17-26, bes. 26: „(...) die (...) neue Gattung ist bestimmt durch einen ironisch-kritischen Realismus“.

622 Hunter (2003), 477. Vgl auch Green (2008), 60: „Though we need to exercise caution in drawing general conclusions - what survives is no more than a tiny fragment of the whole (...)."

623 Die Suche Hartigans (1979) nach poetischen Auseinandersetzungen mit der Großstadt in der griechischen Gattung Epigramm verlief, was die Präsenz der Großstadt in der Literatur anbelangt, ebenfalls ergebnislos: „During the Hellenistic period the poet had little contact with the life of the city (...). The poet at the Museum wrote neither about Alexandria nor any contemporary site. He wrote about the Classical city, its history, its mythology, its suffering. He had no literary interest in the urban environment of his day.“ Hartigan (1979), 106, vgl. auch 103: „The vast majority of our city epigrams are laments for a fallen city, destroyed by war, by nature, or the ravages of time. Others celebrate the mythology of a site. The physical appearance of city attracted some of the epigrammatists."

624 Die Mimiamben stehen zwar in einem städtischen Kontext, wählen aber in der Überzahl als direkten Schauplatz einen Innenraum. In ihnen finden sich kaum Hinweise zur Physis des Ortes, an dem sie spielen. Gleiches gilt auch für die drei Eklogen Theokrits, die in die Forschung als städtische Mimen eingegangen sind. Werden in ihnen Informationen zur räumlichen Physis vergeben, wie z. B. in der Ekloge 2, sind sie sehr allgemein. So urteilt Reinhardt (1988), 85 f.: „Eine Stadt, in der es eine Palästra und Festzüge zu Ehren von Gottheiten gibt, verdient zwar sicher die Bezeichnung ǒotv, um eine Großstadt muß es sich dabei jedoch nicht handeln." Das Idyll 15 verlegt als einziges der drei städtischen Eklogen seinen Schauplatz von einem Innenraum hinaus auf die offene Straße.

625 Der städtische Schauplatz in Menanders Komödien wird stets mit Athen gleichgesetzt. Die Wahl des Schauplatzes ist jedoch „,nicht mehr an die gesellschaftlichen Gepflogenheiten einer besonderen Stadt gebunden“. Vgl. Hunter (1997), 254.

626 Bei Apoll. Rhod. ist die Wiedergabe städtischer Siedlungen auffallend unkonturiert. Vgl. Apoll. Rhod. 1, 234-317; 3, 210-214; 3, 867-890. Dagegen wird der Palast in Kolchis - wohl in Anlehnung an die Beschreibung des Palastes des Priamos in Hom. Il. 6, 3, 215-247 - ausführlicher beschrieben. Bemerkenswert ist bei Apollonios die im Hinblick auf die räumliche Wiedergabetech- 
haben sich aus dem Bezugskreis von Alexandria nur ausgenommen selten erhalten. Vereinzelt leuchten aber bemerkenswert kunstfertige Darstellungen einer großstädtischen Physis grell auf. So imaginiert Theokrit im 15. Idyll, den Adoniazousen, in einer subjektgebundenen Perspektivierung eine lebendige Momentaufnahme vom Straßenleben in Alexandria aus der Sicht zweier Frauen ${ }^{628}$, die sich durch ein aus Menschen bestehendes, ständig veränderndes Gedränge von ihrem Haus aus zu einem Tempel bewegen. Theokrit gelingt es damit bereits, raumspezifische Merkmale in einen konkreten Lebenszusammenhang einzubinden und darzustellen. ${ }^{629}$

Für die römische Literatur, vor allem für die der augusteischen und kaiserzeitlichen Epoche, die im Bezugskreis der antiken Metropole Rom entstand, ergibt sich bereits auf den ersten Blick ein völlig anderes Bild. So unterscheidet sich die Überlieferung an poetischen Texten allein vom Umfang her von denen aus dem Umfeld anderer Großstädte des Mittelmeerraumes. In welcher Weise dabei die Physis eines literarischen Raumes, Großstadt', einer urbs Roma, in den literarischen Texten erfasst und präsentiert wurde, war Gegenstand des vorangehenden Kapitels. Die Auseinandersetzung mit der Großstadt in dieser Literatur geht jedoch noch darüber hinaus. Die Großstadt selbst wird zu einem Gegenstand römischer Literatur.

In einem ersten Teil (4.1) soll zunächst umrissen werden, welche außerliterarischen Voraussetzungen einen derartigen, nicht selbstverständlichen Reflexionsprozess bedingt haben können: In welchem Zusammenhang könnte eine Auseinandersetzung der Autoren mit der Großstadt in Gang gesetzt worden sein? Sind

nik ungewöhnliche Vogelperspektive, die von Eros in 3, 164-166 eingenommen wird. Danek (2009) beobachtet bei Apoll. Rhod. in Hinsicht auf die Vielfalt von Schauplätzen eine größere Beschränkung als bei Homer.

627 Vgl. Abschnitt 2.1.

628 Zum emanzipierten Frauenbild in dieser Ekloge vgl. Griffiths (1981), als distanziert-ironische Darstellung kleinbürgerlicher Verhaltensweisen interpretiert bei Effe/Binder (22001), $18 \mathrm{f}$.

629 Dieses Idyll stellt in der Ausführlichkeit der dichterischen Raumwiedergabe einer Stadt ein Ausnahmezeugnis der griechischen Dichtung dar. Es wäre wünschenswert, eine genauere Untersuchung der griechischen Dichtung dahingehend vorzunehmen, die Präsenz und Funktion der einzelnen Passagen zu erfassen und zu bewerten: Beispielsweise bietet Kall. frg. 260 (Pfeiffer), 6267 die akustische Wahrnehmung eines singenden Wasserträgers, knirschender Wagengeräusche auf der Straße und von Knechten in einer Schmiede bei Tagesanbruch. In Herod. 1, 26-33 findet sich unter den sehr heterogenen Bestandteilen, die zum Lob Ägyptens aufgezählt werden, auch die früheste Erwähnung des Museions von Alexandria (v. 31). Vgl. Cunningham (1971), $66 \mathrm{f}$. Verstärkte Anspielungen in diesem Text auf Alexandria nimmt Knox (1966), 26-29 an. Barner (2003) zeigt anhand einiger Passagen aus Komödien des Aristophanes, dass auch dort Alltagserfahrungen der ,großen Kleinstadt“ Athen ausgestaltet werden, wie zum Beispiel „das Bild des sich Versammelns“ (ebd., 18). „Den Komödiendichter Aristophanes hat offenbar der initiale Prozeß des Sichversammelns der Athener, das Zusammenströmen fasziniert“ (ebd., 16). Unterschiede zwischen einer städtischen und einer großstädtischen Darstellung könnten wohl sinnvollerweise nur in griechischer Literatur herausgearbeitet werden. 
biographische (4.1.1) oder geistig-kulturelle (4.1.2) Vorbedingungen auszumachen, die einen Anstoß begünstigt haben? Derartige Überlegungen müssen sehr allgemein bleiben, da eine Rekonstruktion individueller Beweggründe auf der Basis der uns heute noch vorliegenden Informationen nicht mehr möglich ist. Das Zusammentragen der Informationen dient somit vor allem, um einen Spielraum abzumessen, in dem sich jeder einzelne Autor bewegen konnte.

In einer praefatio zu einem Gedichtband, einem Ausnahmezeugnis für die römische Literatur, äußert sich der kaiserzeitliche Autor Martial über die Entstehungsbedingungen seiner Literatur. Diese werkexternen Aussagen erlauben es, für sein CEuvre exemplarisch zu plausibilisieren, dass der Schritt zu einer Poetisierung der Großstadt und des Großstadtdichters in römischer Literatur tatsächlich vollzogen wurde (4.1.3).

Im Zentrum des zweiten Teils dieses Kapitels (4.2) stehen ausgewählte poetisierte Reflexionen verschiedener Autoren, in denen als ein Gegenstand von Literatur das Verhältnis von Dichtersein und Großstadt ausgelotet wird.

\subsection{Voraussetzungen der Großstadtdichtung}

\subsubsection{Rom als Lebenswirklichkeit. Biographien in der Großstadt}

Über die Lebenswege und -umstände vieler römischer Dichter der augusteischen und kaiserzeitlichen Epoche wissen wir in der Regel nicht viel mehr, als was in ihren eigenen Werken als biographische Offenlegung von Interpreten vermutet wurde. An prominenten Stellen, so insbesondere in Abschlussgedichten ihrer Bücherzyklen, haben einige Autoren die in griechischer Literatur verbreitete Angewohnheit übernommen, eine kurz gehaltene autobiographische Skizze einzubetten, nicht zuletzt, um die vorangehenden Bücher urheberrechtlich zu schützen und als ihr geistiges Eigentum auszuweisen. Vergleicht man diese sogenannten Sphragides ${ }^{630}$ untereinander sowie andere als biographische Quellen anerkannte Belege, sticht eine bemerkenswerte Gemeinsamkeit in der Lebensgeschichte vieler Autoren ins Auge: Die von heute aus noch in ihrem Werk greifbaren Dichter waren in der Minderheit gebürtige Stadtrömer, sie kamen vielmehr aus dem Gebiet des heutigen Italien - das damals aus unterschiedlichen Kulturräumen bestand ${ }^{631}$ - und aus den römischen Provinzen zur höheren Ausbildung in die

630 Die Bezeichnung sphragis für den persönlichen Teil eines Gedichtes resp. einer Gedichtsammlung stammt vermutlich von Terpander (um 675 v. Chr.). Vgl. Hans Armin Gärtner, s.v. Sphragis, in: DNP (2001), Bd. 11, 819. Ausführlich zu den Sphragides vgl. Kranz (1967).

631 Vgl. Henning Wrede, Die Funktion der Hauptstadt in der Kunst des Prinzipats, in: v. Hesberg (1995), 34. 
Hauptstadt oder in deren nähere Umgebung. ${ }^{632}$ Welche Herausforderungen und Chancen sich damit für sie tatsächlich verbanden, kann man in der Regel nur mutmaßen. Die Hauptstadt lud mit einem weiterführenden Bildungsangebot vorrangig den Nachwuchs einer sozialen Oberschicht ein, sich eine politische oder militärische Karriere zu erhoffen. ${ }^{63}$ Soweit rekonstruierbar, entstammten viele dieser Dichter entsprechenden, mehr oder weniger wohlhabenden Familien des Ritterstandes.

Die späterhin berühmten Autoren der augusteischen und frühen Kaiserzeit trafen demzufolge frühestens als Elfjährige in einer dicht besiedelten, lauten und engen Millionenstadt von politischer und kultureller Weltbedeutung ein. Mit diesem Zuzug waren u. U. große persönliche Erwartungen verbunden. ${ }^{634}$ Die Erlebnisse und Wahrnehmungen der Heranwachsenden, die in einem wachen Alter aus kleinund mittelstädtischen Gemeinden in die Großstadt versetzt wurden, sind in schriftlicher Form kaum reflektiert oder festgehalten worden. ${ }^{635}$ Gleichwohl darf

632 Die folgenden Informationen entstammen aus Conte (91994): Quintus Horatius Flaccus: geboren in Venosa (65 v. Chr.) kam er zur Ausbildung nach Rom, reiste als junger Mann nach Athen, kam dort in den Kontakt zu Caesarmördern, konnte aber 41 v. Chr. nach Rom zurückkehren, um 38 v. Chr. wurde er Maecenas vorgestellt, 33 v. Chr. bekam er als Landsitz das Sabinum geschenkt. Publius Ovidius Naso kam aus Sulmo zur Ausbildung nach Rom, ging auch nach Athen und hängte seine politische Karriere an den Nagel, trat in den Messalla-Corvinus-Kreis ein und fand Kontakte zu wichtigen Dichtern Roms. 8 n. Chr. wurde er relegiert und starb im Exil. Marcus Valerius Martialis wurde in Bilbilis zwischen 38 und $41 \mathrm{n}$. Chr. geboren, kam 64 nach Rom, wo er durch die Familie des Seneca in die höchsten Kreise eingeführt wurde. Er gelangte zu einiger Bekanntheit, erhielt hohe Ämter, kehrte aber 98 in seinen Heimatort Bilbilis zurück, wo er um 104 starb. Decimus Iunius Iuvenalis: die spärlichen biographischen Angaben gelten als unzuverlässig. Geboren wurde er wahrscheinlich in Aquinum (Süditalien) zwischen 50 und 60. Albius Tibullus: Wenige Informationen werden über eine anonyme Vita und von anderen Autoren übermittelt. Er starb kurz nach Vergil, wurde vielleicht im ländlichen Latium geboren (Gabii oder Pedum) und stammte aus einer wohlhabenden Ritterfamilie. Er folgte seinem Patron, Messalla Corvinus, auf zahlreiche Militärexpeditionen, in seinen letzten Lebensjahren lebte er womöglich wieder auf dem Lande in Latium. Sextus Propertius: geboren in Umbrien, wahrscheinlich Assisi, stammte aus einer wohlhabenden Ritterfamilie, die aber Landverluste während des Perusinischen Krieges hatte. Er kam zur politischen und militärischen Karriere nach Rom, gehörte dann aber zu einem Zirkel um Maecenas. Calpurnius Siculus: Lebensumstände völlig unbekannt. Publius Papinius Statius: geboren in Neapel zwischen 40 und 50 n. Chr. als Sohn eines Lehrers, hatte über öffentliche Rezitationen und Dichterwettbewerbe Erfolg in Rom und wurde von Domitian protegiert. Aulus Persius Flaccus: Über sein Leben informiert uns eine Vita, die auf Valerius Probus zurückgeht, er wurde von einer wohlhabenden Ritterfamilie in Volterra (Etrurien) 34 n. Chr. geboren, als Elf- oder Dreizehnjähriger soll er zur Schulbildung nach Rom geschickt worden und durch seinen philosophischen Lehrer, den Stoiker Annaeus Cornutus, in Kontakt mit oppositionellen, senatorischen Kreisen gekommen sein.

633 Zur schulischen Ausbildung vgl. Fantham (1998), 25-28.

634 Rom war bis zur Gründung von Konstantinopel (330 n. Chr.) das politische und religiöse Zentrum des Imperium Romanum. Zur ausführlichen Stadtgeschichte Roms vgl. Kolb (2002).

635 Konkret wird der Zuzug erwähnt bei Hor. sat. 1, 6, 76-78 und Ov. trist. 4, 10, 15 f.: protinus excolimur teneri curaque parentis/ imus ad insignes urbis ab arte viros. In den Sphragides des Properz und Ovid werden allein die Geburtsorte hervorgehoben, nicht der spätere Aufenthalt in der Haupt- 
man mutmaßen, dass sie gerade als Zugezogene über ausreichend Vergleichsmöglichkeiten verfügten, sich der Exotik einer Großstadt bewusst zu werden, und ihr Blick womöglich gerade dadurch für deren Spezifika geschärft war.

Über den hier skizzierten Lebenseinschnitt finden sich allein in den Satiren des Horaz und in den Tristien Ovids sehr knapp gehaltene Reflexionen. ${ }^{636}$ Der Sprecher der Satire 1, 6 des Horaz dankt in diesem Zusammenhang seinem Vater für dessen Engagement bei der Ausbildung. Er hebt vier Punkte hervor: erstens, dass der Vater ihn trotz seiner finanziellen Situation in Rom erziehen ließ, zweitens, dass er ihn dabei in einer Weise ausstattete, die ein äußerliches Erkennen seiner Herkunft nicht möglich machte, drittens, dass er ihn von Korrumpierungen fernhielt und viertens, dass der Vater keinen persönlichen Ehrgeiz mit diesen Schritten verband. ${ }^{637}$ Laut Ovids Tristie 4, 10 dagegen trafen sich die persönlichen Wünsche und Begabungen des Sprechers nicht mit den Vorstellungen seines Vaters:

20

at mibi iam puero caelestia sacra placebant,

inque suum furtim Musa trabebat opus.

saepe pater dixit 'studium quid inutile temptas?

Maeonides nullas ipse reliquit opes'.638

Entgegen den väterlichen Ambitionen ${ }^{639}$ wandte sich der Sprecher einer unnützen Kunst (inutile), der Dichtkunst, zu. Als unnütz gilt sie dem Vater wegen ihrer geringen Verdienstmöglichkeiten (nullas ... reliquit opes). Trotz der Gegensätzlichkeit in der jeweiligen Vater-Sohn-Beziehung zeigen diese kurzen Passagen, dass ein

stadt Rom, vgl. Prop. 1, 22; Ov. am. 3, 15. In Verg. georg. 4, 559-566 wird ebenfalls allein der gegenwärtige Aufenthaltsort Parthenope (v. 564) erwähnt. Reflexe des Fremdgefühls finden sich womöglich in denjenigen Gedichten, in denen die Perspektive eines Fremden in Rom nachvollzogen wird und ein Fremder resp. ein neues Buch durch Rom geführt wird, etwa in Prop. 4, 1; Ov. trist. 1,$1 ; 3,1$.

636 Lediglich auf den Besuch einer Elementar- und einer höheren Schule beziehen sich die Iuv. 1, 15-17: et nos ergo manum ferulae subduximus, et nos/ consilium dedimus Sullae, privatus ut altum/ dormiret sowie Hor. epist. 2, 2, 41 f.: Romae nutriri mibi contigit atque doceri,/ iratus Grais quantum nocuisset Acbilles. Ein Zeugnis aus der Spätantike findet sich bei Rut. Nam. 207-210; hier berichtet der Sprecher über seinen Verwandten Palladius, der wie er aus Gallien stammt: Tum discessurus studiis urbique remitto/ Palladium, generis spemque decusque mei;/ facundus iuvenis Gallorum nuper ab arvis/ missus Romani discere iura fori.

637 Vgl. Hor. sat. 1, 6, 71-87: qui macro pauper agello/ noluit in Flavi ludum me mittere, (...)/ sed puerum est ausus Romam portare docendum/ artis quas doceat quivis eques atque senator/ semet prognatos. vestem servosque sequentis, / in magno ut populo, siqui vidisset, avital ex re praeberi sumptus mibi crederet illos./ ipse mibi custos incorruptissimus omnis/ circum doctores aderat. quid multa? pudicum, / (...) servavit ab omni/ non solum facto, verum opprobrio quoque turpi/ nec timuit, sibi ne vitio quis verteret, olim/ si praeco parvas aut, ut fuit ipse, coactor/ mercedes sequerer.

638 Ov. trist. 4, 10, 19-22.

639 Vgl. auch Ov. trist. 4, 10, 15-18: protinus excolimur teneri curaque parentis/ imus ad insignes urbis ab arte viros./ frater ad eloquium viridi tendebat ab aevo,/ fortia verbosi natus ad arma fori. 
Leben in der Hauptstadt vor allem wegen ihres Bildungsangebots vorgezogen und dieses in der Regel als eine wie auch immer bewertete Aufstiegschance - auch finanzieller Art - erkannt und genutzt wurde. In beiden Fällen war aber das Ergreifen des Dichterberufs nicht vorgegeben. Es wird jeweils als eine eigenständige und in diesem Sinne emanzipatorische Entscheidung der Sprecher präsentiert.

Die Autoren verbrachten meist einen zentralen Abschnitt ihres Lebens in der Großstadt Rom und wirkten von dort aus als herausragende Vertreter ihrer Epoche. Die Vorteile, gerade für den Dichterberuf, mögen bei einer Entscheidung, den dauerhaften Standort nach Rom zu verlegen, überwogen haben. Hier boten sich Verdienst- und Förderungsmöglichkeiten durch Alimentierung sowie größere Chancen auf gesellschaftliche Anerkennung durch ein entsprechendes Publikum. Es ist ein naheliegender Schluss, dass in einer Millionenstadt ein weitaus größerer Kreis von Lesern und Hörern mit einem Bedürfnis nach gehobener Unterhaltung zu finden und zudem ein reger Austausch unter Kunstschaffenden zu erwarten war als in ihren Heimatgemeinden. ${ }^{640}$

Die besonderen Lebensbedingungen in einer Metropole spielten demnach eine außerordentlich prägende Rolle in der persönlichen Biographie, gehörten aber gleichzeitig auch zu einem täglichen Erfahrungshorizont der römischen Dichter wie auch ihrer Rezipienten. ${ }^{641}$

\subsubsection{Vorprägungen im Rhetorikunterricht. Von der Schulaufgabe in die Literatur?}

Eine frühe Form der geistigen Auseinandersetzung mit den Spezifika städtischen Lebens bot womöglich bereits der Schulunterunterricht, der im antiken Rom vornehmlich auf die Ausbildung rhetorischer Fertigkeiten abhob. Im Mittelpunkt der Unterweisungen des grammaticus stand für die Neun- bis Dreizehnjährigen noch die Lektüre und Kommentierung hoher Literatur, insbesondere der Historiker und Dichter, an diesen aber sollten sie vor allem den richtigen und guten Gebrauch von Sprache beobachten. Ihre so erworbenen Kenntnisse wendeten die Knaben einer senatorischen und ritterlichen Oberschicht dann in den praeexercita-

640 Als Ort eines solchen Austausches werden die Dichterzirkel um Maecenas und Messalla angefübrt. Vgl. Hor. sat. 1, 10, 81-90 und Ov. trist. 4, 10, 41-56. Über den dem Publikum geschuldeten Erfolg vgl. Ov. trist. 4, 10, 57-60. Austausch unter „Kunst“"schaffenden ist aber auch über die eigene Zunft hinaus im augusteischen Rom zu beobachten. Vgl. die leitmotivischen Übereinstimmungen in Dichtkunst und Architektur, dazu Zanker (42003), $112 \mathrm{f}$.

641 Die lateinische Literatur wurde traditioneller Weise mündlich vorgetragen und war damit vorrangig eine Literatur von in Rom Lebenden für in Rom Lebende. In augusteischer Zeit beginnen die Dichter jedoch, ihre Gedichte in Buchform anzuordnen und herauszugeben. Sie sind damit zwar nicht die ersten Werke, die die Grenzen der Stadt Rom und einen unmittelbaren Zuhörerkreis verlassen, eine Veränderung liegt aber darin, dass bei der Zusammenstellung der Gedichtsammlungen nicht mehr an einen implizierten Hörer, sondern an einen implizierten Leser gedacht wird. Vgl. Fantham (1998), $57 \mathrm{f}$. 
menta, den Elementarübungen, in Form von Modellreden an. Von solchen freieren Übungsformen gab es reichlich verschiedene: Man übte das Nacherzählen bestimmter Inhalte; man übte das Formulieren und Widerlegen von Beweisen; man übte die Ausgestaltung von Gemeinplätzen; man übte, Lobreden auf unterschiedliche Gegenstände zu halten, das Beschreiben von Personen oder Kunstwerken oder die Erörterung von allgemeinen Fragen. ${ }^{642}$ Diese letztgenannte Art der Redeübung nannte man in der Regel ${ }^{643}$ Thesis. Quintilian berichtet darüber in der institutio oratoria:

Thesis autem, quae sumuntur ex rerum comparatione, ut 'rusticane vita an urbana potior' 'iuris periti an militaris viri laus maior?' mire sunt ad exercitationes dicendi speciosae atque uberes, quae vel ad suadendi officium vel etiam ad iudicium disceptationemque iuvant plurimum: (...). ${ }^{644}$

Für das Verfassen von Theseis galten, wie Quintilian schreibt, solche Themenkomplexe als besonders gestaltungsreich (speciosae) und ergiebig (uberes), die aus dem Vergleich „gegebener Verhältnisse“"645 (ex rerum comparatione) genommen werden konnten, also nicht an einen konkreten Fall gebunden waren. Sie entstammten demnach weder den üblichen Themenbereichen des Literaturkanons, noch griffen sie Allgemeinplätze mit verbindlichen Bewertungsmustern auf. Die darzustellenden Sachverhalte sollten vielmehr so grundsätzlicher Natur sein, dass eigene Beobachtungen und Erfahrungen einfließen konnten, die auf eine differenzierte Erörterung hoffen ließen. Dieser generelle Zugriff der Redeübung machte es in besonderer Weise möglich, eine persönliche Lebensanschauung in den Vordergrund zu stellen. Dies erklärt auch, wieso sie nicht nur von Rhetoren, sondern auch von Philosophen geschätzt wurde. ${ }^{646}$

Dem oben zitierten Zeugnis Quintilians nach gehörte der Vergleich des Stadt- mit dem Landleben zu solchen allgemeinen und grundsätzlichen Themen. Bei den Heranwachsenden der Oberschicht wurde somit neben einer genauen Kenntnis des Tätigkeitsfeldes eines Juristen oder eines Militärs auch die der Lebensbereiche Großstadt und Land vorausgesetzt. Gleichzeitig scheint diese Themenstellung im Anfängerunterricht frei von moralisierenden oder vorgegebenen Sichtweisen behandelt worden sein, wie die Art der Aufgabenstellung einer Thesis nahelegt. Denn inhaltlich sollten zunächst einmal Vor- und Nachteile gegenübergestellt

\footnotetext{
642 Andersen (2001), 245-247.

643 Andersen (2001), 247.

644 Quint. inst. 2, 4, 24. Vgl. als Anwendungsbeispiel: Quint. decl. min. 298, 7, 13-14. Vgl. auch Sen. Contr. 2, 1, 11-12; 5, 5: Kritik am Landleben; Sen. Contr. 1, 6, 4; 2, 1, 8: Lob der ländlichen Vorfahren.

645 Übersetzung von Rahn (1975), Bd. 1, 183.

646 Vgl. Cic. orat. 14, 46. Vgl. dazu auch Andersen (2001), 247.
} 
werden, die aus einer eigenen Lebenswirklichkeit gewonnen wurden, und womöglich mit einer persönlichen Stellungnahme verbunden werden.

Eine andere rhetorische Schulübung stellte das Verfassen von Lobreden zur Aufgabe. Typische Themenstellungen bezogen sich auf besondere Menschen, Tiere, oder auch auf Landschaften und Städte. ${ }^{647}$ Bei der Wahl eines möglichen Gegenstandes für diese sogenannten Enkomien ${ }^{648}$ ließ man der Phantasie freien Lauf, beklagte sich aber bisweilen über allzu wilde Blüten. Der Kreativität im Auffinden geeigneter Gegenstände entgegengesetzt wurde dieser Redetyp in besonderer Weise durch ein starres Schema reglementiert. ${ }^{649}$ Es gab obligatorische Punkte, auf die in einer mehr oder weniger verbindlichen Reihenfolge eingegangen wurde. So handelte man z. B. in einem Stadtenkomion einen Katalog fester Kategorien wie Gründer, Klima, Lage, Umgebung und bauliche Gestaltung ab. ${ }^{650}$ Es kamen folglich vorrangig äußerliche Merkmale zur Darstellung, die weniger einem direkten Erleben als rhetorischer Topik geschuldet waren. ${ }^{651}$ Brachte es doch die inhaltliche Festlegung einer Lobrede zwangsläufig mit sich, dass eine zu lobende Stadt ein angenehmes Klima oder eine liebliche Umgebung hatte.

Das Verfassen derartiger Enkomien wie auch Theseis war zunächst eine Anfängeraufgabe und lag weit entfernt vom Anspruch höherer rhetorischer Weihen, eine Grundlage späteren dichterischen Schaffens konnte hier aber gelegt werden. Mit Beginn der Kaiserzeit blieb das Verfassen und Vortragen von Erörterungen und Lobreden ${ }^{652}$ zudem nicht mehr auf den Schulunterricht beschränkt, sondern wurde zu einem allgemein-gesellschaftlichen Unterhaltungsmedium mit großem Publikumszulauf. Damit bot sich insbesondere professionellen Rednern die passende Gelegenheit, ihr Können auch in solchen Redeformen unter Beweis zu stellen; eine Leistung, die nicht selten mit stolzen Honoraren quittiert wurde. ${ }^{653}$

Als eine besondere Herausforderung galt es, sich ein Thema vom Publikum zurufen zu lassen und darauf eine Stegreifrede zu halten. Philostrat berichtet in seinen Sophistenbiographien ( $\beta$ ío $\sigma o \phi \iota \sigma \tau \tilde{\omega} v$ ) über einen derartigen Auftritt des Sophisten

647 Quint. inst. 3, 6-28 nennt als Themenvorschläge Götter, Menschen, Städte, öffentliche Gebäude, Gegenden, Worte und Taten etc.

648 Zur Begriffsentwicklung vgl. Mario Vallozza, s.v. Enkomion, in: HWRh (1994), Bd. 2, Sp. $1152-$ 1155.

649 Vgl. Lausberg (42008), \$ 247.

${ }_{650}$ Vgl. H. Kugler, Art. Städtelob, in: Müller (2003), Bd. 3, 491-494 und ders., Art. Städtelob, in: Ueding (2007), Bd. 8, Sp. 1319-1325.

$651 \mathrm{Zu}$ den laudes urbium vgl. grundlegend Classen (1986).

${ }_{652}$ Man kann wohl ab der Zeit der (ersten) Sophistik (4. Jh. v. Chr.) davon ausgehen, dass Vorträge bereits allein zu Unterhaltungszwecken vorgetragen worden sind. Nach dem 4. Jh. sind Nachrichten darüber aber spärlich. Erst in der Kaiserzeit werden Enkomien in der griechischen Literatur wieder verstärkt produziert. Vgl. dazu Vallozza (1994), Sp. 1156.

653 Vgl. Andersen (2001), 259. 
Alexander in Athen. Dieser habe auf Wunsch des Publikums eine Hypothesis ${ }^{654}$ an die Skythen gehalten, denen er raten soll, ihre frühere Lebensweise wieder aufzunehmen, da sie das Leben in der Stadt krank mache. ${ }^{655}$ An der Themenstellung lässt sich erkennen, wie Alexander trotz der vielleicht überraschend konkreten Aufgabe für seinen nun zu extemporierenden Vortrag auf bekannte Themenbereiche, wie die Schilderungen exotischer Völker oder den Vergleich von Stadt- und Landleben, zurückgreifen konnte.

Auf dem Höhepunkt dieser Mode, der Zeit der sogenannten Zweiten Sophistik (2./3. Jh.), fehlte es allerdings nicht an Kritik und Spott für derartige Massenveranstaltungen. ${ }^{656}$ Aelius Aristides (117-187 n. Chr.) gehört zu denjenigen Vertretern, die die Stegreifrede für sich kategorisch ablehnten. ${ }^{657}$ Seine wohl bekanntesten Reden, enthusiastische Enkomien auf Städte, der ,Panathenaikos` und die sogenannte Romrede, ${ }^{658}$ werden in der Regel sogar als Lesereden betrachtet und generierten somit eine eigene Literaturgattung. ${ }^{659}$

Was den Themenbereich ,Stadt' anbelangt, kann festgehalten werden: Römische Autoren hatten sich mit hoher Wahrscheinlichkeit bereits während ihrer Schulausbildung mit der einen oder anderen Redeform intensiver auseinandergesetzt, kannten Stadt- und Landleben nicht nur aus eigener Anschauung, sondern waren wohl dazu angehalten worden, unterschiedliche Lebensbedingungen zu reflektieren und sich damit in argumentativer Form auseinanderzusetzen. Sie hatten zudem derartige Reden als Musterbeispiele studiert, (von Könnern) gehört oder selbst verfasst. ${ }^{660}$ Der Zugriff der Übungen verlangte von ihnen, einerseits nicht allein vorgefasste Meinungen zu übernehmen, sondern einen eigenen Standpunkt zu gewinnen, andererseits mit obligatorischen positiven Topoi der Stadtenkomien zu jonglieren. Eine Abwertung des Stadtlebens haben diese Angebote einer Auseinandersetzung nicht zwingend herausgefordert.

654 Bei einer Hypothesis erörtert man eine allgemeine Frage (Thesis) anhand einer bestimmten Situation. Vgl. Andersen (2001), $248 \mathrm{f}$.

655 Vgl. Philostr. soph. 2, 5.

656 Quint. inst. 10, 7, 21.

657 Vgl. Philostr. soph. 2, 7.

658 Aristeid. or. 1 und 26. Das Enkomion auf Rom ist überwiegend eine Würdigung des die Oikumene umspannenden römischen Herrschaftsbereiches. Die Perspektive auf die Weltmetropole entspricht vorrangig der einer romanisierten griechischen Oberschicht auf administrative und militärische Auswirkungen römischer Herrschaft. Vgl. dazu: Zahrnt, M., Identitätsvorstellungen in den östlichen Provinzen am Beispiel der Romrede des Aelius Aristides, in: v. Hesberg (1995), 133-151. Als „,...) das bekannteste und einflußreichste Beispiel einer Lobrede auf eine Stadt" wird sie bei Classen (1986), 18 f. gewürdigt. „Es geht um Rom als Zentrum politischer Macht, nicht als Schauplatz städtischen Lebens“ (ebd., 19).

659 Andersen (2001), 266.

660 Seneca d. Ä. berichtet über Reden Ovids bei Deklamationswettbewerben, vgl. Sen. contr. 2, 2, 8 und 9, 5, 17. Vgl. dazu Ov. trist. 4, 10, 23-26. 
Derartige Anregungen können in eine dichterische Verarbeitung einfließen oder dort vertieft werden. Ein genereller Einfluss einer rhetorischen Ausbildung ist in der Dichtung seit langem beobachtet worden. Schaut man auf die Struktur römischer und auch schon griechischer Dichtung, sind Fertigkeiten der Beredsamkeit denkt man an die Reden in Epen, Tragödien oder poetischer Briefliteratur - für eine Vielzahl von Gattungen von großer Bedeutung. ${ }^{661}$ Formen des Städtelobs etwa finden sich in der gesamten antiken Literatur und über diese hinaus. Auch die Gegenüberstellung des Stadt- und Landlebens und der jeweiligen Lebensart ist in verschiedenen Gattungen präsent. ${ }^{662}$ Dichter und andere Schriftsteller bedienten sich demnach stets einer gemeinsamen literarischen Tradition und einer gemeinsamen rhetorischen Topik, deren Spuren sich bis in die frühe griechische Literatur zurückverfolgen lassen. Der communis opinio zufolge wird aber der Dichtung in dem Zeitraum der ausgehenden augusteischen und beginnenden kaiserzeitlichen Epoche eine ausnehmende Rhetorisierung bescheinigt. ${ }^{663}$ Möglicherweise lag mit dieser Affinität auch der Schritt zu einer dichterischen Beschäftigung mit der Großstadt näher denn je, zumal wenn sich in zunehmendem Maße auch Meister des rhetorischen Faches öffentlich mit derartigen Themenstellungen auseinandersetzten, also sich hoch artifiziell in allgemeinen und speziellen Erörterungen über das Stadt- und Landleben äußerten oder Meisterenkomien über Städte schrieben. Ob nun derartige Deklamationen die übrige Literatur elektrisierten oder es sich um umgekehrte oder parallele Wege handelte, ist damit nicht zu beantworten. ${ }^{664}$ Es erklärt aber, wieso rhetorische Denkfiguren über die Stadt als dichterische Beschreibungs- und Erzählformen der literarischen Großstadt verwendet wurden und in der Vielfalt und Breite römischer Großstadtliteratur wiederkehrende Motive und Bewertungsmuster gattungs- und kulturübergreifend zu erkennen sind. Als möglicher Hintergrund der Autoren erfasst man aber damit nur einen äußerst kleinen Bereich der Darstellung der Großstadt in der römischen Dichtung, die weder auf einen Katalog äußerer Merkmale, wie bei einem Städtelob, beschränkt, noch deren poetischer Gestaltungsspielraum einzig auf eine Gegenüberstellung von Stadt und Land begrenzt werden sollte. Den Einzug der Großstadt in die Literatur allein einer rein biographischen Disposition zuzuschreiben, hieße

661 Der satirische Sprecher in der ersten Satire Juvenals meint, bereits der Besuch einer Elementarund einer höheren Schule qualifiziere ihn ausreichend für den Dichterberuf. Vgl. Iuv. 1, 15-18: et nos ergo manum ferulae subduximus, et nos/ consilium dedimus Sullae, privatus ut altum/ dormiret. stulta est clementia, cum tot ubique/ vatibus occurras, periturae parcere chartae.

662 Vgl. dazu Rosen/Sluiter (2007), Eigler (2002).

663 Für den bemerkenswertesten Rhetoriker unter den römischen Dichtern hält Andersen bereits den augusteischen Dichter Ovid, der sein Können in den Heroides unübertroffen unter Beweis stelle (Andersen (2001), 266 f.). Als anerkannt rhetorische Dichtung gelten weiterhin die Dramen Senecas, aber auch Juvenals Satiren und Martials Epigramme.

664 Vgl. Andersen (2001), 267. Fantham (1998), 86, zeigt, wie typische Themenbereich der Poesie, zum Beispiel mythologische, zum Gegenstand rhetorischer Rede werden, sowie poetische Formulierungen, insbesondere die des Vergil, in Prosareden Eingang finden. 
daher, zu kurz zu greifen, wie ihn allein über Themenstellungen rhetorischer Progymnasmata erklären zu wollen. Es handelt sich um eine Folie, vor der die künstlerischen Auseinandersetzungen stattfanden. ${ }^{665}$

\subsubsection{Die Poetisierung einer antiken Großstadt}

In der augusteischen Epoche und der beginnenden Kaiserzeit finden sich vermehrt Stellungnahmen, in denen - um es zunächst sehr vorsichtig zu formulieren - sich als Dichter präsentierende Figuren über die Bedingungen ihres Schreibens reflektieren. Solche Stellungnahmen finden sich überwiegend in poetisch überformten Texten, jedoch existiert auch ein poetologisch ausgerichteter Essay ${ }^{666}$ des kaiserzeitlichen Autors Martial. In ihm äußert er sich über die Entstehungsbedingungen seiner Literatur. Eine Gegenüberstellung zentraler Aussagen dieses Essays und poetisch überformter Aussagen aus seinem Euvre kann zeigen, inwieweit bei poetisierten Darstellungen der Entstehungsbedingungen von Literatur das Verhältnis von Realität und Fiktionalität absichtsvoll verwischt wird.

\subsubsection{Der Stadt abgelauschte Dichtung. Ein poetologischer Essay über Dichtung und Großstadt (Mart. praef. XII)}

Bei einer qualitativen Bewertung und Einordnung lassen sich in der Regel gute Gründe dafür anführen, warum persönlichen Stellungnahmen eines Autors außerhalb des eigenen Euvres größeres Gewicht zugemessen werden sollte als vergleichbaren oder gar gegensätzlichen Äußerungen einer literarisch fingierten Dichter-persona ${ }^{667}$ : In der ersten Gruppe von Texten meint man, eine der Autorenintention nähere Stimme (,authorial voice ${ }^{{ }^{6} 668}$ ) zu hören, in den poetischen Texten dage-

665 Vgl. exemplarisch Cairns‘ (2012) Untersuchung zu Hor. epod. 2 und Tib. 1.

666 Die Titulierung des Widmungsbriefes als Essay ist selbstverständlich anachronistisch, doch soll mit der Verwendung dieses Begriffes darauf hingewiesen werden, dass diese Brief-Form der praefationes wichtige Kennzeichen eines Essays teilt. Vgl. dazu Arnold/Detering (31999), 360-362.

667 In der anglo-amerikanischen Forschung redet man in Bezug auf Juvenal statt der herkömmlichen Gleichsetzung von poetischem Ich und Autor von einer persona als satirischem Sprecher. Vgl. dazu grundlegend Anderson (1982), 197-254. Die Leistung dieser Übertragung einer modernen Theorie auf antike Dichtung liegt darin, dass der Blick auf die satirische Haltung gelenkt wurde, d. h. darauf, dass das satirische Ich einen dem Thema adäquaten Standpunkt einnimmt, der nichts über die tatsächliche Meinung des satirischen Ichs oder gar des Autors aussagen muss, im Sinne einer Charaktermaske. Dennoch zeigt Schmitz (2000), dass die satirische Meinung nicht durchgängig durch einen Charakter (persona) dargestellt wird und sogar innerhalb einer Satire nicht koinzident sein muss. Das Ich wird auf ein „repräsentatives Ich“ (Schmitz (2000), 59) reduziert, das mit seiner Aussage eine Allgemeingültigkeit beanspruchen kann. Ich verwende den Begriff Dichter-persona daher in dem Sinne, dass sich der Sprecher als eine Figur zu erkennen gibt, die einen Dichter darstellen soll.

668 Johannsen (2006), $49 \mathrm{f}$. 
gen eher einer überformten Stimme zu begegnen, die gattungsbedingten Sprechweisen unterliegt.

Derartige außerliterarische Stellungnahmen sind in römischer Literatur Ausnahmeerscheinungen, sie finden sich als sogenannte praefationes ${ }^{669}$ poetischen Werken vorangestellt. ${ }^{670}$ Meist sind sie in Briefform als in sich abgeschlossener Prosatext gestaltet. ${ }^{671} \mathrm{Im}$ Hinblick auf die formalen Eigenschaften unterscheidet sich ein solcher Text somit offenkundig von den folgenden poetischen Texten der Sammlung und wird damit „,besonders nachhaltig als werkexterner Bestandteil des jeweiligen Buches kenntlich gemacht" ${ }^{\text {". }}$.72 Aufgabe solcher praefationes ist es, die Rezeption des nachstehenden poetischen Textes zu steuern. In ihnen spricht der Autor ${ }^{673}$ über sein Werk, über dessen Entstehungsbedingungen, über Intentionen oder über eine gewünschte Rezeptionshaltung des Lesers. ${ }^{674}$

Die zum zwölften, und damit letzten ${ }^{675}$ Epigrammbuch Martials gehörige praefatio ist ein solcher als Brief gestalteter Text. In ihm berichtet der Verfasser recht ausführlich über die Auswirkungen seiner Umwelt auf das eigene literarische Schaffen. Eine derartig konkrete Bezugnahme auf äußere Bedingungen ist inhaltlich nicht nur innerhalb der praefationes Martials singulär ${ }^{676}$, sondern gilt als das einzige (erhaltene) derartige Zeugnis eines Dichters in der gesamten lateinischen Literatur.

Die praefatio ist in Form eines Briefes an einen spanischen Landsmann namens Priscus gerichtet, der sich in Rom aufhält. ${ }^{677}$ Sie zielt zum einen auf die Rechtferti-

669 Zum Begriff vgl. Johannsen (2006), 23-36.

670 Als ein erstes Beispiel einer in Prosa verfassten praefatio vor einem dichterischen Werk gilt die des frühkaiserzeitlichen Dichters Columella, de re rustica, 10. Bis auf die überlieferten praefationes Martials und Statius' finden sich auf weitere lediglich Hinweise. Vgl. Johannsen (2006), $34 \mathrm{f}$.

671 Die praefationes des Martial sind nicht durchgängig als Prosatext gestaltet: Von den zwölf Vorreden sind fünf in Prosa verfasst.

672 Johannsen (2006), 38. Zu Paratexten vgl. Arnold/Detering ( ${ }^{31999), ~ 349-356 . ~ A u s f u ̈ h r l i c h ~ z u ~ p r a e-~}$ fationes als Paratexten vgl. Johannsen (2006), 38-51.

673 Der Gebrauch des Begriffes Autor ist auch im Zusammenhang mit praefationes nicht unumstritten. Johannsen (2006) problematisiert diesen Umstand und präzisiert ihn, indem sie von ,authorial voice“ (ebd., 49) spricht. Trotz aller annehmbaren Fiktionalisierung sei die Stimme dennoch als auktoriales Dichter-Ich gestaltet, im Sinne eines ,implizierten Autors'. Vgl. auch Nünning (32004), s.v. Autor, implizierter, $37 \mathrm{f}$.

674 Vgl. Johannsen (2006), $37 \mathrm{f}$.

675 Vgl. dazu Lorenz (2002), $232 \mathrm{f}$.

676 Johannsen (2006), 108 weist darauf hin, dass sich diese praefatio auch grundlegend in Themenwahl und Ausdruck von den vorangehenden Vorworten in der Buchsammlung Martials unterscheidet.

677 Der Schreiber selbst befindet sich in der spanischen Provinz, seiner Heimat. In der praefatio wird jedoch nicht erwähnt, dass Martials gegenwärtiger Aufenthaltsort Bilbilis zugleich sein Geburtsort ist. Die in der praefatio zum 12. Buch vorauszusetzende Heimkehr des Autors nach Spanien (vgl. Johannsen (2006), 108) wird bisweilen als literarische Fiktionalisierung gewertet, da man bei der Beschreibung der spanischen Provinz greifbare Anschaulichkeit vermisst. Vgl. dazu Holz$\operatorname{berg}(2002), 14 \mathrm{f}$. 
gung einer dreijährigen Schreibpause eines - nach eigenen Aussagen eigentlich hingebungsvollen - Dichters ${ }^{678}$, zum anderen darauf, sich der Qualität des vorliegenden Buches zu vergewissern. ${ }^{679}$ Der Brief beginnt mit dem Eingeständnis eines Schuldbewusstseins:

\section{Scio me patrocinium debere contumacissimae trienni desidiae; quo absolvenda non esset inter illas quoque urbicas occupationes, quibus facilius consequimur ut molesti potius quam ut officiosi esse videamur; nedum in hac provinciali solitudine, ubi nisi etiam intemperanter studemus, et sine solacio et sine excusatione secessimus. Accipe ergo rationem. ${ }^{60}$}

Eine Verteidigung für die säumige Veröffentlichung eines neuen Gedichtbandes bedarf nach Meinung Martials im konkreten Fall überzeugender Argumente. Einerseits ist die entstandene Schaffenspause selbst für bekanntermaßen viel Beschäftigte - wie charakteristischerweise den Großstädter - recht lang geworden, andererseits hält sich der Dichter gegenwärtig in der Provinz auf. Man könne also hier - so räumt der Verfasser ein - gerade nicht die typischen, leidigen (molesti potius) Ausreden viel beschäftigter Städter geltend machen, sondern müsse im Gegenteil die gemeinhin als günstig eingeschätzten Bedingungen für literarisches Arbeiten in der Zurückgezogenheit der Provinz als ein Vorurteil entlarven. Martial wehrt sich demzufolge gegen Allgemeinplätze und trägt hier seine persönliche Anschauung vor: Das ablenkungsarme Leben in der Provinz ist dem subjektiven Empfinden des Autors nach kein idealer Musenhain.

In einer komplexen Argumentation offenbart Martial seine eigentlichen Antriebskräfte zum Dichten und damit die Gründe seiner Schaffenspause:

In qua hoc maximum et primum est, quod civitatis aures quibus adsueveram quaero, et videor mibi in alieno foro litigare; si quid est enim quod in libellis meis placeat, dictavit auditor: illam iudiciorum subtilitatem, illud materiarum ingenium, bibliothecas, theatra, convictus, in quibus studere se voluptates non sentiunt, ad summam omnium illa quae delicati reliquimus desideramus quasi destituti. 681

Der Autor schöpfte vormals seine Inspiration aus drei Quellen: den Zuhörern, den Gegenständen und den verschiedenen Orten literarischer Kommunikation ${ }^{682}$. An erster und vornehmlicher Stelle steht das Publikum, mit dem ihm in besonderer Weise zu kommunizieren erlaubt war. ${ }^{683} \mathrm{Zu}$ seinen Zuhörern stand der Dichter

678 Ne mireris igitur abiecta ab indignante quae a gestiente fieri solebant. Mart. praef. 12, Z. 17 f.

679 Eine ausführliche Besprechung dieser praefatio findet sich bei Johannsen (2006), 107-121.

680 Mart. praef. 12, Z. 1-7.

681 Mart. praef. 12, Z. 7-14.

682 Vgl. zu Orten literarischer Kommunikation in Rom grundsätzlich Heil (2003).

683 Es ist eine der wenigen Stellen in Martials Werk, an denen auf einen auditor statt auf einen lector verwiesen wird. Vgl. Johannsen (2006), 112. In Mart. 9, 81, 1 werden lector et auditor als geneigte 
in engem Kontakt (quibus adsueveram). Die Beziehungen gingen jedoch über ein herkömmliches Vertrauensverhältnis hinaus: Nach eigenen Worten diktierte ihm der Hörer gerade dasjenige, was an seiner Dichtung Qualität hatte. ${ }^{684}$ Er war als Dichter lediglich ein Empfänger der zu ihm redenden Zuhörerschar. Mit dieser „außergewöhnliche[n], paradoxe[n] Pointe rezeptionsästhetischer Überlegungen“"685 gibt Martial zu verstehen, dass nach eigener Einschätzung seine vormaligen dichterischen Leistungen nicht auf seiner aktiven, selbstständigen Dichterpersönlichkeit beruhten, sondern dass er gleichsam als ein passiver Zuhörer die Anregungen seines eigenen Publikums lediglich aufzunehmen hatte. Ferner schätzte er sein Publikum wegen dessen Feinsinnigkeit im Urteil (illam iudiciorum subtilitatem). Eine wichtige Triebfeder seiner Arbeit war die sachliche Bewertung, die ohne Neid und Missgunst abgegeben wurde. Dieser in mehrfacher Hinsicht wichtige Garant poetischer Qualität ist für ihn nicht zu ersetzen.

Anregungen und Herausforderungen fand der Autor auch durch die Gegenstände selbst: illud materiarum ingenium. In dieser anspielungsreichen, schwer zu fassenden Formulierung schreibt Martial den materiae selbst dichterisches Potential zu, das von seiner Person und seinem eigenen dichterischen ingenium völlig losgelöst existiert. Das bedeutet, die materiae waren nicht nur Gegenstände seiner Dichtung, sondern haben - Dichtern oder sogar Musen vergleichbare - eigene schöpferische Kraft. ${ }^{686}$ Dichterisches Talent war in deren Gegenwart entbehrlich. Auch in dieser Hinsicht war der Autor allein ein Aufnehmender.

Rezipienten genannt; in Mart. 7, 52, 6 eine Vorlese-Situation eines Dritten beschrieben. Vgl. P. Howell, Martial's Return to Spain, in: Grewing (1998), 182. Die Betonung des gegenseitigen Hörens (dictavit ... auditor) als Form der Kommunikation zwischen Dichter und städtischem Rezipientenkreis unterstützt die Vorstellung, dass der Kontakt über die gegenwärtige räumliche Distanz hinweg nicht aufrechtzuerhalten ist.

684 Vgl. Johannsen (2006), 112.

685 Barié (1999), 1090.

686 Johannsen (2006), 111 beobachtet, Martial habe in anderen praefationes sein dichterisches ingenium wiederholt, ,in seiner Bedeutung herabgesetzt, aber stets als sein persönliches geistiges Eigentum bezeichnet." Die Zuschreibung eines ingenium an die materia ist außergewöhnlich. Sie findet sich in dieser Form nur noch bei Ov. trist. 5, 1, 27-30: non baec ingenio, non baec componimus arte:/ materia est propriis ingeniosa malis./ et quota fortunae pars est in carmine nostrae?/ felix, qui patitur quae numerare potest! Vgl. auch Johannsen (2006), 110-111. Üblicherweise besteht ein Gegensatz zwischen materia und ars, der zunächst im Zusammenhang theoretischer Überlegungen in der Architektur und darstellenden Kunst besprochen wird, aber auch als literarischer Topos bekannt ist. Vgl. ThLL (1936-1966) 8, s.v. materia III D e 1, Sp. 461. Dabei fällt in der Regel die Wertschätzung der künstlerischen Verarbeitung (ars) höher aus, als dass der Naturzustand eines Gegenstandes (materia) bewundert wird. Vgl. Mart. 8, 50 (51), 7: materiae non cedit opus; Ov. met. 2, 5: materiam superabat opus. Abweichungen von diesem Kunstverständnis dienen oft besonderen Aussageabsichten, etwa zur Formulierung einer hyperbolischen Behauptung oder einer recusatio, um Gegenstände resp. Inhalte (materia) für die eigene Dichtung (ars) abzulehnen, meist weil sie zu anspruchsvoll seien. Die materia der Dichtung sollte stets passend zum Talent des Dichters und zur bevorzugten Gattung gewählt sein. (Hyperbolische Formulierungen: Ov. trist. 1, 5, 56: materia vires exsuperante meas. Ov. trist. 2, 336: materia ne superetur opus.) Vgl. dazu die Einschätzung 
Das gute Arbeitsklima für einen Dichter wurde des Weiteren nach Meinung Martials durch stadtspezifische Kommunikationsorte begünstigt: Im Plural werden Bibliotheken, Theater und Symposien nicht als prominente Orte der Literaturrezeption, sondern als Orte für dichterische Anregungen angeführt.

Am Inspirationspotential der Großstadt für eigenes literarisches Schreiben lässt Martial keinen Zweifel: Alle denkbaren Bereiche literarischer Kommunikation, das Produzieren, das Aufführen und das Rezipieren, sind für ihn aufs engste an die Großstadt Rom gebunden. Als ein vielseitiger Kommunikationsort ist sie Garant, Bezugspunkt und Ausgangspunkt seiner Dichtung, kurz eine ideale Dichterlandschaft. Eine derartige Vertrautheit und Vielfalt bietet das Leben in der Provinz gerade nicht: Die (heimatliche!) Provinz erscheint ihm als Fremde (videor mibi in alieno foro litigare), er selbst fühlt sich im Stich gelassen (destituti).

Accedit his municipalium robigo dentium et iudici loco livor, et unus aut alter mali, in pusillo loco multi; adversus quod difficile est habere cotidie bonum stomachum: ne mireris igitur abiecta ab indignante quae a gestiente fieri solebant. ${ }^{687}$

Die Provinz ist für den Autor Gegenwelt zur Großstadt: Der überschaubaren Zahl kleinstädtischer Bewohner attestiert der Autor Neid und Gehässigkeit. Angesichts dieser eher unliebsamen Kontakte fiele es dem Dichter schwer, täglich seine gute Laune zu bewahren, eine seelische Konstitution, die er für das Dichten brauche. Auf seinen gegenwärtigen Aufenthaltsort führt der Autor somit die dreijährige Schreibpause, seine anhaltende Unlust am Schreiben und stilistische Verunsicherung zurück. Dieser Ort unterscheidet sich in den ästhetischen, moralischen und kommunikativen Bedingungen von dem, was er aus einer räumlichen und zeitlichen Entfernung heraus über das einstige Leben in Erinnerung hat.

Erst durch diesen von ihm aufgebauten Kontrast von Kleinstadt und Großstadt, von provinzieller Gemeinschaft und Hauptstadtkultur, wird deutlich, dass es die großstädtischen Bedingungen des Kulturschaffens sind, die er vermisst: Zuhörer, Anregungen und Orte der literarischen Kommunikation sind eng mit der Tatsache verflochten, dass sie großstädtischen Ursprungs sind. Hier erklärt sich, wieso die Wahl der materia für diesen Autor eben nicht auswechselbar ist: Das Großstädtische war die materia und gerade dieser Inhalt bestimmte die Qualität.

der Leistung Homers bei Plin. nat. 7, 10: nisi forte Homero vate Graeco nullum felicius exstitisse convenit, sive operis forma sive materie aestimetur. In der Formulierung Ov. met. 3, 158 f. (arte laboratum nulla; simulauerat artem/ ingenio natura suo, ...) wird eine derjenigen Martials vergleichbare Auffassung, nämlich dass die Natur ein eigenes ingenium habe, vertreten; doch wird an dieser Stelle vor allem das übliche hellenistische Kunstverständnis weitergegeben (vgl. Bömer (1969), 492 f.). Zur Übereinstimmung von Talent und Gegenstand vgl. Hor. ars 38 f. (materiam ... aequam/ viribus); Ov. am. 1, 1, 2 (materia conueniente modis) und ebd., 19 (nec mibi materia est numeris leuioribus apta); Ov. am. 1, 3, 19 (te mibi materiem felicem in carmina praebe); Ov. trist. 5, 1, 6 (materiae scripto conveniente suae); Plin. epist. 9, 33, 1.

687 Mart. praef. 12, Z. 14-18. 
Die mit dem 12. Epigrammbuch vorliegende Gedichtsammlung versucht, nach dem Empfinden des Autors an ein früheres Schaffen anzuschließen, obwohl die äußeren Bedingungen - eine uninspirierte und uninspirierende Umgebung - diesem wenig zuträglich sind. In seiner Umgebung finden sich keine Anregungen, es leidet daher auch die innere Beteiligung: Die unter diesen Umständen geschriebenen Gedichte, zu denen diese praefatio hinführt, seien in nur wenigen Tagen und ohne die sonst übliche Hingabe ${ }^{688}$ geschrieben.

Tu velim ista, quae tantum apud te non periclitantur, diligenter aestimare et excutere non
graveris; et, quod tibi difficillimum est, de nugis nostris iudices nitore seposito, ne Romam, si
ita decreveris, non Hispaniensem librum mittamus, sed Hispanum.

Die Güte der neuerlichen Dichtung soll zunächst der Landsmann und Freund bewerten, bevor sie in der Hauptstadt dem dortigen Publikum geschickt werde. Der Autor selbst befürchtet, mit dem Ortswechsel seinen Schreibstil verändert zu haben. Pointiert formuliert er diese Besorgnis vor einem „Abgleiten in die Provinzialität ${ }^{“ 690}$ mit der Unterscheidung von Hispaniensis und Hispanus. Unter keinen Umständen soll dem römischen Publikum, das weiterhin einziger möglicher Bezugspunkt seiner Dichtung bleibt, ein Buch übergeben werden, dem nicht nur anzumerken ist, dass es in Spanien - und nicht in der Hauptstadt - entstanden ist ${ }^{691}$ sondern das gar wie ein Buch eines Spaniers wirke, der die Großstadt Rom nicht kennt. ${ }^{692}$

Anspruchsvolles Dichten ist für den kaiserzeitlichen Autor Martial allein in der Großstadt Rom möglich. Für ihn korrelieren Dichtung und Großstadt positiv miteinander. Die Großstadt Rom ist Bezugs- und Ausgangspunkt, Inspirationsraum und dichterische Heimat und somit unbedingte Grundlage seines Schaffens. Hier findet der Autor im Gegensatz zur Provinz Qualität, Quantität und Vielfalt an Anregungen durch Literaturrezipienten, darzustellenden Stoff und Orte der Literaturkommunikation. Des Hinweises auf dieses besondere Junktim Großstadt und Dichtung bedurfte es in früheren praefationes nicht, da sich der Autor - wie auch

688 Vgl. Mart. praef. 12, Z. 18-22: Ne quid tamen et advenienti tibi ab urbe et exigenti negarem - cui non refero gratiam, si tantum ea praesto quae possum -, imperavi mibi, quod indulgere consueram, et studui paucissimis diebus, ut familiarissimas mibi aures tuas exciperem adventoria sua.

689 Mart. praef. 12, Z. 22-27.

690 Johannsen (2006), 115.

691 Vgl. Mart. 3, 1.

692 Die Formulierung ne Romam, si ita decreveris, non Hispaniensem librum mittamus, sed Hispanum wirft ein interessantes Licht auf das Verständnis von „Römersein“, das hier nicht als „,indigen“ verstanden werden kann. Martial selbst stammt aus Spanien. Wenn er meint, einen in Rom lebenden spanischen Landsmann um ein Qualitätsurteil bitten zu können, bedeutet „römisch schreiben“ für ihn, dass jeder in der Hauptstadt Lebende römisch zu schreiben vermag und „,römische“ Literaturbewertungen von einem in der Hauptstadt Ansässigen vorgenommen werden sollte. 
sein Publikum - selbst dort aufhielt. ${ }^{693}$ Erst aus dem Abstand heraus, durch den er über das movens seiner Dichtung zu reflektieren beginnt, wird ihm die Bedeutung der Großstadt für seine künstlerische Arbeit in vollem Umfang bewusst. ${ }^{694}$

\subsubsection{Der Dichter, wie er im Buche steht. Mehrstimmigkeit als Merkmal der Fiktion}

Eine derartige praefatio ist formal gesehen eine wenig verbreitete Art der Äußerung über poetologische Sachverhalte. Vergleichsweise häufiger wird dagegen in den Dichtungen selbst über die Wechselwirkung von Großstadtleben und dichterischem Schaffen reflektiert. Sucht man nach derartigen Aussagen zum Verhältnis von Dichter und Großstadt im weiteren CEuvre Martials, so drängt sich der Eindruck auf, dass die uneingeschränkt positive Einschätzung des Großstadtlebens in Beziehung auf ihre inhaltliche Aussage im Werk Martials singulär bleibt. Meldet sich eine Dichter-persona ${ }^{695}$ zu Wort, provoziert deren Bewertung einen offenen Widerspruch. Die Großstadt bietet diesen Epigrammen zufolge gerade für Dichter ausnehmend schlechte Arbeitsbedingungen: aufgrund jämmerlicher Einkommensverhältnisse ${ }^{696}$, fehlender Mäzene ${ }^{697}$, durch die Verpflichtungen des Klientendienstes und den daraus resultierenden Mangel an Zeit und Muße ${ }^{698}$. Die Großstadt sei sogar ein regelrechtes Hemmnis dichterischen Schaffens. Will man in der Stadt überleben, sollte man sich tunlichst anderen Berufszweigen zuwenden ${ }^{699}$, ansonsten solle man diesen Ort lieber verlassen.

Exemplarisch soll die Betrachtung eines Epigramms (Mart. 3, 4) genügen, um den frappierenden inhaltlichen Widerspruch zu verdeutlichen. Die Dichter-persona hält sich vorübergehend an einem Ort außerhalb Roms namens Forum Cornelii auf. Sie gibt ihrem personifizierten Buch einige Antworten auf mögliche Fragen der ebenfalls personifiziert vorgestellten Stadt Rom an die Hand. ${ }^{700}$ Die Dichter-persona nimmt in diesem Epigramm, dessen Sprechsituation bereits seine Fiktionalität

693 Johannsen (2006), 120 und 158.

694 Martial verwendet einige literarische Topoi der Exilliteratur in der praefatio vgl. Johannsen (2006), 117-120 und beweist sich so als Kenner der entsprechenden Literatur, um die Unterschiede zwischen Provinz und Hauptstadt zu verdeutlichen.

695 Zur Dichter-persona Martials vgl. Johannsen (2006), 49 f.; Lorenz (2002), 4-42, ohne allerdings den Sprecher in den praefationes von dem in den Epigrammen zu trennen. Er kommt zu dem Ergebnis, dass die persona stellenweise durchaus autobiographische Züge trage, aufgrund ihrer vielfach widersprüchlichen und auf Lächerlichkeit zielenden Zeichnung aber keinesfalls mit dem historischen Dichter identifiziert werden dürfe.

696 Mart. 1, 76; 3, 38, 7-10.

697 Mart. 1, 107; 11, 3.

698 Mart. 10, 70; 10, 74; 11, 24.

699 Mart. 1, 17; 1, 76.

700 Vgl. Fusi (2006), 131. 
deutlich markiert, die Gelegenheit wahr, ihren Unmut über die Bedingungen des stadtrömischen Lebens zu äußern.

5

cur absim, quaeret: breviter tu multa fatere:

,Non poterat vanae taedia ferre togae."

,Quando venit?' dicet: tu respondeto: ,Poeta

exierat: veniet, cum citharoedus erit. ${ }^{5} 01$

Diese Worte enthalten keine Liebesbezeugung an das Großstadtleben, im Gegenteil: Im hier präsentierten zweiten Teil des Epigramms wird in vielsagender Kürze das Fernbleiben des Dichters von der Hauptstadt mit dem Ekel vor der Toga begründet. Für den Dichter ist allein ein Kleidungsstück zu einem Reizauslöser einer starken körperlichen Reaktion geworden (taedia, v. 6). Diese Aversion ist eng mit dem als hohl (vanae, v. 6) empfundenen Klientendienst verbunden. ${ }^{702}$ Einen Ausweg aus dieser psychosomatischen Belastung und eine dadurch mögliche Rückkehr in die Stadt sieht der Dichter erst nach der Verbesserung seiner beruflichen und somit finanziellen Situation. ${ }^{703}$ Eine Rückkehr als Dichter wird es nach Aussage dieses Epigramms jedenfalls nicht geben (Poeta exierat, v. 7 f.).

Die Schreibsituation des poeta im Epigramm 3, 4 ist mit der Martials in der praefatio zum 12. Buch durchaus vergleichbar: In beiden Fällen befindet sich ein Dichter außerhalb von Rom, korrespondiert aber mit Rom, und zwar über einen Vermittler. In beiden Fällen ist diese Stadt einziger Bezugspunkt der Dichtung und Ort einer prägenden biographischen Episode. Aus einem räumlichen Abstand reflektieren beide über ihre städtischen Erfahrungen, die sich auf Vorstellungen von idealen Lebensumständen für einen Dicbter beziehen. Die Maßstäbe, die sie an einen idealen Ort anlegen, betreffen allerdings unterschiedliche Aspekte: zum einen die Stadt als literarischen Kommunikationsraum, als Inspirationsraum für eigenes Dichten, zum anderen die Stadt als Arbeitgeber und Garant des Lebensunterhaltes. Während der Autor Martial in seinem Brief das Potential der gesellschaftlichen Strukturen und den Anregungsreichtum der Stadt für sein dichterisches Schaffen hervorhebt, wird im Epigramm die Stadt als ein Ort der Verpflichtungen und Existenzsorgen und somit als Hemmnis dichterischer Arbeit beschrieben. Aus den jeweils angesetzten Maßstäben werden die unterschiedlichen Bewertungen des Stadtlebens erklärbar. Der eine (Martial) sehnt sich nach den vertrauten sozialen Strukturen einer Großstadt zurück, die einer idealen Dichter-

701 Mart. 3, 4, 5-8.

702 Die Toga, vormals Kleidungsstück eines stolzen Stadtrömers, kam als Alltagskleid aus der Mode und wurde in der Kaiserzeit verpflichtend vornehmlich von städtischen Klienten während der morgendlichen salutatio und bei anderen officia getragen, von den anderen nur noch bei öffentlichen Spielen, Opfern und Gerichtsverhandlungen. Vgl. Suet. Aug. 40, 5. Siehe dazu Blanck (21996), $72 \mathrm{f}$.

703 Der Beruf des citharoedus gilt als eine ars pecuniosa, vgl. Mart. 5, 56, 8 f. 
landschaft gleichkommt; der andere (persona) entzieht sich der Großstadt nach einer physisch-psychischen Belastung, die mit dem Dichten selbst kaum etwas zu tun hat. Die Flucht der persona, Ausdruck einer persönlichen Entfremdung, zeigt unmissverständlich, dass die gesellschaftlichen Zwänge ihr individuelles Vermögen überstiegen haben, dass die Großstadt unerträglich wurde. Ihre Aversionen gegen die sozialen Strukturen, in Komprimierung auf ein Kleidungsstück, die toga, sind zum Zeitpunkt des literarischen Sprechens nicht verschwunden, sie nennt aber Optionen einer Rückkehr. Während also praefatio und Epigramm am Bezugspunkt Großstadt für die Rezeption ihrer Dichtung gleichermaßen festhalten, nehmen sie bei der Einschätzung Roms als Inspirations- und Ausgangsort ihrer Dichtung unterschiedliche Positionen ein.

Der hier aufgezeigte Widerspruch ist kein Einzelfall. Einerseits werden nicht nur in der praefatio zum zwölften Buch, sondern auch in anderen Epigrammen adäquate Lebensbedingungen innerhalb der Großstadt benannt ${ }^{704}$, andererseits werden im überwiegenden Teil - die städtischen Lebensbedingungen kritisiert. ${ }^{705}$ Diese Tatsache ist aber lediglich für denjenigen erstaunlich, der in diesem Zusammenhang von einer einzigen, allen Ebenen gemeinsamen Stimme ausgeht und nicht zwischen Autor und dichterischer Stimme unterscheidet. Durch die unterschiedlichen Aussageebenen der praefatio und einem Ich-Sprecher in einem Epigramm ergibt sich die äußerst seltene Gelegenheit, einen „lehrreichen Schock, der sich (...) aus dem Kontrast zwischen literarischen und privaten Dokumenten ein und derselben Person ergeben kann"706, wenigstens in der Einschätzung der Großstadt als Existenzraum für Dichter zu erleben. Die Widersprüche müssen nicht kompliziert mit Brüchen in der Biographie des Autors erklärt werden. ${ }^{707}$ Die epigrammatische Stimme wird durch den Appell der persona an ihren Gedichtband und ein vorweggenommenes Zwiegespräch zwischen Buch und Rom eindeutig als literarisiert und fiktional ausgewiesen. In den Epigrammen spricht folglich nicht der Autor selbst, sondern eine persona, die einen Dichter in einer gattungsbedingten Sprechweise vorgeben soll.

704 Vgl. Mart. 3, 20; 5, 20.

705 Vgl. zur widersprüchlichen Bewertung von Spanien und Rom in den Epigrammen auch Johannsen (2006), 158-161, bzw. Bilbilis und Rom vgl. Merli, Martial Between Rome and Bilbilis, in: Rosen/Sluiter (2006), 327-348.

706 Vgl. Korenjak (2003), 63, der diese Möglichkeit m. E. zu Unrecht für die römische Dichtung zurückweist.

707 Vgl. Howell, Martial's Return to Spain, in: Grewing (1998), 174: „,What was it that made Martial change his mind, within the years or so?" Aufgrund unserer spärlichen und wenig verlässlichen Informationen über das Leben Martials ist eine biographische Erklärung auch nicht unproblematisch. Solche Beobachtungen eines Paradigmenwechsels sind oft der Literatur selbst entnommen und können daher schwerlich als Erklärung derselben dienen. Die durchgehende Ich-Perspektive, die Subjektivität und die starke Emotionalität eines distanzlosen Erzählers dürfen nicht dazu verleiten, die Aussagen der Epigramme autobiographisch zu lesen, selbst wenn ein Ich als eine Dichter-persona gekennzeichnet ist. 


\section{Zusammenfassung}

Zwei Dinge lassen sich an dieser Stelle festhalten. Erstens: Mit den unterschiedlichen Ausführungen in Prosa-praefationes und Epigrammen bedient sich Martial absichtsvoll zweier Aussageautoritäten. In den Epigrammen spricht ein poetisch überformtes, ein vermitteltes Ich, in den praefationes ein autoritatives Ich. Die abschließende Stellung der praefatio in der gesamten Buchsammlung lässt darauf schließen, dass der Großstadt für den Berufsstand des Dichters vom realen Autor überaus geeignete Bedingungen attestiert werden. Sie machen ein persönliches Anliegen sichtbar, entsprechen sie doch, wie in den ersten Sätzen in der praefatio selbst angedeutet, wenig den konventionellen Ansichten seiner Zeitgenossen. ${ }^{708}$ Vor diesem Hintergrund erscheint wiederum die Thematisierung eines großstädtischen Lebensumfelds in der eigenen Dichtung als eine bewusst poetisierte Auseinandersetzung. Römische Dichtung ist demzufolge weit davon entfernt, erlebte Realität in einer in Verse gefassten Literatur lediglich abzubilden. Zweitens: Gegensätzliche Aussagen innerhalb eines Cuvres verweisen auf eine Vielfalt der Perspektiven auf das Stadtleben als Dichterlandschaft. Sie gehören damit in den größeren Zusammenhang einer literarischen Auseinandersetzung der Stadt als Lebens- bzw. Inspirationsraum für Dichter in der augusteischen und kaiserzeitlichen Epoche. Für die Frage nach dem Junktim zwischen Großstadt und Dichtung ist dieser Aspekt von großer Wichtigkeit: Die poetischen Texte setzen sich jeweils mit der Frage auseinander, ob die Großstadt ein für Dichtung geeigneter Ort sei oder nicht. Die Großstadt selbst wird somit zum Gegenstand poetischer Reflexion.

\subsection{Die Großstadt als Dichterlandschaft}

$\mathrm{Da}$ in den meisten Fällen über das Werk hinaus kaum Informationen über die Dichter und Entstehungsbedingungen antiker Literatur vorliegen, sind verschiedene Grade einer Fiktionalisierung zwischen realem Autor als Textproduzenten und dem Ich-Sprecher auf der Textebene für die augusteische und kaiserzeitliche Epoche nicht bestimmbar. Die Fiktionalität - auf die textimmanente Indizien zweifelsfrei verweisen - lässt sich daher nur als solche feststellen. Wenn sich in den folgenden Textbeispielen römischer Dichtung somit Sprecher als Dichter ausweisen, so sind sie nicht mit dem Autor gleichzusetzen und werden daher als Dichterpersona bezeichnet.

Im Mittelpunkt der folgenden Ausführungen stehen Texte römischer Dichtung, die sich inhaltlich mit der Thematik Großstadt und Dichter auseinandersetzen. Über eine entsprechende Wechselwirkung von Dichtung und Großstadt und dem Selbstverständnis eines Großstadtdichters wird eingehend in den Satiren und Briefen des Horaz, den Exilelegien und -briefen Ovids und den Satiren Juvenals ge-

\footnotetext{
708 Vgl. Mart. praef. 12, Z. 4-6.
} 
handelt. Da Ovid und Juvenal die Großstadt sogar bei poetologischen Überlegungen innerhalb programmatischer Texte einbeziehen und einer derartigen Offenlegung eine außergewöhnlich exemplarische Qualität zukommt, sollen die Texte dieser Autoren - entgegen der Chronologie ihrer Entstehung - zuerst vorgeführt werden. Anschließend werden aus dem CEuvre des Horaz, der wohl als erster römischer Autor in dieser Qualität literarisch über die Wechselbeziehung von Großstadt und dichterischem Schaffen handelte, aufschlussreiche Beispiele besprochen. Das Ziel ist damit ein zweifaches: (1) Zum einen geht es um die Frage, worin genau die Wechselberiehung von Großstadt und eigener Dichtung nach Meinung der jeweilige Dichter-persona besteht. (2) Zum zweiten interessiert der Raum-Figur-Bezug, also die Frage, wie sich die konkret dargestellte Physis des literarischen Raumes auf das Selbstverständnis der Dichter-persona auswirkt.

Diese wie auch immer geartete Verflechtung von Raum und Dichter - gleich ob sie nun als ein Musenhain oder eine „Feindin des Poeten“709 charakterisiert wird soll zeigen, inwieweit über die Großstadt überhaupt als ein Inspirationsraum (oder sein Gegenteil) in römischer Dichtung reflektiert wurde und wie ihre Physis ein Gegenstand dieser Literatur war.

\subsubsection{Eine Stadt, die nicht zum Aushalten ist. Der Dichter aus Empörung (Iuv. sat. 1)}

Üblicherweise verteidigt in Programmgedichten eine Dichter-persona ihre Gattungswahl (apologia) und verortet sie in deren literaturgeschichtlichen Tradition. Darüber hinaus weist sie in hellenistischer Manier das als Königin der Gattungen geltende Epos zurück (recusatio). ${ }^{710}$ So geschieht es auch in Juvenals erster Satire, die die Aufgaben einer Programmsatire in vollem Umfang übernimmt, ${ }^{711}$ aber überraschende Abweichungen aufweist. Zu Beginn werden nicht nur das Epos, sondern gleich alle weiteren nennenswerten Literaturgattungen, wie Komödie, Tragödie und Elegie zurückgewiesen. ${ }^{712}$ Die topische Erklärung, mangelndes Talent ${ }^{713}$ verhindere die Abfassung solcher Dichtung, wird ebenfalls abgewandelt: Die Dichter-persona wehrt sich gegen eine Dauerbeschallung (Semper ego auditor tantum?, v. 1) durch Rezitationen, die in der urbs Roma beständig und überall statt-

709 Corbineau-Hoffmann (2003), 7.

710 Zu Merkmalen der recusatio vgl. Lyne (1995), 31-39. Grundlegend vgl. Wimmel (1960); White (1993).

711 Vgl. Braund (1996), 36 und 110-121.

712 Vgl. Iuv. 1, 2-11. Das Epos in v. 2 und v. 7-11; die spezifisch römische Komödie ([fabulas] togatas) in v. 3; Elegie in v. 4; Tragödie in v. $5 \mathrm{f}$.

713 Zum Ende der ersten Satire (Iuv. 1, 150 f.) hin wird die Frage nach dem angemessenen Talent gestellt, aber einem unspezifisch angesprochenen „Du“ in den Mund gelegt: dices bic forsitan ,unde/ ingenium par materiae?'Diese Frage wird in der dialogisch gestalteten Partie allerdings vom Gegenüber nicht aufgenommen. 
finden (tot ubique/ vatibus ocurras, v. $17 \mathrm{f}$.). Mit einer unerträglichen thematischen Monotonie zeitgenössischer ,hoher ${ }^{6}$ Dichtung $^{714}$ begründet sie ihren Entschluss, selbst dichterisch tätig zu werden und sich für derartige Zumutungen durch eigene Literaturproduktion zu revanchieren. ${ }^{715}$ Die Absichtserklärung zu dichten, bedarf unter diesen Bedingungen keiner weiteren Erläuterung. Ihre Inhalte und den Entschluss $^{716}$, sich der Gattung Satire zuzuwenden, will die Dichter-persona aber einem geneigten Publikum erläutern (si vacat ac placidi rationem admittitis, edam, v. 21).

\subsubsection{Nonne libet medio ceras implere capaces quadrivio (...)? ${ }^{717}$ - Großstadt und Dichtung}

Mit dem Seitenwechsel innerhalb der literarischen Kommunikation, vom ,Rezipienten' zum ,Autor', wechselt die Dichter-persona programmatisch den Standort innerhalb der urbs Roma: Eben noch in einer luxuriösen Privatvilla, ${ }^{718}$ in der Lesungen und Rezitationen stattzufinden pflegen, befindet sie sich nun im offenen und öffentlichen Raum der Großstadt, mitten im Menschengetümmel. Es ist ge-

714 Vgl. Iuv. 1, 3-13: impune ergo mibi recitaverit ille (...),/ bic (...)? impune diem consumpserit (...)/ (...) nota magis nulli domus est sua quam mibi lucus/ Martis et Aeoliis vicinum rupibus antrum/Vulcani; (...)/ (...) Frontonis platani convulsaque marmora clamant/ semper et assiduo ruptae lectore columnae.

715 Auf das Überangebot zeitgenössischer Dichtung nicht mit eigenem Schreiben zu reagieren, wäre nach Meinung des Sprechers zwar ein Ausdruck persönlicher clementia, aber unter den gegebenen Umständen wohl eher eine Dummheit: stulta est clementia, (...) periturae parcere chartae; Iuv. 1, $17 \mathrm{f}$.

716 Freudenburg (2001), 209 nennt die Ausgangssituation treffend ,a moment of liberation“, um im Folgenden das Satireschreiben an sich als politische Entscheidung zu interpretieren. Nach einer traumatischen Vergangenheit („traumatic past“, 216) sei es nun wieder möglich, sich auf ,satirische' Weise zu äußern. Freudenburg zeigt eindrucksvoll, dass sich in der zeitgenössischen Geschichtsschreibung (Tacitus, Sueton) und den Briefen des Plinius ähnliche Vorstellungen über die Gegenwart als Zeit der Befreiung im Sinne einer Befreiung zum Reden finden lassen. Der Sprecher der ersten Satire erscheint $\mathrm{m}$. E. allerdings in erster Linie als ästhetisch empfindender Rezipient beleidigt. Die Themenwahl der Dichterkollegen scheint ihm aufgrund der gesellschaftlichen Zustände (vgl. Iuv. 1, 52-57), nicht der politischen, als unangemessen. Zugestehen muss man der Interpretation Freudenburgs, dass bereits im Hellenismus die Opposition gegen das in der Regel gegenüber der jeweiligen Herrschaft affirmativ eingesetzte Epos als politische Aussage gewertet wurde. Vgl. Schwinge (1986), 40-43. Da die Ernsthaftigkeit der Aussage aufgrund der Gattung nicht zwingend vorausgesetzt werden muss, könnte man schließlich gegen Freudenburg auch einwenden, dass die Eingangsverse als Spitze gegen die in der Prosa verbreitete Betrachtungsweise gemeint sind.

717 Iuv. 1, $63 \mathrm{f}$.

718 Vgl. Braund (1996), 75: „He portrays himself as an auditor at a recitation (...), a regular social event in Rome ranging from the private dinner-party (...) to grander affairs to which the educated public was invited." Vgl. Iuv. 1, $12 \mathrm{f}$. Frontonis platani convulsaque marmora clamant/ semper et assiduo ruptae lectore columnae. Dazu Braund (1996), 77 f. Die Privatvilla als umgrenzter und geschlossener Raum, der exklusives und weltabgewandtes Dichten ermöglicht, wird zugunsten des offenen Raumes der Straße verlassen, auf der vermeintlich realistische Dichtung stattfindet, aber auch weniger exklusive. 
nau dieser literarische Raum urbs Roma, der ihr Themen genug bietet. ${ }^{719}$ Die materia (v. 151) für ihre Dichtung findet die Dichter-persona in ihrer unmittelbaren Umgebung; sie müsse nur einen Beobachtungsstandpunkt mitten auf einer beliebigen Straßenkreuzung einnehmen und von dort aus als ein Stenograph städtischen Lebens das Gebaren und Auftreten der Städter auf Wachstäfelchen (v. 63-72) kritzeln. Raum und eigenes dichterisches Schaffen werden unmissverständlich aufeinander bezogen.

Es folgt ebenfalls mitten auf der Straße eine ausführliche Begründung (apologia), warum ihre Wahl dabei gerade auf die Gattung Satire fällt: Beim Anblick der städtischen Bevölkerung könne man nicht an sich halten, sie treibe den Amateurdichter geradezu zum Verfassen von Satiren (difficile est saturam non scribere, v. 30). ${ }^{720}$ Sie ist nach Ansicht der Dichter-persona die einzig angemessene Gattung, um die großstädtische materia darzustellen: eine farrago ${ }^{721}$ (v. 86) aus Einzelstimmen und Dialogen mithilfe der rhythmischen Sprache des Hexameters. Die Themen, die der massenhaften Begegnung mit Menschen im literarischen Raum urbs Roma entspringen, finden poetologisch in der Gattung der Fülle, der satura, ihren angemessenen Rahmen. Eine persönliche Stadterfahrung transformiert zu Literatur bzw. wird mit Hilfe der Satire bewältigt.

Triebfeder der satirischen Sprechweise ist das subjektive Gefühl der Entrüstung (indignatio, v. 79). Selektierte Einzelheiten an den Passanten dienen stets dem Beweis, dass diese in ihrer Abnormität das ganz normale Leben in der Stadt verkörpern. Gleichzeitig verspürt die Dichter-persona gegenüber dieser großstädtischen Gesellschaft einen Unwillen (iniquae .../ ... urbis, v. 30 f.), da sie durch pervertierte charakterliche Verhaltensweisen, übertriebene Verfeinerung in Äußerlichkeiten oder eine Divergenz zwischen gesellschaftlicher Stellung und ethischem Verhalten gekennzeichnet ist. ${ }^{722}$ Aus diesen Widersprüchen resultiert ihre Schreibhaltung, die demzufolge gerade nicht einer unvoreingenommenen Beobachtung entspringt,

719 Die erste Satire bietet eine Vorschau auf die Themen der Satiren des ersten Buches. Vgl. Braund (1996), 30-36. Die vorgestellten Passanten sind Vertreter derjenigen Laster, die Gegenstand der folgenden Satiren werden. Als repräsentative Themenbereiche nennt Braund für das erste Satirenbuch Juvenals das Verhältnis Patron-Klient, Alltagsleben in Rom, Abstieg der Aristokratie vs. Aufstieg der Ausländer, Übermacht des Essens.

720 Kißel (1990), 10, Anm. 4 bringt es auf den Punkt: „(..) als stehende Motive satirischer Programmatik wäre weiterhin (...) [der] Hinweis auf die Grenzen der eigenen Fähigkeiten [zu erwarten] (während das eigene Dichten jetzt nicht mehr durch ,ich kann nichts anderes', sondern bezeichnenderweise durch ,ich kann nicht anders' begründet wird).“

721 In der Echtheit angezweifelt von Willis. Vgl. Textausgabe Iuv., 5.

722 Vgl. Braund (1996), 112. Larmour (2007), 172 hebt hervor, dass die Verletzung von Grenzen allerdings Grenzen im übertragenen Sinne - ein zentrales Anliegen juvenalischer Satire ist: „of gender by the eunuch and the ,Amazon' Mevia, or of social hierarchy by wealthy barber and impoverished aristocrats (...). On the metapoetic level, this reinforces the violation of literary boundaries which Juvenalian satire enacts as it confounds epic metre and language with ,low themes, deploys the technique of rhetoric for comic effect, and imports the conventions of pastoral into an urban setting."“ 
sondern sich aus einem subjektiven Empfinden der Dichter-persona speist. Thre Stellung als objektiver und souveräner Berichterstatter städtischen Geschehens büßt sie damit ein. Die Darstellung der Großstadt, wie sie in den Satiren erfolgt, ist trotz der vorgeblichen Spontaneität des Dichteraktes und der vermeintlichen Realitätsnähe der Schilderungen poetisch überformt. ${ }^{723}$

Gerade dieses moralische Gefühl treibt die Dichter-persona jedoch, einer göttlichen Macht gleich, über ihr natürliches Talent hinaus zum Schreiben (si natura negat, facit indignatio versum, v. 79). Dichterisches Vermögen ist nicht einem eigenen ingenium geschuldet, sondern stellt eine notvendige Reaktion auf die vielfältigen psychischen Herausforderungen in einer Großstadt dar. ${ }^{724}$ Movens ist die vermeintliche Eigenart der urbs Roma. In dieser Gefühlsunmittelbarkeit kommt der Dichterakt der Ergriffenheit eines poeta-vates-Typus gleich. ${ }^{725}$ Die Frage nach einer angemessenen Gattung wird in dieser Programmsatire nicht nach dem eigenen Talent entschieden, sondern nach dem, was die Situation im literarischen Raum erfordert. In diesem Lichte wird nicht die vorliegende Literatur abgewertet, sondern selbstbewusst das Kunstschaffen derjenigen, die sich nicht dieser Gattung zuwenden, als weltfremd diskreditiert.

Trotz der gewaltigen Kraft, die in Form von Schaffenskraft und Inspiration, Themen- und Gattungswahl von der Großstadt ausgeht, blickt die Dichter-persona nicht auf eine anziehende, sondern befremdliche Exotik des Großstadtlebens. Die Großstadt ist ein Panoptikum, in dem sich die Zustände einer allgemeinen Gegenwart $^{726}$ zeigen lassen. Es gelingt der Dichter-persona, die Beobachtungen an den stark individualisierten Menschen ${ }^{727} \mathrm{zu}$ einer allgemeineren Wahrheit zu führen.

723 Zur satirischen Darstellung der Wirklichkeit vgl. ausführlich Schmitz (2000), 20-34.

724 Vgl. Iuv. 1, 150 f.: unde/ ingenium par materiae? Dazu Braund (1996), 94 und 112. Die Dichterpersona gesteht ihre Abneigung, ihren Zorn gegenüber der Großstadt immer wieder offen ein: Iuv. 1, 30 f.: nam quis iniquae/ tam patiens urbis, tam ferreus, ut teneat se,/ (...) cum (...) und 45 f.: quid referam quanta siccum iecur ardeat ira,/ cum (...) bic (...).

725 Zum poeta-vates Typus vgl. Plat. Ion 533-534.

726 Die Überlegung, ob Juvenal in seinen Satiren Menschen seiner Gegenwart beschrieb oder Geschehnisse aus einer nahen Vergangenheit, ist für das zugrundeliegende Untersuchungsinteresse peripher, da der Sprecher der ersten Satire vorgibt, den Menschen zeitgleich zum Schreiben auf der Straße zu begegnen, d. h., innerhalb der literarischen Kommunikation wird die Gegenwart des Sprechers beschrieben.

Die Frage, welche „Gegenwart“ die Dichter-persona oder der Autor Juvenal beschreiben wollte, ist häufig diskutiert worden. Anstoß gaben die Verse Iuv. 1, 170 f. (experiar quid concedatur in illos/ quorum Flaminia tegitur cinis atque Latina). Diese sind eine Antwort des Sprechers auf eine von einem interlocutor geäußerte Warnung vor dem Satireschreiben. Vgl. Anderson (1982), 206-208; Braund (1996), 117-121. Zu Namen und Anspielungen auf historische Personen der Gegenwart Juvenals in der Satire vgl. Townend (1973), 148-160.

727 Die zum Teil recht detaillierten Beobachtungen, die nicht nur äußerliche, sondern auch charakterliche Merkmale einschließen, werden als eine Faszination am Konkreten, die in der römischen Literatur immer wieder zu beobachten ist, und als eine Typisierung entlarvt. Vgl. Lorenz (2006), 315. Die Frage nach der historischen Existenz der namentlich genannten Personen kann mit letzter Gewissheit nie beantwortet werden, sie erhalten allerdings mit ihrem Einzug in die Litera- 
85 quicquid agunt homines, votum, timor, ira, voluptas,

gaudia, discursus, nostri farrago libelli

ecquando uberior vitiorum copia? quando

maior avaritiae patuit sinus? alea quando

hos animos? ?28

Die Verhaltensweisen der Städter, die zu beobachtende Lasterhaftigkeit, die diejenige der Vergangenheit und Zukunft übertrifft, ${ }^{729}$ sind ihr ein Brennspiegel des modernen Lebens. Der literarische Raum Großstadt ist - im Sinne der Vorstellung des orbis in urbe - ein Mikrokosmos einer allgemeinen Gegenwart.

\subsubsection{Cum te summoveant, qui (... $)^{730}-$ Großstadt und Dichter}

Die Dichter-persona ist im literarischen Raum urbs Roma eine von vielen. Sogar als Dichter gehört sie nicht zu einer Rarität im Stadtbild. Ihnen beständig zu begegnen, wird für den gesamten literarischen Raum konstatiert (cum tot ubique/ vatibus occurras, v. 17 f.). Jedoch handelt es sich bei dem Überangebot an Kollegen nach eigenen Aussagen vor allem um Poeten hoher Literatur (vatibus, v. 18) und weniger um Gesinnungsgenossen. Dieses besondere Kennzeichen des literarischen Raumes wird durch die persönliche Alltagserfahrung der Dichter-persona verbürgt:

1 Semper ego auditor tantum? numquamne reponam

vexatus toties rauci Theseide Cordi?

impune ergo mihi recitaverit ille togatas,

bic elegos? impune diem consumpserit ingens

$5 \quad$ Telephus aut summi plena iam margine libri

scriptus et in tergo necdum finitus Orestes?

$9 \quad$ (...) quid agant (...)

12 Frontonis platani convulsaque marmora clamant

semper et assiduo ruptae lectore columnae. ${ }^{731}$

Es gibt zu viele Dichter und vor allem zu viele Dichterlesungen im literarischen Raum urbs Roma. Sie verbrauchen die Lebenszeit anderer (diem consumpserit, v. 4) durch die Länge ihrer Dichtungen (summi plena iam margine libri) scriptus et in tergo

tur den literarischen Status einer Figur. Alle konkreten Anspielungen sollten für ein größeres Publikum verständlich gewesen sein. Vgl. grundlegend Arist. Poetik, $1451 \mathrm{~b}$ und exemplarisch zur Figur des Canius Rufus bei Martial Lorenz (2006), 318.

728 Iuv. 1, 85-89.

729 Iuv. 1, 81 f.: Ex quo Deucalion (...)/ (...) montem ascendet, Iuv. 1, 147-149: Nil erit ulterius quod nostris moribus addat/ posteritas: eadem facient cupientque minores./ omne in praecipiti vitium stetit: (...).

730 Iuv. $1,37$.

731 Iuv. 1, 1-6; 9; $12 \mathrm{f}$. 
necdum finitus ..., v. 5 f.). Sie sprengen durch ihre Vorträge akustisch den privaten Innenraum einer Villa ${ }^{732}$ (clamant/ semper ... assiduo ruptae lectore columnae, v. $12 \mathrm{f}$.). Dieses zeitliche und räumliche Ausufern der Literaturperformanz führt bei der Dichter-persona zu einer akustischen Überreizung (Semper ... auditor, v. 1; vexatus, v. 2) und fordert zur Gegenwehr heraus. Es ist der Notstand, der zu einem unvermittelten räumlichen Wechsel innerhalb der literarischen urbs Roma führt. An diesem neuen, für ihr Dichterverständnis programmatischen Schauplatz befindet sich die Dichter-persona jedoch ebenfalls nicht in der Einsamkeit eines Musenhains, sondern in einem sich beständig bewegenden Menschenstrom. Genau hier ist die eigene dichterische Inspiration am größten.

nonne libet medio ceras implere capaces

quadrivio, cum iam sexta cervice feratur

binc atque inde patens ac nuda paene cathedra

et multum referens de Maecenate supino

signator falsi, (...)

69

occurrit matrona potens, (...). ${ }^{733}$

Als geeigneten Standort für eine simultan ${ }^{734}$ dichtende Wahrnehmungsinstanz nennt die persona eine Straßenkreuzung (quadrivio, v. 64), auf die sich eine aus verschiedenen Einzelpersonen und Gruppen bestehende Menschenmenge von nicht angegebenen Richtungen her auf den Betrachter zubewegt. Keine von ihnen wird wiederholt oder über einen längeren Zeitraum beobachtet, vielmehr gelangen beständig neue Figuren in den Blick. Denn der Betrachter selbst verändert seine Position nicht. Diese transitorische Raumerfahrung bedeutet für die Dichterpersona überreiche (capaces, v. 63) Inhalte für ihre Dichtung:

difficile est saturam non scribere. nam quis iniquae

tam patiens urbis, tam ferreus, ut teneat se,

causidici nova cum veniat lectica Mathonis

732 Die städtische Privatvilla wird implizit über typische Bestandteile des Innenhofes nämlich Platanen, Marmor und Säulen als eine erste räumlich benannte Einzelzone innerhalb des literarischen Raumes urbs Roma angedeutet. Vgl. dazu Braund (1996), 77 f. Die Selektion dieser typischen Bestandteile aus dem Inneren des Gebäudes betont gleichzeitig die räumliche Abgeschlossenheit der räumlichen Gegebenheit. Zur Sprengung des konkreten Raumes durch die erzeugten Schallquellen bemerkt Braund (1996), 78: ,(...) with his (...) vivid picture of the grand house in a state of physical collapse, as if in an earthquake: hence convulsa and ruptae."

733 Iuv. 1, 63-67; 69 .

734 Die Simultanität der Wahrnehmung und des Dichtens ist von programmatischer Wichtigkeit. Dieses Anliegen wird durch die Wahl der Tempora unterstützt (Präsens als Erzähltempus, cum mit Konjunktiv Präsens als cum-narrativum der Gleichzeitigkeit). Die Bedeutung der Gegenwart wird in Absetzung von der Vergangenheit (Iuv. 1, 81-89) und der Zukunft (Iuv. 1, 147-149) deutlich herausgestellt. 


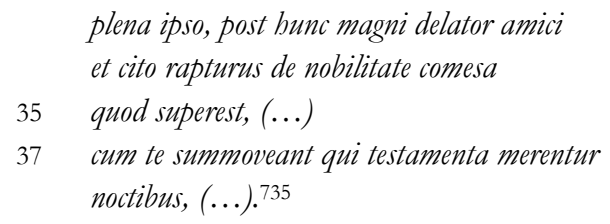

Die Dichter-persona gibt sich in erster Linie als Augenzeuge und selektiert von dem Beobachtungsplatz aus beständig neue Figuren aus der Gruppe der Vorübergehenden. In der dynamischen Veränderung des visuell wahrgenommenen öffentlichen Straßenraums dokumentiert sie als die Wahrnehmungsinstanz eine Serie von flüchtigen Einzelbildern: Sie nimmt, mobile Objekte', einzelne Passanten und Menschengruppen wahr; einige werden auf Sänften vorbeigetragen (lectica, v. 32; cathedra, v. 65), andere gehen zu Fuß vorüber (post bunc <veniat>, v. 33; occurrit, v. 69). Aus der Wahrnehmung verschiedener Fortbewegungsweisen ergeben sich unterschiedliche Blickrichtungen, nämlich nach oben ${ }^{736}$ und auf Augenhöhe. Diese minimal angedeuteten Perspektiven erzeugen in dem ansonsten räumlich eher unstrukturierten, kumulativ präsentierten, Wahrnehmungsbereich ${ }^{\natural 737}$ zwei Ebenen. Selektionen von kleineren Details weisen den Abstand zwischen Wahrnehmungsinstanz und ihrem Wahrnehmungsbereich als gering aus und dokumentieren damit eine enge und dichte räumliche Umgebung. ${ }^{738}$

In besonders anschaulicher Weise werden dreimal Sänften und ihre Insassen beschrieben. ${ }^{739}$ Akzentuiert werden dabei visuell das raumnehmende Volumen der Sänften (nova, v. 32; sexta cervice ... patens et nuda paene v. 64 f.; pensilibus plumis, v. 159) und der Körper des Getragenen (plena ipso, v. 33; referens Maecenate supino, v. 66; illinc despiciat nos, v. 159). Des Weiteren beschreibt die Dichter-persona eine un-

735 Iuv. 1, 30-35; $37 \mathrm{f}$.

736 Vgl. Iuv. 1, 32-36; 64-68; 120 f.; ganz deutlich in 158 f.: qui dedit ergo tribus patruis aconita, vehatur/ pensilibus plumis atque illinc despiciat nos?

737 Als einzige räumliche Beziehung beschreibt die persona das Aufeinanderfolgen zweier Figuren mit der Präpositionalphrase post bunc (Iuv. 1, 33). Braund (1996), 20 spricht deswegen von einer Parade: „Rome presents an inversion of a parade of the finest and most glorious exempla, such as the parade of Aeneas' descendants in Virgil, Aeneid 6. 756-853.“ Der Vergleich mit einer Parade ist insofern passend, als die einzelnen Passanten von der Wahrnehmungsinstanz nacheinander wahrgenommen resp. beschrieben werden. Von einer räumlichen Ordnung in Form einer Parade kann aber nicht die Rede sein. Vgl. Highet (1954), 50: „The satirist is not showing us a procession, but plunging into a mob."

738 Als wohl kleinstes Detail nimmt die Wahrnehmungsinstanz einen - allerdings aufgrund seines Gewichtes auffälligen - Fingerring wahr. Vgl. Iuv. 1, 28 f.: ventilet aestivum digitis sudantibus aurum/ nec sufferre queat maioris pondera gemmae.

739 Auf dem ersten Sitz befindet sich ein Anwalt: causidici nova cum veniat lectica Mathonis/ plena ipso, (v. $32 \mathrm{f}$.), in einer späteren Szene heißt es über einen Testamentsfälscher: cum iam sexta cervice feratur/ binc atque inde patens et nuda paene cathedral et multum referens de Maecenate supino/ signator falsi (...), (v. 64-67) und in einer dritten über einen Giftmörder: qui dedit (...) aconita, vehatur/ pensilibus plumis atque illinc despiciat nos? (v. 158 f.). 
mittelbar taktile Wahrnehmung, etwa wie sich bestimmte Gruppen vorbeidrängeln und andere zur Seite schieben (cum te summoveant, v. 37; cum populum gregibus comitum premit hic spoliator, v. 46). ${ }^{74}$ Gemeinsam ist der visuellen wie taktilen Wahrnehmung, dass sie die Einnabme des öffentlichen Raums durch andere dokumentieren.

Trotz der detaillierten Wahrnehmung und dem Einbezug der (eigenen) Körperlichkeit in die Raumerfahrung besteht zwischen der Dichter-persona und ihrer materia eine innere Distanz. Mit keinem der an ihr vorüberziehenden Passanten tritt sie beim passiven Vorgang des Beobachtens in persönlichen Kontakt. Sie befindet sich außerhalb der von ihr wie auf einem ,Tableau vivant ${ }^{6741}$ wahrgenommenen Gesellschaft, ist Beobachter und Protokollant.

Dabei sind die Menschen für sie weniger eine anonyme Masse, sondern sie kennt Name, Beruf oder charakterliche Merkmale dieser Menschen. Mehr noch: Sie kann den Schein, deren Maskierung durchschauen und die Schurkereien und Unsitten ausmachen. Auch das direkte visuelle und körperliche Erlebnis führt der Dichter-persona ein komplexes, soziales Gefüge vor Augen: So ist die Raumnahme der Figuren für sie ein Abbild unterschiedlicher Normen und sozialer Unterschiede.

Ihre eigenen direkten visuellen Wahrnehmungen überblendet sie durch subjektive Empfindungen und Ressentiments gegenüber den in den Blick geratenen Bewohnern der Großstadt und überlagert sie mit Reflexionen und Verallgemeinerungen. Gegenstand der Satiren sind nicht ausgewählte schrullige Bewohner einer Großstadt, die der Kundige in bestimmten Bereichen der literarischen urbs Roma aufspürt. Der poeta gibt sich als ein zufälliger Betrachter und suggeriert gerade so, dass seine ausschnitthaften Beobachtungen massenhaft vorkommende und allägliche Phänomene der Großstadt sind. ${ }^{742}$ Einzelne werden als Exemplare spezifischer Gruppen und Berufsstände herausgegriffen, an denen sich das Spektrum der städtischen Gesellschaft aufzeigen lässt. ${ }^{743}$ Diese Form der Präsentation hat generelle Auswirkungen auf die räumliche Struktur dieser Satire. Durch einen sprunghaften Gedankengang werden verschiedene Räume in schnellem Wechsel integriert. ${ }^{744}$ Die verschiedenen Bereiche teilen alle das Merkmal der Inklusion in den literarischen Raum ${ }^{745}$, jedoch wird ihre räumliche Beziehung zueinander nicht geklärt. ${ }^{746}$

740 Vgl. auch Iuv. 1, 46-48: cum populum gregibus comitum premit bic spoliator/ pupilli prostantis et bic damnatus inani/ iudicio? Er nennt sich auch der Gruppe der bedauernswerten Klienten zugehörig, die sich nach einem morgendlichen Wettrennen um die sportula drängt. Vgl. Iuv. 1, 101 (nobiscum).

741 Helmbold (1951), 51.

$742 \mathrm{Zu}$ dieser Auffassung kommt auch Schmitz (2000), 57-62.

743 Braund (1996), 36, 112-113.

744 Vgl. Iuv. 1, 55-62: Ein Innenraum wird benannt in v. 56: spectare lacunar, eine Straße in v. 60 f.: dum pervolat axe citato/ Flaminiam.

745 Vgl. Iuv. 1, 30 f.: iniquae/ (...) urbis; 111: in hanc urbem.

746 Vgl. (z. B.) Iuv. 1, 55-57 und 58-61. 
Die assoziative Darbietung führt zu einer mosaikartigen Zersprengtheit in der Raumgestaltung. Auf den öffentlichen und offenen Raum des Menschenstroms kommt die Dichter-persona jedoch viermal innerhalb der Satire zurück. ${ }^{747}$ Von seiner Ausgestaltung her zeigt der literarische Raum damit zweifellos einen ausgeprägt städtischen Charakter. Dass es sich bei der in der Satire beschriebenen literarischen Großstadt um Rom handeln soll, wird nur anhand weniger, indirekter Hinweise kenntlich. ${ }^{78}$ Für das Selbstverständnis als Dichter ist der großstädtische Charakter des literarischen Raumes von größerer Relevanz.

\section{Zusammenfassung}

Diese erste Satire ist eine sehr persönliche Rechtfertigung einer Gattungswahl gegenüber einer nicht genauer spezifizierten Leserschaft, die zum Ende der Satire hin auch dialogisch einbezogen wird. ${ }^{74}$ Durch verallgemeinernde, rhetorische Fragen (quis .../ tam patiens ..., tam ferreus, v. 30 f.; quem patitur dormire, v. 77) und durch den direkten Einbezug in das haptische Erlebnis des Menschenstromes (cum te summoveant, v. 37) $)^{750}$ versucht die persona sie für ihre Beobachtungen und Empfindungen zu vereinnahmen. ${ }^{751}$

Die Dichter-persona zieht von Anfang an und unmissverständlich eine Verbindungslinie zwischen dem sie umgebenden Lebensraum und ihrem eigenen dichterischen Schaffen. Dabei zeichnet sie den literarischen Raum urbs Roma in keiner

747 Vgl. Iuv. 1, 32-39; 46-48; 63-72; 158-161.

748 Dass es sich bei der in dieser Satire geschilderten Stadt um Rom handelt, legt zunächst allein die Gattungskonvention nahe. Der Sprecher in Juvenals Satiren will Lucilius nachfolgen. Vgl. Hor. sat. 1, 10, 3 f.: quod sale multo/ urbem defricuit, charta laudatur eadem. In den Versen Iuv. 1, 128-132 verweisen forum iurisque peritus Apollo/ atque triumphales, inter quas ausus babere/ nescioquis titulos Aegyptius atque Arabarches, / (...) / vestibulis abeunt (...) clientes für einen Ortskundigen auf Rom, wie auch die Nennung wichtiger Zufahrtsstraßen: Iuv. 1, 60 f.: dum pervolat axe citato/ Flaminiam und 171: quorum Flaminia tegitur cinis atque Latina. Die beiden Schauplätze werden durch Referenzen auf städtische Teilelemente als fingierte Handlungszonen im Gebiet der literarischen urbs Roma dargestellt. Eine Zusammenstellung aller Referenzen auf topographische Wahr- und Merkzeichen und städtische Teilelemente in Juvenals Satiren findet sich bei Larmour (2007), $168 \mathrm{f}$.

749 Nach einem längeren Monolog verändert sich im zweiten Teil die Darstellungsweise. Gemäß der Ankündigung einer farrago werden skizzenhaft Dialoge wiedergegeben, zum Ende hin auch ein direkter Dialogpartner mit kurzen Einwürfen eingebunden. Vgl. Iuv. 1, 150 f.: dices hic forsitan: ,unde/ ingenium par materiae?' Zu einem Gespräch in Form eines echten Dialogs kommt es in den letzten Versen, vgl. Iuv. 1, 155- 171.

750 Vgl. Braund (1996), 85: „technical, of the lictors clearing the crowed from the path (...)“. Gegen Adamietz (1993), 325, Anm. 20: „Aus den Testamenten“.

751 Eine Eigenart der ersten Satire ist es, viele Aussagen in der unpersönlichen Form der zweiten Person Singular zu präsentieren. Dieses , $\mathrm{Du}^{\prime}$ ist aber nicht als das eigenständiger Protagonisten zu deuten, sondern soll ein Gegenüber (d. h. den Leser) für die subjektive Meinung des Ichs vereinnahmen. Vgl. Iuv. 1, $97 \mathrm{f}$.: ille tamen faciem prius inspicit et trepidat ne/ suppositus venias ac falso nomine poscas. Zum Einbezug des Lesers durch die unbestimmte zweite Person vgl. Braund (1996), 80. 
Weise topographisch. Er wird vielmehr von einem simultan dichtenden Individuum räumlich als ein dichter, dynamischer Menschenstrom visuell und haptisch erlebt, aus dem exempla für die satirische Dichtung gewonnen werden können. Damit nutzt die Dichter-persona eine besondere, großstädtische räumliche Konstellation aus: die alltägliche, intensive Nutzung der Straße durch zahlreiche Menschen. Sie blickt auf eine vielgestaltige und dichte Menschenmenge, die ihr, dem Einzelnen, als ein Fixpunkt entgegenläuft, die sie durch ihre Dichte gleichzeitig in Gefahr bringt, von ihrer Position verdrängt zu werden.

Die Unbegrenztheit und Vielfalt der Themen entspringen genau dieser transitorischen räumlichen Konstellation. Sie selbst steht medio quadrivio, von wo sie ihre Satiren stante pede schreibt. ${ }^{752}$ Diese satirische Dichterlandschaft ist kein einsamer Musenhain, aber auch kein Kommunikationsort mit anderen Dichtern oder mit einem entsprechenden Publikum. Diese Dichter-persona will gerade nicht die üblichen Themen der hohen Kunst behandeln, die Dichter in geschlossenen Arealen reicher Privatvillen vorführen, sondern eine Dichtung der unbegrenzten und offenen Straße bieten, die unmittelbare Wiedergabe eines den Dichter umgebenden Lebensraums. ${ }^{753}$ Sie hält diesen facettenreichen literarischen Raum für einen ausreichend beeindruckenden Erfahrungsraum, um in einer explizit emanzipatorischen und in diesem Sinne innovativen Literatur einen angemessenen Platz zu erhalten.

Mit Juvenals erster Satire liegt uns ein ungewöhnlich drastisches Zeugnis programmatisch-poetologischer Aussagen über einen direkten Großstadtbezug der Dichtung und dem Selbstverständnis eines Großstadtdichters vor. Dichterische Schaffenskraft speist sich aus dem vielseitigen Anschauungsreichtum eines Raumes, der vorrangig aus agierenden Städtern besteht. Die räumliche Einbindung in die städtische Gesellschaft (Schauplatz) führt zu einer psychisch-emotionalen Überforderung, der der Sprecher mit dem aktiven Akt des Satire-Schreibens Herr zu werden sucht. In dieser Intensität und visuellen Anschaulichkeit wird in keinem anderen überkommenen Eingangsgedicht einer Gedichtsammlung die Großstadt als Inspirationslandschaft und Motor der Gattungswahl vereinnahmt.

752 Die Unmittelbarkeit des visuellen und haptischen Raumerlebens, der bisweilen assoziative Aufbau und die Häufung der rhetorischen Fragen erwecken zwar den Eindruck einer mündlich vorgetragenen Stegreifrede, jedoch wird während der gesamten ersten Satire wiederholt auf das schriftliche Verfassen insistiert: Die Großstadt zu betrachten, heißt Satire schreiben. Vgl. Iuv. 1. 17 f.: stulta est clementia (...)/ (...) periturae parcere chartae, Iuv. 1, 30: difficile est saturam non scribere; Iuv. 1, 63: nonne libet (...) ceras implere capaces. Eine sofortige schriftliche Niederschrift legen Aussagen im Präsens Indikativ nahe. Im Konjunktiv - also als Option - benennt er die schriftliche Nachtarbeit, vgl. Iuv. 1, 51 f.: haec ego non credam Venusina digna lucerna?/ haec ego non agitem? sed quis magis? Gegen Braund (1996), die wiederholt (80) von ,audience“ spricht.

753 Iuv. 1, 51-72. 


\subsubsection{Mutatus locus. Die urbs Roma der Imagination und die Metamorphose des Stils (Ov. trist. 1, 1)}

In Ovids Eröffnungselegie des ersten Tristienbuches verteidigt eine Dichterpersona zwar nicht explizit ihre Gattungswahl oder ordnet sich in eine literarische Traditionslinie ein, ${ }^{754}$ wohl aber verteidigt sie äußere Gestalt ${ }^{755}$ und Qualität ${ }^{756}$ der vorliegenden Dichtung (apologia): Das Buch ist nicht als Prachtband gestaltet, sondern trägt Farben der Trauer und Flecken, die durch Tränen verursacht wurden. ${ }^{757}$ Das Buch spiegelt damit in seinem äußeren Auftreten die inneren Befindlichkeiten einer Dichter-persona wider ${ }^{758}$, die als Verbannte trauert und weint, von Wind und Wetter sowie von beständiger Todesangst getrieben ist. ${ }^{759}$ Ihrer emotionalen Konstitution wegen sei das dichterische Talent (ingenii, v. 36) gewichen und unerwartete Schicksalsschläge ${ }^{760}$ haben zu einem Wandel der Schreibhaltung geführt. Die vorliegenden, den Umständen geradezu abgerungenen Elegien verlangen daher

754 Die genaue Einordnung der Tristien in ein Gattungsschema erweist sich als schwierig. Dies ist bei dem häufig zu beobachtenden Spiel Ovids mit den Gattungskonventionen seiner Zeit (vgl. Ars amatoria als Lehrgedicht oder die Metamorphosen als Epos) nicht überraschend. Die evozierte Verwandtschaft mit der Gattung der Heroides und die Anlehnung an Hor. epist. 1, 20 (vgl. Luck (1977), 2) und Hor. epist. 1, 13 (vgl. Hinds (2006), 416) legen eine Interpretation der Tristien als Episteln nahe. Vgl. auch die für den antiken Briefstil typische Sichtweise auf die Situation des Empfangens anstelle der des Schreibens, bzw. die Aufforderung zur Eile am Ende der ersten Tristie 1, 1, 124-128 aufgrund der großen Entfernung. Schwierigkeiten bereiten aber die verschiedenen Redesituationen bereits im ersten Tristienbuch: Anrede an ein Buch (trist. 1, 1), Gebet auf einer Seereise (trist. 1, 2), Abschied aus Rom (trist. 1, 3), generell fehlende Anredeformel an einen konkreten Adressaten etc. Der entscheidende Unterschied zu der Gattung der Epistel ist, dass in den Tristien der Verfasser als abwesend vorgestellt wird und nicht der Empfänger. Vgl. dazu Hinds (1985), 16: „The invocation here of an epistolary model for the second time in these opening lines $[d . h$. Ov. trist. 1, 1, 1-14, Anm. d. Verf. $]$ - first Horace's Epistles, now Ovid's Epistulae Heroidum - draws attention to the fact that this is poetry which is sent over a distance, poetry which has to speak for an absent writer." Zur Einheit der Tristien als Gattung vgl. Schröder (1999), 88: „Die Stimmung hingegen, eine Benennung ,e temporibus‘, umfasst alle Stücke."

755 Ov. trist. 1, 1, 3-14.

756 Ov. trist. 1, 1, 35-48.

757 Vgl. auch Ov. trist. 1, 1, 5 f.: nec te purpureo velent vaccinia fuco:/ non est conveniens luctibus ille color und $13 \mathrm{f}$.: qui viderit illas, / de lacrimis factas sentiat esse meis.

758 Vgl. besonders Ov. trist. 1, 1, 10: fortunae memorem te decet esse meae.

759 Ov. trist. 1, 1, 41-44: carmina secessum scribentis et otia quaerunt:/ me mare, me venti, me fera iactat biems./ carminibus metus omnis obest: ego perditus ensem/ haesurum iugulo iam puto iamque meo. Ab dem dritten Buch der Elegiensammlung werden die Verhältnisse am Exilort Tomis als Gründe für eine Qualitätsschmälerung hinzugenommen. Aufgrund der poetischen Chronologie der Elegienbücher kann die Dichter-persona diese aber zum fiktiven Zeitpunkt der ersten Elegie nicht kennen. Im ersten Elegienbuch befindet sie sich auf der Überfahrt nach Tomis. Vgl. dazu Luck (1977), 16.

760 Ov. trist. 1, 1, 40. 
Bewunderung. ${ }^{761}$ Denn unter diesen Gegebenheiten wäre es auch einem Homer unmöglich gewesen, anderes zu dichten (recusatio). ${ }^{762}$ Eindeutig zählt die erste Elegie der Gattung ,Tristien“"763 zur Gruppe der Programmgedichte. Ebenso eindeutig ist der literarische Raum urbs Roma nicht Schauplatz dieser Elegie. Dennoch wird gerade ihm eine zentrale Funktion für den Paradigmenwechsel des dichterischen Schaffens zuerkannt.

\subsubsection{1 (...) sine me, liber, ibis in urbem ${ }^{764}$ - Großstadt und Dichtung}

Entsprechend der durchgehenden Schreibsituation eines Verbannten ist in der gesamten Exildichtung ${ }^{765}$ eine unmittelbare, sinnliche Erfahrung der literarischen urbs Roma wie in der ersten Satire Juvenals ausgeschlossen: Der Sprecher befindet sich stets außerhalb Roms. Vom ersten Vers der Eröffnungselegie an weiß der Leser um den Umstand dieser besonderen Entstehungsbedingungen der vorliegenden Literatur: Diese Verse wurden nicht in der urbs Roma geschrieben.

1 Parve - nec invideo - sine me, liber, ibis in urbem:

ei mibi, quod domino non licet ire tuo! ${ }^{766}$

Der Inhalt der gesamten Elegie ist aber ganz darauf gerichtet, dass in Bälde das Buch in die urbs Roma kommen wird. Dass es sich dabei um ein Privileg handelt, deutet bereits das erste Distichon an, darauf wird wiederholt innerhalb der ersten Elegie hingewiesen. ${ }^{767}$ Dem Elegienbuch Tristia wird damit ein Vorrecht eingeräumt, das ansonsten nur der Liebeselegie ${ }^{768}$ zugesprochen wird: Es kann dorthin gelangen, wo der Sprecher selbst gern wäre. Gerade diese subtilen Referenzen an

761 Ov. trist. 1, 1, 45 f.: haec quoque quod facio, index mirabitur aequus, / scriptaque cum venia qualiacumque leget.

762 Ov. trist. 1, 1, 47 f.: da mibi Maeoniden et tot circumspice casus, / ingenium tantis excidet omne malis.

763 Der Titel Tristia ist in den Hss. eindeutig belegt, bei den Epistulae ex Ponto handelt es sich um eine Kombination der Titel epistularum oder Ex Ponto. Zu den Werktiteln vgl. Schröder (1999), 87-89.

764 Ov. trist. $1,1,1$.

765 Die Exildichtung wird meist als eine Einheit behandelt. Sie umfasst die ,Tristia' genannten Elegien in fünf Büchern, vier Bücher poetischer Briefe ,Epistulae ex Ponto' und ein polemisches Gedicht ,Ibis‘. Schröder (1999), 87: „,Ovid betont, dass er den beiden inhaltlich ähnlichen Werken [d. h. trist. und Pont., Anm. d. Verf.], die er vom Ort seiner Verbannung nach Rom sende, unterschiedliche Titel gegeben habe. Vgl. Ov. Pont. 1, 1, 17: rebus idem, titulo differt. Der erste Teil sei miserabilis und das erste wie das zweite triste. Vgl. Ov. Pont. 1, 1, 15 f.: invenies, quamvis non est miserabilis index, / non minus hoc illo triste, quod ante dedi." Vgl. auch dazu Martin (2004), $9 \mathrm{f}$.

766 Ov. trist. 1, 1, $1 \mathrm{f}$.

767 Wiederholt kommt der elegische Sprecher auf diesen Auftrag zurück. Vgl. Ov. trist. 1, 1, 15: vade, liber, verbisque meis loca grata salute, und 57-60: tu tamen i pro me, tu, cui licet, aspice Romam: / di facerent, possem nunc meus esse liber./ ne te, quod venias magnam peregrinus in urbem, ignotum populo posse venire puta.

768 Vgl. Ov. am. 3, 8, 5 f. Anrede an einen Ring: Ov. am. 2, 15, 1-3, bes. 8. Vgl. Dazu auch Amann (2006), $48 \mathrm{f}$. 
die erotische Dichtung enthüllen von Beginn an die ungeheure Bedeutung der urbs Roma für die Dichter-persona: Sie ist ein Ort, zu dem sich der exclusus poeta zurücksehnt, zu dem er aber nicht gelangen kann (ei mibi, quod ... non licet ire ...!, v. 2). Aus diesem Kontext erklärt sich seine elegische Sprechhaltung. ${ }^{769}$ Eine dichterische Tätigkeit bedürfe heiterer Stimmung, Furchtlosigkeit, Ruhe und Zurückgezogenheit. ${ }^{770}$ Diese Umstände sind in der gegenwärtigen Situation für die Dichterpersona nicht mehr gewahrt. Deswegen sei ihr ingenium nicht mehr in alter Form vorhanden (culpabere forsan/ ingeniique minor laude ferere mei, v. $35 \mathrm{f}$.). Die frühere Hingabe (donec eram sospes, tituli tangebar amore, v. 53; nominis ardor, v. 54) entsprach damaligen Umständen (eram sospes, v. 53), sie verlor sich mit der Flucht aus der Stadt. ${ }^{771}$ Durch diese Abwertung der eigenen neuen Dichtung enthüllen sich die spezifischen Antriebskräfte zum Dichten selbst, die sich für den elegischen Sprecher mit dem Aufenthalt in der urbs Roma verbanden: Hier konnte er wohlgelaunt, angstfrei und in Ruhe dichten. Zudem fand er wichtige Stimuli eines großstädtischen Literaturbetriebs wie ein Publikum, Leser und Kollegen vor. ${ }^{772}$ Eine langfristige Entfernung von der geliebten Heimat ${ }^{773}$ urbs Roma wird seine dichterischen Fähigkeiten verlöschen lassen. Den ersten Andeutungen in der Tristie 1, 1 - etwa durch die öffentlich gezeigten Trauerzeichen des Buches ${ }^{774}$ - folgen in einer späteren Epistel, Epistulae ex Ponto 1, 5, explizitere Aussagen. Hier schreibt die Dichterpersona:

$$
\begin{aligned}
& \text { gloria vos acuat, vos, ut recitata probentur } \\
& \text { carmina, Pieriis invigilate choris. } \\
& \text { quod venit ex facili, satis est componere nobis, } \\
& \text { et nimis intenti causa laboris abest. } \\
& \text { cur ego sollicita poliam mea carmina cura? } \\
& \text { an verear ne non approbet illa Getes?775}
\end{aligned}
$$

769 Wichtigstes Merkmal des gegenwärtigen Schauplatzes, an dem das monologisch präsentierte Gespräch mit dem Buch stattfindet und von dem der Leser nicht mehr erfährt, als dass die Dichter-persona von Wind und Wetter getrieben wird (v. 42), ist, dass es nicht in Rom ist (sine me ... ibis in urbem, v. 1). Vgl. Hinds (1985), 16.

770 Vgl. Ov. trist. 1, 1, 39: carmina proveniunt animo deducta sereno; 41: carmina secessum scribentis et otia quaerunt, 43: carminibus metus omnis obest.

771 Aufgrund dieser Begabung kam es aber zur Vertreibung. Vgl. Ov. trist. 1, 1, 56: ingenio sic fuga parta meo.

772 Vgl. Gaertner (2005), 305. Zur Scham über seine eigenen Verse vgl. Ov. Pont. 1, 5, 15 f.

773 In der Exildichtung ist Rom die patria des Poeten. Vgl. Ov. trist. 1, 5, 65-70; Pont. 1, 2, 47 f.; 1 , 3, 35-37; 2, 8, 19 f. Die Geburtsstadt Ovids, Sulmo, nennt der elegische Sprecher freilich in gleicher Weise patria. Vgl. Ov. trist. 4, 10, 3. Rom als patria zu bezeichnen, ist allerdings auch für andere Exilschreiber wie Cicero und Seneca belegt. Vgl. Edwards (1996), 111.

774 Vgl. dazu Amann (2006), 50-53.

775 Ov. Pont. 1, 5, 57-62. 
Das elegische Ich kontrastiert in dieser Passage die Bedingungen der vos, der direkt angesprochenen zeitgenössischen stadtrömischen Dichter, ${ }^{776}$ mit seinen eigenen: Während für diese gloria und die öffentlichen Rezitationen Ansporn zu anspruchsvoller Poesie (Pieriis choris, v. 58) seien, sind seine Exilgedichte ohne jegliche Herausforderungen durch andere unbearbeitet und aus Ablenkung ${ }^{777}$ niedergeschrieben. ${ }^{778} \mathrm{Im}$ Vergleich mit einer Schreibweise, wie sie innerhalb der urbs Roma möglich wäre, sind die eigenen Exil-Elegien wegen fehlender Möglichkeiten, über Literatur öffentlich zu kommunizieren, von geringerem Wert. Die räumliche Entfernung zwischen Dichter und Großstadt ${ }^{779}$ sowie den Dichterkollegen, aber auch der Niveau-Unterschied zwischen dem Publikum in der urbs Roma und an der Peripherie $^{780}$ führen in den Augen der Dichter-persona unweigerlich zu einem Verlust an Qualität der eigenen Dichtung.

sed neque pervenio scriptis mediocribus istuc,

famaque cum domino fugit ab urbe suo.

85

vosque, quibus perii, tunc cum mea fama sepulta est,

nunc quoque de nostra morte tacere reor. ${ }^{781}$

Der Qualitätsunterschied zwischen der vormaligen und gegenwärtigen Dichtung ist nach dem Selbstverständnis der Dichter-persona so groß, dass ein Kontakt der Dichter-persona zu einem gebildeten Publikum längerfristig nicht aussichtsreich ist. Die Kette des Abstieges ist voller fataler Konsequenzen: Die Entfernung zur Großstadt lässt sie nicht mehr anspruchsvoll dichten, dieser Umstand entfernt sie

776 Der Adressat der Elegie ist der zeitgenössische Dichter Cotta Maximus. Zum Katalog der Dichter siehe Ov. Pont. 4, 16, 41-44.

777 Ov. Pont. 1, 5, 29 f.: cur igitur scribam, miraris? miror et ipse,/ et tecum quaero saepe quid inde petam; 48: quo ponam vigilans tempora longa modo? und 55 f.: consequor ex illis casus oblivia nostri:/ hanc messem satis est si mea reddit bumus.

778 Das Verb componere (Ov. Pont. 1, 5, 59) bezieht sich inhaltlich nur auf das Schreiben, nicht auf das Ausfeilen. Vgl. Ov. Pont. 1, 5, 17: nec tamen emendo. Vgl. weiterhin Ov. trist. 5, 1, 71 f.; Ov. Pont. 3, 9, 19 f. und Helzle (2003), 171. Diese nachlässige Form garantiere der Dichter-persona bei den Geten in der Region des Histers für ein Ausnahmetalent gehalten zu werden. Echter Wettstreit und angemessene Anerkennung durch gleichrangige, sprich großstädtische Dichterkollegen und ein entsprechendes Publikum, seien hier jedoch nicht zu realisieren. Vgl. Ov. Pont. 1, 5, 66: inter inhumanos esse poeta Getas. Zur Diskussion über die Echtheit der Stelle vgl. Gaertner (2005), 341. Vgl. auch Ov. trist. 1, 1, 49-54.

779 Ov. Pont. 1, 5, 71-82.

780 Ov. Pont. 1, 5, 61-69.

781 Ov. Pont. 1, 5, 83-86. 
weiter von einem großstädtischen Publikum. Für das nun unerreichbar gewordene stadtrömische Publikum ist sie - obwohl noch schreibend - bereits tot. ${ }^{782}$

Die Inszenierung dieses elegischen Sprechers in einer künstlerischen Abwärtsspirale ist jedoch nicht so eindimensional, wie es vordergründig den Anschein hat. Bereits bei der Lektüre der ersten Elegie fällt auf, dass die Dichter-persona vor allem mögliche Begegnungen ihres neuen Buches innerhalb der urbs Roma imaginiert. Im Wesentlichen geht es ihr dabei um das Auffinden geeigneter Leser (v. 15104) und um die Zusammenführung des gesamten bisherigen dichterischen Schaffens des poeta (v. 105-122).

Die Auswahl des Lesers geschieht mit Sorgfalt, indem dem Buch eine Reihe von Verhaltensregeln an die Hand gegeben werden: Es solle zum wohlwollenden Teil der Bürger Kontakt aufnehmen ${ }^{783}$, sich vor etwaigen Angriffen in Acht nehmen ${ }^{784}$ bzw. den Leser zu einer erwünschten, nämlich nachsichtigen Leseweise lenken. ${ }^{785}$ Dieser soll wiederum die Gedichte nicht nur zur Kenntnis nehmen, sondern auch die vorliegenden Veränderungen ihrem Entstehungskontext gemäß würdigen. So warnt die Dichter-persona: Bei der Kontaktaufnahme sei äußerste Zurückhaltung geboten (cave, v. 22, 25, 87, 104). ${ }^{786}$ Nicht jeder werde dem Buch mit gleichem Einfühlungsvermögen und freudigen Erwartungen begegnen. ${ }^{787}$ Idealer Leser sei jemand, dem das Schicksal der Dichter-persona vertraut ist, ${ }^{788}$ der sowohl ihre einstigen Leistungen auf dem Gebiet der Dichtung kennt, als auch über die Ursachen des weiteren Schicksals informiert und daran interessiert ist. Im Gegensatz zu dem in der praefatio geäußerten Anliegen Martials versucht hier die Dichter-persona nicht an ihre alte Dichtungsweise anzuschließen, um einem großstädtischen Publikum weiterhin zu genügen, sondern sie konstatiert einen Paradigmenwechsel, der zwar mit Besorgnis, aber unredigiert übergeben werden soll. Trotz der zugestandener-

782 Zum Tod als Dichter vgl. Nagle (1980), 21-32. Das Dichterbild ist allerdings in den Exil-Elegien nicht eindimensional: vgl. Ov. trist. 3, 7, 50 oder Ov. Pont. 4, 16, 3 f.

783 Vgl. Ov. trist. 1, 1, 17-20; 27-34; 87 f.

784 Vgl. Ov. trist. 1, 1, 21-26.

785 Zur Beschreibung des idealen Lesers vgl. Ov. trist. 1, 1, 27-34. Bei der Suche nach dem idealen Leser fließen auch Überlegungen ein, ob das Buch dem Kaiser, dem unmittelbaren Verursacher des Exils, übergeben werden soll. Vgl. Ov. trist. 1, 1, 69-104, bes. 95-98: siquis erit, qui te dubitantem et adire timentem/ tradat, et ante tamen pauca loquatur, adi./ luce bona dominoque tuo felicior ipso/ pervenias illuc et mala nostra leves.

786 Vgl. Ov. trist. 1, 1, 87: ergo cave, liber, et timida circumspice mente; v. $101 \mathrm{f}$.: tantum ne noceas, dum vis prodesse, videto. I nam spes est animi nostra timore minor: (...).

787 Vgl. Ov. trist. 1, 1, 63 f.: clam tamen intrato, ne te mea carmina laedant:/ non sunt ut quondam plena favoris erant. Vgl. Ov. tist. 1, 1, 65-67: siquis erit, qui te, quia sis meus, esse legendum/ non putet, e gremio reiciatque suo, / (...) dic (...).

788 Vgl. Ov. trist. 1, 1, 17 f.: siquis, (...), nostri non inmemor illi,/ siquis, qui, quid agam, forte requirat, erit: (...) und 27 f.: invenies aliquem, qui me suspiret ademptum, / carmina nec siccis perlegat ista genis. 
maßen schwierigen inhaltlichen Kost strebt der poeta mit seiner neuerlichen Dichtung selbstbewusst weiterhin eine breite Leserschaft für seine Elegien an. ${ }^{789}$

Die Aufgabe des Buches besteht unzweifelhaft darin, an einen bereits existierenden Kontakt unter den neuen Bedingungen anzuschließen. Von dem Leser erwartet der poeta Verständnis für die Entstehungsbedingungen und eine entsprechende Rezeptionshaltung. Die erste Elegie wird somit zu einer programmatischen Leseanweisung an intendierte Leser ${ }^{790}$, die unverkennbar als Bewohner der urbs Roma vorgestellt sind. Die Großstadt Rom ist damit der Bezugsort der Dichtung, der Ort, an dem der Leser und Begutachter seiner Gedichte lebt. Innerhalb der Exildichtung kommt diese selbstbewusste Seite immer wieder zum Vorschein: ${ }^{791}$ Bald fürchtet der elegische Sprecher, in Rom und von seinem Publikum vergessen zu werden, ${ }^{792}$ bald wünscht er, durch seine Dichtungen weiterhin die geographische Distanz überbrücken zu können und mit den Seinen in Kontakt zu bleiben. ${ }^{793}$ Er überlegt, inwieweit sich das Verschicken seiner Dichtung noch lohne, inwieweit sich überhaupt noch jemand in der Hauptstadt an ihn erinnere. ${ }^{794}$ Diese verschiedenen Variationen einer captatio sind mitnichten Zeugnisse eines Dichters, der gegen das Vergessen anschreibt, sondern decken geradezu auch solche Aussagen wie die in der eben zitierten Epistel 1, 5 - ein städtisches Publikum als Stachel des Ehrgeizes fehle im Exil, er sei als Dichter mit dem Verlassen der Stadt gestorben absichtsvoll sich selbst demaskierend als eine elegische Stilisierung einer Dichterpersona $^{795}$ auf. Derartige Aussagen sollten vielmehr als Ausdruck der Wertschätzung eines großstädtischen Publikums gelesen werden. Aus der Feder des vorgeblich toten Großstadtdichters entstehen mehrere Bücher Exildichtung, die sich an ein in der urbs Roma ansässiges Publikum richten, von diesem zur Kenntnis genommen werden und die sogar an seine bisherige Literatur anschließen können.

So werden auch die Unterschiede zum früheren Schaffen, die gerade zu Beginn der ersten Tristie im Vordergrund standen, zum Ende hin nivelliert. ${ }^{796}$ Zielpunkt

789 Vgl. Ov. trist. 1, 1, 88: ut satis a media sit tibi plebe legi. Vgl. Luck (1977), 14, der darauf hinweist, dass das mit den Elegien angestrebte breite Publikum im Gegensatz zu den Vorstellungen anderer augusteischer Dichter (z. B. Hor. epist. 1, 20) steht.

790 Hinter dem intendierten Leser stehen einerseits die konkreten Adressaten, nämlich Vertreter des öffentlichen Lebens in Rom (v. a. in den Epistulae ex Ponto, vgl. dazu Walde (2005), 167), andererseits ein anonymes stadtrömisches Publikum. Vgl. Martin (2004), 10, Anm. 10.

791 Vgl. Ov. trist. 3, 7, 49-54 oder Ov. Pont. 4, 16, 3 f.

792 Ov. Pont. 1, 7, 3 f.

793 Ov. Pont. 5, 1, 79 f.

794 Vgl. Ov. trist. 3, 10, 1 f.: Siquis adbuc istic meminit Nasonis adempti/ et superest sine me nomen in urbe meum.

795 Zur Stilisierung der persona „Dichter im Exil“ gehört konsequenterweise auch, mit dem Erfolg in absentia zufrieden zu sein. Vgl. Ov. trist. 5, 7, 29 f.: non tamen ingratum est, quodcumque oblivia nostri/ impedit et profugi nomen in ora refert. Ein Qualitätsverlust ist von der modernen Forschung nicht bescheinigt worden. Vgl. Luck (1977), 243-261; Williams (1994), 243-251.

796 Ov. trist. 1, 1, 105-122. 
der Reise für das Buch ist der heimatliche Bücherschrank, in dem es auf seine fratres (v. 107) stoßen wird. Erhält das Buch zwar auch Verhaltensregeln gegenüber den Werken ars amatoria und den metamorphoses ${ }^{797}$, so wird doch an dieser Stelle nicht mehr auf die Unterschiede insistiert, sondern die Geschlossenheit des Gesamtwerkes, das mit dem gleichen Eifer (studium ... idem, v. 108) in Nachtwachen geschaffen wurde, und die Anschlussfähigkeit der neuen Dichtung in den Vordergrund gestellt. ${ }^{798}$

\subsubsection{Tu tamen i pro me, tu, cui licet, aspice Romam ${ }^{799}$ - Großstadt und Dichter}

In der ersten Tristie befindet sich die Dichter-persona nicht (mehr) innerhalb der literarischen urbs Roma. Über den eigentlichen Schauplatz des Zwiegespräches zwischen dem Elegienbuch und dem poeta werden nur rudimentäre Informationen vergeben. An den jeweiligen Außenpunkten der Elegie - den Eingangs- und Ausgangsversen - werden jedoch zwei Räume gegenübergestellt, die zukünftig zum einen von dem Buch (ibis in urbem, v. 1) und zum anderen von der Dichter-persona betreten werden (nobis habitabitur orbis/ ultimus, a terra terra remota mea, v. 127 f.). Mit dieser formal abgebildete räumliche Extremsituation zwischen Zentrum und Peripherie gelingt es nicht nur, den künftigen Aufenthaltsort mit dem literarischen Raum urbs Roma in Beziehung zu setzen, sondern vor allem, die räumliche Entfernung zwischen den beiden herauszustellen: Bereits vom jetzigen Schauplatz aus ist die räumliche Distanz zur literarischen urbs Roma enorm und zu ihrer Überwindung mahnt die Dichter-persona zum Ende der Elegie hin zur Eile (longa via est, propera, v. 127) ${ }^{800}$, zukünftig allerdings wird eine noch größere Distanz zwischen den beiden liegen (orbis/ ultimus, v. 127 f.).

Im Mittelpunkt der Elegie steht die zurückgelassene Stadt. ${ }^{801}$ Der literarische Raum urbs Roma war zwar in der Vergangenheit der Dichter-persona eine sie unmittelbar umgebende Lebenswelt, diese wird aber in dieser Eröffnungselegie nicht als ein ,raum-zeitlicher Fernraum' (spatio-temporally distant frame) präsentiert ${ }^{802}$, sondern

797 Ov. trist. 1, 1, 119-122. Vgl. Hinds (1985), 20-27.

798 Es finden sich in der Exildichtung auffällig viele Anspielungen auf vorhergehende Werke des Autors: neben der auch metrischen Übereinstimmung mit der Liebesdichtung (vgl. dazu Schröder (1999), die darauf aufmerksam macht, dass ein derartiger Titel in Kombination mit dem Versmaß zunächst an die Liebeselegie hätte denken lassen) auch Anspielungen auf die Heroides (Ov. trist. 1, 1, 13 f. verweist auf Prop. 4, 3, 3 f. sowie auf Ov. her. 3, 3 und 11, 1). Explizit erwähnt werden in der ersten Tristie die drei Bücher der Ars amatoria (Ov. trist. 1, 1, 111-116) als unschuldige Vatermörder (vgl. Hinds (1985), 17-20) und die Metamorphosen.

799 Ov. trist. 1, 1, 57.

800 Vgl. Hinds (2006), 416, der die Aufforderung sich zu beeilen für ein Indiz hält, dass es sich bei der vorliegenden Gattung um eine Briefgattung hält.

801 Vgl. Hinds (1985), 16.

802 In der Exilliteratur wird mithilfe der Raumkonstellation Schauplatz-Fernraum in verschiedener Weise kontrastiv gearbeitet. So werden wie bei einer filmischen Blende Ereignisse an den räum- 
als ein ,nicht bestehender Raum' (frame with a non-factual status). Denn weder die Dichter-persona, noch das Buch betritt ihn in der Elegie, auch nicht durch einen zeitlichen Rückgriff. Für den exclusus poeta bleibt die literarische urbs Roma ein ,unzugänglicher Raum' (inacessible frame), woraus sich die programmatische elegische Sprechhaltung begründet. 803

Die konkrete Physis des literarischen Raumes bleibt trotz wiederholter Nennung der entsprechenden Kernwörter (Romam, v. 57; urbem, v. 1; 59) auffällig unbestimmt. ${ }^{804}$ So gibt die Dichter-persona ihrem Buch recht unspezifische Hinweise, in welchen Bereichen innerhalb der urbs es einen geeigneten Leser antreffen kann, obwohl der poeta wiederholt von ihnen spricht. ${ }^{805}$ Nach seiner Vorstellung wird sich das Buch recht unmittelbar einer größeren Gruppe von Menschen gegenübersehen, der es über das Schicksal seines Dichters Auskunft erteilen soll. Keiner der potentiellen Gegenüber wird - im Gegensatz etwa zur ersten Satire Juvenals namentlich genannt oder als Individuum gekennzeichnet. Die Dichter-persona wählt sehr allgemeine Begriffe wie siquis, lector, iudex oder populus, plebs und unterscheidet nicht zwischen Bevölkerung und Leserschaft. ${ }^{806}$

Trotz dieser Vagheit werden die Bereiche als sehr persönliche ,Kontaktbereiche“ vorgestellt, wie konkrete Gesprächsvorlagen (v. 17-48) oder ein haptischer Kontakt (qui te, ... / e gremio reiciatque, v. 65 f.) nahe legen. In der Vorstellung der Dichter-persona nehmen zudem die Bewohner selbst den Kontakt zum Buch auf. Sie

lich extrem entfernten Orten wiedergegeben, die in etwa gleichzeitig geschehen. Anderseits wird der Fernraum in einer zeitlichen Retrospektive zu einem Schauplatz.

803 Diese Elegie teilt nicht genau die räumliche Konstellation des exclusus amator der Liebeselegie. Während der amator auf der Schwelle liegt und an die Tür klopft, also sich an der Grenze zum ,unzugänglichen Raum' (inacessible frame) befindet, entziehen sich die Vorgänge innerhalb des Hauses seiner Kenntnis, er betritt es nicht. Vgl. Prop. 1, 16 (aus der Sicht einer Tür), Catull. 67 (Dialog mit einer Tür); Hor. carm. 1, 25; 3, 10; Tib. 1, 2, 5-10; Ov. am. 1, 6. Der literarische Raum urbs Roma der Tristien und Elegien des Ovids ist diesem Typus verwandt. Der poeta befindet sich allerdings nicht an der Grenze zu diesem Raum und er hat ihn in der Vergangenheit bereits betreten. Innerhalb der Exil-Dichtung betritt der Sprecher ihn allerdings in der Fiktion nicht. Auffällig ist, dass der elegische Sprecher auch in den Beispielen, in denen von Ereignissen aus dem literarischen Raum urbs Roma berichtet wird, auf die Problematik der Wahrnehmung hinweist und die Wahrnehmungsinstanz einer anderen Figur (z. B. fama oder mens) zuschreibt. Vgl. auch Helzle (2002), 256. Er spricht von einer „brückenbildende[n] Kraft“.

804 Vgl. dagegen die Eröffnungselegie Ov. trist. 3, 1, in der ein Römer das Buch als Tourist durch die Stadt führt.

805 Vgl. Ov. trist. 1, 1, 21, 23, 28, 46, 50, 65 f., 88.

806 Vgl. Ov. trist. 1, 1, 13 f.: qui viderit (...), / (...) sentiat, 17: siquis, ut in populo; 18: siquis; 23: lector; 24: populi; 27: invenies aliquem; 31: quisquis erit, 35: culpabere; 37: iudicis officium; 45 f.: index mirabitur (...), / scriptaque (...) qualiacumque leget, 60: populo; 65: siquis erit, 88: plebe; 95: siquis erit, Selbst aus dem eigenen Haus wird kein menschlicher Bewohner explizit benannt, vgl. 105: in nostrum fueris penetrale receptus. Eine Ausnahme stellt bis zu einem gewissen Grad die Figur des princeps dar, deren Aufenthaltsort auch räumlich beschrieben wird: Vgl. Ov. trist. 1, 1, 30: Caesare; 33: principis; 70: Caesareamque domum. 
werden das Buch erkennen und es ansprechen. ${ }^{807}$ Die persona nimmt sogar an, dass das Tristienbuch unmittelbar bei seiner Ankunft als ihr Eigentum erkannt wird:

60

nec te, quod venias magnam peregrinus in urbem,

ignotum populo posse venire puta.

ut titulo careas, ipso noscere colore:

dissimulare velis, te liquet esse meum. ${ }^{808}$

Wenn auch das Buch selbst ein peregrinus, ein Fremdling, sei, verrate dennoch bereits die äußere Farbe - der Trauerflor ${ }^{809}$ - ohne Zweifel dem gesamten Volk seine Herkunft. In der Vorstellung des poeta trifft demnach das Buch als einzelnes innerhalb dieses Makroraumes (magnam urbem, v. 59) ${ }^{810}$ auf eine größere undifferenzierte Gruppe (populus), die das fremde Buch sofort erkennt. ${ }^{811}$ Die Großstadt ist demzufolge als Ganze ein unvermeidlicher Kontaktbereich, der aus zahlreichen Lesern besteht. ${ }^{812}$ Mit dieser räumlichen Darstellung der urbs Roma wird eindrücklich das Selbstverständnis der Dichter-persona demonstriert: Seine Stadt-Bekanntheit ist trotz der Größe der Stadt so groß, dass eine eigene aktive Orientierung für das Buch entbehrlich erscheint, wie auch eine Wegbeschreibung. ${ }^{813}$

Ebenso unpräzise bleibt die Dichter-persona auch bei der weiteren räumlichen Beschreibung, etwa wenn sie ihr Buch auffordert, sich Rom anzusehen:

807 Vgl. Ov. trist. 1, 1, 13: qui viderit illas; v. 18: siquis (...) forte requirat; Ov. trist. 1, 1, 21: quaerenti plura legendum; Ov. trist. 1, 1, 59-62: nec te, quod venias magnam peregrinus in urbem,/ ignotum populo posse venire puta./ ut titulo careas, ipso noscere colore:/ dissimulare nelis, te liquet esse meum; Ov. trist. 1, 1, 93-96: si poteris vacuo tradi, (...)/ (..)/ siquis erit, qui te (...)/ tradat, (...) adi; Ov. trist. 1, 1, 105: cum tamen in nostrum fueris penetrale receptus. Aktives Verhalten wird vom Buch dagegen nur selten explizit vorausgesetzt: Ov. trist. 1, 1, 15: saluta; Ov. trist. 1, 1, 27: invenies aliquem; Ov. trist. 1, 1, 35: ut peragas mandata, liber, culpabere forsan; Ov. trist. 1, 1, 49: ire memento; Ov. trist. 1, 1, 69: forsitan expectes, an in alta Palatia missum.

808 Ov. trist. 1, 1, 59-62.

809 Ov. trist. 1, 1, 6. Dass das personifizierte Buch als trauernder Verwandter gekleidet in die Stadt kommt, erläutert Amann (2006), 50-53.

810 Amann (2006), 69 versteht peregrinus als Provinzler, der - klischeehaft - völlig unwissend über die Zustände in der Großstadt zunächst einmal aufgeklärt wird (nec ... puta, v. 59 f.). Auf der „Produktebene“ könnte es bedeuten, weder Inhalt noch Qualität entsprächen dem eines römischen Buches. Vgl. Mart. praef. 12. In der ersten Tristie wird nachdrücklich betont, dass es sich nicht um hohe Literatur handelt. Vgl. Ov. trist. 1, 1, 35-56.

811 Ähnlich gestaltet schon Ov. trist. 1, 1, 15-17: vade, liber, verbisque meis loca grata saluta:/ contingam certe quo licet illa pede./ siquis, ut in populo, (...).

812 Von Dichterkollegen ist in der ersten Elegie nicht die Rede, erst in späteren Stücken werden diese als willkommene Herausforderer angesehen.

813 Vgl. auch Ov. trist. 1, 1, 23 f.: protinus admonitus repetet mea crimina lector, / et peragar populi publicus ore reus. 
Welche Bereiche konkret gemeint sind, wird nicht genauer benannt, obwohl es unmissverständlich als Privileg des Buches und persönliches Anliegen des poeta formuliert wird, dass das Buch die vertraute und verlorene Großstadt urbs Roma in Augenschein nimmt. ${ }^{815}$

tu tamen i pro me, tu, cui licet, aspice Romam: di facerent, possem nunc meus esse liber. ${ }^{816}$

Der hier ausgesprochene irreale Wunsch, mit dem Buch die Identität tauschen zu wollen, legt offen, wie wichtig der Akt der unmittelbaren Anschaunng für den poeta wäre; was er konkret mit dieser emotionalen und sehr persönlichen Äußerung vor Augen hat, sagt er nicht. Er überlässt es der Imagination des Lesers.

Explizit nennt die Dichter-persona ein ,topographisches Merkzeichen', den Kaiserpalast (Caesareamque domum, v. 70) ${ }^{817}$, der auf einem hohen (alta) Berg liegt ${ }^{818}$, sowie als städtisches ,Teilelement ${ }^{`}$ ihr eigenes Haus (in nostrum ... penetrale, v. 105), dessen Lage nicht beschrieben wird. Die Fixierung auf diese zwei Bereiche zeigt ihre herausgehobene Bedeutung. Eine räumliche Beziehung zwischen ihnen stellt der poeta nicht her. Auch eine Wegbeschreibung bietet er seinem Buch nicht.

Erwogen wird, ob das Buch die Höhe des Palastes ersteigen soll. ${ }^{819}$ Dominant wird an dieser Stelle eine vertikale Raumachse ausgearbeitet, an deren oberen Ende sich der Palast und der Kaiser und an deren unteren sich das Buch befinden wird. Durch eine Vielzahl von Vergleichen - besonders aus dem Mythos - wird diese räumliche Konstellation auf den Verlauf des Schicksals der Dichter-persona übertragen. ${ }^{820}$ Dieser räumlich herausgehobene Ort ist demzufolge aufs engste mit dem Schicksal und mit der vorliegenden Gattungswahl verknüpft. Wird im Folgenden die Offenheit des Kaiserpalastes diskutiert im Sinne der Möglichkeit, diesen als Buch zu betreten, so bedeutet dies auf der einen Ebene die erwägende

814 Ov. trist. 1, 1, 15.

815 Ov. trist. 1, 1, 59: magnam urbem. Vgl. auch Luck (1977), 18.

816 Ov. trist. 1, 1, $57 \mathrm{f}$.

817 Vgl. Ov. trist. 1, 1, 69-104, bes. 95 f.: siquis erit, (...)/ (...) adi. In den Versen wird die Frage behandelt, unter welchen Umständen das Buch den Palast betreten soll.

818 Die räumliche Lage des Kaiserpalastes wird nicht zufällig erwähnt, in ihr spiegelt sich auch die Distanz zwischen Kaiser und der Dichter-persona wider. Vgl. Ov. trist. 1, 1, 71 f.: ignoscant augusta mibi loca dique locorum./ venit in hoc illa fulmen ab arce caput. Es folgen mythologische Vergleiche mit Phaeton (v. 79 f.), Ikarus (v. 89 f.).

819 Vgl. Ov. trist. 1, 1, 69 f.: forsitan expectes, an in alta Palatia missum/ scandere te iubeam Caesareamque domum.

820 Vgl. Ov. trist. 1, 1, 71-74: ignoscant augusta mibi loca dique locorum./ venit in hoc illa fulmen ab arce caput./ esse quidem memini mitissima sedibus illis/ numina; sed timeo qui nocuere deos. 
Erschließung eines weiteren Leseraumes, auf einer anderen Ebene aber auch die Option, die Gattungswahl abzuändern. ${ }^{821}$

Ziel des Romitinerariums ist der Bücherschrank im Stadthaus der Dichter-persona, über dessen räumliche Strukturen das Buch detailliert in Kenntnis gesetzt wird. ${ }^{822}$ Der Bücherschrank des Dichters, der das gesamte CEuvre enthält, befindet sich immer noch innerhalb der urbs Roma und die Beschreibung engster Räumlichkeit, in die das Elegien-Buch aufgenommen wird, weist vor allem auf die Kontinuität dichterischen Schaffens und die Geschlossenheit des Gesamtwerks hin.

\section{Zusammenfassung}

Ginge man nicht von dem historischen Faktum aus, dass der Autor Ovid, der Verfasser der Tristien, eine innige Vertrautheit mit den räumlichen Gegebenheiten der Stadt Rom gehabt haben muss, wie er es auch in anderen Werken beweist ${ }^{823}$, so entstünde in der ersten Elegie der Tristien der Eindruck, der Autor habe keine genaue, um nicht zu sagen eine irrige Vorstellung von der räumlichen Ausdehnung und Menschendichte einer Millionenstadt, geschweige denn von ihrem genaueren topographischen Aussehen. Man könnte annehmen, er wisse lediglich, dass es sich bei Rom wohl um eine große Stadt mit vielen Einwohnern handele und dass in ihr der Kaiser auf dem mons Palatinus wohne. ${ }^{824}$ Der aus Volk, dem Bereich des Kaiserpalastes und eigenem Haus bzw. häuslichem Bücherschrank bestehende literarische Raum hat somit eher römischen, kaum aber großstädtischen Charakter. Keine weiteren topographischen und räumlichen Verhältnisse werden von der Dichter-persona, die ihr Buch auf den Weg nach Rom schickt, angesprochen. Das Nichtbeschreiben des literarischen Raumes entspringt aber doch wohl nicht einer geographischen Unkenntnis des Autors - wie man es für die Landschaft des Exils bisweilen angenommen hat. Es handelt sich um eine poetisierte, literarisch überformte Stadtwahrnehmung, in deren Mittelpunkt die Dichter-persona bzw. ihre Vertretung, das Buch steht. Die weitgehende Abwesenheit räumlicher Beschreibung legt somit das dichterische Selbstverständnis offen. Das Buch agiert nicht aktiv innerhalb der literarische urbs Roma, indem es räumliche Spezifika wahrnimmt, sondern es wird von den dort lebenden Lesern wahrge-

821 Vgl. Ov. trist. 1, 1, 97-100: luce bona dominoque tuo felicior ipso/ pervenias illuc et mala nostra leves./ namque ea vel nemo, vel qui mibi vulnera fecit/ solus Achilleo tollere more potest.

822 Vgl. Ov. trist. 1, 1, 105-122, z. B.: in nostrum penetrale, scrinia curva, aspicies positos ex ordine fratres, palam ostendet, detecta nomina fronte geret, tres procul obscura latitantes parte videbis.

$823 \mathrm{Vgl}$. Ov. ars 1. Diese Beobachtung ist im Hinblick auf diejenigen Urteile wichtig, die aufgrund fehlender Anschaulichkeit die Exilsituation oder - etwa bei Martial - eine Heimkehr des Autors nach Spanien als literarische Fiktionalisierung werten. Fehlende Anschaulichkeit ist kein Fiktionsmerkmal, sondern ein stilistisches Merkmal.

824 Ov. trist. 1, 1, 69 f.: forsitan expectes, an in alta Palatia missum/ scandere te iubeam Caesareamque domum. Der Palatin ist (zusammen mit der domus Caesarea) die einzige topographisch präzise Angabe in der ersten Tristie. 
nommen. Die urbs Roma übernimmt die Funktion desjenigen Ortes, an dem das Buch als Vertreter der Dichter-persona erkannt wird, die weiterhin stadtbekannt ist. Die Abwesenheit räumlicher Beschreibung besitzt für die erste Elegie auch noch in einem weiteren Sinn eine gewisse Folgerichtigkeit. Aufgrund der elegischen Schreibsituation kann sie nicht durch unmittelbare, d. h. direkte Anschauung angestoßen werden. Darstellung und Wahrnehmung der Großstadt sind vollkommen literarisierte, elegische Imaginationen des Sprechers, die der Ergänzung durch die Vorstellungen des Lesers bedürfen. ${ }^{825}$ In diesem Lichte zeigt sich auch die Gestaltung des Raumes: Es ist ein ganz auf die persönliche Dichtung ausgerichteter Raum, dessen Funktion in der Aufnahme durch die Leser und in der Vereinigung mit dem vorhergehenden Cuvre besteht.

Die urbs Roma bleibt als idealer Rezipient, Bezugspunkt des Dichtens und auch als Ort des eigentlichen dichterischen Daseins für den elegischen Sprecher unersetzbar. ${ }^{826}$ Die subjektive Sicht auf die Großstadt als eines allein infrage kommenden Lebens- und Inspirationsraumes und das Verlangen nach den spezifischen Möglichkeiten für das eigene dichterische Schaffen bestimmen die negative Beurteilung der vorliegenden Dichtung von Beginn an wesentlich. Aufgrund der Verbannung des Dichters aus dem stadtrömischen Musenhain kann nur ein in Inhalt und Form defizitärer Trauergesang an den Verlust eines vormals idealen Zustandes erinnern. Das Dichten dient konsequenterweise lediglich der Selbsttröstung und gleichzeitig der Antizipation einer immer wieder erhofften möglichen Rückkehr und Versöhnung. Dieser Paradigmenwechsel, der eine innovative Gattung mit veränderter Themenwahl und Sprechweise begründet, ist einzig dem Verlust der urbs Roma als Lebensmittelpunkt des Dichters geschuldet. Trotz dieser Veränderung, die der Sprecher als eine persönliche Metamorphose ${ }^{827}$ beschreibt, soll die neue Gattung an das frühere Schaffen anschließen, und seine Anerkennung in der urbs Roma weiterhin sichern. Bleibt sie für den Sprecher unzugänglich ${ }^{828}$, ist sie doch weiterhin Garant seiner dichterischen Kontinuität.

\footnotetext{
825 Walde (2005), 155. Vgl. auch Edwards (1996), 129-133.

826 Edwards (1996), 117.

827 Die Metamorphosen sollen um das Schicksal des Sprechers noch erweitert werden, vgl. Ov. trist. $1,1,117-120$.

828 Vgl. den als irreal dargestellten Wunsch in Ov. trist. 1, 1, 58: di facerent, possem nunc meus esse liber.
} 


\subsubsection{Der Einzug der Großstadt urbs Roma in die römische Dichtung}

Laut Corbineau-Hoffmann hält die Großstadt mit den Satiren des Horaz Einzug in die Literatur. ${ }^{829}$ Auch wenn sie dies anhand eines Ausschnitts aus den Episteln demonstriert - die weniger zur Gattung der Satiren als zur philosophischen Diatribe zu rechnen sind -, so ist dieser Einschätzung doch insoweit zuzustimmen, als dass in vielen Satiren und Episteln des Horaz die Wiedergabe räumlicher Merkmale einer Großstadt erstmals und vermehrt in den Blickpunkt der Literatur rückt. Besonders auffallend ist diese hier beginnende andere Qualität der Wiedergabe räumlicher Physis im Vergleich mit den anderen Werken des Horaz, den Oden und Epoden, oder auch mit den carmina Catulls, in denen die urbs Roma zwar verschiedentlich zum ,erzählten Universum' gehört, sie aber selten in ihrer räumlichen Physis veranschaulicht oder gar zum Gegenstand ausführlicher Betrachtung wird.

Auch bei Vergil, dem etwas älteren Zeitgenossen des Horaz, stellt sich der Eindruck ein, als konkreter Raum spiele die urbs Roma in seinem Cuvre eine eher marginale Rolle, ${ }^{830}$ wogegen die klassische Gegenwelt zur Stadt, der ländliche Lebensraum, eine außerordentlich dominante Rolle spielt ${ }^{831}$ : Sein Erstlingswerk, die Eklogen, stellt er in erklärte Nachfolge Theokrits, ,reduziert' sie aber auf rein ländliche Schauplätze. ${ }^{832}$ Die urbs Roma wird zwar erwähnt, die homogene eræählte Welt der vergilischen Bukolik wird jedoch nicht gesprengt. 833

In der Aeneis wiederum scheint die Topographie der urbs Roma im achten Buch durch, jedoch wird sie als futuristische Utopie präsentiert. Aeneas wird von sei-

829 Corbineau-Hoffmann (2003), 7. Diese Einschätzung beruht wohl nicht auf klassisch-philologischen Forschungen. Vgl. z. B. Schäfer (2001), 177: „(...) die römische Dichtung ist - trotz Athens Tragödien- und Komödienschreibern und ihren Philosophen - vielleicht die erste, die sich so stark auf ihre Hauptstadt, sei sie Örtlichkeit oder Idee, bezieht, daß dieser Bezug sie wie ein roter Faden durchläuft, von Plautus bis Rutilius Namatianus, um dann von der nachantiken Romdichtung gesteigert fortgesetzt zu werden." Vgl. Döpp (22003), 37-40 speziell zu Horaz.

830 Vgl. Döpp (2003), 31-36.

831 Das Ländliche wird bei Vergil sehr vielfältig dargestellt. Es finden sich alle drei unterschiedlichen Landschaftszonen: Die zivilisierte, landwirtschaftlich genutzte Landschaft steht im Mittelpunkt der Georgika, die pastorale Landschaft in den Eklogen. Die Wildnis ist bis zu einem gewissen Grad in den Jagdszenen der Aeneis präsent. Vgl. zu allen drei Landschaftszonen in den Eklogen Skoie (2006), 301.

832 Vgl. Schweikle, I.: Art. Ekloge, in: Schweikle (21990), 118. Ebenso wie die Eklogen Theokrits wurden die vergilischen Bucolica als eine spezielle Form literarischer Stadtwahrnehmung interpretiert, da hier eine ausdrücklich zur Stadt konzipierte fiktionale Gegenwelt geboten werde, die aus einem Unbehagen an städtischer Kultur oder gesellschaftlich-politischer Realität entstand. Vgl. Schmidt (1987), 179-196, bes. 188. Coleman (1977), 1. Zu dem Stadt-Land-Gegensatz in den Eklogen Vergils vgl. Skoie (2006), 297-326.

833 Zum Begriff homogene erzählte Welt vgl. Martinez/Scheffel (52003), 127. Zur Einhaltung der Erzählperspektive vgl. quam dicunt statt dicimus und Edwards (1996), 16; Döpp (2003), 31; Skoie (2006), 304 f., 423. Vgl. dagegen die Verweise auf Städte: In Verg. ecl. 9 muss der Name der Stadt (Mantua) umständlich erschlossen werden. Vgl. Schmidt (1987), 191. 
nem Gastgeber Euander über ein arkadisch anmutendes Gelände geführt, welches das spätere Zentrum Roms bilden wird. ${ }^{834}$ Die Ausgestaltung stadtrömischer Topographie ist aus der Entstehungsperspektive und auf aitiologische Aufklärung hin angelegt ${ }^{835}$, explizit werden räumliche Merkmale einer Metropole der augusteischen Gegenwart kaum angedeutet. ${ }^{836}$

Bevor man nun Horaz die Krone des Archegeten römischer Großstadtdichtung aufsetzt, sei daran erinnert, dass er sie womöglich einzig der Überlieferungsgeschichte verdankt. Vorläufer einer literarischen Auseinandersetzung mit dem Makroraum ,Stadt' finden sich bereits in hellenistischer Dichtung, in welchem Umfang, könnte eine genauere Untersuchung zeigen. Indiz für eine entsprechende literarische Rezeption ist, dass in den Satiren des Horaz wiederholt auf griechische und stadtrömische Traditionen verwiesen wird, in der die Dichtung verstanden sein will. ${ }^{837}$ Der hier sprechende poeta sieht sich des Weiteren in der Nachfolge des römischen Satirendichters Lucilius, der - wie der Sprecher zu berichten weiß bekanntermaßen Roms Bürger in seinen Dichtungen heftig attackierte. ${ }^{838}$ Aus dem heutigen fragmentarischen Zustand der Satiren des Lucilius lässt sich nur ein unscharfes Bild gewinnen, wie ausführlich er auch raumspezifische Merkmale der

834 Vgl. Edwards (1996), 14, $31 \mathrm{f}$.

835 Döpp (2003), 35 und 47. Es ist auffällig, dass im gesamten Werk von Vergil, und ebenfalls in den Elegien des Properz und Tibull, ausführlicher auf die Physis der urbs Roma in ihren Anfängen eingegangen wird, kaum aber auf räumliche Merkmale der großstädtischen Gegenwart. In den Liebeselegien Tibulls, Properz' oder Ovids wird ein städtisches Umfeld stets vorausgesetzt, jedoch vergleichsweise selten räumlich ausgestaltet. Dies liegt auch am Gegenstand erotischelegischer Dichtungen, da als Bereiche vor allem Innenräume im Mittelpunkt stehen, auf die durch implizite Referenzen (Tür, Türpfosten, Schwelle) oder intentionale Zustände (Liegen) angespielt wird.

836 Es gibt Überlegungen dazu, ob sich die als im Aufbau befindlich dargestellte Stadt Karthago im Buch I typologisch auf die urbs Roma beziehen soll. Das Modell der Typologie wird in der VergilPhilologie allerdings bisher ausschließlich auf Figuren angewendet. Vgl. Suerbaum (1999), $334 \mathrm{f}$. Klodt (2001), 21 interpretiert allerdings die casa Euandri als ideellen Vorgängerbau der domus $A u$ gusti. Womöglich gelänge es daher auch, eine Typologie der beiden Städte zu plausibilisieren: Reeds (2007) Meinung nach bilden Rom und Karthago keine Oppositionen, sondern zwischen Troja und Karthago ist in der Aeneis eine deutliche Assimilation zu beobachten, die sich wiederum damit beide auf Rom beziehen (ebd., 131). Ebenfalls ist nach Meinung Richard Miles (ders., Rivalling Rome: Carthage, in: Edwards/Woolf (2003), 127-131) die Erinnerung an die punischen Kriege und ihre Bedeutung für die Größe Roms im ,kulturellen Gedächtnis` der Römer omnipräsent. Vgl. bes. zur augusteischen Literatur allgemein (ebd., 129) und zur Bedeutung Vergils Aeneis (ebd., Anm. 25).

837 Inwieweit römische Autoren auf überkommene Muster zurückgriffen, ist nicht mehr rekonstruierbar. Die Affinität dieser Literaturepoche zu den Dichtungen der hellenistischen Epoche legen Übernahmen nahe. Schmidt (1995) wehrt jedoch eine verabsolutierende Annahme ab, römische Autoren seien reine Philologen gewesen, die „ohne etwas zu wollen und zu sagen, aus früherer Literatur wieder Literatur gemacht“ hätten. Vgl. ebd., 103.

838 Vgl. Hor. sat. 1, 10, 3 f.: quod sale multo/ urbem defricuit, charta laudatur eadem. Vgl. auch Hor. sat. 2, 1, 62-70 und Pers. 1, 114 f.: secuit Lucilius urbem, / te Lupe, te Muci, et genuinum fregit in illis. 
urbs Roma in seine Darstellungen eingebunden hat. ${ }^{839}$ Durch einige Fragmente und auch Bezugnahmen späterer Satiriker wie Horaz und Persius lässt sich allerdings mutmaßen, dass es Lucilius nicht nur um aktuelle Tagespolitik und den gesellschaftlichen Kontext von Literatur ging. 840

Verloren sind auch die Satiren des römischen Schriftstellers Varro. Aus den überlieferten Titeln sticht besonders eine mit dem hybriden ${ }^{841}$ Titel Marcopolis hervor. Ein Fragment gibt zu erkennen, dass hier Eingangstore, Wasserleitungen und Kloaken der Stadt metaphorisch mit dem menschlichen Organismus gleichgesetzt wurden. ${ }^{842}$ Varro vergleicht demzufolge „die von Menschen geplante Struktur einer Stadt mit dem natürlich entwickelten Organismus des menschlichen Körpers." "843

Auch die Komödien des Plautus und Terenz spielen überwiegend in einem städtischen Kontext. Diese Komödien sind aber explizit im griechischen Zivilisationsraum verankert. Als direkter Schauplatz dient in der Regel ein recht unspezifischer StraBenabschnitt einer griechischen Stadt, der als unmittelbare Lebensumgebung der Protagonisten präsentiert wird. ${ }^{844} \mathrm{Im}$ Zentrum der Auseinandersetzung steht nicht eine räumliche Physis, sondern der Schauplatz bildet den szenischen Hintergrund anderer dominant verhandelter Themen. Die räumlichen Strukturen wie auch die hinterszenisch angedeuteten städtischen Bereiche Markt und Hafen scheinen damit ähnlich der „Charakterisierung der Personen (...) im Typischen [zu] verharren“. 845

839 Schäfer (2001), 178: „Noch die Splitter seines zertrümmerten Werks haben als Fluchtpunkt Rom.“ Vgl. zur Stadtwahrnehmung bei Lucilius Schäfer (2001), 178: „Stadtansichten, die der Zufall erhalten hat, sie sollen (...), zu einem Rundgang durch Rom zusammengesetzt werden. Es fehlt dabei alles, was keinen Ortsbezug andeutet, auch wenn es wahrscheinlich in Rom spielt, also das allermeiste."

840 Vgl. Fantham (1998), 48; Schäfer (2001), 177 f.

841 Vgl. Fantham (1998), 48.

842 Krenkel (2002), Bd. 2, 287-520, bes. 515 zu Varro Men. 288-291. Vgl. bes. Varro Men. Frg. 290: sensus portae; venae bydragogiae; clavaca intestini; „Die Sinne sind die Eingangstore, die Adern die Wasserleitungen, die Kloaken die Eingeweide." Laut Livius (Liv. 2, 32, 9-12) stammt dieser Vergleich aus einer Rede des Menenius Agrippa anlässlich des Generalstreiks der Plebejer im Jahre 494 v. Chr.

843 Krenkel (2002), Bd. 2, 515.

844 Zum Aufbau einer römischen scaena zur Zeit des Plautus und Terenz vgl. Rosivach (1970) und Johnston (1933). Ausnahmen in der Wahl des Schauplatzes stellen dar: Ter. Haut., das an einer Landstraße spielt, und Plaut. Rud., das an der Küste spielt. Vgl. Barsby (1999), 11.

845 v. Albrecht (21997), Bd. 1, 147. Vgl. Blänsdorf (1978), 190: „Der bequemste Grund, eine Person vorübergehend von der Bühne zu entfernen, ist ein Gang zum Markt, Gericht oder Hafen. Hier werden die Fäden der Dramaturgie am offensten gezogen." Weitere Merkmale einer kleineren Siedlung sind: fehlende Varianz der Bausubstanz (vgl. dagegen Plaut. Ep. 197-200: per omnem urbem quem sum defessus quaerere:/ per medicinas, per tostrinas, in gymnasio atque in foro,/ per myropolia et lanienas circumque argentarias./ rogitando sum raucus factus, paene in cursu concidi). Man geht zu einem zentralen Forum, wo sich alles besorgen lässt (vgl. Johnston (1933), 131-133, bes. 133: „The forum is apparently just around the corner."), die Bewohner kennen sich. Der lexikalische Befund von der Gattungsbezeichnung urbs in der römischen Komödie zeigt m. E. keine erkennbaren 
Eine lebendigere Raumwiedergabe enthalten allerdings einige Figurenberichte, wenn etwa von einer erschöpfenden Suche nach einer Person in einer vielfältigen Stadtlandschaft berichtet oder einem Protagonisten zur Orientierung eine Wegbeschreibung an die Hand gegeben wird. ${ }^{846}$ In den plautinischen Komödien finden sich für die Illusionsbildung der Zuschauer recht überraschend auch direkte Bezugnahmen auf die Großstadt Rom. ${ }^{847}$

Aufgrund der Überlieferungslage ist Horaz aus heutiger Perspektive derjenige römische Dichter, der als erster in seinem dichterischen Werk auf die literarische urbs Roma in größerem Umfang durch entsprechende Kernwörter referiert hat. Besonders in seinen Satiren und den poetischen Episteln sind vielfach Referenzen auf städtische Teilelemente enthalten. Innerhalb anerkannt programmatisch-poetologischer Passagen, etwa den Satiren I 4, I 10 und II 1, lassen sich aber noch keinerlei explizite Aussagen über eine Wechselbeziehung zwischen der urbs Roma und Dichtung finden. Wohl gehen aber Überlegungen zur Themenwahl der Satiren, zur intendierten Leserschaft sowie zu Berührungspunkten mit Dichterkollegen von städtischen Aufführungsbedingungen für die Literatur aus.

\subsubsection{Ein programmatischer Antiurbanismus inmitten der literarischen Großstadt. Großstadt und Dichtung (Hor. sat. 1, 4)}

In der Satire 1, 4 äußert sich eine Dichter-persona zum ersten Mal innerhalb der Satirensammlung zu Fragen der Gattung: Die Gattung Satire, wie sie Lucilius ein-

Abstufungen in qualitativer und quantitativer Hinsicht einer städtischen Siedlung. Griechische Siedlungen verschiedener Größe usw. werden als urbs bezeichnet, stets als räumlicher Gegensatz zu rus. Gleich zu Beginn der plautinischen Mostellaria findet sich etwa der berühmte Schlagabtausch zwischen einem Land- und Stadtsklaven (Plaut. Most. 1-83), bei dem im Lichte ihres Standes das harte Landleben dem leichtlebigen Stadtleben entgegengestellt wird. Diese Semantisierungen gehen auf schematisierte Gegensätze von Stadt und Land zurück, vgl. Schmude (1988), 46-55 und 192-233, und dienen vor allem der Charakterzeichnung des städtischen Sklaven Tranio.

846 Vgl. Plaut. Ep. 195-200; 719 f.; Ter. Ad. 571-585. Tendenziell handelt es sich dabei um Ausnahmen. Für die räumliche Darstellung in den Komödien ist vor allem die Figur des servus currens interessant, die dazu dient, Ereignisse aus einiger Entfernung zu überbringen. Diese Rolle ist von vornherein als Parodie angelegt, da der servus stets „seine Neuigkeiten atemlos (...) vorstößt", Blänsdorf (1978), 190. Eine nähere Untersuchung der Raumgestaltung in den Figurenberichten liegt meines Wissens nicht vor. Sie könnte jedoch für größere Klarheit in der Raumgestaltung in der Komödie sorgen und womöglich auch Unterschiede in der Raumgestaltung bei Plautus und Terenz herausarbeiten. So äußert sich Plautus bereits in den Prologen zur Wahl des jeweiligen Schauplatzes, in Plaut. Men. 258-264 dient der Städtename als Charakterisierung der Bewohner, in Plaut. Pers. 549-560 wird eine virgo über ihren ersten Eindruck von der urbs Athenae befragt.

847 Plaut. Cur. 268 f.: siquidem incubare uelint qui peïurauerint, / locu' non praeberi potis est in Capitolio. Plaut. Trin. 83-85: nam nunc ego si te surrupuisse suspicer/ Ioui coronam de capite ex Capitolio, / quod in columine astat summo. Plaut. Capt. 88-90: et hic quidem hercle, nisi qui colaphos perpeti/ potes parasitus frangique aulas in caput, / vel ire extra portam Trigeminam ad saccum licet.; ebd., 489: omnes $<d e>$ compecto rem agunt, quasi in Velabro olearii. 
führte, folge in Inhalt und Qualität dem Vorbild der Alten Komödie. ${ }^{848}$ Entsprechend diesem Verständnis sind die Satiren dem Ursprung nach zwar nicht echt römisch, aber ein spezifisches Genre, um städtisches (wenn auch nicht explizit großstädtisches) Leben darzustellen. ${ }^{849}$ Seine eigenen Satiren unterschieden sich allerdings von denen seines Vorgängers Lucilius ${ }^{850}$, so der poeta, wie auch von denen zeitgenössischer Dichterkollegen. Anstelle von Versen, die aus dem Stegreif nur so hervorströmen, schreibe er wenig und selten und verfasse daher Satiren auf hohem handwerklichem und geistigem Niveau. Den Vergleich zwischen sich und den Kollegen führt die Dichter-persona noch weiter:

cur metuas me?

nulla taberna meos habeat neque pila libellos, quis manus insudet volgi Hermogenisque Tigelli, nec recito cuiquam nisi amicis idque coactus, non ubivis coramve quibuslibet. in medio qui

75 scripta foro recitent, sunt multi quique lavantes: suave locus voci resonat conclusus. Inanis

boc iuvat, hand illud quaerentis, num sine sensu, tempore num faciant alieno. ${ }^{851}$

Ihre Satiren lägen nicht als Massenware in Buchläden. Sie trage ihre Satiren auch nicht in hellhörigen Bädern oder auf dem Forum vor, sie erreichten demzufolge weder eine breite Leser-, noch Zubörerschaft.

Die Satire 1, 4 ist - ähnlich wie die erste Satire Juvenals - zunächst eine programmatische Schrift über zeitgenössisches Dichter- und Rezeptionsverhalten, von dem man eigenes Dichten absetzt und sich als Dichter zu emanzipieren sucht. ${ }^{852}$

848 Vgl. Hor. sat. 1, 4, 1-5: Eupolis atque Cratinus Aristophanesque poetael atque alii, quorum comoedia prisca virorum est,/ siquis erat dignus describi, quod malus ac fur,/ quod moechus foret aut sicarius aut alioquil famosus, multa cum libertate notabant.

849 Das Herleiten der Satire aus einer griechischen Gattung kann auch einer allgemeinen Mode der Zeit folgen. An dieser Stelle soll es in keinem Fall als Kritik an mangelnder Originalität, sondern als ein Kompliment an Lucilius verstanden werden. Vgl. Hor. sat. 1, 10, 17 und Kießling/Heinze (1959), 70. Zur Alten Komödie (des Aristophanes) als städtische Gattung vgl. Nesselrath (1999), 694 f. Zur Darstellung Athens in den Komödien des Aristophanes vgl. Barner (22003). Dagegen Quint. inst. 10, 1, 93: satura quidem tota nostra est. Diese Behauptung beansprucht eine römische Überlegenheit und vielleicht römische Urheberschaft der Gattung. Vgl. Braund (2001), 102.

850 Vgl. Hor. sat. 1, 4; 1, 10; 2, 1. Lucilius' Dichtung wird in stilistischer (Hor. sat. 1, 10, 20-23) und produktionsästhetischer (Hor. sat. 1, 10, 50-71) Hinsicht kritisiert. In der Traditionslinie der Satiren des Lucilius sieht sich auch Iuv. 1, 19 f. und Pers. 1, $114 \mathrm{f}$.

851 Hor. sat. 1, 4, 70-78.

852 Vgl. Kießling/Heinze (1959), 76 weisen darauf hin, dass das Schmähgedicht aufgrund seiner Verbreitungsmöglichkeiten wohl bereits durch die XII-Tafel-Gesetze verboten worden sei, während die Invektive in Prosa erst durch Augustus im Jahre $12 \mathrm{n}$. Chr. versagt wurde. In der ersten Satire des Persius äußert sich der Sprecher nur in den Rahmenpartien zu seiner dichterischen 
Dennoch setzt dieser Vergleich einen großstädtischen Raum und die dort herrschenden Bedingungen als Kontrastfolie, von der man sich abheben kann, voraus. Für die Frage nach der Funktion, die der Großstadt in programmatischen Texten des Horaz zukommt, ist daher festzuhalten: In einem ausgesprochen exklusiven Habitus meidet diese Dichter-persona größere Auftritte und sucht sich eine überschaubare kleine Zuhörerschaft, amici (v. 73). ${ }^{853} \mathrm{Ihr}$ Unterscheidungsmerkmal von anderen ist, dass sie sich den großstädtischen Verhältnissen gerade entzieht: Sie strebt nicht nach einer breiten Leserschaft; sie ist nicht auf Rezitationen an den zentralen Kommunikationsorten großstädtischer Literatur aus. Diese expliziten Abgrenzungen werfen ein Schlaglicht auf den städtischen Literaturbetrieb, wie er nach Aussage des satirischen Sprechers üblicherweise funktioniert, und betrachten eine vielfältige großstädtische Infrastruktur (Buchhandel, viele Dichterkollegen, Forum, Bäder) als gegeben. Eine städtische Umgebung ist für diese Dichterpersona demzufolge eine Vorbedingung für ihre, unstädtische' Pose.

Dass sie die Großstadt nicht explizit als Ausgangspunkt ihrer Dichtung, und als Inspirationsraum in Form von großstädtischem Publikum, Stoff für eigene Dichtung oder Austausch mit anderen Dichtern ${ }^{854}$ bezeichnet, ist in diesem Lichte nur konsequent. Gleichzeitig imaginiert sie aber auch keinen anderen Ort, der explizit außerhalb der literarischen urbs Roma liegt. ${ }^{855}$ Schauplatz bleibt die literarische urbs Roma. ${ }^{856}$ Die Bedingungen, die er dieser Dichter-persona bietet, sind die, sich als dichterisches Individuum abzugrenzen.

Motivation und kritisiert ebenfalls den in Rom ansässigen Literaturbetrieb (vgl. Kißel (1990), 101-105). Unter den Römern gebe es keine nennenswerten Menschen, auf deren Geschmack man irgendetwas geben könnte. Vgl. Pers. 1, 8-12 und Kißel (1990), 121.

853 In der letzten Satire des ersten Buches, die auch als programmatisch gilt, zählt der DichterSprecher in den letzten Versen die intendierten Leser namentlich (!) auf. Vgl. Hor. sat. 1, 10, 81 90. Außer der Wertschätzung seiner Freunde durch persönliche Nennung führt diese Engführung der Leser zu großer Exklusivität. Sicher nicht ohne Grund stehen diese Verse am Ende des ersten Satirenbuches, die eher Repräsentanten einer Leserschaft darstellen sollen.

854 Die Großstadt ist unbestreitbar für den Autor Horaz Anregungsraum der Satiren. Es wird allerdings an keiner Stelle explizit formuliert. In Hor. sat. 1, 4 heißt es lediglich turba (quemvis media elige turba, Hor. sat. 1, 4, 25), in Hor. sat. 1, 10 heißt es nur über den Vorgänger Lucilius: quod sale multo/ urbem defricuit, charta laudatur eadem., Hor. sat. 1, 10, 3 f. Vgl. auch Hor. sat. 2, 1, 62-70. In der Interpretation schwer zu fassen, ist die in Hor. sat. 2, 6, 16 f. formulierte Frage nach dem Gegenstand der Satiren auf dem Lande: ergo ubi me in montes et in arcem ex urbe removi, q quid prius inlustrem saturis musaque pedestri? Der Fortgang dieser Satire - es folgt ein carmen auf die urbs Roma - legt nahe, dass womöglich auf dem Lande passende Themen für eine Satire nicht zu finden sind.

855 Vgl. dagegen über die Dichterlandschaft in den Oden des Horaz grundlegend Troxler-Keller (1964).

856 In dieser Satire Hor. 1, 4 findet sich die Gattungsbezeichnung urbs (v. 98), allerdings nicht das Toponym Roma. In einer Apostrophe wird das Ethnikon Romanus (v. 85) verwendet. 
4.2.3.2 Das Wogen der Großstadt. Ausreden eines Musensohnes (Hor. epist. 2, 2) - Die Großstadt und der Dichter I

Inwieweit die Großstadt ein anregender oder hemmender Inspirationsraum zum dichterischen Schaffen ist, wird innerhalb programmatischer Stellungnahmen in den Satiren und Episteln des Horaz nicht besprochen. In verstreuten Passagen gerade dieser beiden Werke finden sich jedoch Aussagen über Voraussetzungen dichterischer Arbeit, die an eine konkrete Stadtraumerfahrung einer als Dichter vorgestellten persona geknüpft sind. Die Gegensätzlichkeit dieser Erfahrungen und die damit verbundenen, unterschiedlichen Zuschreibungen an das Großstadtleben zeigen ein äußerst facettenreiches und mehrstimmiges Bild der literarischen Auseinandersetzung zwischen Dichter und Großstadt im CEuvre des Horaz.

Ein prominentes Beispiel findet sich in einem Brief an Florus (epist. 2, 2) ${ }^{857}$ In diesem stellt der Absender in Abrede, seinem Freund einen Brief schuldig geblieben zu sein. Er habe bereits bei dessen Abreise angekündigt, dass er aufgrund seiner Faulheit nicht schreiben werde:

20 dixi me pigrum proficiscenti tibi, dixi

talibus officiis prope mancum, ne mea saevus

iurgares ad te quod epistula nulla rediret. 858

Ebenso vergeblich wie auf einen Brief habe Florus auf die Zusendung von Gedichten (carmina, v. 25) gewartet. Auch diese, so lässt der Absender wissen, schreibe er nun nicht mehr. Hierfür bringt er eine Reihe von Gründen bei: Angesichts seiner guten finanziellen Lage sehe er es für verrückt an zu dichten statt zu schlafen; 859 er sei nun älter geworden und zusammen mit anderen Vergnügungen der Jugend ${ }^{860}$ sei ihm die eigene dichterische Gewandtheit verloren gegangen. ${ }^{861} \mathrm{Er}$ habe Schwierigkeiten, den verschiedenen Geschmacksrichtungen seiner Rezipienten gerecht zu werden. ${ }^{862}$ Und zudem ließen die Lebensbedingungen in der urbs Roma in keiner Weise ein konzentriertes Arbeiten zu. ${ }^{863}$

Der Argumentationsverlauf legt offen, dass der Adressat den Rechtfertigungsversuch nicht allzu ernst nehmen soll, handelt es sich doch offensichtlich um Aus-

857 Zur Person des Florus vgl. Kießling/Heinze (1959), 244. Zur Gesamtinterpretation des Briefes vgl. Kilpatrick (1990), 15-31.

858 Hor. epist. 2, 2, 20-22.

859 Hor. epist. 2, 2, 26-54.

860 Vgl. Kilpatrick (1990), 19.

861 Hor. epist. 2, 2, 55-57, bes. 57: [anni] tendunt extorquere poemata.

862 Hor. epist. 2, 2, 58-64.

863 Hor. epist. 2, 2, 65-86. 
reden einer wenig ambitionierten Dichter-persona.864 Somit kommt auch dem im Folgenden dargebotenen Hinweis auf die Lebensumstände in der urbs Roma von vornherein nicht die Kraft eines durchschlagenden Argumentes zu, sondern er dient als weitere Stufe einer selbstironischen Stilisierung. ${ }^{865}$ Im Lichte dieser Absicht will die Dichter-persona den literarischen Raum als Ort mangelnden Freiraums und als offensichtliches Hindernis für dichterisches Arbeiten verstanden wissen. In knapp zwanzig Versen skizziert der Schreiber daher sein Leben in der Stadt in sehr lebendiger Anschaulichkeit:866

praeter cetera me Romaene poemata censes

scribere posse inter tot curas totque labores?

bic sponsum vocat, bic auditum scripta relictis

omnibus officiis; cubat bic in colle Quirini,

bic extremo in Aventino, visendus uterque;

70

intervalla vides humane commoda. ${ }^{867}$

Mit dem einleitend als rhetorische Frage gestellten Hinweis auf eine Überfülle 868 an Sorgen und Anstrengungen städtischen Lebens weist der Schreiber von vornherein die Möglichkeit, in der Stadt dichten zu können, als absurd zurück. Rom und anspruchsvolles Dichten ${ }^{869}$ - im Vers in Juxtaposition zueinander gestellt (Romaene poemata, v. 65) - schließen sich für den Absender gänzlich aus. Das Toponym Roma ${ }^{870}$ benennt den konkreten Aufenthaltsraum des Schreibers, den Schauplatz. Eine präzisere Bestimmung - wie etwa ein Wohnraum, eine Bibliothek oder eine Gartenbank, wo er seinen Brief verfasst - wird während der gesamten Epistel nicht genannt.871 Diese Raumkonstellation entspricht aber ganz dem

864 Zu den Lebensbedingungen in der Großstadt als konventionelle Ausrede vgl. Mart. praef. 12, Z.

2-4: quo absolvenda non esset inter illas quoque urbicas occupationes, quibus facilius consequimur ut molesti potius quam ut officiosi esse videamur.

865 Vgl. Kießling/Heinze (1959), 243; Becker (1963), 54, Kilpatrick (1990), 15.

866 Vgl. Kilpatrick (1990), 20: „In this section Horace makes skilful use of vivid evidentia (anticipating the later practice of Juvenal) to impress the , court' with the obstacles to composing poetry in town."

867 Hor. epist. 2, 2, 65-70.

868 Das wiederholte tot (Hor. epist. 2, 2, 66) verstärkt den schon beinahe an ein Hendiadyoin erinnernden Ausdruck curas (...)-que labores.

869 Vgl. zu poemata (...) scribere Kießling/Heinze (1959), 253. Diese Formulierung weist auf den speziellen Wunsch des Florus nach lyrischer Dichtung.

870 Hor. epist. 2, 2, 65.

871 Vgl. Hor. epist. 2, 2, 20-22: dixi me pigrum proficiscenti tibi, dixi/ talibus officiis prope mancum, ne mea saevus/ iurgares ad te quod epistula nulla rediret. Die allgemeine Information, dass der Schreiber in der literarischen urbs Roma nicht dichten kann, wird zwar in einigen Abständen wiederholt. Vgl. Hor. epist. 2, 2, 79 f.: tu me inter strepitus nocturnos atque diurnos/ vis canere et contracta sequi vestigia vatum?, allerdings erst recht spät direkt mithilfe des deiktischen bic eindeutig zum Sprecher in Beziehung 
Anliegen des Briefes: Da sich die Dichter-persona mitten in der literarischen urbs Roma aufhalte ${ }^{872}$ - und nicht an irgendeinem Rückzugsort -, kann sie eben keine Gedichte schreiben.

Das Leben in der Stadt besteht für sie aus einer Reihe ${ }^{873}$ von unaufschiebbaren Verpflichtungen gegenüber anderen, die seine Achtsamkeit und Kraftaufwand (curas ... labores, v. 66) fordern. ${ }^{874}$ Die unzählbaren Verpflichtungen (tot, v. 66) Bürgschaft vor Gericht, Besuch einer Rezitation, Besuch kranker Freunde - werden in Form einer Kollage zum Teil über akustische Sinnlichkeit (vocat, ... auditum, v. 67), zum Teil über visuelle (cubat .../ visendus, v. 68 f.) kumulativ präsentiert. Sie bestimmen über die ihm zur Verfügung stehende Zeit, sind für ihn weder vorhersagbar, noch planbar, vielmehr ist er gezwungen, anderes stehen und liegen zu lassen (relictis/ omnibus officiis, v. 67 f.). Diese vielfältige Beanspruchung ist ein dauerhaftes Charakteristikum dieses literarischen Raumes, das die zur Verfügung stehende Zeit der Dichter-persona - vergleichbar mit der Beanspruchung durch Rezitatoren in Juvenals erster Satire - voll ausschöpft.

Innerhalb von drei Versen (v. 67-69) weisen jeweils vier Deiktika auf Personen in disparaten Bereichen innerhalb des literarischen Raumes. Die viermalige Anapher mit einer kurzphrasigen Erläuterung lässt den Eindruck entstehen, dass es sich bei den Ereignissen an verschiedenen Orten um jeweils wahllos herausgegriffene Beispiele handele, von denen es eine beliebig große Anzahl innerhalb der urbs Roma gäbe. Dass zwischen diesen Bereichen erhebliche Entfernungen zu überwinden sind, wird bei den letzten beiden konkret formuliert:

cubat bic in colle Quirini,

bic extremo in Aventino, visendus uterque;

70

intervalla vides humane commoda. ${ }^{875}$

gesetzt. Vgl. Hor. epist. 2, 2, 84 f.: bic ego rerum/ fluctibus in mediis et tempestatibus urbis/ verba lyrae motura sonum conectere digner? Zum Schauplatz: vgl. Hor. epist. 2, 2, 84-86.

872 Vgl. Hor. epist. 2, 2, 66: inter tot curas totque labores?; 79: inter strepitus nocturnos atque diurnos; 85: fluctibus in mediis et tempestatibus urbis. Vgl. auch die zeitliche Präsentation der Ereignisse: In derjenigen Passage, die die Beschreibung des literarischen Raumes betrifft, nähert sich das erzählende Ich (Erzähler) einem erlebenden Ich (Wahrnehmungsinstanz) bis zur Identifikation an. Für den Briefstil unüblich wird das präsentische Erzähltempus gewählt. Laut Martinez/Scheffel (52003), 69-75 könnte man hier vom Typ des „eingeschobenen“ Erzählers sprechen. Vgl. diess., 73 f. „Der Erzähler unterbricht wiederholt sein Schreiben und wird zur handelnden Figur, und als Schreibender hat er eine so geringe Distanz zu seinem Erleben, daß er noch ganz unmittelbar von ihm gekennzeichnet ist.“ Trotz der Unmittelbarkeit der Raumwiedergabe sollen jedoch nicht einmalige, sondern sich wiederholende, alltägliche Ereignisse präsentiert werden, im Sinne einer iterativen Erzählung (Vgl. Martinez/Scheffel (52003), 46 f.) gewählt.

873 Vgl. das anaphorisch wiederkehrende hic, Hor. epist. 2, 2, 67-69.

874 Vgl. Kießling/Heinze (1959), 254.

875 Hor. sat. 2, 2, 68-70. 
Metonymisch wird auf zwei Privathäuser über den intentionalen Zustand des Liegens (cubat, v. 68) referiert, die sich laut der Positionierung innerhalb des jeweils weiträumigen Bereichs eines Hügels (in colle Quirini, v. 68; in Aventino, v. 69) befinden, von denen der zweite sogar in verschiedene Zonen (extremo, v. 69) unterteilt wird. Diese Präsentation dient vor allem dazu, die Disparatheit der beiden Bereiche herauszustellen. ${ }^{876}$ Zwischen den beiden Bereichen sind erhebliche Wegstrecken zurückzulegen (intervalla ... bumane commoda, v. 70), ${ }^{877}$ wie selbst der Adressat aus eigener Anschauung weiß (vides, v. 70). Weit ist diese Entfernung innerbalb des literarischen Raums in fiktionaler Sicht. Innerhalb der literarischen Kommunikation meint der poeta, mit der Zustimmung des Adressaten rechnen zu dürfen. ${ }^{878}$ Die Wegstrecke ist vom Sprecher notwendigerweise zurückzulegen (visendus uterque, v. 69). Der Schreiber macht damit seinem Freund deutlich, dass wichtige Tätigkeiten seines täglichen Lebens in einiger Entfernung zueinander liegen.

Das städtische Leben - so kann man die Auskunft des Schreibers vielleicht generalisieren - lässt wenig persönlichen Freiraum und führt zu einem beständigen Alltagsstress, da man von anderen in Anspruch genommen wird, die jeweils an ihren Aufenthaltsorten aufzusuchen sind. ${ }^{879} \mathrm{Im}$ Anschluss an diese ersten Ausführungen zum Leben eines Dichters in der Stadt formuliert der Schreiber einen denkbaren Einspruch des Adressaten. Der Empfänger meint, man sollte die Zeit auf den zurückzulegenden Wegen nutzen und seinen Gedanken nachhängen, seien doch die breiten Straßen der literarischen urbs Roma leer: ,verum/ purae sunt plateae, nibil ut meditantibus obstet' (v. 70 f.). Diese Möglichkeit wird gemäß dem gewünschten Argumentationsverlauf selbstredend zurückgewiesen und dem Adressaten eine beispielhafte Straßenszene vor Augen geführt.

876 Durch die Verwendung des deiktischen Referenzsystems (extremo, v. 69) wird der Bereich auf dem Aventin standortabhängig vom Quirinal aus lokalisiert, nicht vom Standpunkt des Schreibers aus.

877 Zum Verständnis der Formulierung bumane commoda als Ironie vgl. Brink (1982), 304 f. Er emendiert hier nach Froehlich zu baud sane commoda. Ebenso entscheiden Rudd (1989), 131 und Fedeli (1997), 1412 f. Zur Diskussion vgl. auch Kilpatrick (1990), 98 f. Kießling/Heinze (1959), 254 kommentieren dagegen: „Der Sinn von humane commoda ist sonnenklar: mit beißender Ironie werden diese unmenschlich übermäßigen Entfernungen als ,menschlich angemessen' bezeichnet." Humane verstehen sie als umgangssprachliche Steigerung zum synonymen commodus. In der Formulierung intervalla vides bumane commoda kann intervalla sowohl zeitlich (Kilpatrick (1990), 19: „all with no time between“) als auch räumlich (vgl. Kießling/Heinze (1959), 254: ,„̈̈bermäßige Entfernung") aufgefasst werden.

878 Die Dichter-persona nennt den Quirinal und den Aventin als topographische Koordinaten. Diese Hügel und auch Wohngebiete liegen im Norden und Südwesten der Stadt. Auf einer modernen Stadtkarte Roms liegen sie sich gegenüber und sind durch das Zentrum der Metropole getrennt Vgl. Kilpatrick (1990), 98, Anm. 34. Will man demnach von einem zum anderen gelangen, muss man durch die Innenstadt hindurch und einen Fußmarsch von weniger als $3 \mathrm{~km}$ in Kauf nehmen. Vgl. Kießling/Heinze (1959), 255. Bei der geringen Entfernung von $3 \mathrm{~km}$ ist die Formulierung bumane commoda wohl zweifach ironisch gemeint.

879 Zum Kreis derjenigen, die die Dichter-persona in Anspruch nehmen, gehört letztlich auch der angeredete Florus. 
festinat calidus mulis gerulisque redemptor,

torquet nunc lapidem, nunc ingens machina tignum,

tristia robustis luctantur funera plaustris,

75 hac rabiosa fugit canis, hac lutulenta ruit sus:

i nunc et versus tecum meditare canoros. 880

Nach der Beschreibung der Dichter-persona ist die Straße - für die hier jede Referenz einer näheren Lokalisierung fehlt - kein architektonisch begrenæter Raum, sondern ein städtischer Bereich, in dem sich kumulativ wechselnde Gruppierungen in dichter Abfolge unablässig bewegen. ${ }^{881}$ Attestiert wird ihr eine hohe räumliche Dichte. Hier kommt es zu Begegnungen (nunc, v. 73; hac, v. 75) mit namenlosen, im weitesten Sinne aggressiven Menschengruppen und Tieren (calidus, luctantur, rabiosa), die in sehr schnellem Tempo unterwegs sind (festinat, fugit, ruit), zu denen aber kein Kontakt hergestellt wird. Der schnelle und plötzliche Wechsel der auf ihn eindringenden Sinneseindrücke, der wiederholtes sowie längeres Betrachten ausschließt, lässt sich durch das beispielhafte Voranschreiten einer Wahrnehmungsinstanz ( $i$, v. 76) und die simultanen Bewegungen der anderen mobilen Objekte im Raum erklären. Die Eigenbewegung sowie die Geschwindigkeit der anderen bestimmt den subjektiven Raumeindruck: Die Straße bietet das Bild einer vielgestaltigen Geschäftigkeit und verlangt durch schnelle Szenenwechsel ihren Passanten eine erhöhte Aufmerksamkeit ab. Als Anregungen für eigene Dichtungen nimmt die Dichter-persona dies aber nicht - wie in der ersten Satire die Dichterpersona Juvenals - auf.

Von diesem räumlichen Umfeld, den Menschen und Tieren und technischen Attraktionen, wird eine Vielzahl visueller Eindrücke (ingens, v. 73; robustis, v. 74, lutulenta, v. 75) selektiert. Die in den Blick genommenen Gruppen, (in die Höhe) hebende Baumaschinen (torquet, v. 73), die (zu Füßen) laufenden Tiere (canis, ... sus, v. 75) im Wechsel mit Menschen (redemptor, v. 72), Menschengruppen und Fahrzeugen (funera plaustris, v. 74) erzeugen einen ,Bewegungsbereich', den die Wahrnehmungsinstanz mit verschiedenen Blickrichtungen (auf Augenhöhe und nach oben) als ihre räumliche Umgebung wahrnimmt. Der wiederholte Hinweis auf schwer bewegliche (lapidem, machina, ingens tignum) oder raumnehmende (mulis gerulisque redemptor, v. 72; robustis luctantur funera plaustris, v. 74) Gegenstände vermittelt den Eindruck, dass diese Objekte auch räumliche Hindernisse darstellen.

880 Hor. epist. 2, 2, 72-76.

881 Die Wortwiederholung (nunc ... nunc, v. 73), die Anapher (bac ... hac, v. 75) und der Parallelismus (v. 75) unterstützen den Eindruck, dass es sich bei den Erlebnissen um eine fortlaufende Kette handelt, die in rascher Folge aneinander anschließen. Dieser Eindruck wird durch die metrische Struktur unterstützt. Vgl. Kilpatrick (1990), 99, Anm. 35: „[These verses] are metrical tour de force: a golden line' expresses the formality of the funeral procession, followed by a split line (diairesis between feet 3 and 4) with a bold monosyllabic close (ruit sus) expressing the frantic action of rapid dogs and muddy pigs racing this way and that." Weiterführende Literatur ebd. 
$\mathrm{Zu}$ den visuellen Sinneseindrücken kommen wohl akustische hinzu, genannt werden allerdings lediglich die Geräuschquellen. Die von ihnen erzeugten Laute werden dem Erfahrungshorizont des Lesers überlassen, der Lärmbelästigungen durch einen zu Bauarbeiten dienenden Flaschenzug, Geräusche, verursacht durch einen Leichenzug, durch Fahrzeuge oder durch einen wütenden Hund kennt. Dass auch auf einen städtischen Geräuschpegel verwiesen werden soll, wird durch den Fortgang der Argumentation erkennbar. Die Dichter-persona stellt folgend die Bedürfnisse eines Dichters der anhaltenden Geräuschkulisse in der Großstadt gegenüber.

scriptorum chorus omnis amat nemus et fugit urbem,

rite cliens Bacchi somno gaudentis et umbra:

tu me inter strepitus nocturnos atque diurnos

80

vis canere et contracta sequi vestigia vatum? 882

Die Lebensbedingungen in einer brausenden urbs Roma kontrastiert die Dichterpersona mit wohl als stereotyp ${ }^{883}$ zu bezeichnenden Ich-zentrierten Bedürfnissen eines Dichters. Dazu wechselt sie zu einem ,räumlichen Fernraum' (spatio distant frame), einem Wald (nemus, v. 77). Dieser wird explizit als ,Kontrastraum`zur urbs eingeführt, indem die Präferenz für den Wald (amat, v. 77) der Ablehnung der urbs (fugit, v. 77) gegenübergestellt wird. Der Dichter erfreue sich dort als Schützling (cliens (!), v. 78) des Weingottes Bacchus ${ }^{884}$ an Schlaf und Schatten. Mit der pauschalen Behauptung, der Dichter könne in einem Wald ungehindert seinen Bedürfnissen nachgehen und brauche die Exklusivität des Waldes zum Arbeiten, sei in der Stadt dagegen unablässig einem unerträglichen Lärmpegel ausgesetzt (strepitus nocturnos atque diurnos, v. 79), liefert der Schreiber an dieser Stelle das entscheidende Argument, wieso nicht nur er, sondern auch jeder andere Dichter hoher Literatur (vatum, v. 80) in der Stadt nicht schreiben könne, und macht somit die brausende urbs Roma mit ihrer gesteigerten Lebensintensität zu einem generellen Unort für Dichtung. Innerhalb von der urbs gibt es keinen Rückzugsort. 885

882 Hor. epist. 2, 2, 77-80. Vgl. Kilpatrick (1990), 99, Anm. 36 zur Lesart contracta.

883 Vgl. Tac. dial. 9: adice quod poetis, si modo dignum aliquid elaborare et efficere velint, relinquenda conversatio amicorum et iucunditas urbis, deserenda cetera officia utque ipsi dicunt, in nemora et lucos, id est in solitudinem secedendum est. und Quint. inst. 10, 3, 22-24, Hor. carm. 2, 19; 3, 25.

884 Zu Bacchus als Dichtergott bei Horaz vgl. ep. 1, 19, 3-5 und Troxler-Keller (1964), 56-64. Zur Formulierung cliens Bacchi vgl. Catull. 1, 9: patrona wirgo und Troxler-Keller (1964), 62.

885 Mit dieser Behauptung, nämlich dass der Schreiber durch die Geräuschbelästigung nicht schreiben könne, kommt es allerdings zu einem offenen Widerspruch innerhalb der Epistel, der damit die satirischen, selbstironischen Züge dieser Argumentation erneut demaskiert: Zu Beginn der Epistel 2, 2 erklärt der aus der Stadt schreibende Dichter gerade mit seiner Freude am Schlafen die Vernachlässigung der Dichtung. Vgl. Hor. epist. 2, 2, 54: ni melius dormire putem quam scribere versus? Innerhalb des Gesamtœuvres werden der Zusammenhang von Schlafen und Dichten allerdings sehr eigenwillig eingesetzt. So gibt der Sprecher in Hor. sat. 2, 1, 5-9 sogar zu, dass er dichtet, weil er nicht schlafen kann. Sein Gegenüber schlägt ihm daraufhin effizientere Einschlafmethoden vor, wie das dreimalige Durchschwimmen des Tibers. 
Als Option gilt allein der Musenhain, der außerhalb des literarischen Raumes urbs Roma liegt.

Wie im literarischen Raum urbs Roma der Epistel 2, 2 anspruchsvoller lyrischer Gesang $^{886}$ als eine leise Dichtung ${ }^{887}$ völlig untergeht, zeigen die folgenden Verse:

\section{bic ego rerum \\ 85 fluctibus in mediis et tempestatibus urbis \\ verba lyrae motura sonum conectere digner? 888}

Durch das poetische Bild vom Unwetter auf dem Meer (fluctibus ... et tempestatibus, v. 85) entsteht im Gegensatz zu den vorhergehenden Versen ein anderer räumlicher Eindruck der urbs Roma: Nicht mehr werden in greller Anschaulichkeit Einzelheiten aus dem Stadterleben herausgegriffen, sondern der Vergleich kommt einer Großaufnahme gleich, der die Stadt - eben wie das Meer - als einen unbegrenzten Makroraum darstellt. Das Bild dient dazu, die Gesamtheit aller Bewegungen und Geräusche innerhalb der urbs Roma zusammenzufassen und einer einzelnen dichterischen Existenz gegenüberzustellen und damit deren Übermacht zu beschreiben: Das Dichter-Ich mit den Klängen seiner Lyra steht diesem akustisch akzentuierten, unbegrenzten und unruhigen Raum des Großstadtmeeres gegenüber.

In dieser Passage aus der Epistel 2, 2 soll der Eindruck vermittelt werden, das Stadtleben sei für einen Dichter, und nicht nur für diesen, eine Belastung und ein Hemmnis und in keiner Weise ein Ort der Inspiration. Zu dieser Beurteilung kommt auch Corbineau-Hoffmann: „Ein Schreckbild weitaus eher als ein Refugium für Dichter, steht für Horaz die Stadt in flagrantem, ja geradezu schreiendem Gegensatz zur Poesie, und der Dichter, der sie nicht flieht, sieht sich um seine Ruhe gebracht. (...) Antagonistin der Ruhe und damit a fortiori Feindin des Poeten, erlegt die Großstadt denjenigen, die sich dem Geistigen, dem Schönen und der Konzentration anheim gegeben haben, unzumutbare Beschränkungen auf und wird nicht müde, ihnen die schlimmsten Hindernisse in den Weg zu legen. "889

Die Schilderung der Bedingungen des Großstadtlebens, wie sie uns in der Epistel 2, 2 vorliegen, entspricht allerdings dem Anliegen des gesamten Briefes, nämlich

886 Nach Kießling/Heinze (1959), 247 f. handelt es sich bei den versprochenen carmina (Hor. epist. $2,2,25)$ allein um lyrische Dichtung. Dies legen auch verschiedene Formulierungen im Brief nahe, vgl. Hor. epist. 2, 2, 59 f.: carmine tu gaudes, bic delectatur iambis, / ille Bioneis sermonibus et sale nigro; ebd., 69: poemata; ebd., 76: versus tecum meditare canoros; ebd., 86: verba lyrae motura sonum conectere digner?

887 Kießling/Heinze (1959), 255 sehen in der Wortwahl canoros ebenfalls einen Gegensatz zum Lärm der Großstadt. Die Vorstellung der anspruchsvollen Dichtung als leiser Dichtung findet sich bereits bei Kall. fr. 1, 19 . Hor. epist. 2, 2, 84-86. Corbineau-Hoffmann (2003), 7. 
eine sehr stereotype Begründungsmöglichkeit dafür zu liefern, als Dichter nicht zum Arbeiten zu kommen. In folglich übertriebener Eindimensionalität wird die Darstellung der Lebensumwelt Großstadt dafür eingesetzt, eigenes Schreibverhalten zu legitimieren. ${ }^{890}$ Dass diese Einschätzung für das CEuvre des Horaz aber nicht verallgemeinert werden kann, wird im Folgenden leicht zu zeigen sein. Die Abqualifizierung des Großstadtlebens legt unter diesem Blickwinkel nur die selbstironisch dargestellten Unzulänglichkeiten einer Dichterpersönlichkeit offen, die einen Entschuldigungsgrund für eigene Untätigkeit sucht. ${ }^{891}$ Gerade dieser Argumentation soll und muss entsprechend der literarischen Kommunikationssignale eine klare Absage erteilt werden. Dass die literarische urbs Roma kein Inspirationsraum für einen Dichter darstellen soll, darf - vom Adressaten und idealen Leser - in Zweifel gezogen werden: Die Dichter-persona hinterlässt ihm die Präsentation der Metropole als einen Gegenort zum Musenhain als einen ausgedehnten, dichten Ort der Anspannung, Konzentration und ständiger Bewegung. Die seelische und körperliche Überforderung für die Dichter-persona wird mit Hilfe konkreter visueller und akustischer Wahrnehmungen dargestellt, die zum Abschluss der Passage im Bild des Unwetters zur See (fluctibus ... et tempestatibus, v. 85) zusammengefasst werden. Durch diese virtuose und höchst expressive Schilderung des städtischen Lebens entsteht ein offener Widerspruch von Inhalt und Form: Die inhaltliche Ablehnung der Großstadt als Ort für anspruchsvolle Dichtung bringt zwar keine lyrischen Verse, wohl aber eine multisensorisch vermittelte literarische Großstadtwelt und damit eine ausgenommen anspruchsvolle Poetisierung der Großstadt hervor. Mit diesem Mittel der Übertreibung in Ausdruck und Form bleibt nach der Lektüre der Epistel der Eindruck zurück, dass die urbs Roma für die rezitierende Dichtung doch einen äußerst beeindruckenden Inspirationsraum darstellt. ${ }^{892}$

890 Vgl. auch Hor. sat. 2, 3, 1-16. Als Gesprächseinstieg dieser Satire wird der Vorwurf formuliert, dass eine Dichter-persona trotz eines Landaufenthalts keine Dichtung zuwege bringe. Der „Nörgler" führt es auf ihre Trägheit zurück. Vgl. Hor. sat. 2, 3, 14 f.: vitanda est inproba Siren/ desidia., oder Hor. sat. 2, 6, 16 f.: ergo ubi me in montes et in arcem ex urbe removi,/ quid prius inlustrem saturis musaque pedestri?

891 Im satirischen Euvre des Horaz wird das Landleben m. E. nicht eindeutig als ideale Schaffensform markiert. Im Gegenteil wird die Behauptung, der Dichter ziehe sich aufs Land zurück, um frei von städtischen Verpflichtungen genügend Zeit zum Dichten zu haben, des häufigeren als Ausrede entlarvt. Vgl. Hor. sat. 2, 3, 1-16. Dagegen vgl. Fedeli (1994), 590: „,mentre in realtà essi significano aderenza di Orazio al modo alessandrino di far poesia." Ebenfalls Kießling/Heinze (1959), 218: „Zum Widerspruch [gegen die Behauptung, er, der Dichter, dichte nicht auf dem Land, Anm. d. Verf.] ist er sich zu gut.“ Aber vgl. auch Fedeli (1994), 218: „Orazio si serve con gustosa autoironica del punto di vista di Damasippo.“ Zum Sabinum als Dichterlandschaft vgl. Schmidt (1997).

892 Vgl. Kießling/Heinze (1959), 255. 


\subsubsection{Der dichtende Stadtgänger. Die Großstadt und der Dichter II (Hor. sat. 1, 6;1,9)}

Der städtische Alltag gestaltet sich gemäß der Dichter-persona der Epistel 2, 2 so, dass sie häufig in der Stadt unterwegs sei - von einem Termin zum anderen - und sie diese Tätigkeit am anspruchsvollen Dichten hindere. Der potentielle Vorschlag des Freundes Florus, beim Gang durch die Stadt seinen Gedanken nachzuhängen (,verum/ purae sunt plateae, nibil ut meditantibus obstet.', v. 70 f.), ist nach Ansicht der Dichter-persona nicht nur wegen der großstädtischen Straßenverhältnisse absurd, sondern auch vor der Öffentlichkeit herabwürdigend. Die Lächerlichkeit eines solchen Verhaltens verdeutlicht die Dichter-persona an einem Beispiel aus der Provinzstadt Athen: Ein Gelehrter (ingenium ${ }^{893}$ ) zeigte sich hier schweigend und ins Nachdenken vertieft in der Öffentlichkeit und wurde dafür verlacht. ${ }^{894}$

Die Dichter-persona wählt für ihre Argumentation, wieso man durch die Straßen der urbs Roma nicht ins Nachdenken vertieft gehen kann, die Begebenheit aus einem anderen Zeit- und Raumkontinuum ${ }^{895}$ nicht ohne Grund. Gemäß der strukturellen Einbindung solcher Räume dient die in Athenae angesiedelte Anekdote zunächst einem kontrastiven Vergleich zwischen der Situation einer geachteten männlichen Figur (ingenium) in Athen und der eigenen Situation in Rom. ${ }^{896}$ Der begabte Mann wählte sich Athenae zum Wohnsitz (sibi desumpsit, v. 81) und widmete sich hier sieben Jahre lang seinen Studien. Athenae bietet demzufolge - im Gegensatz zur urbs Roma - Voraussetzungen, sich über mehrere Jahre hin eigenen Studien zu widmen. Ein ebenfalls kontrastives räumliches Kennzeichen dieses Ortes ist: Er ist leer. Athenae wird von dem Schreiber als ein Kontrastraum zur urbs Roma konzipiert. Die in Athen angesiedelte Anekdote ist argumentativ allerdings weniger als Vergleich e contrario, denn als argumentum a fortiori angelegt: Wenn man bereits an einem Ort wie Athen als nachdenklich schweigender Spaziergänger

893 Hor. sat. 2, 2, 81-84. Vgl. Kießling/Heinze (1959), 255 ff. Rudd (1989), 133 interpretiert ingenium als „, a comic figure“. Kilpatrick (1990), 20 sieht in der Person den Studenten Horaz: „Horace is simply repeating here a point raised earlier (41-54): his own choice would have been to remain in Athens to study at the Academy, and now that he has achieved his wish to leave poetry and public life behind he will not give up."

894 Hor. epist. 2, 2, 81-86: ingenium, sibi quod vacuas desumpsit Athenas/ et studiis annos septem dedit insenuitque/ libris et curis, statua taciturnius exit/ plerumque et risu populum quatit: bic ego rerum/ fluctibus in mediis et tempestatibus urbis/ verba lyrae motura sonum conectere digner?

895 Den zeitlichen Rückgriff zeigt der Tempuswechsel vom Präsens zum Perfekt und wieder zum Präsens an. Das hic im Vers 84 weist auf eine räumliche Distanz zum Raum Athenae hin.

896 Die Passage ist nicht die einzige Erwähnung des literarischen Raumes Athenae, bereits zu Beginn seines Briefes kam der Schreiber auf ihn zu sprechen. Vgl. Hor. epist. 2, 2, 41-46: Romae nutriri mibi contigit atque doceri,/ (...)/ adiecere bonae paulo plus artis Athenae, / scilicet ut vellem curvo dinoscere rectum/ atque inter silvas Academi quaerere verum./ dura sed emovere loco me tempora grato (...). Bei dieser Passage handelt es sich um einen Ausschnitt einer kurzen erzählerischen Einlage, eines zeitlichen Rückgriffs (Analepse), in dem der medias in res eingeführte Briefanlaß - „Ich habe dir gesagt, dass ich faul bin und keine Gedichte mehr schreibe“ - nachträglich erläutert wird. 
auf der Straße ausgelacht wird, wie sollte man da erst im tosenden Rom auf der Straße seinen Gedanken nachhängen? ${ }^{897}$

Die Perspektive auf den in einem literarischen Raum eilenden Stadtgänger als verhinderten und der Lächerlichkeit preisgegebenen Dichter ist allerdings nicht die einzige Spielart dieses Themas innerhalb der satirischen Dichtung des Horaz. Und es sind nicht ausschließlich die ausgewiesenen Gegenräume zur literarischen urbs Roma - dem Wald oder einer Provinzstadt -, in denen eine Dichter-persona im Werk des Horaz zum Dichten kommt. Schaut man auf diejenigen Passagen, in denen eine Dichter-persona über ihren Schaffensprozess schreibt, werden recht unterschiedliche Räume als Orte des Dichtens genannt. Überwiegend gehören dazu die privaten Innenräume, deren Lage sich sowohl innerhalb als auch außerhalb der literarischen urbs Roma befindet. Neben diesen Rückzugsorten werden aber auch öffentliche städtische Räume benannt, in denen der Dichter über Inhalte seiner Dichtungen nachdenkt. ${ }^{898}$ Nicht durchgehend wird eine Dichter-persona folglich im öffentlichen Raum allein als eine durch die Stadt hetzende, vom Dichten abgehaltene Figur wiedergegeben. Im Gegenteil: In der berühmten Satire 1, 9 schlendert sie sogar durch die Stadt und denkt dabei durchaus über dichterische Einfälle nach.

Ibam forte via sacra, sicut meus et mos, nescio quid meditans nugarum, totus in illis: accurrit quidam (...). ${ }^{899}$

Die Dichter-persona war ihrer Schilderung nach nicht zielgerichtet oder in großer Eile unterwegs, sondern in gemäßigtem Tempo (Ibam, v. 1). ${ }^{900}$ Ganz ins Nach-

897 Vgl. dazu auch Kießling/Heinze (1959), 256. Neben dieser strukturellen Beobachtung ist im Hinblick auf die Kontrastierung der beiden Räume hervorhebenswert, was die Dichter-persona in der Passage Hor. epist. 2, 2, $41-46$ über ihre Ausbildung sagt: In Rom habe sie die Grundausbildung genossen und habe dort die Ilias gelesen (Romae nutriri mibi contigit atque doceri, / iratus Grais quantum nocuisset Acbilles., v. 41 f.). Über diese Feststellung hinaus wird über Vorteile der literarischen urbs Roma nichts ausgesagt. Über Athen berichtet sie dagegen in diesem Zusammenhang bei weitem anschaulicher und ausführlicher - auch in räumlicher Hinsicht. Im bonae Athenae hier personifiziert - konnte sie ihre Studien fortsetzen und erweitern, hat unter den Bäumen der Akademie (inter silvas Academi, v. 45) nach dem Wahren gesucht, bis sie gegen ihren Willen (emove$r e$, v. 46) diesen ihr angenehmen Ort (grato loco, v. 46) verlassen musste. Bemerkenswert ist die Erwähnung von silvas, vgl. Hor. epist. 2, 2, 77.

898 Vgl. Hor. sat. 1, 4, 133-139. In diesen Versen beschreibt der Dichter seine Arbeitsweise: Im Bett oder beim Spaziergang in städtischen Wandelhallen denke er über das Handeln der Menschen nach und bringe seine Ergebnisse in der Zeit des otium auf Papier. Die porticus ist demnach ein Pendant zum privaten Raum, ein schattiger Rückzugsort, der aber mitten in der Stadt liegt. Vgl. Kießling/Heinze (1959), 87. Zu den Porticus als beliebte Aufenthaltsräume für Händler und Spaziergänger im Zentrum Roms vgl. Zanker ( ${ }^{42003), ~} 147$.

899 Hor. sat. 1, 9, 1-3. 
denken über dichterische Einfälle (nescio quid ... nugarum, v. 2) versunken, ging sie zufällig (forte, v. 1) auf der via sacra - für den Kenner stadtrömischer Topographie auf einer zentralen und breiten Straße - entlang. In dieser Unbefangenheit und Selbstbestimmtheit der eigenen Bewegung wird sie nun erbarmungslos gestört: Ein ihr vermeintlich bekannter Dichterkollege läuft auf sie zu (accurrit quidam, v. 3), begrüßt sie überschwänglich und heftet sich an ihre Fersen, um sich von ihr eine Empfehlung für den Dichterzirkel des Maecenas einzuholen.901 Dabei zeigt er ebenfalls keine Eile, sondern ist bereit, die Dichter-persona überall hin zu begleiten. ${ }^{902}$ Der Verlauf dieser aus Sicht der persona selbstironisch ${ }^{903}$ erzählten Begegnung, die sie nicht nur vom Nachdenken ablenkt, sondern geradezu jeder Selbstbestimmtheit durch eine aufgezwungene Gesellschaft beraubt, wird Gegenstand der Satire. Die harmlose Ausgangssituation ist aber das Bemerkenswerte an dieser Stelle: Es gehört in dieser Satire zum selbstverständlichen Alltagsverhalten (sicut meus est mos, v. 1) der Dichter-persona, am Morgen ${ }^{904}$ einen Spaziergang durch das Stadtzentrum zu machen und über Bonmots nachzudenken. Dass sie dabei unterbrochen wird, ist in der hier entworfenen Konstellation für sie gerade nicht voraussehbar gewesen, sondern scheint eher ein unglücklicher Zufall zu sein. Die Episode entwickelt sich aus einer alltäglichen Situation, deren plötzliche Veränderung erst komisches Potential birgt. Spaziergehen und innere Versenkung an sich werden hier - im Gegensatz zur Epistel 2, 2 - inmitten der literarischen urbs Roma keinesfalls als lächerlich präsentiert. ${ }^{905}$

In einer weiteren Satire, der Satire 1, 6, wird die Darstellung einer Dichter-persona ebenfalls als Stadtgänger im Alltag präsentiert. Gegen den Neid der anderen - so heißt es dort - sucht sie ihr als nicht standesgemäß bewertetes enges Verhältnis zu Maecenas zu verteidigen, indem sie ihren ambitionslosen Lebenswandel beschreibt. ${ }^{906}$ Sie kontrastiert dazu das Leben eines Politikers mit ihrem eigenen Alltag (v. 110-131) und schildert ihre Beschäftigungen, denen sie im Laufe ihres Tages nachgeht. Der literarische Raum wird in der Satire 1, 6 nicht direkt mit dem

900 In Horazens Satire 1, 9, 1 f. ist die Geschwindigkeit nur indirekt zu erschließen. Da der Sprecher beim Gehen nachdenkt, ist mit einer langsamen Bewegung zu rechnen. Das Metrum suggeriert ebenfalls ein gemäßigtes Tempo.

901 Vgl. Hor. sat. 1, 9, 45-47: haberes/ magnum adiutorem, posset qui ferre secundas,/ bunc hominem velles si tradere.

902 Hor. sat. 1, 9, 16 und 19.

903 Vgl. Henderson (1999), 207.

904 Die Tageszeit des Ereignisses muss in den Vormittagsstunden liegen. Vgl. Hor. sat. 1, 9, 35 f.: quarta iam parte diei/ praeterita.

905 Vgl. dagegen Henderson (1999), 226. Bei der Dichter-persona soll es sich trotz aller selbstironischer Selbstdarstellung dennoch um ein angesehenes Mitglied eines stadtbekannten Dichterzirkels handeln, als solches wird es vom Schwätzer angesprochen. Zur räumlichen Gestaltung dieser Satire vgl. Abschnitt 3.3.1.

906 Vgl. Hor. sat. 1, 6, 128 f.: haec est/ vita solutorum misera ambitione gravique. Kießling/Heinze (1959), 107. 
Toponym Roma bezeichnet. Allein die Referenz Marsya (v. 120) verweist für den kundigen Leser auf eine Statue auf einem zentralen Platz Roms. ${ }^{907}$ Durch die Nennung von circus (v. 113), forum (v. 114) und campus (v. 126) wird vor allem die großstädtische Struktur des literarischen Raumes herausgehoben.908

Die Dichter-persona beginnt den Bericht über ihren Alltag mit den Nachmittagsstunden. Zu dieser späten Stunde ist sie in verschiedenen Bereichen innerhalb der urbs Roma unterwegs. Danach nimmt sie zu Hause ein bescheidenes Abendessen ein. Diesem schließen sich die Nachtruhe und die Vormittagsstunden des nächsten Tages an, in denen die Dichter-persona im Bett bleibt, liest und schreibt. Auch später am Tage, wenn sie wieder durch die Stadt schweift oder Sport treibt, ist das Alltagsgeschäft geprägt von einer sorgenfreien Atmosphäre. ${ }^{909}$

Neben allgemein menschlichen Bedürfnissen, wie Essen und Schlafen, und typischen Tätigkeiten als Dichter, wie Schreiben und Lesen, stellt die persona in besonderer Weise das alltägliche Schlendern durch den literarischen Raum urbs Roma als eine adäquate Existenzform eines Dichters heraus. Die dabei waltende Bedächtigkeit des nachmittäglichen Streifzuges wird in den folgenden Versen anschaulich ausgebaut: ${ }^{10}$

\author{
quacumque libido est, \\ 112 incedo solus, percontor quanti holus ac far, \\ fallacem circum vespertinumque pererro \\ saepe forum, adsisto divinis, inde domum me/ (...) refero (...).911
}

Die Dichter-persona ist allein unterwegs (solus), sie spaziert, d. h. sie durchschreitet ziellos ${ }^{912}$ weiträumige, diffus umgrenzte Stadtgebiete, wie einen Markt, die räumliche Umgebung des Circus und das Forum. Die urbs Roma wird folglich auch hier als ausgedehnter Raum präsentiert, nur zeigt die Geschwindigkeit der Eigenbewegung die Dichter-persona frei von zeitlichen Verbindlichkeiten und einer zeitlich

907 Die Präsentation des literarischen Raumes urbs Roma setzt demzufolge eine große Vertrautheit mit der städtischen Topographie des realen Roms voraus. Der Hinweis Marsya obeundus bedarf für heutige Leser der Kommentierung.

908 Allein der mit den üblichen Sprachregelungen vertraute Leser kann diese Orte innerhalb des Raumes mit den prominenten Orten Circus Maximus, Forum Romanum und Campus Martius identifizieren. Klingner signalisiert in seiner Textausgabe über die Kleinschreibung, dass er es als unsperifische Orte innerhalb des literarischen Raumes Rom verstanden wissen will: Innerhalb dieses literarischen Raumes gibt es nur einen einzigen circus, ein einziges forum und einen einzigen campus.

909 Vgl. Hor. sat. 1, 6, 110-128.

910 So urteilt auch Fedeli (1994), 460: ,il verbo [sc. incedere, Anm. d. Verf.] ha un'intonazione maestosa, dietro la quale di scorgere una nota autoironica (...).“

911 Hor. sat. 1, 6, 111-115.

912 Vgl. auch Fedeli (1994), 460: „in percontor e pererro il prefisso seve a creare l'idea di un vagabondare in lungo e in largo." 
terminierten örtlichen Präsenz. Die langsamen Tempi der Gehbewegung, das Schlendern oder das Stillstehen (incedo, pererro, adsisto), werden als selbstbestimmt dargestellt (quacumque libido est). Ebenso verlaufen die Begegnungen mit anderen. Es sind weder zufällige noch störende Begegnungen, noch bewegen sich die anderen durch den literarischen Raum. Es sind Begegnungen, die sich die Dichterpersona nachdrücklich selbst auswählt (percontor ... adsistọ, v. 112/114). Das jeweilige Gegenüber - Gemüseverkäufer und Wahrsager -, spricht sie selbst an (percontor quanti holus ac far, v. 112) bzw. steuert auf sie zu (adsisto divinis, v. 114). Die anderen bleiben schemenhaft und anonym. Im Vordergrund stehen stets die Dichterpersona und ihre raumgreifende Aktivität. Die räumliche Wahrnehmung ist weder durch körperlichen Kontakt oder durch akustische Reize ergänzt. Der öffentliche, unbegrenzte Raum der literarischen urbs Roma ist wie der begrenzte, private Raum ihres Hauses davon frei. Als sinnlich Wahrgenommenes wird nur die zunehmende Hitze erwähnt, der sich die Dichter-persona entzieht (ast ubi me fessum sol acrior ire lavatum/ admonuit, fugio campum, v. 125 f.).

Diese Souveränität über das eigene Leben zeigt sich in einer bewussten Abgrenzung von einem konventionellen Leben in der Stadt: ${ }^{13}$ Die Dichter-persona bewegt sich allein, geht, wohin sie will, und trifft lediglich auf ausgewählte Menschen. In der Selbstbestimmtheit des langsamen Gehens finden ihr in Vergleich zu anderen Städtern unkonventioneller ${ }^{914}$ Lebensstil als Dichter und ihre damit verbundene gesellschaftliche Unabhängigkeit ${ }^{915}$ ihren Ausdruck. ${ }^{916}$ Ist doch ein unbekümmertes Gemüt die innere Voraussetzung des Spazierengehens. ${ }^{917}$

Diese Dichter-persona sehnt sich nicht - wie der Schreiber in der Epistel 2, 2 nach Waldeseinsamkeit und stadtfernen Musenhainen, um dichterisch tätig sein zu können. Im Gegenteil, gerade als Dichter hat sie die Möglichkeit, ein bequemes ${ }^{918}$ Leben in dieser literarischen urbs Roma zu führen. Die Raumerfahrung des bedäch-

913 Vgl. Hor. sat. 1, 6, 119-121: non sollicitus, mibi quod cras/ surgendum sit mane, obeundus Marsya, qui se/ voltum ferre negat Noviorum posse minoris. Dazu Fedeli (1994), 461: „i gerundivi [sc. surgendum (...) obeundus, v. 120; Anm. d. Verf.] indicano quelli che sarebbero stati i suoi obblighi se avesse scelto un altro tipo di vita." Es handelt sich bei den aus der Ich-Perspektive im Präsens geschilderten Erlebnissen wiederum um eine Form der iterativen Erzählung. Vgl. Hor. sat. 1, 6, 128 f.: haec est/ vita).

914 Hor. sat. 1, 6, 127-130.

915 Vgl. auch Fedeli (1994), 460: „Libido (v. 111) mette subito in chiaro la massima libertà, di cui gode il poeta di andare dove desidera." und vgl. Porphyrius über die Wahrsager (v. 114 divinis): altioris dignitatis homines erubescunt, fere in his unlgi circulis stare, quod tamen sibi licere facere, Horatius dicit per vitae libertatem, in qua non esset, si in senatoria dignitate constitutus esset.

916 Hinweise auf die Kombination von Spazierengehen und Dichten finden sich in Hor. sat. 1, 4, 133-139 (die Porticus ist ebenfalls ein Spazierort). Generell zum Spazierengehen als Ausdruck des Otium - hier anlässlich eines philosophischen Gesprächs - vgl. Cic. de fin. 5, 1.

917 Vgl. Hor. sat. 1, 6, 119 über den sorgenfreien Schlaf: deinde eo dormitum, non sollicitus, mibi quod (...).

918 Vgl. Hor. sat. 1, 6, 110 f.: hoc ego commodius quam tu, praeclare senator,/ milibus atque aliis vivo. 
tigen Laufens entspricht ganz der Haltung der Dichter-persona: Sie führt ein Leben in der Stadt, das ambitionslos, aber selbstbestimmt verläuft.

Diese Dichter-persona vereinigt damit einige wichtige Eigenschaften eines literarischen, aber auch kulturellen Phänomens, ${ }^{919}$ das mit Beginn des 19. Jahrhunderts entstand und an die Infrastruktur der Großstadt gebunden war' ${ }^{920}$ : des Flaneurs. Ein Flaneur ist ein Städter, der die Großstadt gehend erfährt, sich ziel- und absichtslos in ihr bewegt und sich von seinen Beobachtungen treiben lässt. Mit dieser Haltung nimmt er eine „mehr oder weniger exzentrische Außenseiterposition gegenüber der Großstadtgesellschaft ${ }^{\text {"921 }}$ ein. In der expliziten Provokation der Dichter-persona in der Satire 1, 6, die ein ambitioniertes Leben zurückweist, und in ihrer Selbstbeschreibung als unabhängiger städtischer Spaziergänger liegt wohl eine Vorform des Typs Flaneur vor. Eine vergleichbare Selbstbeschreibung findet sich aber auch in der Satire 1, 9, in der die Selbstbestimmtheit des Gehens durch das einmalige Ereignis, das im Mittelpunkt dieser Satire steht, unterbunden wird. Als Erzähl- und Wahrnehmungsperspektive moderner Großstadt-Literatur werden häufig der Gang und der Blick des Flaneurs als adäquates Darstellungsmittel der Großstadt gewählt. ${ }^{922}$ Aus diesem Grunde hat der Flaneur der Moderne in seiner ästhetischen Funktion als Reflektor großstädtischer Wirklichkeit stets auch eine Nähe zum Dichter. ${ }^{923}$

\section{Zusammenfassung}

Die verschiedenen Dichter-personae in Horazens Werk werfen ein Schlaglicht auf die Vielgestaltigkeit des Themas ,Großstadt und Dichtung', die sich außerhalb programmatischer Passagen in der römischen Literatur finden. Sie wurden hier vorgestellt, um zu zeigen, in welcher Form sich eine Dichter-persona in diesem CEuvre zur Wechselwirkung von Dichtung und Großstadtleben äußert. Überraschend häufig werden Aussagen über eine dichterische Arbeit mit räumlichen Umgebungen verknüpft. Der Ort ihres Nachdenkens und Verfassens wird im Gegensatz zu anderen Beispielen explizit genannt, etwa das eigene Bett, die Portikus und auch der offene Raum der Straße in der urbs Roma. Gerade das Verlassen des eigenen Zimmers und das Ausschreiten im offenen Raum der Großstadt werden für den Schaffensprozess jedoch unterschiedlich bewertet und gehen gleichzeitig mit der Präsentation unterschiedlicher Raumeindrücke einher.

\footnotetext{
919 Vgl. Severin (1988), 7.

920 Vgl. Neumeyer (1999), 11.

921 Severin (1988), 2. Assmann (22008), 158: „Die Großstadt hat den Flaneur hervorgebracht als ihren Beobachter, der in den Strom der Passanten eintaucht. Er ist ein Müßiggänger, der von keinen pragmatischen Zielen und Bedürfnissen gesteuert ist und dessen Aufmerksamkeit deshalb freigestellt ist, sich auf die Großstadt selbst und ihre Lebensform zu konzentrieren. Der Flaneur ist die Figur, in der das Leben in der Großstadt selbstreflexiv wird.“

922 Vgl. Severin (1988), 7.

923 Vgl. Severin (1988), 9.
} 
Gemeinsam ist den Darstellungen, dass die literarische urbs Roma in Bereiche untergliedert präsentiert wird, die durch die Eigenbewegung einer Wahrnehmungsinstanz zu einem ,räumlichen Kontinuum 'verbunden werden, und dass das Durchschreiten des Stadtraumes als ein alltägliches Ereignis präsentiert wird. Unterschiede bestehen im Tempo, mit dem sich die personae durch den Raum bewegen und in der damit verbundenen unbestimmten oder bestimmten Finalität ihres Bewegungsbereichs. Ebenfalls wird die Widerständigkeit des jeweiligen Wahrnehmungsbereichs unterschiedlich präsentiert. So wird er zum einen als eine schnell wechselnde, dicht gedrängte städtische Umwelt wiedergegeben. Gruppen von Menschen, städtischer Verkehr und Baustellen erweisen sich als Hindernisse auf einer Wegstrecke, denen man als Wahrnehmungsinstanz auszuweichen hat. Die Vielfalt der visuellen und akustischen Sinneseindrücke verunmöglicht es dem Sprecher, dichterisch tätig zu werden. Zum anderen wird das aktive Ausschreiten im städtischen Raum dazu genutzt, um dichterischen Einfällen nachzugehen. Dieses Vorhaben wird durch ein zufälliges Ereignis unterbunden. In einem dritten Beispiel wird durch die Bewegung gerade der Selbstbestimmtheit des eigenen Lebens Ausdruck verliehen. Aussagen über räumliche Widerstände fehlen hier. Der Weg durch die ebenfalls als alltäglich dargestellte literarische urbs Roma verläuft auf bereits gebahnten Pfaden und ohne unvorhergesehene Ereignisse. ${ }^{924}$

Die Anschauungsvielfalt der literarischen urbs Roma wird nirgends infrage gestellt. In einen expliziten Zusammenhang mit der Suche nach einer geeigneten materia für die eigene Dichtung wird sie jedoch nicht gestellt. Vielmehr geht es den Dichter-personae um ihr Selbstverständnis und ihre Selbstbestimmtheit als Dichter, die sie in selbstironischer, satirischer Sprechweise durch verschiedene Raumdarstellungen zu verdeutlichen suchen.

\subsection{Auswertung. Die Großstadt als Gegenstand neuartiger Literatur}

Zahlreiche Autoren der augusteischen und kaiserzeitlichen Epoche sind zwar nicht gebürtige Stadtrömer, verbrachten mit annähernder Gewissheit aber einen prägenden Teil ihres Lebens in der Metropole Rom. Wenn sie das Ergreifen des Dichterberufs in ihrer Literatur meist als eine Emanzipation von Stereotypen gesellschaftlichen Aufstiegs präsentieren, so zeugt eine persönlich gehaltene Stellungnahme des Autors Martial von den für einen Kulturschaffenden ausnehmend günstigen Lebensbedingungen in der Großstadt. In einem poetologisch ausgeleg-

924 In gleicher Weise ließen sich auch Unterschiede in der Darstellung der literarischen urbs Roma als Kontaktbereich ausmachen. Einerseits kommt es zu vielfältigen Begegnungen mit mobilen Objekten, die Wahrnehmungsinstanz tritt mit ihnen jedoch nicht in eine direkte Interaktion, andererseits kommt es gerade zu einer unfreiwilligen Kontaktaufnahme, in einem dritten sucht die Dichter-persona den Kontakt und zeigt sich in der Wahl als selbstbestimmt. 
ten Essay reflektiert er grundsätzlich über die Lebensbedingungen in der Großstadt, die Entstehungsbedingungen von Literatur und die daraus resultierenden Vor- oder Nachteile für sein eigenes literarisches Schaffen. Er beschreibt dabei die Großstadt Rom als den Ausgangs- und Bezugspunkt seiner Dichtung und stellt eigene Erfahrungen konventionellen Vorstellungen über Bedingungen für einen Dichter in Provinz und Metropole gegenüber. Die Großstadt bleibt für ihn ein ingeniöser Kommunikationsort, der Qualitätsgarant seiner Dichtung ist und dem Naturell des Dichters entspricht. Die Aspekte, die er aus der städtischen Lebensumwelt heraushebt, beziehen sich allesamt auf die günstigen Bedingungen für den Berufsstand des Dichters: ein reger Austausch unter Kulturschaffenden, ein Kreis an Hörern und der tägliche Erfahrungshorizont Großstadt, der durch eigene Beobachtungen und Erfahrungen seine Arbeit als Dichter erleichtert. Seine praefatio zum zwölften Epigrammbuch ist ein singuläres Zeugnis eines römischen Dichters. Vergleicht man diese ausnehmend positive Bewertung eines städtischen Lebensumfelds für das Dichten mit den Aussagen einzelner Epigramme Martials, tun sich Widersprüche auf. Jedoch handelt es sich dabei nicht um eine Inkonsequenz des Autors, sondern um eine Poetisierung der Lebensumwelt Großstadt und ihres Großstadtdichters. Nicht die Schilderung einer biographisch erlebten, großstädtischen Realität in Versen ist Anliegen dieser Dichtung, sondern sie zielt auf „eine umfassendere Sicht (...) und ein spannungsreicheres, differenzierteres Erlebnis

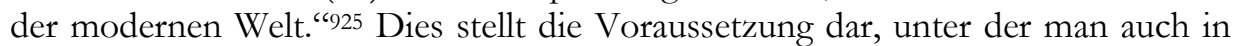
der römischen Dichtung von Großstadtliteratur, als Literatur über die Großstadt, sprechen kann.

Mutmaßungen über die Gründe für eine derartige nicht selbstverständliche und zwingende Poetisierung einer antiken Großstadt, wie sie die griechische Literatur gemäß der heutigen Überlieferungslage wohl nicht bot, können sich jedoch nur auf äußerst vage und allgemeine Aussagen stützen. Mit dem Durchlaufen weiterführender Bildungseinrichtungen waren die Autoren der augusteischen und kaiserzeitlichen Epoche mit einiger Gewissheit zu einer Reflexion über die städtische Lebensumwelt angehalten worden. Durch Modeströmungen ihrer Gegenwart waren ihnen womöglich auch thematische Auseinandersetzungen auf höherem Niveau - als Stegreif- oder Leserede - nicht unbekannt. Auf den Dichterberuf zielte die übliche rhetorische Ausbildung zwar in der Regel ${ }^{926}$ nicht ab, jedoch sind rhetorische Fertigkeiten stets für die Literaturschaffenden von Bedeutung gewesen. Auch inhaltlich lassen sich Auseinandersetzungen mit der Stadt- und Landthematik und des Städtelobs gattungsübergreifend und in der gesamten antiken Literatur ausmachen. Derartige Beobachtungen sensibilisieren für den Umgang mit Einschätzungen wie denjenigen, die eine biographische Stellungnahme oder

925 Traut (1957), 31.

926 Vgl. Iuv. 1, 1, 15-17: et nos ergo manum ferulae subduximus, et nos/ consilium dedimus Sullae, privatus ut altum/ dormiret. Vgl. dazu Braund (1996), 78 f. und Adamietz (1993), 324, Anm. 11. 
eine rein abbildende Darstellung hinter der textimmanenten Auseinandersetzung um die Großstadt und den Dichter sehen, und legen offen, dass sie zu kurz greifen.

Aufschlussreich ist darüber hinaus der Rat der Pädagogen, wann sie die Thematik ,Stadt ${ }^{\varsigma}$ als einen geeigneten Gegenstand für eine Redeübung empfahlen. Wegen der Möglichkeit individueller Beobachtungen und Erfahrungen galt der Vergleich von städtischen und ländlichen Lebensbedingungen für eine Erörterung als besonders ergiebig und ermöglichte auch schon Heranwachsenden, eine persönliche Stellungnahme abzugeben. Den Autoren mag diese Aufforderung zu einer differenzierten und nuancenreichen Sicht auf ihre direkte Lebensumwelt auch für eine literarische Verarbeitung apart geschienen haben.

Eine Facette greifen die Autoren - auch für ihre Programmgedichte - in ihrer Dichtung wiederholt auf: die Verhältnisbestimmung des Großstadtdichters zu der Lebensumwelt Großstadt. Durch eine produktive Auseinandersetzung lässt sich zeigen, dass diese Verhältnisbestimmung alles andere als eindimensional ausfällt und gerade nicht allein ,zum immer gleichen Zeugnis gegen die Stadt" genutzt wird, um „deren negative Wirklichkeit am positiven Ideal des einfachen, unverkünstelten Landlebens“"927 zu messen. Im Gegenteil: Die Texte zeichnen eine äuBerst differenzierte, vielseitige und unkonventionelle Beziehung zwischen Dichtersein und Großstadt und sind gleichzeitig beredtes Zeugnis für die Großstadt als Gegenstand der römischen Literatur.

(1) Wenn nämlich im Zusammenhang mit poetologischen Überlegungen und in Programmgedichten Stellungnahmen über einen intendierten Leser oder über Beweggründe für die jeweilige Gattungswahl zu lesen sind, ist das wenig überraschend. Überraschender ist es aber, wenn nicht eine konkrete Leserschaft - etwa ein Gönner oder ein Freundeskreis - angesprochen wird, sondern ein unspezifisches Publikum, dessen Verbundenheit allein über einen gemeinsamen Aufenthaltsort, zumal eine Großstadt, gewahrt ist. Ebenso überraschend ist es, wenn dem Großstadtleben nicht nur eine große Anschauungsvielfalt attestiert, sondern es auch zur Begründung einer Gattungswahl herangezogen wird. Ein Großstadtbezug der Dichtung in einer solchen Qualität bedarf auch nach Meinung der jeweiligen Sprecher einer Erklärung. Sie liefern diese.

In der Eröffnungssatire Juvenals stellt die Dichter-persona die Monotonie und thematische Weltabgewandtheit zeitgenössischer (konventioneller) Literatur dem eigenen Erleben einer vielfältigen und abwechslungsreichen Großstadtgegenwart gegenüber. Genau hieraus ergeben sich die Entstehungsbedingungen ihrer in diesem Sinne als innovativ zu verstehenden Dichtung. Materia, gattungsbedingte Sprechweise und sogar Genie in Form einer ingeniösen Ergriffenheit sind nach Ansicht der Dichter-persona ihrer unmittelbaren Lebensumwelt geschuldet.

927 Stierle (1993), 53. 
In Ovids Exil-Elegie führt die räumliche Trennung von der Stadt zu einem Paradigmenwechsel in der Sprechhaltung und beeinflusst Qualität der Dichtung wie auch Schöpferkraft der Dichter-persona. Die Entfernung zur Großstadt bedeutet für sie den Verlust einer idealen Existenzform und bewirkt ein elegisches Schreiben, worin sich das vorliegende Werk von ihrer vormaligen Dichtung, aber auch von einer großstädtischen Dichtung allgemein unterscheide. Eine Kontinuität dichterischen Schaffens ist dieser Programmelegie zufolge nicht losgelöst vom räumlichen Umfeld aufrechtzuerhalten. Von der Peripherie des Römischen Reiches aus sendet sie ihre in diesem Sinne auch als innovativ zu verstehenden Elegien an einen Kreis von Lesern in der literarischen urbs Roma, die einziger Bezugspunkt der Dichtung bleiben.

Gemeinsam ist diesen programmatischen Aussagen die in ihnen geäußerte Überzeugung, dass die Dichter der Großstadt ihre Dichtung verdanken. In unterschiedlicher Gewichtung werden der literarischen urbs Roma Eigenschaften als Inspirations- und Rezeptionsraum der jeweiligen Dichtung zugewiesen. Dieses folgenreiche Verhältnis von Dichter und Großstadt gründet sich auf eine besondere Konzentration des Lebens und auf die damit verbundene Möglichkeit der unmittelbaren Anschauung einer Gegenwart oder auf günstige Arbeitsbedingungen und ein adäquates Publikum.

Die Ausgestaltung und der Blick auf die literarische urbs Roma sind jeweils überformt von der Reflexion subjektiver Erfahrungen, die sich in der Gattungswahl (Satire, Elegie) niederschlagen. Zum Zeitpunkt der Reflexion befindet sich der Sprecher in Ovids Elegie trist. 1, 1 außerhalb der urbs Roma. Seine Eindrücke beruhen somit auf der Imagination. Seine in vollem Umfang positive Bewertung trägt aufgrund der postulierten unüberbrückbaren Distanz zu einer klagenden Sprechweise und der Wahl der Gattung Elegie bei. In der ersten Satire Juvenals dagegen wird die Reflexion über die Gegenwart in der Sprechweise der Empörung vorgetragen: Der Lebensraum urbs Roma verlange nach derartiger, satirischer Dichtung. Diese Einschätzung basiert im Gegensatz zu Ovids Elegie auf unmittelbarem Erleben einer die Dichter-persona umgebenden großstädtischen Gegenwart. Dennoch übernimmt auch die literarische urbs Roma für ihn die Funktion des Inspirationsraumes.

Juvenal und Ovid sind diejenigen Autoren, die das Verhältnis des Dichters zur Großstadt als besonders folgenreich präsentieren, indem sie dieses unmittelbar in ein poetologisches Programm einbeziehen. Bei einem Blick auf weitere Dichtung der augusteischen und kaiserzeitlichen Epoche wird offensichtlich, dass Autoren den Zusammenhang von Großstadtleben und dichterischem Schaffen des Öfteren zum Gegenstand ihrer Dichtung gemacht und diese Thematik aus recht verschiedenen Blickwinkeln beleuchtet haben. Dem CEuvre des Horaz kommt die besondere Bedeutung zu, sich als erstes mit dem großstädtischen Raum als Inspirationsort auseinandergesetzt zu haben. Bereits hier finden sich unterschiedliche, ja gegensätzliche Bewertungen auf die Großstadt als Lebensraum für Dichter. Die 
literarische urbs Roma ist in diesen Texten bereits nicht nur beliebiger Handlungsraum, sondern Gegenstand und Bezugspunkt dichterischer Reflexion. Im Zusammenhang mit poetologischen Reflexionen äußert sich eine Dichter-persona zwar nicht explizit zur großstädtischen Lebensumwelt, jedoch wird indirekt deutlich, wie sich das dichterische Selbstverständnis ebenfalls vor den Schaffensbedingungen in einer Großstadt abhebt.

(2) Bei der Präsentation des literarischen Raumes handelt es sich jeweils um pointierte Darstellungen einer spezifischen (auch von Gattungskonventionen geformten) Wahrnehmung. Visuell und haptisch nimmt die - zu Beginn der Satire als akustisch überreizt dargestellte - Dichter-persona Juvenals in nächster körperlicher Nähe den Menschenstrom der Großstadt an einer belebten Straßenkreuzung mitten im offenen Raum der Straße von einem festen Standpunkt aus wahr. Als Beobachterin bleibt sie aber auf Distanz und nimmt keinen Kontakt auf. Diese passiv-sinnliche Erkundung mündet dabei unmittelbar in das schriftliche Verfassen von Literatur. Ort und Gegenstand dieser Literatur ist eine vermeintlich großstädtische Realität. Wenn sich das dichterische Schaffen des stilisierten Amateurdichters eigenen Aussagen nach lediglich auf eine schnelle Mitschrift des Beobachtetens beschränkt, so treiben ihn vorwiegend emotionale Erregung und subjektive Erlebnisse zum Schreiben. Die an ihm vorüberziehenden Menschen sind für den poeta keine anonyme Masse, er erkennt und durchschaut sie und kann räumliches Durchsetzungsvermögen und individuelle Raumnahme als gesellschaftliche Anmaßung entlarven. Aus der subjektiven Bewertung unmittelbarer räumlicher Beobachtungen erwächst die Gattung Satire.

Dem elegischen Ich in Ovids erster Tristie dagegen ist die direkte Wahrnehmung der Stadt nach eigener Aussage verboten. Als exclusus poeta befindet es sich - ebenso wie sein nicht direkt zu Wort kommender Dialogpartner, seine Dichtung, außerhalb des literarischen Raumes urbs Roma und betritt auch diesen nicht, sondern fordert sein personifiziertes Buch auf, den Stadtraum mit eigenen Augen zu betrachten, ohne jedoch weitere Erläuterungen und Orientierungshilfen hinzuzufügen. Mit dieser Raumdarstellung nutzt die Dichter-persona die Möglichkeit, die Großstadt vor dem geistigen Auge des Lesers entstehen zu lassen.

Die Entfernung zwischen Dichter-persona selbst und der römischen Metropole wird räumlich größtmöglich ausgebaut und betont den Ausschluss von einem idealen, städtischen Lebensraum, der sich unverzüglich - noch vor dem Erreichen einer vorrangig als Naturlandschaft geschilderten Welt des Exils - auf das dichterische Selbstverständnis und die Einschätzung der vorliegenden Literatur auswirkt. Bereits die gegenwärtige Entfernung lässt den poeta, der einst Talent besaß, uninspirierte und thematisch monotone Elegien von geringem Wert schreiben. Diesen den Umständen abgetrotzten Gedichten und der Leistung des elegischen Dichters sollte jedoch der ideale großstädtische Leser die genügende Achtung entgegenbringen. Der literarische Raum urbs Roma, der im räumlichen Mittelpunkt der ersten Exil-Elegie steht, ist weitgehend als ein Leseraum gekennzeichnet. Er besteht 
aus anonymen Lesern, die nicht visuell, sondern akustisch, in kurzen Dialogpartien in einem offenen Raum kumulativ und statisch präsentiert werden und denen Person und Biographie der Dichter-persona vertraut sind. Der literarische Raum ist daher - im Gegensatz zu Juvenal - nicht als Wahrnehmungsraum großstädtischer Exotik, sondern als ein literarisch überformter Kontaktbereich, als Kommunikationsort für eigene Literatur gestaltet.

Ebenso überformt zeigt sich der Großstadtraum im Cuvre des Horaz, in dem er verschiedentlich Schauplatz ist. Seine Präsentation wird dabei jeweilig auf die Darstellung der Lebens- und Schaffensbedingungen einer Dichter-persona bezogen. In einer audiovisuellen und somatischen Wahrnehmung wird der literarische Raum als ausgedehnt und dicht präsentiert. Diese räumlichen Bedingungen zeigen eine den Dichter überfordernde Lebensumwelt, innerhalb derer anspruchsvolles Dichten kategorisch ausgeschlossen wird. Dem entgegengesetzt steht die StadtraumWahrnehmung eines poeta, der die Darstellung eines Spaziergangs durch den literarischen Raum urbs Roma nutzt, um eine ambitionslose dichterische Existenz den Konventionen des Stadtlebens entgegenzustellen.

Wie bei den anderen Autoren auch ist der literarische Stadtraum vorrangig durch die Straße repräsentiert, auf der sich die jeweilige Dichter-persona zu Fuß bewegt oder steht. Die literarische urbs Roma mit ihren Menschen, dem Gedränge, dem innerstädtischen Verkehr stellt sich der Dichter-persona auf vielfältige Weise in den Weg. Hier begegnen ihr Menschen oder mobile Objekte, die visuelle, akustische oder haptische Herausforderungen des Stadtlebens darstellen, eine Menge in Bewegung und in wechselnden Konfigurationen, bisweilen als unerwartete Begegnungen, bisweilen als mirabilia cottidiana.

Jeder dieser Autoren wählt absichtsvoll einen öffentlichen und offenen Raum der literarischen urbs Roma zur Reflexion über das Dichtersein, nicht private, nachbarschaftliche oder halböffentliche Rückzugsräume. Er wählt keine wilde und bedrohliche Natur, aber auch nicht die ruhige und beschauliche Landschaft. Er stellt das Dichten damit in einen unmittelbaren Lebensbezug zur Großstadt, präsentiert eine Dichter-persona als simultanes Aufzeichnungsmedium, als mental abhängig oder als emanzipiert. Der Lebensraum Großstadt bietet Anschauungsvielfalt, Anregungsreichtum, ein großstädtisches Publikum und Möglichkeiten der Publikation. Sie wird zum Ausgangs- und Zielpunkt, zum Ort des Dichters, dessen Gattungswahl gerade durch einen persönlichen Bezug zur literarischen urbs Roma zur Disposition gestellt wird. Unterschiedliche Sprechweisen zeigen eine Überformung der räumlichen Darstellung von subjektiven Umständen. Sie führen die literarische urbs Roma jedoch überzeugend als adäquate räumliche Umgebung eines Dichters vor. 
Gemeinsam ist diesen sehr verschiedenen Gattungen auch ihre „Distanz zur hohen und großen Dichtung “928, wobei eine derartige Abgrenzung in den Werken unterschiedlich stark ausgeprägt ist. Dem dichterischen Selbstverständnis nach wird das Schreiben von Satiren und Episteln in Horazens Dichtung nicht zur höheren Literatur gerechnet. So spricht die Dichter-persona innerhalb des Werkes häufiger davon, dass sie ihre Dichtung von dem allgemeinen Literaturschaffen absetzen möchte. ${ }^{29}$ Eine derartige Absage kann vergleichbar mit Juvenals erster Satire als ein avantgardistisches und innovatives Infrage-Stellen eines etablierten Literaturverständnisses gewertet werden. Unelitäre und gleichzeitig selbstbewusste Selbstzuschreibungen werden auch in der ovidischen Exilliteratur zur Stilisierung einer elegischen Dichter-persona eingesetzt. Und in den Epigrammen Martials werden angebliche Qualitätsschwankungen ,als besonderes Charakteristikum der Epigrammdichtung begründet“ und ein „eigenes Wertesystem für die Epigrammdichtung etabliert und damit letztlich sogar eine Überlegenheit gegenüber anderen Gattungen beansprucht. ${ }^{\text {(6930 }}$

Die Poetizität ${ }^{931}$ dieser Literatur ist jedoch evident wie auch diese Werke Zeugnisse hohen handwerklichen Könnens sind und den Autoren ausgewiesene Kenntnisse verschiedener Gattungskonventionen bescheinigen. Die Abgrenzungen entspringen demzufolge vorwiegend einer Haltung der Autoren gegenüber einem vorherrschenden Literaturbegriff, von dessen Vorstellungen und Konventionen sie sich explizit in Themen- und Gattungsgenese abgrenzen wollen. Demzufolge handelt es sich bei den hier näher untersuchten Texten um newartige Kunstwerke, die sich bewusst nicht mehr an kanonisierte Normen halten. Mit dieser Haltung stehen sie in einer Tradition, deren Spuren zur hellenistischen Literatur führen.

Als innovativ sind diese Werke bisher vor allem in formaler Hinsicht bezeichnet worden, als sie eben einen experimentellen Umgang mit Gattungen pflegen ${ }^{932}$ und alle hier ausgewählten Vertreter der augusteischen und kaiserzeitlichen Epoche

928 Cancik (1974), 261.

929 Vgl. Hor. sat. 1, 1, 120 f., 1, 4, 73, epist. 1, 19, 35-49. Vgl. auch Pers. 1, 8-12 und Kißel (1990), 105-105; 121. In der Programmsatire Hor. sat. 1, 4, $39-44$ findet sich die Erklärung, dass der Dichter die Gattung Satire nicht zur Dichtung gezählt wissen will. Vgl. Schmidt (2001), 175-178, der dafür plädiert, dass auch der fehlende Musenanruf nicht nur „bloßer gedankenloser Nachvollzug der satirischen Gattungstradition war. (...) Wir können also davon ausgehen, daß Horaz mit seinem Verzicht auf die Musen (...) eine bewußte Entscheidung getroffen hat. Als Satiriker und Jambiker ist der Dichter allein, will und muß er allein sein, ohne göttliche Berufung, Anregung, Hilfe. Er ist unabhängig, eigenständig, ein Individuum, das der Welt gegenübersteht." Vgl. ebd., $177 \mathrm{f}$.

930 Johannsen (2006), 188 f. Ausführlich zur Selbstdarstellung als Dichter ebd., 122-226 mit zahlreichen Belegen und weiterführender Literatur.

931 Vgl. Lausberg (42008), \ 1115, A 1), p. 535 zum modus poeticus: „(...) der Dichter bedient sich poetischer Mittel, also des Verses und der poetischen Sprach- und Gedankenlizenz.“

932 Vgl. zu Ovids Gattungsexperimenten Holzberg (1997), 20-30. 
den Gattungen - aus heutiger Perspektive - für deren weitere Entwicklung entscheidende, neue Impulse gaben. ${ }^{933}$ Eine inhaltliche Innovationsleistung dieser Literatur könnte man darin sehen, dass sich die Autoren mit einer spezifischen Zeiterscheinung ihrer Gegenwart - dem Lebensraum Großstadt - dichterisch auseinandersetzen und damit quantitativ mehr Elemente der äußeren Welt - im Gegensatz etwa zur vergilischen Epik - absichtsvoll integrieren oder vorgeben, sie zu integrieren.

Nach formalen Gesichtspunkten wird die größte Gruppe aller dieser Untersuchung zugrunde gelegter Werke unter die sogenannten ,Kleinen Gattungen“ subsumiert. ${ }^{934}$ Was sie kennzeichnet: Sie sind auf Kürze, auf Kommunikation, auf Impression hin angelegt. Gerade diese Merkmale wirken sich nicht unerheblich auf die Darstellung des literarischen Raumes urbs Roma aus. Sie sind wesentlich dafür verantwortlich, dass der Eindruck einer ,partikulare[n] Perspektive“9935 auf den literarischen Raum urbs Roma erzeugt wird.936

Aus dem äußeren Umfang des Einzelgedichts ergibt sich eine kurze und prägnante Schreibweise. Man widmet dem jeweiligen Gegenstand keine längere Auseinandersetzung, sondern deutet ihn in kurzen Partien lediglich an. Erwartet werden kann daher keine erschöpfende und ausführliche Behandlung der literarischen Großstadt mittels epischer Ekphrasis, sondern improvisatorisch, impressionistisch gestaltete Skizzen. Ist folglich die Großstadt in der römischen Literatur kein Gegenstand epischer Langdichtung geworden, so wurden diese Einzelgedichte doch in Büchern und Büchersammlungen zu einer Einheit zusammengefasst ${ }^{937}$, die den

933 Vgl. Cancik (1974), 263: „Mit Persius und Juvenal entsteht die Satire im modernen Sinne des Wortes, mit Martial das ,moderne Epigramm', der kurze pointierte Sinnspruch.“

934 Vgl. Cancik (1974). Allgemein zu,Kleinen Gattungen' vgl. Lausberg (42008), \ 1242. Bei den römischen Literaturtheoretikern Cicero, Horaz und Quintilian ist eine Fülle der heute gebräuchlichen Gattungsbegriffe (Elegie, Satire, Pastorale) schon vorhanden. Vgl. Harris (1992), 116. Nicht zu den ,Kleinen Gattungen' sind Ovids Fasti und die ars amatoria zu rechnen. Beide gehören formal zur Gattung des Lehrgedichts, zeigen jedoch ebenfalls deutliche Brüche mit der entsprechenden Gattungskonvention auf. So sind sie z. B. im elegischen Distichon, statt des üblichen Hexameters verfasst. Für die Fasten gilt zudem das Gebot der Kürze, als sie durch ihre Anlage entlang des Kalenders ebenfalls episodenhaft sind.

935 Stierle (1993), 53.

936 Als klein werden sie bezeichnet, da sie nicht den Umfang einer $\pi \varrho \tilde{\alpha} \xi ı \varsigma$ haben wie das Epos und das Drama, also wesentlich kürzer gestaltet sind. So geben sie einen kurzen Dialog oder allein die Antwort auf eine intendierte Frage wieder. Diese Art und Weise der Präsentation wirkt aber so, als ob sie aus einer umfassenderen Form - nämlich einem Drama oder einem Epos - herausgebrochen wären, und um die Rekonstruktion eines Hintergrundes ergänzungsbedürftig wären. Diese Ergänzungen erfolgen in den ,Kleinen Gattungen' außerhalb des in sich geschlossenen und selbstständigen Gedichts „durch die Erlebnisbreite des Autors oder des Publikums“. Lausberg (42008), 601.

937 In augusteischer Zeit beginnen die Dichter ihre Gedichte in Buchform anzuordnen und herauszugeben. Eine entscheidende Veränderung liegt darin, dass bei der Zusammenstellung der Ge- 
jeweiligen fragmentarischen Charakter des Einzelgedichts um weitere Perspektiven ergänzt. Durch die Lektüre des Gesamtwerkes wird „(...) das mit dem Anspruch einer kleinen (...) Einheit auftretende Fragment [in] die umfassendere Einheit des Lebens integriert". .938 Anders gewendet kann man die Innovationsleistung dieser Autoren wie folgt beschreiben: Als besondere Herausforderung der Darstellung des Makroraums ,Großstadt' gilt in der Moderne das Selektionsproblem. ${ }^{939}$ Die römischen Dichter haben die Darstellung dieser materia durch den Griff zu fragmentierenden ,Kleinen Gattungen' gelöst. Man hat einen Makroraum, der sich der Wahrnehmung eines Einzelnen entzieht, in kurzen, skizzenhaften Erzähl-Vignetten präsentiert, die eng an die Perspektive eines subjektiven, meist einzigen Sprechers gebunden sind. Diese wiederum stehen sich gegenüber in Buchsammlungen, aus denen sich wie in einer Collage eine panoramische Sicht des literarischen Raumes ergeben kann.

Auswirkungen auf die Darstellung des literarischen Raumes ergeben sich auch aus der vornehmlich dialogischen Anlage dieser Gattungen. In der szenischen oder monologischen Präsentation halten die Autoren die Fiktion eines Kommunikationsraumes aufrecht. Der damit verbundene Einsatz deiktischer Referenzen hinterlässt den Eindruck einer unmittelbaren Gegenwärtigkeit des dargestellten Raumes wie im Drama. ${ }^{940}$ Trotz aller Suggestion von Mündlichkeit und auch trotz anzunehmender mündlicher Vortragsweise ist jedoch nicht bekannt und auch nicht wahrscheinlich, dass diese Texte durch eine Bühne als außersprachlich existierender Raum unterstützt worden sind. ${ }^{941} \mathrm{Im}$ Gegenteil unterscheiden sie sich doch genau darin von der audiovisuellen, mimetischen Raumkonzeption des Dramas. Wie bei allen erzählenden Texten bleibt auch in diesen ,Kleinen Gattungen' eine direkte Anschauung des Raumes unmöglich. Der Leser bedarf einer Vermittlung. Diese Vermittlungsinstanz kann durch die zwanglose und gesprächsnahe Gedankenführung - in einem sehr viel höherem Maße als das Drama - unterschiedliche räumliche Gegebenheiten in schnellem Wechsel integrieren: Zum einen kann sie durch die Kürze des Einzeltextes innerhalb einer Buchsammlung Ereignisregionen und Schauplätze von Gedicht zu Gedicht rasch wechseln, zum anderen kann sie innerhalb eines Gedichtes durch diese charakteristische vorgeblich spontane und dialogische Gesprächsführung einen Schauplatz um weitere Ereigniszonen ergänzen. Anders betrachtet heißt dies für die Innovationsleistung der Autoren: Die Darstellung eines literarischen Makroraumes wie der Großstadt ist durch die Simultanität der Geschehensabläufe zwangsläufig an die Integration mehrerer Berei-

dichtsammlungen nicht mehr an einen impliziten Hörer, sondern an einen Leser gedacht wird. Vgl. Fantham (1998), $57 \mathrm{f}$.

938 Lausberg (42008), 601.

939 Vgl. Severin (1988), 16.

940 Vgl. Pfister (112001), 23.

941 Laut Braund (1989), 4 hält Livius die Satire für eine dramatische Gattung. 
che gebunden. Genau dieses räumliche Darstellungsproblem löst die römische Dichtung durch die Möglichkeiten räumlicher Vermittlung, wie sie die ,Kleinen Gattungen" bieten.

Durch die Kürze und die dialogische Ausrichtung fehlt in diesen ,Kleinen Gattungen' eine durchgängige Erzählinstanz, die als übergreifendes Orientierungszentrum die verschiedenen Figurenperspektiven ordnen und werten kann, bzw. eine derartige Erzählinstanz ist nur implizit vorhanden. ${ }^{942}$ Stattdessen erlauben es die neuartigen Gattungen, verschiedene Stimmen innerhalb eines Euvres und auch innerhalb eines Einzeltextes gegeneinander zu stellen. In der Bewertung des Dargestellten wird der Leser durch die Sicht des in der ersten Person Sprechenden zwar vereinnahmt, gleichzeitig lässt aber die offene Dialogtechnik eine unbegrenzte Wahl von möglichen Gesprächspartnern zu. Ein vermittelter Raumeindruck kann so infrage gestellt, ergänzt, bestätigt werden. Anders gewendet: Die Darstellung der Großstadt ist zwar vor allem an subjektive Perspektiven gebunden, aber durch die Vielfalt an Stimmen und die dialogisch ausgerichtete Gesprächsweise wird sie multiperspektivisch dargestellt. ${ }^{943}$ Dadurch gelingt es, gerade das Phänomen Großstadt mit ihrer Vielzahl an Menschen und Plätzen in einen unmittelbaren Lebenszusammenhang zu stellen.

942 Vgl. Pfister (112001), 336.

943 Vgl. Aristot. Poet. 7. 


\section{$5 \quad$ Zusammenfassung}

Die Großstadt als literarischer Raum in der lateinischen Dichtung der augusteischen und kaiserzeitlichen Epoche ist eine literaturwissenschaftliche Studie, die einen text- und gattungsübergreifend literarisierten Raum, nämlich die Großstadt, auf seine räumliche Ausgestaltung hin untersucht und versucht, seine darstellerische Relevanz für die Dichtung der augusteischen und kaiserzeitlichen Epoche auszuloten.

Anlass zu dieser Untersuchung war das Urteil der modernen Literaturwissenschaft, die Großstadt sei kein Gegenstand antiker Literatur gewesen. Dieses Urteil, das sich verschiedentlich und unwidersprochen in Handbüchern und Literaturgeschichten findet, ist in seiner Bestimmtheit überraschend. Wenn man sich die Frage stellt, wo dieses oder jenes literarische Werk spielt, so muss man für zahlreiche dichterische Werke der augusteischen und kaiserzeitlichen Epoche konstatieren: Der Handlungsort dieser Literatur ist Rom, und zwar ein Rom, das zweifellos einen urbanen Raum darstellen soll. Im Werk des Horaz, bei Properz, Tibull und Ovid, wie auch in den Epigrammen Martials und in den Satiren Juvenals ist die Großstadt Rom ausnehmend häufig Ort der Literatur, und viele ihrer ,topographischen Merk- und Wahrzeichen' werden zu einem Bestandteil der erzählten Welt. Allein durch die Beobachtungen an der Lexik lässt sich die Präsenz der Großstadt in dieser Literatur belegen: Neben dem Toponym Roma, der Gattungsbezeichnung urbs und Referenzen auf topographische Merk- und Wahrzeichen der Metropole Rom tauchen - vor allem mit und nach Horaz - vermehrt Referenzen auf städti- 
sche ,Teilelemente' auf. Durch die Wiederkehr derartiger Referenzen kann man berechtigterweise von einer ,Konstitutionsisotopie' Großstadt in diesen Texten sprechen.

Der Umstand, dass sich alle hier untersuchten Großstadt-Texte in eindeutiger Weise, wenn auch in unterschiedlicher topographischer Exaktheit und Anschaulichkeit, auf den Georaum Rom beziehen und keine gänzlich fiktionale räumliche Darstellung vorweisen, ist ein gemeinsames stilistisches Charakteristikum ${ }^{944}$, auch wenn das Darstellungsinteresse der Autoren an einem vor allem großstädtischen Raum nicht in Frage steht. Denn dass es den Autoren gerade um die Präsentation großstädtischer Physis ging, lässt sich an denjenigen Passagen ablesen, die weniger stark auf eine stadtrömische Topographie referieren, sondern die lediglich ,zonal ${ }^{6}$ auf den Georaum bezogen sind. In diesen Passagen greifen die Autoren nicht nur auf typisch städtische Teilelemente wie benachbart liegende Häuser, das Forum oder Tempel zurück, sondern sie wählen gerade vorrangig großstädtische Teilelemente wie den Circus, das Theater, besonders hohe Häuserfronten oder Straßenverhältnisse, die sich durch eine enorme Verkehrsdichte auszeichnen.

(A) In einem ersten Abschnitt wurde untersucht, mit welcher Physis dieser literarische Raum aus den Texten hervortritt: Der literarische Raum urbs Roma wird wiederholt in der Dichtung der augusteischen und kaiserzeitlichen Epoche als besonders groß und unbegrenzt, als ein enger, dichter Raum mittels entsprechender Attribute charakterisiert. Diese Eigenschaften werden in den Texten auch räumlich ausgestaltet und spielen in den unmittelbaren Lebenszusammenhang der Figuren hinein. Darin zeigt sich, dass auch in dieser Literatur räumlichen Strukturen eine Bedeutung, die über die obligatorische Verortung einer Handlung hinausgeht, zugewiesen wurde. Aus dem Zusammenspiel verschiedener raumbezogener Informationen lassen sich wiederkehrende räumliche Strukturen identifizieren, die nicht als partikulare, individuelle Merkmale eines innerstädtischen Raumausschnitts präsentiert, sondern die in einen direkten Zusammenhang mit dem umfassenden Makroraum urbs Roma gestellt werden.

(1) Von den dreidimensionalen Eigenschaften eines Raumes tritt vor allem seine flächige Ausdebnung in das Bewusstsein und charakterisiert die literarische urbs Roma in besonderer Weise als einen Makroraum. Dieses räumliche Merkmal wird in vielen Texten als ein Erfahrungswissen der Figuren vorausgesetzt. Es bestimmt das Leben der literarischen Bewohner wesentlich. Das Überwinden von großen Distanzen gehört zu einer Normalität ihrer Lebenswelt, in der soziale Kontakte insbesondere über einen ausgedehnten Raum hin gepflegt werden. Dass gerade nicht die nachbarschaftlichen Kontakte im Mittelpunkt der Darstellung eines Alltagsgeschehens stehen, weist eindringlich auf dieses besondere Merkmal des Raumes hin.

944 Zur Raumdarstellung als stilistischem Merkmal vgl. Würzbach (2001), 45. 
Die Abstände der einzelnen „Bereiche untereinander werden weniger metrisch angegeben, sondern es besteht wiederholt ein innerliterarischer Konsens darüber, dass einzelne Bereiche innerbalb des Raumes Großstadt weit auseinander liegen. Die Figuren verbinden das Überwinden der Distanzen zudem mit einem körperlichen Kraftaufwand und unterscheiden zwischen zumutbaren und unzumutbaren Distanzen. Ausgestaltet wird folglich die besondere Ausdehnung des Makroraums aus seinem Inneren heraus durch das Zurücklegen von Entfernungen und dem zügigen Durchschreiten eines Raumes, dessen Grenzen dabei nicht erreicht werden. Die tatsächliche Ausdehnung der literarischen urbs Roma geht in der augusteischen und kaiserzeitlichen Dichtung stets über die in den Texten verwirklichte Bewegung hinaus.

Die besondere Ausdehnung des literarischen Raumes urbs Roma tritt des Weiteren dadurch ins Bewusstsein, dass die Mobilität der Figuren zwischen den disparaten Bereichen auch als eine Alltagserscheinung beschrieben wird. Die iterative Form des Erzählens weist den Leser darauf hin, dass Distanzen von den Figuren alltäglich zurückzulegen sind, wobei mehrere Bereiche zum Teil in einer festen Abfolge und innerhalb eines Tages angesteuert werden. Wenn nicht mehr nur eine einzelne Distanz und das Erreichen eines bestimmten Ziels im Fokus steht, sondern eine Reihe von Bereichen auf einer Wegstrecke angesteuert werden, so trägt dies zur Vorstellung eines großflächigen, räumlichen Kontinuums ${ }^{6}$ bei.

Die häufig literarisierte Bewegung durch die Großstadt ist in der Regel ziel- und zweckgebunden. Als Bewegungsanlass wird auf soziale Verpflichtungen verwiesen, denen die Figuren nachkommen. Die den Figuren dabei zur Verfügung stehende Zeit spielt für die Geschwindigkeiten der Fußgänger eine herausgehobene Rolle. Durch die besondere Ausdehnung des Raumes ist es möglich, zu spät zu kommen. Daher sind die Figuren teilweise in hohem Tempo unterwegs.

Trotz der Bewegungsanlässe, die dem Zusammenleben innerhalb der urbs Roma geschuldet sind, ist die Großstadt nicht allein als ein sozialer Raum gestaltet. Die Ausgangs- und Endpunkte dieser innerstädtischen Strecken bzw. die Tätigkeiten und Ereignisse innerhalb dieser Bereiche werden häufig nur kurz angedeutet. Im Mittelpunkt steht dagegen das Ereignis des Laufens selbst.

Das In-Bewegung-Sein wird als individuelle Erfahrung beschrieben oder an Anderen werden entsprechende Auswirkungen beobachtet: Die Figuren nehmen an sich und anderen körperliche Reaktionen wie Schwitzen, Erschöpfung oder Krankheit wahr oder versuchen sich, von einem allgemeinen Bewegungszwang zu emanzipieren. Das Passieren der Straße selbst wird ebenfalls als körperlich-sinnliche Erfahrung eines offenen und öffentlichen Raumes präsentiert, indem sie mit Unwägbarkeiten, wie Wetterverhältnissen oder einem hohen Verkehrsaufkommen, konfrontiert werden. Wenn sich der Einzelne durch sich ebenfalls bewegende Menschenmassen hindurch begeben muss, wird die als Alltagserfahrung eines Individuums beschriebene Mobilität zu einem allgemeinen Merkmal des Raumes gesteigert. Es sind wichtige Alleinstellungsmerkmale der literarischen Großstadt in 
römischer Dichtung, dass in ihr zentrale Bereiche des Alltags weit auseinander liegen und die Figuren, die sich in diesem Raum befinden, von einer allgemeinen Mobilität erfasst sind.

(2) Trotz der enormen Distanzen zwischen einzelnen innerstädtischen Bereichen wird die literarische urbs Roma als ein begrenzter Raum vorgestellt. Dies wird in all denjenigen Texten deutlich, in denen sich die Figuren auf kürzere Reisen zu ihren eigenen Landgütern oder in nahegelegene Landstädte begeben. Die Gren₹̨bereiche des literarischen Raumes urbs Roma wie auch Zonen einer Peripherie - etwa eine langsame Abnahme von städtischen Merkmalen - werden allerdings selten ausgestaltet. Grenzlinien, seien es Mauern oder ein Flussverlauf, werden zwar benannt, aber nicht in einer Erzählgegenwart veranschaulicbt, sondern lediglich im Hinblick auf ihre myth-historische Vergangenheit erwähnt. Dieses Negativergebnis ist bemerkenswert, da gerade antike Städte eine kultisch relevante Grenze besaßen und Mauern im Zusammenhang mit anderen städtischen Siedlungen auch in der Dichtung als ein sehr zentrales städtisches Teilelement in Erscheinung treten. Es gibt Indizien dafür, dass man die Ausgestaltung der Grenzbereiche absicbtsvoll unterlassen hat, um der literarischen urbs Roma im Hinblick auf ihre räumliche Ausdebnung einen besonderen Status zuzuweisen. Eine Übersteigerung dieses räumlichen Merkmals zeigt sich in der häufig wiederkehrenden Vorstellung, dass urbs und orbis auch räumlich identisch seien. Diese Vorstellung der Ent-grenzung lässt sich auch an den wenigen Passagen belegen, in denen Zugangsbereiche zur Stadt - wie das Areal um Stadttore - in ihrer Physis dargestellt werden. Die in den Mittelpunkt gerückten Ereignisse, wie Abschied und Begrüßung, stellen zwar derartige Bereiche in einen markant konkreten Lebenszusammenhang, die erwartbare Unterscheidung von typischen räumlichen Merkmalen eines Innen und Außen steht jedoch nicht im Fokus einer räumlichen Ausgestaltung, sondern vielmehr Beobachtungen und Erfahrungen von Prozessen der Verstädterung des Umlandes. Hinsichtlich der Frage nach der Durchlässigkeit dieser Grenze wird auf die Expansion städtischer Merkmale von innen nach außen aufmerksam gemacht, was mit differenten Bewertungen einhergeht. Von einer einseitigen Ablehnung des Städtischen kann dabei nicht die Rede sein. Zu beobachten ist des Weiteren eine Tendenz zu einer geradezu augenfälligen Literarisierung bei der Ausgestaltung der Grenzbereiche, wie beispielsweise die Metamorphose einer Landschaft.

(3) Mit dem Merkmal der Dichte bəw. des Plat2̧mangels tritt eine Eigenschaft der inneren Struktur des literarischen Raumes in den Vordergrund, die zum einen im Zusammenhang mit einer dichten Bebauungssituation vorgeführt wird, zum anderen sich auf eine Konzentration von Menschen bezieht, deren Ursachen in der Simultanität der Geschehensabläufe innerhalb bestimmter Bereiche liegen.

Die dichte Bebaunng wird innerhalb einzelner ,räumlicher Ensembles ${ }^{`}$ - überwiegend an Wohn-, Arbeits- und Straßenverhältnissen - veranschaulicht. Eine Ausgestaltung der räumlichen Verhältnisse erfolgt dadurch, dass der zur Verfügung stehende Raum gleichzeitig von mehreren Figuren als Wohn-, Arbeits- oder öffentlicher 
Transitraum genutzt wird. Aus Figurenperspektive verbinden sich damit Erlebnisse des Übergreifens räumlicher Strukturen auf individuelle Territorialisierungen, insofern die räumliche Beengtheit für sie zu Bewegungshemmnissen führt oder sich in fehlenden Rückzugsmöglichkeiten zeigt. Die Präsentation dieser Bereiche als ,Kontaktzonen“, die von einer hohen Besiedelungsdichte, einer differenzierten Arbeitsteilung und Transitverkehr geprägt sind, steht im Kontrast zu einer ausbleibenden Präsentation einer Interaktion der einzelnen Figuren mit ihrer Lebensumwelt, was als Zeichen ihrer Beziehungslosigkeit und inneren Distanz zu ihr gewertet werden kann.

Im Vergleich zur Präsentation anderer räumlicher Merkmale ist bei der Darstellung räumlicher Dichte die text- und gattungsübergreifende Heterogenität der fiktiven Meinungen auffällig. Inwieweit eine Kennzeichnung des literarischen Raumes als dicht im Sinne von eng bebaut für den literarischen Großstadtraum Rom adäquat ist oder nicht, wird widersprüchlich bewertet. Der Illusionsbildung der Dichtung zufolge zeigt die literarische urbs Roma sowohl eine durchgehend enge Bebauung als auch eng bebaute und weniger eng bebaute Gebiete, oder sie entbehrt einer derartigen inneren Struktur völlig. Neben dieser innerliterarischen Mehrstimmigkeit fällt des Weiteren auf, dass gerade diejenigen Bereiche, an denen das räumliche Kennzeichen der Dichte ausgestaltet wird, recht vage im Georaum der realen Metropole verankert sind. Damit entziehen sich die Autoren einer genauen Nachprüfbarkeit ihrer räumlichen Ausgestaltung durch den Leser. Dies erlaubt ihnen größeren Freiraum. Es handelt sich bei der engen Bebauungssituation demzufolge um ein räumliches Merkmal, an dem die Literarisierung des Raumes besonders ausgeprägt ist.

Aus der enormen Einwohnerzahl, die als Alleinstellungsmerkmal der literarischen Großstadt verschiedentlich in der Dichtung genannt wird, ergibt sich die Formierung von innerstädtischen Konzentrationspunkten. Zu den Zielpunkten gehören räumlich umgrenzte, innerstädtische Bereiche wie das Forum, das Theater oder der Circus. In der Liebeselegie wird auf den Vorteil dieser besonderen Raumkonstellation für das Anliegen ihrer Dichtung hingewiesen. Dargestellt werden die räumlichen Verhältnisse besonders eindrücklich bei der Nutzung des öffentlichen Straßenraums. Die Konzentration an Menschen auf engstem Raum wird dabei wiederholt aus der Perspektive eines einzelnen Passanten, von einer, Wahrnehmungsinstanz ${ }^{6}$, aus dem Inneren der Menschenmasse heraus wiedergegeben.

Der Menschenstrom ist unaufhörlich in Bewegung und als solcher für die Wahrnehmungsinstanz visuell, akustisch und haptisch wahrnehmbar. Der körpernahe Wahrnehmungsmodus schafft kleine, auf engste Nähe gerichtete Bereiche und verdeutlicht dabei eindrücklich die Eingebundenheit des Einzelnen in die innere Struktur des literarischen Raums urbs Roma, zeigt er doch das Individuum in seiner kollektiven Existenz innerhalb des Makroraums. Die Figuren bleiben jedoch zueinander auf Distanz. Ein individueller sozialer Kontakt findet nicht statt. Im 
Mittelpunkt steht vielmehr die Erfahrung der räumlichen Struktur am eigenen Körper, die sie als Hemmnis, Einschränkung und sogar als Gefahr empfinden.

Dieser eindrücklich präsentierte Straßenraum ist nur vage im Georaum der Metropole Rom verankert. Ein genauerer Straßenverlauf lässt sich der Darstellung ebenso wenig entnehmen wie alternative Wege oder Abkürzungen. Im Gegenteil: Die Menschenmasse selbst wird wie ein eigenständiger innerstädtischer Bereich präsentiert, in den man sich hineinbegibt, den man passiert und dessen räumliche Merkmale trotz voranschreitender Eigenbewegung konstant bleiben. Das vorübergehende räumliche Merkmal wird in einer präsentisch-iterativen Erzählweise und nicht auf bestimmte Intervalle beschränkt vorgeführt. Verdichtungen im Straßenraum gehören zu den festen Eigenschaften einer inneren Struktur des literarischen Raums, die sich auf den Lebensalltag der Figuren wesentlich auswirken.

Alle diese räumlichen Merkmale sind raumgebundene Eigenschaften. Gemäß der literarischen Fiktion können sich die Figuren allein durch Emigration diesen Eigenschaften entziehen. Werden innerstädtische Alternativen genannt, sind sie als ,Kontrasträume ${ }^{6}$ ausgestaltet und ihnen wird ein städtischer Charakter abgesprochen.

Der literarische Raum urbs Roma wird in der römischen Dichtung als ,Ereignisregion' beschrieben und als ,Wahrnehmungsbereich' geschaut, gehört, gefühlt. Die Ausdehnung des Raumes, die beengte innere Struktur oder der Reichtum an Menschen sind nicht nur behauptete Eigenschaften, sondern werden als eine körperlich wahrnehmbare Vorstellung aus der Figurenperspektive veranschaulicht. Der offene und öffentliche Straßenraum mit seinem Transitcharakter ist dabei der häufigste ,Schauplatz ${ }^{\prime}$ in der römischen Großstadtdichtung. Ihm wird damit ein besonderer Stellenwert zugeschrieben, um die Spezifika einer Großstadt als Lebensumwelt der Figuren darzustellen. Hier bahnen sich die Figuren einen Weg durch die literarische Großstadt hindurch. Sie begeben sich weit weniger zu Standorten, an denen sich ihnen ein unverstellter Blick bietet. Aus diesem folglich äuBerst engen Bezug zwischen Raum und multisensuell wahrnehmenden Figuren aus dem Inneren heraus lässt sich ein übergreifendes Bewusstsein für die Spezifika des Makroraumes in konkreten Lebenszusammenhängen nachweisen.

(B) In einem zweiten Abschnitt wurde dargestellt, wie die Großstadt als spezifischer Raum zu einem Gegenstand poetischer Reflexion geworden ist. Dazu wurde in aller Allgemeinheit abgesteckt, inwieweit römische Autoren zu einer reflexiven Auseinandersetzung mit den besonderen Spezifika einer Großstadt gelangt sein können. Sowohl biographische Erlebnisse - etwa der Umzug als Heranwachsende in eine Metropole - wie die Auseinandersetzung mit der Stadt- und Landthematik während des Ausbildungsunterrichts zum Rhetor könnten einen derartigen Prozess in Gang gesetzt haben. Ein singuläres, aber einschlägiges Zeugnis über eine persönliche Verhältnisbestimmung zur großstädtischen Lebensumwelt bietet die praefatio zum 12. Epigrammbuch Martials. In ihr äußert sich der Autor ausführlich 
zu den Entstehensbedingungen seiner Literatur und schreibt der Großstadt ausdrücklich ausgenommen gute Schaffensbedingungen zu.

Aus der Gegenüberstellung dieser werkexternen Aussage mit werkimmanenten Stellungnahmen, die eine Dichter-persona zu den Schaffensbedingungen in der Großstadt trifft, wird ersichtlich, dass es sich innerhalb des CEuvres Martials um bewusst poetisierte Auseinandersetzungen handelt. Die Verhältnisbestimmung von Dichter-Sein und Großstadt ist zweifelsfrei ein Gegenstand römischer Dichtung. Die gegensätzlichen Aussagen, die sich innerhalb eines CEuvres finden, verweisen auf eine Vielfalt von Perspektiven auf die Großstadt als einen Lebens- und Inspirationsraum für Dichter, auf literarische Pose oder Ironie. Derartige Reflexionen über die Großstadt und den Dichter finden sich neben Martial in den Werken des Horaz, Ovids und Juvenals.

In der Exildichtung Ovids und den Satiren Juvenals wird das Verhältnis des Dichters zur Großstadt als besonders folgenreich bewertet. Sie beziehen es in programmatischen Texten in ein poetologisches Selbstverständnis ein. Gemeinsam ist diesen Texten die in ihnen geäußerte Überzeugung, dass beide Dichter der Großstadt ihre Dichtung verdanken. Die Bewertung dieses Verhältnisses ist allerdings unterschiedlich und von Gattungskonventionen überformt: Während sich in der ersten Satire Juvenals eine Dichter-persona über die ihn umgebende großstädtische Menschenmasse empört und damit simultan die Gattungswahl Satire legitimiert, führt die unüberbrückbare Distanz zur Großstadt zu der klagend-elegischen Sprechweise der Exil-Elegie. Da im Allgemeinen programmatische Texte in der augusteischen und kaiserzeitlichen Epoche Teil des bereits literarisch überformten Cuvres sind, kann eine Autorenintention hinsichtlich der aufgeworfenen Großstadtproblematik nicht offengelegt werden, wohl aber kann festgestellt werden, dass die Autoren die Großstadt zu einem Thema und zum Gegenstand an sehr zentralen Stellen ihrer Werke machten. Dem CEuvre des Horaz kommt die besondere Bedeutung zu, dass hier das erste Mal - wenn auch nicht in programmatischen Texten - zur großstädtischen Lebensumwelt als einem Inspirationsraum für einen Dichter Stellung bezogen und bereits in recht unterschiedlichen Bewertungen über die Großstadt im Hinblick auf das Kunstschaffen reflektiert wird.

Diese mit und nach Horaz einsetzende neue Qualität der literarischen Auseinandersetzung mit der Großstadt erfolgt im Gravitationszentrum einer innovativen, experimentellen Literatur, und ihre besonderen gattungsspezifischen Merkmale haben eine nicht unerhebliche Auswirkung auf die Ausgestaltung des literarischen Raumes urbs Roma. Die Großstadt wird in vergleichsweise kurzen, beinahe skizzenhaften Erzähl-Vignetten eingefangen und ihre Darstellung ist eng an den Blickwinkel weniger, meist einzelner Personen gebunden, gleichzeitig wird der Leser als Gegenüber direkt angesprochen und in diese Wahrnehmungsperspektive einbezogen. Diese Literatur zeigt ihren Handlungsort und Gegenstand damit nicht in einem panoramischen Gesamtbild, sondern mosaikartig und multiperspektivisch. Jedoch bedeutet dies nicht, dass die Präsentation partikular bleibt und sich 
in einer Fülle räumlicher ,Inseln ${ }^{6}$ und wechselnder unverbundener Einzelschauplätze erschöpft. Immer wieder werden Hinweise vergeben, dass die mehrdimensionale, multisensuelle Wiedergabe eines Raumausschnitts aus der Perspektive einer einzelnen Figur als repräsentativ für den übergeordneten Raum zu verstehen ist. Durch das Übereinanderlegen der zahlreichen, verschiedenen literarischen Verarbeitungen entsteht eine konsistente Vorstellung eines literarischen Raumes, genannt urbs Roma, in der römischen Dichtung. 


\section{Bibliographie}

\subsection{Quellen 946}

Amm. Ammianus Marcellinus, rec. V. Gardthausen, 2 Bd., Stuttgart 1967.

Apoll. Rhod. Apollonii Rhodii Argonautica, rec. H. Fränkel, Oxford 1961.

Aristeid. Aelii Aristidis Smyrnaei quae supersunt omnia, rec. B. Keil, Bd. 2, Leiden 1968.

Aristot. an. Aristotelis de anima liber, rec. W.D. Ross, Oxford 1963.

Aristot. The Athenian constitution, The Eudemian Ethics on virtutes eth. Eud. et vices, ed. with Engl. transl. H. Rackham, Aristotle in XXIII volumes, Vol. 20, Cambridge 1971.

Aristot. Poetik Aristotelis de arte poetica liber, rec. I. Bywater, Oxford 21938. Aristot. sens. Aristotelis de sensu et de memoria libri, ed. A. Förster, Budapest 1942.

Calp. ecl. Calpurnii et Nemesiani Bucolica. Einsidelensia quae dicuntur carmina, ed. C. Giarratana, Turin ${ }^{3} 1943$.

946 Abkürzungen folgen in der Regel nach $D N P$, wurde ein Autor dort nicht erfasst, nach $O L D$. 
Catull.

Cic. Brut.

Cic. de or.

Cic. fin.

Cic. nat. deor.

Cic. orat.

Cic. rep.

Claud.

Demokrit

Dion. Halik.

Gell.

Heraklit

Herod.

Hom. Il.

Hom. Od.

Hor. ars, carm., carm. saec., epist., epod., sat.

Iuv.

Iuv. [ed. Braund]

Kall. fr.

Liv.
C. Valerii Catulli Carmina, rec. R. A. B. Mynors, Oxford 1972. M. Tulli Ciceronis Rhetorica, Tom. I, rec. A. S. Wilkins, Oxford 1970.

M. Tulli Ciceronis Scripta quae manserunt omnia, Fasc. 3. De oratore, ed. K. F. Kumaniecki, Stuttgart et al. 1995.

M. Tulli Ciceronis Scripta quae manserunt omnia, Fasc. 43. De finibus bonorum et malorum, ed. Th. Schiche, Stuttgart 1961.

M. Tulli Ciceronis Scripta quae manserunt omnia, Fasc. 45. De natura deorum, ed. W. Ax, Stuttgart 1961.

M. Tulli Ciceronis Rhetorica, Tom. II., rec. A. S. Wilkins, Oxford 1970.

M. Tulli Ciceronis Scripta quae manserunt omnia, Fasc. 39. De re publica, ed. K. Ziegler, Leipzig 1969.

Claudianus, carmina, ed. J. B. Hall, Leipzig 1985.

Hermann Diels, Die Fragmente der Vorsokratiker. Griechischdeutsch, 3 Bd., Heidelberg 1951-1952.

The Roman Antiquities of Dionysius of Halicarnassus, with an Englisch translation by E. Spelman, Harvard 1961.

A. Gellii Noctes Atticae, rec. P. K. Marshall, 2 Bd., Oxford 1968.

Hermann Diels, Die Fragmente der Vorsokratiker. Griechischdeutsch, 3 Bd., Heidelberg 1951-1952.

Herodae Mimiambi cum appendice fragmentorum mimorum papyraceorum, rec. J. C. Cunningham, Leipzig 1987.

Homeri Ilias, rec. H. van Thiel, Hildesheim 1996.

Homeri Odyssea, rec. P. van der Muehll, Stuttgart 1984.

Q. Horati Flacci Opera, rec. F. Klingner, Leipzig 1959.

D. Iunii Iuvenalis saturae sedecim, rec. I. Willis, Stuttgart et al. 1997.

S. M. Braund, Juvenal and Persius. The Loeb Classical Library 91, Harvard et al. 2004.

Callimachus, ed. R. Pfeiffer, Vol. 1, Oxford 1949.

Titi Livi Ab urbe condita, Tom. I, Libri I-V, rec. R. S. Conway et C. F. Walters, Oxford 1969. 
Lucan.

Lucil.

Lucr.

Mart.

Mascha Kaléko

Off.

Ov. am., ars

Ov. fast.

Ov. met.

Ov. Pont., trist.

Paus.

Pers.

Petron.

Philostr. soph.

Plat. Ion

Plat. Tht.

Plat. Tim.

Plaut. Capt. Cas.

Cur. Ep. Men.

Pers. Rud. Trin.

Truc.

Plin. nat.

Prop.

Ps. Sen. Octav.
Lucanus, De bello civili, ed. D. R. Shackleton Bailey, Stuttgart et al. 1997.

Werner Krenkel, Lucilius. Lateinisch-deutsch, 2 Bd., Berlin 1970.

Lucreti de rerum natura, rec. C. Bailey, Oxford 1957.

M. Val. Martialis Epigrammata, rec. W. M. Lindsay, Oxford 1902.

Mascha Kaléko, Verse für Zeitgenossen, Hg. von Gisela ZochWestphal, Hamburg 1996.

Novum Testamentum Graece, ed. E. Nestle, Stuttgart 1950.

P. Ovidi Nasonis Amores, Medicamina faciei femineae, Ars amatoria, Remedia amoris, ed. E. J. Kenney, Oxford 1994.

P. Ovidi Nasoni Fastorum Libri Sex, rec. E. H. Alton et al., Stuttgart et al. 1997.

P. Ovidi Nasonis Metamorphoses, ed. R. J. Tarrant 2004.

P. Ovidi Nasonis Tristium libri quinque, Ibis, Ex Ponto libri quattuorm Halieutica, Fragmenta, ed. S. G. Owen, Oxford 1951.

Pausaniae Graeciae Descriptio, ed. M. H. Rocha-Pereira, 2 Bd., Leipzig 1989.

A. Persius Flaccus, Satiren. Lateinisch-deutsch, ed. W. Kißel, Heidelberg 1990.

Petronii Arbitri Satyricon, ed. Konrad Müller, München 1961.

Flavii Philostrati opera, rec. C. L. Kayser, 2 Bd., Leipzig 1871.

Platonis Opera, rec. I. Burnet, Tom. III, Oxford 1968.

Platonis Opera, rec. I. Burnet, Tom. I, Oxford 1967.

Platonis Opera, rec. I. Burnet, Tom. IV, Oxford 1968.

T. Macci Plauti Comoediae, rec. W. M. Lindsay, Bd. 2, Oxford 1968.

C. Plini Secundi Naturalis Historiae. Libri XXXVII, ed. C. Mayhoff, Stuttgart 1967.

Sexti Properti Elegiarum Libri IV, rec. P. Fedeli, Stuttgart et al. 1994.

L. Annaei Senecae Tragodiae, ed. O. Zwierlein, Oxford 1986. 
Quin. decl. min. Quintilianus, Declamationes minores, ed. D. R. Shackleton Bailey, Stuttgart 1989.

Quint. inst. $\quad$ M. Fabi Quintiliani Institutionis Oratoriae. Libri XII, ed. L. Rademacher, add. et corr. V. Bucheit, 2 Bd., Leipzig 1971.

Rut. Nam. Rutilius Claudius Namatianus, De reditu suo, rec. P. van de Woestijne, Antwerpen 1936.

Sen. contr. Aennei Senecae oratorum et rhetorum sententiae divisiones colores, ed. A. Kießling, Stuttgart 1966.

Sil. Silius Italicus, Punica, ed. J. Delz, Stuttgart 1987.

Stat. silv. P. Papini Stati Silvae, rec. E. Courtney, Oxford 1990.

Stat. Theb.

P. Papini Stati Thaebais et Achilleis, ed. H. W. Garrod, Oxford 1965.

Suet. C. Suetoni Tranquilli Opera, Vol. I. De vita Caesarum Libri VIII, rec. M. Ihm, Stuttgart 1978.

Tac. dial. P. Cornelii Taciti Libri qui supersunt, Tom. II, Fasc. 2, ed.

E. Koestermann, Stuttgart 1957.

Ter. Ad. Heaut. P. Terenti Afri Comoediae, rec. W.M. Lindsay, Oxford 1973.

Thuk.

Thucydidis Historiae, rec. H. Stuart Jones, 2 Bd., Oxford 1970.

Tib. Albii Tibulli Aliorumque carmina, ed. G. Luck, Stuttgart et al. 21998.

Verg. Aen. ecl. $\quad$ P. Vergili Maronis Opera, rec. R. A. B. Mynors, Oxford 1972. georg.

Vitr.

Vitruvii de architectura libri decem, ed. F. Krohn, Leipzig 1912.

\subsection{Literaturverzeichnis}

\subsubsection{Lexika und Wörterbücher}

DNP Hubert Cancik/Helmuth Schneider, Der neue Pauly. Enzyklopädie der Antike. Altertum, 13 Bd., Stuttgart et al. 1996-2002.

Georges (1969) Karl-Ernst Georges, Ausführliches Lateinisch-Deutsches Handwörterbuch, 2 Bd., Hannover 1969.

$\mathrm{HWdPh} \quad$ Joachim Ritter/Karlfried Gründer, Historisches Wörterbuch der Philosophie, 13 Bd., Darmstadt 1971-2007. 
HWRh

OLD (1992)

RGG

ThLL
Gert Ueding (Hg.), Historisches Wörterbuch der Rhetorik, 10 Bd., Tübingen 1992-2012.

Oxford Latin Dictionary, ed. P. G. W. Glare, Oxford 1992.

Kurt Galling (Hg.), Die Relgion in Geschichte und Gegenwart. Handwörterbuch für Theologie und Religionswissenschaft, 3. völlig neu bearb. Aufl., Tübingen 1957-1965.

Thesaurus Linguae latinae, Bd. 1-9.2, Leipzig 1900-1982.

\subsubsection{Sekundärliteratur und Kommentare}

Adamietz (1993) Joachim Adamietz, Juvenal Satiren. Lateinisch-Deutsch, München et al. 1993.

Amann (2006) Martin Amann, Komik in den Tristien Ovids, Basel 2006.

Andersen (2001) Øivind Andersen, Im Garten der Rhetorik. Die Kunst der Rede in der Antike, Darmstadt 2001.

Anderson (1982) William S. Anderson, Essays on Roman satire, Princeton 1982.

Arnold/Detering Heinz Ludwig Arnold/Heinrich Detering (Hg.), Grundzüge der Literaturwissenschaft, München ${ }^{31999 .}$

Assmann (22008) Aleida Assmann, Einführung in die Kulturwissenschaft. Grundbegriffe, Themen, Fragestellungen, Berlin 22008.

Bachmann-Medick Doris Bachmann-Medick, Fortschritte, Gedanken-Gänge, Ab(2009) Stürze: Bewegungshorizonte und Subjektverordnung in literarischen Beispielen, in: Hallet/Neumann (2009), 257-279.

Bailey (1972) Titi Lucreti Cari De rerum natura libri sex, ed. with prolegomena, critical apparatus, translation and commentary by Cyril Bailey, Vol. 1-4, Oxford 1972.

Baines (2003) Victoria Baines, Umbricius' Bellum civile. Juvenal, satire 3, Greece\&Rome 50.2, 2003, 220-237.

Bal (32009) Mike Bal, Narratology. Introduction to the theory of narrative, Toronto ${ }^{3} 2009$.

Bardon (1973) Catulli Veronensis Carmina, rec. Henri Bardon, Stuttgart 1973.

Barié (1999) P. Barié et al., M. Valerius Martialis, Epigramme. LateinischDeutsch, Düsseldorf 1999.

Barner (22003) Wilfrid Barner, Das Athen des Aristophanes, in: Werner Frick et al. (Hg.), Orte der Literatur, Göttingen 22003, 9-28.

Barsby (1999) John Barsby, Terence Eunuchus, Cambridge 1999.

Beare (1968) William Beare, The Roman stage, London 1968.

Becker (1963) Carl Becker, Das Spätwerk des Horaz, Göttingen 1963. 
Becker (1993) Sabina Becker, Urbanität und Moderne. Studien zur Großstadtwahrnehmung in der deutschen Literatur 1900-1930, St. Ingbert 1993.

Bérard (1955) Homère, Iliade. Odyssée, traduction, introduction et notes par R. Flacelière [lliade], traduction par V. Bérard, introduction et notes par J. Bérard [Odyssée], Bibliothèque de la Pléiade, Paris 1955.

Blanck (21996) Horst Blanck, Einführung in das Privatleben der Römer, Darmstadt 21996.

Blänsdorf (1978) Jürgen Blänsdorf, Plautus, in: Eckard Lefèvre (Hg.), Das römische Drama, Darmstadt 1978, 135-222.

Böhme (1995) Gernot Böhme, Atmosphäre. Essays zur neuen Ästhetik, Frankfurt am Main 1995.

Böhme (22013) Gernot Böhme, Architektur und Atmosphäre, 2. korr. Aufl., München 22013.

Bollnow (1963) Otto Friedrich Bollnow, Mensch und Raum, Stuttgart 1963.

Bömer (1957) Franz Bömer, P. Ovidius Naso. Die Fasten, 2 Bd., Heidelberg 1957.

Bömer (1969) Franz Bömer, P. Ovidius Naso. Metamorphosen. Buch I-III, Heidelberg 1969.

Bowie (1993) Michael N. Bowie, Martial book XII. A commentary, Boston 1993.

Boyle (2003) Anthony J. Boyle, Ovid and the monuments, Bendigo 2003.

Braund (1989) Susanna Morton Braund, City and country in Roman satire, in: dies., Satire and society in ancient Rome, Exeter 1989, 23-47.

Braund (1996) Susanna Morton Braund, Juvenal, Satires, Cambridge 1996.

Braund (2001) Susanna Morton Braund, s.v. Satire, in: DNP 2001, Bd. 11, 101-104.

Braunert (1980) Horst Braunert, Großstadt und Großstadtprobleme im Altertum, in: ders. Politik, Recht und Gesellschaft in der griechischrömischen Antike. Gesammelte Aufsätze und Reden herausgegeben von Kurt Telschow und Michael Zahrnt, Stuttgart 1980, 11-28.

Bréguet (1969) Esther Bréguet, Urbi et orbi. Un cliché et un thème, in: J. Bibauw (Hg.), Hommages à Marcel Renard, Collection Latomus 101, Brüssel 1969, 140-152.

Breitenstein (2009) Natalie Breitenstein, Petronius, Satyrica 1-15. Text, Übersetzung, Kommentar, Berlin et al. 2009. 
Brink (1982) C. O. Brink, Horace on Poetry. Epistles Book II. The Letters to Augustus and Florus, Cambridge 1982.

Brodersen (1995) Kai Brodersen, Terra cognita. Studien zur römischen Raumerfassung, Hildesheim et al. 1995.

Bühler (21965) Karl Bühler, Sprachtheorie. Die Darstellungsfunktion der Sprache, 2. erw. Aufl., Stuttgart 21965.

Bußmann (32002) Hadumod Bußmann (Hg.), Lexikon der Sprachwissenschaft, Stuttgart ${ }^{32002 .}$

Büttner (2006) Stefan Büttner, Antike Ästhetik. Eine Einführung in die Prinzipien des Schönen, München 2006.

Cairns (2012) Francis Cairns, Horace Epode 2, Tibullus 1.1 and rhetorical praise of the countryside, in: ders., Roman Lyric. Collected papers on Catullus and Horace, Berlin et al. 2012, 122-131.

Cancik (1965) Hubert Cancik, Untersuchungen zur lyrischen Kunst des P. Papinius Statius, Hildesheim 1965.

Cancik (1974) Hubert Cancik, Die kleinen Gattungen der römischen Dichtung in der Zeit des Prinzipats, in: Manfred Fuhrmann, Römische Literatur. Neues Handbuch der Literaturwissenschaft, Bd. 3, Frankfurt am Main 1974, 261-289.

Cancik (1996) Hubert Cancik, carmen und sacrificium. Das Saecularlied des Horaz in den Saecularakten des Jahres 17 v. Chr., in: Richard Faber et al., Worte, Bilder, Töne. Studien zur Antike und Antikenrezeption, Würzburg 1996, 99-113.

Canter (1977) David Canter, The psychology of place, London 1977.

Chatman (1980) Seymour Chatman, Story and discourse. Narrative structure in fiction and film, Ithaca, NY 1980.

Chwalek (1996) Burkard Chwalek, Die Verwandlung des Exils in die elegische Welt. Studien zu den Tristia und Epistulae ex Ponto Ovids, Frankfurt am Main et al. 1996.

Citroni (1975) Mario Citroni, M.Valerii Martialis Epigrammaton. Liber Primus, Florenz 1975.

Classen (21986) Carl Joachim Classen, Die Stadt im Spiegel der Descriptiones und Laudes urbium in der antiken und mittelalterlichen Literatur bis zum Ende des zwölften Jahrhunderts, Hildesheim et al. 21986.

Clausen (1994) Wendell Clausen, A commentary on Virgil eclogues, Oxford 1994.

Coleman (1977) Robert Coleman, Vergil Eclogues, Cambridge 1977. 
Coleman (1988) Kathleen M. Coleman, Statius. Silvae Book VI, Oxford et al. 1988.

Collart (1962) Jean Collart, T. Maccius Plautus. Curculio, Paris 1962.

Conte (91994) Gian Biagio Conte, Latin Literature. A history, Baltimore 91994.

Corbineau- Angelika Corbineau-Hoffmann, Kleine Literaturgeschichte der Hoffmann (2003) Großstadt, Darmstadt 2003.

Courtney (1980) Edward Courtney, A commentary on the satires of Juvenal, London 1980.

Cunningham Jan Campbell Cunningham, Herodas Mimiambi, Oxford 1971. (1971)

Curtius (111993) Ernst Robert Curtius, Europäische Literatur und Lateinisches Mittelalter, Tübingen ${ }^{11} 1993$.

Daemmrich Horst S. und Ingrid G. Daemmrich, Themen und Motive in (1987) der Literatur. Ein Handbuch, Tübingen 1987.

Dahlmann (1978) Hellfried Dahlmann, Über den Lärm, Gymnasium 85, 1978, 206-227.

Damschen/Heil Gregor Damschen/Andreas Heil (Hg.), Marcus Valerius Mar(2004) tialis, Epigrammaton liber decimus. Das zehnte Epigrammbuch. Text, Übersetzung, Interpretation, Frankfurt am Main et al. 2004.

Danek (2009) Georg Danek, Apollonius Rhodius as an (anti-)Homeric narrator. Time and Space in the Argonautica, in: Gretblein/Renegakos (2009), 275-291.

Dennerlein (2009) Katrin Dennerlein, Narratologie des Raumes, Berlin et al. 2009.

Dewar (2008) Michael Dewar, The equine cuckoo. Statius' Ecus Maximus Domitiani imperatoris and the Flavian Forum, in: Johannes J. L. Smolenaars et al., The poetry of Statius, Leiden et al. 2008, 65-83.

Döpp (1996) Siegmar Döpp, Cyllarus und andere Rosse im römischen Herrscherlob, Hermes 124, 1996, 321-332,

Döpp (2003) Siegmar Döpp, Das Rom der Dichter: Vergil, Horaz, Ovid, in: Werner Frick et al. (Hg.), Orte der Literatur, Göttingen 22003, 29-49.

Downs/Stea Roger M. Downs/David Stea, Kognitive Karten. Die Welt in (1982) unseren Köpfen, New York 1982. 
Downs/Stea (1985)

Duckworth (1979) George E. Duckworth, T. Macci Plauti Epidicus. Ed. with critical apparatus and commentary, New York 1979.

Dünne/Günzel Jörg Dünne/Stephan Günzel (Hg.), Raumtheorie. Grundlagen(2006)

Dyson/Prior (1995)

Eco (21999)

Edwards (1993) texte aus Philosophie und Kulturwissenschaften, Frankfurt am Main 2006.

Stephen L. Dyson and Richard E. Prior, Horace, Martial, and Rome: Two poetic outsiders read the ancient city, Arethusa 29, 1995, 245-263.

Umberto Eco, Im Wald der Fiktionen. Sechs Streifzüge durch die Literatur, München 21999.

Anthony T. Edwards, Homer's ethical geography. Country and city in the Odyssey, Transactions of the American Philological Assosiation 123, 1993, 27-78.

Edwards (1996) Catharine Edwards, Writing Rome. Textual approaches to the city, Cambridge 1996.

Edwards (1998) Catharine Edwards, Imaginaires de l'image de Rome ou comment (se) représenter Rome? in: Clara Auvray-Assayas (Hg.), Images romaines. Études de Littérature ancienne 9, Paris 1998, 235-245.

Edwards/Woolf Catharine Edwards/Greg Woolf (Hg.), Rome the cosmopolis, (2003)

Effe/Binder Cambridge 2003.

(22001)

Eichendorff

Eigler (1998)

Bernd Effe/Gerhard Binder, Antike Hirtendichtung. Eine Einführung, Düsseldorf et al. 22001.

Joseph v. Eichendorff, Aus dem Leben eines Taugenichts, Text. Materialien. Kommentar, München 1975.

Ulrich Eigler, Augusteische Repräsentationskunst als Text? Zum Problem der Erzählbarkeit von bildender Kunst in augusteischer Dichtung am Beispiel des Schildes des Aeneas, Gymnasium 10, 1998, 289-305.

Eigler (2002) Ulrich Eigler, Urbanität und Ländlichkeit als Thema und Problem der augusteischen Literatur, Hermes 130, 2002, 288-298.

Elliger (1975) Winfried Elliger, Die Darstellung der Landschaft in der griechischen Dichtung, Berlin et al. 1975. 
Ellis (1979)

Emmott (1997)

Ernout/Thomas (1972)

Erren (2003)

Faber (2005)

Fantham (1973)

Fantham (1998)

Faure (1990)

Favro (1993)

Favro (1996)

Fedeli (1985)

Fedeli (1994)

Fedeli (1997)

Fehling (1974)

Fitter (1995)

Fitton-Brown (1985)
Robinson Ellis, A commentary on Catullus, New York et al. 1979.

Catherine Emmott, Narrative comprehension. A discourse perspective, Oxford 1997.

Alfred Ernout/François Thomas, Syntaxe Latine, Paris 1972.

Manfred Erren, P. Vergilius Maro, Georgika, Bd. 2, Heidelberg 2003.

Richard Faber (Hg.), Literatur der Grenze - Theorie der Grenze, Würzburg 1995.

Elaine Fantham, Der, Curculio' des Plautus. Eine Illustration Plautinischer Bearbeitungsverfahren, in: Eckard Lefèvre (Hg.), Die römische Komödie. Plautus und Terenz, Darmstadt 1973, 173-204.

Elaine Fantham, Literarisches Leben im antiken Rom. Sozialgeschichte der römischen Literatur von Cicero bis Apuleius, Stuttgart et al. 1998.

Paul Faure, Magie der Düfte. Eine Kulturgeschichte der Wohlgerüche von den Pharaonen zu den Römern, München et al. 1990.

Diana Favro, Reading the Augustan City, in: Peter J. Holliday (Hg.), Narrative and Event in Ancient Art, Cambridge 1993, 230-257.

Diana Favro, The urban image of Augustan Rome, Cambridge 1996.

Paolo Fedeli, Properzio, Il libro Terzo delle Elegie. Introduzione testo e commento, Bari 1985.

Paolo Fedeli, Q. Orazio Flacco, Le opere II. Tomo secondo. Le satire, Roma 1994.

Paolo Fedeli, Q. Orazio Flacco. Le opere II. Tomo quarto. Le epistole. L'arte poetica, Roma 1997.

Detlev Fehling, Ethologische Überlegungen auf dem Gebiet der Altertumskunde. Phallische Demonstration - Fernsicht Steinigung, München 1974.

Chris Fitter, Poetry, space, landscape. Toward a new theory, Cambridge 1995.

A. D. Fitton Brown, The unreality of Ovid's Tomitan exile, LCM 10, 1985, 18-22. 
Foley (1981) H. P. Foley (Hg.), Reflections of women in antiquity, New York 1981.

Fordyce (1987) C. J. Fordyce, Catullus. A commentary, Oxford 1987.

Fowler (1991) D. P. Fowler, Narrate and describe. The problem of Ekphrasis, JRS 81, 1991, 25-35.

Fraenkel (1972) Eduard Fraenkel, Elementi Plautini in Plauto, Florenz 1972.

Fredericks (1973) S. C. Fredericks, The function of the prologue (1-20) in the organization of Juvenal's third satire, Phoenix 27, 1973, 62-67.

Freudenburg Kirk Freudenburg, Satires of Rome: threatening poses from (2001) Lucilius to Juvenal, Cambridge 2001.

Friedländer (1969) Paul Friedländer, Johannes von Gaza und Paulus Silentiarius. Kunstbeschreibungen justinianischer Zeit, Hildesheim et al. 1969.

Fuhrmann (1968) Manfred Fuhrmann, Die Romidee in der Spätantike, HZ 207, 1968, 529-561.

Fusi (2006) Alessandro Fusi, M. Valerii Martialis Epigrammaton liber tertius, Hildesheim et al. 2006.

Gaertner (2005) Jan-Felix Gaertner, Ovid. Epistulae ex Ponto, Book 1, Oxford 2005.

Galán Vioque Guillermo Galán Vioque, Martial, book VII. A commentary, (2002) Leiden et al. 2002.

Galinsky (1996) Karl Galinsky, Augustan Culture, Princeton 1996.

Gauly (1990) Bardo Maria Gauly, Liebeserfahrungen. Zur Rolle des elegischen Ich in Ovids Amores, Frankfurt am Main et al. 1990.

George (1974) P. A. George, Petronius and Lucan De bello Civili, CQ 24, 1974, 119-133.

Geyssen (1999) John Geyssen, Sending a book to Palatine. Martial 1, 70 and Ovid, Mnemosyne 52, 1999, 718-738.

Giebel (1995) Marion Giebel, Treffpunkt Tusculum. Literarischer Reiseführer durch das antike Italien, Stuttgart 1995.

Giesecke (2007) Annette Lucia Giesecke, The epic city. Urbanism, utopia, and the garden in ancient Greece and Rome, Washington 2007.

Gilula (1991) Dwora Gilula, A walk through town (Ter. Ad. 573-584), Athenaeum 69, 1991, 245-247

Glaser (2005) Horst Albert Glaser, Roma Amor, in: Roland Galle/Johannes Klingen-Protti (Hg.), Städte der Literatur, Heidelberg 2005, 79-97. 
Glotz (1999) G. Glotz, The Homeric city, in: Irene J. F. de Jong (Hg.), Homer. Critical assessments, London et al. 1999, 105-125.

Goebel (1971) Gerhard Goebel, Poeta faber. Erdichtete Architektur in der italienischen, spanischen und französischen Literatur der Renaissance und des Barock, Heidelberg 1971.

Gowers (2012) Emily Gowers, Horace Satires Book I, Cambridge 2012.

Gowing (2005) Alain M. Gowing, Empire and Memory. The representation of the Roman Republic in Imperial Culture, Cambridge 2005.

Grabowski (1999) Joachim Grabowski, Raumrelationen. Kognitive Auffassung und sprachlicher Ausdruck, Opladen et al. 1999.

Green (1990) Peter Green, Alexander to Actium. A historical evolution of the Hellenistic age, Berkeley 1990.

Green (2008) Peter Green, The Hellenistic age. A short history, New York 2008.

Grethlein/ Jonas Grethlein/Antonios Rengakos (Hg.), Narratology and

Rengakos (2009) interpretation. The content of narrative form in ancient literature, Berlin 2009.

Grewing (1998) Farouk Grewing (Hg.), Toto notus in urbe. Perspektiven der Martial-Interpretation, Stuttgart 1998.

Griffiths (1981) Frederik T. Griffiths, Home before Lunch. The emancipated woman in Theocritus, in: Foley (1981), 247-273.

Grünbein (1995) Spiegelgespräch. Tausendfacher Tod im Hirn. Büchner Preisträger Durs Grünbein über Utopien, das Ende der DDR und die Zukunft der Lyrik, Spiegel vom 09.10.1995, Nr. 41, 1995, 221-230.

Grünbein (2005) Durs Grünbein, Antike Dispositionen. Aufsätze, Frankfurt am Main 2005.

Gualandri (1998) Isabella Gualandri, Per una geographia della letteratura latina, in: Guglielmo Cavallo/Paolo Fedeli/Andrea Giardina, Lo spazio letterario di Roma antica, Bd. 2, La circolazione del testo, Roma 1998, 469-507.

Gumbrecht (1988) Hans Ulrich Gumbrecht/K. Ludwig Pfeiffer (Hg.), Materialität der Kommunikation, Frankfurt am Main 1988.

Hallet/Neumann Wolfgang Hallet/Birgit Neumann (Hg.), Raum und Bewegung (2009) in der Literatur. Die Literaturwissenschaft und der Spatial Turn, Bielefeld 2009. 
Haltenhoff (2003) Andreas Haltenhoff et al. (Hg.), O Tempora, o Mores! Römische Werte und römische Literatur in den letzten Jahrzehnten der Republik, München et al. 2003.

Hardie (1983) Alex Hardie, Statius and the Silvae. Poets, patrons and epideixis in the Graeco-Roman world, Liverpool 1983.

Hardie (1986) Philip R. Hardie, Virgil's Aeneid. Cosmos and imperium, Oxford 1986.

HarichHenriette Harich-Schwarzbauer/Thomas Späth (Hg.), Gender

Schwarzbauer/

Späth (2005) Studies in den Altertumswissenschaften. Räume und Ge-

Harrison (2007) Stephen Harrison, Town and country, in: ders. (Hg.), The Cambridge Companion to Horace, Cambridge 2007, 235-247.

Hartigan (1979) Karelisa Hartigan, The Poets and the Cities. Selections from the Anthology about Greek Cities, Meisenheim am Glan 1979.

$\mathrm{Haß}$ (1998) Petra Haß, Der locus amoenus in der antiken Literatur. Zu Theorie und Geschichte eines literarischen Motivs, Bamberg 1998.

Heil (2003) Andreas Heil, Literarische Kommunikation in der späten Republik. Versuch einer Topographie, in: Haltenhoff (2003), 5-50.

Hellwig (1964) Brigitte Hellwig, Raum und Zeit im homerischen Epos, Hildesheim 1964.

Helmbold (1951) William Clark Helmbold, The structure of Juvenal I, University of California publications in classical philology 14, 2, 1951, 47-59.

Helzle (2003) Martin Helzle, Ovids Epistulae ex Ponto. Buch I-II, Kommentar, Heidelberg 2003.

Henderson (1999) John Henderson, Writing down Rome. Satire, comedy and other offences in Latin poetry, Oxford 1999.

Heyworth (1986) Stephen J. Heyworth, Notes on Propertius, Books III and IV, CQ 36, 1986, 199-211.

Heyworth (2007) Sexti Properti Elegos, rec. S. J. Heyworth, Oxford 2007.

Highet (1954) Gilbert A. Highet, Juvenal the satirist, Oxford 1954.

Hinds (1985) Stephen Hinds, Booking the return trip: Ovid and Tristia 1, PcPhC 211, 1985, 13-32.

Hinds (1998) Stephen Hinds, Allusion and intertext. Dynamics of appropriation in Roman poetry, Cambridge 1998. 
Hoffmann (1978) Gerhard Hoffmann, Raum, Situation, erzählte Wirklichkeit. Poetologische und historische Studien zum englischen und amerikanischen Roman, Stuttgart 1978.

Hofmann (1987) Heinz Hofmann, The unreality of Ovid's Tomitan exile once again, LCM 12, 1987, 23.

Hofmann (2001) Heinz Hofmann, Ovid im Exil?.... sumque argumenti conditor mei. Ovids Exildichtung zwischen Biographie und Fiction. Mitteilungen des Deutschen Altphilologenverbands BadenWürtemberg, Heft 2, 2001, 8-19.

Höhn (1951) Karl Höhn, Das Rom des Horaz, Wien 1951.

Hollis (1991) Adrian Swayne Hollis, Ovid Ars amatoria, Book 1, Oxford 1991.

Holzberg (1997) Niklas Holzberg, Ovid. Dichter und Werk, München 1997.

Holzberg (1999) Niklas Holzberg, „Ihres Aeneas’ Stadt wählte sich Venus als Sitz“. Rom aus der Sicht seiner Dichter, in: Mabler (1999), 57-66.

Holzberg (2002) Niklas Holzberg, Martial und das antike Epigramm, Darmstadt 2002.

Hose (1996) Martin Hose, Fiktionalität und Lüge. Über einen Unterschied zwischen römischer und griechischer Terminologie, Poetica 28, 1996, 257-274.

Howell (1980) Peter Howell, A Commentary on book one of the epigrams of Martial, London 1980.

Hühn (2009) Peter Hühn, Event and eventfulness, in: ders. et al. (Hg.), Handbook of narratology, Berlin et al. 2009, 80-97.

Hunink (1992) Vincent Hunink, M. Annaeus Lucanus. Bellum civile Book III. A commentary, Amsterdam 1992.

Hunter (1985) Richard Hunter, The new comedy of Greece and Rome, Cambridge 1985.

Hunter (1997) Richard Hunter, Hellenismus, in: Heinz-Günther Nesselrath (Hg.), Einleitung in die griechische Philologie, Stuttgart et al. 1997, 246-268.

Hunter (2003) Richard Hunter, Literature and its contexts, in: Andrew Erskine (Hg.), A companion to the Hellenistic world, Malden et al. 2003, 477-493.

Hurschmann $\quad$ Rolf Hurschmann, s.v. Sportula, in: DNP 2001, Bd. 11, 857. (2001) 
Hutchinson (2006) Gregory Hutchinson, Propertius Elegies, Book IV, Cambridge 2006.

Jaeger (1995) Mary Jaeger, Reconstructing Rome. The Campus Martius and Horace, Ode 1, 8, Arethusa 28, 1995, 177-191.

Jäger (1998) Dietrich Jäger, Erzählte Räume. Studien zur Phänomenologie der epischen Geschehensumwelt, Würzburg 1998.

Jahn (1993) Bernhard Jahn, Raumkonzepte in der frühen Neuzeit. Zur Konstruktion von Wirklichkeit in Pilgerberichten, Amerikareisebeschreibungen und Prosaerzählungen, Frankfurt am Main et al. 1993.

Janka (1997) Markus Janka, Ovid Ars amatoria Buch 2. Kommentar, Heidelberg 1997.

Janson (1964) Tore Janson, Latin prose prefaces. Studies in literary conventions, Stockholm 1964.

Johannsen (2006) Nina Johannsen, Dichter über ihre Gedichte. Die Prosavorreden in den „Epigrammaton Libri““ Martials und in den „Silvae“ des Statius, Göttingen 2006.

Johnston (1933) Mary Johnston, Exits and entrances in Roman comedy (Plautus and Terence), Geneva, NY 1933.

Jongmann (2001) Willem Jongmann, s.v. Roma. Bevölkerung und Wirtschaft, in: DNP 2001, Bd. 10, 1077-1081.

Kauer (21964) Robert Kauer, Ausgewählte Komödien des P. Terentius Afer zur Einführung in die altlateinischen Lustspiele, Bd. 2: Adelphoe, Leipzig 21964.

Kayser (71961) Wolfgang Kayser, Das sprachliche Kunstwerk. Eine Einführung in die Literaturwissenschaft, Bern et al. ${ }^{71961 .}$

Kenney (1970) E. J. Kenney, „Doctus“ Lucretius, Mnemosyne 23, 1970, 366-392.

Kießling/Heinze Adolf Kießling/Richard Heinze, Q. Horatius Flaccus. Oden (61959) und Epoden/Satiren/Briefe, 3 Bd., Berlin 61959.

Kilpatrick (1990) Ross S. Kilpatrick, The poetry of criticism. Horace, epistles II and ars poetica, Edmonton 1990.

Kißel (1990) Walter Kißel, Aules Persius Flaccus, Satiren, Heidelberg 1990.

Klodt (1998) Claudia Klodt, Platzanlagen der Kaiser in der Beschreibung der Dichter, Gymnasium 105, 1998, 1-38.

Klodt (2001) Claudia Klodt, Bescheidene Größe. Die Herrschergestalt, der Kaiserpalast und die Stadt Rom: Literarische Reflexionen monarchischer Selbstdarstellung, Göttingen 2001. 
Knoblich (2014) Aniela Knoblich, Antikenkonfigurationen in der deutschsprachigen Lyrik nach 1990, Berlin et al. 2014.

Knox (1966) A. D. Knox, Herodas. The mimes and fragments with notes by Walter Headlam, Cambridge 1966.

Knox (2006) Peter E. Knox, Oxford readings in Ovid, Cambridge 2006.

Kolb (2005) Frank Kolb, Die Stadt im Altertum, Düsseldorf 2005.

Kolb (2002) Frank Kolb, Rom. Die Geschichte der Stadt in der Antike, München 22002.

Konstan (2002) D. Konstan, Narrative Space, in: Paschalis/Frangoulidis (2002), 2-10

Korenjak (2003) Martin Korenjak, Tityri sub persona. Der antike Biographismus und die bukolische Tradition, A\&A 49, 2003, 58-80.

Koselleck (1973) Reinhart Koselleck et al. (Hg.), Geschichte - Ereignis und Erzählung, München 1973.

Kranz (1967) Walther Kranz, Sphragis, in: ders., Studien zur antiken Literatur und ihrem Fortwirken. Kleine Schriften, Heidelberg 1967, 27-78.

Krenkel (2002) Marcus Terentius Varro, Saturae Menippeae, herausgegeben, übers. und komm. von Werner A. Krenkel, Bd. 1-4, St. Katharinen 2002.

Kroll (71989) Wilhelm Kroll, C. Valerius Catullus, Stuttgart ${ }^{71989 .}$

Kühner/Stegmann Raphael Kühner/Carl Stegmann, Ausführliche Grammatik der (1912) lateinischen Sprache, Bd. 2.1, Hannover 1912.

Kunst (2006) Christiane Kunst, Leben und Wohnen in der römischen Stadt, Darmstadt 2006.

Labate (1984) Mario Labate, L'arte di farsi amare. Modelli culturali e progetto didascalico nell'elegia ovidiana, Pisa 1984.

Lakoff/Johnson George Lakoff/Mark Johnson, Leben in Metaphern. Kon(1998) struktion und Gebrauch von Sprachbildern, Heidelberg 1998.

Landfester (1977) Manfred Landfester, Handlungsverlauf und Komik in den frühen Komödien des Aristophanes, Berlin et al. 1977.

Larmour (2007) David H. Larmour, Holes in the body: sites of abjection in Juvenal's Rome, in: Larmour/Spencer (2007), 168-210.

Larmour/Spencer David H. Larmour/Diana Spencer, The Sites of Rome. Time, (2007) Space, Memory, Oxford 2007.

Latacz (1980) Joachim Latacz, Horazens sogenannte Schwätzersatire, AU 23,1, 1980, 5-22. 
Lausberg (31967) Heinrich Lausberg, Elemente der literarischen Rhetorik. Eine Einführung für Studierende der klassischen, romanischen, englischen und deutschen Philologie, München ${ }^{31967 .}$

Lausberg ( ${ }^{42008)} \quad$ Heinrich Lausberg, Handbuch der literarischen Rhetorik. Eine Grundlage der Literaturwissenschaft, Stuttgart ${ }^{4} 2008$.

Leach (1974) Eleanor Winsor Leach, Vergil's Eclogues. Landscapes of experience, Ithaca 1974.

Leach (1988) Eleanor Winsor Leach, The rhetoric of space. Literary and artistic representations of landscape in Republican and Augustan Rome, Princeton 1988.

Lefèvre (1991) Eckard Lefèvre, Curculio oder der Triumph der Edazität, in: ders./Ekkehard Stärk, Gregor Vogt-Spira (Hg.), Plautus barbarus. Sechs Kapitel zur Originalität des Plautus, Tübingen 1991, 71-105.

Lehan (1998) Richard Lehan, The city in literature. An intellectual and cultural history, Berkeley et al. 1998.

Leigh (2004) Matthew Leigh, Comedy and the rise of Rome, Oxford 2004.

Lessing (31995) Gottfried Ephraim Lessing, Werke, Bd. 2. Kritische Schriften, Philosophische Schriften, München ${ }^{31995 .}$

Létoublon (2003) Françoise Létoublon, Ilion battue des vents, Troie aux larges rues: la représentation de Troie dans l'Iliade, in: Michel Reddé et al. (Hg.), La naissance de la ville dans l'antiquité, Paris 2003, $27-44$.

Liebermann Wolf-Lüder Liebermann, Provokation durch Literatur. Perspektiven römischer Literaturbetrachtung, in: Hans-Peter Stähli, Wort und Dienst, Jahrbuch der Kirchlichen Hochschule Bethel, NF, Bd. 20, Bielefeld 1989, 197-217.

Lilja (1972) Saara Lilja, The treatment of odours in the poetry of antiquity, Helsinki 1972.

Long (2004) Jacqueline Long, Claudian and the City. Poetry and Pride of Place, in: Widu-Wolfgang Ehlers et al. (Hg.), Aetas Claudianea. Eine Tagung an der Freien Universität Berlin vom 28. bis 30. Juni 2003, München et al. 2004, 1-15.

Lorenz (1987) Thuri Lorenz, Römische Städte, Darmstadt 1987.

Lorenz (2002) Sven Lorenz, Erotik und Panegyrik. Martials epigrammatische Kaiser, Tübingen 2002.

Lorenz (2006) Sven Lorenz, Martial and the writer Canius Rufus, in: Ruurd R. Nauta et al., Flavian Poetry, Leiden et al. 2006, 315-328. 
Luck (1977) Georg Luck, Publius Ovidius Naso. Tristia. Kommentar, Bd. 2, Heidelberg 1977.

Lynch (1975) Kevin Lynch, Das Bild der Stadt, Braunschweig 1975.

Lyne (1995) R. Lyne, Horace behind the public poetry, New Haven 1995.

Maatje (1975) Frank C. Maatje, Versuch einer Poetik des Raumes. Der lyrische, epische und dramatische Raum, in: Alexander Ritter (Hg.), Landschaft und Raum in der Erzählkunst, Darmstadt 1975, 392-416.

Mahler (1999) Andreas Mahler (Hg.), Stadt-Bilder. Allegorie, Mimesis, Imagination, Heidelberg 1999.

Manguel/Guada- Alberto Manguel/Gianni Guadalupi, Von Atlantis bis Utopia. lupi (1981)

Mannsperger (2001) Ein Führer zu den imaginären Schauplätzen der Weltliteratur, bearb. und erw. deutsche Ausg., München 1981.

Brigitte Mannsperger, Das Stadtbild von Troja in der Ilias. Gebäude und Befestigungssysteme, in: Hans-Joachim Behr (Hg.), Troja. Traum und Wirklichkeit, Darmstadt 2001, 81-83.

Martin (1976) Ronald H. Martin, Terence Adelphoe, Cambridge 1976.

Martin (2004) Anna Julia Martin, Was ist Exil? Ovids „Tristia“ und „Epistulae ex Ponto“, Hildesheim 2004.

Martinez/Scheffel Matias Martinez/Michael Scheffel, Einführung in die Erzähl(52003) theorie, München 52003.

Maselli (1995) Giorgio Maselli, Mobilità prospettica sulla villa del Ianiculum (Mart. 4, 64), Aufidus 25, 1995, 49-64.

Mayer (1994) Roland Meyer, Horace Epistles Book I, Cambridge 1994.

Meckseper/ Cord Meckseper/Elisabeth Schraut, Die Stadt in der Literatur, Schraut (1983) Göttingen 1983.

Miller (2002) John F. Miller, Ovid on the Augustan Palatine (Tristia 3.1), in: Vertis in usum. Studies in honor of Edward Courtney, München et al. 2002, 129-139.

Miller (2007) Paul Allen Miller, ,I get around': sadism, desire, and metonymy on the streets of Rome with Horace, Ovid, and Juvenal, in: Larmour/Spencer (2007), 138-167.

Moreno Soldevila Rosario Moreno Soldevila, Martial, Book IV. A Commentary, (2006) Leiden et al. 2006.

Moretti (1999) Franco Moretti, Atlas des europäischen Romans. Wo die Literatur spielte, Köln 1999.

Müller (2003) Jan-Dirk Müller et al. (Hg.), Reallexikon der deutschen Literaturwissenschaft, Berlin et al. 2003. 
Murgatroyd (1994)

Nagle (1980)

Nerdinger (2006)

Nesselrath (1999) Heinz-Günther Nesselrath, s.v. Komödie. I Griechisch, in: DNP 1999, Bd. 6, 692-700.

Neumeister (1991) Christoff Neumeister, Das antike Rom. Ein literarischer Stadtführer, München 1991.

Neumeyer (1999) Harald Neumeyer, Der Flaneur. Konzeption der Moderne, Würzburg 1999.

Newlands (1997) Carole Newlands, The role of the book in Tristia 3.1, Ramus 26, 1997, 57-79.

Newlands (2002) Carole Newlands, Statius' Silvae and the poetics of empire, Cambridge 2002.

Nicolet (1988) Claude Nicolet, L'inventaire du monde. Géographie et politique aux origines de l'Empire romain, Paris 1988.

Nitschke (1989) August Nitschke, Körper in Bewegung. Gesten, Tänze und Räume im Wandel der Geschichte, Zürich 1989.

Nünning (2009) Ansgar Nünning, Formen und Funktionen literarischer Raumdarstellung: Grundlagen, Ansätze, narratologische Kategorien und neue Perspektiven, in: Wolfgang Hallet/Birgit Neumann (Hg.), Raum und Bewegung in der Literatur. Die Literaturwissenschaft und der Spatial Turn, Bielefeld 2009, 33-52.

Nünning (42008) Ansgar Nünning, Metzler Lexikon. Literatur- und Kulturtheorie. Ansätze - Personen - Grundbegriffe, 4. akt. und erw. Aufl., Stuttgart et al. ${ }^{42008 .}$

Paschalis/Fran- Michael Paschalis/Stavros Frangoulidis (Hg.), Ancient narragoulidis (2002) tive. Supplementum 1. Space in ancient novel, Groningen 2002.

Pavlovskis (1967) Zoja Pavlovskis, From Statius to Ennodius. A brief history of prose prefaces to poems, RIL 101, 1967.

Pearce (1992) T. E. V. Pearce, Juvenal 3, 10-20, Mnemosyne 45, 1992, 380-383.

Pfeil (21972) Elisabeth Pfeil, Großstadtforschung. Entwicklung und gegenwärtiger Stand, Hannover ${ }^{2} 1972$. 
Pfister (112001) Manfred Pfister, Das Drama. Theorie und Analyse, München 112001.

Piatti (2008) Barbara Piatti, Die Geographie der Literatur. Schauplätze, Handlungstäume, Raumphantasien, Göttingen 2008.

Purcell (1987) Nicholas Purcell, Town in country and country in town, in: Elisabeth B. MacDougall, Ancient Roman villa gardens, Washington 1987, 187-203.

Purcell (21996) Nicholas Purcell, Rome and its development under Augustus and his successors, in: Alan K. Bowman et al. (Hg.), The Cambridge Ancient History, Vol. 10. The Augustan Empire, 43 b.c.-a.d. 69, Cambridge 21996, 782-811.

Purcell (2000) Nicholas Purcell, Rome and Italy, in: Alan K. Bowman et al. (Hg.), The Cambridge Ancient History, Vol. 11. The High Empire, a.d. 70-192, Cambridge 22000, 405-443.

Rahn (1975) Helmut Rahn, Marcus Fabius Quintilianus. Ausbildung des Redners. Zwölf Bücher, 2 Bd., Darmstadt 1975.

Rea (2007) Jennifer A. Rea, Legendary Rome. Myth, monuments, and memory on the Palatine and Capitoline, London 2007.

Reed (2007) J. D. Reed, Virgil's Gaze. Nation and poetry in the Aeneid, Princeton et al. 2007.

Reeker (1971) Hans-Dieter Reeker, Die Landschaft in der Aeneis, Hildesheim et al. 1971.

Rehm (21960) Walther Rehm, Europäische Romdichtung, München ${ }^{2} 1960$.

Reinhardt (1988) Thomas Reinhardt, Die Darstellung der Bereiche Stadt und Land bei Theokrit, Bonn 1988.

Richardson (1977) L. Richardson, Propertius elegies I-IV, Oklahoma 1977.

Riha (1970) Karl Riha, Die Beschreibung der „Großen Stadt“. Zur Entstehung des Großstadtmotivs in der deutschen Literatur (ca. 1750-ca. 1850), Bad Homburg et al. 1970.

Riikonen (1977) Hannu Riikonen, City and country in Horace's epistle 1, 7, Arctos 11, 1977, 87-101.

Ritter (1975) Alexander Ritter (Hg.), Landschaft in der Erzählkunst, Darmstadt 1975.

Roberts (2001) Michael John Roberts, Rome personified, Rome epitomized. Representations of Rome in the poetry of the early fifth century, American Journal of Philology 122.4, 2001, 533-565.

Roman (2010) Luke Roman, Martial and the City of Rome, JRS 100, 2010, 88-117. 
Römer (1981) Jutta Römer, Naturästhetik in der frühen römischen Kaiserzeit, Frankfurt am Main 1981.

Romm (1992) James S. Romm, The edges of the earth in ancient thought. Geography, exploration, and fiction, Princeton/New Jersey 1992.

Ronen (1986) Ruth Ronen, Space in fiction, Poetics Today 7, 3, 1986, 421-438.

Rosen/Sluiter Ralph M. Rosen/Ineke Sluiter (Hg.), City, countryside, and the (2006) spatial organization of value in Classical antiquity, Leiden 2006.

Rosivach (1970) V.J. Rosivach, Plautine stage settings (Asin., Aul., Men., Trin.), TAPhA 101, 1970, 445-461.

Rösler (1980) Wolfgang Rösler, Die Entdeckung der Fiktionalität in der Antike, Poetica 12, 1980, 283-319.

Rothstein (31966) Max Rothstein, Propertius Sextus. Elegien mit einem Nachwort von R. Stark, 2 Bd., Dublin et al. ${ }^{3} 1966$.

Rudd (1976) Niall Rudd, Lines of enquiry. Studies in Latin poetry, Cambridge 1976.

Rudd (1989) Niall Rudd, Horace Epistles Book II and Epistles to the Pisones ('Ars Poetica'), Cambridge 1989.

Rühl (2008) Meike Rühl, Literatur gewordener Augenblick. Die Silven des Statius im Kontext literarischer und sozialer Bindungen von Dichtung, Berlin et al. 2008.

Ryan (2009) Marie-Laure Ryan, Space, in: Peter Hühn et al. (Hg.) Handbook of narratology, Hamburg 2009, 420-433.

Sandbach (1962) F. H. Sandbach, Some problems in Propertius, CQ 12, 1962, 263-276.

Sartorius (2001) Joachim Satorius (Hg.), Alexandria. Fata morgana, Stuttgart et al. 2001.

Schäfer (2001) Eckhart Schäfer, Lucilius und die Stadt Rom, in: G. Manuwald (Hg.), Der Satiriker Lucilius und seine Zeit, München 2001, 177-187.

Scheithauer (2000) Andrea Scheithauer, Kaiserzeitliche Bautätigkeit in Rom. Das Echo in der Literatur, Stuttgart 2000.

Schirren (1998) Thomas Schirren, Aisthesis vor Platon. Eine semantischsystematische Untersuchung zum Problem der Wahrnehmung, Stuttgart et al. 1998.

Schmid (22008) Wolf Schmid, Elemente der Narratologie, Berlin et al. 22008. 
Schmidt (1987) Ernst A. Schmidt, Bukolische Leidenschaft: oder über antike Hirtenpoesie, Frankfurt am Main 1987.

Schmidt (1995) Ernst A. Schmidt, Lateinische Literatur als hermeneutische Textwissenschaft, in: Ernst-Richard Schwinge (Hg.), Die Wissenschaften vom Altertum am Ende des 2. Jahrtausends n. Chr., Stuttgart et al. 1995, 90-117.

Schmidt (1997) Ernst A. Schmidt, Sabinum. Horaz und sein Landgut im Licenzatal, Heidelberg 1997.

Schmidt (2001) Ernst A. Schmidt, Zeit und Form. Dichtungen des Horaz, Heidelberg 2001.

Schmitz (2000) Christine Schmitz, Das Satirische in Juvenals Satiren, Berlin 2000.

Schmitzer (1994) Ulrich Schmitzer, Vom Esquilin nach Trastevere. Hor. Sat. 1, 9 im Kontext zeitgenössischen Verstehens, in: Severin Koster (Hg.), Horaz-Studien, Erlangen 1994, 9-30.

Schmitzer (1999) Ulrich Schmitzer, Guiding strangers through Rome - Plautus, Propertius, Vergil, Ovid, Ammianus Marcellinus, and Petrach, in: Electronic Antiquity: Communicating the Classics, Vol. 5, 2, 1999.

Schmitzer (2001) Ulrich Schmitzer, Literarische Stadtführungen - von Homer bis Ammianus Marcellinus und Petraca, Gymnasium 108, 2001, 515-537.

Schmitzer (2005) Ulrich Schmitzer, Rom in der (nach-)antiken Literatur. (Re-)Konstruktion und Transformation der urbanen Gestalt der Stadt von der augusteischen Zeit bis zur Moderne, Gymnasium 112, 3, 2005, 250-253.

Schmude (1988) Michael P. Schmude, Reden-Sachstreit-Zänkereien. Untersuchungen zu Form und Funktion verbaler Auseinandersetzungen in den Komödien des Plautus und Terenz, Stuttgart 1988.

Schneider (1995) Katja Schneider, Villa und Natur. Eine Studie zur römischen Oberschichtkultur im letzten vor- und ersten nachchristlichen Jahrhundert, München 1995.

Schoenbeck Gerhard Schoenbeck, Der locus amoenus von Homer bis Horaz, (1962) Heidelberg 1962.

Schöffel (2002) Christian Schöffel, Martial, Buch 8. Einleitung, Text, Übersetzung und Kommentar, Stuttgart 2002. 
Schröder (1999) Bianca-Jeanette Schröder, Titel und Text. Zur Entwicklung lateinischer Gedichtüberschriften mit Untersuchungen zu lateinischen Buchtiteln, Inhaltsverzeichnissen und anderen Gliederungsmitteln, Berlin et al. 1999.

Schulte-Sasse/ Jochen Schulte-Sasse/Renate Werner, Einführung in die LiteWerner (1994) raturwissenschaft, München 1994.

Schweikle (21990) Günther und Irmgard Schweikle, Metzler-Literatur-Lexikon. Begriffe und Definitionen, Stuttgart ${ }^{2} 1990$.

Schwinge (1986) Ernst-Richard Schwinge, Künstlichkeit von Kunst. Zur Geschichte der alexandrinischen Poesie, München 1986.

Seckel (1975) Dietrich Seckel, Hölderlins Raumgestaltung, in: Alexander Ritter (Hg.), Landschaft und Raum in der Erzählkunst, Darmstadt 1975, 45-68.

Seeck (2000) Gustav Adolf Seeck, Die griechische Tragödie, Stuttgart 2000.

Segal (1969) Charles Paul Segal, Landscape in Ovid's Metamorphoses. A study in the transformations of a literary symbol, Wiesbaden 1969.

Senett (1997) Richard Senett, Fleisch und Stein. Der Körper und die Stadt in der westlichen Zivilisation, Berlin 1997.

Severin (1988) Rüdiger Severin, Spuren des Flaneurs in deutschsprachiger Prosa, Frankfurt am Main et al. 1988.

Shackleton Bailey David Roy Shackleton Bailey, Statius Silvae, Loeb Classical (2003) Library 2006, Harvard et al. 2003.

Sharpe (1990) William Chapman Sharpe, Unreal cities. Urban figuration in Wordsworth, Baudelaire, Whitman, Eliot and Williams, Baltimore et al. 1990.

Sim (1996) Unyong Sim, Das himmlische Jerusalem in Apk. 21, 1-22,5 im Kontext biblisch-jüdischer Tradition und antiken Städtebaus, Trier 1996.

Skoie (2006) Mathilde Skoie, City and countryside in Vergil's Eclogues, in: Rosen/Sluiter (2006), 297-325.

Sloman (21968) Arthur Sloman, P. Terenti Adelphi, Oxford 21968.

Smuda (1992) Manfred Smuda (Hg.), Die Großstadt als „Text“, München 1992.

Snell (1946) Bruno Snell, Arkadien. Die Entdeckung einer geistigen Landschaft, in: ders., Die Entdeckung des Geistes. Studien zur Entstehung des europäischen Denkens bei den Griechen, Hamburg 1946, 233-258. 
Spencer (2010) Diana Spencer, Roman landscape. Culture and identity, Cambridge 2010.

Stahl (1985) Hans Peter Stahl, Propertius. ,Love and ,War'. Individual and state under Augustus, Berkeley et al. 1985.

Stauffer (1959) Marianne Stauffer, Der Wald. Zur Darstellung und Deutung der Natur im Mittelalter, Bern 1959.

Stierle (1993) Karlheinz Stierle, Der Mythos von Paris. Zeichen und Bewußtsein der Stadt, München et al. 1993.

Stöcklein (1966) Paul Stöcklein (Hg.), Eichendorff heute. Stimmen der Forschung mit einer Bibliographie, Darmstadt 1966.

Stovesandt (2008) Magdalene Stovesandt, Sechster Gesang (Z). Faszikel 2: Kommentar, in: Anton Bierl/Joachim Latacz (Hg.), Homers Ilias. Gesamtkommentar (Basler Kommentar/BK), Bd. 4, Berlin et al. 2008.

Suerbaum (1999) Werner Suerbaum, Vergils Aeneis. Epos zwischen Geschichte und Gegenwart, Stuttgart 1999.

Sullivan (1991) John P. Sullivan, Martial - The unexpected classic. A literary and historical study, Cambridge 1991.

Tombeur (2003) Paul Tombeur (Hg.), Bibliotheca Teuberiana Latina, BTL 3, München et al. 2003.

Townend (1973) G. B. Townend, The literary substrata to Juvenal's satires, JRS 63, 1973, 148-160.

Traut (1957) René Traut, Die Stadt in der deutschen Erzählkunst des 19. Jahrhunderts, Winterthur 1957.

Troxler-Keller Irene Troxler-Keller, Die Dichterlandschaft des Horaz, Hei(1964) delberg 1964.

Ueding (2007) Gert Ueding (Hg.), Historisches Wörterbuch der Rhetorik, Tübingen 2007.

Ungern-Sternberg Armin von Ungern-Sternberg, Überlegungen zu literarischen (2003) Räumen mit Blick auf die deutsche Literatur des Baltikums, das Baltikum und die deutsche Literatur, Bielefeld 2003.

v. Albrecht (1964) Michael von Albrecht, Silius Italicus, Amsterdam 1964.

v. Albrecht (1992) Michael von Albrecht, P. Ovidius Naso, Ars amatoria. Liebeskunst, lateinisch-deutsch, Stuttgart 1992.

v. Albrecht (2002) Michael von Albrecht, Nach den Satiren. Durs Grünbein und die Antike, in: Bernd Seidensticker und Martin Vöhler (Hg.), Mythen in nachmythischer Zeit. Die Antike in der deutschsprachigen Literatur der Gegenwart, Berlin 2002, 101-116. 
v. Albrecht

(21997)

v. Hesberg (1995)

van Heck (1977)

Vater (1991)

Videau-Delibes

Vischer (1965)

Vollmer (1971)

Vout (2007)

Waiblinger

(32009) a

Waiblinger

(32009) b

Walde (2005)

Wallace-Hadrill (1991)

Walraff (2004)

Walter (1996)

Watson (2003)

Weber (1989)

Weeber (1974)
Michael von Albrecht, Geschichte der römischen Literatur von Andronicus bis Boëthius mit Berücksichtigung ihrer Bedeutung für die Neuzeit, 2 Bd., München 21997.

Henner von Hesberg (Hg.), Was ist eigentlich Provinz? Zur Beschreibung eines Bewußtseins, Köln 1995.

Adrianus van Heck, Breviarum urbis Romae antiquae viatorum in usum composuit, Rom 1977.

Heinz Vater, Einführung in die Raum-Linguistik, HürthEfferen 1991.

Anne Videau-Delibes, Les tristes d'Ovide et l'élégie romaine. Une poétique de la rupture, Paris 1991.

Rüdiger Vischer, Das einfache Leben. Wort- und motivgeschichtliche Untersuchung zu einem Wertbegriff der antiken Literatur, Göttingen 1965.

Friedrich Vollmer, Publius Papinius Statius Silvarum libri, Hildesheim et al. 1971.

Caroline Vout, Sizing up Rome, in: Larmour/Spencer (2007), 295-322.

Franz Peter Waiblinger, Rom. Ein literarischer Reiseführer, Darmstadt ${ }^{3} 2009$.

Franz Peter Waiblinger, Roma - caput mundi. Rom - Hauptstadt der Welt. Lateinische Texte in der Stadt und über die Stadt, München ${ }^{32009 .}$

Christine Walde, Die Stadt Rom in den Exilgedichten Ovids, Grazer Beiträge 34, 2005, 155-174.

Andrew Wallace-Hadrill, Augustan Rome, Melksham 1991.

Martin Walraff, s.v. Romidee, in: RGG 7, Tübingen 2004, Sp. 620.

Uwe Walter, M. Valerius Martialis, Epigramme, Paderborn et al. 1996.

Lindsay und Patricia Watson, Martial. Select epigrams, Cambridge 2003.

Gert Weber, Der literarische Topos „Stadt-Land“ und sein sozial- sowie kulturgeschichtlicher Hintergrund, Berlin 1989. Karl-Wilhelm Weeber, Properz I, 1, 11, RhM 117, 1974, 183187. 
Welch (2005) Tara Welch, The elegiac cityscape. Propertius and the meaning of Roman monuments, Columbus 2005.

Weninger (1994) Robert Weninger, Literarische Konventionen. Theoretische Modelle. Historische Anwendung, Tübingen 1994.

White (1993) Peter White, Promised Verse, Cambridge, Mass. et al. 1993.

Wiedemann (1988)

Willenbrock (1969) Carl Wiedemann, Rom-Paris-London. Erfahrung und Selbsterfahrung deutscher Schriftsteller und Künstler in den fremden Metropolen, Stuttgart 1988.

Williams (1994) Gareth D. Williams, Banished voices, Cambridge 1994.

Williams (2004) Craig A. Williams, Martial, Epigrams. Book two, Cambridge 2004.

Wimmel (1960) Walter Wimmel, Kallimachos in Rom: die Nachfolge seines apologetischen Dichtens in der Augusteerzeit, Wiesbaden 1960.

Witek (2006) Franz Witek, Vergils Landschaften. Versuch einer Typologie literarischer Landschaft, Hildesheim et al. 2006.

Wright (1981) John Wright, Plautus: Curculio. Introduction and notes, Chico 1981.

Wulfram (2009) Hartmut Wulfram, Descriptio ancilla narrationis. Aeneas besichtigt Karthago (Vergil, Aeneis 1, 418-493), RhM 152, 2009, 15-48.

Wulfram (2010) Hartmut Wulfram, Pascua, ager, urbs, Virgilio e l'aqua dolce, in: Arturo Calzona/Daniela Lamberini, La civiltà delle acque tra medioevo e rinacimento, Florenz 2010, 3-17.

Würzbach (2001) Natascha Würzbach, Erzählter Raum. Fiktionaler Baustein, kultureller Sinnträger, Ausdruck der Geschlechterordnung, in: Jörg Helbig (Hg.), Erzählen und Erzähltheorie im 20. Jahrhundert, Heidelberg 2001, 105-129.

Würzbach (2004) Natascha Würzbach, Raumdarstellung, in: Vera Nünning/ Ansgar Nünning (Hg.), Erzähltextanalyse und Gender Studies, Stuttgart et al. 2004, 49-71.

Zanker (42003) Paul Zanker, Augustus und die Macht der Bilder, München 42003.

Zipfel (2001) Frank Zipfel, Fiktion, Fiktivität, Fiktionalität. Analysen zur Fiktion in der Literatur und zum Fiktionsbegriff in der Literaturwissenschaft, Berlin 2001. 
Zwierlein (1990) Otto Zwierlein, Zur Kritik und Exegese des Plautus I: Poenulus und Curculio, AAWM 1990, 4, 253-265.

\subsection{Glossar}

Bereich

Beschreibung

Bewegungsbereich

Blickinszenierungen

Nahaufnabme, Großaufnabme, Zoom, Perspektive von unten, von oben, auf Augenböhe

Eigenort

Ensemble, räumliches

Ereignisregion die ,mittleren bis großen Abschnitte einer Stadt (...), in die der Beobachter hineingeht und [die] (...) aufgrund ihres (...) individuellen Charakters erkennbar" sind. [Lynch (1975), 61] „ein Texttyp, bei dem (...) stabile Eigenschaften einer räumlichen Gegebenheit, einer Figur oder eines Objektes mitgeteilt werden, ohne dass im selben Teilsatz, Satz oder Abschnitt ein bestimmtes, einmaliges Ereignis erwähnt wird." [Dennerlein (2009), 141]

Bsp.: Der Fußboden war aus dem farbigsten Marmor zusammengestellt, der in unseren Gebirgen zu finden ist.

größere $>$ Ereignisregion, die durch das Erzählen von Figurenbewegung entsteht und dadurch mehrere räumliche Gegebenheiten zu einem > räumlichen Kontinuum verbindet. [vgl. Dennerlein (2009), 237]

bildkünstlerische Techniken räumlicher Darstellung im Hinblick auf den gewählten Raumausschnitt (Nahaufnahme-Großaufnahme), auf die Abfolge von gewählten Raumausschnitten (Zoom) oder die zum Raumausschnitt eingenommene Perspektive (von oben, von unten, auf Augenhöbe). [zur eingenommenen Perspektive vgl. Dennerlein (2009), 150-153]

der von einem Objekt eingenommene Ort, „wobei jedes Objekt zu jedem Zeitpunkt genau einen Ort einnimmt“. [Grabowski (1999), 44. Vgl. ebd., 44-46]

$>$ räumliche Gegebenheiten, die unmittelbar aneinander angrenzen (> Kontaket).

Bsp.: Haus-Vorgarten-Straße

räumliche Umgebung, in, an oder bei der sich ein > Ereignis abspielt. [vgl. Dennerlein (2009), 237] 
Erzählen von Ereignissen ein Texttyp, bei dem eine Zustandsveränderung (Geschehen, Handlung und intentionaler Zustand) mitgeteilt werden. [vgl. Dennerlein (2009), 122 f.; Hühn (2009)]

Bsp.: Der Blitz schlug ein. Sie traten in den Garten. Er lag in der Koje.

Fernraum, raum- Raum, der sich strukturell außerhalb des gleichen $>$ räumlichen zeitlicher (distant frame, spatiotemporally)

Gattungsbezeichnung

Gegebenheit, räumliche

Georaum

Grenze

Inklusion

Insel

Knoten- und Konzentrationspunkt und/oder zeitlichen Kontinum wie der > Schauplatz befindet. Durch Wechsel der Erzählebene oder durch Schauplatzwechsel kann er zum $>$ Schauplatz. werden. Häufig wird ein F. als $>$ Kontrastraum zum $>$ Schauplatz gestaltet. [vgl. Ronen (1986), 427 f., 436]

ein raumreferentieller Ausdruck, der Klassen von Räumen und Objekten bezeichnet, in denen sich Figuren aufhalten. [Dennerlein (2009), 77, 209]

Bsp.: Speisezimmer, Problemviertel, Auto

Oberbegriff für Räume, Orte und Objekte [Dennerlein (2009), 70]

den physisch-empirischen Raum, der ,geographisch und morphologisch beschreibbar" ist. [Piatti (2008), 361]

„Linearelemente, die vom Beobachter nicht als Wege benutzt oder gewertet werden“, sondern als „Grenzen zwischen zwei Gebieten, lineare Unterbrechungen des Zusammenhangs; Küsten, Eisenbahnstrecken, Baugebietsränder, Mauern“ bewertet werden. Sie können als „mehr oder weniger überwindbare Schranken gelten, die das eine Gebiet vom anderen abschließen oder (...) als Säume, als Nähte, als Linien, die zwei Gebiete aneinanderfügen, miteinander in Verbindung bringen“". [Lynch (1975), 61 unter ,Grenzlinien (Ränder)']

eine topologische Beziehung zwischen mindestens zwei räumlichen Gegebenheiten. Merkmal der Beziehung, Inklusi${ }^{o n}{ }^{\prime}$ ist es dabei, das die eine in der anderen enthalten ist. [vgl. Grabowski (1999), 50-61]

Bsp.: Der Koffer ist im Scbrank. Berlin liegt in Deutschland.

eine räumliche Makrostruktur, die verschiedene $>$ Bereiche unverbunden und unzusammenhängend wiedergibt. [vgl. Lynch (1975), 107]

intensiv genutzte Zentralpunkte, Ziele und Ausgangspunkte von städtischen Bewegungen. Sie gelten als Knotenpunkte, wenn sie wie Kreuzungen oder Treffpunkte von Straßen zu Verkehrsunterbrechungen führen oder als Konzentrationspunk- 
Konstitutions- Wiederkehr von Textelementen, die demselben Bedeutungsisotopie

te, wenn deren Bedeutung in der Verdichtung von Benutzungszwecken oder in einer ausgeprägten Eigenart besteht. [Lynch (1975), 61 f. unter ,Brennpunkte?

bzw. Erfahrungsbereich zuzuordnen sind, und sich daher zu einem gemeinten, übergeordneten räumlichen Bereich zusammenschließen. [vgl. Mahler (1999), 16-18]

Bsp.: Weltstadt, Menschenströme, Gedränge, Omnibusse, Flughafen, Hochbäuser bilden eine Konstitutionsisotopie Großstadt.

Kontaktbereich > Schauplatz, der durch die gleichzeitige Anwesenheit von Figuren ausgestaltet ist, die miteinander interagieren.

Kontakt

eine topologische Beziehung zwischen mindestens zwei räumlichen Gegebenheiten. Merkmal der Beziehung ,Kontakt' ist dabei, mindestens einen gemeinsamen Raumpunkt zu haben. [vgl. Grabowski (1999), 61-70]

Bsp.: Die Leiter lehnt am Baum.

Kontinuum, Raum, der durch die Bewegung von Figuren oder durch geräumliches meinsame Grenzen $(>$ Kontakt) als zusammenhängend prä(continuous action space)

Kontrastraum

Merk- und sentiert wird. [Konstan (2002), 2]

ein $>$ Fernraum, dessen Eigenschaften denen des $>$ Schauplatzes entgegengesetzt sind. [vgl. Ronen (1986), 428, 436]

Wahrzeichen, topographisches ein raumreferentieller Ausdruck, der ein als bekannt vorausgesetztes oder voraussetzbares Teilelement (Bauwerk, Naturbesonderheit, Sehenswürdigkeit) einer Großstadt des > Georaums bezeichnet und für diese metonymisch verwendet werden kann. [nach Mahler (1999), 14-16]

Bsp.: Louvre, Spree, Big Ben

Merkzeichen ein optischer Bezugspunkt, in den der Beobachter nicht eintritt, dessen äußere Merkmale der Orientierung dienen. Es sind gewöhnlich einfache Objekte wie Gebäude, Schilder, Warenhäuser, Anhöhen. Die „Benutzung von Merkzeichen erfordert die Aussonderung eines einzelnen Elementes aus einer Unmenge von Möglichkeiten.“ [Lynch (1975), 62]

Mobiles Objekt beweglicher dreidimensionaler Gegenstand, der nicht statischer Teil der Erdoberfläche ist. Er kann zur > Ereignisregion werden, wenn Figuren darin lokalisiert werden. [nach Dennerlein (2009), 69]

Bsp.: Schiff, Sänfte, aber auch Fischbauch usw. 
Nähe

Nebenraum (secondary frame)

Raum, nichtbestehender (frame with a nonfactual status)

Raum, transitorischer

Raum, unzugänglicher (inaccessible frame)

eine topologische Beziehung zwischen mindestens zwei räumlichen Gegebenheiten. Merkmal der Beziehung ,Nähe ist dabei, keinen gemeinsamen Raumpunkt zu haben. [vgl. Grabowski (1999), 61-70]

Bsp.: Am Brunnen vor dem Tore stand ein Baum. Wir wohnen in der Nähe von Rom.

Raum, der strukturell an den $>$ Schauplatz anschließt. Er ist durch eine Grenze von ihm getrennt, obwohl er zum selben $>$ räumlichen Kontinuum gehört. Die Figuren können ihre Wahrnehmung auf ihn ausdehnen, ohne ihn zu betreten. [vgl. Ronen (1986), 426, 436]

Bsp.: Als sie im Wohnzimmer am Fenster vorbeiging, sab sie Kinder auf der Straße.

räumliche Referenz, die von einer modalen Äußerung (potential, irreal, zukünftig ...) abhängt. Es handelt sich dabei um einen Raum einer möglichen Welt, der in die Erzählung eingebunden wird. [vgl. Ronen (1986), 428 f., 436]

Bsp.: Sie wäre jetzt gern in der Schweiz.

$>$ Wahrnehmungsbereich, dessen räumliche Eigenschaften durch Figurenbewegung und/oder $>$ mobile Objekte einer ständigen Veränderung unterworfen sind.

Raum, der strukturell an den > Schauplatr, anschließt, aber nicht von Figuren betreten wird/werden kann. Den Figuren liegen über das Innere des Raumes keine Informationen vor. Wird der Raum zugänglich, ist dieser Wechsel meist interpretatorisch signifikant. [vgl. Ronen (1986), 426, 436]

Bsp.: Paraklausithyron-Motiv in röm. Liebeselegie

Referenz, absolu- Ortsangabe, die unabhängig von einem Betrachterstandpunkt te (Standort unab- oder der räumlichen Umgebung bestimmt wird. Darunter hängige Referenz) fallen topologische, georeferentielle, metrische Referenzsysteme. [vgl. Dennerlein (2009), 79-81, 209]

Bsp.: im Haus, auf dem Alexanderplatz, zwanzig Meter weiter

Referenz, deikti- Ortsangabe, die von einem individuellen Betrachterstandsche (standortab- punkt (auch: Origo des Sprechers) abhängt. [vgl. Dennerlein hängige Referenz) (2009), 78 f., 81, 209]

Bsp.: rechts von; hier, herab

Referenz, impli- Informationen, die konkrete Schlussfolgerungen auf die gezite meinte räumliche Gegebenheit zulassen (Metonymie). Dazu gehört die Nennung von den Grenzen und typischen Be- 
Schauplatz

Standort, fester

Teilelement, typisches

Toponym

Umgebung, räumliche

Universum, erzähltes

Wahrnehmung, erzählte standteilen des Raumes, Figuren in ihrer Rollenidentität und Ereignisse und Handlungen, die typischerweise in, an, bei räumlichen Gegebenheiten stattfinden. [Ronen (1986), 422 f. Dennerlein (2009), 95 f.]

tatsächliche und unmittelbare räumliche Umgebung, in, an oder bei der sich ein $>$ Ereignis abspielt und an dem gleichzeitig die Origo verortet ist. Schauplätze können wechseln. Durch das Erzählen von Figurenbewegungen können mehrere Schauplätze zu einem > räumlichen Kontinuum/Bewegungsbereich verbunden werden. [vgl. Dennerlein (2009), 240]

Position der $>$ Wahrnehmungsinstan₹, die sie während der Wahrnehmung nicht verändert; er wird direkt benannt oder kann erschlossen werden. [vgl. Dennerlein (2009), 238, s.v. Position der Wahrnehmungsinstanz]

ein raumreferentieller Ausdruck, der metonymisch als ein wesentlicher Bestandteil eines Raumschemas (z.B. Dorf, Jahrmarkt) verstanden werden kann. [Mahler (1999), 17]

Bsp.: Hochhaus, Flughafen für Großstadt

ein raumreferentieller Ausdruck, der einen vermeintlichen Bezug zum Georaum aufweist. [Dennerlein (2009), 77, 209]

Bsp.: Berlin, Atlantis, Insel Felsenburg

eine Region um ein Objekt herum, die dem Objekt zugeschrieben wird, ihn aber nur als Teilelement enthält. [vgl. Grabowski (1999), 46-50]

Bsp.: Die Tasche liegt beim Klavier. Er stand vor dem Schrank.

die Welt (im raum-zeitlichen Sinn), die durch den Text als gegenwärtig dargestellt wird. Es umfasst darüber hinaus auch die kontrafaktischen Welten, also diejenigen, die in den Vorstellungen, Wünschen, Befürchtungen, Vermutungen usw. existieren. Die möglichen Welten müssen textlich aktiviert sein. [Ryan (2009), 422]

liegt vor, „wenn ein Wahrnehmungsakt durch Wahrnehmungsverben angezeigt wird, oder wenn ein solcher durch das Erzählen impliziert ist." [Dennerlein (2009), 146; vgl. auch ebd. 240]

Bsp.: Die Berge wurden hier noch steiler, die Tannenwälder wogten unten wie ein grünes Meer, und am blauen Himmel oben schifften die weißen Wolken. 
Wahrnehmungs- „derjenige räumliche Bereich, der wahrgenommen wird.“ bereich Kann mit der $>$ Ereignisregion der $>$ Wahrnehmungsinstanz zusammenfallen. [Dennerlein (2009), 241]

Wahrnehmungs- Figur, von der ein Wahrnehmungsakt durch Verben der instanz Wahrnehmung angezeigt wird oder ein solcher impliziert ist durch Subjektivität, Standortabhängigkeit (z.B. Verwendung $>$ deiktischer Referenzen) oder Aktualität. [Dennerlein (2009), 146]

Wege „Kanäle, durch die sich der Beobachter gewohnheitsmäßig, gelegentlich oder möglicherweise bewegt. Es kann sich dabei um Straßen, Spazierwege, Verbindungsstraßen, Wasserwege, Eisenbahnen handeln. " [Lynch (1975), $61 \mathrm{f}$.]

zonal ein > Schauplatz, dessen Lage im Georaum nur ungenau bestimmt werden kann. [Piatti (2008), 363] 
ie Entstehung von Großstädten ist kein Novum der letzten drei Jahrhunderte. Auch im griechisch-römischen Kulturraum gab es bereits Millionenstädte, die in struktureller, kultureller und sozialer Hinsicht heutigen Großstädten durchaus vergleichbar waren. Aber hielt diese besondere Form menschlichen Zusammenlebens auch Einzug in die Literatur ihrer Zeit? Ohne Zweifel wurde in den Dichtungen der augusteischen und kaiserzeitlichen Epoche eine Großstadt wiederholt zum Ort der Literatur gewählt: die Hauptstadt Rom. Die vorliegende Untersuchung geht der Frage nach, inwieweit die Großstadt mit ihren (spezifischen) räumlichen Merkmalen in den zeitgenössischen Werken thematisiert wird und wie die lateinischen Autoren sich zu ihr als einem eigenen literarischen Gegenstand positionieren. 